Maria Thurmair

\title{
Modalpartikeln und ihre Kombinationen
}

Max Niemeyer Verlag Tübingen 1989 


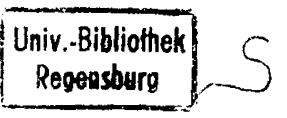

CIP-Titelaufnahme der Deutschen Bibliothek

Thurmair, Maria : Modalpartikeln und ihre Kombinationen / Maria Thurmair. Tühingen: Niemeyer, 1989.

(Linguistische Arbeiten : 22.3)

NE: (iT

ISBN $3-484-3(122.3-2 \quad$ ISSN $01344-6727$

(c) Max Niemeyer Verlag Tühingen 1989

Alle Rechte vorbehalten. Ohne Genchmigung des Verlages ist es nicht gestattet, diese's Buch oder Teile daraus photomechanisch zu vervielfältigen.

Printed in Ciermany. Druck: Weihert-Druck CimbH, Darmstadt. 
INHALTSVERZEICHNIS

\section{VORWORT}

IX

0. EINLEITUNG 1

0.1 Grundsätzliches zur Bedeutung von Modalpartikeln 2 ;

0.2 Der Terminus 'Modalpartikeln' 3.

0.3 Vorkommen von Modalpartikeln 3

$\begin{array}{lll}0.4 \text { Das Belegmaterial } & 5\end{array}$

1. FORMALE BESCHREIBUNG DER MODALPARTIKELN

1.1 Modalpartikeln in der Klasse der Unflektierbaren 7

$\begin{array}{ll}1.1 .1 & 12\end{array}$

$\begin{array}{lll}1.1 .2 & \text { Konjunktionaladverbien } & 13\end{array}$

$\begin{array}{lll}1.1 .3 & \text { Adverbien } & 14\end{array}$

$\begin{array}{llr}1.1 .4 & \text { Satzadverbien } & 14\end{array}$

$\begin{array}{lll}1.1 .5 & \text { Steigerungspartikeln } & 16\end{array}$

$\begin{array}{llr}1.1 .6 & \text { Gradpartikeln } & 17\end{array}$

$\begin{array}{llr}1.1 .7 & \text { Gliederungspartikeln } & 18\end{array}$

$\begin{array}{llr}1.1 .8 & \text { Zusammenfassung } & 19\end{array}$

1.2 Formale Kennzeichen der Modalpartikeln 21

$\begin{array}{lll}X 1.2 .1 & \text { Unflektierbarkeit } & 22\end{array}$

$\begin{array}{ll}1.2 .2 & \text { Unbetonbarkeit }\end{array}$

$\begin{array}{lll}1.2 .3 & \text { Fakultative Elemente } & 24\end{array}$

$\begin{array}{lll}1.2 .4 & \text { Stellung der Modalpartikeln } & 25\end{array}$

1.2.4.1 Modalpartikeln in den Stellungsfeldern 25

1.2.4.2 Modalpartikeln im Mittelfeld 29

1.2.4.2.1 Modalpartikeln und die Thema-Rhema-Gliederung 29

1.2.4.2.2 Modalpartikeln und Personalpronomina 32

1.2 .5 Modalpartikeln in verblosen Strukturen $\quad 35$

1.2.6 Kombination von Modalpartikeln 36

$\begin{array}{lll}\text { 1.2.7 Halt: das distributionelle Grundmuster } & 37\end{array}$

$\begin{array}{lll}1.2 .8 & \text { Mir: eine neue Modalpartikel? } & 38\end{array}$

$\begin{array}{lll}1.2 .8 .1 & \text { Nominalgruppen im Dativ } & 38\end{array}$

$\begin{array}{lll}\text { 1.2.8.2 Der ethische Dativ } & 39\end{array}$ 
1.3 Modalpartikeln und Satzmodus 42

$\begin{array}{ll}\text { 1.3.1 Grundtypen } & 42\end{array}$

1.3.1.1 Formtyp und Funktionstyp

1.3.1.1.1 Die einzelnen Formtypen $\quad 44$

1.3.1.1.2 Funktionstypen und Illokutionstypen 46

1.3.1.2 Distribution der Modalpartikeln $\quad 48$

1.3.2 Selbständige Sätze mit Verb-Endstellung $\quad 49$

$\begin{array}{lll}\text { 1.3.2.1 Stand der Forschung } & 50\end{array}$

1.3.2.2 Modalpartikeln in Sätzen mit Verb-Endstellung 51

1.3.2.2.1 wenn-Sätze $\quad 52$

$\begin{array}{lll}1.3 .2 .2 .2 \quad o b-S a ̈ t z e & 54\end{array}$

$\begin{array}{lll}1.3 .2 .2 .3 \quad d a \beta-S a ̈ t z e & 54\end{array}$

1.3.2.2.4 Sätze mit $w$-Ausdruck und Verb-Endstellung 56

$\begin{array}{lll}1.3 .2 .2 .5 & \text { wo-Sätze } & 58\end{array}$

$\begin{array}{lll}1.3 .2 .2 .6 \quad a / s & o b-S a ̈ t z e & 59\end{array}$

$\begin{array}{lll}1.3 .2 .2 .7 & \text { und } o b / \text { und wie-Sätze } & 60\end{array}$

$\begin{array}{lll}\text { 1.3.2.3 Zusammenfassung } & 61\end{array}$

1.3.3 Modalpartikeln in Sätzen mit infinitem Verb 64

1.3.4 Modalpartikeln und Alternativfragesätze $\quad 66$

1.3.5 Modalpartikeln und Mischtypen $\quad 69$

$\begin{array}{lll}\text { 1.3.5.1 Assertive Fragesätze } & 69\end{array}$

$\begin{array}{lll}\text { 1.3.5.2 Rückfragen } & 70\end{array}$

1.3.5.3 W-Versicherungsfragesätze $\quad 72$

$\begin{array}{lll}\text { 1.3.6 Modalpartikeln in Nebensätzen } & 73\end{array}$

$\begin{array}{llr}\text { 1.3.6.1 Ergänzungssätze } & 74\end{array}$

Exkurs: Indirekte Rede $\quad 75$

$\begin{array}{lll}\text { 1.3.6.2 Adverbialsätze } & 76\end{array}$

$\begin{array}{lll}\text { 1.3.6.3 Attributsätze } & 79\end{array}$

$\begin{array}{lll}\text { 1.3.6.4 Weiterführende Nebensätze } & 81\end{array}$

$\begin{array}{llr}\text { 1.3.6.5 Zusammenfassung } & 81\end{array}$

1.4 Modalpartikeln und Negation $\quad 83$

1.4.1 Sind Modalpartikeln negierbar? $\quad 83$

1.4.2 Modalpartikeln in negierten Sätzen $\quad 84$

$\begin{array}{lll}\text { 1.4.2.1 Satzmodus und Negation } & 84\end{array}$

1.4.2.2 Das Auftreten von Modalpartikeln in negierten Sătzen 90 
2. ANALYSE DER EINZELNEN MODALPARTIKELN 94

$2.1 \quad$ Vorbemerkungen $\quad 94$

2.1.1 Die Bedeutung von Modalpartikeln $\quad 94$

2.1.2 Beschreibungsmethode $\quad 99$

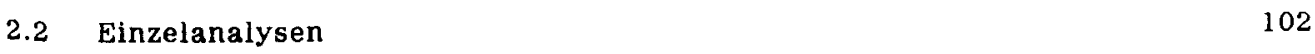

$2.2 .1 \mathrm{Ja} \quad 103$

2.2.1.1 (Unbetontes) $j a \quad 104$

$\begin{array}{lll}2.2 .1 .2 & \text { (Betontes) } J A & 109\end{array}$

2.2.2 Doch 110

2.2.3 Eben 119

$\begin{array}{lll}2.2 .4 & \text { Halt } & 123\end{array}$

$\begin{array}{lll}2.2 .5 & \text { Einfach } & 128\end{array}$

2.2.6 Eh und Sowieso 134

$\begin{array}{lll}2.2 .7 \text { Wohl } & 139\end{array}$

2.2.8 Schon 146

2.2.9 Auch 155

2.2.10 Nicht 160

2.2 .11 Denn 163

$\begin{array}{lll}2.2 .12 \text { Etwa } & 170\end{array}$

2.2.13 Eigentlich $>\quad 175$

2.2 .14 Bloß und Nur 178

$\begin{array}{lll}2.2 .15 \mathrm{Mal} & 184\end{array}$

Exkurs: Die Partikel bitte 186

$\begin{array}{lll}2.2 .16 & \text { Ruhig } & 187\end{array}$

2.2 .17 Aber 190

2.2 .18 Vielleicht 192

2.2.19 Mir 195

$2.3 \quad$ Zusammenfassung 199

3. MODALPARTIKEL-KOMBINATIONEN 203

3.1 Zur Forschung 203

3.2 Beschreibung von Modalpartikel-Kombinationen 204

$\begin{array}{ll}3.2 .1 & \text { Akzeptable Kombinationen } \\ & 207\end{array}$

3.2.1.1 Kombinationen mit $j a \quad 208$

$\begin{array}{lll}3.2 .1 .1 .1 & \text { (Unbetontes) ja } & 208\end{array}$

3.2.1.1.2 (Betontes) $J A \quad 214$

$\begin{array}{ll}3.2 .1 .2 & \text { Kombinationen mit doch } \\ & 215\end{array}$ 
VIII

3.2.1.3 Kombinationen mit auch $\quad 228$

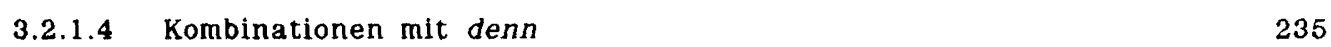

3.2.1.5 Kombinationen mit bloß, nur und mal 243

3.2.1.5.1 Kombinationen mit blo $\beta$ und nur 243

3.2.1.5.2 Kombinationen mit mal 246

3.2.1.6 Kombinationen mit aber und vielleicht 251

3.2.1.7 Kombinationen mit eben, halt, einfach, wohl und schon 255

3.2.2 Bedingt akzeptable und inakzeptable Kombinationen 262

3.2.2.1 Kombinationen in Aussagesätzen 262

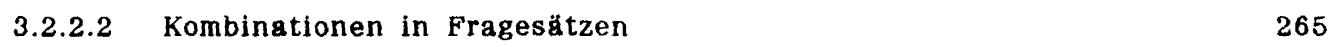

$\begin{array}{lll}3.2 .2 .2 .1 & \text { Entscheidungsfragesätze } & 265\end{array}$

$\begin{array}{lll}3.2 .2 .2 .2 & W \text {-Fragesätze } & 269\end{array}$

3.2.2.3 Kombinationen in Imperativsätzen 271

Exkurs: bitte und die 'Aufforderungspartikeln' 275

$\begin{array}{lll}3.2 .3 & \text { Zusammenfassung } & 277\end{array}$

$\begin{array}{lll}3.3 & \text { Mehrfachkombinationen } & 283\end{array}$

$\begin{array}{lll}3.4 & \text { Syntaktisches Verhalten } & 285\end{array}$

3.4.1 Die Reihenfolge innerhalb der Kombination 285

$\begin{array}{lll}3.4 .1 .1 & \text { Zur Forschung } & 285\end{array}$

3.4.1.2 Stellungsregeln für die einzelnen Modalpartikeln 285

3.4.2 Die Stellung im Satz: offene und geschlossene Kombinationen 290

4. ZUSAMMENFASSUNG 293

$\begin{array}{ll}\text { LITERATURVERZEICHNIS } & 297\end{array}$

Tabelle 1: Partikelklassifikation 20

Tabelle 2: Polyfunktionalität im Bereich der Partikeln 21

Tabelle 3: Formale Kennzeichen der Grundtypen 46

Tabelle 4: Zuordnung von Formtyp und Funktionstyp : 46

Tabelle 5: Distribution der Modalpartikeln in den Grundtypen 49

Tabelle 6: Typen von selbständigen Verb-Letzt-Sätzen $\quad 61$

Tabelle 7: Distribution von Modalpartikeln in selbständigen Verb-Letzt-Sätzen 62

Tabelle 8: Distribution von Modalpartikeln in Nebensätzen $\quad 81$

Tabelle 9: Distribution von nicht in den Grundtypen 90

Tabelle 10: Die Bedeutung der einzelnen Modalpartikeln 200

Tabelle 11: Syntaktisch-distributionell nicht kompatible Modalpartikeln 205

$\begin{array}{ll}\text { Tabelle 12: Modalpartikel-Kombinationen } & 278\end{array}$

Tabelle 13: Distribution der Modalpartikel-Kombinationen 282 
VORWORT

Die vorliegende Untersuchung stellt eine überarbeitete Fassung meiner Dissertation dar, die im Wintersemester 1986/87 an der Philosophischen Fakultät Pür Sprachund Literaturwissenschaft II der Ludwig-Maximilians-Universität München angenommen wurde.

Mein besonderer Dank gilt meinem Doktorvater, Prof. Harald Weinrich, der mein Interesse für die Partikeln geweckt hat und diese Arbeit mit zahlreichen inspirierenden Vorschlägen begleitet hat.

Dank schulde ich auch Herrn Prof. Hans Altmann, der die Untersuchung mit hilfreicher und ermutigender Kritik gefördert hat; ferner bin ich ihm für die Aufnahme in die Reihe 'Linguistische Arbeiten' verpflichtet.

Fur die notwendige fachliche und moralische Unterstützung danke ich vor allem Wilhelm Oppenrieder und Eva-Maria Willkop - neben allen anderen, die auf ihre Weise die Entstehung dieser Arbeit gefördert haben. 



\section{EINLEITUNG}

Die vorliegende Arbeit beschäftigt sich mit den Modalpartikeln der deutschen Sprache. Ziel der Untersuchung ist es, die Modalpartikeln aus möglichst vielen Perspektiven zu beleuchten und mit unterschiedlichen Fragestellungen an das Phänomen 'Modalpartikel' heranzugehen.

Kapitel 1 ist der Syntax der Modalpartikeln gewidmet: Besonderes Augenmerk wird hier zum einen auf die Abgrenzung der Modalpartikel-Funktion von anderen Partikel-Funktionen gelegt. Erst auf der Basis einer genauen Eingrenzung des Untersuchungsgegenstandes ist eine weitere Analyse möglich und sinnvoll. Zum anderen beschäftigt sich dieses Kapitel mit der Interaktion von Modalpartikeln und Satztypen; dabei werde ich mich nicht nur auf das Vorkommen in den 'Grundtypen' (mit Verb-Erst und Verb-Zweit-Stellung) beschränken, sondern auch systematisch Sätze mit Endstellung des Verbs (selbständige und unselbständige) mit einbeziehen. Dabel wird sich u.a. zeigen, daß das Vorkommen und Nicht-Vorkommen von Modalpartikeln auch ein Kriterium bei der Klassifikation von Satztypen sein kann.

In Kapitel 2 wird die Bedeutung der einzelnen Modalpartikeln analysiert. Ziel ist es, für jede Modalpartikel in allen Verwendungsweisen eine einzige Bedeutung anzugeben.

Basierend auf den Ergebnissen der formalen und semantischen Analyse erfolgt schließlich im dritten Kapitel eine detaillierte Untersuchung aller ModalpartikelKombinationen - ein (wie die syntax auch) bisher vernachlässigtes Gebiet der 'Partikologie'. Dabei wird deutlich, daß auch die Kombinationsfähigkeit und NichtKombinationsfähigkeit Schlüsse auf die Bedeutung der jeweiligen Modalpartikeln zuläßt. Es wird sich herausstellen, daß es eine relativ große Zahl von gebräuchlichen Kombinationen gibt. Auch die Stellungsbedingungen in der Kombination und die Distribution der Kombinationen werden erforscht. 


\subsection{Grundsătzliches zur Bedeutung von Modalpartikeln}

Ob Modalpartikeln überhaupt eigene Bedeutung haben, ist immer wieder diskutiert worden.1 Der Grund dafür liegt sicher auch darin, daß Modalpartikeln aus jedem Satz weglaßbar sind, ohne daß ein erkennbarer Informationsverlust eintritt.

Bei der Frage nach der Bedeutung von Modalpartikeln muß man zunächst von der Unterscheidung zweier Bedeutungsebenen ausgehen:

Auf der einen Seite die propositionale Bedeutung (in der Terminologie der Sprechakttheorie; vgl. Austin (1979), Searle (1971)); bei Bühler (1965) die "Darstellungsfunktion", mit der die Sachverhalte vermittelt werden; bei Watzlawick et al. (1982:53) der "Inhaltsaspekt"; das ist die Ebene, auf der der denotative Aspekt zum Ausdruck kommt.

Auf der anderen Seite der nicht-propositionale, der illokutive Bereich, bei Bühler die "Ausdrucks- und Appellfunktion", bei Weydt (1969:61) zusammengefaßt als "Intentionsebene", bel Watzlawick et al. als "Beziehungsaspekt", der anweist, wie die Daten aufzufassen sind (1982:55).

In diesem zweiten Bereich, dem illokutiven Bereich, wirken die Modalpartikeln.2 (Dlese Auffassung wird in der Literatur allgemein vertreten; vgl. dazu bereits Weydt 1969:60ff., Bublitz 1978:38, Franck 1980:21, Helbig/Kötz 1981:7.)

Im wesentlichen dienen Modalpartikeln dazu, eine Außerung in den Interaktionszusammenhang einzubinden. Mit ihnen kann auf den Gesprächspartnern gemeinsames Wissen verwiesen werden, auf Annahmen oder Erwartungen von Sprecher oder Hörer, es kann ein bestimmter Bezug zu elner vorangegangenen Außerung angezeigt werden, oder es kann der Stellenwert, den der Sprecher der Außerung beimißt, gekennzeichnet werden. Insofern modifizieren die Modalpartikeln auf je spezifische Weise Illokutionstypen.

1) So nimmt Krivonosov in seiner Dissertation (1963) - der ersten großen Arbeit uber Modalpartikeln - an, daß die Modalpartikeln. "keine selbständige lexikalische 'Bedeutung' haben, sondern immer nur im Zusammenwirken mit dem Satz" (1963:46) und daß deshalb die "'Bedeutung' einer und derselben Partikel nicht beständig bleibt", sondern "sich von Satz zu Satz" verändert (1963:44; ähnlich auch 1965a:574, 1977a:193 oder 1978:117.) Die ältere sprachwissenschaftliche Forschung bezelchnete diese Partikeln recht vage als "Würzwörter" oder "Färbewörter" u.ä. (vgl. Hertel 1962, Thiel 1962, Trogsch 1962, Adler 1964, Schröder 1965) und in der normativen Stillstik wurden die Modalpartikeln als Flickwörter oder als überflüssige Füllseln abgetan.

2) Die Beantwortung der Frage, ob Modalpartikeln Bedeutung haben, hängt also vor allem davon ab, wie 'Bedeutung' definiert wird, ob damit nur die propositionale Ebene gemeint ist oder auch die illokutive; der Gegensatz: 'Modalpartikeln haben Bedeutung oder haben keine' ist also in der Hauptsache ein terminologischer Gegensatz (vgl. dazu auch Weydt 1977:221 und den Tagungsbericht von Zifonun 1983). 
Der Begriff der Modalităt (durch den die Modalpartikeln ja terminologisch von anderen Partikelgruppen abgegrenzt werden) ist in der linguistischen Literatur viel diskutiert und eher vage, Einigkeit herrscht allenfalls darin, daß Modalitä "nicht Bestandteil des in einem Satz beschriebenen Sachverhalts [ist], sondern etwas, das zusätzlich zu diesem Sachverhalt ausgedrückt wird" (Vater 1975:104).

Durch die Einfuhrung des Begriffs Modalität werden die Modalpartikeln also kaum genauer bestimmt, gesagt ist damit nur, daß sie nichts zum propositionalen Gehalt eines Satzes beitragen, also die Wahrheitsbedingungen nicht verăndern. ${ }^{3}$

Obwohl der Begriff der Modalität zur Charakterisierung der Modalpartikeln nicht viel beitrăgt, möchte ich trotzdem den Terminus 'Modalpartikeln' beibehalten, da es derjenige Begriff ist, ${ }^{4}$ der sich allmählich durchzusetzen scheints ${ }^{5}$ und andere Termini (wie z.B. 'Abtönungspartikel') ăhnliche Probleme aufwerfen.

\subsection{Das Vorkommen von Modalpartikeln}

Der Haupterscheinungsbereich der Modalpartikeln ist die Umgangssprache. Sie treten also vor allem dort auf, wo spontan miteinander gesprochen wird. Daneben finden sich auch zahlreiche Modalpartikeln in Dialogen in der belletristischen Literatur, in der neueren Bühnensprache und in Filmdialogen. Und gerade in diesem

3) Die von Bublitz (1978:6ff.) im Anschluß an die Trennung in kognitive und volitive Modalităt angesetzte dritte Art der Modalität, die emotive Modalităt, die auftritt, wenn der Sprecher "seine Annahmen und Einstellungen wiedergibt, die sich auf das gemeinsam unterstellte Wissen der Kommunikationspartner, ihre Erwartungen, Emotionen und sozialen Beziehungen zueinander beziehen" (7f.) und die hauptsächlich durch die Modalpartikeln ausgedrückt wird, charakterisiert zwar die Modalpartikeln genauer, faßt aber - wenn man den Begriff der 'Modalităt' nicht zu weit ausdehnen will - nicht alle Funktionen der Modalpartikeln.

4) Für das sprachliche Phänomen der Modalpartikeln existieren in der linguistischen Literatur zahllose Termini: z.B. 'emotional-expressive Partikeln' (Erben 1972), 'adjungierte Adverbialia' (Engel). 'modale Partikeln' (Krivonosov), 'Verknüpfungspartikeln' (Becker 1976), 'Satzpartikeln' (Asbach-Schnitker 1975, Hartmann 1975 etc.), 'kommunikative Partikeln' (Rath 1975), 'illokutive Partikeln' (Helbig/Kötz 1981), 'Einstellungspartikeln' (Doherty 1985), 'Abtönungspartikeln' (Weydt 1969 etc.. Hentschel 1986) und eben 'Modalpartikeln' (Weydt 1977, Bublitz 1978, Kemme 1979, Franck 1980, Gornik-Gerhardt 1981. Heinrichs 1981 , Bastert 1985 und Borst 1985).

Trotz der unterschiedlichen Bezelchnungen ist aber meist von dem gleichen Phänomen die Rede, es handelt sich um eine unterschledlich große Gruppe von Partikeln, deren Kern immer gleich ist.

5) Nur Weydt, der noch den 1977 erschienen Band "Aspekte der Modalpartikeln" nannte, und seine Schüler verwenden inzwischen wieder vermehrt den Terminus 'Abtönungspartikel' (vgl. u.a. Hentschel 1986). Die Begriffe 'Abtönungspartikel' und 'Modalpartikel' sollen hier als synonym betrachtet werden." 
Textsortenbereich erfüllen die Modalpartikeln eine wichtige Funktion: Sie tragen nämlich wesentlich dazu bei. Umgangssprache zu 'simulieren' und zu konstituieren, da manche anderen grundlegenden Merkmale der gesprochenen Sprache oft fehlen; Modalpartikeln haben also in diesen Texten oft auch eine Alibifunktion.6

Weitere Faktoren für den gehäuften Modalpartikel-Gebrauch Innerhalb der Umgangssprache hat Hentschel (1980 und neuerdings genauer: 1986:238ff.) anhand einer statistischen Untersuchung von Alltagsgesprächen aus dem Freiburger Korpus aufgezeigt: der Gebrauch von Modalpartikeln steigt, je privater, d.h. informeller, persönlicher und assoziativer der Charakter des Gesprächs ist. ${ }^{7}$

Was die Frequenz einzelner Modalpartikeln betrifft, so ist das natürlich in starkem Maße davon geprägt, in welchem Satztyp die jeweilige Modalpartikel auftritt (vgl. dazu unten Kap. 1.3). Modalpartikeln, die in Aussagesätzen auftreten können, haben dementsprechend eine höhere Frequenz als andere, die beispielsweise nur in Exklamativsätzen vorkommen. Insofern sind Aussagen zur Frequenz bestimmter Partikeln mit Vorbehalt zu verstehen.

Die adäquate Verwendung bestimmter Modalpartikeln kann auch von der Beziehung der Gesprächspartner zueinander abhängen, also davon, ob diese Beziehung symmetrisch oder asymmetrisch ist (vgl. dazu genauer Hinrichs 1983:234ff.). Die Verwendung bestimmter Modalpartikeln von seiten der 'schwächeren' Position kann unangemessen sein, z.B. bloß in Imperativsätzen oder etwa.

Geht man davon aus, daß Modalpartikeln auch den 'Ton' einer Außerung mitbestimmen können (vgl. Franck 1980:30) und weiter, daß für die Positionen im asymmetrischen Dialog ein bestimmter Ton oder ein bestimmtes 'Register' angemessen ist, dann läßt sich daraus auch ableiten, da $\beta$ und warum die Verwendung von Modalpartikeln mit den verschiedenen Positionen in der asymmetrischen Interaktion zusammenhängen kann.

Worauf die durch eine bestimmte Modalpartikel bewirkte Unangemessenheit im Ton beruht, wird bei der Bedeutungsbeschreibung der einzelnen Modalpartikeln (Kapitel 2) deutlich werden.

6) Modalpartikeln kommen aber auch in nicht primär dialogischen Textsorten vor; z.B. lassen sich Partikeln wie ja, doch oder eben auch in wissenschaftlichen Texten finden.

7) Der Grad der Privatheit wurde anhand von folgenden sieben Merkmalen gemessen (jedes Merkmal umfaßt eine Skala von zwölf Punkten, grundsätzlich bedeutet eine höhere Punktzahl einen höheren Privatheitsgrad): Grad der Vertrautheit der Teilnehmer, Situationsvertrautheit, Gesprächsthema, Grad der Gleichberechtigung der Teilnehmer, Kommunikationsort und -medium, Interaktionshæufigkeit und Gesprächsverlaup (assoziativ, argumentativ, deskriptiv). 


\subsection{Das Belegmaterial}

Die in dieser Untersuchung herangezogenen Beispielsätze sind zum größten Teil Belege; zugrunde liegt ein Korpus mit circa 2000 Belegen.

Ein großer Teil davon ist aus Korpora der gesprochenen deutschen Standardsprache entnommen, vor allem den "Telefondialogen" (hg. von Brons-Albert, abgekürzt ' $\left.B A^{\prime}\right), 8$ zu einem geringeren Tell auch den "Texten gesprochener deutscher Standardsprache". Bei den "Telefondialogen" wurden gewisse dialektale Erscheinungen, die wohl auch nicht immer konsequent transkribiert wurden, der Umgangssprache angepaßt. ${ }^{-}$Dies scheint mir insofern gerechtfertigt, als dialektale Erscheinungen (wie Verschleifungen u.ä.) bei der Untersuchung der Modalpartikeln kaum eine Rolle spielen. Die Kennzeichnung von Pausen durch Punkte und von Redeabbruch durch Schrägstriche wurde ubernommen. Die Belege aus den "Texten gesprochener deutscher Standardsprache" ('Freiburger Korpus', abgekürzt FK) werden ohne die dort verwendeten Transkriptionszeichen notiert (mit Ausnahme der Kennzeichnung von Pausen durch Punkte und Redeabbruch durch Schrägstrich); ebenso ist die Groß- und Kleinschreibung den Regeln angepaßt. Sowohl bei den "Telefondialogen" als auch bei den "Texten gesprochener deutscher Standardsprache" wurden den Sprechern fiktive Namen gegeben anstelle der im Original verwendeten Buchstaben. Ein weiterer Teil von Belegen stammt aus zwel Werken, die 'redigierte gesprochene Sprache' zeigen: F.X.Kroetz' "Chiemgauer Gschichten" und E.Runges "Bottroper Protokolle". 10

Diese Textsammlungen mit authentischer bzw. redigierter gesprochener Sprache decken auch unterschiedliche Dialektgebiete $a b$ und ermöglichen somit eine gewisse Neutralisierung des Faktors Dialekt.

Zu einem weiteren großen Teil stammen die Belege aus schriftlichen Quellen, teilweise aus der belletristischen Literatur (z.B. H.Böll oder M.Bieler), aus verschiedenen Zeitungen und Zeitschriften (hauptsächlich aus der "Süddeutschen Zeitung", abgekurzt SZ) und aus verschiedenen Asterix-Heften ${ }^{11}$.

8) Die genaueren bibliographischen Angaben sowie die Angaben zu allen anderen schriftlichen Texten und die dabei verwendeten Abkürzungen finden sich im Literaturverzeichnis (S.297).

9) Z.B. nämlich statt nämig (122), irgendwann statt ürtwann (53) oder irjentwann (119) oder eigentlich statt einlisch (131).

10) Beiden Werken liegen Interviews zugrunde, bei Kroetz blieb der dialogische Charakter erhalten, während Runge nur den Part des Interviewten bringt.

11) Bei den Asterix-Heften handelt es sich zwar um Übersetzungen, aber da die Asterix-Hefte bekannt sind für ihren sensiblen Umgang mit der Sprache, muß wohl für das Deutsche nicht so sehr von einer tbersetzung im strengen sinne sondern eher von einer 'Nachdichtung' gesprochen werden; deshalb können diese Texte auch als Belegmaterial dienen. 
Bei allen angeführten in schriftlicher Form vorliegenden Belegen wird die Quelle angegeben.

Die letzte Gruppe von Beispielen umfaßt Hörbelege, die vor allem aus Alltagsgesprächen, zu einem geringeren Teil auch aus Filmdialogen stammen. Bei dieser Belegen handelt es sich um Gedăchtnisprotokolle, die 'gereinigt' (also ohne Zögerungssignale, Pausen, simultanes Sprechen etc.) notiert wurden; die Quelle wird hier nicht angegeben.

Konstrulert werden Beispiele (meist abweichende) hauptsächlich dann, wenn eine These durch Gegenüberstellungen untermauert werden sollte. (Bei Beispielen, die hinsichtlich ihrer (In-)Akzeptabilität zweifelhaft waren, wurden auch verschiedene Informanten befragt - zur Absicherung der eigenen Intuition.) Bei der Untersuchung der Kombinationen wurde zum Teil mit einem Test gearbeitet (mehr dazu S.206).

Bei der Beschreibung der formalen Eigenschaften der Modalpartikeln (Kap. 1) wird meist auf die Angabe des Kontextes verzichtet. Bei der Bedeutungsanalyse aber sind dle Belege in der Regel in einen Kontext eingebettet; dabel handelt es sich entweder um eine Vorgängeräußerung, aus der der situative Kontext bereits hervorgeht, oder um eine kurze Beschreibung der Situation.

Inakzeptable oder auch ungrammatische Beispielsätze werden mit '"' markiert, Sätze die in threr Akzeptabilität Praglich sind, mit '?' oder - als stärkere Variante - '?"'. 


\section{FORMALE BESCHREIBUNG DER MODALPARTIKELN}

Das folgende Kapitel beschäftigt sich mit formalen Eigenschaften, die die Gruppe der Modalpartikeln betreffen.

Zunächst werden andere Partikelfunktionen kurz beschrieben, um die Gruppe der Modalpartikeln davon abgrenzen zu können bzw. um auch die Ränder der Gruppe genauer bestimmen zu können. In einem zweiten Schritt werden die formalen Eigenschaften der Modalpartikeln selbst mit allen Abweichungen einzelner Partikeln dargestellt. Vor allem der Klassifikation von Partikeln wird in der Forschung kaum Beachtung geschenkt.

Das dritte Unterkapitel beschäftigt sich mit dem Auftreten von Modalpartikeln in den verschiedenen Satztypen. Dabei soll auch auf die sogenannten 'Randerscheinungen' wie selbständige Sätze mit Verb-Endstellung eingegangen werden, sowie aup das Auftreten von Modalpartikeln in Nebensätzen. Letzteres ist eher exkursorisch zu verstehen und sollte als Anregung nicht nur für die Modalpartlkelforschung, sondern auch für die Beschreibung der Nebensätze gesehen werden.

Das vierte Unterkapitel behandelt Modalpartikeln und Negation bzw. das Auftreten von Modalpartikeln und der Partikel nicht. Auch hier geht es vor allem um Phänomene, die die gesamte Gruppe der Modalpartikeln betreffen.

\subsection{Modalpartikeln in der Klasse der Unflektierbaren}

Unter einer Wortklasse wird im allgemeinen die Gesamtheit von Wörtern mit gemeinsamen Merkmalen verstanden (vgl. z.B. Flämig 1977:42). Umstritten ist dabei allerdings, wie diese Mcrkmale aussehen sollen; es lassen sich nämlich semantische, syntaktische und morphologische sowie gemischte Klassifikationen unterscheiden. Eine Klassifikation nach syntaktischen Kriterien führt m.E. besonders im Bereich der Partikeln am weitesten; es ist aber sicherlich nicht zwingend, die Einteilung nur nach einem einheitlichen Kriterium vorzunehmen.

Eine morphologische Eigenschaft, nämlich die Flektierbarkeit, teilt zunăchst den Wortschatz in zwei große Klassen: die Flektierbaren und die Unflektierbaren. Diese 
große Zweiteilurg findet sich in den meisten Klassifikationen (vgl. z.B. Wahrig 1973 oder Flämig 1977). Im Bereich der Unflektierbaren liegen natürlich die Grenzen einer morphologisch orientierten Einteilung von Wortarten; hier ist eine weitere Betrachtung nach syntaktisch-distributionellen Merkmalen nötig.

Im folgenden soll versucht werden, die große Klasse der Unflektierbaren, in die neben Modalpartikeln auch Präpositionen, Konjunktionen, Adverbien, Gradpartikeln etc. gehören, nach syntaktisch-distributionellen Kriterien zu unterteilen.

Die Klasse der Unflektierbaren und damit die Einordrung der Modalpartikeln in den Kanon der Wortarten wird in der Literatur recht unterschiedlich behandelt. Vor allem wird dabei auch der Begriff 'Partikel' verschieden gehandhabt. Einmal werden unter Partikeln - im weiteren Sinne - alle wörter zusammengefaßt, die unflektierbar sind, zum anderen werden unter Partikeln - diesmal im engeren Sinne - alle Unflektierbaren verstanden, die nicht Präpositionen, Konjunktionen, Adverbien (vgl. 2.B. Flämig 1977:45) oder Sat\%adverbien (Modalwörter) sind (vgl. z.B. Helbig/Kötz 1981:491 oder AKADEMIE-Grammatik 1981:491).

Dementsprechend finden sich auch unterschicdliche Einteilungen im Bereich der unflektierten wörter.

Bei einem Verständnis von Partikeln im engeren Sinne wird von einer Klasse der Unflektierbaren ausgegangen, die zerfällt in Adverbien, Konjunktionen, Präpositionen und Partikeln, wobei problematisch ist, daß das Hauptmerkmal der Partikeln eben ihre Unflektierbarkeit ist und sie sich somit in diesem wichtigen Kriterium nicht von den anderen Kategorien unterscheiden.

Die andere Auffassung sieht - "im Sinne eines partikelzentrierten Weltbildes" (Eisenberg 1986:199) - 'Partikeln' als Oberbegriff,' ${ }^{1}$ unter dem die einzelnen Klassen gleichrangig nebeneinander stehen. ${ }^{2}$

Diese Einteilung scheint mir am ehesten den Partikeln gerecht zu werden; deshalb soll hier von folgender Klassifikation ausgegangen werden: 'Partikel' als Oberbegriff umfaßt (mindestens) die Partikelklassen Präpositionen, Vergleichspartikeln,

1) Zum Status dieser Klasse vergleiche stellvertretend für viele Jespersen (1924:91): "This (...) class may be negatively characterized as made up of all these words that cannot find any place in any of the first four classes."

2) Annlich findet es sich z.B. bel DUDEN (1984:345ff.), der als Untergruppe allerdings nur Adverbien. Präpositionen und Konjunktionen ansetzt, wobei hier das Modaladverb 'Auffangbecken' für z.b. die Gradpartikeln oder Modalpartikeln ist.

3) Für die Benennung der einzelnen Partikelgruppen wären auch Termini denkbar, die jeweils auf '-partikel' enden. Das wäre beispielsweise im Bereich der Präpositionen eine hilfreiche Lösung, da man dann die Möglichkeit hätte, zwischen Kategorie und Funktion auch terminologisch zu unterscheiden ('Präpositionspartikel' als Kategorie: Präposition oder Verbzusatz als mögliche Funktionen von Präpositionspartikeln). Allerdings wird die Benennung problematisch 
Konjunktionen, Konjunktionaladverbien, Adverbien, Satzadverbien, Modalpartikeln, Steigerungspartikeln, Gradpartikeln, Negationspartikeln, Gliederungspartikeln und Interjektionen.

Die Partikeln im gesamten sind als Wortart zu sehen; die einzelnen Subklassen dagegen nicht als Wortarten, sondern als Funktionen, in denen bestimmte Partikeln auftreten können. Damit ist auch leichter zu erklären, daß viele Partikeln polyPunktional sind, d.h. in mehreren Funktionen auftreten können (s.u. S.21).

Wenn im folgenden also von bestimmten Partikelgruppen die Rede ist, so soll damit immer eine bestimmte Funktion gemeint sein, die eine Gruppe von Partikeln übernehmen kann. Wenn also z.B. von der Modalpartikel doch die Rede ist, soll immer die Partikel doch in Modalpartikel-Funktion (im Unterschied z.B. zur Partikel doch in Konjunktions-Funktion) gemeint sein.

$\mathrm{Da}$ bei den Partikeln morphologische Kennzeichen - wie es sie im Bereich der flektierbaren Lexenie gibt - fehlen, läßt sich ihre Funktion nur aufgrund ihres Verhaltens im Text erkennen. Inwieweit sich die Modalpartikeln in syntaktischer Hinsicht von den anderen Partikelgruppen unterscheiden und wo sich Abgrenzungsprobleme ergeben, soll im folgenden gezeigt werden. Nicht immer kann jedoch eine Lösung angeboten werden.

Zunächst werde ich die syntaktischen Kennzeichen der verschiedenen anderen Partikelgruppen darstellen, wobei ich auf die Gruppen, bei denen keinerlei Uberschneidungen mit den Modalpartikeln gegeben sind, nur kurz eingehen werde. Der Vergleich mit den anderen Partikelgruppen erscheint mir insofern wichtig, als auf diese Weise eine genaue Abgrenzung verschiedener Funktionen voneinander möglich ist.

In vielen Fällen wurde in der Modalpartikel-Forschung dieses Problem nicht weiter beachtet - Abgrenzungsprobleme vor allem im Vergleich mit anderen Partikelgruppen stellen kein zentrales Forschungsinteresse dar. ${ }^{5}$ Auch die Tendenz der Modal-

bei den ohnehin zusammengesetzten Termini 'Satzadverb' und 'Konjunktionaladverb'. Deshalb wird hler folgende Terminologie verwendet: Mit 'Partikel' bezeichne ich einen unflektierbaren Ausdruck, die einzelnen Partikelgruppen bzw. Partikeln in den einzelnen Funktionen heißen (wie in traditioneller Terminologie üblich) Präposition, Konjunktion, Adverb, daneben Satzadverb etc.

4) Die Modalpartikel-Forschung verfährt in dieser Hinsicht recht inkonsequent: zum Teil wird das Modalpartikel-Vorkommen als Funktion bezelchnet (Weydt 1969:51), zum Teil wird von einer Wortart Modal- bzw. Abtönungspartikel gesprochen, deren Elemente Homonyme in anderen Wortarten haben (Weydt/ Hentschel 1983:4f., Hentschel 1986:3f.; vgl. dazu auch Thurmair 1988:176).

5) Vgl. dazu z.B. die Untersuchung von Harden (1983), der die beiden "Modalpartikeln" eigentlich und überhaupt untersucht, ihren Status als Modalpartikeln aber nicht weiter begründet. Dabei ist die Einordnung von überhaupt als Modalpartikel nur schwer zu rechtfertigen, und auch bei eigentlich ist es in gewissen Fällen problematisch. Vgl. dazu auch Wolski (1986), der seine Zuord- 
partikel-Forschung zu Monographien über einzelne Partikeln ${ }^{6}$ ist ein Indiz dafür. Generell läßt sich für die Partikel-Literatur feststellen, da $\beta$ zwar einzelne Partikelgruppen behandelt werden, selten aber erfolgt ein abgrenzender Vergleich mit den restlichen Partikelfunktionen.

Daß es eine Reihe von Partikeln gibt, die sich trotz der genauen Beschreibung der einzelnen Partikelgruppen zunächst nicht elnordnen lassen, soll nicht geleugnet werden. Aber es ist - wenn die einzelnen Funktionen klar voneinander abgegrenzt sind - zumindest möglich, diese Partikeln einer Gruppe zuzuweisen, mit der sie möglichst viele Eigenschaften gemeinsam haben, sie also als Partikeln zu definieren, die am Rand einer Gruppe liegen.

Eines der wichtigsten Unterscheidungskriterien bei der Partikel-Klassifikation ist das Stellungsverhalten. Als topologisches Grundmodell für den deutschen Aussagesatz soll hier von der (virtuellen) Zweiteiligkeit des Verbs (u.a. gebildet durch Partikelverben und durch Tempus-, Modus- und Genusformen) ausgegangen werden. Die beiden Teile des Verbs gliedern den Satz in drei (Stellungs-)Felder: Vorfeld, Mittelfeld und Nachfeld.

Eine wichtige Rolle bei dem Versuch, die Unflektierbaren zu klassifizieren, spielt die Besetzung des Vorfeldes. In der Regel darf im Vorfeld nur ein Satzglied bzw. Stellungsglied stehen. Anders herum ausgedrückt: Was im Vorfeld stehen kann, zeigt immer satzgliedhaftes Verhalten bzw. hat Satzgliedwert (vgl. zu den Problemfällen Lühr 1985).

Ein Problem stellen in diesem Zusammenhang zunächst die Konjunktionen dar. Bereits seit Drach ist es üblich, sie nicht zum Satz zu rechnen (vgl. Engel 1970 und Velde 1977). Tatsächlich bilden Konjunktionen und die Konstituente im Vorfeld zusammen kein Satzglied. Die Position der Konjunktionen soll deshalb als Vorvorfeldposition bezelchnet werden. Als Indiz dafür, daß die Position der Konjunktionen wirklich vor dem Vorfeld ist, kann gelten, daß sie auch vor dem Verb auftreten in Sätzen, die kein Vorfeld haben (z.B. in Imperativsätzen).

Innerhalb der Vorvorfeldposition kann weiter unterschieden werden zwischen der Position der Konjunktionen (Intonatorisch integriert) und anderen Partikeln, die meist intonatorisch nicht integriert sind, einen Akzent tragen können und vom Restsatz durch eine Pause abgesetzt sind, die im Schriftbild durch Komma, Doppelpunkt oder Gedankenstrich markiert wird. ${ }^{7}$ Hier treten hauptsächlich bestimmte

nung 24 verschiedenen Funktionsklassen bzw. -typen jedenfalls nicht formal begründet (vgl. bes. Kap. 8.3 und 9.2).

6) Vgl. z.B. Gornik-Gerhardt (1981) (zu schon), Bastert (1985) (zu doch), Borst (1985) (zu doch, ja, schon) und Hentschel (1986) (zu ja, doch, halt und eben).

7) Thim-Mabrey (1985:248) nennt diese zwei Positionen Nullstelle vs. Junktionsstelle, trennt diese aber aufgrund funktionaler Kriterien. Inwieweit sich die 
Partikeln wie z.B. Konjunktionaladverbien oder Gliederungspartikeln auf, aber auch Anreden oder Ausrufe sowie Freies Thema (zur Funktion der Vorvorfeldausdrücke vgl. auch Thim-Mabrey 1988).

Bei der nun folgenden Klassifikation von Partikeln wird also geprüft, ob eine Partikel im Vorvorfeld auftreten kann, und ob sie dort intonatorisch integriert ist oder nicht.

Als weiteres Stellungskriterium wird untersucht, ob eine Partikel isoliert verwendet werden kann. Der Unterschied zwischen isolierter Verwendung und der nichtintegrierten Vorvorfeldposition liegt darin, daß bei letzterer die Partikel immer von einem Satz gefolgt sein muß; vgl. den Unterschied:

(1) Max: Wann bist du denn gekommen?

Uli: Heute. (isoliert)

"Heute, ich bin gekommen. (nichtintegrierte Vorvorfeldposition)

(2) Ute: Wie baut man ein Hügelbeet?

Ina: Ja, also das weiß ich auch nicht so genau.

Jedenfalls. (isoliert)

Jedenfalls, das ist sehr schwierig. (nichtintegrierte Vorvorfeldposition)

Weiter wird geprüft, ob die Partikel alleine im Vorfeld stehen kann und ob sie gegebenenfalls zusammen mit einer Bezugskonstituente vorfeldfähig ist (die attributive Verwendung von Adverbien bleibt hier unberücksichtigt).

Zusätzliche Kriterien sind die Fähigkeit einer Partikel, als Antwort auf eine Entscheidungsfrage oder eine $w$-Frage aufzutreten.

Schließlich wird noch berücksichtigt, inwieweit die Partikeln einer Gruppe sich untereinander verbinden können, sei es koordinierend (d.h. z.B. mit der Konjunktion und) oder als Kombination (d.h. ohne Konjunktion) und ob das Auftreten der Partikeln satzmodusabhängig ist (zum Satzmodus vgl. auch Kap. 1.3).8

Nach einer kurzen Beschreibung der einzelnen Partikelfunktionen sollen die Ergebnisse in einer Übersicht zusammengefaßt werden (s. S.20). Partikelfunktionen, bei denen sich keine Uberschneidungen mit möglichen 'Modalpartikel-Kandidaten' ergeben, wie Präpositionen, Vergleichspartikeln und Interjektionen, werden nicht weiter

beiden Positionen formal genügend unterscheiden, um auch terminologisch getrennt werden zu können, inwieweit also beispielsweise die Pause immer realisiert wird, müßte noch genauer erforscht werden.

8) Die angeführten Kriterien erfassen natürlich keineswegs alle Unterschiede zwischen den einzelnen Partikelgruppen - genügen aber für eine Abgrenzung der Modalpartikeln von den anderen Gruppen. Mögliche weitere Unterscheidungskriterien wären z.B.: mögliche Stellung im Mittelfeld oder im Nachfeld, Auftreten in (unselbständigen) Nebensätzen, Stellung in bezug auf die Negationspartikel und Fähigkeit, kontrastlerend negiert zu werden (bei Modalpartikeln immer inakzeptabel) oder Skopusbereich (Modalpartikeln haben - im Unterschied z.B. zu Gradpartikeln - immer Satzskopus; vgl. u.a. Weydt 1969:68 und Hartmann 1976:116 sowie (unzutreffend) Krivonosov 1963:260f. und Helbig/Kötz 1981:11f.). 
betrachtet. Die Eigenschaften der Modalpartikeln werden ausführlich in Kap. 1.2 erläutert. Die syntaktischen Eigenschaften der Negationspartikeln werden hier nicht weiter behandelt, denn diese Gruppe konstituiert sich vor allem aufgrund eines semantischen Kriteriums (mehr zur Negation s.u. Kap. 1.4). Syntaktisch verhalten sich die einzelnen Negationsträger sehr unterschiedlich (z.B. nicht in bestimmten Vorkommen wie eine Gradpartikel, keineswegs wie ein Satzadverb).

\subsubsection{Konjunktionen}

Das wesentliche funktionale Kennzeichen von Konjunktionen ist, daß sie Sätze oder einzelne Satzteile miteinander verbinden. Dabei macht die Konjunktion Angaben über die Art der Verknüpfung (vgl. Brauße 1983:2). Innerhalb der Konjunktionen lassen sich subordinierende und koordinierende Konjunktionen unterscheiden. Da subordinierende Konjunktionen Verb-Endstellung bewirken und aufgrund dieses syntaktischen Kriteriums klar einzuordnen sind - und sich außerdem keine Ubberschneidungen mit Ausdrücken in Modalpartikel-Funktion ergeben, sollen sie hier nicht weiter betrachtet werden. Koordinierende Konjunktionen treten (bei Sätzen mit Verb-Zweit-Stellung) mit einem Stellungsglied, mit dem sie keine Konstituente bilden, im Vorvorfeld auf, wenn sie ganze Sätze verbinden (vgl. (3)):

(3) Wir wollten das Auto heute verkaufen; und ich finde den Fahrzeugbrief einfach nicht mehr.

Außer der Konjunktion aber können in diesem Fall die Konjunktionen nicht im Mittelfeld stehen.

Auch im Vorvorfeld mit einer Intonationspause - im Schriftbild durch Komma o.ä. repräsentiert - lassen sich die koordinierenden Konjunktionen nachweisen:9

(4) Typisch, daß man ausgerechnet in dieser Jahreszeit reiste. Und: Warum hatte sie den Wintermantel nicht mitgenommen? (Ke, 187)

Isoliert kommen Konjunktionen ebenfalls vor, meist als reaktive Außerung; sie sind nicht erfragbar und können nicht als Antwort auftreten.

(5) Tom: Ich habe jetzt doch beim Verbraucherschutz angerufen. Su: Und?

9) Auch die unterordnenden Konjunktionen weil und manchmal auch obwohl werden in der gesprochenen Sprache gelegentlich im Vorvorfeld eines Verb-ZweitSatzes verwendet:

(i) Da ein Zuckerl und dort eins und alles freiwillig, damit du als Gewerkschaftler schon von Haus aus unwahrscheinlich schlecht liegst. Weil die sagen doch: Ohne Gewerkschaft. ( $\mathrm{Kr}, 70$ )

(ii) wo Se schon. sehen, wie ich damit zurecht komme. Obwohl, das stell ich mir furchtbar vor, wenn ich das noch nie gemacht hab. (BA, 177) 


\subsubsection{Konjunktionaladverbien}

Unter dem Begripf 'Konjunktionaladverbien' soll hier eine Gruppe von Partikeln (wie immerhin, außcrdem, jedoch, trotzdem, schließlich etc.) zusammengefaßt werden, deren Funktion der der koordinierenden Konjunktionen entspricht; d.h. auch Konjunktionaladverbien verknüpfen zwei Teilsätze inhaltlich, verhalten sich aber syntaktisch anders als Konjunktionen. Konjunktionaladverbien können nämlich im Unterschied $\mathrm{zu}$ den koordinierenden Konjunktionen - alleine das Vorfeld besetzen,10 d.h. sie zeigen satzglicdhaftes Verhalten; vgl.:

(6) Aber er (=Lerby) ist eben keine "fränkische Eiche", wie sich Matthäus mit Recht sieht - schließlich hat er alle Kontakte von Rummenigge, dem Alteren, bis zu Rummenigge, dem Jüngeren, ohne Folgen überstanden. (SZ)

(7) Das Wetter war eigentlich recht gut, trotzdem sind wir richt Schi gefahren.

Die Position im Vorvorfeld ist bei den Konjunktionaladverbien nur nicht-integriert - also mit deutlicher Intonationspause - möglich; vgl.:

(7a) ... trotzdem wir sind nicht schi gefahren.

(7b) ...trotzdem: wir sind nicht Schi gefahren.

(8) Vielleicht könnte das Weiße Haus geeignete Videoclips zu einem Trainingsprogramm zusammenstellen. Immerhin, das Freudestrahlen klappte schon ganz hübsch. (SZ)

Auch im Mittelfeld können Konjunktionaladverbien auftreten (und auch hierin unterscheidet sich ihr Stellungsverhalten von dem der koordinierenden Konjunktionen, wenn diese ganze Sätze verbinden):

(9) Wir sollten die Heizung anstellen. Wir haben schließlich schon Oktober.

Konjunktionaladverbien können keine Antwort auf Fragen bilden - und hierin unterscheiden sie sich von den Adverbien.

Ein Teil der Konjunktionaladverbien kann auch isoliert auftreten:

(10) Anke: "Das werden auch einige sein!". Nee, das is ja ein anderes "werden", das ist ja kein Futur-werden.

Peter: Jaja.

Anke: Immerhin.

Peter: Immerhin! (BA, 81)

Konjunktionaladverbien sind satzmodusabhängig: sie treten alle in Aussagesätzen auf, können nicht in Exklamativen vorkommen und zum Teil (z.B. immerhin, schließlich) nicht in Fragesätzen, Imperativsätzen oder Wunschsätzen (zu den Satztypen s.u. Kap. 1.3.1).

Bestimmte Partikeln wie doch und nur Pungieren sowohl als Konjunktionen als auch als Konjunktionaladverbien:"11

10) Eine Ausnahme stellt nämlich dar, das nicht im Vorfeld stehen kann.

11) Einen weiteren Vorschlag zur Unterteilung der Partikeln in diesem Bereich bringt Thim-Mabrey (1985); sie setzt drei Gruppen von "Satzkonnektoren" an: 
(11) Der Zustand der Frau habe sich etwas stabilisiert, doch schwebe sie noch immer in Lebensgefahr. (SZ) (Konjunktionaladverb)

(11a) ...doch sie schwebe noch immer in Lebensgefahr. (Konjunktion)

\subsubsection{Adverbien}

Die' 'echten' Adverbien lassen sich (nach semantischen Gesichtspunkten) unterteilen in lokale (hier, dort), temporale (jetzt, gestern) und modale im weiteren Sinne (gern). Dabei können durchaus noch Subkategorien (wie z.B. durative und iterative Adverbien) unterschieden werden.

Adverbien sind nicht flektierbar, sind aber zum Tell steigerbar und insofern morphologisch nicht völlig unveränderbar (wie die anderen Partikeln).

Adverblen als Adverbiale können allein das Vorfeld füllen, zeigen also satzgliedhaftes Verhalten; vgl.:

(12) Jetzt haben wir endlich einen neuen Mitarbeiter.

Häufig sind Adverbien erfragbar durch wann?, wo?, und wie? und können umgekehrt auch isoliert als Einwortsatz auftreten:

(13) Carl: Wann wird der Film denn gesendet?

Hans: Morgen.

\subsubsection{Satzadverbien}

Mit dem Begripf Satzadverbien ${ }^{12}$ wird eine Gruppe von Partikeln ${ }^{13}$ wie vermutlich, hoffentlich, sicher, bestimmt, vielleicht, tatsächlich, natürlich, kaum, leider, klugerweise etc. in Verwendungen wie (14)-(16) bezeichnet:

(14) Vielleicht könnte das Weiße Haus geeignete Videoclips zu einem Trainingsprogramm zusammenstellen. (SZ.)

(15) Die Abiturthemen werden sicher wieder recht abgedroschen sein.

(16) Leider müssen wir heute früher Schluß machen.

die Konjunktionen, die nur an der Nullstelle (d.h. nicht-integriert im Vorvorfeld) auftreten können, die Konjunktionaladverbien, die nur an der Erststelle (d.h. allein im Vorfeld) und die Para-Konjunktionen, die sowohl an der Nullstelle als auch an der Erststelle vorkommen können (28ff.). Allerdings möchte ich diese Klassifikation hier nicht aufgreifen, da ich eine weitere Partikelfunktion zum einen für verwirrend halte und außerdem Thim-Mabreys These. die Para-Konjunktionen (und nur diese) seien auf einen "elliptischen metakommunikativen Hypersatz" (220) zurückzuführen, nicht teilen kann. In dieser Arbeit sollen die Ausdrücke, die Thim-Mabrey als Para-Konjunktionen bezeichnet, eingeordnet werden als Partikeln, die sowohl Konjunktionen als auch Konjunktionaladverbien sein können (vgl. dagegen Thim-Mabrey 1985:115P.).

12) Admoni (1982:207) nennt diese Ausdrücke Modalwörter; die Termini 'Satzad' verb' und 'Modalwort' behandle ich als synonym.

13) Die u.a. von Bublitz (1978:36) angeführte Fähigkeit bestimmter Satzadverbien. steigerbar zu sein (wahrscheinlich - wahrscheinlicher) bezieht sich nicht aul das Element in Satzadverb-Funktion. 
Satzadverbien bringen die subjektive Einschätzung eines Sachverhalts durch den Sprecher zum Ausdruck; diese Einschätzung kann entweder den Realitätsgrad des Sachverhalts betreffen (kaum, wahrscheinlich, vermutlich, sicher) oder aber die emotionelle Einstellung des Sprechers ausdrücken (leider, hoffentlich) (vgl. Admoni 1982:207).

Satzadverbien modifizieren - im Gegensatz zu den modalen Adverbien - in der Regel den Gesamtsatz, haben Satzskopus. Topologisch verhalten sich Satzadverbien wie Stellungsglieder, d.h. sie können bei einem Satz mit Zweitstellung des finiten Verbs alleine das Vorfeld füllen (vgl. oben (14) und (16)); $;^{14}$ bisweilen finden sie sich auch intonatorisch abgesetzt im Vorvorfeld (vgl. (17)).

(17) Jetzt weiß ich, woran das liegt. Natürlich, Strauß, der ist doch Oberbayer. (SZ)

Satzadverbien sind - im Gegensatz zu echten Adverbien - nicht erfragbar:15

(15a) "Wie werden die Abiturthemen wieder recht sein?

Satzadverbien können als Antwort auf eine Entscheidungsfrage dienen (vgl. (18)); in diesem Fall sind sie auch in einen möglichen Antwortsatz integrierbar:

(18) Chef: Haben Sie die Korrespondenz erledigt?

Sekretärin: Sicher. /Sicher habe ich das gemacht.

Satzadverbien sind satzmodusabhängig: alle Satzadverbien können in Aussagesătzen auftreten, und nur einige wenige (wirklich, tatsächlich, bestimmt, möglicherweise) finden sich auch in anderen Satzmodi (vgl. dazu auch Lang 1979:206f.):16

14) Lediglich in der Variante $z u$ einem adjektivischen oder partizipialen Attribut oder - seltener - fokusbindend treten Satzadverbien auch zusammen mit einer Konstituente im Vorfeld auf: Das bestimmt wichtigste Detall in dieser Salson sind die Schulterpolster.

15) Allerdings kann die subjektive Einschätzung eines Sachverhalts durch einen Sprecher unter Umständen durch Fragen wie (i) erfragt werden:

(i) A: Liebst du mich? B: Ja. A: Liebst du mich sicher oder vielleicht?

Vgl. dagegen Lang (1979:207), der die These vertritt, Satzadverbien könnten "nicht alternativ erfragt oder gegenübergestellt werden".

16) Geht man in diesem Zusammenhang von der von Lang (1979:201) vorgeschlagenen Unterteilung der Satzadverbien in die Gruppen A (vermutlich, wahrscheinlich, möglicherweise, vielleicht), B (bedauerlicherweise, leider, überraschenderweise, klugerweise) und $\mathrm{C}$ (tatsächlich, wirklich) aus, so zeigt sich, daß die Satzadverbien, die auch in anderen Satzmodi als dem Aussagesatz auftreten, denen der Gruppe $C$ (wozu ich auch bestimmt rechnen würde) entsprechen, mit zwei (von Lang übersehenen) Ausnahmen: die Satzadverbien möglicherweise und vielleicht, das allerdings nicht immer klar von der Modalpartikel abzugrenzen ist, können auch in Fragen auftreten:

(i) Wissen Sie vielleicht, wer hier für die Nachzahlungen zuständig ist?

(ii) Ist dieser Bricf möglicherweise der Grund für Ihr seltsames Verhalten?

Die (erweiterte) Gruppe $C$ der Satzadverbien sollte m.E. eine Sonderstellung einnehmen, da die Elemente dieser Gruppe offensichtlich kaum satzmodusabhängig sind und zusätzlich intensivierende Funktion haben. Das Vorkommen von vielleicht und möglicherweise in Fragen bleibt dann weiterhin elne noch zu klärende Ausnahme. 
(19) Studierst du wirklich/tatsächlich noch?

(20) Bist du im Frühjahr auch bestimmt fertig?

(21) Wer hat tatsächlich bezahlt?

(22) Ruf aber bestimmt an!

Die Restriktionen in der Verwendung der meisten Satzadverbien in Fragen, Aupforderungen und in wünschen lassen sich dadurch erklären, daß die durch die entsprechenden Satzadverbien ausgedrückte subjektive Einstellung mit den Verwendungsbedingungen kollidiert, die durch den Satzmodus enstehen: Sowohl bei Aufforderungen als auch bei wünschen besteht der gewünschte bzw. geäußerte Sachverhalt zum Zeitpunkt der Außerung nicht, bei Fragen ist er in irgendeiner Hinsicht offen. Ein nicht-existenter bzw. offener Sachverhalt kann aber in seiner Gültigkeit weder eingeschränkt (z.B. durch vermutlich oder wahrscheinlich) noch beurteilt (wie z.B. durch leider) werden. Ahnlich kann auch das Nicht-Auftreten von Satzadverbien in Ausrufen erklärt werden: Mit einem Ausruf drückt der Sprecher seine oberraschung über einen sachverhalt aus, der aber feststeht und deshalb auch nicht in seiner Gültigkeit eingeschränkt werden kann.

Satzadverbien sind nicht koordinierbar und untereinander kaum kombinierbar (vgl. dazu genauer Bartsch 1971:226ff. und Lang 1979:204ff.).

(23) Lena ist leider wirklich verreist.

Lena kommt wahrscheinlich klugerweise später.

(24) "Lens kommt wahrscheinlich vermutlich morgen.

"Lena kommt wahrscheinlich angeblich morgen.

"Lens kommt vermutlich bekanntlich morgen.

"Lena kommt hoffentlich leider morgen.

(25) "Lena ist leider und wirklich verreist.

"Lena kommt wahrscheinlich und vermutlich morgen.

\subsubsection{Steigerungspartikeln}

Steigerungspartikeln sind eher von ihrer semantischen Funktion her als Gruppe zu definieren: Sie intensivieren die durch ihr Bezugselement ausgedrückte Bedeuturg. Dieses Bezugselement ist in den meisten Fällen ein (relationales) Adjektiv, seltener ein Adverb oder Verb. Stelgerungspartikeln stehen unmittelbar vor ihrem $B e^{-}$ zugselement (sofern es nicht das Verb ist) und können auch nur mit diesem zusammen verschoben werden

(26) Dein Gedicht hat mir sehr gut gefallen.

Zusammen mit ihrem Bezugselement kann dic Steigerungspartikel auch im Vorfeld stehen, allein jedoch nicht (m.E. auch dann nicht, wenn das Verb die Bezugskonstituente ist); vgl. (26a) und (26b):

(26a) Sehr gut hat mir dein Gedicht gefallen. 
(26b) "Sehr hat mir dein Gedicht gut gefallen.

?"Sehr hat mir dein Gedicht gefallen.

Steigerungspartikeln sind betonbar und sie sind erfragbar:

(27) Ina: Wie teuer sind diese Rennräder?

Hans: Irrsinnig teuer.

Auch (isollert) als Antwort auf Entscheidungsfragen treten Steigerungspartikeln auf; in diesem Fall stellt das Verb das Bezugselement dar:

(28) Ina: Liebst du sie?

Hans: Sehr.

Steigerungspartikeln lassen sich auch kombinieren; vgl.:

(29) Das war echt total gut.

Bei der Gruppe der Steigerungspartikeln kann man unterscheiden zwischen Partikeln, die nur als Steigerungspartikeln auftreten (wie sehr, ungemein) und (ehemaligen) Adjektiven, die diese Funktion übernehmen können (wie ungewöhnlich. wahnsinnig, irre).

Steigerungspartikeln stellen eine - besonders in gesprochener Sprache und in der Jugendsprache - höchst produktive Wortklasse dar.

\subsubsection{Gradpartikeln}

Die Gruppe der Gradpartikeln setzt sich zusammen aus Ausdrücken wie nur, bloß, lediglich, allein, ausschließlich, einzig, auch, selbst, gerade, eben, wenigstens etc. Unter dem Terminus 'Gradpartikel' sollen hier mit Altmann (1976:1) Partikeln verstanden werden, die "mit einer (im allgemeinen kontrastiv betonten) Konstituente semantisch verknüpft werden und diese Konstituente in eine quantifizierende $\mathrm{Be}-$ ziehung zu typgleichen Konstituenten setzen". Dabel ist quantifizierende und skallerende Interpretation möglich. Gradpartikeln haben immer eine Bezugskonstituente, die von der Gradpartikel fokussiert wird. In deriRegel steht die Gradpartikel "unmittelbar vor derjenigen Konstituente, der sie syntaktisch zugeordnet ist" (Altmann 1978:22), und der Satzakzent liegt aup der jewelligen Zuordnungskonstituente (Altmann 1978:97).17

(30) Bis jetzt hab ich nur die Armel angenäht; den Kragen mach ich später.

In seltenen Fällen kann der Fokus einer Gradpartikel auch der ganze Satz sein. Gradpartikeln können nicht allein das Vorfeld füllen, sind aber zusammen mit ih-

17) Das von Willkop (1988:63) angeführte isolierte Vorkommen einiger Gradpartikeln als Antwort wird hier nicht weiter berücksichtigt: Hast du heute schon gearbeitet? - Nur! 
rer Bezugskonstituente ${ }^{18}$ im Vorfeld möglich (vgl. (31)) - auch nach einer Konjunktion (vgl. (32)):

(31) Lediglich die Neureichen tragen heute noch goldene Armbanduhren.

(32) Eine Nachtbar für die Geschäftsleute aus dem Westen? Aber auch das ist 24 haben - im Forum ganz solide. (SZ)

In einem Satz können mehrere Gradpartikeln im Regelfall nur mit unterschiedlichen Bezugskonstituenten auftreten; sie sind also kaum kombinierbar - allenfalls mit Gradpartikeln aus verschiedenen semantischen Gruppen; vgl.:

(33a) Auch nur ein Osterei würde mir genügen.

(33b) "Ich habe lediglich einzig ein Osterei.

Durch die Konjunktion und können Gradpartikeln in seltenen Fällen auch koordiniert werden; vgl.:

(34) Einzig und allein eln deus ex machina kann uns jetzt noch helfen.

\subsubsection{Gliederungspartikeln}

Unter Gliederungspartikeln sollen diejenigen Partikeln verstanden werden, die isoliert auftretend im Sinne einer Reaktion des Sprechers verwendet werden können. Dazu gehören auch die sonst als 'Antwortpartikeln' bezeichneten Partikeln ja, nein und doch. Wichtigstes gemeinsames Kennzeichen der Gliederungspartikeln ist ihre dialogsteuernde Funktion (vgl. dazu genauer Willkop 1988).

Formal zeichnen sich die Gliederungspartikeln dadurch aus, daß sie als Vor- odei Nachschaltungen nicht syntaktisch und intonatorisch integriert sind (also vor dem Vorfeld oder nach dem Nachfeld bzw. parenthetisch eingeschoben auftreten) und $\mathrm{da} \beta$ sie isoliert verwendet werden können, also als Satzäquivalente fungieren bzw. satzwertig sind; vgl.:

(35) Chef: Sind die Werbebriefe schon raus?

Lehrling: Hab ich gestern schon gemacht, ja.

(36) Liss: Und dann meinte sie, ja, das hätte sie ja noch keinem erzählt. Aber das wär ja eigentlich Quatsch, warum sollte man das keinem erzählen, das wär ja nichts Schlimmes!

Anna: Ja, ne?

LIsa: Eben. Solang sie sich dabei wohlfühlt. (BA, 53)

Gliederungspartikeln können nicht syntaktisch integriert werden ${ }^{19}$ - und das

18) Vgl. dagegen Jacobs (1983:40ff.), der die These vertritt, Gradpartikeln und das Element im Vorfeld seien keine Konstituente.

19) Da Gliederungspartikeln nicht in einem Satz integriert auftreten können, ist das Kriterium der Satzmodusabhängigkeit bei innen etwas problematisch; au! jeden Fall können aber die meisten Gliederungspartikeln im Vorvorfeld und nach dem Nachfeld jedes Satztyps auftreten (vgl. Willkop 1988:61, 72) - und sind insofern nicht satzmodusabhängig. 
unterscheidet sie von den ebenfalls isoliert als Reaktion und nicht integriert im Vorvorfeld auftretenden Satzadverbien:

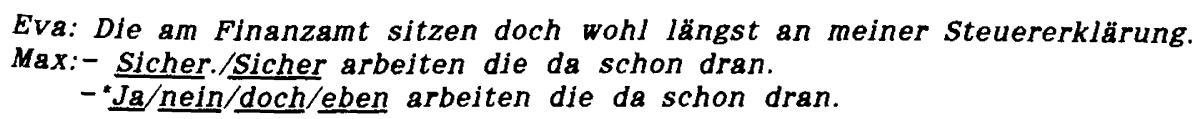

$J a$, nein und doch unterscheiden sich von den anderen Gliederungspartikeln dadurch, daß sie auch als Antwort auf Entscheidungsfragen stehen können.

Gliederungspartikeln sind untereinander kombinierbar; vgl.:

Olga: Ja, an sich müßt ich Sie beglückwünschen, aber ich seh gar nich ein, ich meine, is schon lange her, als ich Sie eben Sie gesehn hab, aber. daß Sie überhaupt abnehmen mußten!

Karl: Ja, doch. (BA, 146)

steuernd - können auch viele Interjektionen eingesetzt werden. Syntaktisch wer-
den diese genau wie die Gliederungspartikeln meist isoliert oder nicht-integriert verwendet; $20 \mathrm{vgl}$ :

(39) Anna: Dann hat se mir auch erklärt, woran das liegt, daß mir das wieder passiert ist, das läg nur daran, daß ich zu oberflächlich wäre und überhaupt nicht nachdenken würde.

Lisa: $\underline{A u}$ !

Anna: und, öh, aus mir würde ja nie was, wenn ich nen eigenen Haushalt mal hätte, dann würd ich im eigenen Dreck verkommen.

Lisa: Au! (BA, 44)

\subsubsection{Zusammenfassung}

Abschließend soll hier eine Ubersicht gegeben werden über die syntaktischdistributionellen Eigenschaften der verschiedenen Partikelgruppen.

Um die Matrix nicht zu unubersichtlich zu gestalten, ist bei den einzelnen Partikelgruppen das jeweils prototypische Verhalten beschrieben. Idiosynkrasien einzelner Ausdrücke in einem Kriterium habe ich dabei vernachlässigt. Verhalten sich mehrere Partikeln einer Funktion in einem Kriterium unterschiedlich, wird das mit einer Doppelmarkierung angezeigt.

Angaben in Klammern beziehen sich auf ausgesprochen seltene Phänomene. (Die Kennzeichen der Konjunktionen beschreiben nur die koordinierenden Konjunktionen, da sich nur hier Uberschneidungen mit anderen Partikelfunktionen ergeben.) Die Modalpartikeln sind hier mit aufgefüht, um zu zeigen, in welchen Punkten sie sich von anderen Partikelfunktionen unterscheiden. Ihre Eigenschaften werden ausführlich in Kap. 1.2 besprochen.

20) Aus diesem Grund sollten (wie Willkop 1988 vorschlägt) einige der Interjektionen zu den Gliederungspartikeln gerechnet werden. 
Tabelle 1: Partikelklassifikation

\begin{tabular}{|c|c|c|c|c|c|c|c|c|}
\hline & $\begin{array}{l}\text { Koord. } \\
\text { Konj. }\end{array}$ & $\begin{array}{l}\text { Konj-- } \\
\text { adv. }\end{array}$ & $\begin{array}{l}\text { Ad- } \\
\text { verb }\end{array}$ & $\begin{array}{l}\text { Satz- } \\
\text { adv. }\end{array}$ & $\begin{array}{l}\text { Steig:- } \\
\text { part. }\end{array}$ & $\begin{array}{l}\text { Grad- } \\
\text { part. }\end{array}$ & $\begin{array}{l}\text { Gliede- } \\
\text { rungsp. }\end{array}$ & $\begin{array}{l}\text { Modal- } \\
\text { part. }\end{array}$ \\
\hline betonbar & + & + & + & + & + & + & + & - \\
\hline isoliert & + & $+/-$ & + & + & + & - & + & - \\
\hline $\begin{array}{l}\text { Vorvorfeld } \\
\text { nicht-integr. }\end{array}$ & + & + & - & + & - & - & + & - \\
\hline $\begin{array}{l}\text { Vorvorfeld } \\
\text { integriert }\end{array}$ & + & - & - & - & - & - & - & - \\
\hline $\begin{array}{l}\text { alleine im } \\
\text { Vorfeld }\end{array}$ & - & + & + & + & - & - & - & - \\
\hline $\begin{array}{l}\text { mit Bezugs- } \\
\text { konst.Vorfeld }\end{array}$ & - & - & - & - & + & + & - & - \\
\hline $\begin{array}{l}\text { Antwort auf } \\
\text { Entsch.frage }\end{array}$ & - & - & - & + & + & - & $+1-$ & - \\
\hline $\begin{array}{l}\text { Antwort auf } \\
\text {-Frage }\end{array}$ & - & - & + & - & + & - & - & - \\
\hline koordinierbar & & - & + & - & - & $(t)$ & - & - \\
\hline kombinierbar & $(+)$ & - & $(+)$ & $(+)$ & + & $(+)$ & + & + \\
\hline $\begin{array}{l}\text { satzmodus - } \\
\text { abhängig }\end{array}$ & - & + & - & + & - & - & - & + \\
\hline
\end{tabular}

Daß es sich bei den hier etablierten Partikelgruppen nicht um Wortarten oder Wortklassen handelt, sondern um Funktionen, die bestimmte Partikelgruppen übernehmen können, wurde schon angesprochen. Das zelgt auch die Tatsache, daß die meisten Partikeln polyfunktional sind, also in zwel und mehr Funktionen auftreten können.

Diese Funktionen lassen sich aber durchaus - wie oben gezeigt - unterscheiden, und die Unterschiede können syntaktisch-distributionell ausgedrückt werden. Natürlich bestehen $z$ wischen den einzelnen Partikelfunktionen distributionelle Obergangszonen (wie ich sie im nächsten Kapitel für die Modalpartikeln genauer darstellen werde), aber im Text gibt es in den meisten Fälen genug Faktoren, die disambiguierend wirken. Darauf werde ich bel der Beschreibung der einzelnen Partlkeln genauer eingehen.

Die Polyfunktionalităt einiger Partikeln zeigt die folgende Ubersicht. 
Tabelle 2: Polyfunktionalität im Bereich der Partikeln

\begin{tabular}{|c|c|c|c|c|c|c|c|c|c|c|}
\hline & $\begin{array}{l}\text { Koord. } \\
\text { Konj. }\end{array}$ & $\begin{array}{l}\text { Konj:- } \\
\text { adv. }\end{array}$ & $\begin{array}{l}\text { Ad- } \\
\text { verb }\end{array}$ & $\begin{array}{l}\text { Satz- } \\
\text { adv. }\end{array}$ & $\begin{array}{l}\text { Steig- } \\
\text { part. }\end{array}$ & $\begin{array}{l}\text { Grad- } \\
\text { part. }\end{array}$ & $\begin{array}{l}\text { Gllede- } \\
\text { rungsp. }\end{array}$ & $\begin{array}{l}\text { Modal- } \\
\text { part. }\end{array}$ & $\begin{array}{l}\text { Nega- } \\
\text { tionsp. }\end{array}$ & $\begin{array}{l}\text { Adjek- } \\
\text { tiv }\end{array}$ \\
\hline $\begin{array}{l}\text { aber } \\
\text { allein } \\
\text { auch } \\
\text { denn } \\
\text { doch } \\
\text { eben } \\
\text { eigentlich } \\
\text { einfach } \\
\text { ja } \\
\text { kaum } \\
\text { nicht } \\
\text { nur } \\
\text { schließlich } \\
\text { schon } \\
\text { vielleicht } \\
\text { wenigstens }\end{array}$ & $\begin{array}{l}+ \\
+ \\
+ \\
+ \\
+\end{array}$ & $\begin{array}{l}+ \\
+ \\
+\end{array}$ & $\begin{array}{l}+ \\
?^{21} \\
?^{21} \\
+ \\
+\end{array}$ & + & + & $\begin{array}{l}+ \\
+\end{array}$ & $\begin{array}{l}+ \\
+ \\
+ \\
+ \\
+ \\
+ \\
+ \\
+\end{array}$ & $\begin{array}{l}+ \\
+ \\
+ \\
+ \\
+ \\
+ \\
+ \\
+ \\
+ \\
+\end{array}$ & + & $\begin{array}{l}+ \\
+ \\
+\end{array}$ \\
\hline
\end{tabular}

\subsection{Formale Kennzeichen der Modalpartikeln}

Das Polgende Kapitel beschäftigt sich mit den formalen - d.h. morphologischen und syntaktischen - Ejgenschaften der Modalpartikeln. Dabei sollen die Kriterien dargestellt werden, mit denen die Modalpartikeln in der Regel definiert und von anderen Partikelfunktionen abgegrenzt werden. Vor allem möchte ich in diesem Zusammenhang auch auf die Problematik dieser Kriterien und auf generelle Abgrenzungsprobleme eingehen.

Dies werde ich zunächst an den Partikeln erläutern, die im allgemeinen ${ }^{24}$ zu den Modalpartikeln gerechnet werden: aber, auch, bloß, denn, doch, eben, eigentlich, einfach, etwa, halt, ja, mal, nur, ruhig, schon, vielleicht und wohl.

21) Gemeint sind hier satzintegrierte akzentuierte Vorkommen wie: Und die Bibel hat doch recht!. In der Forschung werden doch bzw. denn in dieser Funktion zum Teil (unbefriedigend) als Adverbien bezeichnet (vgl. z.B. Hentschel 1986: 126) oder (unzutreffend) als Abtönungspartikel (z.B. Weydt et al. 1983:162 und Weydt 1986:401). Weiter unten (s.S. 110f.) werden diese Partikeln in der angefuhrten Funktion zusammen mit betontem schon und wohl (versuchsweise)

22) als 'Affirmationsadverbien' klassifiziert.

Es handelt sich hier um Vorkommen von ja wie in: Diese Art von Pädagogik kann offenen Einblick aushalten, ja fordert zum Mitmachen auf, bei denen die

23) Funktion von $j a$ am ehesten der einer Konjunktion entspricht.

23) Vgl. dazu genauer S. $146 \mathrm{ff}$.

24) Vgl. u.a. Becker (1976), Bublitz (1978), Franck (1980), Heinrichs (1981), Helbig/Kötz (1981), Hentschel (1986), Kemme (1979), Weydt (1969) und Weydt/ Hentschel (1983). 


\subsubsection{Unflektierbarkeit}

Als zur Klasse der Partikeln gehörig sind Modalpartikeln natürlich immer morphologisch unveränderbar. Dieses Kriterium gilt zwar für alle Modaipartikeln bzw. modalpartikel-verdächtigen Ausdrücke, ist aber kein geeignetes Kriterium, um die Modalpartikel-Funktion einer Partikel von anderen Funktionen derselben Partikel zu trennen.

Eine Ausnahme stellen hier bloß, eben, eigentlich, einfach und ruhig dar, die auch als Adjektive auftreten und in dieser Funktion natürlich flektierbar sind. Hies machen aber andere Kriterien (z.B. die Stellung) die Unterscheidung zwischen der Funktion als Adjektiv und der als Modalpartikel unproblematisch.

\subsubsection{Unbetonbarkeit}

Als eine weitere Haupteigenschaft der Modalpartikeln gilt, daß sie unbetont bzw. unbetonbar sind (vgl. dazu schon Weydt 1969:68). Trägt ein Ausdruck, der auch Modalpartikel sein kann, einen Akzent, liegt er in einer anderen Funktion vor, etwa als Gradpartikel oder als Satzadverb; hier wirkt also der Akzent disambiguierend (vgl. Bublitz 1978:37):

(1a) Daß der nie zu Hause ist, wundert mich nicht. Der ist auch POLITIKER. ${ }^{25}$ (auch = Modalpartikel)

(1b) Tom: Mein Vater ist Politiker. Und deiner? Tim: Der ist AUCH Politiker. (auch = Gradpartikel)

(2a) Wie HEISST du eigentlich? (eigentlich = Modalpartikel)

(2b) Wie heißt du EIGENTLICH? (eigentlich = Satzadverb) ${ }^{26}$

Tatsächlich können Modalpartikeln keinen (syntaktischen) Fokusakzent tragen, müssen aber - wenn sie nicht einsilbig sind - einen Wortakzent haben.

Eine Ausnahme hinsichtlich der Unbetontheit von Modalpartikeln stellen nur die Partikeln ja, bloß und nur in bestimmten Verwendungen, meist Imperativsätzen. dar; (dabei muß $j a$ in dieser Verwendung einen Akzent tragen, bei blo $\beta$ und nut ist er Pakultativ):

(3) Mach $\underline{J A}$ deine Hausaufgaben!

(4) Vergiß BLOSS das Blumengießen nicht!

(5) Mach NUR nicht wieder die Schneeketten zu früh runter!

Nun kann man das Kriterium der Unbetonbarkeit als notwendiges Kriterium sehen dann können ja, bloß und nur in dieser Verwendung nicht als Modalpartikeln bezeichnet werden. Dies ist allerdings recht unplausibel, da die Funktion der drel

25) Großschreibung soll in dieser Arbeit Akzentuierung anzeigen.

26) Zum intonatorischen Verhalten von eigentlich und zur Abgrenzung von eigent" lich als Satzadverb und als Modalpartikel vgl. Oppenrieder/Thurmair (1988). 
Partikeln durchaus der Funktion der Modalpartikeln gleicht. Gilt das Kriterium der Unbetonbarkeit nicht als notwendig, ergeben sich aber bei anderen Partikeln unter Umständen Abgrenzungsprobleme, denn eine Partikel dürfte dann nicht nur aufgrund ihrer Betonung nicht als Modalpartikel klassifiziert werden.

Tatsächlich aber handelt es sich in Fällen wie (3)-(5) um einen anderen Akzent als beispielsweise in ( $1 \mathrm{~b})$ oder (2b). Der Akzent auf $j a, b l o \beta$ und nur ist kein Fokusakzent; es gibt bel diesen Außerungen immer ein weiteres betontes Element:

(3a) Mach JA deine HAUSAUFGABEN!

(4a) Vergiß BLOSS das BLUMENGIESSEN nicht!

Vermutlich handelt es sich in diesen Fällen bei dem Akzent auf den Partikeln um einen 'emphatischen' Akzent. Dafür spricht auch, daß alle diese Modalpartikeln dazu dienen, einen Illokutionstyp 'dringliche Aufforderung' oder 'Drohung' zu kennzeichnen und auch, daß (wie noch gezeigt wird (Kap. 2.2.14)) nur - das als Modalpartikel lediglich in negierten Außerungen akzentuiert werden kann - diese Illokution auch nur in negierten Aufforderungen anzeigen kann.

Für alle anderen Verwendungen von bloß und nur und für alle anderen Modalpartikeln gilt aber das Kriterium der Nicht-Akzentuierbarkeit; und es gllt immer, daß Modalpartikeln (im Unterschied zu Partikeln in anderen Funktionen) keinen Fokusakzent (vgl. (6)) tragen können.

Auch kontrastierende Negation (vgl. Jacobs 1982:34ff.) ist bei anderen Partikelgruppen in begrenztem Umfang möglich, bei Modalpartikeln aber immer inakzeptabel (s. auch Kap. 1.4):

(6) Er: Sie ist doch gekommen.

Sie: (Nein.) "Sie ist HALT gekommen.

(7) Er: Frau Fischer und Herr Blück haben vermutlich ein Verhältnis.

Er: Frau Fischer und Herr Blunck haben vermutlich ein Verhälnis.
Sie: Die haben nicht vermutlich ein Verhältnis, sondern ganz sicher. Sie hat es mir nämlich erzählt.

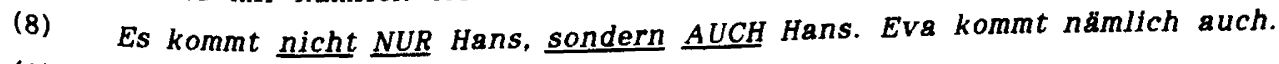

(9) 'Er hat das nicht doch, sondern halt gemacht.

Modalpartikeln können also nicht durch Akzent hervorgehoben werden und auch nicht durch bestimmte Stellungsveränderungen (etwa Herausstellung). Sie sind auch nicht erfragbar. Es gibt also keine Möglichkeit der Hervorhebung oder auch Thematisierung von Modalpartikeln. ${ }^{27}$

27) Andere Partikelgruppen, wie z.B. Satzadverbien, Gradpartikeln oder Konjunktionen sind $z$ war auch nicht durch ein w-Wort erfragbar; aber es ist in gewissem Umfang" möglich, sich (metasprachlich) durch Fragen - oft AlternativPragen - aup sie zu beziehen; vgl.:

(i) A: Ich habe gehört, die beiden sollen ein Verhältnis haben.

$B$ : Haben sie vielleicht ein Verhältnis oder sicher?

(ii) A: Naja, zur Zeit ist er leider den ganzen Tag daheim.

B: Wieso leider? Nervt dich das denn? 


\subsubsection{Fakultative Elemente}

Modalpartikeln, die keinen Satzgliedstatus haben, gelten - wie viele andere Partikelgruppen auch (z.B. Gradpartikeln) - als fakultative Elemente; d.h. also, aufgrund formaler Kriterien sind Modalpartikeln weglaßbar (aus semantisch-pragmatischen natürlich nicht immer).

Es scheint allerdings Satztypen zu geben, in denen eine Modalpartikel auch aus syntaktischen Gründen obligatorisch ist; dabei lassen sich drei Fälle unterscheiden:

1. Zunächst ein Vorkommen von doch in Verb-Erst-Sätzen:

(10) Dann kam der Olschock. Die Krise traf Marseille extrem schmerzhaft, ist doch der riesige Hafen zu achtzig Prozent vom Olgeschäft abhängig. (ZEIT)

(11) Aufs Amüsante ist man leicht zu programmieren, zumal in einer Freitagnacht im August. Signalisierte doch der Thementitel der Gesprächsrunde Ironie und lief doch als Auftakt nochmal jener fabelhafte Loriot-Sketch. (SZ)

In den Beispielen $(10) /(11)$ ist doch obligatorisch; ${ }^{28} \mathrm{vgl.:}$

(10a) ...traf schmerzhaft. "Ist der riesige Hafen $z u$ achtzig Prozent vom Olgeschäft abhängig.

Die Sätze mit doch lassen sich mit leichter Bedeutungsveränderung in Sätze mit der Konjunktion denn umformen; vgl.:

(10b) ... traf schmerzhaft, denn der riesige Hafen ist (doch/schließlich) vom OIgeschäft abhängig.

Das könnte ein Hinweis darauf sein, daß doch hier in konjunktionaler Verwendun vorliegt. Dagegen sprechen aber alle Arten der Umformung, die bei einer Konjunktion oder einem Konjunktionaladverb möglich sein müßten, denn bei einer Umfor mung bleibt die Art der Konjunktion (d.h. die semantische Relation zwischen den beiden Sätzen) nicht erhalten; vgl.:

(10c) ...traf schmerzhaft, doch der Hafen ist vom Olgeschäft abhängig. entspricht nicht:

...traf schmerzhaft, doch ist der Hafen vom Olgeschäft abhängig.

M.E. muß doch in Verwendungsweisen vom Typ (10) und (11) als Modalpartikel klassifiziert und damit auch als obligatorisch betrachtet werden.

2. Nahezu obligatorisch sind Modalpartikeln auch in Wunschsätzen:

(12) Hätt ich meiner Tochter nur/bloß/doch geglaubt!

(13) Wären Sie sich nur/bloß/doch nicht begegnet!

(14) Hättest du nur/bloß deinen Mund gehalten!

(iii) Karl: Doch! Ein hartgekochtes Ei darfsde auch essen! Iris: Und die Salatgurke? Oder entweder oder? (BA, 154)

28) Diese Strukturen gleichen in ihrer Funktion den (mehr in der Umgangsspracht gebräuchlichen) Strukturen mit wo...doch (vgl. dazu auch 1.3.2.2.5). 
Läßt man in (12)-(14) die Modalpartikeln weg, so ist die Lesart als Wunschsatz kaum mehr aufrechtzuerhalten (die Intonation reicht hier offensichtlich nicht aus), der Satz verliert seine Selbständigkeit und wird Konditionalsatz; vgl.:

(12a) Hätt ich meiner Tochter geglaubt (, säße ich jetzt nicht im Gefängnis). entspricht: Wenn ich meiner Tochter geglaubt hätte,...

Mit einem einleitenden ach läßt sich die Lesart als wunsch allerdings halten:

(12b) Ach, hätt ich meiner Tochter geglaubt!

Auch hier sind m.E. Modalpartikeln (sehr häufig auch in den Kombinationen doch bloß oder doch nur) oder aber Gliederungspartikeln wie ach für die Lesart als Wunsch obligatorisch.

3. Ahnlich verhält es sich bei bestimmten selbständigen Sätzen mit Verb-Endstellung:

(15) Daß du JA rechtzeitig heimkommst!

(16) Wenn sie doch käme!

(17) Wo er's nur immer herkriegt, diese witze! (Polt)

(18) Bald hatten wir die Pimpfenknäuel erreicht. Ich legte mich auf einen der ächzenden, schwankenden Haufen. Wer da wohl drunterlag. (Ke, 60)

Auch hier verlieren die Sätze ohne Modalpartikeln ihre Selbständigkeit, und die Lesart ändert sich; vgl.:

(15a) Daß du rechtzeitig heimkommst (, wünsch ich mir).

Allerdings kann bei diesem Typ von Sätzen - z.B. in (17) oder (18) - die Intonation die Funktion der Modalpartikeln eventuell übernehmen. So ist (18a) bei entsprechender Intonation auch als selbständiger Satz denkbar:

(18a) Wer da drunterlag?

Auf diesen Typ von Sätzen mit Verb-Endstellung werde ich aber in Kap. 1.3.2 noch näher eingehen.

Die Beispiele (10)-(18) haben deutlich gemacht, daß Modalpartikeln nicht immer rein fakultative Elemente sind. In den Sätzen vom Typ (12)-(14) ist es dabei offensichtlich weniger von Bedeutung, welche der drei möglichen Modalpartikeln auftritt, wichtig ist nur, daß überhaupt eine Modalpartikel vorkommt.

\subsubsection{Stellung der Modalpartikeln}

\subsubsection{Modalpartikeln in den Stellungsfeldern}

In diesem Abschnitt soll das Verhalten der Modalpartikeln bezüglich der drei Stellungsfelder (Vor-, Mittel- und Nachfeld) untersucht werden.

Modalpartikeln können nicht im Vorfeld eines Satzes, d.h. vor dem finiten Verb in Zweitstellung auftreten. In diesem Punkt unterscheiden sie sich von den meisten 
anderen Partikeln, z.B. den Gradpartikeln, die immerhin zusammen mit ihrer Bezugskonstituente im Vorfeld stehen können (vgl. dagegen aber Jacobs 1983: 40ff.), sowie von den Satzadverbien und den Konjunktionaladverbien, die (allein) vorfeldfüllend sind.

Bel den Modalpartikeln ist das Kriterium der Nicht-Vorfeldfahigkeit nur in drei Fällen möglicherweise problematisch:

1. Der erste Fall, in dem Modalpartikeln im Vorfeld auftreten können, betrifft die Kombination Fragewort und Modalpartikel im Vorfeld. Diese Kombination ist als verkürzte Außerung relativ häufig (s.u. S.36), ist aber auch - in beschränktem Umfang - in vollständigen $w$-Fragesätzen möglich; vgl.:

(19) Wieso eigentlich empfindet der Wissenschaftsrat die langen Studienzeiten an bundesdeutschen Universitäten als "alarmierendes Signal"? (SZ)

(20) Biologen befürchten einen Artenschwund um dreißig Prozent. Wozu eigentlich brauchen wir Hasen? (SZ)

(21) Warum bloß llebt sie diesen Schwachkopf?

(22) Was nur findet sie an ihm?

(23) Warum auch sollte ich nett $z u$ ihm sein?

Eine mögliche Erklärung für dieses Stellungsverhalten könnte folgendes sein: Da Modalpartikeln illokutionstypabhängig und illokutionsmodifizierend sind und wElemente im Deutschen relativ deutliche Illokutionsindikatoren sind, ist eine 'Klitisierung' der Modalpartikel möglich.

Die Kombination $w$-Wort und Modalpartikel kann allerdings im indirekten Fragesatz kaum in dieser Form auftreten (vgl. (20a) und (22a)); das ist ein Indiz dafür, daß nicht ein durch eine Modalpartikel modifiziertes Fragewort vorliegt (wenn man davon ausgeht, daß es sich um dasselbe $w$-Element handelt).

(20a) ?"Ich möchte bloß wissen, wozu eigentlich wir Hasen brauchen. Ich möchte bloß wissen, wozu wir eigentlich Hasen brauchen.

(22a) ?"Ich frage mich, was nur sie an ihm findet. Ich frage mich, was sie nur an ihm findet.

2. Als zweiter problematischer Fall hinsichtlich des Vorfeldverhaltens von Modalpartikeln wird häufig die Partikel eigentlich angeführt (vgl. z.B. Bublitz 1978:35 und 112f., Gornik-Gerhardt 1981:34 und Weydt/Hentschel 1983:10 .); diese Partikel. die in Fragen eindeutig zu den Modalpartikeln zu zählen ist, kann in Aussagesätzen durchaus vorfeldfullend auftreten, vgl.:

(24) Sie mag Faßbinder-Filme elgentlich ganz gern.

Eigentlich mag sie Faßbinder-Filme ganz gern.

Tatsächlich aber liegt im Aussagesatz und akzentuiert im Fragesatz mit eigentlich ein Satzadverb vor, und nur bei unbetontem Vorkommen in Fragen ist eigentlich 
Modalpartikel (vgl. dazu genauer Oppenrieder/Thurmair 1988); somit ist also eigentlich keine Ausnahme hinsichtlich des Vorfeldverhaltens von Modalpartikeln.

(25) EIGENTLICH heißt sie Katharina, aber alle nennen sie Ina. ('im Grunde', 'wirklich'; Satzadverb)

(26a) Wie heißt du EIGENTLICH? (= 'wirklich'; Satzadverb)

(26b) Wie HEISST du eigentlich? ( $\neq$ 'wirklich'; Modalpartikel)

3. Der dritte Fall betrifft Modalpartikeln in komplexen (appositiven) Attributen zu Nominalphrasen (vgl. Jacobs 1986:107f.):

(27) Dieser ja leider viel zu früh verstorbene Komponist hat uns eine Reihe von großartigen Werken hinterlassen.

Auch hier ist aber m.E. das Kriterium der Nicht-Vorfeldfähigkeit nicht verletzt: Das Attribut ist als verkürzte Prädikation aufzufassen und hat eine eigene Illokution; der Geltungsbereich der Modalpartikel erstreckt sich nur auf das Attribut; vgl. auch (28):

(27a) Dieser Komponist ist ja leider viel zu früh verstorben; er hat uns eine Reihe von...

(28) Kreativität entfaltet sich nicht in gerade noch zugelassenem Freiraum, sondern in 'Spruch und Widerspruch', Dialog, Argumentation, Ringen um die doch wohl letztlich gemeinsame Sache. (SZ)

Zusammenfassend läßt sich also feststellen, daß Modalpartikeln im Vorfeld nur in seltenen Fällen (kombiniert mit einem $w$-wort) auftreten können. Sie können aber niemals allein das Vorfeld füllen, zeigen also kein satzgliedhaftes Verhalten.

Das Kriterium der Nicht-Vorfeldfähigkeit sollte also bestehen bleiben; es hilft auf jeden Fall, Modalpartikeln von Gradpartikeln und Satzadverbicn abzugrenzen: Satzadverbien füllen in der Regel das Vorfeld, Gradpartikeln können mit ihrer Bezugskonstituente im Vorfeld stehen, wobei aber diese Bezugskonstituente in der Regel kein Fragewort sein kann.29 Außerdem ist die Nicht-Vorfeldfähigkeit ein Kriterium, um Modalpartikeln von Konjunktionaladverbien abzugrenzen, eine Unterscheidung, die bei bestimmten Partikeln wie z.B. schließlich nicht immer getroffen wird. So klassifizieren z.B. Weydt et. al. (1983, bes. 156 und 159ff.) allerdings, immerhin, jedenfalls, ohnehin, schließlich und überhaupt als 'vorfeldfähige Abtönungspartikeln'. Die meisten dieser Partikeln gehören allerdings - sowohl wegen ihrer Distribution als auch wegen ihrer Funktion, zwei Aussagen zu verknüpfen - zu den Konjunktionaladverbien. Ließen sich alle der angeführten Ausdrücke zu den Konjunktionaladverbien rechnen, könnte das Kriterium der Nicht-Vorfeldfähigkeit

29) Lediglich in Versicherungsfragen (vgl. Kap. 1.3.5.3) wie (i) ist eine Gradpartikel mit einem (immer akzentuierten) w-Element möglich:

(i) A: Sogar die CSU hat für den Kandidaten der Grünen gestimmt.

$B$ : Sogar WER hat für ihn gestimmt? 
von Modalpartikeln bestehen bleiben; vgl. zunächst (29) und (30), die das unterschiedliche Stellungsverhalten der (mutmaßlichen) Konjunktionaladverbien und der Modalpartikeln zeigen:

(29a) Das Auto ist alt; allerdings/immerhin ${ }^{30}$ fährt es noch.

(29b) Das Auto ist alt; allerdings/immerhin: es fährt noch.

(29c) Das Auto ist alt; es fährt allerdings/immerhin noch.

(30a) 'Das Auto ist klein; halt/eben sind billige Autos so.

(30b) "Das Auto ist klein; halt/eben: billige Autos sind so.

(30c) Das Auto ist klein; billige Autos sind halt/eben so.

Wie wichtig die Untersuchung der Stellungsbedingungen der Partikeln ist, zeigt sich hier noch einmal deutlich: Fine rein semantisch-funktionale Festlegung der Konjunktionen und Konjunktionaladverbien als Verknüpfung zweier Aussagen ist zu vage, da diese Funktion z.B. auch von bestimmten Modalpartikeln (wie auch) übernommen werden kann. Erst die Stellungsbedingungen machen weitere Unterscheidungen deutlich. Allerdings mu $\beta$ wohl ein 'jbergangsbereich zwischen Modalpartikeln und Konjunktionaladverbien angenommen werden; hier liegt z.B. die Partikel ohnehin. $^{31}$ Die Gemeinsamkeiten und Unterschiede dieser beiden Gruppen müßten noch genauer erforscht werden.

Als eine Bedingung für Modalpartikeln soll auf jeden Fall gelten: Modalpartikeln können nie allein das Vorfeld füllen (vgl. (31)), sie können aber auch nicht (mit Ausnahme der Position hinter einem Fragewort) mit einer Konstituente im Vorfeld stehen; da sie auch im Nachfeld nicht möglich sind (vgl. (32)), ist ihr Platz also nur im Mittelfeld (vgl. (33)):

(31) Ja hast du ihn gesehen. Einfach sind Männer so.

*Du hast dir deine Haare geschnitten ja. "Komm her bloß!

(33) Du hast doch Peter gesehen. Und dann gibst du ihm das Buch eben. Kannst du mir denn helfen?

Auch die Position von Modalpartikeln im Vorvorfeld ist nicht möglich; ebenso kommen sie isoliert nicht vor, denn sie können im Unterschied zu Satzadverbien und Adverbien weder als Antwort auf eine Frage noch als isolierte Reaktion verwendet werden. Die Partikeln ja, eben und doch in dieser Funktion rechne ich zu den Gliederungspartikeln. Problematisch ist hier lediglich das Vorkommen von schon in Sätzen vom Typ (34); (vgl. dazu genauer die Analyse von schon (Kap. 2.2.8)).

30) Die anderen von weydt erwähnten Partikeln (z.B. schließlich, überhaupt, jedenfalls) zeigen dasselbe Stellungsverhalten.

31) Ohnehin ist als Synonym von sowieso zu sehen, zeigt aber anderes stellungsverhalten, da ohnehin im Vorfeld auftreten kann. 
(34) Bernd: Ich würde gern spazierengehen. Ist das Wetter nicht herrlich?

Eva: Schon. Aber ich hab doch keine Zeit.

\subsubsection{Modalpartikeln im Mittelfeld}

\subsection{Modalpartikeln und die Thema-Rhema-Gliederung}

Innerhalb des Mittelfeldes kann die Position der Modalpartikeln durchaus variieren, ${ }^{32}$ die Stellung hängt dann von ganz bestimmten Faktoren ab.

Dazu folgendes Beispiel:

(35) Susanne hat $<>$ gestern $<>$ ihrer Tochter $<>$ das versprochene Buch $\langle>$ geschenkt.

Im Mittelfeld sind Modalpartikeln (hier z.B. ja und doch) an allen mit < > bezeichneten Stellen möglich (vgl. dazu Hentschel 1983:46).

Aufgrund dieser Beweglichkeit im Mittelfeld wird den Modalpartikeln oft als eine weitere Funktion zugeschrieben, die Grenze zwischen Thema und Rhema ${ }^{33}$ zu bilden. 34

So weist schon Krivonosov $(1965: 502 ; 1966: 139)$ darauf hin, daß zwischen Verb (gemeint ist das finite Verb in Sätzen init Anfangs- oder Zweitstellung) und Modalpartikel nur das "Gegebene im Satz", "das Thema der Aussage" stehen kann und daß nach nur das "Gegebene im Satz", "datzglieder folgen, die "im Satz das Ziel der Aussage, eine neue Mitteilung oder das Rhema der Aussage darstellen". Ahnlich heißt es auch bei Hentschel (1986:212ff.): "Die Partikel lgemeint sind bestimmte Modalpartikeln; M.T.l steht vor dem Rhema des Satzes" (vgl. auch Borst 1985:132ff.).

Zunächst zur These von Krivonosov, daß alle thematischen Elemente vor der Modalpartikel auftreten; dies trifft nicht immer zu:

Die erste Ausnahme betrifft das Auftreten einer 'offenen' Modalpartikel-Kombination (mehr dazu in Kap. 3.4.2).

In seltenen Fällen können auch beim Auftreten einer Modalpartikel Teile des Themas nach dieser stehen, zum Beispiel wenn der infinite Verbteil Rhema ist; vgl.:

(36) Uli: Mein Gott, mir graut vor dieser Bahnfahrt morgen mit Rucksack und den schweren Taschen.

Eva: Weißt du was? Wir sollten die Taschen einfach AUFGEBEN. ${ }^{35}$

aber auch: Wir sollten einfach die Taschen AUFGEBEN.

(37) Andi: Müllers Taschenrechner hat mir gute Dienste geleistet.

Max: Du hast diesem Menschen das Ding doch ZUR(iCKGEGEBEN?

aber auch: Du hast diesem Menschen doch das Ding ZURUCKGEGEBEN? (übernommen von Borst 1985:150)

32) Vgl. dagegen unzutreffend Franck (1980:20), ähnlich auch Bublitz (1978:36f.).

33) Mit Thema und Rhema sollen hier bekannte vs. neue Elemente bezeichnet werden (vgl. dazu u.a. die Arbeiten von Daneš (z.B. 1970/74); vgl. zu diesem Komplex auch Gülich/Raible (1977: Kap.II.1)).

34) Die Modalpartikeln selbst gehören weder zum Thema noch zum Rhema.

35) Das Rhema wird im folgenden in Großbuchstaben und nicht-kursiv geschrieben. 
(38) Asterix: Ich bring den Kessel in meine Hütte.

Obelix: Wie blöd, die gute Zwiebelsuppe wegzuschütten und stattdessen

Sesterzen reinzutun.

Asterix: Aber Obelix, mit Sesterzen kann man doch Zwiebelsuppe KAUFEN!

(A XIII, 8)

Thematische Elemente, die nach einer Modalpartikel auftreten (wie in den Beispielen oben), ${ }^{36}$ sind meistens Wiederholungen (vgl. (38)) oder Paraphrasen, ${ }^{37}$ kaum Pronomina (vgl. (36a) und (37a)): ${ }^{38}$

(36a) (wie oben.)

Wir sollten sie einfach AUFGEBEN.

aber: "Wir sollten einfach sie AUFGEBEN.

(37a) (wie oben.)

Du hast es ihm doch ZURUCKGEGEBEN?

aber: "Du hast doch es ihm ZURUCKGEGEBEN?

Inwieweit allerdings die nominalen Paraphrasen reine thematische Elemente sind. ist fraglich.

Nun zum zweiten Teil der These, wie sie auch von Hentschel (vgl. 1983:48 und 1986:212) vertreten wird: Modalpartikeln müssen vor dem Rhema stehen.

Folgende Beispiele ${ }^{39}$ unterstützen diese These:

(39) Gast: Ich hätte gern ein Fanta.

Kellner: Tut mir leid, das führen wir nicht.

Gast:- Ach, dann bekomme ich eben EIN COLA.

- "Ach, dann bekomme ich EIN COLA eben.

(40) Ina: ...an Iris Kolb kanns de dich doch auch noch erinnern, ne?

Ute: Ja, so ne Kleine, ne?

Ina: Hm. Die hat ja NACH FRANKREICH GEHEIRATET. (BA, 183)

'Die hat NACH FRANKREICH ia GEHEIRATET.

36) Interessanterweise ist in Beispiel (38) dic Modalpartikel nach dem thematischen Element ' $Z$ wiebelsuppe' kaum möglich; falls man allerdings auch ' $Z$ wi $e^{-}$ belsuppe' zum Rhema rechnet (bzw. die Beziehung zwischen objekt und Verb). entspricht die Stellung in (38) den 'normalen' Bedingungen.

37) Vgl. zu diesem Komplex Borst (1985: S.132ff.), der sich genauer mit den Stellungsbedingungen der Modalpartikeln $j a$, doch und schon bezüglich anderet Elemente im Mittelfeld befaßt. Interessant ist hier, daß schon im Vergleich $z^{4}$ den beiden anderen Partikeln eingeschränkter in seinen Stellungsmöglichkeiten ist. Die Untersuchung der Mittelfeldelemente hinsichtlich ihres syntaktischen Status' führt dabei offensichtlich zu keinen signifikanten Ergebnissen. Wichtib für die Stellung der Partikeln ist lediglich der Mitteilungswert der anderen Elemente. Borst berücksichtigt allerdings den Fall, daß das finite Verb Rhem ${ }^{8}$ ist, nicht.

38) Lediglich bei Enklise von denn bzw. ' $n$ an das Verb sind (natürlich) auch thematische Pronomen nach der Modalpartikel zulässig: Was liest'n du jetzt? $\mathrm{Da} \beta$ in den anderen Fällen die Pronomina nicht nach der Modalpartikel stehen können, kann auch daran liegen, daß thematische Pronomina häufig enklitisch verwendet werden, Enklise an eine Modalpartikel aber nicht möglich ist.

39) In den meisten Beispielen handelt es sich hier um Nomina mit indefinitem $\mathrm{Ar}^{-}$ tikel. Allerdings kann vom Auftreten eines indefiniten Artikels nicht immer darauf geschlossen werden, da $\beta$ die Elemente rhematisch sind. 
(41) So etwas! Wer kocht jetzt? Wir wollen Ihnen doch noch EIN ABSCHIEDSESSEN geben. (Si, 298)

"Wir wollen Ihnen EIN ABSCHIEDSESSEN doch noch geben.

Problematisch ist diese These allerdings in $\mathrm{zwei}^{40}$ Fällen:

1. Rhematische Elemente können im Vorfeld eines Satzes mit Verb-Zweit-Stellung auftreten, dann kann die Modalpartikel aufgrund ihres Stellungsverhaltens nur nach (oder in) dem Rhema vorkommen:

(42) Mutter: Wer hat sich ein Fahrrad gekauft? Fritz: PETER hat sich doch ein Fahrrad gekauft.

(43) Gabi: Da hat wahrscheinlich wieder keiner den Mülleimer ausgeleert. Phil: Nein, das stimmt nicht! MAX hat doch vorher den Eimer mit runtergenommen.

2. Ebenfalls problematisch ist die Stellung der Modalpartikeln, wenn das finite Verb Rhema des Satzes ist.

Auch in diesem Fall können Modalpartikeln natürlich nur nach dem Rhema auftreten. Hentschel (1986:213) stellt dafür eine zweite Regel auf: "Bildet das Plektierte Verb das Rhema, so kann die Partikel die letzte Stelle im Satz einnehmen." Nun ist aber die Regel (korrekterweise) als fakultative Regel formuliert, was bedeutet, daß die Modalpartikel nicht am Ende stehen muß; vgl.:

(44) Tom: Da gibts doch jetzt diese BMX-Räder. Und Ruth möchte unbedingt so eins haben. Jetzt hat sie ein gebrauchtes an der Hand, das allerdings immer noch ziemlich teuer ist.

Hedi: Und was macht ihre Mutter?

Tom: Naja, du kennst sie doch. Sie KAUFT eben dieses Fahrrad.

(44a) Sie KAUFT dieses Fahrrad eben.

Weiter gibt es - immer noch bei rhematischem Finitum - Fälle, in denen die Modalpartikel nicht nur nicht am Ende stehen muß (wie oben), sondern gar nicht am Ende stehen kann; vgl.:

(45) Mensch, daß die Anna Launen hat, das darfst du dem willi aber nicht erzählen.

Der VERURTEILT doch Launen.

aber: Der VERURTEILT Launen doch.

(46) (Mit (45) als Vortext)

Daß der Willi den Hans so nett findet...

Der HAT doch Launen

Der $\underline{\text { HAT }}$ Launen doch. ${ }^{41}$

40) Der dritte möglicherweise problematische Fall (die Stellung von akzentuierten Pronomina vor der Modalpartikel), den Hentschel (1986) ebensowenig berücksichtigt wie die hier angeführten, wird in Kap. 1.2.4.2.2 analysiert.

41) Der Grund dafur hier angeführten, wirtikel nach 'Launen' nicht akzeptabel ist, könnte eventuell sein, daß das Verb und das objekt oder zumindest die Beziehung zwischen Verb und objekt zum Rhema gehören. 
Der NORGELT doch nicht/bestimmt/wieder.

-Der NORGELT nicht/bestimmt/wieder doch.

Die vorangegangenen Beispiele haben wohl hinreichend deutlich gemacht, da $\beta$ der Schluß, den Hentschel aus der eben nur möglichen, aber nicht einmal immer möglichen und nie obligatorischen Distanzstellung von Modalpartikel und rhematischem Finitum zieht, ${ }^{42}$ nämlich "Die Partikel bezieht sich auf das Rhema des Satzes" (1986:231), unzutreffend ist.

\subsection{Modalpartikeln und Personalpronomina}

Im folgenden soll die Stellung der Modalpartikeln im Mittelfeld genauer untersucht werden, insbesondere die Stellung von Modalpartikeln und pronominalen ${ }^{43}$ Elementen. Wie im vorangegangenen gezeigt, treten im Mittelfeld rhematische nominale Elemente in der Regel nach Modalpartikeln auf (vgl. oben (39) bis (41)). Unakzentuierte Pronomina, die allgemein als thematisch gelten, erscheinen vor der Modalpartikel (Ausnahme: bei Enklise von ' $n$ an das Verb), was die oben angeführten Aussagen zum Zusammenhang der Stellung von Modalpartikeln und der Thema-Rhema-Gliederung zunächst bestätigt:

(48) Ich kann dir das doch mitbringen.

"Ich kann doch dir das mitbringen.

Akzentuierte Pronomina`4 aber können sowohl vor als auch nach Modalpartikeln stehen; vgl.:

(49) Du brauchst nicht abzuspülen.

Das kann ja ICH machen/Das kann $\underline{I C H}$ ja machen.

(50) Meier: Ich kann nichts sehen. Gehen Sie doch aus dem Weg!

Müller: Gehen SIE doch aus dem Weg!/ Gehen doch SIE aus dem Weg!

(51a) "Wer zum Teufel ist das?" und "Wer zum Teufel ist denn DAS?" murmelte mir Henry Kissinger einige Male ins Ohr. (SZ)

(51b) Ute: ...hab ich angefangen, ne DIN-Norm zu übersetzen und da (...)/

Ina: Was is DAS denn? (BA, 186)

Zumindest in Außerungen wie (49) und (50) müßten die Pronomina nach Hentschel (1986) und Borst (1985) aufgrund des hohen Mitteilungswertes als rhematisch (vgl. dagegen aber AKADEMIE-Grammatik 1981:102ff.) eingestuft werden. Das aber ist

42) Ausgangspunkt dafür ist die Tatsache, daß im Deutschen [in Verb-Erst- und -Zweit-Sätzen; M.T.] die Teile, die am engsten zum Verb gehören, immer am weitesten von diesem entfernt stehen (vgl. Hentschel 1986:213).

43) Trotz ausführlicher Beschäftigung mit den Stellungseigenschaften der Modalpartikeln betrachtet Hentschel (1986) diesen Fall überhaupt nicht - und zwat mit dem Hinweis (1986:208) auf die größere Bewegungsfreiheit der nicht-pronominalen Satzteile.

44) Akzentuierte Pronomina berücksichtigt auch Borst (1985) nicht. 
ein weiteres Argument gegen die aufgestellte These, Modalpartikeln stünden immer vor dem Rhema. 45

Das unterschiedliche Stellungsverhalten von akzentuierten (rhematischen?) Pronomina und rhematischen Nominalphrasen läßt sich nur dann erklären, wenn man neben der Unterscheidung 'bekannte' vs. 'nicht-bekannte'46 Elemente (was der Unterscheidung thematisch vs. rhematisch entspricht) eine weitere Unterscheidung in 'auffällige' vs. 'unauffällige' Elemente einführt. Die akzentuierten Pronomina und zunächst beziehe ich das nur auf die Personalpronomina der 1. und 2. Person - sind bekannte Elemente, da sie (bzw. ihre Referenten) immer situativ präsent sind, sind aber - wegen des Akzents - auch auffällige Elemente. Damit ergibt sich folgendes Stellungsverhalten im Mittelfeld:

$\begin{array}{ll}\text { + bekannt / - auffällig } & \text { vor der Modalpartikel } \\ \text { + bekannt / + auffällig } & \text { vor und nach der Modalpartikel } \\ \text { - bekannt / + auffällig } & \text { nach der Modalpartikel }\end{array}$

Diese Analyse wird umso plausibler, wenn man das Verhalten der Personalpronomina der 3. Person mit einbezieht: Ausgegangen wird hier von den beiden Reihen er/ sie/es und der/die/das. Als Pronomina sind beide als bekannte Elemente einzustufen, unterscheiden sich aber darin, daß er/sle/es unauffällig und der/die/das (auch in unbetonter Verwendung) auffällig ist. Besonders in der Umgangssprache treten akzentuiert fast nur der/die/das auf; d.h. die er-Reihe kann auch durch Akzentuierung kaum $\mathrm{zu}$ einem hervorgehobenen Element werden. Der Unterschied zwischen beiden Pronomen-Reihen spiegelt sich im Stellungsverhalten: In der Regel treten nur der/die/das im Mittelfeld vor und nach der Modalpartikel auf; vgl.:

(52a) Wo geht denn die hin?

(52b) Wo geht die denn hin?

(52c) Wo geht sie denn hin?

(52d) "Wo geht denn sie hin?

Die Stellung von sie nach der Modalpartikel (52d) wäre allenfalls bei akzentuiertem Pronomen möglich, ist aber m.E. kaum akzeptabel.

Die Kennzeichnung von sprachlichen Elementen mit den beiden angeführten Eigenschapten erklärt auch das stellungsverhalten von nicht-pronominalen Elementen, deren Referenten situativ präsent sind, also z.B. Eigennamen oder Nominalphrasen wie mein Mann etc. Hervorgehoben können sie wie die Pronomina vor und nach der Modalpartikel stehen:

45) Würde man die akzentuierten Pronomina allerdings als thematisch bezeichnen, wären die in (49)-(51) dargestellten Stellungsvarianten kein Gegenbeispiel zu Hentschels oder Borsts These, daß die Modalpartikel vor dem Rhema auftritt.

46) Man könnte hier auch von 'situativ präsent' oder 'nicht-präsent' sprechen. 
(49a) Du brauchst nicht abzuspülen.

Das kann mein MANN/PETER ja machen./

Das kann jg mein MANN/PETER machen.

Eine kleine Einschränkung bzw. Differenzierung bezüglich der oben angeführten Analyse ist $\mathrm{zu}$ machen. Dazu folgende Beispiele:

Hast DU aber große Füße!

'Hast aber $\underline{D U}$ große Füße!

(54) Hat DIE vielleicht einen kurzen Rock an! 'Hat vielleicht DIE einen kurzen Rock an!

(55) Was hast $\underline{D U}$ bloß für komische Ansichten! *Was hast bloB DU für komische Ansichten!

In Exklamativsät\%en können Modalpartikeln nur nach (akzentuierten) Personalpronomina im Mittelfeld stehen. Man kann dies zum einen daraup zurückführen, daß in Exklamativsätzen ohnehin andere Stellungsregeln gelten (so ist z.B. in (53) und (54) die Verbstellung variabel; s.u. S.45). Man kann die unterschiedliche Stellung der akzentuierten Pronomina im Exklamativsatz aber auch erklären, wenn man dle zur Hervorhebung dienenden Mittel mit einbezieht. Es handelt sich nämlich in Exklamativen wie (53)-(55) um einen anders realisierten (und wahrgenommenen) Akzent als beispielsweise in (49): Der Exklamativakzent weist typischerweise einen späteren und höheren Gippel aup als der Kontrastakzent, und die $\mathrm{Nu}^{-}$ kleussilbe (oder die Gesamtăußerung) ist stark gelängt (vgl. dazu genauer Batlinel 1988). Zudem ist die Position des Exklamativakzents variabel (s.u. S.45).

Man müßte also das Schema für die Abfolge im Mittelfeld dahingehend modifizieren. daß bel auffäligen Elementen weiter danach unterschieden wird, ob das betreffende Element durch einen Kontrast- oder durch einen (nicht stellungsfesten) Exklamativakzent hervorgehoben wird: beim Exklamativakzent ist nur die stellung det Modalpartikel nach dem Pronomen zulässig. ${ }^{47}$

Abschließend sei noch kurz darauf hingewiesen, daß sich die verschiedenen Modal' partikeln hinsichtlich ihrer stellung nicht gleich verhalten; einige können kaum ${ }^{48}$ vor akzentuierten Personalpronomina auftreten.49

47) Diese Abfolge gilt auch, wenn der Exklamativakzent nicht auf das Pronomen Pällt; vgl.: Hat der vielleicht GEFLUCHT! vs. 'Hat vielleicht der GEFLUCHT!

48) Die Partikeln nur und bIoß ändern ihre Funktion mit dem Stellungswechseli vor akzentuierten Pronomina liegen sie in Gradpartikel-Funktion vor:

(i) Wer hat $\underline{D I C H}$ bloß/nur verraten? (Modalpartikel)

Wer hat bloß/nur DICH verraten (und sonst niemanden)? (Gradpartikel)

49) Die genauen Abfolgen von Modalpartikeln und anderen Elementen im Mittelfeld sind noch nicht vollständig erforscht; z.T. sind nämlich auch unbetonte Personalpronomina nach der Modalpartikel möglich, was mit den generellen Abfol' geregeln im Mittelfeld (z.B. Subjekt vor Objekt) zusammenhängt:

(i) A: Seit wann hast du denn den Faust?

B: Den hast DU mir doch / doch DU mir / mir doch DU / mir DU doch zum Geburtstag geschenkt. 
(56) An den Autoschlüssel hättest $\underline{D U}$ doch/eben/halt denken müssen.

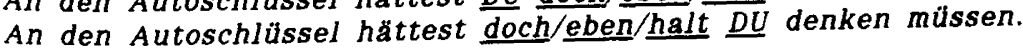

(57) Hast $D U$ einfach das Auto genommen? ?Hast einfach $\underline{D} U$ das Auto genommen?

(58) Was hast $\underline{D U}$ schon für Chancen.

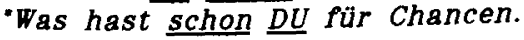

Zusammenfassend läßt sich über die stellung der Modalpartikeln im Mittelfeld (auch im Verhältnis zur Thema-Rhema-Gliederung) folgendes sagen: (kontrastiv) akzentulerte Pronomina und akzentuierte Nominalphrasen, die situativ Präsentes bezeichnen, können sowohl vor als auch nach den meisten Modalpartikeln stehen. Wenn nicht das finite Verb Rhema ist und wenn das Rhema nicht im Vorfeld ist (und somit das Rhema aufgrund der Mittelfeld-Gebundenheit der Modalpartikeln nur vor diesen stehen kann), dann müssen Modalpartikeln vor dem Rhema stehen. (Daß sie dabei nicht immer auch nach dem Thema, also an der Grenze stehen, werde Ich auch weiter unten (S.290ff.) noch einmal zeigen.)

Wegen dieser doch nicht eindeutig zu formulierenden stellungseigenschaften der Modalpartikeln bezüglich der Thema-Rhema-Gliederung eines Satzes geht m.E. Hentschel (1986:234) auch zu weit, wenn sie meint: "Die Partikel ist ein Indikator Pür das Rhema des Satzes." Plausibler scheint mir die Feststellung, daß Modalpartikeln aup die Thema-Rhema-Struktur eines Satzes reagieren.

\subsubsection{Modalpartikeln in verblosen Strukturen}

Wie oben festgestellt, können Modalpartikeln nur im Mittelfeld von (verbhaltigen) Sätzen auftreten. So lautet auch eins der allgemein akzeptierten Kriterien für Modalpartikeln.

Allerdings sind Modalpartikeln auch in verblosen Außerungen möglich, vgl.:

(59) Franz: Soll ich dir mal meine Urlaubsbilder zeigen?

Bea: Jg nicht/bloß nicht!

Im Beispiel (59) genügt offensichtlich eine der beiden Modalpartikeln (In Verbindung mit der Negationspartikel), um eine bestimmte Illokution - nämlich eine Drohung - auszudrücken. Die Partikel nicht, die in anderen Kontexten auch allein auftreten kann, stellt ja nicht unbedingt eine Drohung dar (eher eine Warnung). Aupfallend ist, daß diese struktur nur negiert möglich ist (während verbhaltige Satze gleicher Funktion mit $j a$ und blo $\beta$ auch ohne nicht auftreten), und außerdem, daß es sich hier genau um die betonten Varianten von Modalpartikeln handelt.

Der zweite Typ der Verwendung von Modalpartikeln in verblosen strukturen betrifft Außerungen mit der Modalpartikel halt, durch deren Gebrauch der Sprecher anzeigt, daß er keine Begründung für sein Verhalten geben kann oder will: 
(60) Vater: Warum hast du dich denn nicht beschwert?

Sohn: Halt so./So halt.

Beispiel (60) zeigt auch, daß es sehr problematisch ist, hier von Ellipsen zu sprechen. Welche Art zugrundeliegender Satz sollte konstruiert werden? Und selbst wenn ein Satz wie z.B. 'ich hab das halt so gemacht' angenommen würde, könnte die Variante so halt ohnehin nicht integriert werden.

Ahnliches gilt auch für das von Hentschel (1986:229) beobachtete Vorkommen von halt in Außerungen wie:

(61) Vater: Warum tust du das?

Sohn: Weil halt/darum halt.

Die folgenden Beispiele (62) - (65) weisen alle das gleiche Muster auf, nämlich $w$-Wort und Modalpartikel:

(62) Ruth: Ja, un, öh, dann hab ich, öh, krieg ich . jetz . vorgestern en Bußgeldbescheid

Andi: Ach je! Wieviel denn? (BA, 191)

(63) Warum hast du dich denn nicht mit ihm versöhnt? Warum bloß/nur?

(64) Pastor Heitbrecher hat sich im Himmel versteckt. Gerken Rudi hat sich gar nicht versteckt. Warum auch.

(65) Mutter: Wer hat denn dieses Chaos veranstaltet? Vater: Na, wer wohl?

Oft wird dabei eine Frage (entweder eine eigene oder die eines Gesprächspartners) wiederholt, ${ }^{\text {so }}$ wobei nur das Fragewort zusammen mit der Modalpartikel geäußert wird. Die Position unmittelbar nach dem Fragewort ist - mit unterschiedlichet Akzeptabilităt bei den einzelnen Modalpartikeln - auch in verbhaltigen w-Fragen möglich (die Variante, in der die Modalpartikel im Vorfeld steht; s.o. S.26):

(63a) Warum bloß/nur hast du dich nicht mit ihm versöhnt?

(64a) (?)Warum auch sollte er sich verstecken?

(65a) ?"Wer wohl hat dieses Chaos veranstaltet?

\subsubsection{Kombination von Modalpartikeln}

Wie die meisten anderen Partikelgruppen sind auch die Modalpartikeln nicht koor dinierbar, d.h. durch und bzw. oder verbindbar.

Kombinationen von Modalpartikeln ohne Konjunktion sind aber durchaus möglich und auch sehr häufig. Dabei sind die Kombinationen von Modalpartikeln bestimm' ten Gesetzmäßigkeiten unterworfen, und zwar sowohl, was ihre Kombinierbarke $e^{i l}$ betrifft (also welche Modalpartikeln semantisch und syntaktisch-distributionell

50) Die Fragen in (63) und (65) unterscheiden sich formal von dem in Kap 1.3.4.5.2 besprochenen Satztyp "Rückfragen" vor allem dadurch, daß sie kill steigendes Tonmuster aufweisen. 
verträglich sind), als auch, was die Reihenfolge in der Kombination betrifft. Einige Kombinationen (wie doch mal, ja auch, denn schon, doch bloß) können als beinahe lexikalisiert angesehen werden.

Eine Analyse der akzeptablen und der inakzeptablen Kombinationen kann aber erst erfolgen, wenn die Bedeutung jeder einzelnen Modalpartikel beschrieben ist. Auch die Stellungselgenschaften können erst später (in Kapitel 3) dargestellt werden.

\subsubsection{Halt: das distributionelle Grundmuster}

Wie sich im Vorhergehenden gezeigt hat, läßt sich kaum ein Kriterium auf alle die Funktionen bestimmter Ausdrücke anwenden, die in der Literatur als Modalpartikel-Funktion bezeichnet werden. Erhebliche schwierigkeiten macht in diesem Zusammenhang auch die Polyfunktionalität fast aller Partikeln, so daß im Einzelfall oft nicht entschieden werden kann, ob idiosynkratische Merkmale einer Modalpartikel vorliegen oder eine weitere Partikelfunktion. Die Partikel halt allerdings, die unbestritten in Modalpartikelfunktion auftritt, läßt sich eindeutig von anderen Vorkommen (z.B. der Imperativform von halten) trennen. Diese Partikel sollte m.E. als Vertreterin des distributionellen Grundmusters von Modalpartikeln angesehen werden - ähnlich wie lediglich am besten das distributionelle Grundmuster der Gradpartikel-Gruppe vertritt.

Das Grundmuster ${ }^{51}$ der Modalpartikeln sieht dann so aus:

- sie sind unflektiert

- sie sind unbetont bzw. unbetonbar

- sie sind fakultative Elemente

- sie sind nicht erfragbar

- sie haben Satzskopus

- sie können nicht negiert werden (vgl. 1.4)

- sie stehen nur im Mittelfeld

- sie stehen meist vor dem Rhema

- sie sind satzmodusabhängig (in welchen Satzmodi sie auftreten, ist für jede Modalpartikel spezifisch (vgl. 1.3))

- sie können den lllokutionstyp modifizieren

- sie sind (mit bestimmten Beschränkungen) untereinander kombinierbar

Alle Abweichungen von diesem Grundmuster, bei denen keine deutlichen semantischen Veränderungen festzustellen sind, sollten als Idiosynkrasien der einzelnen Modalpartikeln angesehen werden.

51) Hier bleiben natürlich alle Ausnahmen unberücksichtigt. 


\subsubsection{Mir: Eine neue Modalpartikel?}

Im folgenden möchte ich zeigen, daß das Lexem mir (und dir) ${ }^{52}$ in der Verwendung. die traditionell ethischer Dativ genannt wird, eine Reihe von Eigenschaften mit den Modalpartikeln gemeinsam hat. ${ }^{53}$ Dabei werde ich zunächst nur auf dit formalen Eigenschaften eingehen. Eine semantische Beschreibung erfolgt spätet (Kap. 2.2.19).

Zunächst soll das syntaktische Verhalten des ethischen Dativs mit dem Verhalter aller anderen freien Dative verglichen werden.

\subsubsection{Nominalgruppen im Dativ}

In der Literatur (vgl. dazu Engelen 1975, Krohn 1980 und Wegener 1985) werde" neben dem Dativobjekt auch eine Reihe sogenannter Preier Dative unterschieden :

- Dativus commodi:

(66) Ich öffne ihm die Tür.

- Dativus incommodi:

(67) Die Blumen sind mir vertrocknet.

- Pertinenzdativ:

(68) Sie sieht ihm ins Gesicht.

- ethischer Dativ:

(69) Fall mir nicht hin!

- Dativus iudicantis:

(70) Du arbeitest $\underline{\mathrm{Ihr}} \mathrm{zu}$ wenig.

Anhand verschiedener in der Literatur aufgeführter Tests kann das unterschied liche Verhalten der freien Dative folgendermaßen zusammengefaßt werden:

\begin{tabular}{|c|c|c|c|c|c|}
\hline & Commodi & Incommodi & Pertinenz & Ethicus & Iudicantis \\
\hline vorfeldfähig & + & + & + & - & + \\
\hline $\begin{array}{l}\text { Satz ohne Dativ } \\
\text { grammatisch }\end{array}$ & + & + & - & + & + \\
\hline $\begin{array}{l}\text { nominal } \\
\text { verwendbar }\end{array}$ & + & + & + & - & + \\
\hline $\begin{array}{l}\text { kann mit anderem } \\
\text { Dativ zus. auftreten }\end{array}$ & - & - & - & + & + \\
\hline
\end{tabular}

52) Die zu mir ausgeführten allgemeinen oberlegungen gelten auch für dir aly ethischer Dativ. Diese Verwendung ist allerdings kaum mehr gebräuchlich un wird auch nicht mehr von allen Sprechern akzeptiert. (Im Bairischen 40 Osterreichischen allerdings scheint dir noch häufiger aufzutreten; vgl. den Beleg (23) auf S.198.))

53) Eine ähnliche Auffassung scheint neuerdings auch $H$. Wegener zu vertrete vgl. auch Jacobs (1986:107f.). 


\subsubsection{Der ethische Dativ}

Wie die Matrix oben zeigt, nimmt der ethische Dativ gegenüber den anderen freien Dativen eine Sonderstellung ein und zwar sowohl, was die Vorfeldfähigkeit, als auch, was die nominale Verwendung betrifft. Auch die Tatsache, daß ein ethischer Dativ in Außerungen möglich ist, die bereits einen Dativ enthalten, zeigt diese Sonderstellung. Zudem ist er der einzige Dativ, der ohne verlust an denotativer Bedeutung weggelassen werden kann; bei seiner Eliminierung ändert sich nur die konnotative Bedeutung einer Außerung. Wegen dieser besonderen Eigenschaften des ethischen Dativs soll nun der Frage nachgegangen werden, ob der ethische Dativ möglicherweise kein Dativpronomen ist, sondern zur Partikel geworden ist. ${ }^{54}$

Der Ethicus taucht in zwei Varianten auf: in der Form mir und in der Form dir (mit den S.38 Fn.52 erwähnten Einschränkungen), also offensichtlich in der 1. und 2. Person Singular Dativ des Personalpronomens. ${ }^{35}$ Weitere Formen des Paradigmas sind nicht möglich; vgl.:

(69) Fall mir nicht hin!

(69a) 'Fall ihm nicht hin!

Wenn es sich also bei mir und dir um zwei Personalpronomina handelt, besetzen sie nur zwei Stellen im ganzen Paradigma; außerdem ist nominale Verwendung grundsätzlich nicht möglich; vgl.:

(71a) Komm mir bloß rechtzeitig heim!

Auch die Tatsache, daß neben dem ethischen Dativ noch ein weiterer Dativ stehen kann, läßt vermuten, daß es sich beim ethischen Dativ nicht mehr unbedingt um ein Personalpronomen im Dativ handelt, da eine Dativleerstelle im Satz vom Ethicus nicht gefüllt wird, vgl.:

(72) Und mach mir dem Vater die Schuhe ordentlich sauber!

Im Polgenden soll gezeigt werden, daß der ethische Dativ gut zur Gruppe der Modalpartikeln paßt. Die Bezeichnung '-partikel' mag allerdings etwas problematisch erscheinen: Zum einen handelt es sich immerhin um eine flektiertes Lexem, das allerdings - wie oben gezeigt - in dieser Funktion unflektierbar ist. Zum anderen existieren beim ethischen Dativ - wenn auch nicht mehr bei allen Sprechern - immerhin zwei Formen - insofern könnte doch von einer Veränderbarkeit dieser Ausdrücke gesprochen werden. Dem allerdings kann entgegengehalten werden, da $\beta$

54) Finen ersten Hinweis darauf gibt z.B. die Bemerkung Helbigs (1981:330), der ethische Dativ sei "fast partikelhaft" gebraucht; Wegener (1985:51ff.) stellt einige Gemeinsamkeiten zwischen Ethicus und Modalpartikeln fest.

Gemeinsamkeiten zwischen Eührten Verwendungen von uns, euch und Ihnen und Wegener (1985:50) ange - Pronomina der 3. Person halte ich für ungebräuchlich und nicht akzeptabel. 
es sich um zwei Partikeln handelt, die beide unveränderbar sind. Als Argument dafür läßt sich anführen, daß mir und dir nicht austauschbar sind; vgl.:

(69) Fall mir nicht hin!

'Fall dir nicht hin!

(73) Du bist mir vielleicht ein Früchtchen!

'Du bist dir vielleicht ein Früchtchen!

Trotz der möglichen Einwände ist es m.E. gerechtfertigt, mir (und dir) zur Klasse der Modalpartikeln zu rechnen. Mit diesen teilen sie folgende Eigenschaften:

- Die Partikelo6 mir ist unbetont bzw. unbetonbar, vgl.:

(69) 'Fall MIR nicht hin!

- Mir kann in der Verwendung als Partikel nicht im Vorfeld stehen; vgl.:

(69) 'Mir fall nicht hin!

In den Fällen, in denen mir das Vorfeld besetzt, hat es eine andere Funktion es ist dann Personalpronomen (in den meisten Fällen mit Kontrastakzent); vgl.:

(74a) Du bist mir ein guter Freund! (je nach Intonation ethischer Dativ oder Personalpronomen)

(74b) Mir bist du ein guter Freund, aber ihr...

(Personalpronomen; vgl.:

$\underline{I h m}$ Dem Vater bist du ein guter Freund, aber ihr...)

Die Partikel mir hat ihren Platz also immer im Mittelfeld; bei Verb-Erst- und Verb-Zweitstellung folgt sie in der Regel dem finiten Verb direkt; vgl.:

(75) Du bist mir vielleicht ein linker Hund!

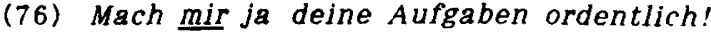

Personalpronomina allerdings können zwischen Verb und Partikel auftreten; vgl:

(77) Und bleiben Sie mir gesund!

(78) Da gehst du mir aber rechtzeitig heim!

In Sätzen mit End-Stellung des Verbs (Kap. 1.3.2.) folgt mir entweder unmittel' bar der Konjunktion oder dem Subjekt, vgl.:

(79) Daß du mir ja rechtzeitig heimkommst!

(80) Daß mir der Franz aber auch wirklich zum Arzt geht!

Auch mir kann nicht nach einem rhematischen Satzelement stehen.

- Wie alle Modalpartikeln ist mir (und auch dir) stark satzmodusabhängig (vg) Kap. 1.3.1.).

- Die Partikel mir kann - ähnlich wie die Modalpartikeln - den Illokutionsty einer Außerung modifizieren.

- Mir ist nicht fokussierbar; es kann weder durch stellungsveränderungen nod durch Betonung hervorgehoben werden; es gibt also auch hier - wie bei det

56) Im folgenden soll mit der Bezeichnung 'Partikel mir immer die Verwendull gemeint sein, die traditionell als ethischer Dativ bezeichnet wird. 
Modalpartikeln - keine Möglichkeit, die Partikel zu thematisieren; ebenso ist sie nicht erfragbar; vgl.:

(69) Mutter: Fall mir nicht hin!

Kind: "Wem soll ich nicht hinfallen?

- Die Partikel mir kann keine Antworten auf Fragen bilden (das Personalpronomen mir natürlich schon).

- Mir kann nicht negiert werden; vgl.

(81) Mach mir deine Hausaufgaben ordentlich!

"Mach nicht mir deine Hausaufgaben ordentlich!

- Auch hinsichtlich der Kombinierbarkeit verhalten sich mir (und dir) wie Modalpartikeln: sie lassen sich ohne weiteres mit anderen Modalpartikeln kombinieren:

(82) Du bist mir vielleicht ein Held!

(83) Komm mir bloß nicht mit einem unehelichen Kind heim!

(84) Und bleiben Sie mir ja gesund!

(85) Die Politiker, das sind dir doch welche!

Mir und dir allerdings sind nicht miteinander kombinierbar, vermutlich aufgrund semantisch-pragmatischer Restriktionen.

Die vorangegangenen Ausführungen haben wohl deutlich gezeigt, daß sich mir (und dir) syntaktisch genauso verhalten wie die Modalpartikeln. Auch in ihren semantischen Eigenschaften gleichen sie diesen.

Wegen all dieser Gemeinsamkeiten möchte ich vorschlagen, mir (und dir) in der Verwendung, die traditionell "ethischer Dativ" genannt wird, zu den Modalpartikeln zu zählen. Damit sind m.E. diese beiden Ausdrücke zutreffender charakterisiert als mit der Zuordnung zu den freien Dativen.

Auch im Unterricht des Deutschen als Fremdsprache ist es vermutlich einfacher, mir und dir als Modalpartikeln zu beschreiben, bei denen die Bedeutung der Personalpronomina noch mitschwingt, als sie als Personalpronomina im Dativ zu bezeichnen, deren Verwendungsweisen und Restriktionen mit dieser Kategorisierung nur schwer verständlich gemacht werden können.

Im folgenden werden diese Modalpartikeln behandelt (einige von ihnen sind dabei eher am Rand der in 1.2.7 definierten Gruppe anzusiedeln, die Abweichungen vom distributionellen Grundmuster sind angegeben): aber, auch, bloß (kann auch betont vorkommen), denn, doch, eben, etwa (kann nach njcht stehen), eigentlich, einfach, halt, ja (kann auch betont vorkommen), mir (ursprünglich flektierte Form), nur (kann auch betont vorkommen), ruhig, schon, sowieso/eh (treten betont auf), vielleicht und wohl. 


\subsection{Modalpartikeln und Satzmodus}

Aufgrund der Satzmodusabhängigkeit der Modalpartikeln sollen hier die verschié denen Satztypen genauer behandelt werden.

Die Modalpartikel-Forschung hat in den meisten Fällen in diesem Bereich die for' male Seite der Sprache zuwenig betrachtet und oft formale und funktionale Eigen' schaften vermischt. Deshalb wird hier ein Satzmodussystem zugrundegelegt, d\& Form und Funktion einer Außerung genau trennt. Dabei werde ich mich nicht nل' auf Grundtypen von Sätzen beschränken. Da nämlich Modalpartikeln die illokutiv Kraft einer Außerung spezifizieren oder modifizieren können, können sie nur it Sätzen mit eigenständigem illokutiven Potential auftreten; oder andersherum argl' mentiert: alle Sät\%e, in denen Modalpartikeln auftreten können, haben eigene ill kutive Kraft. Insofern kann die Untersuchung sowohl der Satztypen, in denen $g^{\ell^{\prime}}$ nerell Modalpartikeln auftreten können (abgesehen davon, welche dies im speziel len sind) als auch die Untersuchung der Satztypen, in denen grundsätzlich kelp Modalpartikeln möglich sind, interessante Aufschlüsse auch über den Status die $5^{t^{\ell}}$ Satztypen geben. Aus diesem Grunde werde ich hier auch genauer auf sätze m Verb-Endstellung (selbständige wie unselbständige) eingehen.

\subsubsection{Grundtypen}

Die Klassifikationskriterien für Satztypen bzw. Satzarten bzw. Satzmodi in del einzelnen Grammatiken sind recht unterschiedlich und oft nicht klar formulie Neben Klassifikationen, die auf funktionalen Kriterien (z.B. bei Schulz/Griesba 1982:427ff.) beruhen und Klassifikationen, die auf rein formalen Kriterien basier (z.B. bei Eichler/Bünting 1978:34ff. auf dem realisierten Verbstellungstyp), werdel meist funktionale und formale Kriterien gemischt verwendet, wobei häufig d Verhältnis der beiden zueinander unklar bleibt.

In der Regel werden - relativ unabhängig von den angewandten Kriterien gleichen Satztypen, nämlich Aussagesatz, Fragesatz und Aufforderungssatz, et

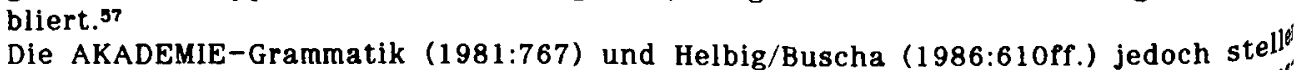
fünf Typen von Sätzen auf: Aussage-, Frage-, Wunsch-, Aufforderungs- und $A^{4}$ rufesätze, eine Typik, die mir angemessen erscheint.

\subsubsection{Formtyp und Funktionstyp}

In dieser Arbeit soll von einer strikten Trennung von Form und Funktion ausge' gangen werden; dabei stütze ich mich im wesentlichen auf das von Altmann (198 1987) aufgestellte Satzmoduskonzept.

57) Vgl. z.B. auch Helbig/Buscha (1980:541) oder den DUDEN (1984: 560f.), der der zweiten Gruppe allerdings noch den Wunschsatz ansetzt, oder Admo (1982:261f.). Oft wird der Fragesatz noch unterteilt. 
Der Formtyp eines Satzes konstituiert sich durch eine Reihe formaler Kennzeichen. Dabel muß sich jeder Formtyp durch mindestens ein Kennzeichen von jedem anderen Formtyp unterscheiden. Es werden also nur solche Kriterien angesetzt, die an mindestens einer Stelle des Satzmodussystems distinktive Funktion haben (vgl. Altmann 1984:134). Relevant sind grammatische (Im engeren Sinne) und intonatorische Kriterien sowie die kategoriale Fullung. Die Bedeutung rein grammatischer Kennzeichen bedarf wohl keiner besonderen Rechtfertigung; sie waren auch bisher in eher traditionellen Beschreibungen relevant für die Erstellung einer Satztypik. Die intonatorischen - d.h. suprasegmentalen - Kennzeichen werden häufig nicht als relevant anerkannt. Allerdings ist für den Gesprächspartner auch die Intonation ein wesentliches Mittel, um verschiedene Satzmodi zu unterscheiden. Die kategoriale Füllung ist zu trennen von der konkreten lexikalischen Füllung; d.h. entscheldend ist zur Feststellung des Satzmodus z.B. weniger, welches $w$-Element auftritt, sondern vielmehr, ob überhaupt ein Element aus der Gruppe der $W$-Ausdrücke vorhanden ist. (Ahnliches gilt Im Bereich der Sätze mit Verb-Endstellung Pür die Konjunktionen.)

Die formalen Kriterien, die hier zur Unterscheidung der Formtypen herangezogen werden, sind im einzelnen:

- Verbstellung: zugrunde liegt dabei das bereits erwähnte topologische Grundmodell. Aup die Satztypen, bei denen das finite Verb am Ende steht, gehe ich weiter unten ein (Kap. 1.3.2); hier sollen (als Grundtypen) nur Sätze mit Anfangsoder Zweit-Stellung des finiten Verbs betrachtet werden.

- Verbmorphologie: hier ist entscheidend, ob das finite Verb imperativisch markiert ist, und falls nicht, ob es eine Konjunktiv-II-Form aufweist.

- Tonmuster: hier soll danach unterschieden werden, ob der Intonationsverlauf Pallend oder steigend ist. ${ }^{38}$

- Akzent: relevant ist hier das Auftreten elnes Exklamativakzentes. Dieser ist von den 'normalen' Akzenten (kontrastive, emphatische oder neutrale) durch die Realisierung und die Position zu unterscheiden. ${ }^{39}$

- Kategoriale Fallung: dieses Kriterium bezieht sich hier nur darauf, ob ein wElement (also Fragepartikeln wie wer, wann, wo etc.) vorhanden ist oder nicht. Die Aufnahme von (bestimmten) Modalpartikeln als Kriterium soll hier gerade nicht erfolgen.

58) Das Tonmuster wird hier in der Regel durch die Interpunktion angedeutet.

59) Die Tonmuster wird hier in der Regel durch variabel; von der Realisierung her untersition des Exklamativakzenta die Nukleussilbe oder die Gesamtäußerung stark gelängt er sich dadurch, daß dypischerweise sehr spät in der Nukleussllbe liegt (vgl. Batliner 1988). 
Zunächst sollen die Formtypen und die ihnen entsprechenden Funktionstypen dat gestellt werden, und es soll gezeigt werden, in welchen Typen welche Modalpal tikeln auftreten können.

\subsection{Die einzelnen Formtypen}

In dieser Arbeit soll von den folgenden sieben Formtypen ausgegangen werd (orientiert an Altmann 1984:137):

1. Aussagesatz: Beim Aussagesatz steht der finite Tell des Verbs an zweiter stel le, das Verb ist nicht imperativisch markiert, das Tonmuster ist fallend, der Sal enthalt kein $w$-Element:

(1) Ich bin nicht Stiller.

2. Entscheidungsfragesatz: Hier steht das finite Verb an erster Stelle des Satz das Verb ist nicht imperativisch markiert; der Intonationsverlauf ist in der Reb steigend, kann aber auch fallend sein.

(2) Kennst du das Land, wo die Zitronen blühn?

3. Wragesatz: Das finite Verb steht an zweiter Stelle und ist nicht impera visch markiert. Das Vorfeld ist von einem $w$-Wort besetzt, das Tonmuster ist allgemeinen fallend.

(3) Wer reitet so spät durch Nacht und Wind?

4. Imperativsatz: Hier steht das finite Verb in der Regel an erster Stelle und imperativisch markiert; elne eindeutige morphologische Markierung des Verbs il allerdings nur bei der 2. Pers. Singular vor. Bei den Formen der 2. Pers. Sing und Plural fehlt meist das Subjektspronomen (und in diesem Fall ist auch ver Zweit-Stellung zulässig). Ist es vorhanden, so muß bei der Pluralform ebenso bel der Sie-Form und beim Adhortativ das Verb an erster Stelle stehen. In diest Fall ist der Imperativsatz vom Entscheidungsfragesatz nur uber das Tonmuster unterscheiden:

(4) Geben Sie Gedankenfreiheit!

Der Entscheidungsfragesatz weist also (wenn überhaupt) nur dann fallendes Tol muster auf, wenn keine Verwechslung mit einem Imperativsatz möglich ist.

5. Wunschsatz: In Wunschsätzen besetzt das finite Verb die erste Position und konjunktivisch markiert; genauer gesagt: die Verbformen sind Konjunktiv-II-F men. Das Tonmuster der Wunschsätze ist fallend.

(5) Wär ich doch ein Königssohn! 
6. (Satz-)Exklamativsatz: Beim Exklamativsatz ist das Kriterium der Verbstellung nicht differenzierend: ob das Verb an erster oder an zweiter stelle steht, ändert nichts an der Funktion des Satzes (vgl. (6)); diese fakultative Stellung des Verbs soll als ein Kriterium für den Exklamativsatz gelten.

(6) Hast DU einen tollen Pelzmantel! $D U$ hast (vielleicht) einen tollen Pelzmantel!

Das finite Verb eines Exklamativsatzes ist (im allgemeinen) indikativisch markiert, das Tonmuster fallend. Zusätzlich weisen Exklamativsătze immer einen Exklamativakzent (s. S.34) auf:

(7) Mensch, hast DU eine Nase! Mensch, hat DIE eine Nase! (Kr, 162)

Die Position des Exklamativakzents ist bei gleicher Verwendung eines Satzes variabel: typischerweise liegt er auf thematischen Elementen - oft auch auf einem skalierend $\mathrm{zu}$ interpretierenden Ausdruck; auch Akzentsplitting ist möglich. Vgl.:

(7a) Mensch, hast DU eine Nase!

Mensch, hast du eine NASE!

Mensch, hast DU eine NASE!

7. W-Exklamativsatz: Bei W-Exklamativsätzen steht das (im allgemeinen) indikativisch markierte Verb an der zweiten Stelle, im Vorfeid tritt ein $w$-Element, und zwar meist wie oder was für ein auf. Im Normalfall ist das $w$-Element mit einem wertenden Adjektiv oder Adverb verbunden. Das bewertete Element trägt dabei einen (thematischen) Akzent. Der Intonationsverlauf eines $w$-Exklamativsatzes ist fallend.

Wie SCHNELL vergeht doch die Zeit!

Die folgende Tabelle gibt einen zusammenfassenden Oberblick über alle hier angenommenen Formtypen und die Kriterien, die zur Beschreibung verwendet werden. 60

60) Natürlich ist diese Obersicht insofern idealisiert, als die Kennzeichen nicht immer eindeutig differenzieren; so ist z.B. im Berelch der Verbmorphologie die imperativische, indikativische oder konjunktivische Form nicht bei jedem Verb erkennbar. In diesen Fällen müssen zusätzliche Kriterien angenommen werden; darauf kann hier allerdings nicht näher elgegangen werden. (Verwiesen sei dazu u.8. auf Oppenrieder 1987 und Luukko-Vinchenzo 1988.) 
Tabelle 3: Formale Kennzeichen der Grundtypen

\begin{tabular}{|c|c|c|c|c|c|c|c|c|c|}
\hline & \multicolumn{2}{|c|}{ VERBSTELLG } & \multicolumn{3}{|c|}{ V-MORPHOL. } & \multicolumn{2}{|c|}{ TONMUSTER } & \multirow{2}{*}{$\begin{array}{l}\text { w-ELEMENT } \\
\text { obligator. }\end{array}$} & \multirow{2}{*}{$\begin{array}{l}\text { EXKLAM: } \\
\text { AKZENT }\end{array}$} \\
\hline & $V-1$ & $\mathrm{v}-2$ & Imp. & Ind & Konj. & steig. & fall. & & \\
\hline Aussagesatz & - & + & - & + & + & - & + & - & - \\
\hline $\begin{array}{l}\text { Entscheid. } \\
\text { Pragesatz }\end{array}$ & + & - & - & + & + & + & $(+)$ & - & - \\
\hline$w$-Fragesatz & - & + & - & + & + & $(-)$ & + & + & - \\
\hline Imperativs. & + & $(t)$ & + & - & - & - & + & - & - \\
\hline Wunschsatz & + & - & - & - & + & - & + & - & - \\
\hline $\begin{array}{l}\text { (Satz-)Ex- } \\
\text { klamativs. }\end{array}$ & + & + & - & + & $(-)$ & - & + & - & + \\
\hline $\begin{array}{l}\text { w-Exklama- } \\
\text { tivsatz }\end{array}$ & - & + & - & + & $(-)$ & - & + & + & $(+)$ \\
\hline
\end{tabular}

\subsection{Funktionstypen und Illokutionstypen}

Ein Formtyp konstituiert sich also durch die oben aufgestellten formalen Ken $n^{\prime}$ zeichen; jedem Formtyp - d.h. der Summe aller Kennzeichen - ist genau ein Funk tionstyp zugeordnet; jeder Funktionsunterschied ist also auch an einem Form unterschied Pestzumachen. Ein Formtyp wird zum direkten Ausdruck einer propo' sitionalen Grundeinstellung verwendet (vgl. dazu Bierwisch 1980 und Lang 1981). Die Zuordnung von Formtyp zu Funktionstyp (ausgedrückte propositionale Grund einstellung) läßt sich schematisch so darstellen (vgl. dazu auch Altmanl 1984:134):

Tabelle 4: Zuordnung von Formtyp und Funktionstyp

\begin{tabular}{|lll}
\hline Formtyp & Funktionstyp & propositionale Grundeinstellung \\
Aussagesatz & Assertion & sagen, da $\beta$ \\
Entscheidungsfragesatz & & \\
w-Fragesatz & Frage & fragen, ob/w- \\
Imperativsatz & Aufforderung & erreichen wollen, da $\beta$ \\
Wunschsatz & Wunsch & wüschen, da $\beta$ \\
Exklamativsatz & & \\
w-Exklamativsatz & sich wundern, daß/wie sehr \\
\hline
\end{tabular}


Damit ist die sehr abstrakt $\mathrm{zu}$ verstehende strukturelle Satzmodus-Grundbedeutung eines Satzes erfaßt.

Die konkrete lexikalische Füllung ergibt im Zusammenwirken mit dem Funktionstyp einen bestimmten Illokutionstyp.

Dieser Illokutionstyp kann nun der ausgedrückten propositionalen Grundeinstellung entsprechen, 61 die propositionale Grundeinstellung kann aber auch durch bestimmte einstellungsanzeigende Mittel spezifiziert und modifiziert werden (vgl. dazu Doherty 1985). Diese Mittel sind vor allem Modalverben, performative Verben, Satzadverbiale und eben auch Modalpartikeln (deshalb werden diese auch als 11lokutive Indikatoren bezeichnet). Inr Zusammenwirken ergibt einen bestimmten Illokutionstyp, der in dle Sprechhandlung eingeht, die ein Sprecher durch das Außern eines Satzes vollzieht.

Will ein Sprecher also die durch den Satzmodus ausgedrúckte Grundeinstellung modifizieren (bis hin zur Umdeutung, was der "ungeraden" Verwendung bei Altmann (1987:24) entspricht), muß er zusătzliche Mittel verwenden, um dies auch für den Gesprächspartner deutlich zu machen. Die Illokution läßt sich für den Gesprächspartner systematisch mit Hilfe interpretativer Strategien aus den formalen Indikatoren des Funktionstyps, der lexikalischen Fülung und dem Kontext erschließen.

Die Mittel, die die tatsächliche illokutive Kraft einer Außerung bestimmen, sind hierarchisch geordnet: So kann z.B. eine Modalpartikel wie ruhig erst dann in einem Aussagesatz auftreten, wenn dessen propositionale Grundeinstellung bereits durch Modalverben modifiziert ist.

Im Rahmen dieser Arbeit ist es natürlich von besonderem Interesse, wie durch Modalpartikeln die abstrakten Funktionstypen bzw. die bereits durch lexikalische Mittel modifizierten Illokutionstypen spezifiziert oder modifiziert werden können.

Daß für die Bedeutungsbeschreibung der Modalpartikeln die konkrete lexikalische Fullung und der Verwendungskontext eine wesentliche Rolle spielen, wurde bereits erwahnt. Insofern muß der Kontext in die Beschreibung mit einbezogen werden, da ja dle kontextfrele Bedeutung der Modalpartikeln gerade auch in Hinwelsen darauf besteht, welche Elemente des Kontextes der Hörer berücksichtigen muß (vgl. dazu auch Franck 1980:167).

Was aber hler nicht eingehend betrachtet werden kann, ist, daß eine bestimmte Außerung in einem speziellen Kontext weitere Umdeutungen erfahren kann, die unabhängig von der sprachlichen struktur erfolgen.

61) Das läßt sich mit der "Basisillokution" (vgl. z.B. Sökeland 1980) vergleichen; d.h. der Illokutionstyp entspricht dann genau der - abstrakt zu verstehenden - propositionalen Grundeinstellung. 
Hier werden nur Veränderungen behandelt, die an einem spezifischen Aspekt del sprachlichen Struktur - eben an den Modalpartikeln - Pestzumachen sind.

Die Etablierung der Funktionstypen bzw. die Beschreibung der propositionalel Grundeinstellungen bietet den Vorteil, daß Unterschiede, die bei gleichem Illok $u^{\circ}$ tionstyp durch die Verwendung verschiedener Formtypen entstehen, mittels ver schiedener ausgedrückter propositionaler Grundeinstellungen erklärt werdel können.

So sind die Unterschiede zwischen $(9 a-c)$, die alle dazu dienen (können), ein 'Aufforderung' auszudrücken, an den unterschiedlichen propositionalen Grund' einstellungen (nämlich 'erreichen wollen, daß', 'sagen, daß' und 'Pragen, ob') fest' zumachen.

(9a) Bring die Ski in den Keller!

(9b) Du bringst die Ski in den Keller.

(9c) Bringst du die Ski in den Keller?

Im weiteren wird folgende Terminologie zugrundegelegt: 'Aussagesatz', 'Entschel' dungsfragesatz' etc. bezeichnen die Formtypen, 'Aussage', 'Frage' etc. die Funk' tionstypen.

Uber die durch Modalpartikeln modifizierten Funktions- und Illokutionstypel werden die Einzelanalysen Aufschluß geben.

(Auf die Frage, ob das Auftreten von Modalpartikeln durch den Funktions- bz Illokutionstyp oder den Formtyp bestimmt wird, gehe ich weiter unten (S.201) ein.)

\subsubsection{Distribution der Modalpartikeln}

Die folgende Ubersicht zeigt die Distribution der hier behandelten Modalpartikell auf die oben beschriebenen sieben Formtypen. Beispiele für jede Verwendungsweist finden sich dann bel den Einzelanalysen in Kapitel 2. 
Tabelle 5: Distribution der Modalpartikeln in den Grundtypen

\begin{tabular}{|c|c|c|c|c|c|c|c|}
\hline & $\begin{array}{l}\text { Aussage- } \\
\text { satz }\end{array}$ & $\begin{array}{l}\text { Entschei- } \\
\text { dungs- } \\
\text { fragesatz }\end{array}$ & $\begin{array}{l}w \text {-Frage- } \\
\text { satz }\end{array}$ & $\begin{array}{l}\text { Impera- } \\
\text { tivsatz }\end{array}$ & $\begin{array}{l}\text { Wunsch- } \\
\text { satz }\end{array}$ & $\begin{array}{l}\text { (Satz-)Ex- } \\
\text { klamativ- } \\
\text { satz }\end{array}$ & $\begin{array}{l}\text { w-Exklama- } \\
\text { tivsatz }\end{array}$ \\
\hline aber & & & & & & + & 62) \\
\hline $\begin{array}{l}\text { auch } \\
\text { bloB }\end{array}$ & + & + & + & + & & & + \\
\hline $\begin{array}{l}\text { blo } \beta \\
\text { denn }\end{array}$ & & & + & + & + & & + \\
\hline $\begin{array}{l}\text { denn } \\
\text { doch }\end{array}$ & + & + & + & & + & & + \\
\hline eben & $\begin{array}{l}+ \\
+\end{array}$ & & + & $\begin{array}{l}+ \\
+\end{array}$ & + & & + \\
\hline eigentlich & & + & + & & & & \\
\hline einfach & + & + & & + & & & \\
\hline $\begin{array}{l}\text { etwa } \\
\text { halt }\end{array}$ & $t$ & + & & & & & \\
\hline $\begin{array}{l}\text { halt } \\
\text { ja }\end{array}$ & + & & & + & & & \\
\hline$J_{A}$ & + & & & + & & & \\
\hline $\mathrm{mal}$ & + & + & & + & & & \\
\hline mir & + & & & + & & + & \\
\hline nur & 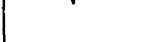 & & + & + & + & & + \\
\hline ruhig & + & & & + & & & \\
\hline schon & + & & + & + & & & \\
\hline $\begin{array}{l}\text { sowieso/eh } \\
\text { vielleicht }\end{array}$ & + & 63) & & & & + & \\
\hline wohl & + & $\begin{array}{l}+ \\
+\end{array}$ & + & & & & \\
\hline
\end{tabular}

\subsubsection{Selbstāndige Sătze mit Verb-Endstellung}

Das Auftreten von Modalpartikeln in den oben beschriebenen 'Grundtypen' von Satzmodi wird in der Literatur vielfach - allerdings mit unterschiedlicher Genauigkeit - besprochen. Kaum Beachtung fand dagegen bisher die Distribution der Modalpartikeln in anderen Satztypen, wie z.B. den selbständigen Sätzen mit VerbEndstellung - wohl auch deshalb, weil diese als Satztypen selten berücksichtigt werden. Eine Untersuchung des Auftretens von Modalpartikeln in diesen Formen kann allerdings recht aufschlußreich sein, da nicht zuletzt daraus wiederum Schlüsse gezogen werden können über den Status der Verb-Letzt-Typen.

Die Phänomene, um die es im folgenden geht, sind Sätze wie (10)-(15), also Sätze, die eine oder mehrere Konjunktionen oder einen w-Ausdruck als Einleitungselement (Klammeröffner) und das finite Verb in Endstellung aufweisen:

(10) Wenn ich das wüßte!

(11) Ob der die Arbeit bis März fertigbringt?

(12) Daß du mir keinen Unsinn machst!

(13) Wie das hier wieder ausschaut!

(14) Als ob ich nicht gensusogut singen könnte.

62) Heute kaum mehr gebräuchlich.

63) Seltene Variante; wird hier nicht weiter betrachtet. 
Sătze vom Typ (10)-(15) zeigen ein Wortstellungsmuster, das im Deutschen eigentlich fur Nebensätze charakteristisch ist. Darin liegt wohl auch der Grund, warum der Status und die Einordnung dieser Sätze noch ungeklärt ist.

Es läßt sich aber zeigen, daß derartige Sätze auch zum Ausdruck einer propositionalen Grundeinstellung dienen, $d a \beta$ sie eigene lllokutive Kraft haben und somit selbständig sind. Das wird nicht zuletzt durch das Auftreten der Modalpartikeln nahegelegt (vgl. auch die Gegenüberstellung auf S.82).

\subsubsection{Stand der Forschung}

Ein deutliches Bild von der unsicheren Forschungslage bietet die AKADEMIEGrammatik (1981): Haftka (717) spricht bei der Verwendung von selbständigen Sätzen mit Verb-Endstellung von "Reduktionen eines ubergeordneten Satzes" (dile hler als 'Ellipsenhypothese' bezeichnete Auffassung), Jüttner (767) dagegen von "selbständige[n], hinsichtlich der Satzintention spezifizierte[n] Sätze[n]" und meinl zu wenn-Wunschsätzen explizit, man könne "solche Sätze nicht aus einfacher Tilgung der abergeordneten Sätze innerhalb von Satzverknüpfungen erklären" (772). Jüttner wie auch $A$. Buscha (1976) nennen diese Sätze "isolierte Nebensätze". Dabel wird der Terminus 'Nebensatz' wohl nur aufgrund der Ubereinstimmung mit (echten) Nebensätzen bezüglich Wortstellung und Einleitungselement beibehalten. Andere Grammatiken erwähnen das Phänomen entweder nur kurz oder ignorieren es vollig.

Die erste ausführlichere Darstellung der selbständigen Sätze mit Verb-Endstellunb stammt von A.Buscha (1976). Sie geht davon aus, daß diese Sätze einer "Tenden" der gesprochenen Sprache zur Verkürzung [!]" entgegenkommen (279) und beschreibt die "isolierten Nebensătze" als isolierte Frage-, Wunsch-, Ausruf-, und Aufforderungssätze. Ihre Klassifikation erfolgt mit Hilfe eines Tests, bei dem de' Verb-Letzt-Satz in einen übergeordneten Satz eingebettet wird; dieser enthält be stimmte Verben, die die Sprecherintention zeigen sollen und ist Grundlage det Klassifikation. Auch hier lassen sich also Reste der Ellipsenhypothese feststellen.

Weuster will in ihrer 1983 entstandenen Untersuchung deutlich machen, "da $\beta$ es syntaktische, semantische und pragmatische Indizien dafür gibt, daß es sich [bel den Sătzen mit Verb-Endstellung; M.T.] um selbständige Sätze handelt" (1983:21). Dabei weist Weuster m.E. aberzeugend nach, daß die 'Ellipsenhypothese' nicht haltbar ist, unter anderem auch deshalb nicht, well nicht für jeden Typ von Verb-Letzt-Satz ein entsprechender übergeordneter Satz konstruiert werden kan (vgl. z.B. S.38 und ob-Sätze oder S.60f. wenn-Sätze). Um die Illokution diesel Sätze festzustellen, verwendet allerdings auch Weuster da, wo Einbettung möglich ist, wieder Matrixsatze mit performativen Verben (vgl. z.B. S.47: ich frage hiermit $o b . .$.$) . Die zweite Methode, die Weuster anwendet, ist das Bilden von "syntakti-$ schen Paraphrasen", also die Umstellung der Elemente eines Satzes mit Verb-End" stellung.

Für eine zunächst formorientierte Betrachtung dieser Satztypen scheint mir diese Umstellung eln Kriterium (unter anderen Kriterien) zu sein, mit deren Hilfe sich die Verb-Letzt-Sătze und ihre Funktion kategorisieren lassen.

Gegen die Konstruktion von Matrixsätzen spricht, daß aus dem Verb-Letzt-satz selbst in der Regel nicht ablesbar ist, welcher Matrixsatz nun gerade konstruiert 
werden muß. Natürlich hångt ein entsprechender übergeordneter satz immer auch von der jewelligen einleitenden Konjunktion ab, aber es sind dennoch meistens mehrere Matrixsătze mőglich.

Man muß davon ausgehen, daß - und das scheint mir inzwischen unbestritten festzustehen - diese Sătze mit Verb-Endstellung eigenständige sätze sind und elne elgene Illokutive Kraft haben. Aus diesem Grund soll hier auch der m.E. neutralste Terminus '(selbständiger) Satz mit Verb-Endstellung' bzw. 'Verb-Letzt-Satz' gewăhlt werden, weil durch diese Bezeichnung die selbstăndigkeit der sătze deutlicher wird als z.B. bel den Bezeichnungen 'isolierte Nebensätze' oder 'nicht-eingebettete Satztypen'. Die abhängigen sătze mit Verb-Endstellung werden hier traditionell als 'Nebensätze' bezeichnet.

Jeder Typ von Verb-Letzt-sătzen läßt sich nun einem der in 1.3 .1 besprochenen Typen zuordnen. Insofern scheint es mir methodisch gerechtfertigt, die Zugehörigkeit zu einem der Grundtypen unter anderem durch Umstellung des finiten Verbs zu überprüfen. Dabei gilt eine Umstellung nur dann als möglich, wenn sich die Funktion und die Illokution des Satzes nicht ändern und wenn keine zusätzlichen Elemente eingefügt werden müssen.

Im Polgenden sollen also die elnzelnen Typen von sătzen mit Verb-Endstellung nach Form und Funktion beschrieben werden, in einem zwelten Schritt wird dann gepruft, welche Modalpartikeln auftreten können bzw. müssen.

\subsubsection{Modalpartikeln in sătzen mit Verb-Endstellung}

Eine erste Untertellung der sätze mit Verb-Endstellung soll zunächst nach dem Einleitungselement erfolgen.

Einleitungselemente von Verb-Letzt-Sätzen können nur bestimmte Konjunktionen und w-Ausdrucke sein. Aus der Bedeutung des Einleitungselements läßt sich in einigen Făllen (z.B. bei ob) bereits ein Rückschluß aup die mögliche Funktion zlehen.

Nach dem Einleitungselement sollen hier folgende Typen von selbständigen Sätzen mit Verb-Endstellung unterschieden werden:

1. wenn-Sätze

2. $o b-$ Sätze

3. daß-Sätze

4. Satze mit $w$-Ausdruck

5. wo-Sătze

6. als $o b-/ a l s$ wenn-Sätze

7. und ob-/und wie-satze

Bei der formalen und funktionalen Analyse dieser Gruppe werden folgende Kriterien eine Rolle spielen: 
- die Verbmorphologie.

- die Frage, ob ein Modalverb obligatorisch ist.

- die Frage, ob der Satz in einen Satz mit Anfangs- oder Zweit-Stellung des $\mathrm{fl}^{-}$ niten Verbs umgeformt werden kann und ob das Einleitungselement erhalten bleibt oder nicht. Weiter wird geprüft, ob das Verb morphologisch verändert werden muß. Falls die Umformung nicht möglich ist, soll geprüft werden, warum nicht und unter welchen Bedingungen eine Umformung möglich wäre. Hier wird sich bereits zeigen, daß Modalpartikeln eine wichtige Rolle spielen.

- das Vorliegen eines Exklamativakzentes.

\subsubsection{1 wenn-Satze}

Nachdem die wenn-Sătze hinsichtlich der oben angeführten Kriterien uberprül wurden, ergaben sich folgende Typen:64

\section{1. wenn-Wunschsstze}

(16) Wenn ich nur heimdürfte!

(17) Ach, wenn ich nur auch solche EItern hatte!

Das finite Verb dieser sätze steht immer im Konjunktiv, der Satz läßt sich II einen Satz mit Anfangsstellung des Verbs umformen, wobei es sich dabei eindeutif um einen Wunschsatz handelt - darauf deutet auch die Partikel ach in (17) hin:

(16a) Dürfte Ich nur heim!

(17a) Ach, hätte ich nur auch solche Eltern!

Im wenn-Wunschsatz sind (neben ach) die Modalpartikeln doch, nur oder bloß obligatorisch (vgl. (18)-(20)), was sie aber im Wunschsatz mit Anfangsstellung def Verbs mögllcherweise auch sind (vgl. oben S.24f.).

(18) Wenn er doch käme!

(19) Wenn ich nur wegkonnte!

(20) Wenn sie bloß nicht so verbohrt wäre in dieser Sache!

Einen Sonderfall stellen folgende Sätze dar, die ebenfalls wunschcharakter habel

- aber auch Zweifel anzeigen:

(21) Wenn das mal gutgeht!

(22) Wenn Sie sich da nur nicht irren!

64) Neben den angeführten Typen gibt es noch eine Art von wenn-Sätzen, dle wohl am ehesten als Aussagesätze einzuordnen sind: Natürlich hätt ich in nicht so anschwindeln dürfen! Aber mein Gott! Wenn er (auch) jeden Mist glaubt! Dieser Typ soll hier aber nicht weiter betrachtet werden, da auct nicht eindeutig entschieden werden kann, ob derartige Sätze wirklich sel $b^{b^{\prime}}$ ständig sind. 
Bel diesen Sätzen ist das finite Verb immer indikativisch marklert, was gegen elne Interpretation als Wunschsatz spricht. Auch ist der Satz ohne Anderung der Illokution nicht umformbar; vgl.:

(21a) Das geht mal gut. (entspricht nicht (21))

Mit dem Satzadverb hoffentlich allerdings entsprechen die Aussagesätze den wennSätzen:

(21b) Hoffentlich geht das gut.

(21b) könnte ein Indiz dafür sein, daß es sich bei (21) um eine Mischung aus Aussage und Wunsch handelt.

In diesen Sătzen treten die Modalpartikeln mal, bloß und nurs auf; vgl. oben (21) und (22) und:

(23) Wenn das bloß kein Reinfall wird!

\section{2. wenn-Aufforderungssătze}

Bel diesem Typ (vgl. (24) und (25)) handelt es sich um Außerungen, die als höfliche Aufforderungen zu interpretieren sind:

(24) Wenn Sie da drüben warten wollen?

(25) Wenn Sie einstweilen Platz nehmen möchten?

Diese Sătze enthalten immer ein Modalverb (was die Interpretation als Aufforderung erleichtert), können indikativisch oder konjunktivisch sein und sind - unter Wegfall der Konjunktion - in einen Satz mit Verb-Anfangsstellung (und zwar einen Entscheidungsfragesatz) umwandelbar; vgl.:

(25a) Möchten Sie einstweilen Platz nehmen?

In diesen wenn-Sätzen kann (neben der Partikel bitte) lediglich die Modalpartikel mal auftreten:

(26) Wenn Sie mir (bitte) mal den ordner reichen könnten?

\section{3. wenn-satze in Obergangsbereich}

Der letzte Typ von wenn-Sătzen läßt sich schwer elnordnen. Am ehesten handelt es sich hier um Sätze, die im Ubergangsberelch zwischen Aussagesatz und Exklamativsatz liegen:

(27) Meln Gott, der Olaf!! Wenn ich den schon seh!

Der Akzent spricht hier fur eine Einordnung als Exklamativsatz; gegen diese Einordnung spricht allerdings das Auftreten der Modalpartikel schon.

Dlese Sătze haben immer ein Verb im Indikativ und sle lassen sich auf keine Welse umformen; vgl.:

(27a) Mein Gott, der Olaf!! Ich sehe den schon. (entspricht nicht (27))

Hier tritt nur und obligatorisch die Modalpartikel schon auf:

65) Das Auftreten von bloß und nur spricht für eine Einordnung als Wunsch. 


\subsubsection{2 ob-Sătze}

Selbständige ob-Sätze sind Fragesätze. Mit einem Teil von ihnen (vgl. (31)) kant auch eine Aufforderung zum Ausdruck gebracht werden.66

(29) Ob's hier was zu trinken gibt? (B1, 92)

(30) Hier kann man vom Frühstück bis zum Abendbrot alle Mahlzeiten des Tages elnnehmen. $O b$ das Sinn hat? Ob das gut ist? (SZ)

(31) Ob du (bitte) das Auto volltanken könntest?

Bel echten Fragen wie (29) und (30) steht das Pinite Verb immer im Indikativ; all Sătze dieses Typs lassen sich umwandeln in einen Entscheidungsfragesatz:

(29a) Gibt's hier was zu trinken?

Die ob-Fragesätze enthalten meist die Modalpartikel wohl:

(32) Auf seinen Breeches hatte er Lederbesatz. Ob er wohl jemals ritt? (Ke, 148)

(33) ob Ich wohl die Prüfung bestehe?

\subsubsection{3 daß-Sătze}

Bel den $d a \beta$-Sätzen lassen sich drei sehr unterschledliche Typen feststellen, $w^{y}$ sicher auch mit der wenig speziellen Bedeutung der Konjunktion daß zusammen' hăngt.

\section{1. daß-Aufforderungssåtze}

Mit der ersten Gruppe von daß-Sätzen werden Aufforderungen ausgedrückt - w zwar ziemlich 'starke' Aufforderungen, die auch oft ais Drohungen interpretief' werden müssen:

(34) Daß du dich JA anständig benimmst!

Bel Sätzen dieses Typs ist das Verb immer indikativisch markiert - eine Imper ${ }^{\prime}$ tivform ist nicht möglich. Bei der Umformung in einen entsprechenden Satz $\mathbb{m}^{\prime \prime}$ Anfangsstellung des Verbs muß dieses in eine Imperativform umgewandelt (oder $e^{l l}$ entsprechendes Modalverb eingefügt) werden, um die Illokution beizubehalten; vgl: (34a) Benimm dich anständig!

In $d a \beta$-Aufforderungssatzen sind Modalpartikeln obligatorisch; hier treten vor $a^{\prime}$ lem $J A$ und bloß sowie mir auf. Daneben können auch und nur (in der Kombinatiol nur $J A$ ) sowie dialektal die Varianten fei JA und man $J A$ vorkommen.

66) Zum Tell kann wohl auch eine (drohende) Aufforderung mit ob-Sätzen, denen $a b$ den Hauptakzent trägt, zum Ausdruck gebracht werden: $O B d u$ kommst! Diese Sätze korrespondieren mit dem weiter unten (S.143f.) zu be sprechenden Verb-Erst-Typ: WIRST du wohl kommen! Die Variante mit scheint mir allerdings marginal zu sein. 


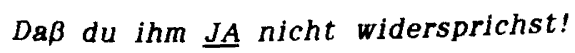

(36) Halt den Mund! Halt den Mund! Daß es JA niemand hört im Haus! (Kr, 169)

(37) Daß bloß keiner dem Hans was von dieser Sache erzählt!

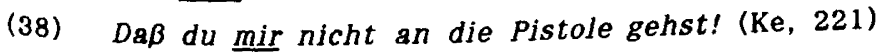

(39) Daß du nur JA jeden Tag übst!

(40) Also, du bleibst jetzt bis heute abend bei der Oma. Und daß du auch brav bist! Ich will keine Klagen hören, wenn ich zurückkomme!

\section{2. daß-Wunschsätze}

Bei daß-Wunschsätzen kann das finite Verb nur im Konjunktiv stehen; Sätze dieses Typs lassen sich ohne weiteres - unter Wegfall der Konjunktion - in einen Wunschsatz mit Verb-Erststellung umformen. Die Konjunktivform muß dabei immer erhalten bleiben; vgl.:

(41) Daß er doch käme!

(41a) Käme er doch!

Hier tritt nahezu immer die Modalpartikel doch auf. ${ }^{67}$

Einen Sonderfall der $d a \beta$-Wunschsätze stellen Außerungen wie (42) dar, die keine Konjunktivform enthalten:

(42) Daß er nur nicht in schlechte Gesellschaft gerät!

Diese Sätze lassen sich - wenn das Verb in den Konjunktiv gesetzt wird - in einen Wunschsatz umformen, dessen Illokution aber der des Verb-Letzt-Satzes nicht ganz entspricht (vgl. (42a)). Ohne Anderung des Verbmodus kann - unter Auslassung von nur - ein Aussagesatz gebildet werden; in diesem Fall aber muß z.B. hoffentlich eingefügt werden, nur so bleibt die Funktion der Außerung erhalten (vgl. (42b) und (42c)).

(42a) Geriete er nur nicht in schlechte Gesellschaft!

(42b) Er gerät nicht in schlechte Gesellschaft.

(42c) Hoffentlich gerät er nicht in schlechte Gesellschaft.

In den angeführten daß-Sätzen treten obligatorisch die Modalpartikeln nur oder blo $\beta$ aup.

Mit diesen Außerungen drückt der Sprecher eine bestimmte Hoffnung aus - insoPern ähneln sie den entsprechenden wenn-Sătzen (s.o. S.52f.); vgl.:

(42d) Wenn er nur nicht in schlechte Gesellschaft gerät!

\section{3. daß-texklamativsătze}

Die letzte Gruppe von $d a \beta$-Sätzen soll hier den Exklamativsätzen zugeordnet werden; vgl.:

67) Doch kann lediglich dann fehlen, wenn durch andere Kennzeichen - wie z.B. die Partikel oh - der Wunsch angezelgt wird: $O h, d a \beta$ sie ewig bliebe, die schöne Jugendzeit! 
Daß ich dich hier treffen würde!

(44) Daß ich das noch erleben muß!

Diese Sätze weisen einen Exklamativakzent ${ }^{68}$ auf. Sie sind nicht in einen entsprechenden Satz mit Anfangs- oder Zweitstellung des Verbs umwandelbar; vgl.:

(43a) Würde ich dich hier treffen. (entspricht nicht (43))

(43b) Ich würde dich hier treffen. (entspricht nicht (43))

In den Exklamativsätzen mit daß lassen sich die Modalpartikeln auch und dock Pinden, ${ }^{69}$ sowie die Kombination aber auch (vgl. (45)-(47)).

(45) Daß es auch soweit kommen mußte!

(46) Daß du dir das doch nie merken kannst!

(47) Daß die sich aber auch überhaupt keine Mühe geben!

\subsection{Satze mit w-Ausdruck und Verb-Endstellung}

Ausgenommen sind hier Sätze mit nicht-lokalem wo, da sich dieses anders verhäll als die anderen w-Ausdrücke (s.u. S.58).

Verb-Letzt-Sätze mit $w$-Wort treten als Fragesätze und als Ausrufesätze auf. Als dritte Variante gibt es noch textsortenspezifische w-Wort-Sätze, deren Zuordnunb etwas problematisch ist. Es handelt sich nicht um echte Ergänzungsfragen, auch nicht um Aussagen. Weuster (1983:54) bezeichnet sie als "verweisende Ergän" zungspragen"; vgl.:

(48) Warum wir nicht Weltmeister geworden sind

(49) Wie sich Boris auf Wimbledon vorbereitet

Die Sätze dieses Typs treten hauptsächlich als Schlagzeilen oder Titel auf un zeigen dem Hörer bzw. Leser, daß im folgenden Text die Lücke, die durch das Wort eröpfnet wird, init Information gefüllt wird. Da diese Sätze textsortenspezt fisch sind und außerdem hier im allgemeinen keine Modalpartikeln vorkommen kö $n^{\prime}$ nen, ${ }^{70}$ sollen sie nicht weiter behandelt werden.

68) Einen Sonderfall stellen Sätze wie (i)/(ii) dar; sie weisen zwar keinen Exk ${ }^{18^{\prime}}$ mativakzent auf, drücken aber auch eine Verwunderung des Sprechers aus:

(i) Bayerisch. Das sei'n komisches Volk. Daß das nun auch Deutsche sind. (kel (ii) Daß die Menschen nicht in Frieden leben können. (Ke, 92)

69) Die Tatsache, daß die für den Exlamativsatz typische Modalpartikel aber nu in der Kombination und die zweite Exklamativpartikel vielleicht gar nich auftreten kann, ist vermutlich dadurch zu erklären, daß mit diesen da $\beta$-E $\mathbb{X}^{\prime}$ klamativen ein Staunen über das Zutreffen eines Sachverhalts und nicht wie in den Exklamativen mit aber und vielleicht (mehr dazu s.u. Kap. 2.2. ${ }^{1}$ - ein Staunen über einen bestimmten Grad angezeigt wird.

70) Ganz ausgeschlossen sind Modalpartikeln allerdings nicht (vgl. dageget Altmann 1987:28):

(i) Wo Sie auch ruhig mal nackt zum Einkaufen gehen können (FKK-Blatt)

(ii) Warum Steffi Graf einfach gewinnen mußte 
1. -Fragesătze mit Verb-Endstellung

Bei diesen Fragesätzen kann das Verb im Indikativ oder im Konjunktiv stehen. Die

Sätze sind ohne weiteres in $w$-Fragesätze umformbar; vgl.:

(50)

Das Haus, an dem Anno 1903 stand, war von einer einzigen Bombe zer-

(50a) drückt. Wo wohl die Pekinesen abgeblleben waren? (Ke, 168)

(50a) Wo waren wohl die Pekinesen abgeblieben?

(51) Ich kuckte in den Spiegel. Wie wohl Menschen aussehen, die abgebrannt

(51a) sind? (Ke, 190)

(51a) Wie sehen wohl Menschen aus, die abgebrannt sind?

Diese Fragen sind aufgrund der Stellung im Dialog (und der Modalpartikel) gut zu unterscheiden von Rückfragen (s.u. Kap. 1.3.5.2) wie in (50b):

(50b) Walter: Wo waren die Pekinesen abgeblieben?

Mutter: Wo die Pekinesen abgeblieben waren? Das weiß ich auch nicht.

In den meisten Fällen tritt in den Fragesätzen mit w-Wort die Modalpartikel wohl aup (vgl. (50)/(51)), daneben sind aber auch nur, bloß und schon zu finden:

"Wie der bloß beim Militär zurechtgekommen ist", sagte meine Mutter, "der

war doch immer so unpraktisch..." (Ke, 134)

(54) Woher der gute Krambach das nur wußte?

Die Modalpartikel schon verwandelt auch hier die Außerungen in rhetorische Fragen, die zum Teil expressiven Charakter haben:

(55) Mein Gott! Wie du das schon machst! Du solltest einfach kein Werkzeug in die Hand nehmen.

(56) Ich kenn den Mann ein bißchen. Wie der schon schaut; der stiert durch die Gegend und hat überhaupt nichts Nettes an sich. (Kr, 140)

Interessant ist bei den $w$-Fragesätzen mit Verb-Endstellung, daß die fragesatztypischen Modalpartikeln denn oder etwa nicht auftreten; bzw. wenn sie auftreten, können die sätze nicht mehr als selbständige Verb-Letzt-Sätze verstanden werden

(57)

Wle ich denn damit zurechtkomme (, wollte er wissen).

1.

Verb-Letzt-sästivătze mit Verb-Endstellung

sind trägt von de Element im Satz einen Exklamativakzent, ansonsten entspricht der Satz (58) Form her den $w$-Fragesătzen:

(59) Was für tolle Ideen der hat!

Auch Schau mal, die Puppe! Wie seidig ihre Haare sind!

le umpose Sätze lassen sich in Exklamativsätze mit finitem Verb an zweiter Stel(58a)

Was hat der für tolle Ideen! 
In Fxklamativsätzen mit w-Wort können nur die Modalpartikel doch (seltenel auch) und die Kombination aber auch auftreten:

(60) Welch lebhafte Phantasie mein Bruder doch hat!

(61) Wie sehr doch die Erinnerung täuscht!

(62) In was für Kneipen du auch gehst! Da wundert mich gar nichts mehr!

(63) Wie toll die gber guch aussieht!

\subsection{WO-Sätze}

Neben dem lokalen wo, das sich wie die anderen w-wörter verhält, gibt es ein das wie eine Konjunktion verwendet wird; als solche stellt es eine Konzessivrela' tion her. Häufig tritt dieses wo auch zusammen mit doch auf.

Verb-Letzt-Sätze mit wo als Einleitungselement sind folgende:

(64) Was, du kommst heute nicht? Wo ich doch extra einen Kuchen für dich gebacken habe.

(65) Dieser Plan hat Katharina derart fasziniert, - wo sie doch selbst so eine ordentliche, planende, fast genial planende Person ist - daß sie immer lange davorstand. ( $\mathrm{Bö} \mathrm{b}, 76$ )

(66) Meike: Bist du sicher, daß zwischen Gabi und Phil nichts mehr ist? Nina: Neenee, da ist nichts mehr. Wo sie jeden Tag zum Benno ins Krankenhaus rennt.

Außerungen dieses Typs können als Aussagesätze eingeordnet werden (vgl. aud' Oppenrieder 1987:187), und zwar handelt es sich um Aussagesätze, die oft eif deutliche Vorwurfskomponente enthalten. In der Regel finden sich in diesen Sätzt Modalpartikeln (und zwar fast immer doch), sie sind aber vereinzelt auch on Modalpartikel möglich (vgl. (66)).

Das Verb der wo-Sätze kann im Indikativ oder Konjunktiv auftreten. Die săt lassen sich in Aussagesätze mit Verb-Zweitstellung71 umformen; allerdings egl| dabei wo weg - auch das ist ein Zeichen dafür, daß hier wo nicht als w-Fragt ausdruck, sondern als Konjunktion zu sehen ist. Vgl.:

(67a) Wo du das (doch) genau weißt. $\rightarrow$ Du weißt das (doch) genau.

Die Modalpartikel doch kann hier kombiniert werden mit auch und ruhig, bel de Kombination doch ruhig erhält die Außerung eine Aufforderungskomponente.

(68) So, jetzt weißt du's endlich. Wo das doch auch der Grund war, daß ich nicht $z u$ diesem Fest gegangen bin.

(69) Also ich versteh nicht, warum du dich jetzt auf einmal so anstellst. Wo d das doch ruhig für mich machen könntest. Ist doch wirklich nichts dabei.

71) Daneben gibt es auch eine Verb-Erst-Variante mit obligatorischem doch (vif oben S. 24): (66) Da ist nichts mehr. Rennt sie doch jeden Tag zum Benno if Krankenhaus. 


\subsubsection{6 als ob-sătze}

Sätze mit einleitendem als $o b$ - seltener als wenn - und Verb-Endstellung sollen hier als Aussagesätze eingeordnet werden:

Aber: "Als ob ein Spion sich mitten in ein Lokal setzt", sagte meine Mutter. (Ke, 195)

Als ob ich hier schon was zu sagen hätte.

Als ob er es gerochen hätte! (Ke, 188)

Als wenn du was davon verstündest.

Das Pinite Verb dieser Sätze steht in der Regel im Konjunktiv, der Indikativ ist seltener.

Parallel zu den selbständigen als ob-Sätzen gibt es eine Variante mit als und Verb-Erststellung:

(72a) Als hätte er es gerochen!

Diese Variante ist insofern ein Sonderfall, als sie in der abhängigen Verwendung eines der wenigen Vorkommen ohne Verb-Endstellung ist. ${ }^{72}$ Bei den entsprechenden Vergleichs(neben)sätzen stehen sich nämlich in gleicher Funktion die Varianten als ob/wenn und Verb-Endstellung und als ohne Verb-Endstellung gegenüber:

(74a) Es sieht so aus, als ob ihr jetzt endlich der Durchbruch gelungen wäre.

(74b) Es sieht so aus, als ob ihr jetzt endilich der Durchbruch gelungen

Dieser im Regelfall unselbständige als-Satz ist also - wie seine Verb-Letzt-Varianten - auch selbständig möglich. In diesem Fall steht das Verb immer im Konjunktiv.

Die als/als ob/als wenn-Sätze lassen sich in einen Satz umformen, bei dem das dann indikativische Verb an zweiter Stelle steht; gleichzeitig muß die Polarität der Proposition 'umgedreht' werden (bel (73) also ein Negationszeichen eingefügt Werden); es entsteht ein Aussagesatz, bei dem allerdings die oft vorhandene Vorwurfskomponente nicht mehr vorhanden ist: ${ }^{73}$

(73a) Als wenn du was davon verstündest. $\rightarrow$

Die Du verstehst davon nichts.

Tatsache, daß bei einer Umformung die Proposition 'umgedreht' werden muß. liegt vermutlich in der speziellen Funktion dieser Konjunktionen, die in der abhängigen Verwendung (verdeutlicht durch den Konjunktiv) dazu dienen, einen ir-

72) Die anderen Varianten sind Konditional-Sătze ohne wenn (mit Verb-Erst-Stellung) und Sätze nach Verba dicendi (mit Verb-Zweitstellung):

(ii) Käme sie rechtzeitig, könnten wir doch noch ins Kino. Iin Sie bemerkte trocken, genau das habe sie befüchtet. Im Unterschied zu der Verwendung mit als steht hier allerdings keine Kon-

73) Diesen. Dem Status von als in diesen Verwendungen ist noch nachzugehen. sages Vorwurfskomponente kann allerdings erhalten bleiben, wenn in den Aussagesatz doch eingefügt wird: (73b) Du verstehst doch davon nichts. 
realen Sachverhalt darzustellen. Schon hier kann ja oft zusätzlich erschlosset werden, daß die Umkehrung des im Nebensatz bezeichneten Sachverhalts zutrifft:

(75) Er benimmt sich, als ob er im Lotto gewonnen hätte. (Dabei spielt er gar nicht Lotto.)

Bei den selbständigen als/als ob-Sätzen nun trifft immer die Umkehrung zu.

Die einzige Modalpartikel, die hier - allerdings selten - auftreten kann, ist in teressanterweise schon, eine Partikel, die in w-Fragesätzen ein eindeutiger Anzei' ger für rhetorische Fragen ist, also auch dort in Außerungen auftritt, deren pro' positionaler Gehalt umgedreht werden muß (mehr dazu s. Kap. 2.2.8).

\subsubsection{7 und ob/und wie-Sätze}

Sätze mit Verb-Endstellung und einleitendem und $o b$ und und wie $e^{74}$ sind wohl al: Aussagesätze, allerdings mit einer deutlichen emphatischen bzw. expressiven Kom ponente einzustufen. Als Exklamativsätze würde ich sie deshalb nicht einordnet weil sie als adäquate Antwort auf eine Frage möglich sind und meist auch" verwendet werden, was für Exklamativsätze nicht gilt; vgl.:

$$
\begin{aligned}
& \text { Eva: Würdest du dich denn freuen? } \\
& \text { Max: Und ob ich mich freuen würde! } \\
& \text { Und wie ich mich freuen würde! }
\end{aligned}
$$

Ich betete zu meiner Privatgöttin Santa Claude um Fliegeralarm. Und er kam. Und wie! (Ke, 162)

Problematisch ist bei diesen Sätzen eine eventuelle Umformung. Bei und ob-Sätzl müßten beide Konjunktionen wegfallen, allerdings fehlt dann dem so entstanden ${ }^{\prime}$ Aussagesatz die Expressivität, die der und ob-Satz aufweist:

(76a) Ich würde mich freuen.

Wenn man in (76a) eine Modalpartikel wie vielleicht einfügt, bleibt $\mathrm{zwar}$ die pressivität erhalten (vgl. (76b)), der Satz ist aber eindeutig ein Exklamativs und als solcher nicht mehr eine adäquate Antwort auf eine Frage:

(76b) Ich WURDE mich vielleicht freuen!!

(76b)' Eva: Würdest du dich denn freuen?

Max: ?'ICh WURDE mich vielleicht freuen!!

Für die und wie-Sätze gelten dieselben Einschränkungen bei der Umformung, s' bieten aber zusätzlich die Möglichkeit, wie im Vorfeld zu belassen:

(76c) Wie würde ich mich Preuen!

Auch hier entsteht ein eindeutiger Exklamativsatz, der dieselben Probleme aul' wirft wie oben Satz (76b).

74) Der Unterschied zwischen einleitendem und ob, das mehr die Tatsache, w und wie, das mehr den Grad betont, soll hier nicht berücksichtigt werden. 
Die und wie- und und ob-Sätze sollen hier also als Aussagesätze eingeordnet werden, wobei sie allerdings an der Grenze zu den Exklamativsätzen liegen.

Mit und $o b$ oder und wie eingeleitete Sätze können keine Modalpartikeln enthalten.

\subsubsection{Zusammenfassung}

Die Polgende Ubersicht zeigt noch einmal alle Typen von selbständigen Sätzen mit Verb-Endstellung und ihre Formmerkmale.

Tabelle 6: Typen von selbständigen Verb-Letzt-Sätzen

\begin{tabular}{|c|c|c|c|c|c|c|c|c|c|}
\hline & 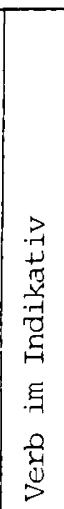 & 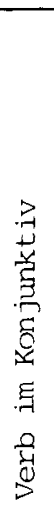 & 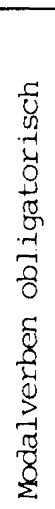 & 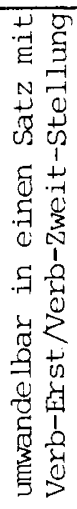 & 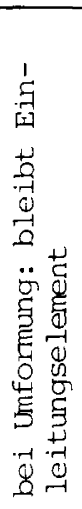 & 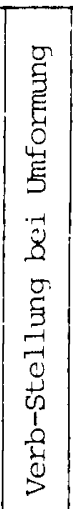 & 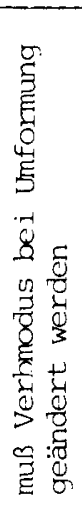 & 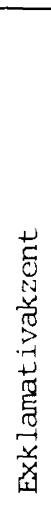 & 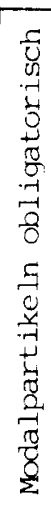 \\
\hline wenn-Wunsch & - & + & - & + & - & $\mathrm{V}-1$ & - & - & + \\
\hline wenn-Wunsch (?) & + & - & - & - & & & & - & $?$ \\
\hline wern-Aufforderung & + & + & + & t. & - & $\mathrm{V}-1$ & - & - & - \\
\hline wenn-Aussage/Exklamativ & + & - & - & - & & & & + & + \\
\hline ob-Frage & + & + & - & + & - & $V-1$ & - & - & - \\
\hline daß-Aufforderung & + & - & - & + & - & $\mathrm{V}-1 \mid$ & + & - & + \\
\hline daB-hunsch & - & + & - & + & - & $\mathrm{v}-1$ & - & - & $(-)$ \\
\hline dab-Wunsch (?) & + & - & - & - & & & & - & + \\
\hline daß-Exklamativ & + & + & - & - & & & & + & - \\
\hline w-Frage & + & + & - & + & + & $v-2$ & - & - & $?$ \\
\hline W-Exklamativ & + & + & - & + & + & $\mathrm{V}-2$ & - & + & - \\
\hline wo-Aussage & + & + & - & + & - & $v-2$ & - & - & - \\
\hline als ob-Aussage & $(+)$ & + & - & + & - & $v-2$ & + & - & - \\
\hline und ob/und wie- & + & + & - & $(-)$ & & & & - & - \\
\hline
\end{tabular}


Die folgende Ubersicht zeigt zusammengefaßt die Distribution der Modalpartikeln in Sätzen mit Verb-Endstellung.

Tabelle 7: Distribution von Modalpartikeln in selbständigen Verb-Letzt-Sätzen

\begin{tabular}{|c|c|c|c|c|c|c|c|c|c|c|c|c|c|c|c|c|c|c|}
\hline & $\begin{array}{l}-4 \\
8 \\
0\end{array}$ & $\begin{array}{l}\vec{y} \\
\text { J } \\
\end{array}$ & $\begin{array}{l}0 \\
0 \\
0 \\
0\end{array}$ & $\begin{array}{c}\square \\
0 \\
\square\end{array}$ & $\begin{array}{l}5 \\
8 \\
0\end{array}$ & $\begin{array}{l}5 \\
8 \\
8\end{array}$ & $\begin{array}{c}5 \\
0 \\
-7 \\
+4 \\
5 \\
0 \\
.9 \\
0 \\
0\end{array}$ & $\begin{array}{l}0 \\
3 \\
0 \\
0\end{array}$ & $\begin{array}{l}+ \\
\text { 岂 } \\
\end{array}$ & $\stackrel{\pi}{\square}$ & $\overleftarrow{5}$ & 疋 & $\begin{array}{r}\stackrel{.}{1} \\
\stackrel{\Xi}{E}\end{array}$ & 音 & 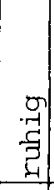 & $\begin{array}{l}E \\
0 \\
0 \\
0\end{array}$ & 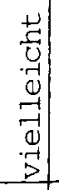 & $\begin{array}{l}-1 \\
0 \\
3\end{array}$ \\
\hline wenn-Wunsch & & & + & & + & & & & & & & & & + & & & & \\
\hline daß-hunsch & & & & & + & & & & & & & & & & & & & \\
\hline wenn-Wunsch (?) & & & + & & & & & & & & & + & & + & & & & \\
\hline daß-Wunsch (?) & & & + & & & & & & & & & & & + & & & & \\
\hline daß-Exklamativ & +1 & + & & & + & & & & & & & & & & & & & \\
\hline w-Exklamativ & +1 & + & & & + & & & & & & & & & & & & & \\
\hline ob-Frage & & + & & & & & & & & & & & & & & & & +1 \\
\hline$w$-Frage & & & + & & & & & & & & & & & + & & + & & + \\
\hline daß-Aufforderung & & + & + & & & & & & & & + & & + & + & & & & \\
\hline wenn-Aufforderung & & & & & & & & & & & & + & & & & & & \\
\hline wo-Aussage & & +2 & & & + & & & & & & & & & & +2 & & & \\
\hline als ob-Aussage & & & & & & & & & & & & & & & & + & & \\
\hline und ob/und wie-Aussage & & & & & & & & & & & & & & & & & & \\
\hline wenn-Aussage/Exklamativ & & & & & & & & & & & & & & & & + & & \\
\hline
\end{tabular}

1) Nur mit auch kombiniert:

2) Nur mit doch kombiniert.

Die vorangegangene Ubersicht weist einige interessante Phänomene auf. Auffallend ist zunächst, daß ein Typ überhaupt keine Modalpartikeln enthalte kann, und zwar die und ob/und wie-Außerungen. Möglicherweise liegt das daran daß sie immer als Wiederholungen einer vorangegangenen Außerung (meist des $\mathrm{Ge}^{\prime}$ sprächspartners) auftreten (vgl. dazu auch 1.3.5.2).

Weiter fällt auf, daß - obwohl einige dieser Typen mit Verb-Endstellung einde ${ }^{\prime}$ tige Fragen sind - die typischen Fragesatz-Partikeln denn oder etwa nicht zulB̈s sig sind. Auch die Tatsache, daß bestimmte Partikeln wie vielleicht und eben $g^{g t}$ nicht, und aber nur in der Kombination stehen können, ist bemerkenswert.

Aufschlußreich könnte hier sein, inwieweit das Elnleitungselement (bei gleichel Funktion) das Auftreten von Modalpartikeln steuert. Hier lassen sich keine ein' deutigen Regularitäten erkennen: bei den Wunschsätzen ist das Einleitungselement und nicht der Funktionstyp wlchtig (der wenn-Satz läßt wesentlich mehr Modal' 
partikeln zu als der da $\beta$-Satz), bei den Exklamativsätzen ist das Einleitungselement (also $d a \beta$ oder $w$-Wort) offensichtlich irrelevant.

Bei den belden daß- bzw. wenn-Sätzen, die nicht klar zugeordnet werden konnten (Wunsch?/Aussage?), spricht gerade das Auftreten der Modalpartikeln nur und bloß für eine Einordnung als Wunsch.

Die unterschiedliche Verteilung der Modalpartikeln in den beiden Fragetypen ( $o b$ und w-Wort) läßt sich ganz einfach damit erklären, daß die einen EntscheidungsPragen sind $(o b)$ und die anderen Ergänzungsfragen. Bei diesen beiden Fragetypen ist ja auch schon bel den Grundtypen die Distribution der Modalpartikeln recht unterschiedlich (s.o. S. 49 Tabelle 5).

Aufforderungen mit $d a \beta$ und mit wenn unterscheiden sich deutlich in ihrem Modalpartikel-Vorkommen. Das liegt daran, daß die wenn-Aufforderungen immer höfliche, abgeschwächte und die daß-Aufforderungen immer sehr dringliche Aufforderungen darstellen. Auffallend ist hier, daß bestimmte andere (wie sich zeigen wird für Aufforderungen typische) Modalpartikeln wie doch nicht auftreten können.

Bel den als Aussagen klassifizierten wo-Sätzen ist interessant, daß weitere für den Aussagesatz typische Modalpartikeln wie ja und eben nicht vorkommen können.

Etwas aus der Reihe fallen die als ob-sätze, die hier ebenfalls zu den Aussagesătzen gerechnet wurden: Sie enthalten manchmal die Modalpartikel schon, die allerdings auch sonst in Aussagesătzen steht, können aber keine anderen Modalpartikeln aufweisen.

Bel den selbständigen Satztypen mit Verb-Endstellung ist also sowohl die Funktion als auch (allerdings in geringerem Maße) das Einleitungselement für das Auftreten von Modalpartikeln relevant.

Zusammenfassend läßt sich sagen, daß die sătze mit Verb-Endstellung eine markierte Form zum Ausdruck einer bestimmten propositionalen Grundelnstellung darsteilen.

Das zeigt sich z.B. beim Vergleich von Entscheidungsfragen mit Verb-Erststellung und solchen mit $o b$ und Verb-Endstellung:

(78a) Ob's hier was zu trinken gibt? (Bi, 92)

(78b) Gibt's hier was zu trinken?

Während (78b) eine echte Informationsfrage darstellt, bei der der Sprecher davon ausgeht, daß der Hörer die Antwort kennt, ist (78a) eine Frage, bei der der Sprecher davon nicht unbedingt ausgeht, und es ist eine Frage, die der Sprecher auch an sich selbst stellt. Insofern stellt (78a) im Vergleich zu (78b) die markierte Form dar. 
Ahnlich ist es auch beim Vergleich von Aufforderungen:75

(79a) Daß du ihm (JA) nicht widersprichst!

(79b) Widersprich ihm (JA) nicht!

Die Tatsache, daß Verb-Letzt-Sätze markierte Formen sind, erklärt zum einen warum es keine 'reinen' Aussagesätze mit Endstellung des Verbs gibt (alle als Aussage klassifizierten Typen haben ja immer noch eine zusätzliche Komponentel und könnte zum anderen auch der Grund dafür sein, daß einige Modalpartikein (wie z.B. denn ${ }^{76}$ ) nicht auftreten. Außerdem könnte damit erklärt werden, warull bestimmte $d a \beta$ - und wenn-Sätze, die einen Wunsch ausdrücken, keinen Konjunkti enthalten, der sonst ja ein obligatorischer Anzeiger für das Ausdrücken einet Wunsches sind.

An der Bedeutung der Modalpartikeln ändert sich (vermutlich) nichts, ob sie it einem der in 1.3 .1 besprochenen Grundtypen oder in einem der hier besprochenen 'markierten' Typen auftreten; die selbständigen Sätze mit Verb-Endstellung können jedoch bei der Bedeutungsbeschreibung der Modalpartikeln (Kapitel 2) nur an Rande erwähnt werden.

\subsubsection{Modalpartikeln in Sătzen mit infinitem Verb}

Ebenso wie bei den oben besprochenen selbständigen Sätzen mit Verb-Endstellunt Ist auch der Status der Sätze mit infinitem Verb bzw. der "infiniten Hauptsatz" strukturen" - wie Fries (1983) Phänomene wie (80) und (81) nennt - nicht klar.

(80) Rasen nicht betreten!

(81) Bitte hier warten!

Auch in diesem Fall wird in der Forschung häufig von Ellipsen gesprochen." Fries (1983) versucht demgegenüber zu zeigen, daß es sich bel "infiniten Haupt" sätzen" nicht um Ellipsen handelt. Er weist m.E. überzeugend nach, daß keines" wegs Reduktionen von Hauptsätzen mit Modalverben angenommen werden können. Auch auf der kommunikativ-pragmatischen Ebene sind diese Außerungen selbstän' dig; sie haben ein eigenes illokutives Potential.

Nicht zuletzt spricht die Produktivität derartiger Konstruktionen gegen eine inter' pretation als Ellipse.

75) Hier ist allerdings der Vergleich nicht so deutlich, da bei den da $\beta$-Auffor' derungen bestimmte Modalpartikeln obligatorisch sind.

76) Wie sich noch zeigen wird, stellt denn eine semantisch relativ unspezifisc ${ }^{\text {t }}$ Partikel dar (vgl. 2.2.11).

77) Stellvertretend sei hier nur Brinkmann (1971:281) zitiert, der Sätze vom Ty? $(80) /(81)$ als Formen bezeichnet, bei denen "auf das Modalverb verzichtet ist". 
Nach formalen Kriterien lassen sich (in Anlehnung an Fries 1983, bes. S.21) folgende Typen von infiniten Strukturen unterscheiden: ${ }^{78}$

1. Infinitiv:

(82) Bitte anschnallen!

2. Nominalphrase und Infinitiv:

(83) Antragsteller bitte hier warten!

3. $w$-Ausdruck und Infinitiv:

(84) Wozu sich aufregen?

(85) Das Theater war abgebrannt.(..) Was also tun? (SZ)

4. Nominalphrase (mit und) und Infinitiv:

(86) Der und uns in Versuchung führen? (Ke, 248)

(87) Ich (und) trinken?

Typ 2) und 4) unterscheiden sich zum einen dadurch, daß bei 4) ein und eingefügt werden kann und zum anderen dadurch, daß die Nominalphrase bei 2) nur indefinit und bei 4) nur definit sein kann.

Von der Funktion her sind 1) und 2) als Aufforderungen zu betrachten, 3) als Frage und 4) als Ausruf oder emphatische Aussage. Typ 4) ist kontextabhängig, er kann in der Regel nur als Reaktion auf eine Außerung, in der die gesamte Proposition bereits thematisiert ist, stehen; ${ }^{79}$ vgl.:

(86) In sachlicher Hinsicht schien ihm die 6. Bitte des Vaterunsers erklärenswert. "...und führe uns nicht in Versuchung." "Als ob Gott uns in Versuchung führt, nun denkt mal an, der liebe Gott, ähm-nähm, der seinen Sohn gegeben und hat ans Kreuz schlagen lassen... Der und uns in Versuchung führen?" (Ke, 248)

Die frequentesten Typen infiniter sätze sind mit Sicherheit Typ 1) und 2), also die Aufforderungen.

Modalpartikeln nun können in beschränktem Maße auftreten, was ein weiteres von Fries nicht beachtetes - Argument für die Selbständigkeit dieser Sätze ist.

In den Aufforderungen mit Infinitiv sind folgende Modalpartikeln belegt: mal, JA, bloß, nur und einfach.

(88) Das Münster mit den alten Klostergebäuden. Eckhoff führte uns hinüber.(..) "Alle mal herhören! Wenn wir da nun reingehen, dann sind wir uns bewußt. daß dieser Dom ein Erzeugnis deutschen Geistes ist!" (Ke, 55)

(90) Jetzt alle mal aufstehen!

(90) Und jetzt JA nicht kucken! Das soll nämlich eine Oberraschung werden.

(91) Zwei Lehrer standen zur Auswahl: ein kleiner dicker mit Glatze und ein größerer finsterer mit einem Kopf wie ein Uhu(...). Bloß nicht zu dem Uhu kommen! (Ke, 38)

78) Die von Fries weiter aufgestellten Typen werden hier nicht berücksichtigt.

79) Dieser Typ von Außerung beweist eindeutig, daß hier nicht von einer Ellipse gesprochen werden kann. 
(92) "Konzertlager", wurde gesagt, und: "Das rächt sich." Aber bloß den Mund halten - "Junge, hörst du?" - Herr Hitler müsse es ja wissen. (Ke, 190)

(93) Nur nicht krank werden! Das kann ich mir jetzt gar nicht leisten.

(94) Im Jahre 1866 reiste eine französische Ballett-Truppe nach New York, doch, ach das Theater war abgebrannt. (.) Was also tun? Ganz einfach improvisieren! (SZ)

Bel den verwaltungssprachlichen, eher stereotypen Aufforderungen vom Typ Rasen nicht betreten werden kelne Modalpartikeln verwendet, was sicher auf die Textsorte zurückzuführen ist. In diesen Fällen läßt sich allerdings häufig die Partikel bitte finden.

Daß Aufforderungen mit dieser Struktur, die ja ebenfalls als markierte Form $z u$ bezeichnen ist, meist verstärkte Gebote bzw. Aufforderungen darstellen, zeigt sich daran, daß die ebenfalls aufforderungstypischen Modalpartikeln ruhig oder auch doch und schon, die alle Aufforderungen in spezifischer Weise abschwächen (meht dazu s.u. bei den Einzelbesprechungen in Kap. 2), nicht auftreten. Die einzige Ausnahme ist hier die Modalpartikel mal.

Auch in den Fragen mit Infinitiven lassen sich Modalpartikeln finden; vgl.:

Wozu denn hingehen?

Warum auch sich aufregen?

\subsubsection{Modalpartikeln und Alternativfragesātze}

Einen besonderen Satztyp stellt der Alternativfragesatz dar. Er ist als Kombin $8^{-}$ tion von (mindestens) zwei Entscheidungsfragesätzen aufzufassen. Gekennzeichnet Ist er durch Verb-Erststellung, ein oder zwischen den dem Hörer zur Wahl gestell' ten (letzten beiden) Alternativen, jeweils eigenen Akzenten auf diesen Elementen und einem besonderen Tonmuster: bei einer 'geschlossenen' Alternativfrage, bei det der Hörer von den genannten (meist zwei) Alternativen eine auswählen soll, ${ }^{80}$ steigt die Tonhöhe auf dem akzentuierten Element vor oder an und fällt auf dem zweiten akzentuierten Ausdruck ab. Bei einer 'offenen' Alternativfrage, bei der de' Sprecher neben den genannten Wahlmöglichkeiten noch die Möglichkeit weiteret Alternativen zuläßt (vgl. (99)), kann der Tonhöhenverlauf im zweiten Konjunkt auch steigend sein (vgl. zur Intonation genauer Luukko-Vinchenzo 1988:171ff.). In jedem Fall aber gibt der Sprecher dem Hörer Alternativen zur Antwort vor, wes halb die adăquate Antwort eine der genannten oder eine weitere denkbare Alter

80) Daß der Gesprächspartner natürlich nicht immer tatsächlich eine Möglichkeit auswählt, zeigt (i):

(i) Nelli: $M u \beta$ ja ab 1.2. nach Gummersbach.

Bea: Ja. Freust dich drauf, oder findsdes schlimm?

Nelli: Och, hab ich jetzt noch keine Meinung zu. (BA, 60) 
native ist, aber nicht, wie bei den Entscheidungsfragen, ja oder nein ${ }^{\beta 1}$ (auch dann nicht, wenn eine weitere Alternative angeschlossen wird). Von den möglichen Antworten her gleichen die Alternativfragen also den w-Fragen.

(97) Iris: Ach gehts jetzt um die Diät oder gehts jetzt um die Leber?

Karl: Um die Diät gehts. (BA, 150)

(98) Elke: Ja, und was fürn Papier? Kariert oder liniert das Blatt odern normales Din A 4 Blatt?

Mona: Ja, ${ }^{82}$ en normales weikes Blatt, Gottes willen nich kariert. (BA, 12)

Im Obstgeschäft: Was für Apfel möchten Sie? Wollen Sie Gloster? Oder Cox? Kundin: Ich nehme Jonathan.

Von den Alternativfragen zu unterscheiden sind Entscheidungsfragen, innerhalb derer zwei Elemente mit oder koordiniert sind. In diesem Fall ist die Frage zu verstehen als eine Entscheidungsfrage, die nach dem Zutreffen eines beide Alternativen umfassenden Sachverhalts fragt, und - für den Fall des Zutreffens gleichzeltig nach einer Spezifizierung. In diesem Fall ist als Antwort wie bel den Entscheidungsfragen $j a / d o c h$ oder nein möglich; bei einer affirmativen Antwort wird auch eine der beiden Alternativen angeschlossen - andernfalls ist die Antwort nicht ganz adäquat. Bei elner Negation ist dieser Anschluß natürlich nicht nötig. Gilt allerdings eine mögliche weitere Alternative, so daß der die genannten Alternativen umfassende Sachverhalt zutreffend ist, wird meist mit nein, aber geantwortet.

(100) Uta: Ich habe soviel Wolle geschenkt gekriegt. Kannst du vielleicht stricken oder häkeln?

In (100) Pragt die Sprecherin zum einen, ob die Gesprächspartnerin überhaupt mit Wolle arbeiten kann, will aber zum anderen bei einer Antwort mit ja auch wissen, Welche der beiden Alternativen zutrifft. Insofern sind mögliche Antworten:

(100a) - Ja, ich kann ganz gut stricken.

- Ja, beides.

- Nein.

- Nein, aber ich kann weben.
Intonatorisch unterscheiden sich diese Außerungen von den Alternativfragen dadurch, daß sie nur einen - normalerweise fallend realisierten - Akzent (auf der letzten Alternative) haben, der Tonverlauf bei der ersten Alternative nicht steigend ist und auch keine Pause vor oder realisiert wird. Von den 'klassischen' Entscheidungsfragen unterscheiden sie sich dadurch, daß sie kaum mit steigender Intonation am Ende der Außerung vorkommen. Ein weiterer Unterschied ist die

\footnotetext{
81) $J_{Q}$ und nein als Antworten kommen zwar manchmal vor, aber nur, wenn der Gepragte auf die erste Alternative reagiert hat, bevor die zweite aus-

82) Dasprochen wurde (vgl. Conrad 1978:125).

Red $j a$ in Monas Außerung ist nicht als Antwortpartikel zu sehen, sondern als Redeübernahmesignal (vgl. genauer Willkop 1988:86ff.)
} 
Position der infiniten Verbteile: bei den Entscheidungsfragen treten sie meistens ganz am Ende auf, bei Alternativfragen nicht.

Diese Fragen mit koordiniertem oder stehen wohl an der Grenze zwischen Alternativfragen und Entscheidungsfragen, was sich zum einen an den (adäquaten) Antworten zeigt und zum andern eventuell durch die Intonation bestätigt werden könnte. ${ }^{83}$

In den ('klaren') Alternativfragen vom Typ (97) treten Modalpartikeln selten auf. sind aber nicht ausgeschlossen. Möglich sind nur denn und eigentlich, die beide sowohl in Entscheidungsfragen als auch in $w$-Fragen vorkommen.84 Dabei ist das Auftreten von Modalpartikeln vor allem dann akzeptabel, wenn zwei ganze Sätze koordiniert werden; vgl.:

(101) Max: Tropft da eigentlich ein Wasserhahn oder regnet es? Uli: Das ist der Wasserhahn im Bad. Die Dichtung ist kaputt.

Wenn nicht ganze Sätze koordiniert werden, so kann es sich um Alternativfragen mit der oben beschriebenen Intonation oder um Entscheidungsfragen mit Koordination handeln. Treten in diesen Sätzen nun Modalpartikeln auf, so sind sie mit der 'Alternativfrage-Intonation' offensichtlich vor allem dann akzeptabel, wenn eine Komparativform wie z.B. lieber erscheint (vgl. (102a) vs. (102b)); andernfalls werden sie wohl eher mit der für Entscheidungsfragen mit Koordination typischen Intonation geäußert (vgl. (102c)). Den Unterschied zwischen diesen beiden Typen zeigen auch noch einmal die Antwortmöglichkeiten ((102a) und (102c)):

(102a) Max: Möchten Sie denn lieber studieren $\rtimes$ oder arbeiten $\downarrow$ Uli: Studieren.

(102b) ?Möchten Sie denn studieren $\lambda$ oder arbeiten $\downarrow$

(102c) Max: Möchten Sie denn studieren oder arbeiten $\downarrow$ Uli: Nein. (Ich bleibe zunächst beim Baby.)

Ganz kurze Alternativfragen können offensichtlich keine Modalpartikeln enthalten:

(103a) Möchten Sie "eigentlich $/{ }^{*}$ denn Tee oder Kaffee?

(103b) Gehst du "denn/"eigentlich in Leichtathletik, Gymnastik oder Volleyball?

83) Insgesamt gesehen bedarf der Komplex der Alternativfragen noch einer ge nauen Untersuchung, insbesondere, was die Intonation und mögliche Antworten betrifft. Geklärt werden müßte auch, inwieweit beispielsweise Außerungen wil (i), die eine Entscheidungsfrage mit einer $w$-Frage koordinieren, Alternativ ${ }^{-}$ fragen sind: (i) Ist denn dieses Opernhaus für diejenigen gedacht, die mit dell Schiff anreisen (...) oder wie ist das Problem inzwischen gelöst für die Autos? (übernommen von Hang 1976:198).

84) Diese Beobachtung steht im Widerspruch zu Altmann (1987:41). Dessen These, Kombinationstypen (wie der Alternativfragesatz) und Mischtypen (wie die Assertive Frage) könnten ebenso wie die infiniten Hauptsatzstrukturen "(ver" mutlich) keine Modalpartikeln enthalten", scheint kaum mehr haltbar zu sein. (Vgl. dazu auch Kap. 1.3.3 und 1.3.5.1) 
Einen weiteren Sonderfall stellen Alternativfragen dar, bei denen das zweite KonJunkt die Negation des ersten beinhaltet. Auch in diesem Fall ist die adäquate Antwort das Nennen einer der beiden Alternativen. ${ }^{85}$

In derartigen Alternativfragen treten häufiger Modalpartikeln (auch hier denn und eigentlich) auf:

(104) ...und die andern standen vor der Tür und ham gefragt: "Ja, klappts denn jetzt, oder klappts nich?" (BA, 48)

(105) Nelli: Da wird doch schon lange was gequakt, is das eigentlich zu nem Gesetz gekommen oder nich?

Bea: Ich hab keine genaue Ahnung, ich glaub aber, das Gesetz ist noch nich raus. (BA, 60)

\subsubsection{Modalpartikeln und Mischtypen}

Die im folgenden unter dem Stichwort 'Mischtypen' behandelten (eher marginalen) Satztypen lassen sich grob in zwel Gruppen teilen: die erste Gruppe umfaßt die Assertiven Fragesätze, die zwelte enthält die Rückfragen und die w-Versicherungsfragesätze, die sich beide dadurch auszeichnen, daß sie ganz spezifische Sequenzierungseigenschaften aufweisen, zu ihrem Formtyp also auch eine bestimmte Art von Vorgängeräußerung gehört. Die Typen der zweiten Gruppe können keine Modalpartikein enthalten.

1.3.5.1 Assertive Fragesātze

Der Assertive Fragesatz ist eine Mischung der Formtypen Aussagesatz und Entscheidungsfragesatz. Von ersterem übernimmt er Verbstellung (d.h. Verb-Zweit) und -modus, von letzterem das stets steigende Tonmuster (vgl. Altmann 1984:138):

(106) (Elke und Mona sprechen über einen Schriftsteller.)

Mona: Der hat viel geschrieben?

Elke: Wahnsinnig viel Literatur (BA, 13)

(107) Sie suchen eine Orig.-Tageszeitung, erschienen am Tag Ihrer Geburt? (SZ)

Sehr hăupig finden sich hier auch sogenannte 'tag questions' (VergewisserungsPragen), die die Frageinterpretation verdeutlichen. In diesem Fall ist das Tonmuster des Verb-Zweitsatzes fallend, das der 'tag question' steigend:86

(108) Du Hanna, hier der Rock gehörte wohl der Mutter, gell? (FK III, 73)

(109) Würdest du dich ned/ du erinnerst dich nie an deine Kindheit, oder? (FK III, 37)

\footnotetext{
85) In seltenen Fällen kommt allerdings auch ja oder nein vor, was sich dann Reist auf die erste Alternative bezieht. Die Tatsache, daß darauf aber oft Rückfragen erfolgen, zeigt, daß $j a / n e i n$ in diesen Fällen eine nicht ganz adä-

86) Inate Antwort ist.

nen weit man Außerungen mit 'tag questions' zu den Assertiven Fragen rechnen sollte, ist noch zu klären.
} 
An Modalpartikeln treten in den Assertiven Fragen doch und die Kombinationel doch nicht etwa und doch wohl nicht etwa ${ }^{87}$ auf (vgl. dazu auch S.223ff.):88

(110) Sie kommen doch zur Betriebsfeier?

(111) Du hast doch nicht etwa die Krauses eingeladeng9

In den nun folgenden Satztypen sind Modalpartikeln in keinem Fall zulässig.

\subsubsection{Rückfragen}

Der erste Typ von Außerungen, die keine Modalpartikeln enthalten, betrifft alle Fälle, bei denen eine Außerung als Frage wiederholt wird.90 Dabei bringt det Sprecher immer zusätzlich eine bestimmte Intention zum Ausdruck. Hier lassen sich folgende (formal recht verschiedene) Typen unterscheiden:

1. Rückfragen auf vorangegangene Außerungen des Gesprächspartners (allerding' kaum auf Exklamative oder Wünsche - und am häufigsten auf Aussagesätze), dll von diesen Kennzeichen wie Verbstellung. Verbmodus, eventuell ein w-Element abernehmen, sich von diesen aber dadurch unterscheiden, daß ihr Tonmuster immet steigend ist, daß Modalpartikeln nicht wiederholt werden ${ }^{91}$ und daß eventuel gegebenenfalls Deiktika entsprechend verăndert werden:92

(112) Uli: Was is denn/ hat denn der Freund bestanden?

Caro: Der is is noch nich fertig.

UII: Der is noch nich fertig? $(\mathrm{BA}, 25)^{93}$

87) Die Modalpartikel wohl alleine tritt m.E. nur zusammen mit einer 'taf question' auf, die das steigende Tonmuster übernimmt.

88) Vgl. dagegen die These von Altmann (1987:48) oder Luukko-Vinchenzo (1988: 165), der Assertive Fragesatz sei mit Modalpartikeln nicht kompatibel.

89) Außerungen wie (110) können auch mit nicht-steigendem Tonmuster realisiet werden. In diesem Fall sind sie nicht als Assertive Fragen, sondern als Aus' sagesätze zu klassifizieren (vgl. dazu auch S.116).

90) In der Wiederholung sind gegebenenfalls Modalpartikeln lediglich dann möglich wenn die Außerung 'papageienhaft' nachgeplappert oder nachgeäpft wird:

(i) Mutter: Mach bloß die Tür zu!

Sohn: Mach bloß die Tür zu! Was die heute wieder hat...

(ii) Sie: Erzähl doch mal, was Diana angehabt hat. Du warst doch dort. Er: Du warst doch dort. Meinst du, ich hab nichts anderes zu tun bei einem Einsatz als auf die Kleidung von Di zu achten?

In diesem Fall aber ändert sich - im Unterschied zu den angeführten Typen' weder die Intonation noch ein anderes Kennzeichen, so daß man bei derartiget Außerungen nicht von einem eigenen Typ sprechen kann.

91) Andere Elemente wie Vokativ werden ubrigens auch nicht wiederholt:

(i) Er: Ich schau dir in die Augen, Kleines.

Sie: $D u$ schaust mir in die Augen? Was für ein Quatsch!

92) Vgl. dazu Altmann (1984:138), der aber keine Ruckfragen auf Exklamative un Wünsche zuläßt (vgl. dagegen Meibauer 1987:340ff.) und auch nichts darubel aussagt, ob Wechsel der Deiktika möglich oder zulässig ist.

93) Die Rückfragen aup Aussagesätze (wie in (112)) unterscheiden sich von del Assertiven Fragen durch die Position im Dialog und dadurch, daß in del 
(113) Er: Ich liebe dich doch/eben.

Sie: Du liebst mich ("dochent? Was fur eine Lüge!

(114) Max: Ist 'Casphanca' eirentllch/denn sehenswert?

Thea: Ist 'Casablanca' sehenswert? Wie kannst du nur so etwas tragen!

Wio die Beispiel schon zeigen, ist es die Funktion dieser Ruckfragen, bestimmte Aspekte der vorangegangenen Außerung in Frage zu atellen, zu bezweifeln oder zu kritisieren, etwa die Berechtigung zum Ausfikhen der Sprachhandlung (vgl. Altmann 1984:138) oder bestimmte Inhaltliehe Aspekte.94 Auf derartige Rückfragen Polgt hägfig eine Rechtfertigung des ersten Sprechers.

2. Beim zweiten Typ handelt es sich um Wiederholungen von vorangegangenen Fragen in indirekter Form, d.h. mit Verb-Letzt-Stellung und bei einer vorausgehenden Entscheidungsfrage mit $o b$ als Eipleltungselement. Sie zeichnen sich ebenfalls durch steigenden Fonhöhenverlauf und gegebenenfalls Wechsel der Deiktlka ausi auch sie kännen kelne Modalpartikeln enthalten.

(115)

Zeuge: Warum ich das ("eigentlich) so lange verschwiogen habe?

(116) Uli: Hast du denn die Steuererklärung schan gemacht?

Eva: Ob ich ("denn) die Steuererklsirung sehon gemacht habe?

Diese Außerungen dienen dem Spfegher dazu, die geforderte Antwort hinauszuzögern. Daß es kelne echten Fragen, sondern eben Wiederholungen sind, zelgt sich auch daran. daß in diesem Fall der Fragende selbst verpflichtet ist, eine Antwort zu geben (vgl. dazu auch Luukko-Vinchenzo 1988:104ff. und 187). In der Wiederholung treten oft auch Proformen auf:

(117)

Richter: Wie sind Sie denn auf die Idee mit dem Oberfall gekommen?

Angeklagter: Wie ich darauf gekammon bin? Also das war so...

3. Als weiteref Typ von Wlederholungen sind hier Fragen anzuführen, die - wie die vorangegangenen - Verb-Letzt-Stellung (und ob oder w-Einleitungselement) aupweisen. Sie unterscheiden sich von den unter 2. ansprochenen Typen zum einen dadurch, daß sie fallendes Tonmuster aufweisen und zum anderen dadurch, daß hier der ursprüngliche Sprecher - meist mit Zeichen der Ungeduld - seine Frage wiederholt, weil er keine adăquate Antwort bekommen hat.95 Auch hier sind in der Wlederholung Modalpartikeln nicht zu finden.

Rückfragen ansonsten frage-unvertrăgltche Ausdrücke wie z.B. bestimmte Satzadverbien auftreten dürfen (vgl. Oppenrieder 1987:184), und funktional dadurch, daß die Assertive Frage nicht einen Aspekt der Vorgăngeräußerung

94) In Frage stellt oder kritisiert.

"Echern erschelnt mir der für diesen Außerungstyp oft angenommene Terminus

5) Vgl.

mativau auch Luukko-Vinchenzo (1988:96ff. und 177ff.), die hier von "ult1ativem (Wort- bzw. Satz-)Fragesatz" spricht. 
(118) A: Wie lange bist du (denn/eigentlich) schon hier?

B: Hopfen -

A: Wie lange du ("denn/"eigentlich) schon hier bist?

B: Malz.

A: Wie lange du ("denn/"eigentlich) schon hier an der Theke bist.

B: Bier trinke ich.

(Beispiel ohne Modalpartikeln übernommen von Luukko-Vinchenzo 1988:96)

(119) Mutter: Hast du eigentlich deine Aufgaben schon gemacht?

Kind: Du, dieser Film ist wahnsinnig interessant.

Mutter: $O b$ du deine Aufgaben ("eigentlich) schon gemacht hast?

\subsubsection{W-Versicherungsfragesătze}

Der zweite Typ von sequentiell gebundenen Satztypen sind die ' $w$-Versicherungs' Pragesätze' (eine Mischung aus $w$-Fragesatz und Aussagesatz):96 Sie weisen Ver ${ }^{\prime}$ Zweitstellung auf, steigendes Tonmuster und ein obligatorisch akzentuiertes Element, das im Vorfeld oder im Mittelfeld stehen kann (vgl. Altmann 1984:138). Hier greift der Sprecher eine vorangegangene Außerung des Gesprächspartners aul bei der er ein Element akustisch oder inhaltlich nicht verstanden hat oder das ${ }^{t}$ anzweifelt. Dieses wird in der Versicherungsfrage durch das $w$-Element vertreten das den Akzent trägt.97 Versicherungsfragen setzen also immer eine Außerunf voraus, in der das erfragte Element bereits genannt war.

(120) Uwe: Und dann hat sie eben im Urlaub ihre Diss geschrieben.

Dani: WANN hat sie ihre Diss geschrieben?

Sie hat ihre Diss WANN geschrieben?

(121) Sie: Ich bin schwanger.

Er: Du bist WAS?

In Versicherungsfragesätzen können weder Modalpartikeln aus der Vorgängeräuße' rung übernommen werden, noch sind fragesatz-typische Partikeln wie denn od! eigentlich möglich.

(120a) WANN hat sie ("eben/"denn) ihre Diss geschrieben? Sie hat ihre Diss ("eben/"denn) WANN geschrieben?

Zweisilbige w-Elemente tragen in diesem Satztyp den Akzent auf der ersten sib (vgl. Wunderlich 1986:50f.); Außerungen mit einem so akzentuierten w-Elemell sind dadurch klar als Versicherungsfragen einzuordnen und können somit ke $e^{\text {int }}$

96) In anderer Terminologic (vgl. z.B. Wunderlich 1986 oder Meibauer 1987) if auch hier von "Echofragen" gesprochen. 97) Bei einem vorangegangenen Imperativ muß in der Versicherungsfrage mit ${ }^{0 l}$
len umschrieben werden, bei einer Entscheidungsfrage kann auch ob wh Verb-Endstellung verwendet werden:

(i) A: Mach bloß das Hypokotyl nicht kaputt!

$B$ : Ich soll WAS nicht kaputtmachen?

(ii) A: Hast du denn das Indossament schon fertig?

$B$ : Ob ich WAS schon fertig habe? 
Modalpartikeln enthalten; vgl. den Unterschied in (122a) und (122b), die natürlich auch in entsprechend unterschiedlichen Kontexten vorkommen:98

(122a) Womit macht man das denn?

(122b) Womit macht man das denn?

Die Tatsache, daß in Rückfragen und Versicherungsfragen keine Modalpartikeln auftreten können, ist ein Indiz gegen die These von Meibauer (1987:350ff.), die "Echopragen" (wie er sie nennt) seien als Redewiedergabe einzustufen; in den 'klaren' Fällen von indirekter Rede und Redewiedergabe sind nämlich alle Modalpartikeln zulässig (vgl. Kap. 1.3.6.1). Außerdem handelt es sich m.E. bei den angefuhrten 'Wiederholungen' auch deshalb nicht um Redewiedergabe, well ja der Sprecher immer zusätzlich eine bestimmte - von der 'Ursprungsäußerung' abweichende Funktion ausdrückt, sei es Kritik, Zweifel, Verwunderung oder Unverständnls. Genau deshalb können auch die Modalpartikeln, die ja eine andere Einstellung des Vorgăngers anzeigen, bzw. auf dieser operieren, nicht übernommen werden.99 $\mathrm{D} a ß$ keine anderen (fragesatz-typischen) Modalpartikeln eingefügt werden können, liegt vermutlich am formalen Mischcharakter der angefuhrten Satztypen.

\subsubsection{Modalpartikeln in Nebensātzen}

Da Modalpartikeln die Illokution eines Satzes verstärken oder modifizieren können, müßte ihr Auftreten in Nebensätzen beschränkt sein. Bei den in Kap. 1.3.2 behandelten Sätzen mit Verb-Endstellung war ja das Vorkommen von Modalpartikeln ein wichtiges Argument für die Selbständigkeit dieser Sätze. Sie haben eben ein eigenständiges Illokutionspotential, was gerade durch das Auftreten von Modalpartikeln bewlesen wird, bzw. weil sie eigene illokutive Kraft haben, sind Modalpartikeln möglich.

98) Einen ähnlichen Typ stellen die "w-Fortsetzungsfragesätze" dar, mit denen der Sprecher an eine Vorgängeräußerung anknüpft (oft explizit angezeigt durch und), um eine bestimmte Zusatzinformation zu erhalten (vgl. Oppen(dann 1987:169). Auch hier kann das w-Element im Vorfeld oder im Mittelfeld (dann mit rhematischem Akzent) stehen; der Unterschied zum Versicherungs(i)

(i) A: Am nächsten Tag bin ich dann nach Frankreich gefahren.

99) Interessand du bist wo über die Grenze gefahren?

ausessanterweise kann - im Gegensatz zu der z.B. durch ein Satzadverb standrückten Einstellung - die durch Modalpartikeln angezeigte nicht Gegenschied der Rückfrage, also z.B. angezweifelt werden. Auch das ist ein Unterzelnen in der oben (S.23) schon angesprochenen 'Thematisierbarkeit' der einzelnen Partikeln. 
Um das Auftreten von Modalpartikeln in Nebensätzen zu beschreiben, sollen hier ausgehend von einer funktionalen Gliederung 100 - folgende Nebensatztypen unterschieden werden:

\section{Ergänzungssätze,}

Adverbialsätze mit folgenden Untergruppen:

1. Temporalsätze,

2. Lokalsätze,

3. Modalsätze (Instrumental-, Vergleichs-, Proportionalsätze),

4. Kausalsätze,

5. Konzessivsätze,

6. Adversativsätze,

7. Konditionalsätze,

8. Konsekutivsätze,

9. Finalsätze,

Attributsätze (restriktive und nicht-restriktive),

weiterführende Nebensätze.

Welche Nebensätze welche Modalpartikeln enthalten können, wird im Polgenden dargestellt; dabei wird kein Anspruch auf Vollständigkeit erhoben. Die Ausführungen sind auch als Anregungen für eine Untersuchung der Nebensätze aus dem Blickpunkt der Partikelforschung zu sehen.

\subsubsection{Ergănzungssătze}

Was das Auftreten von Modalpartikeln in Ergänzungssätzen betrifft, müssen hier zwel Gruppen unterschieden werden: Einmal Ergänzungssätze, die von verba di cendi (im weiten Sinn verstanden) abhängen, sowie alle anderen Ergänzungssätze Erstere betreffen das Phänomen der indirekten Rede.

In den Ergänzungssätzen, die nicht von verba dicendi abhängen, können nie $\mathrm{MO}^{-}$ dalpartikeln auftreten; vgl.:

(123) $D a \beta$ er $\left({ }^{\left.* j a /{ }^{*} \text { doch }\right) ~ s o l c h e ~ u ̈ b l e n ~ G e s c h i c h t e n ~ u ̈ b e r ~ m i c h ~ e r z a ̈ h l t, ~ a ̈ r g e r t ~ m i c h . ~}\right.$ (Subjektsatz)

(124) Ich erfahre morgen, ob ich ("denn/"etwa) geprüft werde. (Objektsatz)

(125) Ich freue mich, daß er mir ("ja/"doch/"wohl/"eben) diese Sache gestanden hat. (Präpositionalobjektsatz)

Bei den Ergänzungssätzen, die von verba dicendi abhängen, ist offensichtlich dil Funktion als Redewledergabe entscheldender für das Auftreten von Modalpartikel als der syntaktische Status des Ergänzungssatzes.

100) Diese Unterteilung ist angelehnt an Admoni (1982:277ff.), AKADEMIE-Gram matik (1981:777ff.), DUDEN (1984:667ff.), Eisenberg (1986:330ff.) und Helblg. Buscha (1986:680ff.). 


\section{Exkurs: Indirekte Rede}

Der Hauptverwendungsbereich der Modalpartikeln ist - wie bereits erwähnt - die gesprochene Sprache. Insofern ist es interessant $z u$ beobachten, wie sich Modalpartikeln in indirekter Rede verhalten.

Indirekte Rede ist, syntaktisch gesehen, eine sehr heterogene Erscheinung, weshalb hier alle Phänomene unter dem Gesichtspunkt ihrer Funktion - also der Redewiedergabe - besprochen werden sollen. Indirekte Rede kann auf drei Weisen angezeigt werden: erstens durch ein redeeinleitendes Verb, zweitens durch eine Konjunktion ( $d a \beta$ und $o b$ ) oder ein $w$-Wort mit Verb-Endstellung und drittens durch eine Konjunktivform des finiten Verbs. Im Normalfall wird die indirekte Rede durch zwei dieser Merkmale gekennzeichnet, das redeinleitende Verb (als obligatorisches Merkmal) und Konjunktivform, Konjunktion oder Verbstellung. In längeren Passagen der Redewiedergabe kann auf die Wiederholung der Redeeinleitung, auf die die Konjunktivformen jeweils zurückverweisen, verzichtet werden.

In allen Formen der indirekten Rede sind Modalpartikeln möglich. Das heißt aber auch, daß hier nicht syntaktische Kriterien entscheidend sind, sondern funktionale. Denn nur in diesem Bereich sind Modalpartikel in Ergänzungssätzen (fast immer in Objektsätzen) möglich. Der Grund dafür liegt in der Funktion der indirekten Rede: Modalpartikeln helfen, die Rede eines Sprechers möglichst authentisch wiederzugeben.

In der indirekten Rede treten alle Modalpartikeln auf; die wichtigsten zeigen die Polgenden Belege, ${ }^{101}$ die nach den Funktionen der entsprechenden Außerungen geordnet sind:

(126) Ihr sei auch die Geschichte der völlig mißglückten Ehe bekannt. Sie habe ja von vornherein abgeraten. (Bö $\mathrm{b}, 57$ )

(127) Er sei doch sehr erstaunt, daß noch keinerlei Maßnahmen zu einer Fahndung nach "Karl" eingeleitet worden seien. Schließlich sei doch dieser Karl offensichtlich zusammen mit Götten im Café Polkt aufgetaucht, habe sich ebenfalls in die Party gedrängt, und seine Rolle erscheine ihm, Korten, doch recht undurchsichtig, wenn nicht verdächtig. (Bö b, 64) Wie rasend riß er sich die Hörer herunter, aus denen überlaut ein Foxtrott quäkte. Das sei schon eine Crux mit uns. (Ke, 64)

(129) Nee, also meine Mutter meinte auch neulich, ob ich denn nich jetzt endlich mal heiraten wollte.(..) Ja, als meine Mutter mich anrief, und mir erzählte, daß meine Schwester sich Silvester verloben wollte, da hab ich gefragt, ob sie denn jetzt von mir wollte, daß ich mich vor Silvester noch verlobte. (BA, 42)

101) Bei rück einigen dieser Belege liegt das redeeinleitende Verb im Text zu weit $z u-$ rück, um hier mit aufgeführt zu werden; der Anzeiger für indirekte Rede ist dann lediglich im Konjunktiv zu sehen. 
(130) Wir warteten auf Hannes. Endlich kam er (...). Ob wir die Wartezeit auch nach Kräften genutzt hätten? (Ke, 122)

(131) Als Katharina am späten Nachmittag mit diesen Aussagen konfrontiert wur de (...), war es Hach, der ihr (..) nahelegte, ob diese Herrenbesuche etwa die Herren gewesen wären, die sie gelegentlich nach Hause gebracht hätten Katharina, die über und über rot geworden war, aus Scham und Arger, fragte spitz zurück, ob es etwa verboten sei, Herrenbesuche zu empfangen. (Bö b, 28)

(132) ...und sie werde sich Karneval über erholen und nie, nie wieder mit einem andern Mann als ihm tanzen, und nie mehr anders als südamerikanisch, un nur mit ihm und wie es denn dort sei? (Bö b, 51)

(133) Einmal kam uns ein Mann entgegen, der ging recht gebückt. Warum der wohl so gehe, fragten wir. (Ke, 25)

(134) "Wenn du wüßtest, wie widerlich du aussiehst." Er solle mal in'n Spiegel kucken. ( $\mathrm{Ke}, 72)$

(135) Ich solle mein Schulbrot auch JA aufessen, es wegzuwerfen, sei eine arge Unsitte. ( $\mathrm{Ke}, 36)$

(136) Wenn man bedenke, daß sie als Hamburgerin noch keinen Fuß auf den Boden Helgolands gesetzt habe, nicht einen einzigen! Wie sei es bloß möglich! (Ke, 74)

(137) Immer ist der Wirt zwischen den Tischen unterwegs, und wenn der Teller mit den Spaghetti auf Piraten-Art auf den Tisch kommt, sagt er, da werde man noch schau'n, das sei vielleicht scharf. (SZ)

Die Bedeutung der einzelnen Modalpartikeln ändert sich in der indirekten Rede nicht.

\subsubsection{Adverbialsåtze}

Das Verhalten der Modalpartikeln in den Adverbialsätzen ist je nach Typ ver' schleden, was einigen Aufschluß über die einzelnen Typen von Nebensätzen geben könnte. ${ }^{102}$

1. Temporalsătze

Hier sind Modalpartikeln grundsätzlich nicht möglich; vgl.:

(138) Während ich ("eben) in Berlin studierte...

Als wir ("ja) spazieren gingen...

Bevor sie ("doch) geht...

\section{Lokalsåtze}

Auch hier können keine Modalpartikeln auftreten:

(139) Wo ich ("eben/"doch/“jg) aufgewachsen bin, gibt es einen interessanten Brauch: das Kirtarennen.

102) Vgl. dagegen Hentschel (1986:201ff.), die allerdings zum einen von ande ref $^{e^{\prime}}$ syntaktischen Gegebenheiten ausgeht (so behandelt sie z.B. bestimmte sel ${ }^{b^{\prime}}$ ständige Verb-Letzt-Sätze bei den Nebensätzen) und zum andern mit $k 0^{n^{\prime}}$ struierten Beispielsätzen arbeitet, die m.E. nicht immer akzeptabel sind. 
Die lokalen Adverbialsätze stehen allerdings oft an der Grenze zu den lokalen Relativsätzen; in letzteren sind Modalpartikeln nun wieder möglich.

\section{Modalsãtze}

Bei den Modalsätzen werden hier drei Untertypen unterschieden; diese verhalten sich unterschiedlich, was das Auftreten von Modalpartikeln betriff:

3a) Instrumentalsătze

Hier sind Modalpartikeln kaum möglich:

(140) Du hast mir damit wirklich sehr geholfen, daß du ("ja/"doch/"eben) meine Katze gehütet hast.

(141) Sie hat die Prüfung bestanden, indem sie ("ja/*doch/?eben/?halt) Tag und Nacht gelernt hat.

\section{3b) Vergleichssătze}

Hler können Modalpartikel wleder auftreten:

(142) Dennoch nahm Jaga, die zunächst von einer anderen jungen Magd, dann von der Kutschersfrau so gut versorgt worden war, wie man eben in KleinMocre den Nachwuchs zu versorgen pflegte, (...) eine gewisse Sonderstellung ein. (En, 50)

(143) Wie es halt so ist, hat man uns immer wieder vertröstet. Das mag wohl auch mentalitätsbedingt sein. (SZ)

(144) Petron hat dem Volk der ehemaligen Sklaven aufs Maul geschaut. Man redet, wie eben die Leute reden, von einer Beerdigung, vom Wetter (...). (SZ)

Vermutlich sind Modalpartikeln hier möglich, well diese Nebensätze eine ähnliche Funktion haben wie weiterfuhrende Nebensätze.

3c) Proportionalsatze

Hier können Modalpartikeln nicht vorkommen:

(145) Je mehr ich ("ja/" ruhigt mich die ganze sache.

4. Kausalsătze

Kausalsätze können Modalpartikeln enthalten; das ist eln Hinweis darauf, daß sie

eigenständige illokutive Kraft haben. Belegt sind hier vor allem die Modalpartikeln ja und doch, außerdem auch eben und halt.

(146) Du kannst mich ab morgen beschimpfen, soviel du willst, weil ich euer Vertrauen ja wirklich mißbraucht habe. (Bö b, 82)

(147) Ich dachte, es war schönes Wetter, weil es im Augenblick doch sehr schön ist. (BA, 11)

(148) Und . ds ham sich aber die (..) Eltern wahnsinnig beschwert, und wollen den jetz von der Schule bringen, weil er eben $z u$ autoritär is. (BA, 166)

(149) Kein Mißklang mischte sich in den Schlußbeifall, so als wäre mit dieser Versinnlichung der abstrakten Geschäfte schon alles in Butter, weil alles halt eine Komödie ist und folglich auch wieder sehr weit weg. (SZ)

(150) Doch ich dachte, du stündest besser mit ihnen I=den RömernJ. Um so mehr, als die Römer die regelmäßigen Steuerzahler doch begünstigen. (A XIII, 7) 
Darauf, daß dle Kausalsätze eigenständige Aussagen sind und vomit eigene illokutive Kraft haben, deutet auch die Tatsache hin, daß die (katusale) subórdinierende Konjunktion weil besonders in der gesprochenten spriche zunehmend als koordinie rende Konjunktion verwendet wird (und auch die Ahnlichkeit mit der Konjunktion denn):

(151) Franz: Es gibt aber doch gute Jungsozialisten. Wie stehts damit? Schorsch: Ich weiß nicht. Hab mit dene auch nicht vilel zut tún, weil - die wollten mich auch schon haben, glaub aber nicht; daj ich da... (Kr, 76)

\section{Konzessivsātze}

Auch in Konzessivsätzen treten Modalpartikeln auf;103 hauptsächlich handelt es sich dabei um doch; in beschränktem Maße scheint auch ja zulässig zu seln:

(152) Sie war es, die uns nicht gebührend empfangen hatte, obwohl mein Vater doch mit ihrem Mann Schulter an Schulter gegen die Franzosen gekämpft hatte. (Ke, 78)

(153) Wie kommt es bloß, daß innerhalb einer halben stunde, obwohl man doch nur Kaffee aufgegossen, Knäckebrot, Butter und Honig aus dem Schrank geholt und die paar Gepäckstücke in die Diele gestellt hat, schon das Chaos ausgebrochen zu sein scheint. (Bö b, 75)

(154) Der hat die Prüfung nicht bestanden, trotzdem er ja recht intelligent ist. In einem speziellen Typ von konzessiven Nebensätzen tritt obligatorisch auch au! das eventuell als Modalpartikel zu bezeichnen ist:

(155) Wenn es auch aufdringlich wirken mag, ich frag morgen wieder nach.

(156) Was auch immer geschehen wird, ich verrate nichts.

\section{Adversativsătze}

In Adversativsätzen sind Modalpartikeln ebenfalls zulässig:

(157) Gestern ist sie den ganzen Tag zu Hause geblieben, während sie doch sonst bei schönem Wetter meistens einen Ausflug macht.

\section{Konditionalsătze}

Konditionalsätze enthalten in der Regel kelne Modalpartikeln; vgl.:

(158) Wir werden die Aufführung machen, falls wir ("eben/"ja/"wohl) genügend Geld zusammenbringen.

Auch bei Konditionalsätzen ohne Konjunktion mit Anfangsstellung des Verbs treten keine Modalpartikeln auf:

(159) Sollte er ("ja/"wohl/"eben) rechtzeitig kommen, gehen wir noch ins Kino. In konditionalen wenn-Sätzen allerdings erscheinen manchmal die Modalpartikeln eben und halt:

103) Auf die Illokutive Selbständigkeit der Konzessivsätze deutet auch hier die Tatsache hin, daß die Konjunktion obwohl, die mit Abstand die häufigst konzessive Konjunktion ist, auch wie eine koordinierende Konjunktion ver wendet werden kann: Ja, das [Filialleiterin zu sein] wär nicht schlech obwohl, das is wieder eine Verantwortung. ( $\mathrm{Kr}, 119)$ 
(160) Die Hausgemeinschaft besteht nämlich aus vier solchen Häusern, also aus $z$ weiundreißig Parteien und wenn da eben größere, öh, Reparaturen notwendig sind, oder so die Feñsteranstriche, das wird gemeinsam gemacht. (BA, 130)

(161) Wenn ich halt tausend Mark verdienen tät, also auf die Hand, dann tät sie nimmer arbeiten müssen. $(\mathrm{Kr}, 33)$

8. Konsekutivsätze

Auch hier lassen sich Modalpartikeln nachweisen, und zwar ja (meist in Kombination mit auch), doch und eben.

(162) Die hat ihn so angehimmelt, daß er doch glatt aus dem Gleichgewicht gekommen ist.

(163) Er hat sich bei diesem Tanzwettbewerb so verausgabt, daß er dann ja auch drei Tage nicht zur Arbeit gehen konnte.

(164) Die war gestern so durcheinander, daß sie eben auch ihre Schlüssel ver-

9. Pinalsătze

Auch Finalsätze können Modalpartikeln onthalten. Auffallend ist, da $\beta$ sie keinesWieg. Wie bisher alle anderen Nebensätze (außer im Bereich der indirekten Rede) Modalpartikeln enthalten, die in Aussagesätzen auftreten, sondern daß sie Modalpartikeln wie nüf; $J A$ und (allerdings seltener) blo $\beta$ enthalten, also Modalpartikeln, die für Aufforderungef tỵlseh sind. Am häufigsten ist dabel die Kombination nur $J A$, daneben kommt auch $J A$ vor (vgl, auch 3.2.1.1.2),

(165) Tante Silbi, wenn die losfahre, nach Schrolberhau, dann nehme sie einen Tag vorher Abführtabletten und anschließend was zum Stopfen, um nur JA Hicht aufs Elsonbahnklo zu müssen. (Ke, 75)

(166) Ufid dahin muß ich alles lesen, was andere Leute über Wahrheit geschrieben haben, daß̈ ICH Hilti. LA Hichts Palsch mach.

(167) Ich muß also meinen Vorrat varetecken, damit ihn JA keiner sieht. (Kr 109) Sefon diese Besonderheit zeigt wohl, daß es durchaus lohnenswert wäre, das AupWeise von Modalpartikeln in Nebensätzen noch genauer zu untersuchen. Aup diese stäraleßeft sileh m. E. Sowohl Rackschlüsse auf die Selbständigkeit oder Unselbtärialigkelt als auch auf die Funktion bestimmter Nebensatztypen ziehen.

1.3 .6 .3

Attributsătze

Bei den prototypischen Attributsătzen, den Relativsätzen, muß zwischen den reim allgen uhd den nicht-restriktiven unterschieden werden. Modalpartikeln sind tikeln können nur in flcht-restriktiven Relativsătzen möglich; von den Modalparauch) auftreten: 
(168) Die bayerische CSU betreibt es mit ihrem Programm "Freude in der Schule zur Zeit wieder einmal so vehement, als nehme sie den Bruch einiger Fen sterscheiben, die man ja später durch Butzenscheiben ersetzen kann, nichi ungern in Kauf. (SZ)

(169) An H. Lermanns Erstlingsfilm, der ja auch prompt den 1987 zum ersten N( verliehenen "Filmpreis Rheinland-Pfalz" bekam, stimmte (fast) alles. (SZ)

(170) Dle Geschichte der Bewohner des Winterhauses: eine 7ojährige Mutter, ein stellungsloser Lehrer, seine Frau, die sich mit vier Kindern (die eben nich die nervend gespielten, sondern wirkliche Kinder jener Zeit waren) herumschlagen muß. (SZ)

Der Grund dafür, daß in nicht-restriktiven Relativsätzen Modalpartikeln auftrett können, llegt auch hier darin, daß diese Relativsätze eigenständige Propositione darstellen (vgl. dazu auch Franck 1980:234).

Bemerkenswert ist, daß auch das betonte $J A$ bzw. die Kombination nur $J A$ nicht-restriktiven Relativsätzen auftreten können; dadurch erhält der Satz ein Pinale Komponente:

(171) Die Kleinen, die nur JA nichts verpassen wollten, standen hinter der Tür und linsten durchs Schlüsselloch.

Restriktive Relativsätze lassen in der Regel keine Modalpartikeln zu (vE) (172)); ${ }^{104}$ Relativsätze, die sowohl restriktiv als auch nicht-restriktiv interpré tiert werden können, werden durch das Hinzufügen einer Modalpartikel zu nichl' restriktiven Relativsätzen; vgl. das von Hartmann (1986:151) übernommene (173).

(172) Derjenige, der ("ja/"doch) als letzter heimkommt, sollte das Tor schließen.

(173a) Autos, die laut sind, sollten mit elner geschlossenen Motorkapsel versehel werden.

(173b) Autos, die ja laut sind, sollten...(=alle Autos; nicht-restriktiver Rel.satz) Das Vorkommen bzw. die Nicht-Einfügbarkeit einer Modalpartikel (besonders of der Modalpartikel $j a$ ) ist also eine Unterscheidungshilfe bei der Interpretation of $^{\circ}$ restriktiven vs. nicht-restriktiven Relativsätzen.

104) Einige Belege mit Modalpartikeln in mit ziemlicher Sicherheit restrikttv interpretierenden Relativsätzen finden sich in melnem Korpus; dabei wir der Satz mit halt (ii) wesentlich akzeptabler. Vgl. auch (iii), einen fret Relativsatz.

(i) Und früher wieder, wissen Sie, In der Epoche, aus der ich eben komme (...) glauben Sie mir, schon damals haben die sogenannten modernen Ideen mehr Anhänger gehabt, als man ahnt.

(A.Schnitzler, Der Weg ins Frele, Frankfurt 1978:147).

(ii) Ich hab mitm Rechtsanwalt gesprochen (...) und der meinte eben, ja, $c^{\text {l }}$ solle auf jeden Fall nen Bekannten angeben, dem ich den Wagen halt gellehen hab. (BA, 193)

(1ii) Christian Fischer gibt dem Alfred, was ihm die Bearbeitung halt noch gelassen hat: die etwas müde Haltung eines Hallodri. (SZ)

Interessanterweise sind von den für Aussagesätzen typischen Modalpartikej die Partikel halt und zum Tell auch eben in wesentlich mehr Nebensätzen akzeptabel als beispielsweise ja oder doch (vgl. z.B. die konditionalen went Sätze oder die Instrumentalsătze). 


\subsubsection{Weiterfahrende Nebensatze}

Auch in den weiterführenden Nebensätzen treten Modalpartikeln auf, was sich in diesem Fall wleder darauf zurückführen läßt, daß die Sätze eine eigenständige illokutive Kraft haben. Möglich sind hier vor allem die Modalpartikeln ja und doch sowie die Kombination ja auch:

(174) Die Staatsbürgerliche Vereinigung in Koblenz diente als Geldwaschanlage, was ja einen Steuerhinterziehungs-Tatbestand darstellt. (SZ)

(175) Heute ist er schon wieder zu spät gekommen, was doch schon letzte Woche der Grund für den Anpfiff war.

(176) Er wollte unbedingt diesen Keks haben, was dann ja auch letztendlich zum $z$ weiten Weltkrieg geführt hat.

\subsubsection{Zusammenfassung}

Die Polgende Ubersicht zeigt zusammenfassend die einzelnen Typen von Nebensätzen und die darin auftretenden Modalpartikeln.

Tabelle 8: Distribution von Modalpartikeln in Nebensätzen

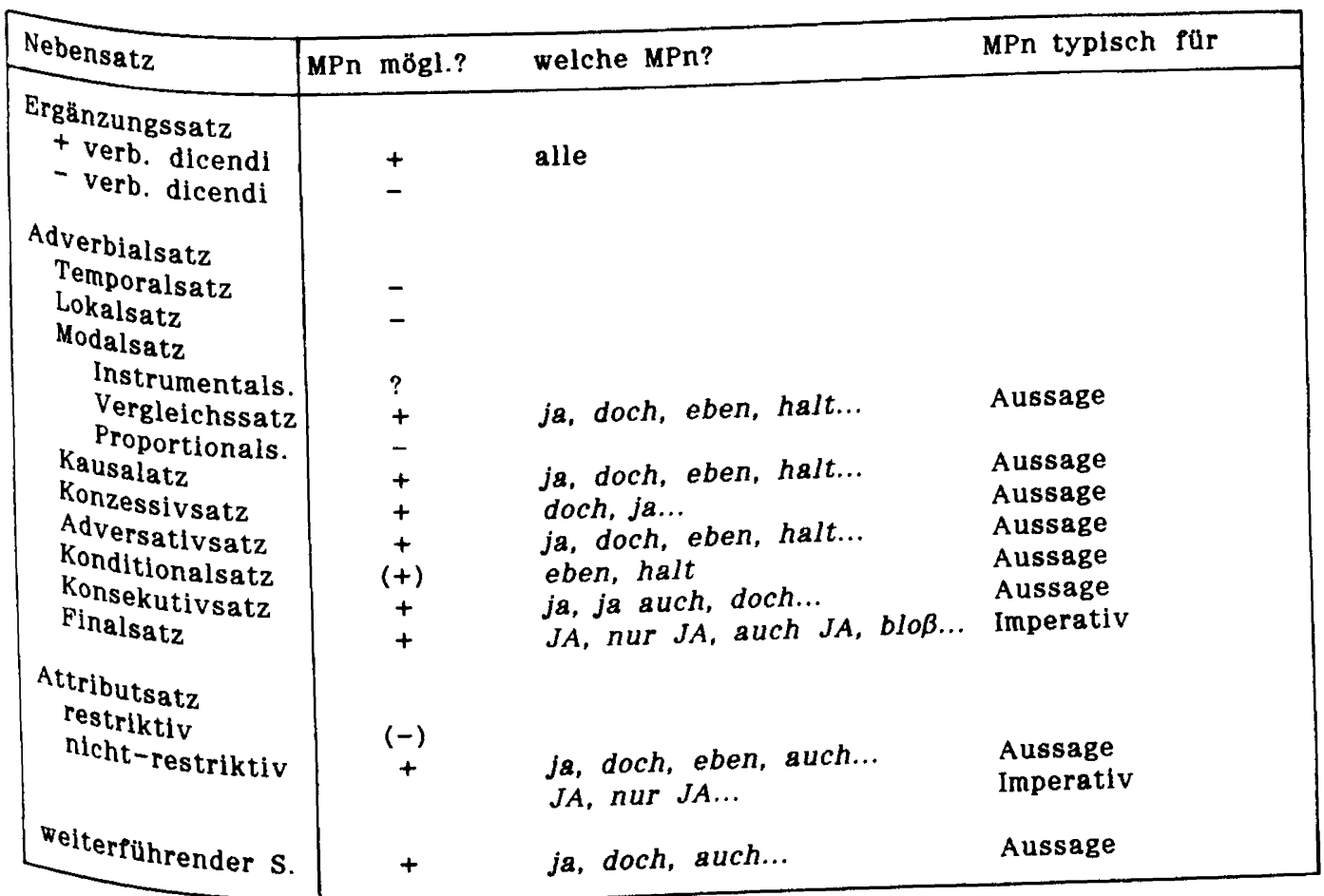


Das Auftreten von Modalpartikeln in Nebensätzen kann im Rahmen dieser Arbel' nicht bis ins letzte Detail erforscht werden. Wichtig erschien es mir in diesel

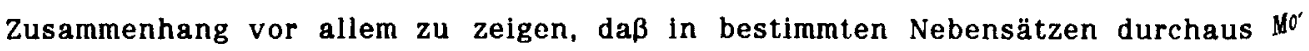
dalpartikeln auftreten können, was wiederum Erkenntnisse über die Nebensăt liefert: Es handelt sich dann um lllokutiv eigenständige Nebensătze. Die Restrik' tionen im Auftreten von Modalpartikeln sind sowohl aup die Funktion der Neben' sätze als auch auf die Bedeutung der einzelnen Modalpartikeln zurückzuführêl ( $\mathrm{Zu}$ untersuchen bliebe z.B., warum halt weniger beschränkt ist als etwa ja.)

Es wurde allerdings nicht genauer untersucht, ob innerhalb einer Gruppe vol Nebensätzen die diversen Konjunktionen Einfluß auf das Auftreten von Modalpar tikeln haben. Vermutlich führt das allerdings zu keinen signifikanten Ergebnissen. Zum Abschluß sollen noch einmal die selbständigen Sätze mit Verb-Endstellung mil den Nebensätzen verglichen werden:

Wie die vorangegangenen Ausführungen gezeigt haben, ist das Auftreten vol Modalpartikeln in Nebensätzen doch recht aupfälligen Beschränkungen unterworfe? während in den selbständigen Sätzen mit Verb-Endstellung immer Modalpartikel stehen können, Ja manchmal sogar obligatorisch sind. Das aber macht die obet (S.50) erwähnte Ellipsenhypothese und die damit verbundene Methode, die sel $b^{\prime}$ ständigen Verb-Letzt-Sătze aus komplexen Satzgefügen abzuleiten bzw. die Metho' de, diese Sätze einzubetten (vgl. Weuster 1983), umso fragwürdiger: Die eing $f^{\prime}$ betteten Sätze sind nämlich - eben aufgrund der in ihnen enthaltenen Modalpat" tlkeln - oft inakzeptabel, oder zumindest in ihrer Akzeptabilität fragwürdig.

Das soll die folgende Gegenüberstellung von Sätzen verdeutlichen, die Weuster $2^{\prime \prime}$ einen als selbständige Sätze mit Verb-Endstellung anführt und die sie im Rahmé ihrer Beschreibung auch in übergeordnete sätze einbettet. (Die a-Varianten b $\ell^{\prime}$ zeichnen die selbständigen Sätze mit Verb-Endstellung, die b-Varianten zeiget dieselben Sätze eingebettet, also als Nebensätze.)

(177a) Warum du wohl nie zu Rand kommst?

(177b) ?"Keiner begreift, warum du wohl nie zu Rande kommst.

(178a) Wenn er doch käme!

(178b) 'Wenn er doch käme, wäre alles gut!

(179a) Daß er doch noch bei uns wäre!

(179b) 'Ich wünsche, daß er doch noch bei uns wäre.

Die angeführten Beispiele zeigen wohl deutlich die illokutive Eigenständigkeit df in Kap. 1.3.2 besprochenen Sätze mit Verb-Endstellung und die Rolle, die Modal' partikeln hier spielen. 
In diesem Kapitel sollen zwel Aspekte behandelt werden: Zum einen wird der Frage nachgegangen, ob Modalpartikeln negierbar sind, zum anderen soll das Auftreten von Modalpartikeln in negierten Sätzen untersucht werden.

\subsubsection{Sind Modalpartikeln negierbar?}

Die in der Uberschrift formulierte Frage müßte eigentlich - wenn man die Terminologie von Jacobs (1982)108 zugrundelegt - genauer heißen: können Modalpartikeln im semantischen Bereich (Skopus) eines Negationselementes stehen?

Bel nicht-kontrastierender Negation ist dies - wie z.B. bei den Satzadverbien auch - nicht zulässig: der Skopus des Negationselements darf nicht weiter sein bzw. muß enger sein als der der Modalpartikel.

Auch kontrastierende Negation ist bei Modalpartikeln - im Unterschied z.B. zu Satzadverbien - nicht möglich (s.o. S.23).

$\mathrm{Da}$ nun aber der Skopus der Negation im Regelfall (zu den Ausnahmen vgl. Jacobs 1982:373ff. und 401 ff.) dem entspricht, was (bei einem Satz mit Verb-Endstellung) auf das Negationselement folgt, ist auch erklärlich, warum die Modalpartikel vor einem Negationselement steht. Bei Verb-Zweitstellung kann allerdings das Negationselement auch im Vorfeld und damit - getrennt durch das finite Verb - vor der Modalpartikel stehen, im Mittelfeld gilt jedoch die Abfolge Modalpartikel vor

(1a) ...,weil doch/1a niemand ihre Ansichten genau kennt.

(1c) Niemand kennt doch/1a ihre Ansichten genau.

Schließlich kennt doch/ja niemand ihre Ansichten genau.

Auch hier läßt sich eine Ausnahme $e^{106}$ anführen: Die Modalpartikel etwa tritt nur
in in der Form nicht etwa in Aufforderungs- und Aussagesätzen (dort auch häufig in der Verbindung doch nicht etwa) auf; vgl.:

(3) Glaub nicht etwa, daß ich dir nochmal helfe!

(3) Der soll nicht etwa das Gefühl kriegen, ich lauf ihm nach.

105) Mit render Jacobs (1982) soll hler unterschieden werden $z$ wischen nicht-kontrastietigster Negation und kontrastierender Negation, die notwendig mit einer richbes. vers. 34ff.). Diese Unterscheidung ersetzt - zusammen mit der Einführung Bereich (=sker Arten des Negationsbezugs (syntaktischer Bereich, semantischer

10 scheidun (=Skopus) und Fokus) - die herkömmliche (unzulängliche) UnterAup die von Satznegation und Satzteil-/Wortnegation (vgl. bes. 39ff.).

Elnzele zweite (scheinbare) Ausnahme, nämlich einfach, werde ich bel der Relanalyse (Kap. 2.2.5) eingehen. 
(4) Du hast doch nicht etwa geraucht? ${ }^{107}$

Daß es sich hierbei allerdings nicht um Negation der Modalpartikel etwa handell werde ich weiter unten bei der Einzelbesprechung (Kap. 2.2.12) zeigen.

\subsubsection{Modalpartikeln in negierten Sătzen}

Was das Auftreten von Modalpartikeln in negierten Sätzen betrifft, meint Rell (1977:40):

Ein wesentlicher Störfaktor sind dabel (bei der Negation; M.T.l Modalpartikell sei es, daß sie Assertionen kommentieren, sei es, da $\beta$ sie nichtdeklaratif Sprechakte illokutiv modifizieren: Vielfach jedenfalls sind die negierten ver' sionen zu solchen Sätzen entweder nicht grammatisch oder stellen bedell tungsmäßig nicht die natürlichen Pendants dar, vgl. (45) vs. (45'):

(45) a. Max hat mich heute vielleicht wieder geärgert.

b. Der Hinz ist aber ein Schlaumeler.

c. Das find ich schon eine tolle Leistung, daß er das geschafft hat.

d. Kannst du mir mal die Kiste tragen helfen?

(45') a." Max hat mich heute nicht vielleicht wieder geärgert.

b." Der Hinz ist aber kein Schlaumeier.

c." Das finde ich schon keine tolle Leistung, daß er das geschafft hat.

d. Kannst du mir nicht mal die Kiste tragen helfen?

Bei den beiden Sätzen (45)a und (45)b liegt die Nicht-Negierbarkeit allerdint nicht an den Modalpartikeln - wie sich noch zelgen wird; Satz (45')d ist akzeptabel, ist jedoch nicht als negierte Version von (45)d zu sehen. Tatsäch ${ }^{1 l^{\prime}}$ problematisch ist das Beispiel (45)c.

Bevor ich jedoch auf die Beispiele von Reis genauer eingehe, scheint es mir wict' tig, zunăchst das Vorkommen der Partikel nicht in den einzelnen Satzmodi zu w tersuchen, und zwar in Satzmodi ohne Modalpartikeln, um festzustellen, ob $R^{\prime}$ striktionen in der Verwendung von nicht an den Modalpartikeln festzumachen sit $^{\text {in }}$ oder bereits am Satzmodus selbst.

\subsubsection{Satzmodus und Negation}

Es läßt sich nachweisen, daß die Verwendung eines Negationsträgers - und möchte ich hauptsächlich auf nicht eingehen - vom Satzmodus abhängig ist; def beeinflußt Funktion und Distribution von nicht. Im folgenden soll das Vorkom von (nicht-kontrastierendem) nicht (und der zum Teil zum Vergleich herange ${ }^{20 g^{\prime}}$ nen anderen Negationsträger) in derjenigen Verwendung untersucht werden, be der ganze Restsatz im semantischen Bereich des Negationsträgers liegt. ${ }^{108}$

107) Die Funktion dieser Außerungen wird weiter unten (S.223ff.) besprochen.

108) Das entspricht in etwa der Verwendung, die - zumindest bei nicht - $t^{8}$ tionell als Satznegation bezeichnet wird. 
Semantisch-pragmatisch kann Negation als Zurückweisen von Annahmen und Erwartungen des Gesprächspartners und somit als Korrekturanweisung gesehen werden (vgl. genauer Schmidt 1973 und Weinrich 1975).

\section{Aussagesatz}

Ohne Einschränkungen läßt sich nicht in Aussagesätzen verwenden; auch alle anderen Negationsträger sind ohne welteres möglich; lediglich nein unterliegt - und das gilt für alle Satzmodi - bestimmten Beschränkungen, was die Verwendung im Satz betrifft: hier kann nein nur in korrigierender Funktion - und insofern syntaktisch und intonatorisch nicht integriert - auftreten.

\section{Entscheidungsfragesatz}

Hier ist die Verwendung von nicht problematischer.

Nach Schmidt (1973:193) ist in diesen sätzen die "verwendung des negationselementes in der regel kommunikativ Irrelevant"; demzufolge sieht Schmidt auch zwikeinen kommunikativen Unterschied:

(5) Möchtest du ein Glas Wein?

(6) Möchtest du nicht ein Glas Wein?

Gerade Schmidt, in als elne komme klasse kommunikatlver dürfte derationen mit analoger kommunikative nicht als "kommunikativ [!] irrelevant" beschreiben.

Tatsăchlich besteht zwischen (5) und (6) ein wichtiger kommunikativer Unterschied hinsichtlich der Sprecher-Erwartung.

Beim Auftreten von nicht in Entscheidungsfragesätzen müssen zunächst einmal 2Wei Verwendungsweisen unterschieden werden, zwei Verwendungsweisen, die sich oberplächlich past immer an einer Unterscheidung betont vs. unbetont festmachen lassen.

Im Beispiel (7) hat die Partikel nicht - je nach Betonung - zwei verschiedene Funktionen und tritt auch in unterschiedlichen Kontexten auf (vgl. (7a) und (7b)):109

Sind Sie nicht katholisch?

Sind Sie NICHT katholisch? Ich habe das vorausgesetzt bei jemandem, der sich um eine Stelle als Pastoralassistent bewirbt.

(7b) Peter: Sagen Sie: Sind Sie nicht katholisch?

Ruth: Ja, wieso?

Peter: Dann könnten Sie uns vielleicht erklären, wie das mit der Unfchlbarkeit des Papstes ist?

109) Kürschner (1983:81ff.) spricht hier einmal von "einfach-negativen E-Fragen" Fragen" m.E. die "emphatisch-negativen E-Fragen". Dicht hier nicht besonders gut. 
Ist das nicht betont oder kann es ohne Bedeutungsveränderung betont werdet (7a), so zeigt der Sprecher damit an, daß er bislang von einer positiven Vorinfor" mation ausgegangen war und nun durch ein sprachliches oder nicht-sprachliches Geschehen, das dieser Vorinformation widerspricht, dazu kommt, diese in Frage stellen und eventuell korrigieren zu müssen. Deshalb implizieren derartige Fragef immer ein gewisses Erstaunen seitens des Sprechers. Der Sprecher stellt dem Ge sprächspartner also eine echte Frage (vgl. dazu auch Franck 1979:9). Hier hal nicht demnach seine urkprungliche Funktion, d.h. Verneinung auf der propositio' nalen Ebene.

Etwas anders ist die Funktion von nicht zu beschreiben, wenn es unbetont unl unbetonbar in einem Entscheidungsfragesatz (wie (7b)) auftritt: mit diesel Außerungen suggeriert der Sprecher den positiven Sachverhalt (vgl. Franck 1979:9) und zeigt damit, daß er eine bestätigende Antwort erwartet. Nicht in dieset zweiten Verwendung hat abtönende Funktion und kann zu den Modalpartikelp gerechnet werden.

Das folgende (von Franck 1979:9 übernommene) Beispiel zeigt noch einmal dif unterschiedliche Funktion von nicht und die unterschiedliche Kontextverankerung:

(8a) Pans eines Pianisten kommen aus einem Konzert, einer von ihnen sagt: Hat or nicht gut gespielt?

(8b) Einer der Fans kommt mit enttäuschter Miene vom Konzertbesuch zurück; darauf sagt ein Zuhausegebllebener:

Hat er NICHT gut gespielt?

Ein weiteres Argument für die Trennung der belden Funktionen von nicht ist dil zulässige Verwendung anderer Negationselemente mit Satzskopus (mit Ausnahn von keineswegs und kelnesfalls, die in Entscheidungsfragesätzen nicht auftreten können); vgl. (9):

(9a) Sind Sie nicht Richter? (abtönend, Modalpartikel)

(9b) Sind Sie NICHT RIchter? (Negationspartikel)

(9c) Sind Sie KEIN Richter?

(9c) kann nur als echte Negation verstanden werden; sowohl bei ( $\theta \mathrm{b}$ ) als auch $b$ (9c) liegt der Außerung ein 'ich glaubte bisher fest, Sie seien Richter' zugrunde. Die unterschiedliche Funktion von nicht zeigt sich schließlich auch an den möglit chen Antworten (vgl. Franck 1979:10):

(8a) Hat er nicht gut gespielt? Ja./ Doch./ Nein.

(8b) Hat er NICHT gut gesplelt? Doch./ Nein.110

(9c) Sind Sie KEIN RIchter? Doch./ Nein.

110) Vgl. dazu Kürschner (1983:81f.), der meint, js wäre hier allenfalls möglich wenn die Proposition der Frage wiederholt warde; diese Verwendung ersche in $^{\text {h }}$ mir aber ungebräuchlich. 
Auch die Tatsache, daß auf (8a) ohne weiteres mit ja geantwortet werden kann, zeigt, daß es sich hier um abtönendes nicht bzw. die Modalpartikel nicht handelt.

Fragen mit abtönendem nicht (also der Modalpartlkel) sind meist Fragen nach einer Bestätigung (vgl. dazu auch Blanken 1983), keine Informationsfragen; der Sprecher erwartet, daß der Gesprächspartner die Gültigkeit des Sachverhalts bestatigt. In dieser Verwendung kann nicht durch kein anderes Negationszeichen ersetzt werden. Häufig - aber keineswegs immer - sind Fragen mit der Modalpartikel nicht rhetorische Fragen.

Auf die Bedeutung des hier als Modalpartikel klassifizierten nicht gehe ich weiter unten (Kap. 2.2.10) genauer ein.

3. W-Pragesātze

In w-Fragesätzen kann die Negationspartikel nicht ohne weiteres auftreten. Bei dlesen Außerungen muß allerdings der Inhalt der w-Frage und dessen Nicht-Zutreffen bereits bekannt sein. Mit der $w$-Frage wird lediglich eine Spezifizierung zu einem oder ein Grund für einen bereits als unzutreffend vorausgesetzten Sachverhalt gefordert:

(10) Wer von Ihnen hat die Prüfung nicht bestanden?

Die Tatsache, daß nicht in w-Fragesätzen immer in seiner Grundfunktion auftritt. Wird dadurch gestützt, daß auch andere Negationsträger ${ }^{111}$ in $w$-Fragesätzen verwendet werden können:

(11) Warum hat keiner rechtzeitig abgegeben?

In-Fragesätzen kann nicht als Modalpartikel nicht auftreten. Selbst in rhetorischen w-Fragen, bei denen ja meist die Lücke durch ein Pronomen oder Adverbiale mit "dlametraler Umdeutung" (Abdullaev 1977:267) zu füllen ist (vgl. (12)), kann nicht nur in seiner negierenden Funktion vorkommen;112 vgl. (13):

(12) Wer konnte sich damals schon ein Auto leisten? (Niemand.)

Wer hatte denn damals nicht Angst?

(Niemand hatte nicht Angst = Alle hatten Angst)

\footnotetext{
111) Wie andere Satzadverbien ist auch keineswegs in $w$-Fragen (mit Ausnahme

112) Dan Rückfragen) nicht zulässig.

dungen meint Meibauer (1986:141), das "rhetorische nicht" könne in Verbin-

(i). mit dem Konjunktiv auch in w-Fragen vorkommen und bringt Beispiel nales. handelt es sich hier aber immer um negierendes - also propositio(i) Wer nicht; vgl. (ia) vs. (ib):

Wer ließe ihn nicht neidlos ziehen und hielte sich derweil nicht an die

(ia) Konkurrenz, sondern ans Eingemachte?

(ib) Wer ließe ihn nicht neidlos ziehen? (= Alle lassen ...)

Wer ließe ihn neidlos ziehen? (= Niemand läßt...)
} 


\section{Imperativsătze}

Auch das Auftreten von nicht in Imperativsätzen entspricht der Grundfunkt10 von nicht als Negationspartikel. Die Funktion von nicht ist hier weniger die Kor" rektur der Erwartung, sondern eines beim Gesprächspartner tatsächlich vorhan denen oder vermuteten Handlungsplans. Mit Ausnahme von keineswegs sind in Im perativsätzen auch alle anderen Negationselemente möglich.

\section{Wunschsătze}

Die Verwendung von nicht in Wunschsätzen entspricht ebenfalls der Grundfunktiof von nicht. Allerdings ist auch hier - ähnlich wie in w-Fragesätzen - das Nicht' Zutreffen des Sachverhalts bereits bekannt. Ansonsten aber sind die verwent" dungsbedingungen eines Wunschsatzes mit und ohne nicht die gleichen. Auch" wunschsätzen lassen sich andere Negationsträger nachweisen.

\section{Exklamativsatz}

Das Auftreten von nicht in einem Exklamativsatz mit Verb-Erst- oder ver ${ }^{\prime \prime}$ Zweit-Stellung ist wesentlich eingeschränkter als in den anderen Satzmodi. 'ECl' negiert' können Exklamationen nicht werden; d.h. nicht kann als Negationspartit" mit Satzskopus nicht auftreten. ${ }^{113}$ Grund dafür ist die pragmatische Funktion Exklamativsătzen: sie drücken die obberraschung eines Sprechers darüber aus. " welch hohem Grad etwas der Fall ist. Insofern kann nicht gleichzeitig durch di Negation angezelgt werden, daß dies nicht zutrifft.

Auch die anderen Negationsträger können in Exklamativsätzen nicht verwen nd $^{d e^{\circ}}$ werden:

(14) "Mensch, ist das kein Schlaumeier!

(15) "Hat der vielleicht niemanden geliebt!

Als Modalpartikel ist nicht in Exklamativsätzen ebenfalls nicht möglich. ${ }^{114}$

113) In einer seltenen Variante ist negierendes nicht allerdings dann mog $g^{\text {il }}$ wenn sein Skopus so eng ist, daß das graduierte Element des Exklams (und hier sind nur quantifizierende Ausdrücke zulässig) außerhalb dif Skopus steht: Mein Gott, haben DIE vielleicht viele Waren nicht verkauft!

114) Bei dem von Roncador (1977:109) angeführten Beispiel (i) Ist das nicht he lich?! handelt es sich zwar um die Modalpartikel nicht (Roncador merkt ${ }^{8}$ an, daß nicht hier keineswegs den Sachverhalt neglert); allerdings ist nach meiner Klassifikation kein Exklamativsatz: eine fakultative Verb- 2 . stellung ist nämlich nicht möglich. Sätze wie (i) wüde ich von der Form den Entscheidungsfragesätzen zuordnen, von der Illokution her sind sie als rhetorische Fragen zu bezeichnen. 


\section{7. w-Exklamativsatz}

W-Exklamativsätze können aus denselben Gründen wie die anderen Exklamativsätze nicht negiert werden; d.h. die Negationspartikel nicht kann mit Satzskopus hier nicht auftreten:115

(16) "Wie hinterhältig diese Leute nicht sind!

In der Modalpartikel-Funktion kann nicht in $w$-Exklamativsätzen durchaus vorkommen - allerdings nur ${ }^{116}$ in der Verbindung mit einem allquantifizierenden Ausdruck:117

(17) Wo will sie nicht überall gewesen sein!

(18) Ach, wer da nicht alles auftaucht aus der "feinen" Gesellschaft! (SZ)

(19) Wen hat sie nicht alles eingeladen! Die halbe Firma!

Auch hier sind andere Negationsträger nicht möglich, was ein Indiz dafür ist, daß nicht in Modalpartikel-Funktion vorliegt:

(20) Wie frech sie doch $z u$ niemandem ist!

Zusammenfassend läßt sich also sagen: Belm Vorkommen von nicht müssen zwei Verwendungsweisen unterschieden werden: einmal das Auftreten als Negationspartikel110 und zum anderen das Auftreten als Modalpartikel.119

115) Auch hier lassen sich (wie bei den Exklamativsätzen) marginale Verwendungen anführen, bei denen das gradulerte Element - ebenfalls oft ein quantifizierender Ausdruck - außerhalb des Negationsskopus steht:

(i) Diese Prüfung war furchtbar. Was hat er alles nicht gewußt!

116) Ein anderes Vorkommen von nicht wie z.B.: Wie sehnlich hat man nicht mehr gebräuchlich (vgl. Roncador 1977:110).

117) $\mathrm{Vgl}$. noch einmal die unterschiedlichen Stellungsbedingungen:

(1) Was weiß er nicht alles! (Modalpartikel)

118) Hier mus weiß er alles nicht! (Negationspartikel) rend-negierendem nicht und nicht-kontrastierend neglerendem. Was die Verine einzelnen Satzmodi betrifft, so ung von kontrastierendem nicht auf die einzelnen bei nicht-kontrastiergeben sich bel den gleichen Satzmodi Problem und den Exklamativen: Bei rendem nicht, nämlich den Entscheidungs den Entscheidungsfragen ist kontrastierendes nicht vermute o.a. auftritt:

(i) auch ein Satzadverb wie vielleicht oder moglich, sondern gestohlen?

Hast du das Geld möglicherweise nicht gefunden, nur unter den $\mathrm{S} .88$

Fn den Exklamativen ist das Negationselement norn-Anschluß ist allerdings - Palls genannten Bedingungen zulässig. Der sondls möglich, aber wohl nicht nötig. In überhaupt akzeptabel ist en Fälen kontrastierendes nicht vorInsofern ist fraglich, ob in diesen Fas:34f.). Insgesamt gesehen scheint aber Kontrastnegation von Jacobs 1982.34 kx akzeptabel; sie würde auch merkwurdige pragmatische Bedingungen voraussetzen:

(ii) "? Beispiele für kontrastierendes nicht in anderen Satzmodi:

(iii) Wer hat nicht bezahlt, sondern anschreiben lassen?

(lv) Mach nicht das Fenster zu, sondern die Heizung an! 
Nicht in Negationspartikel-Funktion (mit Satzskopus) und nicht in Modalpartikel Funktion lassen sich in Polgenden Satztypen nachweisen:

Tabelle 9: Distribution von nicht in den Grundtypen

\begin{tabular}{|lcc|}
\hline & $\begin{array}{l}\text { Negationspartikel } \\
\text { (betonbar) }\end{array}$ & $\begin{array}{l}\text { Modalpartikel } \\
\text { (unbetont) }\end{array}$ \\
Aussagesatz & + & + \\
Entscheidungsfragesatz & + & \\
w-Fragesatz & + & \\
Imperativsatz & + & + \\
Wunschsatz & + & + \\
Satzexklamativsatz & & + \\
w-Exklamativsatz & & + \\
\hline
\end{tabular}

\subsubsection{Das Auftreten von Modalpartikeln in neglerten Sătzen}

Hier muß - entsprechend der Funktionsdifferenzierung bei der Partikel nicht ${ }^{\circ}$ unterschieden werden $z$ wischen dem Auftreten von Modalpartikeln in negierten satzen, d.h. dem Vorkommen von Modalpartikeln gemeinsam mit der Negations' partikel nicht und dem Auftreten von Modalpartikeln und der Modalpartikel nicht Letzteres unterliegt anderen Beschränkungen und wird bei den Modalpartikel Kombinationen behandelt (s.u. S.241p. und 265pf.).

Nach der kleinen Ubersicht oben kann die Negationspartikel nicht nur in fune def sieben Satzmodi auftreten.

Vergleicht man dies nun mit der Tabelle 5 auf s.49, die die Verteilung der Modal' partikeln auf die einzelnen Satzmodi zeigt. so kann man also von vornherein a $\mathbf{u}^{\circ}$ schließen, daß die Modalpartikeln, die in Exklamativsätzen vorkommen, spez tet $^{\mid t}$ aber und vielleicht, dle Negierbarkeit von Außerungen beeinflußten, da hier - il vorher gezelgt - Auftreten der Negationspartikel nicht oder auch anderer Neg $\mathrm{g}^{\circ}$ tionsträger ohnehin im allgemeinen nicht möglich ist. ${ }^{220}$ Damit erklärt sich a ull $^{\text {li }}$ die Inakzeptabilităt der ersten beiden von Reis (1977:40) angeführten Beisplele (s.o. S.84):

(v) Hatt ich doch nicht das Bargeld mitgenommen, sondern die Schecks!
119) Inwieweit sich die beiden in ihrer Grundbedeutung gleichen, werde ich we ${ }^{\text {tet }}$

unten (Kap. 2.2.10) zeigen.
120) Bel dem marginalen Fall eines Exklamativs mit engem Negationsskopus sint aber und vielleicht im übrigen durchaus verwendbar (s. das Beispiel $\mathrm{s}^{\circ} 9^{\text {in }}$ Fn.113). 
(45a) Max hat mich heute vielleicht wieder geärgert.

"Max hat mich heute nicht vielleicht wieder geärgert.

In beiden Fällen handelt es sich nämlich um Exklamativsätze (die Zeichensetzung ist hier irrefürend): sie lassen sich ohne Bedeutungsveränderung auch in Exklamatlvsătze mit Verb-Erststellung umwandeln. Die Inakzeptabilität der von Reis angeführten Beispiele ist also keineswegs auf die beiden Modalpartikeln zurückzuführen.

Im weiteren muß polglich nur noch das Auftreten von Negationspartikel und Modalpartikel in Pün Satzmodi überprüft werden, um festzustellen, welche Modalpartikeln wirklich sensitiv auf Negation reagieren bzw. umgekehrt, wann Negation auf Modalpartikeln sensitiv reagiert.

Bel den folgenden Modalpartikeln bestehen keinerlei Beschränkungen hinsichtlich des Auftretens mit der Negationspartikel nicht: auch, bloß, denn, doch, eben, elgentlich, etwa, ja und wohl. Schwierigkeiten ergeben sich bel den Partikeln mal, ruhig und schon.

1. $\mathrm{mal}$

Die Modalpartikel $\mathrm{mal}$ tritt in drei Satzmodi auf, wobei es sich vom Illokutionstyp her bel Außerungen mit mal immer um Aufforderungen handelt.

In negierten Imperativsätzen und Aussagesätzen kann die Modalpartikel mal zwar vorkommen, ist allerdings (z.B. auch im Vergleich zu doch) sehr selten - und nicht immer voll akzeptabel:

Hilf mir mal nicht! Ich muß das auch alleine können.

(22) ?Mach mal nicht die Tür zu!

Auch mit anderen Negationsträgern ist das Vorkommen von mal möglich; vgl.:

mal niemandem von der Geschichte!

Du könntest mal keinen Ingwer nehmen.

tung des Adverbs viel deutlicher mal kommt allerdings m.E. die temporale

nen; d.h. hier liegt mal mögllcherweise nicht in Modalpartikel-Funktion vor.

In Entscheidungsfragesätzen kann nicht ja sowohl als Modalpartikel als auch als Negationspartikel auftreten. In beiden Fälien ist es mit mal kombinierbar. Dabei steht die Negationspartikel nicht nach mal und die Modalpartikel nicht vor mal;
Vgl.:121

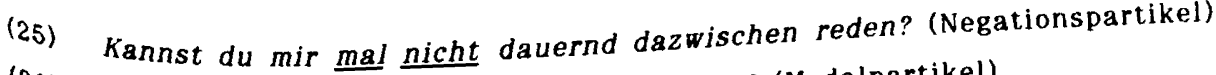

(26) Könntest du mir nicht mal schnell helfen? (Modalpartikel)

121) Aup die Verbindung von nicht (ein)mal als Polaritätsclement zu sogar kann hier nicht eingegangen werden. 
In dem von Reis (1977:40) angeführten Beispiel (45c) handelt es sich um dil Modalpartikel nicht; insofern stellt (45c)' tatsächlich nicht die negierte version von (45c) dar - diese wäre wie (45c)":

(45c) Könntest du mir mal die Kiste tragen helfen? vs.

(45c)' Könntest du mir nicht mal die Kiste tragen helfen?

(45c)"?Könntest du mir mal nicht die Kiste tragen helfen?

Zusammenfassend läßt sich sagen, daß die Modalpartikel mal relativ selten zusam" men mit Negationsträgern auftritt - und daß in diesen Fällen bei mal die temp $0^{\circ}$ rale Komponente besonders deutlich wird.

\section{2. ruhig}

Auch die Modalpartikel ruhig und Negationselemente scheinen nicht zusammet vorzukommen. Bublitz (1978:84) meint dazu:

Steht ruhig, so ist vorhersagbar, daß in seiner Umgebung keine Negationspar" tikel wie nicht vorkommt. Mit ruhig kann man jemanden auffordern, etwas 2 tun (Geh ruhig hin!), etwas zu unterlassen (Bleib ruhig weg!) jedoch nicht etwas nicht $\mathrm{zu}$ tun, indern man Negationspartikeln verwendet ("Geh Iuhi nicht hin!).

Nun ist das letzte Beispiel nicht unbedingt inakzeptabel; es sind durchaus Kof' texte denkbar (vgl. (27) oder (28)), in denen ruhig mit Negationselement auftrete kann. Bedingung ist nur, daß über den Sachverhalt in seiner negierten for bereits gesprochen wurde, d.h. die Negation darf nicht vom Sprecher neu einge' führt werden:

(27) Ina: Ich habe noch soviel zu erledigen; aber ich weiß nicht, wie oft ich $e^{s}$ mir leisten kann, nicht in dieses Seminar zu gehen.

Ute: Ach, geh ruhig diese Woche nicht hin! Es ist sowieso eine Wiederholungsstunde angesetzt.

(28) Du willst also morgen nicht zu dieser Prüfung gehen? Na, geh ruhig nicht hin! Wirst schon sehen, was passiert!

Aup den möglichen Grund dafür, daß ruhig zumindest sensitiv auf Negation req giert, komme ich bel der Beschreibung von ruhig (Kap. 2.2.16) zurück.

\section{3. schon}

Auch die Modalpartikel schon unterllegt gewissen Beschränkungen, was das Auf treten in negierten Sätzen (Aussage-, Imperativ-, w-Fragesatz) betrifft.

Bel den Aussagesätzen können futurische mit schon eher negiert werden, während die Akzeptabilität bei manchen nicht-futurischen wesentlich geringer ist; vgl.:

(29) Es wird schon nicht so schlimm werden.

(30) Es wird uns schon niemand sehen.

(31) Auf Ihren blonden Kopf werden sie schon nicht gleich schießen. (SZ)

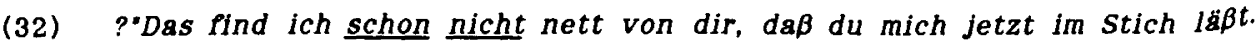

(33) Es ging schon nicht sehr fein zu in diesem Hotel. 
In (32) würde man wohl eher auf ein Lexem wie gemein ausweichen. Interessanterweise wird z.B. (32) akzeptabel, wenn zwischen Modalpartikel und Negation ein Element eingefügt wird - also bei Distanzstellung von Modalpartikel und Negationspartikel; vgl. auch (34):

(32a) Das find ich schon gar nicht nett...

Das find ich schon allein deswegen nicht nett..

(34) Den Werner kann ich schon überhaupt nicht leiden.

Andererseits sind bestimmte (nicht-futurische) 'beschwichtigende' schon-Außerungen auch bei Kontaktstellung von Negationspartikel und schon akzeptabel:

(35) $A$ und $B$ sprechen im Zug über den anwesenden $C$.

A: Denk dir nichts, der kann schon kein Bairisch./

Der versteht uns schon nicht.

Auch Imperativsätze mit schon treten kaum negiert auf; aber auch sie werden akzeptabler, wenn Negationselement und Modalpartikel in Distanzstellung stehen:

(36) 'Jetzt geh schon nicht hin!

(37) Jetzt plag dich schon deswegen nicht so $a b$ !

Die Modalpartikel schon tritt schließlich auch im w-Fragesatz nur sehr elngeschrånkt zusammen mit nicht oder einem anderen Negationsträger aup. Diese Fragen sind aufgrund der Leistung von schon immer rhetorische Fragen (mehr dazu 8.u. Kap. 2.2.8); vgl.:

(38) Wann hat schon niemand Lust?

(39) ?Wer lebt schon nicht in chronischem Geldmangel?

(40) ?Wer hat damals schon kein Parteiabzeichen gehabt?

Auch die Modalpartikel schon und die Negationspartikel reagieren also sensitiv aufeinander.

Dle vorangegangenen Ausführungen haben gezeigt, daß lediglich mal, ruhig und schon Einfluß auf die Negierbarkeit von Sätzen haben, oder umgekehrt: Negationstrảger beeinflussen das Auftreten dieser drei Modalpartikeln. 


\subsection{Vorbemerkungen}

\subsubsection{Die Bedeutung von Modalpartikeln}

Bereits zu Beginn dieser Arbeit (Kap. 0.1) wurde darauf hingewiesen, daß die $B e^{\prime}$ deutung der Modalpartikeln im nicht-propositionalen, im illokutiven Bereich lief Im folgenden soll nun diese Bedeutung beschrieben werden. Dabei werde ich ald kurz auf verschledene Ansätze in der Forschung eingehen.

Weydt, dessen Arbeit "Abtönungspartikel" 1969 die Modalpartikel-Forschung in Bundesrepublik einleitete, sieht in seiner umfassenden Definition die Bedeutution bzw. Funktion der Modalpartikeln darin, "die stellung des Sprechers zum Gesagt" zu kennzeichnen" (1969:68). Tatsächlich ist dies eine Funktion der Modalpartike allerdings ist damit - auch bei einem weiten Verständnis des Begriffs 'stellun' bzw. 'Haltung' - die Funktion der Modalpartikeln nicht erschöpfend beschriebe ausgehend davon, daß Modalpartikeln auf der Beziehungsebene, also zwischen det Gesprächspartnern wirken und daß sie wesentlich interaktionsbezogene Elemen sind, muß auch der Aspekt des Gesprächspartners ${ }^{1}$ und der Kontext mit einbezober werden.

Mit Modalpartikeln kann der Sprecher nämlich dem Gesprächspartner Hinwe darauf geben, wie er das Gesagte aufassen und wo er es einordnen soll, so Hinweise darauf, wie der Sprecher die Außerung bewertet, wie er die Vorgänger äußerung aufgenommen hat oder wie er das wissen und die Erwartungen des ${ }^{\circ 0^{\prime}}$ rers einschätzt. Diese Hinweise soll der Hörer natürlich auch in seiner Reakt berücksichtigen; auf diese Weise ist es auch eine der Funktionen der Modalparti keln, den Gesprächspartner in einer bestimmten Richtung zu beeinflussen.

1) Dieser Aspekt taucht bei Weydt $(1969: 22,62)$ kur\% auf; deutlicher kommt Horrerorientiertheit bei Bublitz (1978:38) zum Ausdruck, der von "Verstehe" anweisungen" spricht, und bei Gornik-Gerhardt (1981:18), die Modalpartike sieht als "Instruktionen an den Hörer (...), wie er die Proposition verste soll". Vgl. auch Kemme (1979:7, 15f.), Weydt/Hentschel (1981:326) oder et al. (1983:5 und 13). 
Auch kann mit Modalpartikeln Bezug genommen werden auf verschiedene Aspekte der Sprechsituation (vgl. dazu auch König 1977a:117 und Burkhardt 1982:153): Mit ihnen kann Vorinformation aufgegriffen, der Bezug zu vorangegangenen Beiträgen gekennzelchnet werden, ein 'Meta-Kommentar' über den Vorgängerbeitrag abgegeben Wle Nachfolgendes vorbereitet werden. Somit können Modalpartikeln Inhalte von Außerungen im dialogischen Kontext verankern (vgl. dazu Franck 1980:252 und Gornik-Gerhardt 1981:13). Modalpartikeln regeln folglich auch "den Bezug des im MP-Satz Gesagten zur konversationellen 'Umwelt'" (Franck 1980:213).2 Deshalb muß el elner Bedeutungsbeschreibung der Modalpartikeln auch der sprachliche oder/ und situative Kontext berücksichtigt werden.3

Elne Beschreibung der Semantik von Modalpartikeln kann demnach nur im dialogischen Rahmen erfolgen." Deshalb sind hier zunächst einige kurze Bemerkungen zu den Basisprinzipien eines Dialogs' nötig.

Ein Dialog konstituiert sich vor allem durch zwel wesentliche Prinzipien: durch 980.48). des Sprecherwechsels und durch das Prinzip der Kohärenz (vgl. Franck Das Prines

Prinzip der Kohärenz (so Franck 1980:481. weiter) wird zum einen wirksam als Gespräch, legitimiert durch das Kooperationsprinzip von Grice (vgl. Grice 1975): Ein ten. dh artner wird den Beitrag seines Gegenübers zunăchst immer als kohärenPretion. aup die augenblickliche Kommunikationssituation bezogenen Beitrag intereren, da er seinem Gegenüber Kooperativität unterstellen darf ("in dubio pro

2)

Coseriug aup Kontext bzw. Situation, den die Modalpartikeln leisten, sieht dleser (1980:206) als ein typologisches Gestaltungsprinzip des Deutschen: "In konter Hinsicht ist das Deutsche, wie das Altgriechische, eine 'situations-und Spractbezogene' Sprache; oder, wenn man so will, elne 'Sprech-Sprache': eine Spreche, die sehr zahlreiche und verschiedenartige Determinationen des

8elbst Aupgrund aupenommen hat."

werden des engen Zusammenhangs zwischen Modalpartikeln und Kontext We die Modalpartikeln auch manchmal mit den Deiktika verglichen, da sie Hentese die Sprechsituation mit einbeziehen; vgl. Franck (1980:25) und Die Zlehung alpartikel-Forschung zeigt in ihrem Werdegang eine allmähliche Einbeaus - von Sprecher, Hörer und Kontext: Erst ging man nur vom Sprecher Halt - d.h. die Bedeutung der Modalpartikeln wurde nur darin gesehen, die lyse also degt mit Doherty (1985) vor) -, bezog später auch den Hörer mit ein, tikeln Tatsache, inwieweit der Sprecher durch den Gebrauch von Modalparauch auf den Hörer Bezug nimmt, und erst in einigen jüngeren Ansätzen wird

5) Von der Kontext mit betrachtet. (Eine konversationsanalytische Beschreibung Das Modalpartikeln stellt Franck (1980) dar.)

der Redmale Gerüst' eines Dialogs, also Anfang, Beendigung sowie die Vergabe nlcht weiter relevant ist. 
Kohärenz" (Franck 1980:49)). Jeder Gesprächstellnehmer erwartet also eine $k 0^{\circ}$ härente Fortsetzung seines Beitrags; wird diese Erwartung durchbrochen, muß dief angezeigt werden.

Zum anderen wird Kohärenz sprachlich manifest durch Mittel im propositionaleb Bereich (wie z.B. die Konjunktionen), aber auch durch Mittel im nicht-propositio nalen Bereich: hier wirken die Modalpartikeln.

Kohärenz zeigt sich also darin, daß jeder Beitrag mit dem vorangegangenen ver" bunden ist und seinerseits bestimmte Fortsetzungsmöglichkeiten eröffnet. Diest beiden Verbindungsprinzipien sind von unterschiedlicher Gewichtung, je nachde ob es sich um einen primär reaktiven oder primär initiativen Beitrag handelt.

Nun dient ein Dialog nicht nur dem Austausch von Informationen; deshalb reagier ein Gesprächspartner, der die sprecherrolle ubernommen hat, nicht nur auf del vorangegangenen Beitrag, sondern wird dem Gesprächspartner, der nun die Horer rolle abernommen hat, auch zeigen, wie er dessen Beitrag aufgenommen hat, bé zleht also Stellung dazu. Zusätzlich kann er dem Hörer anzeigen, wie er seinel elgenen Beitrag verstanden wissen will und (vor allem bel primär initiativen Außerungen) welche Reaktion er seinerseits wieder vom Hörer erwartet.

Von grundlegender Wichtigkeit ist in diesem Zusammenhang die Oberprüfung de den Gesprächspartnern gemeinsamen Basis in bezug auf gemeinsames Wissen, $g^{\ell}$ meinsame Annahmen, Oberzeugungen und Erwartungen. Diese gemeinsame Basis wit deshalb fortlaufend überprüft, Erwartungen und Annahmen werden bestätigt odel revidiert und so in Obereinstimmung gebracht.

Die Modalpartikeln als primär dialogbezogene Elemente haben ihre Funktion nun unterschledlichen Pür die Interaktion relevanten Bereichen.

So können bestimmte Modalpartikeln dazu dienen, sich der für das Gelingen odel gar Zustandekommen der Kommunikation wichtigen gemeinsamen Basis zu versi' chern. (Lutten (1979) bezeichnet in diesem Zusammenhang speziell die Modalpgr" tikeln doch, eben und ja als "Konsensus-Konstitutiva", die durch den Rekurs die gemeinsame Basis dazu beitragen, daß in Argumentationszusammenhängen $e^{i n}$ Konsens zustande kommt.) 6

Andere Modalpartikeln können den Gesprächsverlauf insofern steuern, als sle vor găngerbeiträge in bestimmter Welse bewerten (schon oder auch), die Fortsetzungs mögllchkeiten des Gesprächspartners beeinflussen und modifizieren (z.B. die Modal'

6) Bei unredlichem Gebrauch können die Modalpartikeln auch Konsens verhinder indem sie Sachverhalte als allgemein bekannt oder offensichtlich und dam als akzeptiert markieren, auch wo sie es nicht sind, und so dem Gesprächs partner die gleichberechtigte Teilnahme an der Argumentation verwehren ( $v q^{\prime}$ Kemme 1979:16). 
Partikeln etwa und auch, die Fragen eine bestimmte Tendenz verleihen), Sequenzen beenden (eben) oder thematische Ubergänge anzeigen (eigentlich).

Bestimmte Modalpartikeln können auch eingesetzt werden, um Zustimmung zu erhelschen, und auf diese Weise den Dialog steuern.

In allen Fällen dienen die Modalpartikeln dazu, auf bestimmte Weise IllokutionstyDen zu modifizieren oder auch zu verdeutlichen (vgl. auch König 1977a:117; Weydt 1977:225 oder Franck 1980:21, 31; Helbig (in Helbig/Kötz 1981:16) spricht von den Partikeln als 'lllokutiven Indikatoren'; Sökeland 1980:55ff. bezelchnet sie als 'Sekundărindikatoren'.)

Aus der Interaktionsbezogenheit der Modalpartikeln folgt, daß ihre Bedeutung nur in elnem größeren Rahmen als dem Satz adäquat beschrieben werden kann. Obwohl die Erkenntnis von der besonderen 'Kontextsensitivität' der Modalpartikeln in der Forschung allgemein anerkannt zu sein scheint, wird immer noch viel zu häufig mit isolierten, oft auch konstruierten Sätzen gearbeitet. Auch der Weg. den bei8pielsweise Helbig (in Helbig/Kötz 1981:23) geht, nämlich von opfensichtlich konanderten Sätzen aus einen möglichen Kontext zu suchen, sollte m.E. in der 'echten' Richtung gegangen werden: Zuerst müssen die Modalpartikeln in einem legungen Dartikel anstellen und Schlüsse ziehen, warum z.B. dieser Satz mit jener Modaltext nis einem anderen (und in diesem Fall legitimerweise konstruierten) KonNodalpartikeln möglich ist. Am Anfang aller Hypothesen über die Bedeutung von tuatlonen stehen? Die Interdependenz

2u der verden müssen.

7)

gl. dagegen aber die erhellende These 6 von Wolski (1986:353): "Die Bedeudenen Partikeln springt nicht aus einem Korpus heraus. Die Ausdrücke, mit pus hartikelbedeutungen beschrieben werden, springen nicht aus einem Kornerlei aus. Zur Rekonstruktion der Bedeutung von Partikeln bedarf es kei$V_{g l}$. authentischer Beispiele."

Gefahr ldich die merkwürdige Argumentation von Hentschel (1986:122): "diese tersur [die Vernachlässigung des Kontextes; M.T.] wird schon durch den Un$\mathrm{Da}_{\mathrm{a}}$ dichungsgegenstand selbst, nämlich durch die Abtönungspartikeln, gebannt. kommue wörter als metakommunikative Delktika dem Zwecke dienen, auf den allein kann schon eine Garantie dafür, daß dieser nicht vernachlässigt werden zugl. Satze, in denen Abtönungpartikeln vorkommen, enthalten dadurch stets Werden Informationen über den Kontext, der so mit Leichtigkeit erschlossen erden kann". 
So stellt schon Krivonosov fest - ausgehend von der Tatsache, daß eine Partill ihre Bedeutung nur zusammen mit dem Satz erhält -, daß die Bedeutung ein Partikel "sich von Satz zu Satz" verändert (1963:44).

Deutllcher noch kommt dies bei Helbig (1977:400) zum Ausdruck: "Eine detaillier tere Beschreibung müte (...) die elnzelnen Lexeme nach ihren Bedeutungen spe $2^{\circ}$ plzieren (etwa: auch1, auch, auch3, auch, auch," . Tatsächlich stellt Helbig " seiner didaktisch orientierten Arbeit (Helbig/Kötz 1981) fünf verschiedene 'guch und sleben verschiedene 'doch' auf. Dabel läßt sich eln Zusammenhang zwischei den einzelnen Funktionen oft nur schwer erkennen. (Vgl. ähnlich auch Heinricls 1981:120, 196.)

Diese bedeutungsmaximalistische Position scheint aus mehreren Gründen nich haltbar:

Zum einen ist es relativ unwahrscheinlich, daß jeder Sprecher mehrere (z.T. bis sechs) Varianten einer Modalpartikel gespeichert hat - abgesehen von den andé ren Funktionen elner Partikel (vgl. auch Hentschel 1986:121).

Zum anderen ist die bedeutungsmaximalistische Position sehr problematisch, w man vom Standpunkt des Hörers ausgeht: dieser hătte nämlich keine Anhalts" punkte dafür, welche Variante einer Modalpartikel der Sprecher nun gerade Sinn hatte, falls sich diese Varianten weder durch Akzent noch durch Vorkom in verschiedenen Satzmodi unterscheiden.

Auch in der Praxis, also z.B. dem Unterricht des Deutschen als Fremdsprache, sint derartige Ergebnisse schwer zu verwerten.

So wird auch in der neueren Forschung meist ${ }^{9}$ die bedeutungsminimalistische posi tion vertreten: vgl. dazu u.a. König (1977a), Bublitz (1978), Weydt/Hentschel (1983), Doherty (1985), Wolski (1986) sowie Hentschel (1986), die alle nur eint Bedeutung annehmen.

Auch in dieser Untersuchung soll grundsätzlich davon ausgegangen werden, dy jede Modalpartikel eine einzige Bedeutung hat.

Dabei kann es allerdings vorkommen, daß sich bel einer Modalpartikel, die in vet schiedenen Satzmodi auftreten kann, die Bedeutung im Zusammenwirken mit def Satzmodus 'verschiebt'. Eine solche Verschiebung könnte auch vom Hörer erkan werden; denn der Hörer kann z.B. eine 'Frage' von einer 'Aufforderung' unter' scheiden und kann deshalb auch eventuelle Anderungen in der Bedeutung ein $^{e^{f}}$ Modalpartikel je nach Satzmodus unterscheiden.

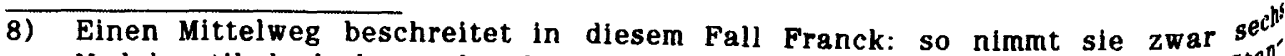
Modalpartikel-doch an, beschrelbt aber füne davon als Varianten des $\mathrm{stan}^{\prime \prime}$ dardfalls und zeigt, "daß sich die Bedeutungsvarianten im wesentlichen konventionalisierte Implikaturen beschreiben lassen, die aus den jewelligen lokutions-und Kontexteigenschaften abgeleitet werden können" (1980:175). 
Grundsatzlich ist also bei den Modalpartikeln eine Grundbedeutung anzunehmen, dle je nach Satzmodus verschieden ausgeprägt sein kann.9

Die charakteristische Interdependenz von Modalpartikeln und Kontext darf also kelneswegs zu der Annahme führen, mit Jeder Anderung des Kontextes ăndere sich auch die Bedeutung einer Modalpartikel; es muß möglich sein, aus der Analyse all der verschiedenen Kontexte, in denen eine Modalpartikel auftreten kann, die eine (kontextfreie) Bedeutung jeder Modalpartikel 'herauszuschälen'.10

\subsubsection{Beschreibungsmethode}

Bel der hier vorliegenden Bedeutungsbeschreibung der einzelnen Modalpartikeln -ird also davon ausgegangen, daß jede Modalpartikel in allen Kontexten eine Merkmal Bedeutung hat. Diese Bedeutung soll hier mit Merkmalen bzw. Bündeln von 2u sehen. nomischen, die der Metasprache angehören. Sie sind Mittel zu einer einfachen, ökoDie

angerkmale oder Merkmalkombinationen, die zur Beschreibung der Modalpartikeln sătzliche werden, beschreiben die zentrale Bedeutung jeder Modalpartikel; zuDle spezielle Bedeutungskomponenten lassen sich aus diesem Bedeutungskern ableiten. daß elne Satzmodusabhängigkeit der Modalpartikeln kann es mit sich bringen, bungsmethode. Wirkt. Aue ein Merkmal), in den einzelnen Satzmodi auf unterschiedliche Weise konnen, wup der anderen Seite sollte ein angenommenes Merkmal auch erklären , warum eine Partikel in bestimmten Satzmodi nicht auftreten kann.

9) $V$ gl

Giv Im Gegensatz zur hier vertretenen Auffassung Krivonosov (1977a:193): Gemeind dieselbe modale Fartikel hat in verschiedenen Satzbautypen weniger Satztyp". (...) als verschiedene modale Partikeln in ein und demselben

10) Vor allem Diese Auffassung wird nicht zuletzt durch die Kombinations- und Aufschluß durch die Nicht-Kombinationsfähigkeit von Modalpartikeln widerlegt. (1980.ußreich ist in diesem Zusammenhang die Bemerkung von Franck beste:167), die kontextfrele Bedeutung der Modalpartikeln könne "gerade darin textes daß Hinwelse gegeben werden, welche Kategorien des Gebrauchskon-

11) mit ein berucksichtigt d.h. in bestimmter Welse in das Interpretationsverfahren $\mathrm{Vgl}$. dazu

loder dazu z.B. auch Weydt (1977:224): "Wenn es gellingt, Gesamtbedeutungen

12) del von funktionelle Bedeutungen) zu ermitteln, so darf man sich diese als Bün-

Dle im Merkmalen vorstellen". Vgl. dagegen Rath (1975:225).

Bedeut Zusammenhang mit der Merkmalbeschreibung aufgeworfene Frage, ob Merkmalen 'tatsächlich' aus Tellen, d.h. Komponenten oder linguistischen sprochen bestehen, ist hler Palsch gestellt; nicht von 'tatsächlich' sollte gescheldun werden, sondern von 'zweckmäßig': "Da Sprachsysteme auf Unterchen, dingen beruhen, ist es zweckmaßig, von solchen Komponenten zu spre, die der genauen Unterscheidung von Wörtern dienen" (Leisi 1973:42). 
Ziel dieser Bedeutungsbeschreibung ist es, jede Modalpartikel mit möglichst wenth Merkmalen zu beschreiben. Dabel dürfen zwel verschiedene Modalpartikeln nicli die gleiche Merkmalkombination aufweisen, es sel denn, es handelt sich um Syn" nyme. Relevant sind ja gerade auch die Komponenten, die die Modalpartikell voneinander unterscheiden.

Der Auswahl und Aufstellung der Merkmale kommt also große Bedeutung w Grundsätzlich sollten die Merkmale so gewăhlt werden, daß sle nicht nur für det gerade analysierten Bereich der Sprache 'passend' sind (also hier die Modalpart' keln), sondern auch für andere Berelche. Die meisten der hier angenomment? Merkmale lassen sich auch bei anderen konversationsbezogenen Ausdrücken, z.B. den Gllederungspartikeln, finden (vgl. dazu Willkop 1988). Aber auch in ande' ren Bereichen können diese Merkmale relevant sein: so läßt sich z.B. das Mert' malpaar 〈BEKANNT〉/〈UNBEKANNT〉, das bel der Beschreibung der Modalpartikel" eine Rolle spielen wird, auch für die Artikel anwenden.

Díe Merkmale, die hier verwendet werden, sind grundsätzlich binär angelegt. wird sich aber zeigen, daß nicht unbedingt beide 'Pole' eines Merkmalpaars bel def Beschreibung der Modalpartikeln ausgeprägt sind. Auf die Gründe dafür gehe später ein (S.199).

Wie schon erwähnt, liegen die Funktionen jeder einzelnen Modalpartikel au w terschiedlichen Ebenen. Auch die zur Bedeutungsbeschreibung angenommenen we t $^{\prime \prime}$ male sind deshalb auf unterschiedlichen Ebenen anzusiedeln.

Eine erste große Gruppe von Merkmalen bezieht sich in Form einer Bewertung ${ }^{8}$ den Außerungsinhalt. ${ }^{13}$ Das betrifft zum einen die Einordnung des dargeste $\|^{1 t^{t}}$ Sachverhalts in den wissensbestand (z.B. 〈BEKANNT〉 oder 〈EVIDENT〉), hinsichtilil

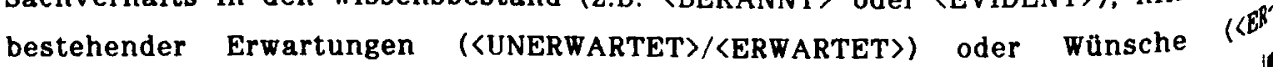
WUNSCHT $>/\langle$ UNERWUNSCHT〉). Diese Merkmale dienen also hauptsächlich der Dialog immer wieder notwendigen Absicherung gemeinsamer wissensinhalte, do Bezug auf Annahmen und Erwartungen, dem Absțimmen von Bewertungen. A diese Merkmale können weiter danach spezifiziert werden, ob sle sich auf de Sprecher oder den Hörer bezlehen ('Bekannt' Pür wen?; dieser Bezug wird durt den Index 'S' bzw. ' $H$ ' markiert). Ein Bezug auf den Hörer (also sein wissen def seine Erwartung) ist dabel natürlich als Annahme des Sprechers über das Hofer

13) Diese Merkmale - und damit die entsprechenden Modalpartikeln - be $z^{\mathrm{j}^{\mathrm{f}} \mathrm{fe}^{\mathrm{e}^{\prime}}}$ sich also auf die propositionale Ebene; die Bedeutung der mit ihnen bes $\mathrm{ch}^{\text {th }} \mathrm{g}^{\mathrm{l}}$ benen Modalpartikeln liegt dennoch im nicht-propositionalen Bereich; $2^{t}$ gehören selbst nicht zur 'Sachverhaltsbeschreibung' und können damit 'bl nicht selbst im semantischen wirkungsbereich anderer propositionsbezog Ausdrücke stehen. 
Wissen oder die Hörererwartung zu verstehen. Auch wenn ein Merkmal und damit
de Bedeutung einer Modalpartikel sprecherbezogen ist, ist der für Modalpartikeln
relevante Hörerbezug vorhanden, da der Sprecher einen derartigen 'Kommentar' ja
immer mit elner ganz bestimmten Absicht äußert. Diese Absicht besteht darin, den
Gesprăchspartner zu einer bestimmten Reaktion zu bewegen, etwa zur Zustimmung
oder zu oder zu einer Anderung seiner Annahmen.

Direkt im Bereich des Partnerbezugs liegt als zweite Gruppe das Merkmalpaar 〈KORREKTUR〉/〈ZUSPRUCH〉: Das Merkmal 〈KORREKTUR〉 ist als ein Hinweis zu sehen, daß bestehende Erwartungen oder Annahmen geändert werden bzw. werden sollen. Im Falle der Modalpartikeln handelt es sich dabei um eine 'Korrekturan"relsung' an den Hörer. (Sprachliche Mittel, um eine Eigenkorrektur auszudrücken, sind vor allem im Bereich der Gliederungspartikeln zu finden.) Das Merkmal 〈ZUSPRUCH〉 dagegen weist den Gesprächspartner an, seine Annahmen oder Erwartungen weiter gelten zu lassen.

Elne dritte Gruppe

den Außerun von Merkmalen zur Modalpartikel-Beschreibung bezieht sich auf mit auch ungsakt selbst: er wird vom Sprecher verstärkt oder abgeschwächt (woals Einsche Relevanzzuschreibung erfolgt) oder eingeschränkt (hier zu verstehen In der viertenkung einer der Bedingungen für einen bestimmten sprechakt).

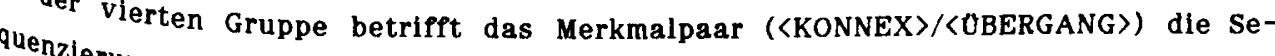
gangeneng, also den Bezug einer Außerung zu elner anderen und zwar vorange'elnfachen' Außerung. ${ }^{15}$ Neben dem Merkmal 〈KONNEX〉, das das Herstellen einer Elgenschaft (thematischen) Verbindung beschreibt, gibt es auch Merkmale, die die zur Vorgăn bestimmter Modalpartikeln beschreiben, eine 'quallfizierte' Beziehung tet wird.

Um es noch einmal zu betonen: die Merkmale sind als ein (verkürzendes) Beschreiein Merkmal Gebrauch der mit Bezug auf die propositionale Ebene ist, so heißt das: Durch den bekannt ist. Dle vortelle

Beschreibute einer Analyse mit Merkmalen liegen auf der Hand: zum einen wird die tersuchung ökonomischer, deutlicher und präziser, ein Vortell, der bel der Unung von Modalpartikel-Kombinationen von unschätzbarem Wert ist.

14) Der von vezug zur Nachfolgeăußerung (Francks "Vorwärtskonnex") ist natürlich

15) (Franck anderem Status als der zum Vorgänger: Er geht "ins Ungewisse" Dies ist 1980:65). der Vort insofern eine nicht völlig korrekte Redeweise, als in vielen Fällen Orgängerzug auch eine nicht-sprachliche Handlung sein kann. 
Zum anderen sind die Ergebnisse auch in der Fremdsprachendidaktik leichter ver" wertbar.

Ziel der Bedeutungsanalyse ist es also, die (zentrale) Bedeutung jeder Modalps: tikel mit Hilfe eines sparsamen, einfachen Inventars von Merkmalen ${ }^{16}$ zu be schreiben. Dabei wird versucht, neben den 'Standardverwendungen' einer Modalpar' tikel möglichst alle Verwendungsweisen $\mathrm{zu}$ beschreiben. Letzteres kann allerdings Im Rahmen dieser Untersuchung nicht immer geleistet werden. ${ }^{17}$ Darin ist abef keinesfalls ein Nachteil zu sehen. Die Analyse einer größeren Anzahl von Elementen, in diesem Fall der Modalpartikeln, muß ja keineswegs zu einer ungenaueren Beschreibung der einzelnen Partikeln führen - gerade auch im Vergleich lassen sich wichtige Erkenntnisse gewinnen.

Die Beschrelbung des Zusammenhangs der Modalpartikel-Bedeutung mit der des anderen Funktion(en) der Partikel, also das Aufzeigen der 'übergreifenden Bedel' tung' (nach Weydt/Hentschel 1983), kann in dieser Analyse nicht konsequent ver Polgt werden; eine gemeinsame Grundbedeutung wird nur dann angegeben, wenn si augenfallig ist. Dle Angabe elner Grundbedeutung ist m.E. auch nicht immer mög lich oder sinnvoll.18

\subsection{Einzelanalysen}

Bel den nun folgenden Elnzelanalysen steht die Bedeutungsbeschreibung der $10^{\circ}$ dalpartikeln im Vordergrund. ${ }^{19}$ Auf Abgrenzungsprobleme wird nur noch in spezletlen Fallen eingegangen (besonders bel schon und einfach). ${ }^{20}$

Die Analyse Jeder Modalpartikel ist unterglledert nach den Satzmodi, in denen sil auftritt. Gewisse Wiederholungen lassen sich hier insofern nicht vermeiden, als js nachgewlesen werden soll, daß ein Merkmal beim Vorkommen einer Modalpartikel in

16) Dle hier angenommenen Merkmale beziehen sich auf relativ grundlegende Kon' zepte des Dialogs, die weit verbreitet sind (es lleße sich darüber spekulierent. ob nicht einige dieser Konzepte universal sind).

17) Verwiesen sei hierzu auch auf die zahlreichen Monographien zu einzeln en $^{\text {n }}$ Partikeln: z.B. Asbach-Schnitker 1975 (zu aber), Bastert 1985 (zu doch), Bors 1985 (zu doch, $j a$ und schon), Gornik-Gerhardt 1981 (zu schon) oder Hentschel 1986 (zu ja, doch, eben und halt).

18) Vgl. dazu z.B. den m.E. mißglückten Versuch von Hentschel (1986:171), fuf

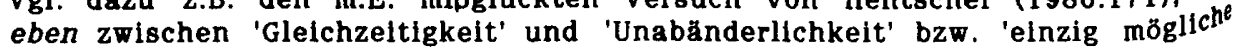
Konsequenz' eine gemeinsame Bedeutung herzustellen.

19) Bel den Bedeutungsanalysen werden tellweise Beschreibungen aus der vorlie genden Literatur abernommen. Auf eine ausfahrilche Diskussion der For schungsliteratur muß in diesem Rahmen allerdings verzichtet werden.

20) Zur Abgrenzung der Modalpartikel-Funktion von der Gradpartikel-Funktion (relevant u.a. bel blok, nur und auch) vgl. Altmann (1976) und (1978). 
allen Satzmodi 'greift'. (Wie schon erwähnt, gehe ich hier allerdings im wesentlichen nur mehr aup die 'Grundtypen' (vgl. 1.3.1) ein.)

Dabel wird die Bedeutung jeder Modalpartikel nach Möglichkeit auch durch die Analyse von Beispielen authentisch gesprochener Sprache (vor allem aus dem KorPus von Brons-Albert) dargestellt.

Zur Oberprüfung der Bedeutungshypothesen wurden daneben verschiedene Verfahren angewendet, die jedoch nicht in jedem Fall im einzelnen aufgefuhrt werden: 2.B. der Vergleich elner Außerung mit Modalpartikel mit einer ohne, der Vergleich 2Deier Außerungen mit verschiedenen Modalpartikeln, Veränderung des Kontextes und Einsetzen einer Modalpartikel in konterdeterminierende Kontexte. In diesem spezlellen Fall, wenn also eine These durch Gegenüberstellungen untermauert werden sollte, mußten Beispiele (meist abweichende Beispiele) konstruiert werden.

Eine weitere Verifizierung der für die besprochenen Modalpartikeln angenommenen Bedeutungen stellt dann die Untersuchung des Kombinationsverhaltens (Kapitel 3) dar.

Dle Reihenfolge der analysierten Partikeln richtet sich danach, in welchen Satzmodi die Partikel prototypisch auftritt (begonnen wird mit den 'Aussagesatz-typi(chen'), und ist auch davon bestimmt, daß ăhnliche Partikeln möglichst nacheinander besprochen werden (z.B. eben und halt, denn und etwa), um die Gemeinsamkeiten und Unterschiede deutlicher zu machen; letztes Kriterium für die Reihenfolge der analysierten Partikeln ist die Frequenz.

2.2.1 Ja

Neben seiner Verwendung als Modalpartikel fungiert ja vor allem als GliederungsDartikel ( $\mathrm{ggl}$. 1.1.7). Die Modalpartikel tritt in zwel Varianten auf: unbetont in Aussagesătzen (als häufigste Modalpartikel; nach Hentschel 1986:246ff.) und immer

betont in Imperativsätzen (im folgenden $J A$ ).

schiedlihme zweler verschiedener Partikelvorkommen läßt sich mit der unter$b_{O B}$ (die ebenfalls akzentulerte Modalpartikel verwendet im Unterschied $\mathrm{zu} J A$ bei gleicher Bedeutung auch nicht-akzentuiert (mehr werden) und mit dem stellungsverhalten in Kombinationen begründen (1) Er hat ja auch immer seine Aufgaben gemacht. Mach auch JA deine Aufgaben! 


\subsubsection{1 (Unbetontes) ja}

In der Verwendung von ja im AUSSAGESATZ lassen sich zwei Arten unterscheiden: die 'einfachen' Aussagen und diejenigen, die hier 'emphatische Aussagen' genan n' $^{\prime}$ werden. Letztere werden häufig den Ausrufen zugeordnet (z.B. Bublitz 1978:94) Zunächst einige Beispiele für ja in den einfachen Aussagen:

(2) Olga: und siehmal, im Auto hasde wenigstens freie Sicht, da hasde ja'n Scheibenwischer. (BA, 137)

(3) Das wundert mich nicht, daß der Paul immer solche Kopfschmerzen hat. De' raucht ja elne Zigarette nach der anderen.

(4) Kollegstufe hatten wir nicht; das gabs ja damals noch gar nicht.

(5) Ein Reporter spricht über Mutterschaftsbezüge:"..und dann wurde noch einl andere Lösung vorgeschlagen, natürlich ohne die Bezüge zu erhöhen, denn der Staat muß ja sparen."

(6) 1931 war Hitler ja noch nicht an der Macht.

Uber die Bedeutung von $j a$ in Aussagesätzen herrscht weitgehend Einigkeft $\left(v b^{\prime}\right.$ z.B. Weydt 1969:36ff., Bublitz 1978:97, Franck 1980:232): Mit ja zeigt der Sprecht' an, daß die Proposition nach seiner Meinung auch dem Hörer bekannt ist. Für soll deshalb das Merkmal 〈BEKANNT> stehen. Vgl. dazu folgendes Beispiel:

(7) Eine bekannte Schauspielerin kommt zur Lehrerin ihres Sohnes in die Sprechstunde. Die Kollegen, die das beobachtet haben, sagen später zu def Lehrerin: Sie haben heute ja hohen Besuch gehabt."

Da die Kollegen wissen, daß es "hoher Besuch" war und annehmen, da $\beta$ es $8^{4}$ die Lehrerin weiß, verwenden sie ja. Kann bei der Angesprochenen dieses Wis nicht vermutet werden, würde die Außerung der Kollegen wie (7a) lauten:

(7a) Sie haben heute hohen Besuch gehabt. (Wissen Sie das?)

Da der Sprecher dem Hörer eine diesem bekannte Information mitteilt, verletzt eine Konversationsmaxime, und zwar die Grice'sche Maxime der Quantität (ngd Grice 1975:45). Durch den Gebrauch von ja signalisiert der Sprecher aber ault gleichzeitig, daß er bewußt Bekanntes äußert.

Wenn $j a$ als Verweis auf ein vom Sprecher angenommenes Hörerwissen fehlt, die Proposition als neue Information interpretiert werden. Man stelle sich die $\mathrm{Be}^{\mathrm{i}^{\prime}}$ spiele $(2)-(6)$ ohne ja vor. Kommt dies in einer Situation vor, wo dem Hörer die $e^{s^{4}}$ Nichtwissen fälschlich unterstellt wird, kann er diese Annahme zurückweisen (vb) Bublitz 1978:97):

(6a) Vater: 1931 war Hitler noch nicht an der Macht.

Sohn: Jaja, das weiß ich auch; aber er hatte doch einigen Einfluß.

(3a) ...Paul raucht eine Zigarette nach der anderen.

Außert ein Sprecher (3a) auf einem Fest, wo sowohl der Hörer als auch Paul $80^{\circ}$ wesend sind, so ist die Information als nicht bekannt gekennzeichnet, und 
Hörer, dem damit unterstellt wird, er habe Pauls Verhalten nicht bemerkt, kann daraup z.B. mit einem Satz wie (3a)' reagieren. Dagegen wäre (3a) angemessen, wenn nur der Sprecher auf diesem Fest war und dem daheimgebliebenen Hörer seine Beobachtungen mitteilt.

(3a)' Ja, das ist mir auch schon aufgefallen.

borückweisen eines dem Hörer unterstellten Nichtwissens, das meist mit einem Insofern verbunden ist, kann eben durch den Gebrauch von ja verhindert werden. der Hörenn ein Sprecher auch ja einsetzen, wenn er sich nicht sicher ist, ob die Information schon hat.

Aus dem von ja geleisteten Verweis auf Bekanntes läßt sich auch die Gültigkeit der Proposition ableiten. ${ }^{21}$ Mit der Partikel ja wird zwar - wie unter anderem auch mit doch und eben - die Proposition gekennzeichnet, die Partikeln beziehen sich also auf die propositionale Ebene, sind aber dennoch selbst nicht propositional: sie verändern - im Unterschied zu Satzadverbien wie vermutlich - den Wahrheitswert einer Außerung nicht.22 Die illokutive Modifikation durch die Modalpartikel $j_{a}$ ist in einer (mit dem Verweis auf die Bekanntheit der Proposition begründeten) Bestätigung der Aussage zu sehen; das zeigt sich z.B. bei Behauptungen daran, daß diese nicht weiter begründet oder bewiesen werden müssen (vgl. Franck 1980:232). Insofern kann der Einsatz von ja auch Bestätigung und Bekräftigung bewirken. Diese bestätigende Funktion hat ja auch als Gliederungspartikel.

Aupgrund

Verlaup seiner Bedeutung erfüllt ja eine wichtige Funktion für den Gesprächsgen, Wissenn Kommunikation setzt eine gemeinsame Basis in bezug auf ErwartunDurch dien oder Oberzeugungen zwischen den beiden Gesprächspartnern voraus. lotwendigen von ja kann sich der Sprecher der für den Gesprächsverlauf bekannt ist, Gemeinsamkeiten versichern; er nimmt zwar an, daß der Sachverhalt Begenofi, erwähnt ihn aber explizit, um sicherzugehen, daß er auch dem Hörer artig ist, da er oft von Bedeutung für den weiteren Gesprächsverlauf ist. ${ }^{23}$

21) Dagegen

daß gen nimmt Hentschel (1986: bes.163) zunächst als Bedeutung von ja an,

2ie Beken Sachverhalt als "richtig oder zutreffend" kennzeichnet und sieht

Der

(propugegebenermaßen nicht ganz einfach zu fassende) Unterschied zu dem Aussitionalen) Satzadverb bekanntlich, durch das $j a$ in manchen 'einfachen' l56ff) ersetzt werden kann (vgl. dazu genauer Bublitz/Roncador 1975: aup der liegt darin, daß die (illokutive) Modalpartikel ja ein 'Metakommentar' terakt Intentionsebene (nach Weydt 1969:62f.) ist und wesentlich stärker insind (*abezogen ist. Das zeigt sich u.a. daran, daß Rückfragen nicht möglich bekanntlis heißt hier 'ja'? vs. Was heißt hier 'bekanntlich'?) und daß die mit

23) Bprachslich behauptete (!) Bekanntheit wesentlich leichter vom $\mathrm{Ge}-$ Auf diese

Funktion Weise läßt sich auch die von Lindner (1983:181) angenommene tion von ja, nämlich einen Ausschnitt "in den Vordergrund, ins Bewußt- 
Durch diesen Verweis aup das gemeinsame Wissen aktualisiert ja den Bezug ${ }^{4}$ Gesprächspartner (vgl. Franck 1980:233).

Das Markieren einer Proposition als bekannt kann auch den Zweck haben, die ent sprechende Information beim Hörer zwar zu aktivieren, sie aber im Hintergrund belassen; durch ja wird dann dem Hörer bedeutet, dem dargestellten Sachverhalt eben weil er bekannt ist - nicht die volle Aufmerksamkeit zu widmen; vgl.:

(8) Ins: und . öm...an . Iris Kolb kanns de dich doch auch noch erinnern, ne?

Ute: Ja, so ne Kleine, ne?

Ins: Mhm. Die hat ja nach Frankreich geheiratet.

Ute: Ja? Toll!

Ina: Ja, wußtest du das nich?

Ute: Nee.

Ina: Die hat doch, ich weiß nich, ich glaub, ein Jahr später, oder sowat., hat die geheiratet, die hat auch ihr Studium überhaupt nich zuende gemacht. soweit ich das weiß.

Ute: Ah so . $h m$.

Ina: Und die, öh, is jetz für ein Jahr oder sowat nach Indien gefahren, dil machen da so ne Weltreise. (BA, 183)

Ina hat ihre Information ('die hat nach Frankreich geheiratet') durch ja als be' kannt markiert. Wie der weitere Gesprächsverlaup zeigt, war das eigentlich Neth was sie erzählen wollte, und woraup Ute ihre Aufmerksamkeit konzentrieren sollt die Information über die Weltreise. Da Utes Reaktion auf Inas als bekannt $m^{2 f^{\prime}}$ kierten Inhalt der Außerung aber zeigt, daß Ute diese Information nicht hatte, er $^{\text {r }}$ läutert Ina diese zunächst näher.

Mit ja kann der Sprecher also dem Hörer auch ein wissen unterstellen, das dife $e^{e^{l}}$ gar nicht hat oder haben kann; der Hörer kann dann diese Unterstellung imply oder explizit zurückweisen; vgl. oben (8): Utes Reaktion Ja? Toll! ist als diesbezüglicher Hinweis zu verstehen, den Ina auch richtig interpretiert (wupto du das nich?).

Je nachdem, was der Sprecher damit erreichen will, wenn er dem Hörer bewußt bestimmtes Wissen unterstellt, muß der Gebrauch von $j a$ in diesen Fällen unter schiedlich bewertet werden: Natürlich kann ja - durch die Aktualisierung des ${ }^{B}$ zugs zum Gesprächspartner - die von Hentschel (1986:159) hervorgehobell freundliche, Vertraulichkelt und Nähe signallsierende wirkung haben; es kann auch perflde (im Sinne Reiters 1980) gebraucht werden; letzteres ist m.E. vor ${ }^{l^{\prime}}$ lem auch für bestimmte der noch zu besprechenden emphatischen Aussagen fe $\mathrm{s}^{\mathrm{t} z \mathrm{u}^{\prime}}$ stellen. Was aber letztlich durch den Gebrauch von ja, wenn es ein wissen unterstellt, zusätzlich bewirkt wird, ist vom Kontext abhängig und kann nicht Bedeutung von $j a$ zugeschrieben werden.

sein des Adressaten" zu bringen, erklären: durch den Gebrauch von ja "G $\ell^{\prime}$ ein bestimmtes Wissen beim Hörer aktiviert und als für den momentanen ${ }^{n} e^{t}$ sprächsstand relevant - allerdings nicht unbedingt zentral - gekennzeichn 
Die zweite Verwendungsweise ist das Vorkommen von ja in den emphatischen Aussagen. Dlese Außerungen können zwar als Ausrufe bezeichnet werden, sind aber keine Exklamativsätze im oben definierten Sinne (s. S.45): Ein Wechsel in der Verbstellung (zwischen Anfangs- und Zweitstellung) ist nicht möglich, ein Exklamativakzent liegt nicht vor, und auch die sprechereinstellung ist eine andere: In emphatischen Aussagen mit ja drückt der Sprecher ein Staunen darüber aus, daß eln Sachverhalt zutrifft und nicht - wie bei den Exklamativsätzen mit aber und Vlelleicht - über einen bestimmten Grad oder ein Maß, in dem ein Sachverhalt der Pall ist.24

(9)

(10) Mensch, der kann ja singen! (Hätt ich dem gar nicht zugetraut.)

Auch in Kind kommt vom Spielen heim. Die Mutter: "Du blutest ja!"

den: der diesen Außerungen kann für ja das Merkmal 〈BEKANNT> angesetzt werist, bprecher nimmt an, daß für den Gesprächspartner die Information bekannt Diese Bekannthicht an, daß sie für ihn neu ist (vgl. Hartmann 1977:108).

cher eine emphati Aussage über seinen Gesprächspartner macht (wie in (10)). In anderen Anlaßshen Außerungen sind in jedem Fall alle Elemente der Situation, die der lich und die Außerung des Sprechers sind, gleichermaßen auch dem Hörer zugängErstaunen damit bekannt, so daß auch der Sachverhalt, über den der Sprecher sein kann.20 kundgibt, vom Hörer schon wahrgenommen und ihm somit bekannt sein Beobachtung der Sprecher nun nicht wissen kann, ob der Hörer die gleiche markieren, gemacht hat wie er, wird er seine Außerung eher mit ja als bekannt gen sich der Hörer dann wehren kann wie in (11)):

24) $\mathrm{E}$ rechnderer Typ von ja-Außerungen, der ebenfalls häufig den Ausrufen zugeHier wird (vgl. Franck 1980:230), gehört m.E. zu den 'einfachen' Aussagen. bestehi dert dprecher nämlich kein Staunen darüber, daß ein Sachverhalt Sachu, sondern eine emotional gefärbte Bewertung zu einem vorangegangenen

(i) verhalt (der seinerseits durchaus erstaunlich sein kann); vgl.:

Anna: Wir ham nach fünfeinhalb Jahren noch keins [Kind].

Lisa: Mensch, ist das schon solange her?

Anna: Ja!

Hier hat Poh! Is ja Wahnsinn! (BA, 41)

sowohl ja vor allem die Funktion, durch den Verweis auf die Bekanntheit

25) des Hörer Bewertung des Sprechers zu bekräftigen als auch die Zustimmung Eline $A$ rers zu unterstellen.

Par Außerung bel der Zeitungslektüre etwa (wo Information ja zunächst nur Kandidan Gesprächsteilnehmer verfügbar ist) wie: Die CSU hat ja für den werden. der Grünen gestimmt! würde deshalb in dieser Form nur gemacht schon, wenn dem Hörer die Information bereits zugänglich war, er also z.B. Zeitung gelesen hat. 
Beim Radiohören im Auto:

Sie: Du, das ist "Sympathy for the Devil"!

Er: Ja, das hab ich doch schon nach den ersten zwei Schlägen erkannt.

Mit ja in ihrer Außerung würde die Sprecherin ihrem Gesprächspartner dagefel zugestehen, da $\beta$ er dieselbe Beobachtung bereits gemacht hat.

I) $a$ ja auch in den emphatischen Aussagen Bekanntheit für den Hörer signalisier zeigt sich weiter daran, daß es in Erzählungen, die dem Gesprächspartner nevi $^{\mathbb{k}^{*}}$ Information vermitteln, nicht eingesetzt werden kann:

Ich hab neulich die Inge getroffen! ?'Die hat ja ihre Diss jetzt fertig! Was den Sprecher betrifft, so signalisieren die emphatischen Außerungen mit meist die plötzliche Kenntnisnahme eines bereits bestehenden Sachverhalts (vt Hartmann 1977:108).

Aufgrund seiner Bedeutung wird $j a$ oft auch in emphatischen Aussagen verwendel Aufgrund seiner Bedeutung wird ja oft auch in emphatischen Aussagen verwent
die eine Feststellung über den Gesprächspartner zum Inhalt haben; vgl. oben
und:

(13) Du hast ja grüne Augen!

(14) Nelli: Feiert ihr vor Silvester noch ma?

Bea: Ja!

Nelli: Ach, du has ja Geburtstag! (BA, 68)

In diesen Fällen ist ja nahezu unerläßlich, denn eine einfache Feststellung sich sonst kaum über eine anwesende Person machen; die Aussage wäre trivial: (13a) ?"Du hast grüne Augen. (als Feststellung gesprochen)

In negativ konnotierten Außerungen wie (15), die sich an einen anwesenden tort richten, ist der Gebrauch von ja als einigermaßen perfide zu bezeichnen: dem ${ }^{\text {to }}$ rer wird nämlich unterstellt, inm selbst sei der Inhalt der Außerung auch bek an $^{\text {nol }}$ (15) Du spinnst ja.

Auch in den oben in Kapitel 1.3.4 angeführten Verwendungsweisen von $j a$ in

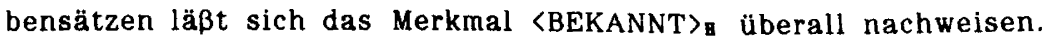

Ja, aber der will so viel absetzen, weil der ja als freier Mitarbeiter. $b^{e^{f}}$ beitet hat und noch gar nichts bezahlt hat an Steuern. (BA, 123)

In Beispiel (16) markiert die Sprecherin durch $j a$ den dargestellten Sachverhalt auch für ihre Gesprächspartnerin bekannt.

Die bel verschiedenen Autoren angeführten Einschränkungen in der verwent von $j a^{26}$ gelten für alle Modalpartikeln und haben nichts mit der speziellen ful tion von $j a$ zu tun. Lediglich die Restriktionen von ja in Nebensätzen $\mathrm{na}^{\mathrm{ch}}$ stimmten Verba dicendi lassen sich auf die Bedeutung der Modalpartikel jo

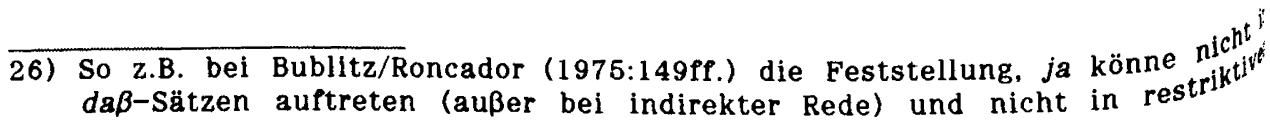
Relativsätzen. 
rückführen: ja kann nicht nach Verben auftreten, die neue Information einführen, we ankündigen (vgl. (17)) oder Verben, die ein Bestreiten ausdrücken, wie leugnen ( $\mathrm{vgl}$. (18)), da ein Sachverhalt, der bestritten wird, nicht gleichzeitig als bekannt markiert werden kann (vgl. dazu genauer Hartmann 1976:116ff.):

(18) "Er leugnete, $d a \beta$ er die Zeugin ja unter Druck gesetzt habe.

erklar Tatsache, daß ja eine Proposition als bekannt markiert, läßt sich auch lären, warum diese Partikel nicht in Fragen auftreten kann.

2.2.1.2 (Betontes) $J A$

(19) akzentuierte Variante $J A$ tritt in der Regel in IMPERATIVSATZEN auf: Ein Gast wird aus einem Lokal geworfen:

(20) Ulassen Sie sich hier JA nicht mehr blicken!

Mutter zur Tochter:

$J_{A}$ dient homm nicht zu spät heim!

des Sprecherwilleiner Verstärkung des illokutiven Akts, genauer: der Verstärkung werden. JA kann so zu einer Warnung oder Drohung die in diesen wird deshalb mit dem Merkmal 〈VERSTARKUNG〉 beschrieben, genau wie Die Hervorhen Verwendungen bedeutungsgleiche Modalpartikel bloß (s.u. S.182f.)

Banz unbedingung und Verstärkung des Sprecherwillens ( $J A$ im Sinne von 'ich will Vorkommen von seltener von $J A$ in Aussagesätzen (in Verbindung mit den Modalverben dürfen, nachweisen. In oder sollen ${ }^{27}$ ), die immer eine bestimmte Verpflichtung ausdrücken, der Wille In finalen Nebensätzen und in Relativsätzen (vgl. oben 1.3.6) wird hoben. (21)

(22) Ich darf JA meine Autoschlüssel nicht vergessen!

(23) Sie beeilte sich maßlos, um nur JA nicht zu spät zu kommen.

Der Zusammenhand die JA nichts verpassen wollten, linsten durchs Schlüsselloch ist damit $z u$ mit der unbetonten Variante ja mit dem Merkmal 〈BEKANNT> Bekräftigung der durch $J_{A}$ der eigenen Außerung bewirkt; und aus dieser Bekräftigung ist die angezeigte Verstärkung abzuleiten.

27) Hier zelgt

tlonen sich, daß die sprachlichen Mittel, die als Modifikatoren von Illoku-

toren sind ken können, hierarchisch geordnet sind: Modalverben als Modifika- 


\subsubsection{Doch}

Die Partikel doch läßt sich in fünf verschiedenen Funktionen nachweisen: nebl der Modalpartikel-Funktion zunächst als Konjunktion und als Konjunktionaladvert (s.o. S.13f.). Mit der Gliederungspartikel doch wird aup eine negierte Außerun reagiert; sie dient dazu, die Negation zurückzuweisen und die gegenteilige Propo ${ }^{\circ}$ sition zu behaupten. Häufig steht doch nach einer negierten Entscheidungsfrage und wird deshalb - zusammen mit $j a$ und nein - auch oft als Antwortpartikel be zeichnet.

Schließlich kommt doch satzintegriert und immer akzentuiert vor. Auch in dieset Verwendung kann doch der Zurückweisung einer vorangegangenen Negation dienen (Und die Bibel hat DOCH recht!). Diese kann auch nur impliziert sein (und ist ef $^{\text {f }}$ nach meinen Beobachtungen auch meist). In dieser Funktion ähnelt doch del (ebenfalls akzentuierten) wohl (s.u. S.139) und schon (s.u. S.146). Man könnt diese Gruppe als Affirmationsadverbien ${ }^{28}$ bezeichnen.29 Neben der Funktion un dem damit verbundenen obligatorischen Kontrastakzent ist den Elementen diesel Gruppe noch gemeinsam, daß sie in der Regel im Mittelfeld eines Satzes auftreten (Doch unterscheidet sich allerdings von schon und wohl nicht nur dadurch, $\mathrm{da} \beta^{e^{5}}$ vor allem implizite Negationen zurückweist, sondern auch dadurch, daß es auch

28) Dem Unterschied $z$ wischen den drei Partikeln in der Funktion als 'Affirms' tionsadverb' ist noch nachzugehen. Ein Unterschied liegt sicher darin, da $\beta$ m satzintegriertem doch selten auf einen expliziten negierten Vorgänger reagiert wird (in diesem Fall ist schon üblicher); vgl.:

A: Sie geht nicht.

B: Doch./ Sie geht DOCH./ Sie geht SCHON.

Auch drückt schon (wie auch das relativ seltene wohl) m.E. einen deutliché ren Widerspruch aus. Eine (spekulative) Erklärung: mit schon wird der negier te Vorgänger negiert (vgl. sie kommt nicht nicht $=$ sie kommt schon), währen mit doch die vorangegangene Negation (bzw. der Widerspruch) aufgehoben wir und $\mathrm{zu}$ einer davorlfegenden (nicht-negierten) Behauptung zurückgegangel

29) Weydt et al. (1983:162) bezeichnen diese Variante von doch (unzutreffend) gls Abtönungspartikel; auch die in Weydt (1986:401) für betontes doch, woll denn und eigentlich aupgestellte These, durch den Akzent würde das durch die Partikel gegebene Metaurtell (damit bleibt die Partikel offensichtlich $A^{b^{\prime}}$ tönungspartikel) in das Zentrum gerückt und als das Wesentliche des Satzes bezeichnet, ist m.E. inadäquat. Tatsächlich trägt doch (wie auch wohl un schon in vergleichbaren Verwendungen) einen Kontrastakzent, ist also Rhemb. der Rest des Satzes Thema. Es ist aber m.E. prinzipiell ausgeschlossen, als "Metakommentare" (Weydt 1986:401) Pungierende Ausdrücke (wie es Modal" partikeln sind) kontrastiert werden können, und dabei Metakommentar 2 einer Proposition bleiben. Die angeführten Verwendungen mit Kontrastakzen können also nicht Modalpartikel-Funktion haben. (Daß es für doch $\mathrm{e}^{\mathrm{in}}$ gemeinsame Bedeutungskomponente dieser und der Modalpartikel-Funktion wie auch der anderen Funktionen - gibt, steht dem nicht entgegen.) 
auf Widerspruch in affirmativer Form reagieren kann; deshalb kann doch nämlich auch mit einem Negationsträger auftreten: Sie macht das Fest jetzt doch nicht. Insofern ist gerade für doch der Begriff 'Affirmationsadverb' nicht ganz treffend.) Eventuell ist auch betontes denn (s. S.163) zu den Affirmationsadverbien zu rechnen, das sich von den anderen aber dadurch unterscheidet, daß es nicht in Aussagesätzen, sondern nur in w-Fragesätzen auftritt.

Die Modalpartikel doch ist die neben ja am häufigsten verwendete Partikel. Sie kann in Aussagesätzen, Imperativsätzen, Wunschsätzen, w-Exklamativsätzen und in bestimmten w-Fragesätzen auftreten.

Zum Auptreten von doch in AUSSAGESATZEN:

(1)

Heinz: Hast du mal deinen Pullover ausgezogen und den . im Schwimmbad meinetwegen abgegeben oder in der/

(2) Anna: Nee, ich war doch seit Jahren nicht mehr schwimmen. (BA, 4)

Lisa: Ich glaub, ich muß gleich auch mal losziehen, und mir Tampons holen, ich hab nämlich nur noch ein par!

Anna: Ja, hoffenlich findesde en offenes Geschäft. Es macht doch alles

(3) Inventur. (BA, 48)

Pflicht. (Si, 308)

Was regen sie sich denn so auf, Sonderführer? Ich tue doch nur meine

(4)

Hans: Ich wollt mich für die Hefte bedanken!

Doris: Ach!

Hans: Sin vorgestern angekommen!

Doch Doris: Is doch nich nötig! (BA, 110)

zeigt eine gewisse Ahnlichkeit mit ja, insofern der Sprecher mit doch eben-

taluf etwas auch dem Hörer Bekanntes verweist. Für doch soll deshalb eben-

alls das Merkmal <BEKANNT> angenommen werden. ${ }^{30}$ Dabei kann es sich um

einen nur den beiden Gesprächspartner bekannten Sachverhalt handeln (vgl. dage-

Ben unzutreffend Rath 1975:236); häufig wird aber auch auf allgemein bekanntes

Wissen verwiesen:

(5)

Ich weiß nlcht, ob ich einfach ohne Einladung auf diesen Empfang gehen

soll. Das macht man doch nicht.

(6)

Und in den fünfziger Jahren, da hatte ich Kleidergröße 36. Damals war doch

Worin

die schlechte Zeit. Da gabs doch nichts.

(6) aber unterscheidet sich doch von ja? Vgl.:

(6a) Damals war doch die schlechte Zeit. Da gabs doch nichts.

Damals war ja dle schlechte Zeit. Da gabs ja nichts.

30)

Doherty (1982:174) vertritt dagegen die Ansicht, nicht wegen des sprachlichen Mittels doch werden Außerungen als bekannt verstanden, sondern "einzig und allein wegen unserer allgemeinen Erfahrung, nach der [die] Sachverhalte (...) dem Angesprochenen im Normalfall schon bekannt sind." Natürlich sind die Mitterhaite als solche im Normalfall schon bekannt, aber doch und ja sind Mittel, diese Bekanntheit zu markieren; zusätzlich können mit ihnen auch Sachverhalte als bekannt gekennzeichnet werden, die es nicht sind. 
Das vom Sprecher beim Hörer angenommene Wissen wird durch den Gebrauch voł doch weniger assertiert, sondern der Hörer wird angewiesen, dieses Wissen $z u^{b e^{\prime}}$ rücksichtigen. ${ }^{31}$ Meistens geht nämlich der doch-Außerung eine sprachliche def nicht-sprachliche Handlung des Gesprächspartners voraus, aus der der sprechef schließen muß, daß dieses Wissen beim Partner im Moment nicht präsent ist odé von ihm nicht berücksichtigt wird. Diese 'Gegen-Indizien' sind in (1) z.B. dir Frage, die einen nicht zutreffenden Sachverhalt präsupponiert, in (2) die geplan Handlung der Gesprächspartnerin und in (3) ist es ein bestimmtes Verhalten, ds der Sprecher noch einmal explizit thematisiert.

Aufgrund der vorliegenden Gegen-Indizien sind doch-Außerungen häufig th widerspruchsanzeigenden Ausdrücken (wie aber, nein, Quatsch etc.) eingeleitet:

(7) Asterix hat Geld in der Hand: Riech mal!

Obelix: Riechen? Aber Geld riecht doch nicht! (A XIII, 44)

(8) Quatsch, Verlobter! Ich habe doch überhaupt keinen Verlobten! (Si, 23) Der Sprecher zeigt also durch doch neben dem Verweis auf Bekanntes auch daß der Gesprächspartner seine bisherigen Annahmen und Erwartungen oder sel $^{\text {il }}$ bisheriges Verhalten korrigieren soll und zwar aufgrund des ihm eigentlich be kannten Wissens. Doch trägt deshalb (neben 〈BEKANNT> z) zusätzlich noch ds Merkmal 〈KORREKTUR〉. 32

Dadurch, daß mit doch auf auch dem Hörer bekanntes Wissen verwiesen und so $^{\text {il }}$ Konsens hergestellt oder aufrechterhalten wird, weisen derartige Außerungen $\mathbf{s t s}^{\mathbf{8} 5^{\prime}}$ ken Partnerbezug auf, die Position des Gesprächspartners wird berücksichtigt auch wenn er korrigiert wird. Die Proposition einer doch-Außerung wird als $g^{\text {tith }^{\text {th }}}$ gesehen, der Sprecher setzt Zustimmung voraus. Die Tatsache, daß der Spreth den Hörer korrigiert, erklärt, warum doch-Außerungen häufig mit gewissem $\mathrm{Na}^{\mathrm{Cl}^{\prime}}$ druck geäußert werden (vgl. auch die Zeichensetzung in den Beispielen (4), ( (8)). Insofern können doch-Außerungen (aber nur in Verbindung mit einer be stimmten Intonation) auch hervorgehoben sein; vgl. dagegen Rath (1975:237), Hervorhebung als eine Funktion von doch ansieht.

Je nach Inhalt der Außerung, Kontext und Beziehung der Gesprächspartner 2 ue $^{\text {in }^{\prime \prime}}$ ander können doch-Außerungen - da sie ein irgendwie geartetes Fehlverhalt des Gesprächspartners korrigieren - einen Vorwurf implizieren ( $\mathrm{gl}$. (10)), $\mathrm{kr}^{\mathrm{r}} \mathrm{i}^{\mathrm{l}}$ an der vorausgegangenen Außerung oder Handlung ausdrücken (wie oben (3)) 31) Ahnlich Hartmann 1976:121; vgl. auch Lütten (1979:36), die hier von ein
"appellativen Rekurs" spricht.

32) Hier ist auch der Zusammenhang zwischen Modalpartikel, Gliederungs $\mathrm{p}^{2 \mathrm{r}^{\mathrm{t}}} \mathrm{j}^{\mathrm{j}}$ und Affirmationsadverb $\mathrm{zu}$ sehen. Die von Hentschel (1986:148) ange Bedeutungbeschreibung: "Doch drückt einen Widerspruch zwischen zwei Bezlo punkten aus" scheint mir etwas zu stark. 
diese dann gegebenenfalls vage negativ bewerten (vgl. Franck 1980:178) oder auch

(9) nachsichtig belehren (vgl. (9)).

Mutter: Du, das geht doch nicht, du kannst doch nicht Sahne zu deinen

(10) Pommes bestellen. Das paßt doch gar nicht zusammen.

Uli: Seit wann hast du denn den "Zauberberg"?

In (10) Rita: Den hast du mir doch vor zwei Jahren zum Geburtstag geschenkt.

Sachverhalt zeigt Rita durch den Gebrauch von doch an, daß der von Uli erfragte 2u einer diesem eigentlich bekannt sein müßte, und fordert ihn diesbezüglich Wurp Korrektur auf. Gleichzeitig impliziert ihre Außerung einen leichten VorArf, da Uli den Sachverhalt offensichtlich vergessen hat.

sogenannte oft angeführte Funktion von doch, an einen Sachverhalt zu erinnern, das angenomme "erinnernde doch" (vgl. z.B. Franck 1980:181ff.), läßt sich mit den hier meinsame ausgeprägte) sen wieder Merkmal 〈KORREKTUR〉 signalisiert dem Gesprächspartner, dieses Wis(11)

(12) Wir müssen doch noch irgendwo ein paar Nägel haben. Du hast doch letztes .Jahr ein Mörike-Seminar besucht. Kann ich da mal die

Vor allem doch-

sprächspartners doch-Außerungen, die an eine Handlung oder Eigenschaft des $\mathrm{Ge}^{-}$

(13) Du

(14) Du hast doch versprochen, dich um die Photos zu kümmern! Und??

Wie bei ja hast doch keine Ahnung von dem Geschäft. Also laß es lieber!

terstellt ja können natürlich mit doch ebenfalls Sachverhalte nur als bekannt unliche Wirkun Werden. Auch hier können damit im Gesprächsverlauf ganz unterschiedSo bietet

Sprecher sich doch in Erzählungen als eine Art 'Hintergrundmarkierer' an: Der $S_{a c h}$ markiert bestimmte für den Fortgang der Erzählung weniger wichtige Hörer ' kann und seing Wissen', der dadurch diese Information im Hintergrund belassen nicht mehr mit Aufmerksamkeit auf die wirklich wichtige (und dann natürlich information richten kann.

33) Hentschel

schen (These) zwei "Präsuppositionen der Außerung, nämlich zum einen 'das weißt du' also einend zum anderen 'daran denkst du im Augenblick nicht' (Antithese)", ellen einen Widerspruch zwischen der potentiellen und der (vermuteten) aktustark Erinnerung des Gesprächspartners. "Widerspruch" scheint mir hier zu zu den sein, außerdem wird der Hörer ja durch doch angewiesen, jetzt daran im Auken, der zweite Satz müßte also korrekterweise lauten "daran denkst du Merkmal nick nicht, aber denke von jetzt an daran". Hier scheint mir das (KORREKTUR〉 zutreffender. 
(15) Ruth und Lisa unterhalten sich; Lisa weiß nicht, was Ruth am Vorabend gemacht hat.

Ruth: Gestern abend war ich doch im Kino und da hab ich den Josef getroffen und weißt du, was mir der erzählt hat?...

In argumentativen Sequenzen dagegen kann die Unterstellung, der Sachverhalt sel dem Gesprächspartner bekannt, ein Mittel sein, Sachverhalte als allgemein bekangl und gültig darzustellen, ohne sie zu thematisieren.

Aussagesätze mit doch weisen häufig expressive oder emotionale Färbung 24 . Derartige Außerungen werden in der Forschung meist als Ausrufe bezeichnet." M.E. gehören solche Außerungen aber (ähnlich wie die entsprechenden mit ja ( $\mathrm{v}$ ) S.107 Fn.24)) zu den Aussagen: der Sprecher drückt nämlich nicht Staunen darübet aus, daß der im doch-Satz bezeichnete Sachverhalt zutrifft; ${ }^{35}$ oft kommentiert ${ }^{e^{?}}$ eine erstaunliche Vorgängerhandlung (vgl. (17)). Die Kriterien zur Klassifizierunt bestimmter doch-Außerungen als Ausrufe sind meist vage; die Grenze zwisch Aussagen und den als Ausrufen kategorisierten Außerungen ist unscharf, da doct Aussagesätze - wie oben dargestellt - immer auch mit einem gewissen Nachdruck einer bestimmten Expressivität geäußert werden können.

Auch in diesem Typ von Aussagen läßt sich doch mit den beiden Merkmale $\langle B E K A N N T\rangle_{\text {B }}$ und 〈KORREKTUR〉 beschreiben:

Diederich, ein überzeugter Monarchist, erlebt, wie der Kaiser einem Aufstand entgegentritt.

"Ein Junger Mensch mit einem Künstlerhut ging neben Diederich, er sagte: 'Kennen wir. Napoleon in Moskau, wie er sich solo unter die Bevölkerung mischt.' 'Das ist doch großartig!' behauptete Diederich, und die Stimme versagte ihm." (Ma, 45)

Diederich geht davon aus, daß das Handeln des Kaisers großartig ist und daß jedet dies weiß bzw. wissen und erkennen sollte. Die abfällige Bemerkung des jungel Mannes bildet einen Gegensatz zu Diederichs Annahmen; durch den Gebrauch vol doch fordert er den Gesprächspartner auf, seine Ansichten zu korrigieren und in zuzustimmen.

Durch doch können in solchen Fällen auch beim Gesprächspartner nur vermutet abweichende Ansichten von vornherein entkrăftet werden und so die Erwartunb' daß der Partner zustimmt, betont werden; vgl.:

(17) Bin ich ja froh, daß das Kind nich mitgefahren war, stell dir das mal vor. Is doch Wahnsinn! (..) Das ist doch Wahnsinn! (BA, 137)

34) Z.B. Bastert 1985:78, Bublitz 1978:112, Hentschel 1986:131 (als "Exklamations" satz") und Franck 1980:187, die hier von einem "emphatischen doch" spricht.

35) Der bel ja-Aussagesätzen etablierte Untertyp 'emphatische Aussage' bZ" 'Ausruf' (S. 107f.) setzt eben voraus, daß der Sprecher staunt, daß ein $\mathrm{Sac}^{\mathrm{h}}$, verhalt zutrifft. Vom Formtyp her wăren diese Außerungen aber allemal Aus" sagesätze: der Typ 'Exklamativsatz' weist ja typischerweise einen Exklamativ' akzent auf (s. S.34) und drückt ein Staunen über einen bestimmten Grad a s. $^{\text {s. }}$ 
(18)

Derartige dist doch das Letzte!

doch-Außerungen sind häufig, aber nicht immer, negativ konnotiert (vgl.

Gesprăch 90:187); bei einer positiven Außerung ist die gegenläufige Ansicht des

artners meist eindeutiger zu erkennen:

Jetzt nörgel nicht so rum! Das ist doch wirklich traumhaft hier!

Als Ausrufe mit doch - hier hăufig in Kombination mit glatt - sind Polgende

Außerungen einzuordnen: ${ }^{36}$

(20)

Stellt der doch glatt den Rotwein in den Kühlschrank!

Und da sagt er doch glatt - ich hab mir ehrlich denkt, ich hör nicht

recht! -: Falls da jemand von der SDAJ dabei ist (...), dann möcht ich

euch sagen, das gibts fei heute noch in der DDR. (Kr, 178)

Im Unterst doch der mit'm Traktor in die Kirche!

in derchied zu den bisher angeführten Aussagesätzen welsen diese Außerungen

Funk Regel Verb-Erststellung auf, ein Wechsel zu Verb-2weitstellung bel gleicher

tivsă ist aber möglich. Diese Ausrufe stehen an der Grenze zu den ExklamaDie

oben angenommenen Merkmale von doch, 〈BEKANNT> und 〈KORREKTUR〉, können hier nur auf die Erwartung bzw. Annahmen des Hörers bezogen werden: Der Sprecher äußert ein starkes Erstaunen über den dargestellten Sachverhalt, der meist eine Normabweichung beschreibt und zeigt an, daß auch der Hörer weiß, wie der entsprechende Sachverhalt im Normalfall aussieht, und, daß der Hörer seine Erwartungen und Annahmen diesbezüglich korrigieren muß. Der starke Hörerbezug. der bei Exklamationen sonst nicht in diesem Maße gegeben ist, zeigt sich auch daran, daß diese Außerungen nur als Aussagen uber Dritte bzw. in der dritten Polgten auftreten, sie also in der Regel Erzählungen sind über einen bereits ergten Sachverhalt - auch wenn das Verb im Präsens steht.

Auch in den W-EXKLAMATIVSATZEN wird der Sachverhalt als dem Hörer bekannt Bekennzeichnet, zumindest ist er für den Hörer genauso offensichtlich wie für den Sprecher, da derartige Exklamative fast nur in der aktuellen situation verwendet "erden können. Betreffen sie wirklich einmal einen Sachverhalt in der Vergangenhelt (vgl. (25)), so handelt es sich immer um eine beiden Gesprächspartnern ge-

(23) (bzw. vom Sprecher als gemeinsam dargestellte) Uberzeugung: Wie tanzt sie doch gut!

\footnotetext{
36) Hento Höhtschel (1986:131) klassifiziert diesen Typ zusammen mit Das ist doch die
Sie mils Exklamationssatz.

38) Werden. Mit der kann z.B. in (20) auch der anwesende Hörer gemeint sein; dann llegt aber indirekte Verwendung vor.
} 
(25) Ach, Ginger Rogers! Wie hat die doch toll getanzt!

Die durch doch ausgedrückte Korrekturanweisung bezieht sich hier (wie in den 0. Außerungen vom Typ (17)) auf beim Hörer nur vermutete Gegenansichten, so ds der Sprecher auf diese Weise seine Außerung letztlich bekräftigt.

Als eine weitere Variante läßt sich doch in Außerungen vom Typ (26) nachweiset (26) Sie haben den Katalog doch bis zur Eröffnung fertig?

Bei steigender Intonation handelt es sich hier vom Formtyp her um den Mischif 'Assertive Frage' (s.o. S.69f.): Zweitstellung des Verbs als Indiz für Aussages steigendes Tonmuster als Indiz für Frage. Vom Funktionstyp her handelt es sid dann eindeutig um Fragen.

Eine Frage-Interpretation kann aber auch bei gleichbleibendem oder fallendef Tonmuster durch andere Mittel erreicht werden. Neben 'tag questions' wie of

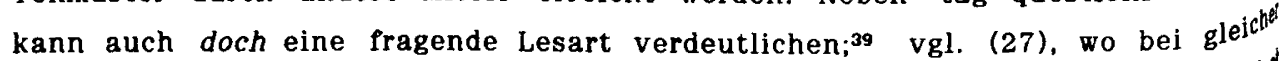
(nicht stelgender) Intonation die Frageinterpretation bei der Außerung mit dol wesentlich deutlicher ist.

(27) Wir haben doch genügend Brot vs. Wir haben genügend Brot Daneben ist auch der Inhalt der Außerung relevant: Gerade wenn Feststellungt über (zukünftige) Handlungen des Gesprächspartners gemacht werden, liegt dif Frage-Lesart besonders nahe; vgl. oben (26) und:

(28) Schon als Kind habe er Gehalt gekriegt, habe alles selbst bezahlen müs $s^{t^{4}}$ "Darf ich mal 8 Kronen haben für mein neues Schulbuch?" - "Aber wieso, du kriegst doch Gehalt?" (Ke, 210)

Letztlich aber entscheidet auch die Kontexteinbettung darüber, ob Frageinterpt tation vorliegt: bei gleicher (nicht stelgender) Intonation ist (29a) als Frage (29b) als Aussage zu interpretieren.

(29a) Du nimmst doch Zucker in den Kaffee (Dann bring ich welchen.)

(29b) Du nimmst doch Zucker in den Kaffee (Hast du je darüber nachgedacht. wieviele Kalorien das pro Tag sind? Ich habs mal ausgerechnet.)

Das Merkmal (KORREKTUR〉 kann bei diesen Außerungen auch auf den Sprecher zogen werden. Es zeigt in diesem Fall an, daß der Sprecher seine (durch die Fot der Außerung nahegelegte) Behauptungshandlung korrigiert: er ist eben nicht $v^{\circ l^{\prime}}$ lig von der Geltung des Sachverhalts überzeugt, sonst könnten derartige $A u \beta e^{r}$ gen nicht als Fragen verstanden werden. Für diese Interpretation spricht, auch 'tags' (vor allem oder) eine Vermutung des Sprechers anzeigen (können) (W) Willkop 1988: bes. 276). Das Merkmal (KORREKTUR〉 könnte so auch erklären.

39) Vgl. auch Franck (1980:184f.), die doch hier als Frage-indizierend bezeich pr $^{\text {t }}$ wenn andere Indikatoren nicht eindeutig sind. 
rum $j a$ eben nicht in derartigen Fragehandlungen auftreten kann. ${ }^{40}$ 〈KORREKTUR> Hörer aber weiter auch dahingehend verstanden werden, da $\beta$ der sprecher vom also dissen will, ob eine Korrektur seiner ursprünglichen Annahmen nötig ist, ob Prage geführten Zwelfel an dem zur Debatte stehenden Sachverhalt, die zu der versicherunrt haben, berechtigt sind. Fragen mit doch sind nämlich immer RückDas Merlosfragen (vgl. Franck 1980:186).

beziehen, daß 〈BEKANNT> ist in doch-Außerungen mit Frageillokution darauf zu es muß daß der erpragte Sachverhalt auch dem Sprecher Im Grunde bekannt ist; ren, daß spezifiziert werden zu 〈BEKANNT〉s. Das läßt sich darauf zurückfühist: im im Vergleich zu den Aussagen in Fragen die Wissensverteilung umgedreht Verweis Normalfall verfügt der Sprecher eben nicht über das erfragte Wissen; ein dingungen anzeigt bekntes wissen durch doch, was ja immer spezielle Verwendungsbechers beziczzeigt, kann sich daher bel der Frage nur auf das Wissen des SprePragen eine starke Antwortpräferenz: der Sprecher erwartet Bestätigung.

Auch in den - allerdings seltenen - W-PRAGESATZEN wird ein Sachverhalt erprảsent dem Sprecher eigentlich bekannt ist, den er nur in diesem Moment nicht schnell hin. Daraup deuten auch die häufig auftretenden Lexeme gleich oder

(30) Win. Auch hier lautet das Merkmal also 〈BEKANNT>s.

(31) interessi doch gleich das deutsche Nachrichtenmagazin, das sich für derlei We bemerkt Goethe doch so treffend?

In WUNCHSATZEN muß in der Regel eine der Modalpartikeln doch, nur oder bloß (32) (s.o. S.24).

(33) Mensch, hatt ich doch den Herz-Zehner behalten!

Dle Verwentest du doch das Rauchen aufhören!

Sprecher Weiß, daß er winscht, daß ein bestimmter Sachverhalt besteht oder bestanden hätte. seiner er nicht bestanden hat oder besteht und wei $\beta$ auch, daß es nicht in Mit doch zeliegt, den Sachverhalt herbeizuführen (vgl. genauer Scholz 1987).

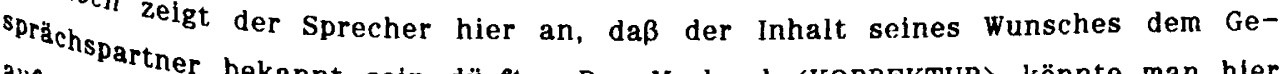
aup die vomer bekannt sein dürfte. Das Merkmal 〈KORREKTUR〉 könnte man hler hypothetisch Sprecher gewünschte Korrektur der Wirklichkeit beziehen - wobei dies zu verstehen ist, da der Sprecher ja eigentlich weiß, daß eine Ande-

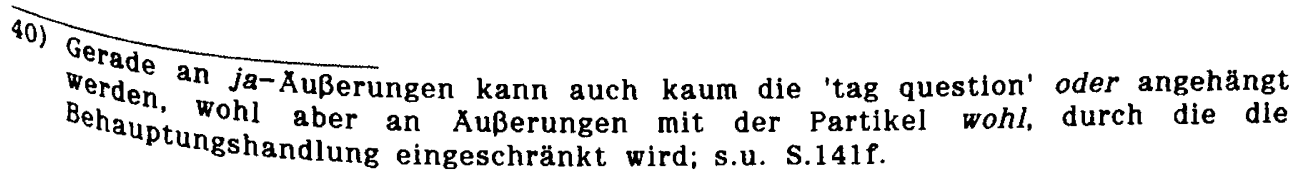


rung der Realität unmöglich ist. Insofern würde durch das Merkmal (KORREKTUR) hier auch eine Verstärkung des Wunschcharakters bewirkt."1

Möglicherwelse dienen aber auch die drel Modalpartikeln doch, nur und blo $\beta$ ledig lich der Sicherung der Wunschlesart, also als 'Wunschanzeiger'; einen Unterschied zwischen (33a) und (33b) kann ich jedenfalls nicht feststellen:

(33a) Könntest du doch das Rauchen aufhören!

(33b) Konntest du nur das Rauchen aufhören!

IMPERATIVSATZE mit doch stellen eine sehr häufige Variante dar:

(34) Mach doch das Licht an! Du verdirbst dir ja die Augen.

(35) Bringen Sie doch Ihren Freund mit!

Auch hier lassen sich die oben angenommenen Merkmale 〈BEKANNT〉 REKTUR> nachweisen. Das, wozu aufgefordert wird, ist im Augenblick der Außerun nicht gegeben, der Gesprächspartner zeigt ein Verhalten, das der Aufforderung $2^{4^{\circ}}$ widerläuft (und zwar - wie meist bei Aufforderungen - eher ein nonverbalest. Nun ist das ein Kennzeichen, das bel Aufforderungen fast immer besteht, so s $^{\text {th }}$ müßten sie nicht geäußert werden; durch doch wird dieser Gegensatz allerding zusätzlich hervorgehoben und der Angesprochene aufgefordert, sein verhalten ${ }^{\nu}$ korrigieren.

Diese Korrekturanweisung zeigt sich einigermaßen deutlich auch daran, da $\beta$ doct in negierten Aufforderungen nur dann verwendet werden kann, wenn die Handlunb bereits vor dem Zeitpunkt der Außerung begonnen hat (vgl. (36)) oder als g $^{g^{2 t}}$ schon zurückliegt (vgl. (37)); in diesen Fällen ist die Kombination mit immer be' sonders häufig (vgl. Franck 1980:189). Negierte Aufforderungen ohne doch dageget können auch verwendet werden, wenn der sprecher dem Hörer einen bestimnten Handlungsplan nur unterstellt; vgl. (38) und (39):42

(36) Macht doch nicht so einen Krach!

(37) Erzähl doch nicht immer alles der Frau Kling! (Die ist doch die schlimmstl Klatschbase im ganzen Haus.)

(38) Und bleib nicht zu lange in der Kneipe!

"Und bleib doch nicht zu lange in der Kneipe!

(39) Vergiß nicht, Geld $z u$ wechseln!

'Vergiß doch nicht. Geld zu wechseln!

Die angeführten Beispiele haben gezeigt, daß auch in Imperativsätzen für doch ${ }^{4}$ Merkmal 〈KORREKTUR〉 angenommen werden kann. Das Merkmal 〈BEKANNT>a ist den Aufforderungen mit doch gleichfalls nachzuweisen: In der Regel ist dem $\mathbb{H}^{\text {of }}$

41) Das Merkmal 〈KORREKTUR〉 könnte so erklären, warum durch die Modalpartityer doch eine Außerung eindeutig zu einem Wunsch wird. (Dagegen spricht allet dings, daß auch nur und bloß allein in Wunschsätzen möglich sind.) dings, daß auch nur und bloß allein in Wunschsätzen möglich sind.)
42) Die Beisplele (38) und (39) sind allerdings akzeptabel, wenn zusätzlich
eingefügt wird; normalerweise aber tritt dann kein doch auf. 
nămlich entweder aus der Situation oder aufgrund bestimmter Konventionen der Sprecherwille bereits bekannt, d.h. er wei $\beta$, da $\beta$ er die Aufforderung bereits hätte ausführen sollen.

(40)

Mutter zum Kind: Jetzt hör doch mit diesem Gejammere auf! Es gibt heute

(41) kein Eis.

Asterix und Obelix besuchen Falbala, in die Obelix verliebt ist.

Falbala: Setzt euch doch ein wenig zu mir!

Sie setzen sich und alle schweigen. Nach einiger Zeit sagt Asterix zu

Wegen delix: Sag doch was! (A X, 11)

des Merkmals 〈BEKANNT $\rangle_{\mathrm{B}}$ ist doch z.B. in (42) inakzeptabel (die Kombina(42) doch mal wäre allerdings möglich):

Eine Frau schaut aus dem Fenster auf die Straße und sieht ein kleines Kind dort spielen. Sie ruft es: "Komm doch her!

Imperativsätze mit doch können je nach Kontext Befehle, Vorschläge (43), Ermunterungen ((44); hier wird auf das Wissen über Verhaltenskonventionen verwiesen)

(43) Mach doch Pizza, wenn soviele Leute kommen!

Nehmen Sie doch noch ein bißchen Niere, meine Herren! (Si, 527)

In allen Verwendungsweisen von doch lassen sich also die angenommenen Merkmale 〈BEKANNT〉 und 〈KORREKTUR〉 nachweisen, wobei 〈BEKANNT〉 in den meisten Fällen aup das Wissen des Hörers bezogen ist und nur in den Fragen auf das des sprächspartnch 〈KORREKTUR〉 ist in den meisten Fällen als Korrektur des Gea der

manchmal auch nur unterstellt sein kann, braucht doch keine direkte (sprachliche Verwendet-sprachliche) Vorgängerhandlung, kann also auch gesprächseinleitend sowieso, die den (vgl. oben (12)). Darin unterscheidet sich doch z.B. von eh und die Modie den direkten Vorgängerbeitrag korrigieren. Verglichen mit ja ist doch alpartikel mit der spezielleren Bedeutung.

2.2 .3

Eben

Das Lexem eben kommt als Adjektiv, als Adverb mit temporaler Bedeutung, als tritt eben , als Gliederungspartikel und als Modalpartikel vor. Als Modalpartikel Zunächst in den Satztypen Aussagesatz und (seltener) Imperativsatz auf.

(1) ZUm AUSSAGESATZ:

Heinz: Wie sollt ihr denn an Wanzen kommen?

Anna: Ja, das weiß ich eben auch nicht. (BA, 3) 
(2) Hanna: Jawohl, daß ich nämlich Schwierigkeiten mit Männern hab, das is völlig normal. Ich bin ebn keine gutaussehende Frau, und das is normal, ${ }^{\text {sl }}$ dicke Frauen ham ebn keine Männer, sondern Schwierigkeiten. (Kr, 153)

(3) Peter will Karin für eine kleine Gefälligkeit bezahlen.

Karin: Also, hör ma, das is ja nu keen (), also ik schick dir die hin, un wenn du dich darüber freust, dann freu ik mich ooch.

Peter: Na klar freu ich mich dadrüber!

Karin: Naja, siehsde. Un wenn ich dir die nich schicken will, dann schicke ik se eben nich. (BA, 103)

Sam wollte den Leoparden nicht stören und brachte das Fahrzeug deshalb nur so in Position, daß nicht alle Photographierwünsche in Erfüllung gin gen. So ist das eben in freier Wildbahn. (SZ)

In Außerungen mit der Modalpartikel eben zeigt der Sprecher an, daß der darb $\beta^{f^{\prime}}$ stellte Sachverhalt evident ist und auch für den Gesprächspartner evident sell sollte. Eben soll deshalb mit dem Merkmal 〈EVIDENT $\rangle_{\mathrm{B}}$ beschrieben werden. viel fach kann der Sachverhalt dabei aus dem Kontext, der Situation (vgl. (2)) def allgemeinem Wissen erschlossen werden. So sollte in (1) der Inhalt von A ${ }^{\text {o }}$ Außerung auch für Heinz offensichtlich sein; Anna hat nämlich einige zeit vo sh $^{\text {th }}$ geäußert: Wanzen? Wie hab ich mir dat denn geholt (BA, 2). Vgl. auch:

Franz: Wie entsteht der (Akkord)?

Marina: Der wird gestoppt. Sagn mir, da kommt die Ware rein und das $m^{8}$ jemand. Und der wird gstoppt. Das is irgend jemand. Is egal wer. Und $d 8$ steht einer daneben, und der stoppt ebn dann.

Rosi: Das is eben der Stopper. (Kr, 108)

Eben-Außerungen unterliegen im Unterschied zu solchen mit $j a$ oder doch stimmten Sequenzierungsbedingungen: Sie knüpfen immer an einen vorgänge $e^{\text {th }}$ an; deshalb erhält eben noch das Merkmal 〈KONNEX〉, das diese Eigenschaft th $^{\prime}$ rakterisiert. Man stelle sich eine kontextlose Außerung wie (6) vor; diese evollt immer einen ganz bestimmten Vorgängerkontext:

(6) Leinen sollte man eben nicht kochen.

Wegen des Merkmals 〈KONNEX〉 können eben-Außerungen nicht, wie Außer z.B. mit doch, in redeeinleitenden oder themenwechselnden Außerungen stehen: Was ich dich mal fragen wollte, du hast doch eine Arbeit über Mörike ${ }^{f^{f}}$ schrieben, kann ich die mal haben?

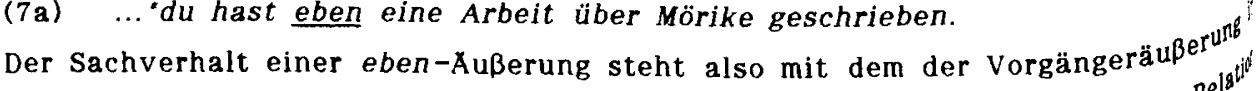
einer bestimmten Relation. Das kann ganz generell eine Bedingung-Folge-Re $\mathrm{e}^{\mid g^{\text {il }}}$ sein; die eben-Außerung gibt dann die Folge an, die (eben weil der Sache als evident gekennzeichnet wird) auch evident ist; vgl. oben (3) und: (8) Reinhold Messner hat gesagt: "Wenn ich hoch hinaufsteige, kann ich elf
sehr tief in mich hineinsehen." (SZ) 
(9)

...siebenhundertfuffzig Kalorien un dann darfsde abends nochmal zwohundertfuffzig essen. Was dann wieder. im Grunde son/kanns en richtig schönen Quark machen, mit/mit Ananas drin, so un/ mußt eben Süßstoff nehmen, darfs kein/keinen Zucker verwenden. (BA, 155)

(10) (= Wenn du eine Diät machst, mußt du (eben) Süßstoff nehmen.)

Evi: Du, das ist ganz blöd heute, ich hab noch so wahnsinnig viel zu tun.

Pit: Gut, komm ich eben morgen. So dringend ist es ja nicht.

In den meisten Fällen aber liegt eine kausale Beziehung vor. Dabei liefert die eben-Außerung eine (durch die Darstellung eines offensichtlichen Sachverhalts)

evidente Begründung bzw. Erklärung für die Vorgängeräußerung oder Implikaturen aus ihr. Da diese Begründung oder Erklärung vom Sprecher als allgemein evident markiert wird, gilt sie auch als einzig mögliche Begründung oder Erklärung. In der Vorgängeräußerung wird in solchen Fällen oft ein problematischer Sachverhalt thematisiert oder zumindest impliziert.

(11)

Gundi: Oh Gott, jetzt ist das T-Shirt völlig eingelaufen!

(11a) Lina: Tja, du hast es eben zu heiß gewaschen.

(12)

Tim: Mensch, du bist ja völlig trocken!

Daß durch: Ja, das ist eben Goretex.

daß den eben die kausale Beziehung verdeutlicht wird, zeigt sich auch daran,

(13)) und eben-Außerungen gerne eine Frage nach einem Grund vorausgeht (vgl. ungebräuch daran, daß in diesem Fall die Antwort ohne Partikel (vgl. (13a)) eher

(13) Ualich ist, und dann das übliche weil verwendet werden muß.

Hans: Warum sind nur die Frauen so hinter dir her?

(13a) Peter: Ich bin eben unwiderstehlich.

Häupig (?)Ich bin unwiderstehlich. vs. Weil ich unwiderstehlich bin.

generischem eben in allgemeingültigen Aussagen (mit Verbform im Präsens und

(14) Wubjekt), besonders auch in Stereotypen:

Was von der Ungenauigkeit übrigbleibt, wenn nicht 30 , sondern eine Milli-

stellenten hinter dem Komma stehen, kann sich unsereins schwer vor-

locker. (SZ) so ist er eben, der Japaner, er will es wissen, er läßt nicht

(15) (SZ)

Eben eignet sich

begründenden sich hier besonders gut, weil es der Aussage Evidenz verleiht und so

sein muß.

Aus ahnilich

Entschuldigungen Gründen wird eben oft in lapidaren Erklärungen und oberflächlichen

(vgl. Trömel-Plötz 1979:322):
(16) Reni.

Reni: Warum hast du denn deine Fahrzeugpapiere nicht dabei?

Mein Gott, ich bin eben schusselig. 
Da mit eben ein Sachverhalt als unmittelbar für Sprecher und Hörer evident $g^{e^{-}}$ kennzeichnet wird, gilt er auch als allgemein gültig. Deshalb kann eben auch nicht in Fragen stehen. ${ }^{43}$ In vielen Fällen kann der sprecher mit einer eber Außerung neben der allgemeinen Evidenz noch implizieren, daß der Sachverhall unabänderlich ${ }^{44}$ ist, seinem und des Gesprächpartners Eingreifen entzogen. Daher kommt auch die resignierende Komponente, die eben-Außerungen oft haben.4 Einschränkungen von eben-Xußerungen sind zwar selten, aber nicht unmöglich (vgl. dagegen Trömel-Plötz 1979:321):

(17) Die Männer sind eben stark verunsichert, aber die werden's schon noch lernen.

Auch in IMPERATIVSATZEN läßt sich eben mit den Merkmalen 〈EVIDENT>s un $\langle$ KONNEX〉 beschreiben:

(18) Frank: Mein Gott, jetzt ist schon Mitte August und ich muß doch meine Arbeit im Oktober abgeben, und ich hab noch nicht einmal die Hälfte. Eva: Dann bleib eben mal zu Hause und arbeite! Wenn du jeden Abend un terwegs bist, kommst du nie voran.

(19) Nina: Heute früh hab ich schon wieder die S-Bahn verpaßt. Paul: Steh eben morgen früher auf!

(20) Mutter sieht Kind: "Komm eben her!

Auch Aufforderungen mit eben sind nur möglich, wenn sie sich direkt auf et t $^{8}$ Vorhergehendes beziehen ( $\mathrm{vgl}$. (20)), in der Regel eine Außerung, die ein Proble

43) Das von Hentschel (1986:166) angeführte Beispiel für eben in "Intonations s $^{88^{\circ}}$ gen" (Und dann hast du es ihr eben gesagt $\uparrow$ ) halte ich für inakzeptabel.

44) Hentschel (1986:168) nimmt als Grundbedeutung von eben 'Unabänderlichkel' an. Dies ist aber m.E. sekundär und aus der Evidenz eines Sachverhalts ${ }^{\text {nth }}$ zuleiten. In einer Außerung wie (10) will der Sprecher durch eben sicher nlets die Unabänderlichkeit des Sachverhalts anzeigen, zumindest ist es keines die zentrale Funktion von eben. Die Auffassung Engels (1968/ 1971:92), eill stelle die Unabänderlichkeit eines Sachverhalts als unerheblich hin (ähn

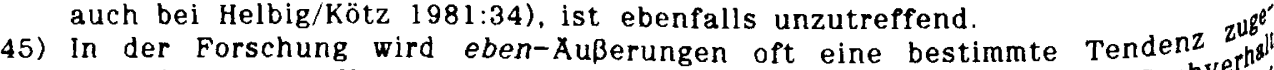
schrieben; so stellt Trömel-Plötz (1979:323) fest, daß eben einen Sachver is negativ bewertet. Das gilt sicher nur für einen Teil der Außerungen und on nicht auf eben zurückzuführen. So wird z.B. in (12) einfach nur stolz dy jede Bewertung ausgedrückt. Hentschel (1986:196) versucht nachzuweisent dile Außerungen mit eben nicht in einen "freundlichen Kontext passen". Auch $\mathrm{KO}^{\mathrm{O}}$ se Behauptung ist wohl etwas zu stark - m.E. sind dafür Faktoren wie text oder Intonation verantwortlich. So kann Ach, dann komm ich eben morb wieder, macht nichts! durchaus in einem "freundlichen Kontext" stehen. Bewertung einer eben-Außerung hängt also von anderen Faktoren ab Kontext, Beziehung zwischen den Gesprächspartnern, Intonation etc.). Auch die Ansicht Francks (1980:235ff), eben drücke einen Kompromi $\beta$, ein $2{ }^{\circ}$ geständnis des Sprechers (in Sätzen der 1.Person) aus bzw. verlange es $e^{\text {bel }}$ Hörer (in Sätzen der 3. Person), trifft nicht für alle Verwendungen von fil $^{\circ}$ zu. Francks Bedeutungsbeschreibung ist wohl darauf zurückzupühren, dap pin th nicht zwischen eben und halt trennt, und mehr Beispiele mit halt an das auf jeden Fall verbindlicher ist als eben. 
darstellt. Auch hier impliziert der Sprecher durch den Einsatz von eben, die Handlung, zu der er auffordert, sei eine (auch für den Hörer) offensichtliche und die einzig mögliche Lösung für das im Vorgängerbeitrag geäußerte Problem. Vermutlich sind deshalb die eben-Aufforderungen fast immer durch dann eingeleitet. um diesen Zusammenhang zu explizieren; vgl.:

(18a) Wenn du deine Arbeit rechtzeitig fertig haben willst, dann bleib eben mal zu Hause und arbeite.

Aufforderungen mit eben sind nicht als Befehle zu interpretieren, sondern eher als Ratschläge, die allerdings - wegen des Merkmals 〈EVIDENT〉 - meist sehr rechthaberisch wirken. Ein echtes Eigeninteresse des Sprechers an der Ausführung der Handlung ist hier nicht vorhanden.

Im Kommunikationsablauf kommt eben eine große Bedeutung zu. Eben-Außerungen können rechthaberisch sein, da der Sprecher dem Hörer bedeutet, der Sachverhalt sei evident und somit gültig und damit zu erkennen gibt, daß der Sachverhalt nicht begründet werden braucht. Insofern ist eben auch ein Mittel des Argumentierens, das über problematische oder noch $\mathrm{zu}$ problematisierende Sachverhalte hinwegtäuscht bzw. hinwegtäuschen kann (vgl. Lütten 1977:249).

Die Evidenz und damit auch die Faktizität und Geltung des Sachverhalts, die der Sprecher mit eben anzeigt, können natürlich auch nur scheinbar sein - ebenso wie die oft ausgedrückte Unabänderlichkeit eines Sachverhalts. In dieser Hinsicht kommt mir eben in seinem Gebrauch 'perfider' vor als ja.

Der Gesprächspartner ist nach dem Gebrauch der Modalpartikel eben in seinen Fortsetzungsmöglichkeiten stark eingeschränkt: er kann die Behauptung kaum an2Weifeln oder in Frage stellen (vgl. Trömel-Plötz 1979:322). Der Sprecher gibt mit einer eben-Außerung zu verstehen, daß der Sachverhalt für inn in dieser weise leststeht, daß er nicht weiter darüber diskutieren will und das Thema damit abgeschlossen ist. So kann eben den Abschluß eines Themas bewirken, und deshalb (21) sich eben-Außerungen gut als Schlußwort (vgl. Trömel-Plötz 1979:321): In Dänemark heiße es "Skol", sagte Sörensen. Dies war weniger von Interesse. In Deutschland heiße es eben "Prost" und damit basta. (Ke, 231)

\subsubsection{Halt}

Die Modalpartikel halt wird in der Regel als die süddeutsche Variante von eben mesen. Deshalb werden die beiden Partikeln als bedeutungsgleich bezeichnet und 1980. Zusammen abgehandelt (vgl. z.B. Bublitz 1978:81, Kemme 1979:17 und Franck $0: 235$ ). Allerdings bestehen seit geraumer Zeit eben und halt im süddeutschen 
wie im norddeutschen Raum nebeneinander (vgl. dazu auch die Ausführungen bel Hentschel 1986:174ff.); Belege zu beiden Partikeln waren sowohl im Korpus von Brons-Albert zu finden, das hauptsächlich Sprecher mit ripuarischem Dialekt ent hält und bei Hentschel (1986) mit Sprechern aus dem Berliner Raum als auch um gekehrt in den 'Chiemgauer Gschichten' von Kroetz, in denen süddeutsche bz bairische Sprecher erzählen.

Die beiden Modalpartikeln eben und halt, die beide in den Satzmodi Aussagesat und Imperativsatz auftreten, gleichen sich zwar in ihrer Bedeutung, sind abe? nicht als Synonyme zu sehen. Dafür spricht zum einen ihr unterschiedliches ver halten in den Kombinationen (mehr dazu in Kapitel 3) und die Tatsache, daß sie miteinander kombiniert werden können (echt synonyme Partikeln wie z.B. eh und sowieso werden nach meinen Beobachtungen nie kombiniert) und zum anderen dil Tatsache, daß eben und halt nicht beliebig austauschbar sind; vgl.:

(1a) Du kannst deine Freunde schon mitbringen. Wir haben halt kein Bier mehr.

(1b) 'Wir haben eben kein Bier mehr.

(2a) Ich geh gern mit auf die Bergtour. Aber ich bin halt nicht mehr so fit seit meiner Operation.

(2b) ?*Aber ich bin eben nicht mehr so fit seit meiner Operation.

(3a) Er: Das Essen ist ja sehr gut hier!

Sie: Schon; man kann halt nicht draußen sitzen.

(3b) ?"Schon; man kann eben nicht draußen sitzen.

(4a) Er: Ich muß noch Rosinen kaufen. Für den Obstsalat
Sie: Brauchts das denn?

Er: Ja, paßt dir das nicht?

Sie: Naja, in einen Obstsalat gehören halt keine Rosinen, find ich.

(4b) ?*Naja, in einen Obstsalat gehören eben keine Rosinen, find ich.

(5a) Monika will Hans um einen Gefallen bitten, zögert aber, ihn anzurufen. Nach einiger Zeit sagt ihre Freundin:

Jetzt ruf den Hans halt an!

(5b) "Jetzt ruf den Hans eben an!

(6a) Nach einem heftigen Krach zwischen Vater und Sohn sagt die Mutter zum Sohn, der in seinem Zimmer sitzt:

Ach, red halt noch einmal mit dem Vater! Der meints doch nur gut.

(6b) "Ach, red eben noch einmal mit dem Vater!

(7a) Er zieht seinen Mantel an. Sie zu ihm: Bleib halt heute mal zu Hause!

(7b) "Bleib eben heute mal zu Hause!

Es gibt also sowohl in Aussagesätzen als auch in Imperativsätzen Vorkommen vol $^{0}$ halt, in denen eben inakzeptabel (oder wenigstens deutlich schlechter) ist. Beispiele, in denen halt anstelle von eben wirklich inakzeptabel ist, lassen ${ }^{j^{j / t}}$ m.E. nicht finden, aber es gibt doch Vorkommen, wo halt inadäquater ist:

(8) Der Wal ist eben ein Säugetier. vs. ?Der Wal ist halt ein Säugetier. 
(9)

Der Krieg ist eben unmoralisch. vs. ?Der Krieg ist halt unmoralisch.46

(10) Tim: Mensch du bist ja ganz trocken!

Hans: Das ist eben Goretex. vs. (?) Das ist halt Goretex.

Auch in Kontexten, wo halt und eben austauschbar sind, läßt sich ein Unterschied

2wischen den beiden Modalpartikeln feststellen vgl.:

(11) Wir sehen das eben verschieden. vs. Wir sehe.

(12) Wir sehen das eben verschieden. vs. Wir sehen das halt verschieden.

(13) Männer sind eben so. vs. Männer sind halt so.

Ich hab dich doch gewarnt.

In allenrorvideos sind eben grausam. vs. Horrorvideos sind halt grausam.

angeführten Beispielen scheinen Außerungen mit halt im Vergleich zu

kommt abgeschwächter zu sein, weniger apodiktisch und verbindlicher. Wodurch

diese Abschwächungsleistung von halt zustande?

In den $A$

Vorgănger AUSAGESATZEN stellt zunächst auch halt (wie eben) eine Verbindung zum

(14) Ger her (Merkmal 〈KONNEX〉); vgl.:

Es war nur ein Rappel, meint der Doktor. nicht das Herz. Sie ist halt wet-

terfühlig, und die senile Demenz wird auch schuld sein.

(15) (= Weil sie wetterfühlig ist, war es nur ein Rappel)

Der Reim hätte gern den Mark angestellt aber auf ne (...) richtige Stelle

und da hat sich. die Personalstelle quergelegt (...) Ja, und dann hab ich

gesagt, dann geb ich halt dem Mark, bis die nächste Viertelstelle, die wär

im März freigeworden. (...) geb ich dem solang meine Viertelstelle. (BA, 64)

Im Unterschied es hilft, geb ich dem Mark meine Stelle)

sondern als

mit dem Merkmal <

Plausiblen

Folge aus diesem);

Erklärungen diesem); der Sprecher konzediert zwar, daß es auch noch alternative

stellte Erklä. geben mag, bedeutet dem Hörer aber, für diesen Fall die dargeapodiktisch als eben.47

46) $V(8)$

Vgl. Trömel-Plötz (1978:8); allerdings geht Trömel-Plötz (m.E. unzutreffend;

47) einen im S.122 Fn.45) davon aus, daß halt deshalb inadäquat ist, weil es

Mit dieser allgemeinen negativ bewerteten Sachverhalt abmildert.

(1986:178f Beschreibung lassen sich auch die Ergebnisse von Hentschel Passung inf.) vereinbaren (die sich allerdings von der hier vertretenen Aufkeln eb insofern unterscheidet, als sie als Grundbedeutung der beiden Parti$\mathrm{P}_{\mathrm{e}}$ eines und halt 'Unabänderlichkeit' annimmt): Hentschel versucht, mit Hil"emotionalendrucksdifferentials den Unterschied in den - wie sie es nennt Sle kommt oder expressiven Konnotationen" von eben und halt zu Passen. gleicherm zu dem Ergebnis, daß eben "im nord- wie im süddeutschen Bereich empfunden als eher hart, klar, stark, aktiv, selbstbewußt und egoistisch nahme" (103) wird" (185), Pür halt dagegen als Konnotation "persönliche Anteil(193) anzunehmen ist, was "warm und herzlich" (193) wirkt. 
Damit ist halt ein Mittel, die eigene Aussage zu bekräftigen (indem sie eben als plausibel und folglich als gültig markiert wird) und so die eigene Position zu ver" stärken, ohne daß die Aussage so kategorisch oder rechthaberisch wirkte wie beim Gebrauch von eben. Auf diese Weise kann ein Sprecher halt auch zur Bekräftigunt seiner Außerung einsetzen, um seine Unsicherheit verdecken. Deshalb kann hall auch so gehäuft verwendet werden wie in (16):

...also, det hat sich irgendwie so eingespielt, det so halt jeder vielleicht halt einmal die Woche halt einkauft ungefähr. (..) Wenn wa kochen, denn kochen wa auch für alle, also dann fragen wa halt, wer da is, weil wa (..) ja, wir sind halt auch, auch halt öfter mal weg so zwischendurch und da fragen wa halt. (Beispiel übernommen von Hentschel 1986:255).

Durch das Merkmal 〈PLAUSIBEL〉 läßt sich auch erklären, warum Einschränkungel bei Außerungen mit halt viel leichter möglich sind als bei Außerungen mit eben:

(17a) Er hat eben keine Geduld. ?*Aber er wird das auch noch lernen.

(17b) Er hat halt keine Geduld. Aber er wird das auch noch lernen.

Da der Sprecher durch die Kennzeichnung der Außerung als plausibel auch anzeigh da $\beta$ es noch andere Alternativen gibt, kann mit halt auch ein Zugeständnis des Sprechers ausgedrückt werden, wenn er eine Feststellung über sich se lbst $^{\text {bl }}$ macht:48 in diesen Fällen wird auch der Sachverhalt nicht als unabänderlicn $g^{e^{\prime}}$ kennzeichnet; vgl. (18a) und dagegen (18b):

(18a) Ich bin halt schusselig. (Aber ich werde mir Mühe geben.)

(18b) Ich bin eben schusselig. (Und daran ist nichts $z u$ ändern.)

Auch die themenabschließende Wirkung ist bei halt lange nicht so stark wie bel eben; vgl.:

(19a) In Deutschland heiße es eben "Prost" und damit basta. (Ke, 231)

(19b) "In Deutschland heiße es halt "Prost" und damit basta.

In den IMPERATIVSATZEN läßt sich halt ebenfalls mit den Merkmalen 〈PLAUSIBE und 〈KONNEX〉 beschreiben:

(20) Max: Ich weiß nicht, was mit dem Auto los ist, da scheppert dauernd was Inge: Ja, dann fahr halt mal in die Werkstatt und la $\beta$ es inspizieren.

(21) Reni: Hast du ne Ahnung, wo es hier eine Eisenwarenhandlung gibt? Anna: Nö, aber schau halt im Branchenverzeichnis nach!

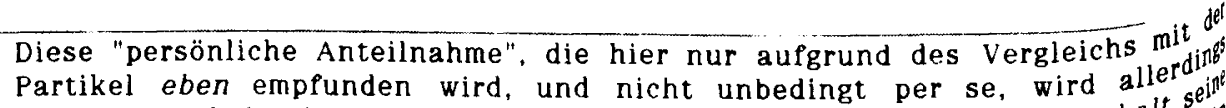
m.E. genau dadurch erreicht, daß der Sprecher mit dem Einsatz von halt $\mathbf{s}^{\mathrm{e}} \mathrm{jp}^{\mathrm{j}}$ Außerung insofern abschwächt, als er sie nicht als evident, sondern nur ver" vorliegenden Fall als plausibel kennzeichnet; auf diese Weise führt der ple $^{\text {fl }}$ gleich mit der kategorischen Partikel eben zur Annahme von Konnotatio be? wie 'persönliche Betroffenheit' und ähnlichem. Diese Konnotation sollte a nicht der Partikel halt selbst zugeschrieben werden.

48) Hier trifft Francks Bedeutungsbeschreibung (1980:235ff.; vgl. S.122 Fn.45) ${ }^{4}$ 
Die Imperativsätze beziehen sich (wie die mit eben) direkt auf einen Vorgängerzug (Merkmal 〈KONNEX〉), wobei oft ein kausaler Zusammenhang besteht; deshalb erscheint häufig dann; vgl.:

(22) Lore: Ja, abends is schlecht, wenn der Vater fährt, der fährt abends nit gern. Schon gar net nach Köln.

Der Gabi: Ja! Dann müßt ihr euch halt in unser Auto quetschen! (BA, 27)

de Lösuner betrachtet den Inhalt seiner Aufforderung als plausible, einleuchtennicht Lôsung für ein (im Vorgänger geäußertes) Problem, kennzeichnet diese aber er Handiktisch als einzig mögliche Lösung, sondern gesteht dem Hörer zu, daß nicht alungsalternativen und somit Gründe haben mag, die Handlung bisher noch eben-Aupgeführt zu haben. Insofern sind diese Aufforderungen schwächer als .

Aufgrund der beschriebenen Bedeutungen von halt und eben können jetzt auch die Fälle erklärt werden, in denen die beiden nicht austauschbar sind.

Zunächst zu den Aussagesätzen: Da mit eben wegen des Merkmals 〈EvidENZ〉 anAlternativen daß keine anderen Möglichkeiten in Frage kommen, bei halt dagegen anderen Pührten Beispichkeiten deutlich anerkannt werden bzw. relevant sind; In den angeeinen Sachvielen, in denen eben (nahezu) inakzeptabel ist, äußert der Sprecher geräußerungerhalt, der in allen Fällen eine plausible Begründung für eine Vorgänder Sprecher oder Implikaturen aus dieser ist, handelt jedoch nicht danach. So gibt frund hat (' (1) dem Gesprächspartner nach, obwohl er einen plausiblen GegenBeständnis desan lädt keine Leute ein, wenn man nichts anbieten kann'). Das Zuund (3)) Sprechers zeigt sich sprachlich auch an Mitteln wie schon (in (1) In den aber (in (2)), naja, find ich (in (4)).

lung. zu lmperativsätzen mit halt liegt der Fall ähnlich: Auch hier ist die Handche konsequer aufgefordert wird, nicht eine evidente und deshalb die einzig mögliJun dann, wz aus dem Vorgänger, sondern eine plausible. Inakzeptabel wird eben $S_{0}$ ist in wenn die plausible Lösung nicht die evidente, die offensichtlichste ist. lür den (6) auch der Mutter klar, daß die evidente und naheliegendste Lösung Wie (7) zeigt der Rückzug in sein Zimmer ist.

aber für zeigt, kann die Aufforderung des Gesprächspartners zu einem plausiblen. (was ja diesen nicht evidenten Verhalten auch im Interesse des Sprechers sein Aupforderungen eben-Aufforderungen nicht der Fall ist; s.o. S.123); insofern können "esentlich len mit halt auch fast Bitten sein - und deshalb ist halt mit bitte leichter zu kombinieren als eben (s.u. S.276f.). 
Die wenigen Fälle, in denen halt etwas ungebräuchlicher ist als eben (vgl. obell $(8)-(10))$ kann man damit erklären, daß es sich in diesen Fällen um wirklich evi dente Sachverhalte handelt (z.B. ein Naturgesetz in (8)), so daß man nicht durch den Gebrauch von halt eventuell andere Möglichkeiten offenhalten muß.

Uberspitzt könnte man vielleicht sagen: halt kann immer dann nicht durch $e^{\text {bel }}$ ersetzt werden, wenn das Plausible nicht evident ist; da aber umgekehrt das $\mathrm{EV}^{\mathrm{V}^{\dagger}}$ dente (in der Regel) auch plausibel ist, ist erklärt, warum eben immer durch hol" $\mathrm{zu}$ ersetzen ist.

\subsubsection{Einfach}

Das Lexem einfach tritt neben seinem Vorkommen als Adjektiv in einigen unter schiedlichen Partikelfunktionen auf. Dabei ist von der Bedeutung des Adjekti ${ }^{56}$ bzw. Adverbs in allen Verwendungsweisen noch eine Bedeutungskomponente vor" handen. Sätze wie (1) aber machen deutlich, daß die Partikel einfach einen Fun k $^{\prime}$ tionswandel durchlaufen hat:

(1) Diese Sache ist einfach schwierig.

Die Partikel einfach ist insofern interessant, als sich hier zeigen läßt, wie ede $^{l^{l^{\prime}}}$ tungskomponenten von der propositionalen auf die lllokutive Ebene übertrab werden können (vgl. Franck 1980:238).

In der Verwendung als Partikel lassen sich drei verschiedene Varianten feststel ${ }^{\prime}$ len. Von diesen kann die dritte Variante, bei der einfach ein attributiv oder r $^{f^{8}}$ dikativ verwendetes Adjektiv fokussiert, recht gut von den anderen beiden $a^{b g^{e}}$ grenzt werden. In dieser Funktion (paraphrasierbar mit 'schlichtweg') soll $e^{\text {ingli }^{\text {gl }}}$ zu den Steigerungspartikeln (s.o. S.16f.) gerechnet werden:

(2) Der Typ hat einen einfach umwerfenden Charme!

(3) Ich finde den Urlaub mit den Eltern echt einfach riesig! (Leserbrief)

(4) Einfach toll ist dieser Film!

\section{Der Funktionswechsel}

Die folgenden beiden Varianten der Partikel einfach sind schwieriger zu un $^{\text {tet }}$ scheiden. Aber gerade das ist auch ein Zeichen dafür, daß sich einfach in el ubergangsbereich befindet.

Die zwei Verwendungsweisen von einfach sollen zunächst für Aussagesätze ${ }^{b^{\prime}}$ schrieben werden. Der Unterschied in den beiden Funktionen läßt sich zum $e^{\text {int }}$ 
anhand der Negation und am Akzent, zum anderen auch an der unterschiedlichen Paraphraslerbarkeit und Kontexteinbettung zeigen.

Bei der ersten Variante muß die Außerung eine Handlung darstellen; diese ist als eine von vielen möglichen Alternativen zu sehen. Mit einfach wird nun die Handlung als problemlose Handlung beschrieben, die auf unkomplizierte Weise ausgeführt wird; einfach bezleht sich also auf den Modus. Deshalb könnte einfach in diesem Fall als eine Art Modaladverb bezeichnet werden.49 Meist ist es in dieser Verwendung mit 'kurzerhand' paraphrasierbar, was ja auch in etwa die Bedeutung

'Ohne langes Zögern', 'auf einfache Weise' hat. Und dann war das Ganze viel zu weit, weil der Schnitt nämlich Größe 44 war. Da hab ich einfach $z$ wei Abnäher und ein paar Falten reingemacht, Bei der zweitent gehts.

qualifiziert, Funktion von einfach wird nicht mehr die Handlung als einfach sich nicht, sondern die Illokution (vgl. Franck 1980:241); d.h. einfach bezieht die durch aup die in der Proposition beschriebene Handlung selbst, sondern auf Spielsweise das Außern des Satzes vollzogene Handlung; die Außerung kann beitritt eine eine unkomplizierte und naheliegende Erklärung darstellen; deshalb Grund aup. (6)

Eva: Wieso bist du denn so sauer?

Wern nun : Ach, ich hab heute einfach keine Lust zu arbeiten.

als einfach einfach auf der propositionalen Ebene wirkt, also die Handlung selbst tionspartikel und unkompliziert charakterisiert, dann kann es auch nach der NegaWie die ander nicht stehen; das einfach auf der illokutiven Ebene dagegen kann (7) anderen Modalpartikeln auch - nur vor der Negationspartikel stehen; vgl.: Du kannst da nicht einfach hingehen, du mußt schon wenigstens anrufen (8) Durher.

Während bannst da einfach nicht hingehen. Diese Leute sind unmöglich.

und durch (7) die Art der Handlung. ihr Modus, durch einfach beschrieben wird Außerung nicht dieser Modus negiert wird, bezieht sich einfach bei (8) auf die argumentativent. Die Proposition 'du kannst da nicht hingehen' ist in diesem gründung zu sehen.

49) Gegen

dings eine Klassifizierung als Satzadverb - wie sie Franck (1980:238) aller-

terscheicht "mit syntaktischem Anspruch, sondern nur als Andeutung der Unvornimmt der interaktionsgerichteten und der propositionalen Bedeutung" alleine - sprechen eine Reihe syntaktischer Gründe: u.a. kann einfach nicht as Vorfeld füllen oder als Antwort auf eine Frage auftreten. 
Bei der Verwendung von einfach als Modaladverb tritt häufig noch die Partikel nach einfach auf. Das ist ein weiteres Indiz dafür, daß es sich hier um ein $0^{\circ}$ daladverb handelt.

(9) Ich kann das nicht einfach so vergessen. ('auf diese einfache Weise')

Bei affirmativen Aussagen ist der Unterschied zwischen den beiden Funktionel von einfach etwas schwieriger zu fassen, läßt sich aber eventuell an unterschiet lichen Betonungsinustern Pestmachen und auch anhand der unterschiedlichen kon" texteinbettung:

(10a) Sie formuliert EINFACH. (Modaladverb)

(10b) Sie FORMULIERT einfach. (Modalpartikel; Beispiel von Hartmann (1979:134)

(11a) Du meine Güte! Wenn mir so was passiert wäre! Wenn mich jemand so be leidigt hätte! Aber der Max...Der hat das EINFACH vergessen. (='einfach so'; Modaladverb)

(11b) Ja natürlich müßte der Andi längst da sein. Aber weißt du, was ich gla $u^{\text {be }}$ Der hat das einfach VERGESSEN. Da würd ich mir keine Sorgen machen. (Modalpartikel)

Bei Aussagesätzen, die keine Handlungen beschreiben, ist einfach nur noch in ${ }^{\text {tef }}$ klaren Modalpartikel-Funktion möglich, und kann dann auch nur vor der $\mathrm{Neg}^{8^{\prime}}$ tionspartikel nicht stehen.

(12) Reni: Mich stört es einfach, wenn es so unordentlich ist.

Eva: Mich stört es einfach nicht; deshalb räume ich später auf als du.

"Mich stört es nicht einfach.

Auch in den Imperativsätzen und den Entscheidungsfragesätzen treten beide ${ }^{v^{\prime}}$ rianten von einfach, das Modaladverb und die Modalpartikel, auf; vgl.:

(13a) Geh nicht einfach hin, sondern ruf vorher an! (einfach liegt im propositionalen Bereich)

(13b) Geh einfach nicht hin! (einfach liegt im illokutiven Bereich)

(14a) Schreib ihm EINFACH!

(14b) SCHREIB ihm einfach! (Beispiel von Hartmann 1979:134)

(15) Schneidest du dann den Stoff einfach ab, oder muß man den vorher irgent" wie versäubern? ( = 'kurzerhand'; Modaladverb)

(16) Warum geht sie jetzt schon? Hat sie einfach keine Lust mehr? Oder meingt du, es ist wieder irgendwas mit ihrem Magen?

In den $w$-Fragesätzen kann die Partikel einfach nur in mit warum oder wies $0^{e^{i^{\prime}}}$

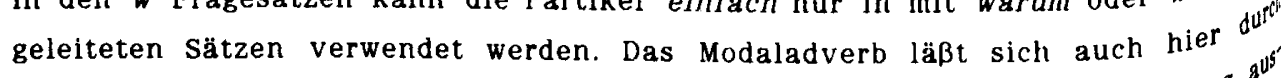
'kurzerhand' paraphrasieren und bezieht sich auf die Art, wie die Handlung geführt wird (vgl. (17)). Selten kann hier auch die Modalpartikel stehen (bo 18b). 50

Warum machst du jetzt einfach das Fenster auf?

50) Die Verwendung in $w$-Fragesätzen soll hier nicht weiter behandelt werden. 
(18a) Warum kann er nicht einfach den Mund halten? (Modaladverb)

Warum kann er einfach nicht den Mund halten? (Modalpartikel)

Die vorangegangene Funktionsunterscheidung der Partikel einfach in ein Modaladverb und eine Modalpartikel mag an manchen Stellen schwer nachvollziehbar erscheinen, zumal ja in beiden Fällen eine ähnliche Bedeutung angenommen werden konnte, die sich aus der Bedeutung des Adjektivs ableiten läßt.

terschist die Trennung dieser beiden Funktionen gerechtfertigt: wegen der unchen Paraphrasierbarkeit, des Akzents und vor allem auch aufgrund des Gerade an

Propositin einfach läßt sich der Prozeß der Úbertragung von Bedeutung von der Entstehen einer auf die illokutive Ebene (vgl. Franck 1980:238) und damit das Verwund einer Modalpartikel gut zeigen. Und deshalb ist es auch nicht weiter Underlich, wenn die beiden Funktionen nicht so gut zu trennen sind.

Die odalpartikel

Auch bei der Verwendung als Modalpartikel läßt sich - wie schon erwähnt - die

Bedeutung des Adjektivs/Adverbs noch feststellen.

der Vorgän halt stellt auch einfach eine (meist kausale) Verbindung zum Inhalt Grund auchäußußung her (Merkmal 〈KONNEX〉; vgl. (6)) und kann aus diesem

(6) auch nicht in rede- oder themeneinleitenden Außerungen stehen.

(6a) Iris: Wieso bist du denn so sauer?:

(6a) Iris: Ach, ich hab heute einfach keine Lust zu arbeiten.

lch bin heute so sauer, weil ich keine Lust habe zu arbeiten.

AUSSAGESATZE mit einfach stellen eine unkomplizierte, naheliegende und offendar (vgl. Erklärung oder Begründung für den Sachverhalt der Vorgängeräußerung halt als (19)); das kommt - wie bei eben - dadurch zustande, daß der Sachver(19) evident gekennzeichnet wird.

Whahrend einer heftigen Auseinandersetzung.

ich. "Seite seine Hand auf meiner Schulter. "Nimm die Pfote weg!" brüllte

reizt..." "gestern abend auf'n Beinen", sagte er. "Du bist einfach über-

Unterschied zu eben zeigt der Sprecher durch einfach aber an, daß der Sach-

(20) Hanna: für ihn selbst evident ist; vgl.:

zu esse Und ich will das rausfinden: Hast du Hunger? Hast du nur Lust, was

rausgekriegt, ich hab einfach ganz selten Hunger, ich fress einfach in mich
rein. (Kr, 162)

den Gesprä macht deutlich, daß durch einfach ein Sachverhalt als nicht auch für chspartner offensichtlich gekennzeichnet wird; Hanna berichtet ja ge- 
rade von einer Erkenntnis ('und ich hab rausgekriegt'), von der sie nicht annell' men kann, daß sie für ihren Gesprächpartner auch offensichtlich ist.

Die Modalpartikel einfach erhält demnach das Merkmal 〈EVIDENT)s.

Den Unterschied zwischen eben und einfach zeigt auch (21); die einfach-Außer uth ist stärker auf den Sprecher bezogen und ist wohl eher eine Reaktion auf eipi Erfahrung des Sprechers, während mit der eben-Außerung eher auf eine Erfahrull des Gesprächspartners (oder auch eines Dritten) reagiert wird:

(21) Man lernt einfach nie aus. vs. Man lernt eben nie aus.

Da mit einfach Evidenz nur für den Sprecher angezeigt wird, ist es kaum akzepts bel in allgemeingültigen Aussagen wie z.B. (22):

(22a) ?"Wale sind einfach Säugetiere.

(22b) ?"Die Erde dreht sich einfach um die Sonne.

Da der Sachverhalt nicht als evident auch für den Gesprächspartner markifet wird, wirkt einfach wesentlich verbindlicher als eben und gleicht in dieser fin" sicht eher halt. Vgl.:

(23) Ich bin einfach ungeschickt. vs. Ich bin eben ungeschickt.

Wenn sich eine einfach-Außerung allerdings aup eine Handlung oder Handlungs $\mathrm{s}^{\circ} \mathrm{o}^{\circ}$ tive des Gesprächspartners bezieht und dafür eine Begründung oder Erklärung $\mid i^{\prime}$ fert, so zeigt der Sprecher damit an, da $\beta$ er die Motive des Partners für le $\mathrm{e}^{\mathrm{i} h^{\prime}}$

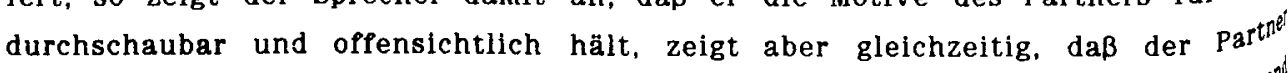
dies nicht wahrhaben will. In diesem Fall ist die einfach-Außerung stärker w $^{\mathrm{t}}$ perfider als die entsprechende eben-Außerung. Vgl. die Beispiele (24) und $(25)$ einfach in (24) ließe sich umschreiben: 'für mich ist dieser Grund offensicht lich $^{\text {th }}$ für dich aber scheinbar nicht'; eben in (25) dagegen ließe sich umschreiben: "fv uns beide ist es offensichtlich'. Einfach ist hier stärker, weil der Gesprächspag gl" $^{\prime \prime}$ nerin ja unterstellt wird, daß sie diese Erklärung bzw. Begründung, die sogar die Sprecherin offensichtlich ist, nicht sieht oder nicht sehen will.

(24) Andi: Warum bist du denn so früh gegangen?

Lilo: Ach, ich war irgendwie müde.

Anna: Du warst einfach sauer, weil du nicht im Mittelpunkt gestanden hast. Deswegen bist du so früh gegangen.

(25) (wie oben.)

Du warst eben sauer.

Die Außerung in (25) würde wohl in einem etwas anderen Kontext stehen; vgl::

(25a) Lilo: Das tut mir leid, daß ich gestern so früh gegangen bin.

Anna: Du warst eben sauer. (Das kann ja auch mal vorkommen.)

Aufgrund des Merkmals 〈EVIDENT> können einfach-Außerungen im Dialog oft ähnliche themenabschließende Funktion haben wie eben-Außerungen, sind allet dings verbindlicher als diese. Vgl. von oben (19) sowie (26), das am Ende $e^{\text {ipt }^{p^{4}}}$ Zeitungsreports steht, und (27): 
(19)

(26) Während einer Auseinandersetzung: ...Du bist einfach überreizt.

Er [der Wettersturz] setzte die Asse in die Lage, ihr Potential auch bei lausigen Bedingungen eindrucksvoll vorzuführen. Die amerikanischen Leichtathleten sind keine Schönwetter-Athleten. Sie sind einfach gut. (SZ)

Lisa: Aber oft war ich schon so weit, daß ich die Maschine so eingestellt habe, da $\beta$ die Knöpfe überhaupt nicht mehr von der Maschine runtergingen. Dann hab ich angerufen, ich könnte nicht weiterarbeiten. Es wär was mit der Maschine nicht in Ordnung. Ich bin da einfach verrückt geworden bei,

In da unten ganz alleine. ( $\mathrm{Kr}, 240)$

(27) berichtet Lisa von ihren Erfahrungen während der Spätschicht. Die einfach-Außerung stellt eine offensichtliche und einfache Erklärung für ihr Verhalten dar; damit ist dieses Thema aber soweit abgeschlossen.

Ahnlich ist es in dem Beispiel (19): Mit der Aussage 'du bist einfach überreizt' macht der Sprecher eine das ganze vorherige Verhalten der Frau erklärende Außerung; gleichzeitig entzieht er sich damit der Verpflichtung, nach weiteren Erklärungen oder Gründen suchen zu müssen. Auch diese Funktion können einfachAußerungen erfüllen.

Da mit

Außerungeinfach oft abschließende Feststellungen angezeigt werden, können diese (28) ungen auch eine resignierende Komponente enthalten:

Peter: Nicht von der Krankenkasse oder von der Altersversicherung her, weil die muß ja sein, gell, ich mag ja auch einmal eine Rente ham, wenn ich so alt bin, aber die Steuern sind einfach $z u$ hoch. $(\mathrm{Kr}, 31)$

In den ENTSCHEIDUNGSFRAGESATZEN tritt die Modalpartikel einfach relativ selten auf; auch hier ist die zur Frage gestellte Proposition eine für den Sprecher evidente Erklärung:

(16)

Warum geht sie jetzt schon? Hat sie einfach keine Lust mehr? Oder meinst du, es ist wieder irgendwas mit ihrem Magen?

Auch in den IMPERATIVSATZEN läßt sich einfach mit den Merkmalen 〈KONNEX) und 〈EVIDENT〉s beschreiben. Einfach-Aufforderungen stellen immer eine simple, Pü: den Sprecher offensichtliche Lösung für ein im Vorgängerzug geäußertes Problem dar; sie sind wie eben-Aufforderungen meistens als Vorschläge oder Ratschläge zu sehen.

(29)

Evi: Stell dir vor, am Wochenende kommt meine ganze Familie zum Essen.

(30) Ruth: Ach, mach einfach Auflauf! Den kann man gut vorbereiten.

Das macht doch nichts, wenn deine Haare nicht in Ordnung sind. Bind dir einfach ein Tuch drum, dann merkt das doch keiner!

$\mathrm{Gan}_{z}$ offensichtliche, also auch für den Gesprächspartner offensichtliche Lösungen

(3) ein Problem wirken deshalb mit einfach eher ironisch; vgl.:

Frank: Meine Güte, ich sollte doch am Montag meine Arbeit abgeben und jetzt hab ich höchstens die Hälfte fertig. Und heute abend ist dieses Fest, morgen wollte ich segeln gehn und am Sonntag krieg ich Besuch.

Eva: ?Dann bleib einfach zu Hause und arbeite! 
Mit eben dagegen wäre die Aufforderung völlig adäquat. Auch daran läßt sich zei gen, daß sich das Merkmal 〈EVIDENT〉 bei einfach nur auf den Sprecher bezieht. Schließlich zeigt den Unterschied zwischen eben und einfach auch die Tatsache. daß bei einfach-Aufforderungen Rückfragen des Gesprächspartners wie in (32) adäquater scheinen als bei eben-Aufforderungen:

(32a) Lisa: Ich weiß nicht, wie ich mich bei den Hausers bedanken soll.

Inge: Dann schick ihnen einfach ein paar Kinokarten!

Lisa: Meinst du, das ist das Richtige?

(32b) (wie oben.)

Inge: Dann schick ihnen eben ein paar Kinokarten!

Lisa: ?Meinst du, das ist das Richtige?

Der Gebrauch von eben in (32b) ist nur dann wirklich angemessen, wenn für bejde Sprecherinnen offensichtlich ist, daß das Schicken von Kinokarten hier der richti ge Weg ist, wenn sie also beispielsweise vorher schon dárüber gesprochen haben oder bei ähnlichen Gelegenheiten schon Kinokarten geschickt haben. In diesem Fg.l! wäre die Rückfrage Lisas nicht ganz adäquat.

Die in den vorangegangenen Abschnitten besprochenen drei Modalpartikeln ebell halt und einfach bilden von ihrer Bedeutung her eine Gruppe. Gemeinsam ist ihnen allen die Stellung im Interaktionszusammenhang und die Art des Bezugs ${ }^{2}$ ut $^{t}$ Vorgängeräußerung, weshalb sie ja auch alle das Merkmal 〈KONNEX〉 erhaltef haben. Der Unterschied zwischen den Partikeln liegt in der Bewertung des $\mathrm{Sach}^{\mathrm{h}^{\circ}}$

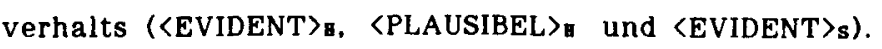

\subsubsection{Eh und Sowieso}

Diese beiden Partikeln werden in der Modalpartikel-Literatur kaum berücksichtigt. sie werden in der Regel nicht zu den Modalpartikeln gerechnet. Erwähnt werder sie lediglich bei Weydt/Hentschel (1983) und bei Hentschel (1986) sowie bel Schlieben-Lange (1979), die sich mit den bairischen Partikeln eh, halt und beschäftigt.

Weydt/Hentschel (1983) zählen eh und sowieso nicht zu ihren Abtönungspartike lnt $^{\text {Int }}$ sondern zu den Partikeln mit abtönungsähnlicher Funktion. Ihre Kriterien da pitis. ein Lexem den Partikeln mit abtönungsähnlicher Funktion zuzuordnen, sind fol' gende: die Partikeln haben keine Homonyme in anderen Kategorien, viele Element dieser Gruppe sind vorfeldfähig und sie ändern ihre Bedeutung unter der Betonunth nicht (1983:5).

Nun treffen diese Kriterien zum Teil auf die 'klassischen' Modalpartikeln a ${ }^{4}$ " nicht zu: halt hat kein Homonym in einer anderen Partikelgruppe, und blo un $^{\mathrm{n}}$ 
nur ändern bei Akzentuierung ihre Bedeutung nicht. Das dritte Kriterium - die Vorfeldfähigkeit der 'abtönungsähnlichen' Partikeln - gilt aber bei eh und soWiesosi genau nicht.

Betrachtet man alle Partikeln, die Weydt/Hentschel (1983) als Partikeln mit abtönungsăhnlicher Funktion bezeichnen, so lassen sich alle - außer eh und sowieso den Konjunktionaladverbien zuordnen; das wurde weiter oben (in 1.2.4.1) genauer gezeigt.

Gegen eine Einordnung von eh und sowieso als Modalpartikel spricht zum einen das mögliche akzentuierte Auftreten der beiden Partikeln; zum anderen könnte die Tatsache dagegen sprechen, daß sowieso auch allein als Reaktion vorkommen kann (interessanterweise übrigens im Unterschied zu ohnehin und $\mathrm{zu}$ eh); in diesem Fall ist aber sowieso zu den Gliederungspartikeln $\mathrm{zu}$ rechnen. Auch die Bedeutung von sowieso ist dann eine etwas andere; als Gliederungspartikel bedeutet sowieso in 'twa 'selbstredend', 'klar'; allerdings lassen sich die Bedeutung von sowieso als Gliederungspartikel und als (mutmaßliche) Modalpartikel auf eine gemeinsame Bedeutung zurückführen.

Im Polgenden sollen also eh und sowieso zu den Modalpartikeln gerechnet werden, da die Gegenargumente mir nicht gewichtig genug erscheinen und sich außerdem diese beiden Partikeln von ihrer Bedeutung her recht gut den Modalpartikeln zuordnen lassen. In den meisten Punkten stimmen eh und sowieso auch syntaktisch mit den Modalpartikeln überein: sie sind nicht vorfeldfüllend. sie sind satzmodusabhängig, sie sind nicht erfragbar und nicht negierbar. Sowieso und eh sind am Rand der Modalpartikelgruppe anzusiedeln.

Die Partikeln eh und sowieso in Modalpartikel-Funktion sollen hier als Synonyme Belten. Unbestritten ist, daß eh ursprünglich als süddeutsch/österreichische VaPlante von sowieso zu sehen war (vgl. u.a. Weydt et al. 1983:163). Allerdings bestehen sowieso und eh im süddeutsch/österreichischen Dialektgebiet schon lange nebeneinander; zum anderen scheint sich eh in anderen Dialektgebieten langsam auszubreiten; so finden sich z.B. in dem Korpus von Brons-Albert (1984) eine Reihe von Sprechern mit ripuarischem Heimatdialekt, die sowohl eh als auch so- ieso verwenden.52 Es scheint sich hier um denselben Vorgang wie bei eben und $h_{a / t} z u$ handeln; im Unterschied zu letzteren kann ich allerdings bei eh und soWieso keine Gebrauchsunterschiede feststellen. Möglicherweise entwickeln sich 51) Als dritte Partikel in dieser Gruppe wäre ohnehin zu nennen; diese gehört aber eher der Schriftsprache an und soll hier nicht weiter betrachtet werden. Syntaktisch gesehen ergibt sich bei ohnehin das Problem, daß es beschränkt

52) Vorfeldfähig ist.

Im dazu auch die Aussage von Hentschel (1986:53), eh sei mittlerwelle auch In Hochdeutschen ansatzweise heimisch geworden. 
Funktionsunterschiede erst noch, wenn die Partikeln lange genug nebeneinandet bestanden haben.

Im polgenden werden deshalb die beiden Partikeln gemeinsam als Synonyme behan delt werden; das gilt auch für die Untersuchung ihrer Kombinierbarkeit mit ande' ren Modalpartikeln.

Die beiden Partikeln eh/sowieso kommen hauptsächlich in AUSSAGESATZEN vof. können aber in seltenen Fällen auch in Entscheidungsfragesätzen ${ }^{53}$ auftreten.

(1) Nelli: Vielleicht hasdann doch was an der Uni zu tun oder sonst was / Bea: Ja, irgendwann fahr ich auf jeden Fall mal hin, weil ich /öh, aber bis jetz hab ich no nichts getan, ich sollte einige Bücher lesen, und die hab ich aber no nich angeguckt, da komm ich eh! (BA, 71)

Leo: Ach nee, wär mir auch noch egal gewesen, dann hätte man alles mit einem Abwasch gemacht, mehr als zwei (Kinderl wolln wer sowieso nich. Nina: Ja, is aber viel Arbeit, die auf einmal! Leo: Ja, aber ein oder $z$ wei is sowieso scheißegal! (BA, 99)

Anna: Wieso? Is Kinder adoptieren was Schlimmes?

Lisa: Nein. Aber es gehört sich nicht. Weiß auch nicht, also, meine Mutter hat sowieso ganz komische Ansichten. Neulich hat se mich (...) gefragt, (..) ob ich mir vorstellen könnte, en geschiedenen Mann zu heiraten. (BA, ${ }^{43}$ )

Durch den Gebrauch von eh/sowieso zeigt der Sprecher zunächst einmal an, def der Sachverhalt seiner Außerung schon feststand, gültig und ihm bekannt war vof dem aktuellen Gespräch.s Deshalb soll für eh/sowieso zunächst das Merkm ${ }^{3 /}$ 〈BEKANNT>s stehen, das sich nur auf das Wissen des Sprechers bezieht und $n^{\text {hlt }}$ aup das des Hörers.

Sagen Sie. in ner Stunde komm ich sowieso, um die Ubersetzungen abzugeben! Dann könn wers hier machen! (BA, 26)

Im Beispiel (4) handelt es sich um ein Gespräch zwischen einem Manager und $^{\text {d }}$ seiner Privat-Lehrerin. Der Manager hat einige Fragen, eine französische ober

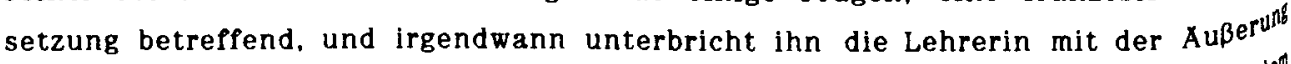
(4). Durch sowieso zeigt sie an, daß sie von vornherein - also bereits vor dep Gespräch - unabhängig von des Managers Problemen vorhatte, zu ihm zu kommefli der Sachverhalt war ihr also von Anfang an bekannt.

Die Tatsache, daß sich das Merkmal (BEKANNT>s hier nur auf das wissen des Sprechers bezieht, zeigt sich daran, daß Außerungen, die eine (zukünftige) $\mathrm{H}^{2 \mathrm{n}^{\mathrm{t}^{\prime}}}$ lung des Gesprächspartners zum Inhalt haben, kaum möglich sind (deshalb kön ne? eh und sowieso auch nicht in Aupforderungen verwendet werden); vgl.:

53) In Entscheidungsfragesätzen können die beiden Partikeln offensichtlich nut in Kombination mit der Modalpartikel nicht auftreten (Gehst du nicht so ${ }^{1 / e^{\prime}}$ jede Woche zum Friseur?). Dieses Vorkommen wird wegen seiner geringen $\mathrm{Fl}^{\prime}$ quenz nicht weiter betrachtet.

54) Hier liegt auch der Zusammenhang zwischen eh und der Konjunktion ehe. 
(5)

Und wegen der Bücher... ?*Du kommst sowieso morgen, da können wir die austauschen.

(Dis le sowieso-Außerung in (5) wäre dagegen in der Form 'ich komm sowieso morgen' Völlig adäquat.) In Fällen wie in (5) muß die Außerung, um wirklich angemessen ${ }^{55}$ zu sein, zusätzlich doch oder ja enthalten, die Bekanntheit des Sachverhalts auch lür den Hörer anzeigen.

Dle Leistung von eh und

nicht vollständig erfaßt. ${ }^{56}$ Auch die Außerungen mit eh und sowieso unterliegen $\mathrm{gan}_{2}$ bestimmten Sequenzierungsbedingungen, sie beziehen sich auf eine direkt Vorhergehende (sprachliche oder seltener nicht-sprachliche) Handlung (meist) des Gesprächspartners. Diese stellt charakteristischerweise einen irgendwie problematischen Sachverhalt dar. Mit der eh/sowieso-Außerung schränkt nun der Sprecher diese Vorgängeräußerung in ihrer Relevanz ein; das kann manchmal sogar soweit Pühren, daß sie als irrelevant gilt. Für diese Leistung von eh/sowieso soll Zusätzlich das Merkmal 〈RELEVANZEINSCHRANKUNG〉v stehen. ${ }^{37}$ Der Grund für die Relevanzeinschränkung wird in der eh/sowieso-Außerung ausgedrückt. Gleichzeitig ist mit der Einschränkung der Relevanz eine Korrekturanweisung an den Hörer verbunden; er wird angewiesen, diesen für ihn neuen Sachverhalt im folgenden zu berücksichtigen; ${ }^{38}$ eh/sowieso erhalten deshalb außerdem noch das Merkmal <KOR-

REKTUR>. Diese beiden Merkmale soll folgendes Beispiel deutlich machen:
(6)

Ein Gespräch zwischen dem Direktor einer Schule und einer Studentin, die sich um einen Aushilfsposten beworben hat.

Studentin: Wie lang is denn der Kollege vermutlich krank?

Direktor: Ach, das weiß ich nich. Das kann Wochen un Monate sein.

Studentin: Ja. Also aber/ aber jetz nich en Jahr oder so, also so lang . würdichs. nich gernel

Direktor: Ja, das hoffen wir alle nicht. Un wenn der ein Jahr, dann kommt Sowieso ein neuer.

Studentin: Ah so, ja. (BA, 175)

55) Eine Außerung wie in

'stark' Außerung wie in (5) ist - wenn überhaupt - nur möglich, wenn sie als Macht Aufforderung gemeint ist; in diesem Fall muß der sprecher eine

56) tige position innehaben, die es inm erlaubt, derartige Aussagen über zukünf-

$V_{g l}$. Handlungen des Gesprächspartners zu machen.

nur dagegen Weydt/Hentschel (1983), die als Funktion von eh und sowieso unabhen Aspekt angeben: "eh drückt aus, daß eine Aussage auf jeden Fall,

eine Hangig vom jeweiligen Kontext gilt" (19) bzw. "sowieso drückt aus, daß

7) Der Handlung auf jeden Fall (...) ausgeführt werden würde (21)".

Ahnlich ' $v$ ' steht für 'Vorgänger'.

gen und spricht auch Eder (1975:46) von einem "Zurechtrücken der Erwartunthese und Schlüsse des Partners." Allerdings kann ich Eders BedeutungshypoAuße nicht ganz zustimmen: Er geht von einer Dreier-Stufung aus, wobei ehzu enungen den Versuch ausdrücken, "den zweiten Zustand der Situationsfolge anzuknuäpten bzw. ungeschehen $z u$ machen und dafür direkt an den ersten relchendpen" (1975:44). M.E. ist aber eine zweistufige Analyse durchaus aushend. (Vgl. dazu auch Schlieben-Lange 1979:316.) 
Die Studentin hat Befïrchtungen, daß die Anstellung als Aushilfe für sie zu langt dauern könnte. Der Direktor reagiert nun mit der Darstellung eines Sachverhalts. der diese Befürchtungen weitgehend beseitigt. Durch den Gebrauch von sowiest zeigt er, daß dieser Sachverhalt für inn schon bekannt war und daß aufgrund dieses Sachverhalts die vorangegangene Außerung nur eingeschränkt relevant ist: gleichzeitig signalisiert er seiner Gesprächspartnerin, daß sie ihre Erwartungen und Annahmen korrigieren soll. Die Tatsache, daß die studentin mit ah so all diese $A$ ußerung reagiert und das Thema auch nicht weiter zur sprache bringt. zeigt, daß sie die Korrekturanweisung angenommen hat.

Vgl. auch das folgende Beispiel:

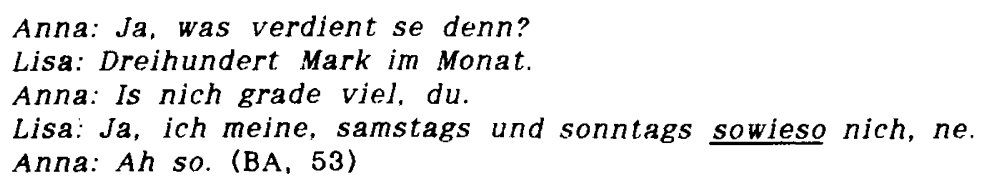

Auch hier zeigt Anna durch ah so die erfolgte Korrektur ihrer Annahmen an. Die durch eh oder sowieso ausgedrückte Relevanzminderung kann sich in seltenel Fällen auch auf ein nichtsprachliches Verhalten beziehen:

(8) Sie hetzt durch die Wohnung.

Er: Jetzt hat die Vorstellung eh schon begonnen. (Jetzt brauchst du dich auch nicht mehr zu beeilen.)

Wenn der Sprecher sich mit sowieso oder eh auf eine explizite, einen negative Sachverhalt beschreibende Vorgängeräußerung bezieht, wird die Leistung der part keln häufig noch durch wendungen wie 'macht nichts', 'ist nicht so schlimm' $e^{t c}$ verdeutlicht; vgl.:

(9) Max: Das Bier war lejder nicht im Kühlschrank.

Rolf: Macht nichts, ich hab sowieso nen empfindlichen Magen.

Mit sowieso oder eh kann ein Sprecher auch eine eigene Außerung in ihrer Relé vanz einschränken: vgl. (10) und (11), wo mit naja cin weiteres Indiz für die $A^{b^{\prime}}$ schwächung vorliegt:

(10) Gespräch über Mütter.

Also, so, ich mein, meine Ansichten erzähl ich ihr nich, ne. Ich geh Kon" flikten nach Möglichkeit da aus dem Weg, weil ich $n / n i c h$ weiß, wozu $e^{S}$ führen soll, ich kann sie sowieso nich bekehren, ne. (BA, 47).

(11) Gestern hab ich ne tolle Bluse gesehen. Allerdings für 150 Mark. Naja, ich hab eh schon viel zu viel zum Anziehen.

Dadurch, daß der Sprecher durch den Einsatz von eh oder sowieso ausdrückt.

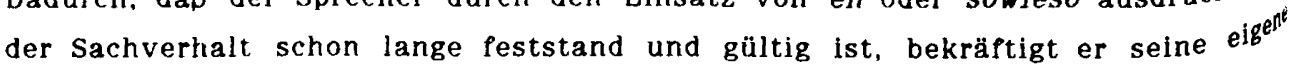
Aussage gleichzeitig. 
Manchmal kann bei einer eh/sowieso-Außerung, auch impliziert sein, daß der Sachverhalt, weil er schon lange feststeht, auch urabänderlich ist, und insofern kann die Außerung eine resignative Haltung ausdrücken; vgl. oben (10).

Mit eh/sowieso-Außerungen wird häufig ein bestimmtes Thema bzw. ein Aspekt eines Themas abgeschlossen. Sie können nicht redecinleitend oder themeneinleitend gebraucht werden, da sie sich ja auf eine Vorgängeräußerung oder -handlung beZiehen.

Wegen der Korrekturanweisung, die mit eh und sowieso verbunden ist, können sie Außerungen mit doch gleichen. Allerdings kann durch den Einsatz von eh/sowieso kein Vorwurf ausgedrückt werden, wie mit doch-Außerungen, da letztere einen Sachverhalt ja als dem Gesprächspartner eigentlich bekannt kennzeichnen, erstere jedoch nicht; vgl.:

(12a) Peter: Dann braucht sie nicht arbeiten. Weil, wenn sie ein Kind hat oder Zwei, dann gings auch nicht..

(12b) Ute: Dann geh ich sowieso nicht mehr arbeiten. (Kr, 31)

Ute: Dann geh ich doch nicht mehr arbeiten.

Die Auerung Utes in (12b) ist als Vorwurf $z u$ verstehen im Sinne von 'das weißt du, hast du das denn vergessen?'; in (12a) dagegen ist es ein nur für sie feststehender Sachverhalt, den sie als ein zusätzliches Argument ins Gespräch bringt.

2.2.7

WohI

Whl kann als Adverb auftreten und in einer Variante, die oben (s.S.110f.) als APpirmationsadverb bezeichnet wurde. Bei diesem Vorkommen (immer akzentuiert, moist im Mittelfeld, selten im Vorfeld) wird eine vorangegangene Negation aufgeloben und somit der Vorgängeräußerung widersprochen; vgl:

(1)

"Das habe ich nicht gewußt!" schrie sie a tempo. A tempo schrie er zurück. "Das haben Sie sehr wohl gewußt!" (Si, 519)

Unstritte

Tei] wird ist die Kategorisierung von untetontem wohl in Aussagesätzen: zum elchnet es als Satzadverb (vgl. Bublitz 1978:84), zum Teil als Modalpartikel beIn einem (vgl. Asbach-Schnitker 1977:40f.).

(b2w. 'ich bestimmten Typ von Aussagesätzen kann wohl nämlich mit 'vermutlich' keit 'ich vermute') paraphrasiert werden; dann schränkt der Sprecher die ciültig-

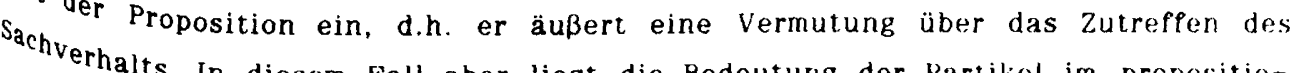
nalen rien für im niür Modalpartikeln, die ja gerade dadurch definiert sind, daß ihre Bedeutung -propositionalen, also im illokutiven Bereich liegt. Dies spricht gegen eine 
Einordnung von wohl als Modalpartikel und eher für eine Einordnung als Satzad verb. 39

Gegen die Zuordnung $z u$ den Satzadverbien läßt sich die Tatsache anführen, d\& wohl andere syntaktische Eigenschaften hat als die meisten Satzadverbien: ${ }^{s}$ kann es weder auf eine Entscheidungsfrage antworten noch das Vorfeld besetzt (s.o. S.14f. die Kriterien für Satzadverbien). Andererseits liegt im Aussagesatz if manchen Fällen die Bedeutung von wohl nicht (nur) auf der propositionale sondern (auch) auf der illokutiven Ebene. In diesen Fällen kann wohl dann a uct nicht mehr durch 'vermutlich' paraphrasiert werden. Bei wohl ist also in Aussabe' sätzen ein Ubergangsbereich anzusetzen zwischen der Modalpartikel-Funktion un der Satzadverb-Funktion. Und da hier keine scharfe Grenze zu erkennen ist, sol' len im folgenden alle (unbetonten) Verwendungen im Aussagesatz beschriebet werden.

Außer in Aussagesätzen tritt die Modalpartikel wohl noch in Entscheidungsfrag $\mathbb{E}^{\ell^{\prime}}$ sätzen und $w$-Fragesätzen auf. Alle Verwendungsweisen lassen sich mit dem Merk" mal 〈EINSCHRANKUNG〉 beschreiben.

Bei den AUSSAGESATZEN kann durch wohl also die Gültigkeit des Sachverhalli eingeschränkt werden (hier ist auch die Verbindung zu vermutlich zu sehen); vgl: (2) Tragicomix ist mit einem Truppentransport aufgebrochen. Zur Stunde wird er wohl gerade von Massillia aus nach Afrika eingeschifft. (A X, 17)

(3) Wenn das so weiter schneit, werde ich morgen wohl früher aufstehen mils' sen und Schnee schaufeln.

(4) Das tut mir leid, wenn mein Sohn Ihren Mantel bekleckert hat. Das hat et wohl nicht mit Absicht gemacht.

Die durch wohl angezeigte Einschränkung kann sich daraup beziehen, da $\beta$ Sprecher nicht genügend Evidenzen dafür hat, die Geltung eines Sachverhalts ( $u^{n^{\prime}}$ eingeschränkt) zu behaupten, z.B. weil es sich um übernommene Erfahrungen odel Meinungen handelt (vgl. (6) und (7)). Aus diesem Grund ist wohl auch nicht ${ }^{k}$ zeptabel, wenn der Sprecher Behauptungen über allgemein gültige und evident Sachverhalte äußert oder bestimmte Feststellungen über sich selbst macht ( g $^{l}{ }^{(\beta)}$ und (9)).

(5) Das da drüben ist wohl der zuständige Sachbearbeiter.

(6) Ich mein, die erzählen immer viel von dieser Referendarzeit, ne. Am An fol solls wohl gemütlich sein, hinterher sehr anstrengend. (BA, 60)

59) Der Unterschied zu ja, das sich auf die Proposition bezieht, liegt darin, in $j a$ die Proposition bewertet und kommentiert, aber nicht verändert, wo hl $^{\text {it }}$ t $^{\prime}$ diesen Verwendungen aber die Proposition verändert, sie in ihrem Wahrhe ${ }^{\text {li }}$ gehalt einschränkt. 
(7)

Und da ham Carla und Ina aber gesagt, sie ständen im Examen, un sie können das nich organisieren und Ina, die muß wohl sowieso unheimlich sauer auf Hedwig sein, die hat der wohl'n Hochzeitsgeschenk geschickt, und da hat Hedwig nich drauf reagiert. (BA, 184)

(9) Die Erde ist wohl eine Kugel.

"Ich bin wohl blauäugig. (vgl. aber: Ich bin wohl zu (!) gutmütig.)

In den Beispielen (5) und (6) llegt wohl im Ubergangsbereich; Indiz dafür ist auch, daß es hier nicht mehr durch 'vermutlich' ersetzt werden kann. Die Sprecherin schränkt durch wohl weniger die Gültigkeit des Sachverhalts 'am Anfang solls gemütlich sein' ein, sondern die von ihr vollzogene Behauptung. Das Merkmal 〈EINSCHRANKUNG) bezieht sich hier also auf den illokutiven Akt.

Dadurch, daß der Sprecher mit wohl seine Behauptung einschränkt, gibt er dem Hörer gleichzeitig mehr Möglichkeit, die Behauptung zu bestätigen oder zu widerlegen. Wohl engt also nicht wie eben die Fortsetzungsmöglichkeiten des Hörers ein, sondern weitet sie aus; wohl gibt dem Hörer Spielraum (vgl. Trömel-Plötz 1978:18). Durch den Gebrauch von wohl kann der Sprecher auch Vermutungen äußern, die

dazu dienen, dem Hörer eine Stellungnahme zu 'entlocken':
(10)

Nora: Und dann ging auch noch irgendwo eine Rakete in die falsche Richtung los, so daß alles nach hinten stürzte, und jeder sich mit seinem eigenen Sekt begoß

Eva: (lacht) na, war wohl ne lustige Fête

Nora: ja, vor allen Dingen nach Mitternacht wurde es dann sehr lustig! (BA, 72)

Frageh eignen sich deshalb Aussagesätze mit wohl besonders gut, um eine ven Sa Sinn läßt sich so erklären: der Sprecher macht eine Behauptung über einen einerhalt, die er aber durch den Gebrauch von wohl einschränkt; er äußert also eine 'tentative Behauptung'. Will der Hörer kooperativ reagieren, wird er - wenn er mehr Information hat - den Sprecher entweder in seiner Einschränkung bestätỉgen oder gegebenenfalls widerlegen. Dazu ist er bei wohl-Ǎßßerungen umso mehr Verplichtet, wenn der Sprecher - was sehr häufig ist - eine Aussage über den (1) macht. Vgl.:

Asterix zu Obelix, der verliebt ist:

(12) Unter uns, sie gefällt dir wohl, die kleine Falbala, was? (A X, 8)

Sie sind wohl nach Bonn gekommen, um uns allen telefonisch die Feind-

(13) Schaft anzusagen? (Bö a, 127)

Bea: Du arbeitest wohl ununterbrochen, sach ma?

In diesem Felli: Nee, ich hab doch... (BA, 70)

über Gefühle wird die Frage-Interpretation nicht nur durch den Inhalt (Aussage

noch durchle oder Handlungen des Angesprochenen), sondern auch sehr häufig durch 'tag questions' oder Ausdrücke mit ähnlicher Funktion gesteuert (vgl. 
die Beispiele oben). Steigende Intonation weisen diese Außerungen allerdings nicht auf; deshalb sind sie auch nicht zu den Assertiven Fragen (s.o. S.69f.) zu rech nen. ${ }^{60}$

Eine große Gruppe von Aussagesätzen mit wohl stellt eine negative Bewertunt meist über den Gesprächspartner oder auch über Dritte dar und weist vermutlich gerade deshalb häufig eine gewisse expressive Färbung auf.61

Du spinnst wohl! Woher soll ich denn das Geld nehmen für ein BMX-kad?

(16) Im Heer wird der Sold ausgehandelt

Der Zenturio: 6 .Asse pro Tag!

Der Söldner: Beim Hermes! Ihr scherzt wohl! (A X, 22)

(17) Der Typ da drüben, der hat sie wohl nicht mehr alle!

Durch die Modalpartikel wohl wird auch hier die Behauptung eingeschränkt und danit die Außerung abgeschwächt. (Die Wirkung von wohl liegt hier also im ill ${ }^{\circ}$ kutiven Bereich.) Beispiel (14) oder (15) etwa wirken ohne die Modalpartikel deut licher und unverbindlicher, mit ihr dagegen etwas milder (vgl. (14) vs. (14a)) d $^{d g}$ sie wie ( $14 \mathrm{~b})$ umschrieben werden können:

\section{(14) Du spinnst wohl! \\ (14a) Du spinnst! \\ (14b)' Ich behaupte mit Einschränkung, daß du spinnst.}

Somit wird dem Angespruchenen -- wenn auch nur formal - Gelegenheit gege $e^{\text {el }}$. die Behauptung richtigzustellen. Man vergleiche die Außerung (14) mit: Du spin n $^{4}$ eben! Die Möglichkeit zur Richtigstellung hat der Gesprächspartner umso ment. wenn der Sprecher 'tags' verwendet; vgl.:

(14c) Du spinnst wohl, was? oder?

(ierade die Tatsache, daß bei wohl-Außerungen durchweg 'tags' verwendet werd ln $^{n}$ können (die ja vor allem dazu dienen, Vermutungen des sprechers anzuzeigen), ist auch ein Indiz dafür, daßs es sich um eingeschränkte, tentative Behauptung ${ }^{e^{n}}$ handelt. 62

60) Die Tatsache, daß solche Außerungen der Form nach Aussagesätze und somil $^{76}$ Behauptungen (wenn auch eingeschränkte) sind, erklärt die von Conrad ( $19^{70}$ festgestellte Antworterwartung: Conrad rechret diese Außerungen zu den pros $^{\text {s }}$ sumptiven Fragen, das sind Fragen, die hinsichtlich der "Vorstellungen, zeugungen und Annahmen des Fragestellers" (83) markiert sind. Dabei nim $2 \nu^{\prime}$ der Sprecher bei Fragen mit wohl an, daß die Proposition der Außerung ${ }^{4}$ trifft.

$61)$ Asbach-Schnitker (1977:5:3) bezeichnet derartige Außerungen als Ausrufe ${ }^{18}$

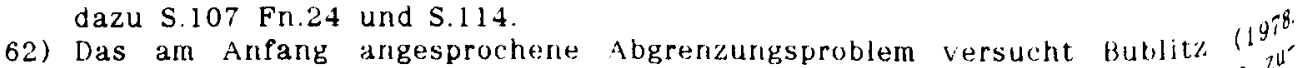
$85 \mathrm{ff}$.) dadurch zu umgehen, daß er die Modalpartikel wohl nur in Fragen te $^{y^{\prime}}$ läßt, die aber auch die Form von Aussagesätzen aufweisen können. Auf dit Weise läßt sich allerdings die Grenze zwischen Satzadverb und Mudalpart th $^{\text {tht }}$ wohl auch nicht feststellen, denn der Berriff Frage(handlung) ist doch 
ENTSCHEIDUNGSFRAGESATZE mit der Modalpartikel wohl sind relativ selten. Fragen mit wohl werden eher als ob-Fragesätze realisiert; vgl.:

Ein Ehepaar kommt nach Hause. Beim Aufsperren der Tür sagt sie: Ob die Kinder wohl abgespült haben?

(19)

Ob ich wohl diesmal die Prüfung bestehe?

Denkst du wohl noch an mich?

anchmal wohl richtet der Sprecher auch an sich selbst ${ }^{63}$ (deshalb werden sie 'deliberative' oder 'nachdenkliche' Frage bezeichnet); er erwartet sich durchaus eine Reaktion des Gesprächspartners. Bei diesen Fragen handelt es meist um Fragen, die nicht auf das Wissen des Hörers abzielen, das er in (19) Fällen ebensowenig hat oder haben kann wie der Sprecher (vgl. (18) und (19)), sondern eher nach seiner Vermutung, seiner Meinung oder seiner Erwartung Pragen (vgl. Asbach-Schnitker 1977:50). Das Merkmal 〈EINSCHRANKUNG〉 bezieht sich also auch hier auf den illokutiven Akt, es handelt sich um ein 'einge'schränktes' Fragen, da ja eine der normalen Verwendungsbedingungen für Fragen (Sprecher weiß/nimmt an, daß Hörer die Antwort wei $\beta$ ) nicht erfüllt, sondern modi-

Die ist (Sprecher weiß/nimmt an, daß Hörer die Antwort nicht weiß).

ist also eingeschränkt (vgl. Bublitz 1978:87); der Sprecher erwartet aber zumindest gende dem. Fragen mit wohl wirken höflicher als Fragen ohne wohl, da der Fra1979 Gesprächspartner verminderte Erkennbarkeit zugesteht (vgl. Reiter Bei

Bei entspre

Fragen sein ohne wohl - aber z.B. nicht mit denn-Fragen) eine Aufforderung intendiert ni $\mathrm{vgl}$. (21):

In Könnten Sie mir wohl helfen, den Kinderwagen die Treppe hinaufzutragen? Fragesatziform Fall handelt es sich wegen des Merkmals 〈EINSCHRANKUNG〉 und der $\operatorname{Ein}$

(22)

(23) Wirst du wohl still sein, Steffi?! Du weckst doch das Baby auf. Wirst du wohl die Klappe halten? 
(24) Beim Heimwerken: Gehst du wohl auf?!

Mit diesen Außerungen, die häufig auch an Tiere oder (widerspenstige) Dinge $g^{\ell^{\prime}}$ richtet sind, werden Aufforderungen mit einern drohenden oder auch beschwörendent Unterton ausgedrückt.

Diese Aufforderungsinterpretation aber kommt nicht durch die Modalpartikel zustande; $;^{64}$ entsprechende Außerungen sind nämlich auch ohne wohl möglich:

(25) Waldi, GEHST du her!

(26) BIST du jetzt endlich ruhig!

Diese Außerungen unterscheiden sich formal von Entscheidungsfragesätzen vor at lem durch die Intonation: Zum einen liegt immer ein starker Akzent auf dem fin ten Verb am Satzanfang, zum anderen weisen diese Außerungen fallendes Ton $\mathrm{m}^{\prime}$ ster auf.60 Intonatorisch sind diese Außerungen also ein besonderer Typ und $n^{\mathrm{j}^{\mathrm{h}}}$ zu den Entscheidungsfragesätzen zu rechnen. ${ }^{66}$

Daß gerade (und nur) die Modalpartikel wohl in diesen Außerungen auftreten $\mathrm{kan}$ könnte daran liegen, daß sie aufgrund ihrer Bedeutung einer Aufforderungshan ${ }^{2}$ lung jedenfalls nicht entgegensteht. Einen Unterschied zwischen diesen Auflor ${ }^{d l^{\prime}}$ rungen mit und ohne wohl kann ich nicht feststellen.

In den W-FRAGESATZEN wird - wie bei den Entscheidungsfragen - durch die ${ }^{p g^{\prime \prime}}$ tikel wohl die Fragehandlung hinsichtlich der Fähigkeit des Gesprächspartners antworten eingeschränkt. Häufig treten die w-Fragen mit wohl auch mit ve f $^{b^{\prime}}$ Endstellung auf; vgl.:

(27) Wie geht es wohl der Inge in ihrem neuen Job?

(28) Was wird wohl noch alles auf uns zukommen?

(29) Wie sie wohl gelebt haben mögen im oftmals wüsten blanken Haus? (SZ)

(30) Woran das wohl liegt?

Der Sprecher richtet also auch bei einer $w$-Frage die Frage an sich selbst erwartet vom Hörer allenfalls eine Vermutung, aber kein sicheres Wissen. 64) Insofern irrt Asbach-Schnitker (1977:53), wenn sie wohl hier als Indikator
Sprechakttyps Aufforderung bezeichnet. Unzutreffend auch Weydt/Hents (1983:18), die meinen, wohl sei fester Bestandteil dieser Konstruktion.

65) Diese Sätze sind zu vergleichen mit ob-Verb-Letzt-Sätzen, die ebenfalls $e^{1}$ starken Akzent am Satzanfang (also auf $o b$ ) aufweisen und eine Auffordl darstellen; vgl. oben S.54 Fn.66.

66) Der Unterschied $z$ wischen diesem Typ von 'starken' Aupforderungen (wie (2) und den 'höplichen' Aufforderungen in der Form eines Entscheidungs ${ }^{\text {tgl }}$ satzes (wie (21)) liegt also - und das gilt für Vorkommen mit und ohne ${ }^{\prime}$ gleichermaßen - vor allem in der Intonation, aber auch an den verben: dalverben wie können und dürfen und vor allem Konjunktiv-II-Formen f $^{00}$ neben steigender Intonation - relativ sichere Indikatoren für höfliche ${ }^{j}$ je derungen; vgl.: Könntest du mir jetzt (wohl) helfen? vs. Wirst du mir (wohl) helfen! 
Das zeigt sich daran, daß z.B. Fragen nach dem Befinden des Hörers mit wohl inadäquat sind:

(31) "Wie geht es dir wohl?

Und Fragen wie (32), die der Hörer (bei normalem Geisteszustand) beantworten können muß, sind nur in zwei Făllen adäquat: Wenn entweder der Sprecher ausdrücklich sich selbst fragt, die Antwort also z.B. raten will; in diesem Fall signalisiert wohl dem Hörer, nicht zu antworten - dann ist er m.E. auch von der Verpflichtung zu einer Reaktion befreit. Oder wenn auch der sprecher selbst die Antwort weiß und in diesem Fall ist wohl eher ironisch zu verstehen. Manchmal kann die ganze Außerung auch drohend wirken (vgl. auch (33)).

(32) Wie alt bist du wohl? Wo bist du wohl geboren?

(33) Wie hast du das wohl gemacht? Der Gangster: Was macht man wohl mit Leuten wie Ihnen? Wo führt es wohl hin, wenn man sich mit der Polizei einläßt?

W-Fragesätze mit wohl treten häufig auch verkürzt und als Reaktion auf eine (34) Frage auf; vgl.:

Uli: Von wem ist denn der Brief?

Es handelt

Wort eröpfnete sich hier um einen Sonderfall rhetorischer Fragen: die durch das wZu Püllen; viele Lücke ist nicht mit einem negierenden Pronomen oder Adverb etc. Antwort vielmehr zeigt der Sprecher an, daß es genau eine mögliche 'positive' Modalpartikel, die Sprecher wie Hörer bekannt ist; vgl. (35), ein Beispiel ohne handlung. Insofern handelt es sich auch hier um eine eingeschränkte Frage$s_{c h} n_{;}$all in dieser Verwendung gleichen sich die beiden Modalpartikeln wohl und eher in vollings tritt wohl eher in verkürzten Außerungen auf, schon dagegen

(35) vollständigen (s.u. S.154); vgl. (36). Jetzt nörgel nicht so rum! Wer wollte unbedingt nach Spanien? Und wer hat

(36) inmer gesagt, da könnte man sich prima erholen? (Das warst doch du.)

Karl: Wer hat denn dieses Jahr den 'Jedermann' gespielt?

Evi: Na, wer wohl?

Wer wird den schon gespielt haben? 


\subsubsection{Schon}

Bei der Partikel schon lassen sich die unterschiedlichen Partikelfunktionen nicht $^{\text {h }}$ immer klar voneinander trenren. Klare Fälle sind die Beispiele (1)-(3); in (1) ist schon Temporaladverb, in (2) Gradpartikel (vgl. König 1977b) und in (3) Modal' partikel: 67

(1) Ihr seid schon da?

(2a) Reutte liegt schon in Tirol.

(2b) Schon für wenig Geld erhalten Sie heute ganz passable Taschenrechner.

(3a) Wer verliert schon gern beim Spiel?

(3b) Komm schon!

In einer Verwendung wie (4) wird mit schon, das hier einen Kontrastakzent trägh

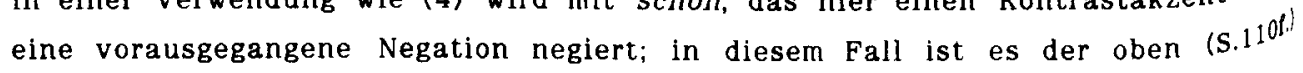
etablierten Gruppe der Affirmationsadverbien zuzuordnen.

(4a) Angeklagter: Das habe ich nie gesagt.

Kläger: Das haben Sie schon gesagt! Dafür gibt es Zeugen.

(4b) Hanna: Was danach kommt, is gar nich wichtig, so is!

Reni: Bloß daß bei dir das ebn schon wichtig war. ( $\mathrm{Kr}, 158)$

Im Unterschied $\mathrm{zu}$ den noch $\mathrm{zu}$ besprechenden Vorkommen wie (5) und (6) $2^{\mathrm{e} \mathrm{i}^{\mathrm{l}}}$ schon hier nur widerspruch an, eine Weiterführung (z.B. mit aber) ist nich $^{\text {hl }}$ nötig. ${ }^{68}$

Wesentlich mehr Probleme bei der Zuordnung zu einer der Partikelfunktion machen die folgenden Verwendungen:

(5a) Ina: Das find ich ja toll, daß du jetzt ein Auto hast.

Max: Schon. (Aber es kostet halt auch viel.)

(5b) Peter: Hilft er dir nicht im Haushalt?

Ute: Schon, aber mit was für einem Gesicht.

In allen diesen Fällen liegt schon (das hier mit offenem oder geschlossenem ${ }^{10}$ gesprochen wird) betont vor - oder kann zumindest betont verwendet werden, gegen eine Einordnung als Modalpartikel (wie sie z.B. Gornik-Gerhardt (1981) vot nimmt), sprechen könnte, ebenso wie die Tatsache, daß schon (nahezu) isoliert ${ }^{\text {ls }}$ Reaktion oder Antwort auftreten kann; diese Funktion tcilt es mit den satzadver'

67) In Verwendungsweisen wie in (i) liegt schon m.E. in einem Ubergangsber $e^{\mathrm{j}^{\mathrm{t}^{\mathrm{l}}}}$ zwischen Modalpartikel und Gradpartikel: (i) Wenn ich schon 300 Mark füt "th' Paar Stiefel zahle, müssen die auch warm sein. In diesem Fall wird die Als sage auf einer Skala der 'Nicht-Selbstverständlichkeit' eingeordnet, wobej ${ }^{88}$ ! Aussage mit schon auf dieser Skala höher liegt (vgl. Gornik-Gerhardt ${ }^{19} \mathrm{abl}^{\mathrm{l}}$ $114 \mathrm{ff}$.). Ahnlich ist es auch in der Verbindung mit (gar) nicht: Der

68) Merkwürdigerweise gehen auf diese m.E. häufige Verwendung von schon we de dell Franck (1980) nuch Gornik-Gerhardt (1981) ein, obwohl sich beide mit Varianten von schon beschäftigen, die partiellen Widerspruch ausdrücken. 
bien (s.o. S.14f.) und mit den Gliederurigpartikeln (s.o. S.j8f.). Von den Satzadverbien nun unterscheidet sich schon dadurch, daß es nicht im Vorfeld eines möglichen Antwortsatzes stehen kann (vgl. (5a)'), und von den Gliederungspartikeln dadurch, $d a \beta$ es auch in einem möglichen Antwortsatz integriert auftreten kann; vgl. (5a)" und $(5 \mathrm{c})$ :

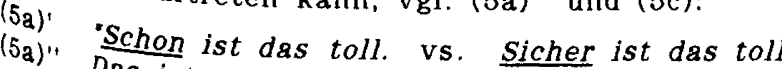

(5c) Das ist schon toll. vs. "Das ist nein toll.

Franz: Was steckt denn da dahinter? Ihr habts eine schöne WohnungUte: Schön is schon da herin, sicher! Hat aber auch einen Haufen Geld

(5c)' gekostet die E'inrichtung. (Kr, 19)

Schon Ute: Schon! Hat aber auch einen Haufen Geld gekostet.

doch. Das ist also nicht im gleichen Sinne ein Satzäquivalent wie ja, nein oder nahezu zeigt auch die Tatsache, daß schon zwar isoliert stehen kann, aber Ahnlich obligatorisch eine aber-Außerung folgt.

(6a) problematisch ist auch folgende Verwendung:

Hans: Also ich kann für morgen kein Auto organisieren.

(6b) Inge: Ich schon.

A: Grüne und rote Kleider stehen mir überhaupt nicht.

B: Grüne schon, finde ich, aber rot paßt nicht zu deinen Haaren.

(6c) Franck 1980:195)

Franz: Staatlich gibts doch eine Krippe überall?

Auch in

zeichnet diesem Fall ist die Einordnung umstritten: Franck (1980:194f.) z.B. beals Antwortpartin Verwendungen wie (6), das meist mit [0:] ausgesprochen wird, partikel. Pranck

Vorang (1980:195ff.) hat festgestellt, daß in allen Fällen ((5) und (6)) eine ihrer Gültigene Behauptung "partiell bejaht und partiell bestritten [wird], d.h. in sich schon eit eingeschränkt (wirdl auf eine Teilbehauptung" (195). Dabei verhält negierten, nach einer negierten Vorgängeräußerung anders, als nach einer nicht schon-satim ersten Fall wird durch schon die vorangegangene Negation für die im durch satz wiederholte Teilaussage aufgehoben (vgl. (6a,b)), im zweiten Fall wird in $z$ weip eine positive Tellaussage bestätigt, eine andere dagegen nachfolgend a)

b) SCHON

CHON $P_{1}$ : Ass $\left(P_{1}\right)$ und/aber Neg $\left(P_{2}\right)$

Vorgänger: Ass $\left(P_{1}\right)$ und Ass $\left(P_{2}\right)$

SCHON $P_{1}$ : Ass $\left(P_{1}\right)$ und nicht Ass $\left(P_{2}\right) / \mathrm{Neg}\left(P_{2}\right)$ (Franck 1980:197)

69) Antwort

70) Nämlich

Die von ja, nein und doch.

müßten Franck nicht behandelten Vorkommen wie (4) (Affirmationsadverb) en mit folgendem Schema dargestellt werden: 
In den angeführten Fällen besteht die Funktion von schon also darin, für die Vorgängeräußerung oder auch Implikaturen daraus eine Teilbestätigung und einen Teilwiderspruch anzuzeigen, sie also in ihrer Geltung einzuschränken. Diese Einschränkung eines Vorgängerzuges findet sich auch bei schon in ModalpartikelFunktion.

Verwendungen wie (6) (und bei (5) zumindest die satzintegrierten Vorkommen) liegen wohl in einem obergangsbereich zwischen Affirmationsadverb und Modalparti kel. Gegen eine Einordnung als Affirmationsadverb spricht, da $\beta$ in den angeführten Fällen der Vorgänger nur teilweise bestritten wird. Das zeigt sich auch an def Akzentstruktur; vgl.:

(6c) In MUNCHEN SCHON, (aber nicht in TRAUNREUT.) vs.

(4a) Das haben Sie SCHON gesagt.

Die Modalpartikel schon tritt in drei Satzmodi auf: im Aussagesatz, im Imperativ satz und im $w$-Fragesatz. In dieser Verwendung ist schon unbetont.

Zunächst zu den AUSSAGESATZEN:

Hier läßt sich zwar die Geltungseinschränkung eines Vorgängerzugs immer noch nachweisen, sie ist aber nicht immer so explizit wie bei den oben angeführten Varianten.

(7) Franz: Also den Akkord tatsächlich über die Grenze lbei 250] treiben, das darf nicht sein, das schadet euch.

Marina: Ja, einmal in der Woch kann ich schon 300 machen, aber ofter fallt auf. (Kr, 109)

(8) Eva: Du hättest eben niemals das ganze Geld auf einmal überweisen dürfen. Ute: Ja, da hast du schon recht; aber ich hab geglaubt, es wäre alles okgy.

(9) Arno: Das Essen bei Inge war ja fürchterlich.

Clara: Naja irgendwo schon, aber sie hat sich doch sehr viel Mühe gegeben.

Die Funktion von schon ist auch hier, nur Telle der Vorgängeräußerung zu bestá tigen, ihr also nur eingeschränkte Geltung zuzuerkennen. Deshalb soll schon $\mathrm{m}^{\text {it }}$ dem Merkmal 〈GELTUNGSEINSCHRANKUNG〉v beschrieben werden. Vgl. (7): Mari ${ }^{8}$ zelgt an, daß 'man darf den Akkord nicht über die Grenze treiben' nur elngé schränkt gilt, denn einmal in der Woche ist es eben doch möglich. In Beispiel (8) werden Implikaturen aus der Vorgängeräußerung (Vorwurf bzw. Tadel) einge schränkt, indem die Sprecherin Gründe für ihr Handeln anführt.

Der Sprecher bestätigt also durch den Einsatz von schon Teile der Vorgängeräußé rung und weist Telle zurück. Das kann z.B. bedeuten, daß der Sprecher prinzipte $e^{i l}$ die vorangegangene Behauptung bestätigt, sie aber für den vorliegenden Fall nicht

Vorgänger: Neg (P)

SCHON (P): Ass (P)

In diesem Fall wird die gesamte Vorgängeräußerung (ohne die Negation) derholt. 
akzeptiert und sie insofern in threr (Allgemein-)Gültigkeit einschränkt. Deshalb können Außerungen mit schon oft einlenkend sein.

Die Eins

Vorgängeräußerung ist besonders in Verwendungen wie (8)

einem weiteren argumentativen Schritt verbunden: Der Sprecher räumt

etwas ein.71

Die Geltungseinschränkung von schon kann sich auch auf eine eigene Vorgängerăußerung beziehen; vgl.:

(10)

Doris: Ach Gott, ne, für mich wär das nischt.

Hans: Nee?

Doris: Ich wär in Englisch total doof!

Hans: Ach so'n paar Bildergeschichten, das schaffsde do auch!

Doris: Ich hab ganz kurz reingeguckt, naja ma kommt schon irgendwie mit.

(BA 110)

Her

schränkt Doris ihre eigene Behauptung 'ich wär in Englisch total doof' durch

chon-Satz in ihrer Geltung (zumindest was Comics betrifft) ein. Ein weiteres

Indiz dafür ist auch naja.

Bel

en Gegenargumenten kann - so Franck (1980:204) - die Komponente

'Werstrebend zugeben/äußern' hinzukommen. In diesem Fall ist die schon-Auße-

rung oft von einer obwohl-Außerung gefolgt, die in der Regel Ausdrücke wie

sonst, normalerweise, eigentlich, im Grunde etc. enthält; der Sprecher zeigt dann

mit seiner Außerung an, daß seine Haltung zu einem bestimmten Sachverhalt in

dlesem aktuellen Fall nicht zutrifft, er also seine grundsätzliche Position (die in

der obwohl-Außerung noch einmal expliziert wird) hier einschränken muß (vgl.

(1 la)). Häufig steht schon dann auch in Ausdrücken mit einem verbum dicendi in der ersten Person (vgl. (1 j b)):

(11a) Also das Konzert gestern

(11b) nichts anfangen kann.

Umgekeh muß schon zugeben, das Konzert gestern war toll.

ben ehrt wird in Außerungen wie (12), die durch die Verwendung von Modalver-

Wiese direktive Komponente erhalten, der Gesprächspartner durch schon ange-

aufen, selne Gegenposition, für die der Sprecher die Gründe im Prinzip anerkennt,

Pranck 1980. und den im schon-Satz dargestellten Sachverhalt zuzugeben (vgl.

(12)

Du solltest schon etwas Besonderes kochen. Schließlich ist es das erste

Mal, daß die Haugs zu Besuch kommen.

71) Vol.

Spr. dazu Franck (1980:205), die schon hier als Illokutionsindikator für einen spechakt der Einräumung bezelchnet. Eventuell könnte deshalb für schon ein dungelleres Merkmal angesetzt werden; da dies allerdings für andere Verwenungsweisen (z.B. die zukunftsbezogenen schon-Außerungen) nicht gilt, und umgekehrt das Merkmal <GELTUNGSEINSCHRANKUNG $\rangle_{v}$ in diesem Fall auch 'greift', soll nur dieses Merkmal verwendet werden. 
Eine mögliche Gegenposition kann auch nur angenommen werden und so von vorn herein in ihrer Geltung eingeschränkt werden; auf diese Weise kann der sprechet möglichen Einwänden vorbeugen, was letztlich zu einer stärkung der eigenen $A 4^{\circ}$ sage pührt.

(13) Olaf hat sein Fahrrad selbst repariert. Das ist schon eine Leistung für jemanden, der bis vor zwei Monaten nicht einmal wußte, wie ein Schraubenzieher aussieht.

(14) Sie neigte ein bißchen zur Exzentrik, hatte ihr Haus düster und ihr eigenes Zimmer tiefschwarz gestrichen. Ihre Partys galten als wild. Sie verstand schon $z u$ leben und hatte auch das Geld dazu. (SZ)

(15) Der Martin ist schon geschickt. Wie der mir heute in null komma nix die Schleuder repariert hat...

Ein unterstellter Einwand in (13) wäre z.B. 'sein Fahrrad selbst reparieren isl keine Leistung'. In Fällen wie $(16)-(18)$ hat schon wohl hauptsächlich die Funk' tion, durch die 'Quasi-Einschränkung' die eigene Außerung berechtigter, abgesi' cherter, plausibler erscheinen zu lassen.

(16) Hans: und grad das paßt dem andern wahrscheinlich wieder nich, während sie in/in ihrer Märtyrerrolle aufwächst, ne. und auf Grund dessen vielleich grade zum Saufen bringt, ne. Oder auch ihn anstachelt, weiter zu machen. Doris (lacht)

Hans: Ja, das is schon verworren, so.

Doris: Jaja, manchmal ist es schon ganz schön schwierig! (BA, 117)

(17) Es ist schon ein Kreuz mit dir.

(18) ...mit dem Blitzlicht, das war ne gute Investition, muß ich schon sagen funktioniert immer. (BA, 15)

Die Grundbedeutung der Modalpartikel schon läßt sich also beschreiben mit 'Eln' schränkung möglicher Gegenargumente', die sowohl eigene als auch fremde se $e^{\text {il }}$ können. Damit ist auch erfaßt, daß der sprecher grundsätzlich akzeptiert, daß ${ }^{\text {s }}$ Gegenargumente gibt (was bei Außerungen mit eben z.B. nicht der Fall ist) und daß diese Gegenargumente in gewisser Weise ihre Berechtigung haben, aber be ${ }^{i^{-}}$ spielsweise nicht im vorliegenden Fall. (Den Gegenargumenten wird ja mit sch nicht völlig widersprochen.)

Mit einer großen Gruppe von Aussagesätzen, die schon enthalten, bezieht sich ${ }^{\text {fel }}$ Sprecher auf die Zukunft:

(19) Andi: Meine Güte, jetzt müßte ich bis zur Prüfung noch drei Bücher lesen. Aber ich kann einfach nicht mehr. Ich fall bestimmt durch.

Uli: Du wirst es schon schaffen.

(20) Es geht um den Kauf einer Wohnung.

Olga....Und da gibt's durchaus Sachen für . unter 100.000 (...)

Lena: Ja, gibts hier auch. Also, ja, doch, diese eine zu 80.000.

Olga: Also, ich meine, es muß natürlich auch wat sein, aber. wart da $m^{8}$ auf ne günstige Gelegenheit, es muß nich die erstbeste sein, wir finden schon was. (BA, 138) 
(21) Franz: Bist fertig bist /mit der Zusatz-Ausbildungl, vergehn runde zehn Jahr. Wie gehts mit dem Geld in der Zeit?

Schorsch: Ach, ich komm schon irgendwie durch. (Kr, 77)

Auch in diesen Fällen reagiert der Sprecher auf einen Vorgängerbeitrag, der oft Probleme thematisiert oder zumindest eine pessimistische Haltung impliziert. Durch schon wird nun die Geltung dieser explizit dargestellten oder zu erschließenden Probleme eingeschränkt; so ließe sich schon in (19) umschreiben: 'du hast Gründe Pür deine pessimistische Haltung, aber die möchte ich für diesen Fall einschränken und dir sagen: du wirst es schaffen'.

Ahnlich läßt sich schon in (22) erklären, wo keine explizite Außerung vorausgeht: (22)

Nach umständlichen Wegbeschreibungen:

Direktor: ...Das is der Weg, den Sie über die Severinsbrücke fahrend machen können/nehmen können.

Studentin: Jo. Ah, irgendwie wer ichs schon finden. (BA, 174)

Die Tatsache, daß der Direktor den weg sehr umständlich erklärt, ist ein Indiz dafür, daß er vermutet, die Studentin würde Schwierigkeiten haben, den Weg zu linden. Die Studentin schränkt eine daraus abgeleitete Behauptung wie 'Sie werden Schwierigkeiten haben den Weg zu finden' durch den Gebrauch von schon ein; eine zusătzliche Beschwichtigung wird in diesem Text auch durch die Verwendung von ah erreicht (ähnlich auch in (21)).

Zukunftsbezogene schon-Außerungen können eine beruhigende, tröstende oder auch überzeugende Wirkung haben, da der Sprecher durch den Gebrauch von schon die explizit geäußerten oder erschließbaren Befürchtungen des Gesprächspartners zurückweist und somit eine gewisse Sicherheit zeigt, den Sachverhalt so zu behaupten.r2 Franck (1980:208) hat darauf hingewiesen, daß derartige Außerungen nur Hoffnung, nicht aber Furcht ausdrücken können. (Verwendungen wie Es wird schon schiefgehen sind nicht wörtlich zu verstehen.) Aus diesem Grund sind wohl bei den futurischen schon-Außerungen Aussagen mit expliziter Negation eher möglich (s.0. S.92): dann nämlich, wenn die Befürchtung des Gesprächspartners als nichtnegierte Aussage zu sehen ist; vgl.:

72) Gornik-Gerhardt (1981 Außerung -Gerhardt (1981:88f.) geht davon aus, daß die Gründe, die zu der sind. geführt haben, für den Hörer plausibel und somit präsupponiert Grün. M.E. geht es aber bei diesen Außerungen nicht um das Anführen von ohne der Sprecher kann auch gegen den evidenten Anschein und damit ihr jeden plausiblen Grund eine derartige schon-Außerung machen und mit schon beruhigende, beschwichtigende Wirkung erreichen. Die Funktion von sprä ist hier nur darin zu sehen, daß die pessimistische Haltung des $\mathrm{Ge}-$ Der vopartners nicht (zumindest nicht im vorliegenden Fall) akzeptiert wird. Bekann Gornik-Gerhardt (1981:93) geführte Nachweis für die Plausibilität und Beispietheit der Gründe ist nicht überzeugend, da die Inakzeptabilität des daraue ("Das ist schon nicht das Medikament, das wird der Föhn sein) nicht nen, zurückzuführen ist, daß sich die beiden Gesprächspartner nicht kenen, sondern schlichtweg an der Negation liegt. 
(23) (Befürchtung: 'Sie werden schießen)

Auf Ihren blonden Kopf werden sie schon nicht gleich schießen. (SZ)

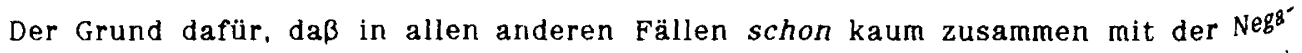
tionspartikel nicht oder anderen Negationsträgern auftreten kann (s.o. S.92f.) liegt darin, daß schon eingeschränkte Geltung (d.h. aber Teilbestätigung und Teil widerspruch) anzeigt, mit Negationsträgern dagegen die Geltung bestritten wird Insofern kollidieren die Verwendungsbedingungen von schon und Negationsträgern. Noch einmal ein Vergleich der Modalpartikel mit den oben angeführten Verwendun gen von schon, die im Ubergangsbereich zwischen Affirmationsadverb und Modal' partikel (Beispiele (5) und (6)) liegen. Der Unterschied zwischen diesen (betonte? bzw. betonbaren) Varianten und den (unbetonten) Modalpartikeln ist darin $\mathrm{zu}^{\mathrm{s}^{\circ}}$ hen, daß bei ersteren ein expliziter, negierter Vorgänger vorausgehen muß, dess $s^{e^{n}}$ Negation mit schon teilweise oder ganz aufgehoben wird, bei der Modalpartikel aber nicht. (Deshalb kann sich auch nur die Modalpartikel auf eine Präsupposition beziehen.) Das zeigt sich ganz deutlich, wenn man bei den angeführten Modalpar" tikel-Beispielen schon betont, was ganz bestimmte Kontextbedingungen schaff: "If diesem Fall ist als Vorgänger nur ein expliziter, negierter Satz möglich; vgl. (1 ${ }^{g}$ und genauso (10a) oder (17a):

(19a) Du wirst es SCHON schaffen. Notwendiger Vorgänger: Ich werde es nicht schaffen.

(10a) Man kommt SCHON irgendwie mit.

(17a) Das ist SCHON ein Kreuz mit dir.

Von der Bedeutung her gleichen sich diese beiden Varianten von schon aber $\mathrm{in}^{\mathrm{SO}^{\circ}}$ fern, als in beiden Fällen Geltungseinschränkung vorliegt. Wegen dieser Annlich" keit läßt sich auch zwischen der Modalpartikel-Verwendung und den anderen vor kommen keine klare Grenze ziehen. ${ }^{73}$

Auch in den IMPERATIVSATZZEN werden mit der Modalpartikel schon tatsäch $\left.\right|^{\mid i^{l} l^{\natural}}$ oder mögliche Einwände des Gesprächspartrers eingeschränkt und für den konk $k^{r \ell^{\prime}}$ ten Fall zurückgewiesen. Die Einwände können explizit geäußert werden oder miv' sen z.B. aus dem Zögern des Angesprochenen erschlossen werden; vgl.:

73) Grundsätzlich ist m.E. schon nicht nur in dieser Hinsicht, sondern auch in 'klaren' Modalpartikel-Funktion noch nicht erschöpfend analysiert. Mir sche $\mathrm{se}^{\text {' }}$ z.B. auch in manchen Fällen der Modalpartikel-Verwendung etwas von wil skalierenden Bedeutung der Gradpartikel schon vorhanden zu sein. oder ${ }^{j^{k}}$ ist es sonst $z u$ erklären, daß die Antwort a) in folgendem Beispiel wesent $e^{i p^{i}}$ akzeptabler ist und b) eher ironisch zu verstehen ist - außer man legt ${ }^{t} f^{i}$ andere Bewertungsskala (Vegetarier!) zugrunde? (Die Akzpetabilität sich auch nicht, wenn man in der Frage die Reihenfolge der Glieder tauscht.)

(i) Er: Soll ich morgen Blumenkohlauflauf machen oder was mit Fleisch?

a) Sie: Blumenkohlauflauf ist schon okay.

b) ?Fleisch ist schon okay. 
(24) Legionärsausbildung.

Ausbilder:...jetzt üben wir mit dem Gladius, dem Schwert! Es sind natürlich Ubungswaffen aus Holz!

Obelix rührt sich nicht.

Ausbilder: Na los! Wehr dich!

Obelix: Aber wo es doch aus Holz ist!

Asterix: Mach schon, Obelix! Wir verlieren nur Zeit. (A X, 27)

(25)

"Wenn Herr General $Z$ weifel an meincn Worten hegen, ersuche ich, augenblicklich ein Führungs-Blitzgespräch nach Köln anzumelden!" "Aber Sie müssen doch verstehen..." (lange Diskussionenl " (..), dann sind die Folgen unabsehbar...Und nun melden Sie schon endlich Köln an!" (Si, 70/71)

Er: Tanzen wir?

Sie: Nein, diese südamerikanischen Tänze kann ich leider nicht.

Er: Das ist doch gar nicht schwer. Na los, komm schon!

Imperativsätze mit schon werden in Situationen geäußert, in denen offenkundig ist, daß der Sprecher bereits auf die Ausführung der Handlung wartet; d.h. der Angesprochene weiß, daß er die Handlung längst hätte ausführen sollen (vgl. Franck 1980:208 und Gornik-Gerhardt 1981:101). (In dieser Hinsicht gleichen sie Aufforderungen mit doch.) Sprachliche Indizlen dafür sind z.B. auch Elemente wie endlich in (25) oder na los! in (26). Je nach Kontext können schon-AufforderunBen Ungeduld oder Nachsicht ausdrücken. ${ }^{74}$

$\mathrm{Für}_{\mathrm{r}}$ das Zögern des Angesprochenen erkennt der Sprecher durch den Gebrauch von schon mögliche Gründe an - hierin unterscheidet sich schon von doch in Aufforderungen -, schränkt diese aber in ihrer Geltung ein und fordert den Hörer auf, seine bisherige Position aufzugeben.

In R-FRAGESATZEN ist die Modalpartikel schon immer ein Indikator für rhetorische Fragen.75 Rhetorische Fragen sind als Behauptungen zu verstehen, bei denen in der Regel die durch den w-Ausdruck eröffnete Lücke durch ein negierendes Pronomen, Adverb oder einen entsprechenden negierenden Ausdruck gefullt ist.

Wie schon Rhetorizität bewirken kann, läßt sich folgendermaßen erklären: Das Merkmal 〈GELTUNGSEINSCHRANKUNG〉 bezieht sich hier auf eine Implikatur oder Folgerung aus der Vorgängeräußerung, die als Präsupposition dem w-Fragesatz zuBrundeliegt. Bei einer $w$-Frage ohne schon ist ja die Präsupposition 'es gibt ein $x$, 'ür das gilt $\mathrm{p}^{\prime}$ zugrundeliegend, bei einer Frage mit schon wird nun diese in ihrer Geltung eingeschränkt, was zu der Präsupposition 'es gibt kein $x$, für das gilt p' Pührt. (Die Geltungseinschränkung ist hier allerdings relativ stark.) Eine Frage mit

\footnotetext{
74) In der Literatur wird schon in Aufforderungen meist die Bedeutung "Ungeduld"

75) Zugeschrieben (vgl. z.B. Helbig/Kötz 1981:36 oder Weydt et al. 1983:102). er zweite Indikator für Rhetorizität ist die Modalpartikel auch. Schon und a $u c h$ unterscheiden sich in ihrer Distribution insofern, als schon sehr selten in warum-Fragen steht, auch dagegen fast nur in diesen (vgl. dazu Franck 1980:210 und Meibauer 1986:115).
} 
schon ist deshalb also immer eine rhetorische Frage, und damit eine negierte Behauptung. Mit dieser Behauptung ihrerseits wird widerspruch bezüglich eines Aspekts des Vorgängerzugs angezeigt, da ja eine Folgerung aus diesem zurückgewiesen wird. Darauf deutet auch hin, daß diese schon-Fragen oft mit aber (vgl. $(27) /(28)$ ) eingeleitet sind. Die Geltung anderer Teile der Vorgängeräußerung aber bleiben von dieser Zurückweisung unbetroffen. In (28) etwa wird der Vorgänger vorab explizit bestätigt, aber die daraus ableitbare Folgerung 'man gibt Kindern nichts Ungesundes' wird mit der schon-Frage zurückgewiesen.

(27) Anna: Also, wenn mir jemand anbieten würde, mir mein Gehalt so zu zahlen. ich würd nich arbeiten gehen!

Lisa: Ja, ich auch nich, Mann! Da wärn wir ja auch dumm. Aber wo findet man schon jemanden, der das macht, du.(BA, 52)

(28) Keine Frage: Kinder müssen gesund essen. Aber wer kommt schon gegen Pommes und Schokolade, Limonade und Naschereien an? (SZ)

(29) Das alles - sie habe der Blum fünfzehn Zeitungsausschnitte hingelegt habe diese nicht getröstet, sie habe nur gefragt: "Wer liest das schon? Alle Leute, die ich kenne, lesen die ZEITUNG". (Bö b, 55)

Auch durch eine rhetorische w-Frage mit schon wird also der Vorgängeräußerung nur teilweise widersprochen; dabei gibt der schon-Satz die Begründung für den (Teil-)Widerspruch an (vgl. Bublitz 1978:93). Die Teilzustimmung, die ja auch für andere Verwendungen von schon charakteristisch ist, kann auch explizit geäußert werden (vgl. (27) und (28)).

Einen Sonderfall stellen rhetorische w-Fragen dar, bei denen die durch den Ausdruck eröffnete Lücke nicht durch ein negierendes Pronomen o.ä. besetzt werden muß, sondern bei denen es genau eine mögliche ('positive') Antwort gibt, die dem Hörer auch bekannt ist (s.o. S.145). Dieser Typ von rhetorischen Fragen ist - wenn eine Frage schon enthält - nur dann möglich, wenn die schon- $\AA u \beta e^{-}$ rung eine Reaktion auf eine andere Frage ist:

(30) Uwe: Was hast du denn heute gemacht?

Mara: Na, was werd ich schon gemacht haben? (Gearbeitet natürlich.)

Hier wird durch schon nicht die der Frage zugrundeliegende Präsupposition eingeschränkt (die Frage wird auch nicht durch schon zu einer rhetorischen Frage. sondern aufgrund ihrer kontextuellen Einbettung); die durch schon angezeigte Einschränkung kann sich hier nur daraup beziehen, daß der sprecher die Vorgängeräußerung und zwar genauer: die Relevanz oder Berechtigung des Frageakts $e^{i n^{-}}$ schränkt. Da der Sprecher seinem Partner mit einer derartigen 'rhetorischen Echó Prage' anzeigt, daß es nur eine - und zwar eine offensichtliche - Antwort $\mathrm{a}^{4}$ seine Frage gibt, eine Antwort, die der Gesprächspartner längst weiß, und da $e^{e ?}$ sich deshalb seine Frage hätte sparen können, wirken diese Fragen meist re ${ }^{h^{\mathfrak{h}}}$ unhöflich. 
Die Partikel auch liegt vor als Konjunktion, als Gradpartikel und als ModalPartikel. Als Modalpartikel tritt auch auf in Aussagesätzen, Entscheidungsfragesätzen, w-Fragesätzen und - allerdings wesentlich seltener - in Imperativsätzen und $w$-Exklamativsätzen. ${ }^{76}$

Gerade in den Aussagesätzen ist die Unterscheidung zwischen auch in Gradpartikel- und in Modalpartikel-Funktion 77 oft recht schwierig. Als Unterscheidungskriterien bieten sich die Intonation (die Modalpartikel kann nie betont sein), der Vorangegangene Kontext, und das Vorfeldverhalten an (die Modalpartikel kann nicht in Vorfeld stehen). ${ }^{78}$ Vgl. (1); übernommen von Weydt/Hentschel (1983:7):

(1a) Peter: Russisch ist ganz schön schwer.

Max: Deutsch ist AUCH nicht einfach. (Gradpartikel)

(1b) Ali: Ich hab von dem Text nicht alles verstanden.

Max: Naja, Deutsch ist auch nicht EINFACH. (Modalpartikel)

Im AUSSAGESATZ stellt die Modalpartikel auch immer eine Verbindung zur vorhergehenden Außerung her; dafür wird das Merkmal 〈KONNEX〉 angenommen.

(2)

Elke: Stell dir vor, der Peter hat eine Eins im Staatsexamen!

(3)

Gisi: Der hat auch ziemlich viel dafür geschuftet.

(4)

1. Soldat: Der Sold ist da!

2. Soldat: Wird auch Zeit! (A XIII, 13)

Anna: Bei der Demo gestern waren fast keine Leute.

Karl: Klar. Die haben auch alle Angst nach diesen vielen Verhaftungen.

Mit auch zeigt der Sprecher an, daß der in der Vorgängeräußerung dargestellte achverhalt für ihn erwartbar war. Deshalb soll auch mit dem Merkmal <ERWAR$T E T\rangle_{V / s}$ beschrieben werden.79 Der auch-Satz liefert dabei die Begründung dafür, warum der Sachverhalt der Vorgängeräußerung ${ }^{80}$ den Erwartungen des Sprechers 76)

Dedeutung der Modalpartikel auch ist eirigermaßen schwer zu fassen. Das zeigt sich auch an den in der Literatur angebotenen Beschreibungen; vgl. Bublitz 1978:118ff., Dittmann 1980, Weydt/Hentschel 1983:6f. Die beste Analy-

77) Se stammt von Franck 1980:2108f.

Probleme macht hier auch, daß bei der Gradpartikel-Funktion der Skopus nicht immer offensichtlich ist; vgl. Verwendungen wie: Reg dich nicht auf, so

78) Schlimm wars auch wieder nicht.

nisse meinen Beobachtungen gibt es allerdings dennoch manchmal Mißverständtiert, wenn die Modalpartikel vom Gesprächspartner als Gradpartikel interpretiert wird, was sich an Rückfragen wie: Was heißt 'auch'? Wer/Was etc. denn

79) Noch? zeigt.

(bei bei einer Bewertung der Vorgängeräußerung als 'erwartet' oder 'unerwartet' (bei denn und etwa) immer Sprecherbezug vorliegt, verzichte ich im folgenden

80) auch wegen der besseren Lesbarkeit auf den zusätzlichen Index ' $S$ '.

ranck (1980:216) hat daraup hingewiesen, da $\beta$ sich in Beispielen wie (i) auch bezit auf den Sachverhalt, sondern auf das Außern der Vorgängeräußerung bezieht (im Sinne von 'daß du das sagst, ist nicht erstaunlich, denn...'): 
entspricht (vgl. Franck 1980:212). Der Inhalt der auch-Außerung und der der Vorgängeräußerung stehen also in einer kausalen Beziehung.

Die Bedeutung von auch in (4) etwa läßt sich so umschreiben: 'Ich habe erwartet, daß zu dieser Demo wenig Leute kommen, denn die haben jetzt alle Angst.' Ein weiteres Indiz für die Bedeutung von auch sind häufig mit dieser Partikel zusammen auftretende Ausdrücke wie 'klar' (vgl. (4)) oder 'kein Wunder' etc.; vgl. auch (5), wo die Erwartung des Sprechers explizit thematisiert wird:

(5) Angestellter: Wenn ihr Geld einzahlen wollt, geht rauf zur Kasse. Asterix: Ich komm nicht zum Einzahlen, sondern zum Abheben. Angestellter: Das hätte mich $\underline{\text { auch }}$ gewundert. (A XIII, 41)

Auch-Außerungen können zusätzlich erklärenden oder rechtfertigenden Charakter bekommen, besonders, wenn sich der Sprecher mit einem auch-Satz auf eine eigene Außerung bezieht (vgl. Franck 1980:215); auch in diesem Fall wird der dort dar gestellte Sachverhalt als erwartbar gekennzeichnet aufgrund der auch-Außerung.

(6) Anna: also meine Schwiegereltern und meine Eltern, die. ham sich (...) erst zweimal gesehn einmal bei unserer Hochzeit und das zweite mal bei Karls einer Ausstellung. Da kamen se beide hin, aber sonst sehn die sich nie! Lisa: Jaja Anna: Können auch nix mitenander anfangen! (BA, 38f.)

(7) Und wie ich nach Hause kam: lch stieg an der Haltestelle aus - und meine Frau stieg da ein. Sie wußte das ja nicht, daß ich kam ich hatte ja auch nie geschrieben, konnte ja auch nicht. (BP, 23)

Die Behauptung im auch-Satz gilt nicht als bekannt für den Hörer; handelt $e^{s}$ sich dabei um einen nach Ansicht des Sprechers auch dem Hörer bekannten sachverhalt, wird auch mit ja verbunden (vgl. (7)), eine Kombination, die häupiger ist als auch alleine.

Aus dem für auch angenommenen Merkmal 〈ERWARTET>v läßt sich ableiten, daß die Vorgängeräußerung in ihrer Geltung bestätigt wird (hierin unterscheidet $s^{i^{c}}$ auch von schon, ${ }^{\mathbf{1 1}}$ das die Geltung des Vorgängers einschränkt).

Bestimmte pragmatische Implikaturen aus der Vorgängeräußerung wie z.B. Erstaunen (vgl. Franck 1980:212) oder Kritik werden allerdings durch das Merkmal 〈ERWARTET>v von auch entkräftet; ${ }^{22} \mathrm{vgl}$. (2) oder auch (8):

(8) Tochter: Papi, ich will nicht, daß du schon wieder wegfährst.

Vater: Das weiß ich ja; aber ich bring dir dafür auch was Schönes mit.

(i) A: Das Bild hängt zu hoch.

B: Dir kann man auch nichts recht machen.
81) Bei den von Bublitz (1978:118) angeführten futurischen Beispielen Die werder auch wieder heilen, bei denen er eine Ahnlichkeit zwischen schon und a uch sieht, handelt es sich um die Gradpartikel: Skopus von auch ist die; außerder

kann auch hier nicht unbetont sein.
82) Die von Bublitz (1978:119) angenommene Bedeutung von auch "in der Begrün"
" dung eines impliziten Widerspruchs gegen eine vorangegangene Implikatur" stehen, ist allerdings zu speziell. 
Wegen der Geltungsbestätigung der Vorgängeräußerung können auch-Außerungen nicht mit einer widerspruchanzeigenden Partikel wie nein eingeleitet sein ( $\mathrm{vgl}$. Franck 1980:212; vgl. (9)) - es sei denn, es handelt sich um eine Antwort aup eine Frage (vgl. (10)). Wegen der Abschwächung bestimmter Implikaturen aus der Vorgängeräußerung können jedoch naja oder aber als Einleitung fungieren (vgl. (8) oder (11)).

(9)

Elke: Mensch, dein Pullover ist ja irre warm!

Bea: Ja, das ist auch reine Mohairwolle. Mein bestes Stück.

"Nein, das ist auch Polyacryl.

Sie: Bist du heute dazugekommen, den Rasen zu mähen?

Er: Nein; es war auch schon dunkel, wie ich daheim war.

Oft tritt auch in Außerungen auf, mit denen explizit die Relevanz einer Vorgängeräußerung abgeschwächt wird (wie das ist egal etc.), wobei in dieser ein (meist eigenes) Unvermögen dargestellt wird.

(1)

Ich weiß ja gar nich, wat da drauf is, hab ich schon wieder längst verges-

Die dargestellte Funktion von auch macht

Fon auch macht deutlich, daß durch den Gebrauch von ach Außerungen immer in einen größeren (oft argumentativen) Kontext eingebettet werden. ${ }^{83}$

Auch in ENTSCHEIDUNGSFRAGESATZEN kann auch mit dem Merkmal (ERWARTET) beschrieben werden; in diesem Fall bezieht es sich jedoch nicht auf eine vorgänBeräußcrung, sondern auf den in der Frage geäußerten Sachverhalt.

(12)

Heute haben wir die Fürstin zum Gabelfrühstück! Werden Sie auch pünktlich zurück sein, Herr P.ittmeister? (En, 80)

(13)

(14) Erzählst du auch bestimmt nichts? Sonst darf ich wieder nicht raus!

(15) Vor dem Austeilen der Mitbringsel: Wart ihr auch brav?

(16) Am Beginn eines Urlaubs: Haben wir auch genug Geld dabei?

Manfred und ich gehörten zu den wenigen Auserwählten, die mit Hannes Mit di Radausflüge machen durften. "Habt ihr auch tüchtig aufgepumpt?" (Ke, 122) Frage dargen Fragen macht der Sprecher deutlich, daß er die Gültigkeit der in der in nergestellten Proposition, also Zustimmung erwartet (in positiven Fragen ja, stimmte Fragen nein). Entscheidungsfragen mit auch zeigen demnach eine be$1979: 8)$

\footnotetext{
83) der ist der Zusammenhang zwischen der Konjunktion, der Gradpartikel und Die Modalpartikel auch zu sehen.

san Weydt/Hentschel (1983:7) angenommene Bedeutung von auch in Aus"oft ätzen, "das Ausgesagte in einen größeren Zusammenhang" zu stellen, der "oft ein Begründungszusammenhang" ist, ist jedoch - wie die vorangegangene Analyse gezeigt hat - zu unspezifisch.
} 
Mit einer auch-Frage wird immer eine Verbindung zu einer anderen (sprachlichen oder nicht-sprachlichen) Handlung hergestellt (Merkmal 〈KONNEX〉): der Sprechef versichert sich mit der auch-Frage eines Sachverhalts, der meist Voraussetzung für eine geplante Handlung ist (vgl. König 1977a:128 und Franck 1980:217). So ist z.B. in (14) das Brav-Sein die Voraussetzung für das Verteilen der Geschenke odet in (15) ausreichend Geld Voraussetzung für einen angenehmen Urlaub. Je nach Einstellung des Sprechers zu dieser Handlung können die Fragen deshalb auch eine besorgte oder ängstliche Haltung ausdrücken. Da die entsprechende Antwort vom Sprecher nicht nur erwartet, sondern auch erwünscht wird - eben weil die zustimmende Beantwortung und damit die zur Frage gestellte Handlung Voraussetzung für eine andere Handlung ist - soll hier zusätzlich das Merkmal 〈 $\mathbb{R}^{R^{-}}$ WUNSCHT $>$ s angenommen werden.

Der in den Fragen dargestellte Sachverhalt ist meist aufgrund allgemeiner Norm n $^{n}$ und Gesetzmäßigkeiten erwartbar und insofern 'normale' Voraussetzung für die $g^{e^{-}}$ plante Handlung; er kann aber auch auf individuellen Vorstellungen des Sprecher ${ }^{5}$ beruhen, die dann meist, aber nicht immer (vgl. dagegen Körig 1977a:129) auch dem Gesprächspartner bekannt sind.

(17) Ist mein Badewasser auch ganz kalt?

(18) Die kleine Sekretärin, die hoch hinaus will (Jean Harlow), probiert ein Kleid: "Ist es auch durchsichtig?", fragt sie die Verkäuferin besorgt. (S2)

Der dargestellte Sachverhalt ist aber in jedem Fall eine notwendige Voraussetzunb für etwas anderes - und das kann der Hörer aufgrund des Gebrauchs von a ch $^{\text {h }}$ erschließen.

Ahnlich wie in den Entscheidungsfragesätzen läßt sich auch in IMPERATIVSATZN - einer eher marginalen Variante - beschreiben: auch hier entspricht die Hand lung, zu der aufgefordert wird, einer allgemein gültigen Norm, und die krfüllunb der Aufforderung wird deshalb vom sprecher erwartet. Aufforderungen mit a th $^{\text {th }}$ sind häufig verbunden mit schön und werden typischerweise von Erwachsenen ${ }^{\nu}$ Kindern, oder jedenfalls bei asymmetrischer Beziehung zwischen den Gesprächs" partnern geäußert:

(19) Nun iß auch schön!

(20) Und sei auch brav!

W-FRAGESATZE mit der Modalpartikel auch sind immer rhetorische Fragen. Dies $^{s}$ läßt sich möglicherweise so erklären: Auch steht typischerweise in Fragen $\mathfrak{m}^{\mathrm{j}^{\mathrm{l}}}$ warum/wieso (vgl. Franck 1980:218 und Meibauer 1986:115), also in Fragen $n^{a^{c^{h}}}$ dem Grund. Geht man nun davon aus, daß auch als Modalpartikel eine Vorgänger 
ăußerung begründet, mithin einen Grund angibt, so kollidierte dies mit den regu-

lären Bedingungen einer warum-Frage; diese muß also rhetorisch sein. ${ }^{84}$ (21)

Dje Frau war ziemlich ruhig, jammerte nicht, fragte bloß immer wieder: "Wo mögen sie nur sein" und erzählte ständig, daß sie bloß eben mal ausgestiegen sei, um was zu holen. (...) "Warum bleibt sie auch nicht im Zug sitzen, in dieser Zeit, was hat sie denn auszusteigen?" (Ke, 428)

Ina: Oh Gott, jetzt hat die schöne Seidenbluse einen Fettfleck! Mutler: Ja, warum ziehst du auch zum Kochen keine Schürze an?

Auch in diesen Fällen wird durch auch eine Verbindung zur Vorgängeräußerung markiert (Merkmal 〈KONNEX〉): die auch-Außerung (ohne warum) führt eine Begründung für den im Vorgängerbeitrag dargestellten Sachverhalt an; dabei wird mit auch angezeigt, daß dieser Sachverhalt aufgrund von Normen, Gesetzmäßigkeiten Oder Erfahrungswerten vom Sprecher erwartet wurde (Merkmal (ERWARTET>v).

$\mathrm{Di}_{\mathrm{i}}$ einem $w$-Fragesatz mit auch vorausgehende Außerung bezeichnet - wie Franck (1980:218) festgestellt hat - in der Regel einen unerfreulichen Sachverhalt (vgl. Oben $(21) /(22)$ und das von Franck (1980:218) übernommene (23a)). Das läßt sich damit erklären, daß diese Fragen als rhetorische Fragen implizite Behauptungen sind wie 'es gibt keinen Grund, warum du...'. Als erklärende Reaktion aup einen

(23) Inge: Ich fühl mich heut so schlecht.

Nora: Kein Wunder. Warum gehst du auch immer so spät ins Bett?

Inge: Ich fühl mich heut so wohl.

In den Nora:?"Kein Wunder. Warum gehst du auch immer so früh ins Bett?

che seltenen rhetorischen Fragen mit anderen w-Ausdrücken hat auch die gleidar Funtion, nämlich anzuzeigen, daß der Sprecher den in der Vorgängeräußerung (24)

)

Der Jochen muß 4.000 Mark Kaution bezahlen! Aber wer unterschreibt auch einen Mietvertrag, ohne ihn vorher genau durchzulesen?

In den

In der D-EXKLAMATIVSATZEN kann auch in seltenen Fällen auch allein auftreten,

(25) Regel aber erscheint es in der Kombination aber auch.

Edler von Salchow und Ferdinand von Germitz. Nichtsnutze vom Lande.(..)

Wenn sie welche gefunkt kriegten, dann lachten sie: Geschieht uns ganz

Auch in recht, oh, oh, was sind wir auch für blöde Kerle. (Ke, 236)

den in dieser Verwendung kann sich das Merkmal 〈ERWARTET) von auch nur auf

mit orgängerbeitrag bzw. eine vorangegangene Handlung beziehen, da es sonst den Verwendungsbedingungen eines Exklamativs kollidierte.

84) "sanck (1980:219) dagegen erklärt die Rhetorizität damit, daß auch hier eine aupgeindeutige Tendenz bewirkt, daß die Frage nicht mehr als echte Frage a gefaßt werden kann". 
In allen Verwendungsweisen läßt sich also für auch neben dem Merkmal 〈KONNEX) das Merkmal 〈ERWARTET> nachweisen. In den Aussagesätzen und den $w$-Fragen (sowie w-Exklamativen) bezieht es sich auf die Vorgängeräußerung, in Entscheidungsfragen auf die auch-Außerung selbst. In letzteren kommt zusätzlich das Merkmal 〈ERWUUNSCHT〉 hinzu.

Mit sowieso hat auch gemeinsam (in Aussagesätzen), daß es eine Außerung in einen größeren argumentativen Zusammenhang einordnet. Die beiden Partikeln unterscheiden sich aber insofern, als auch den Vorgängerbeitrag bestätigt und $\mathrm{er}^{\mathrm{r}^{\circ}}$ klärt oder begründet, sowieso den Vorgängerbeitrag aber gerade durch das Anführen eines weiteren Arguments einschränkt.

Aufgrund dessen können auch und sowieso kaum im selben Kontext vorkommen und $^{\text {nd }}$ sind deshalb auch nicht kombinierbar; vgl. die unterschiedliche Kontexteinbettung:

(26) Ruth: Die Mona ist vielleicht immer nervös.

Paul: Die trinkt auch viel Kaffee, da wundert mich das nicht.

(27) Ruth: Oh je, wir haben für heute abend nichts zu trinken.

Paul: Ach, da machen wir einfach Kaffee. Die Mona, die trinkt sowieso viel Kaffee, da wird ihr das am Abend nichts machen.

Mit eben hat auch gemeinsam (in Aussagesätzen), daß ein kausaler Bezug zur vor gängeräußerung etabliert wird; sie unterscheiden sich aber dadurch, da $\beta$ auch die Vorgängeräußerung wertet und nicht - wie eben - die Außerung mit der Partikel.

\subsubsection{Nicht}

Wie oben in Kapitel 1.4 ausführlich erläutert, kann nicht als Modalpartikel in Entscheidungsfragesätzen oder $w$-Exklamativsätzen auftreten. In den Exklamativ sätzen ist nicht immer mit einem allquantifizierenden Ausdruck wie alles verbun den (vgl. (1)); diese Variante soll hier nicht weiter behandelt werden.

Gehören Sie etwa auch zu den Rettungslosen, die inmer noch Briefe versenden, statt Telephon zu quasseln? Was hat die Post nicht alles getan. uns von unserem Laster zu heilen! (SZ)

Die ENTSCHEIDUNGSFRAGESATZE mit nicht können als Fragen fungieren (vgl. (2) und (3)), sehr häufig sind sie rhetorische Fragen, die oft auch emphatisch $g^{\ell^{\prime}}$ äußert werden.

In den Fragen hat nicht vor allem die Funktion, die Erwartung des Sprechers hin $^{\text {" }}$ sichtlich der Antwort zu verdeutlichen:

(2) Beim Gutenachtsagen legte sie mir die Hand auf die Stirn. "Sieht sie nicht aus wie eine Gräfin?" (Ke, 11)

(3) Sollte man den Marktplatz nicht lieber neu gestalten? Rathaus, Museum un - ja, Kirche oder Kino, das war die Frage. (Ke, 48) 
(4) Schau mal die Kleine da drüben! Ist die nicht bezaubernd?
Der Sprecher zeigt durch den Gebrauch der Modalpartikel nicht, daß er eine Be-
stätigung des in Sachung des in der Frage geäußerten Sachverhalts, also die Gültigkeit dieses ger jaes

tung, doch. Fragen mit nicht sind demnach Fragen mit starker AntworterwarTARTE Suggestivfragen. Diese Leistung von nicht soll mit dem Merkmal <ERJe

Überhdem, wie stark die Erwartung des Sprechers ist, daß der Gesprächspartner Pische eine Fragen. Die Grenzen zwischen Fragen und rhetorischen Fragen sind fließend, Die Zuordnung muß vor allem über den Kontext erfolgen (vgl. Grésillon 1980:281). ge Entscheidung darüber, ob es sich bei einer Außerung um eine rhetorische Frage oder eine Frage mit Antworterwartung handelt, hängt aber auch vom semantischen Gehalt ab: Wenn eine Außerung mit der Modalpartikel nicht eine gegenwärtige oder zukünftige Handlung oder Einstellung des Gesprächspartners zum Inhalt hat, kann es sich nur um eine Frage handeln und nicht um eine rhetorische Frage (vorausgesetzt, eine rhetorische Frage wird als implizite Behauptung verstanden), ${ }^{d a}$ der sprecher keine Feststellung über zukünftige Handlungen oder Einstellungen

des Partners machen kann; vgl.: "Willst du nicht runterlaufen und auf Wiedersehen sagen?" fragte meine (6) Mutter. (Ke, 97)

Die Frage keine Auch in torische Frage.

nicht $b_{2 \text {. }}$. aus, daß er die Geltung des in der Frage geäußerten Sachverhalts erwartet, (7) Starker, daß der Sachverhalt für ihn gültig ist.

Habe ich dich nicht immer wieder vor diesem Mann gewarnt?

(8) (= Ich habe dich immer wieder gewarnt.)

Außerungen konnte er uns das antun! Haben wir ihm nicht alles gegeben?

Vităt geả mit der Modalpartikel nicht können auch mit einer gewissen Expressigeäußert werden; das gilt besonders für Sätze mit dem Verb sein. ${ }^{86}$ Auch bei

\footnotetext{
85) Wie

(6) Wort oben (S.86f.) schon erläutert, ist gerade die Tatsache, daß mit ja geant6) Dertet werden kann, ein Indiz für die Modalpartikel-Funktion.

1977.119e Außerungen werden oft als Ausrufe bezeichnet (vgl. z.B. Roncador Phet:111). Nach meinem Verständnis handelt es sich hier eher um expressive Katorische Fragen, da der Sprecher nicht unbedingt Staunen signalisiert (zur ategorisierung von Außerungen als Ausruf siehe auch S.107 und S.114).
} 
diesen Außerungen ((9) und (10)) drückt der Sprecher seine Bestätigungserwartull aus. Auch hier trägt nicht also das Merkmal 〈ERWARTET〉s.

(9) Ist das nicht schön! Eine Koalition der Vernunft hat alles zu einem glück lichen Ende gebracht. (SZ)

(10) Stell dir vor, das Finanzamt hat meinen Einspruch nicht anerkannt. Ist do nicht eine Schweinerei?

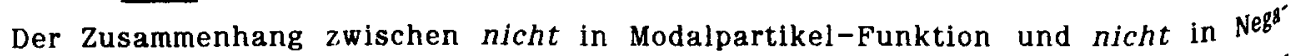
tionspartikel-Funktion läßt sich so erklären: Durch den Gebrauch der Negation $5^{\circ}$ partikel nicht in Aussagesätzen zeigt der Sprecher dem Gesprächspartner, dif dieser seine Erwartung oder Annahme in bezug auf den im Aussagesatz geäuß $e^{t^{t ! n}}$ Sachverhalt verwerfen und korrigieren muß (vgl. Schmidt 1973:191). In den Ent" scheidungsfragen deutet der Gebrauch der (meist betonten) Negationspartikel nill darauf hin, daß der Sprecher bis dahin von einer positiven Erwartung oder vor ${ }^{\text {in }}$ formation ausgegangen war, nun aber irgendein Ereignis, das dieser Erwartulf widerspricht, dazu geführt hat, daß er seine Erwartung in Frage stellen un eventuell korrigieren muß (s.o. S.86). Der Sprecher stellt in diesem Fall also del Hörer die Frage, ob eine Korrektur nötig ist:

(11) Was? Haben Sie NICHT gewählt? Das gibts doch nicht.

Bei der Modalpartikel nicht ist die Korrekturanweisung nur schwach vorhanden; ${ }^{\text {jt }}$ kann hier darauf bezogen werden, daß der Sprecher dem Hörer aufgrund der angé zeigten starken Bestätigungserwartung signalisiert, eventuelle gegenteilige ErW' tungen zu korrigieren; deshalb könnte hier zusätzlich das Merkmal 〈KORREKT T ${ }^{\mathbb{R} \text { ) }}$ angenommen werden. Dieses Merkmal erklärt auch die funktionale Ahnlichkeit vol nicht-Außerungen mit doch-Außerungen; vgl.:

(9a) Ist das nicht schön! vs. Das ist doch schön!

Die Variante mit doch ist in ihrem Behauptungscharakter stärker, well es $\mathrm{sill}^{\mathrm{i}^{l}}$ hier nicht mehr um einen Fragesatz handelt, sondern um einen Ausagesatz un $^{\text {th }}$ somit nicht einmal mehr formal (eben durch die Frageform) die Geltung des $\mathrm{sact}^{\mathrm{c}^{\prime}}$ verhalts offen ist. Selbst bei einer rhetorischen Frage kann sich der Sprecher ${ }^{\text {j }}$ auf die Frageform seiner Außerung zurückziehen (vgl. Grésillon 1980:275).

Zentral ist bei nicht aber die angezeigte Antworterwartung und nicht die Korre $\mathrm{k}^{\mathrm{k}^{\prime}}$ turanweisung. Nicht als Modalpartikel gehört somit in die Reihe derjenigen Pa $\mathrm{rt}^{\mathrm{t}^{\prime}}$ keln, die eine starke Antworterwartung ausdrücken und so den Gesprächspar ${ }^{\text {t } \text { th }^{4}}$ steuern.

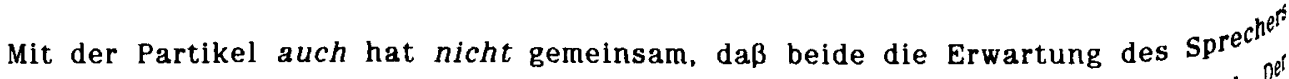
signalisieren, daß der in der Frage ausgedrückte Sachverhalt bestätigt wird. ${ }^{\text {de }}$ Unterschied $z$ wischen den beiden liegt zum einen darin, daß auch-Fragen $\mathrm{k}^{\mathrm{k} \mathrm{i}^{\mathrm{n}}}$ Korrektur anzeigen, zum anderen in der Einbettung in den Kontext; und $z w^{2 r} B^{f^{f}}$ 
nauer darin, daß der in der auch-Frage dargestellte Sachverhalt mit einem anderen in Beziehung steht insofern, als er eine notwendige Voraussetzung darstellt, und, daß die Bestätigung der Geltung des Sachverhalts bei auch-Fragen nicht nur erwartet, sondern erwünscht wird. Vgl.:

(2b) Sieht sie nicht aus wie eine Gräfin?

(12) Sieht sie $\underline{\text { auch }}$ sus wie eine Gräfin?

Der Mann von Lisa... Ist der nicht Professor? (Ich bin mir jetzt nicht ganz sicher, aber ich habe so etwas mal gehört).

(13) Der Mann von Lisa...Ist der auch Professor? (Sonst können wir ihn nämlich nicht $\mathrm{zu}$ der Podiumsdiskussion einladen, wir brauchen doch jemand vom Lehrkörper.)

2.2 .11

Denn

Dle Partikel denn läßt sich zunächst als kausale, koordinierende Konjunktion "lachweisen, die im Unterschied zu der subordinierenden Konjunktion da einen kannten Grund angibt. Außerdem tritt denn als regionale umgangssprachliche diesem von dann auf. Die dritte Variante von denn ${ }^{87}$ ist immer betont: in stehen Fall kann denn nur im $w$-Fragesatz nach einer vorangegangenen Negation bien (Vgl. (1)); es könnte zu den oben (S.110f.) etablierten Affirmationsadver(1)

Anna: Sind das Flöhe?

Heinz: Nein!

Anna: Was DENN?

Als Heinz: Wanzen! (BA, 2)

Pragesatzartikel tritt denn nur in den Satztypen Entscheidungsfragesatz und w$\mathrm{Vgl}$. auf. ${ }^{\circ \theta}$ Denn ist eine in Fragen ausgesprochen häufige Modalpartikel;

(2) dazu folgenden Text

Lisa: Auch wenn ich bei meinem Onkel aufm Dorf bin, ne. Da in der Kneipe: "Ja, Lisa, wie is das denn? Wann könn mer denn unsere Sonntagsschuhe solehen?" - "Ja", sag ich, "wieso das denn? Ich hoffe, die zieht ihr jeden

donntag an!" "Ja, willst du denn nich ma bald heiraten?" - "Nee, wieso das in der denn?" "Ja, das macht man doch so!" (BA, 41)

$I_{d_{2}}$ Ü̈r ür die hohe Frequenz dieser Partikel) und findet sich in dieser verkürten

87) Eventuel

$v_{0}$ tuell handelt es sich bei dieser Verwendung ebenfalls um eine Variante

88) Stelle dann; im süddeutschen Sprachgebiet ist nämlich betontes denn an dieser In Verber ungebräuchlich, stattdessen wird dann verwendet.

anderen indung mit weiteren Modalpartikeln läßt sich denn allerdings auch in $D_{a_{S}}$ ist Satztypen nachweisen (z.B.: Das führte denn auch dazu, daß...oder den, ob denn doch die Höhe!). Bei dieser Verwendung ist nicht zu entscheies sich um Modalpartikel-Funktion handelt (s.u. S.222). 
Form auch in schriftlichen Texten, die Umgangssprache 'simulieren'; dabei kann" enklitisch am finiten Verb, an einem Personalpronomen oder - bei Ellipse Verbs - am $w$-Ausdruck auftreten:

(3a) Was is'n mit dir los, Mensch? Du siehst irgendwie anders aus. (Bi, 174)

(3b) Wieviele Frauen hat' $\underline{n}$ der? (Bi, 165)

(3c) 'S ganze Leben is hart - warum soll ich'n da weich sein? (Bi, 197)

(3d) Wieso'n das? (Bi, 132)

ENTSCHEIDUNGSFRAGESATZE mit der Modalpartikel denn können echte Fragen ${ }^{0^{t}}$ oder rhetorische Fragen, die oft auch mit Emphase ausgesprochen werden. Defir kann also zwar in rhetorischen Fragen stehen, kann aber nicht - wie schon Indikator für Rhetorizität bezeichnet werden; ob es sich bei einer bestimm denn-Außerung um eine rhetorische Frage handelt, muß aus dem Kontext her ${ }^{\left(0^{\prime \prime}\right.}$ gehen.

Durch Fragen mit denn wird immer direkt auf den Interaktionszusammenhang ${ }^{e^{2 l^{4}}}$ genommen (vgl. König 1977a:122); denn zeigt an, daß der Anlaß für die Frage der aktuellen Kommunikationssituation liegt (vgl. auch Franck 1980:224 Hentschel/Weydt 1983:268).

In vielen Fällen ist dieser Anlaß in der (fremden) Vorgängeräußerung zu such es kann sich aber auch um eine Beobachtung des Sprechers handeln. Wegen dieft Funktion von denn, an einen Vorgänger anzuknüpfen, soll es das Merk 〈KONNEX〉 erhalten.

(4) "...und im letzten Jahr war ich sogar vom Klassenunterricht befreit! D8 bekam ich dann Bücher, deutsche und polnische und durfte, wenn ich sil ausgelesen hatte, darüber Aufsätze schreiben." "Polnisch...?" warf Konrad erstaunt ein, "kannst du denn auch Polnisch?" (En, 40)

(5) Jo: Willst du morgen mitkommen zum Baden? Mia: Hast du denn zur Zeit Urlaub?

(6) Mitten in der Nacht wachte ich auf. Ich lag auf dem Gang. Plaid weg, kelin Stroh. Lange dauerte es, bis ich meinen Platz gefunden hatte. War ich dely mondsüchtig? (Ke, 54)

Der Anlaß für die denn-Frage stellt einen für den Sprecher unerwarteten $5^{g^{l}}$ verhalt dar; vgl. (4): Konrad war bis zu diesem Zeitpunkt davon ausgegangen. das Mädchen nur Deutsch kann; ihre Außerung widerspricht seiner Erwartung, so stellt er seine Frage. Denn erhält deshalb noch das Merkmal (UNERWARTET) das sich auf die Vorgängeräußerung oder -handlung bezieht. Aufgrund dessen $2 e^{\prime}$ gen Entscheidungsfragen mit denn häufig ein gewisses Erstaunen seitens Sprechers (ähnlich auch Bublitz 1978:59, Weydt et al. 1983:19). Der in der dell. Frage dargestellte Sachverhalt ist oft die Voraussetzung für den unerwartet Anlaß. 
Da durch Fragen mit denn an eine für den Sprecher unerwartete sprachliche oder nicht-sprachliche Handlung des Gesprächspartners angeknüpft wird, werden sie häufig dazu verwendet, Begründungen, Rechtfertigungen oder Erklärungen für diese Handlung zu fordern. Sie können auch einen Vorwurf implizieren; vgl.:

(7)

Du bist ja immer noch nicht angezogen! Wir wollten doch heute etwas früher los. Hast du das denn vergessen?

Die Tatsache, daß denn eine Verbindung zu einem im Situationszusammenhang

vorangegangenen unerwarteten Tatbestand signalisiert, zeigt sich daran, daß es kaum in gesprächseröffnenden Fragen wie (8) - (10) oder einen Themenwechsel einleitenden Fragen (wie (11)) verwendet werden kann:

(8)

Guten Tag, ich hab mal ne Frage zu dem NEC P 16: Hat der ?"denn eine serielle Schnittstelle? Und ist ?"denn da im Preis das Betriebssystem mit

(9) drin?

(10) Guten Tag, hier ist Uli. Ist (*denn) die Hiltrud da? (BA, 25)

"Entschuldigung, könnten Sie mir denn sagen, wo's hier nach Klein-Heubach (1) geht?99

Olga: Deshalb bin ich sehr dafür, daß es [das Meerschweinchen] jeden Tag

läuft, damit der Kreislauf in Ordnung bleibt.

Lena: Ja.

Olga: Och ja, mein Mäuschen.

Lena: Och, die sin anfällig, die Viecher.

Olga: Habt ihr die/(?"denn) in die Samstagszeitung ma reingeguckt, ob da

noch was für euch Interessantes war? (BA, 134)

Auch Pür rhetorische Fragen läßt sich zeigen, daß sie sich auf einen für den Sprecher unerwarteten Anlaß beziehen; auch hier trägt denn also die Merkmale 〈KONNEX〉 und 〈UNERWARTET>v. Oft tritt denn in diesen Außerungen in Kombination mit nicht auf.

(12)

Bist du denn noch zu retten? Kauft in sündteuren Boutiquen eine Seiden-

(13) bluse nach der andern und läßt die kechnung an mich schicken.

Arme Psychologie! Immer neue Studien über unser kleines blödes Leben legt sie vor. (..) "Jaissesdenndiemöglichkeit!", ruft jedesmal das Publikum, und

(14) dann denkt es, daß es das eigentlich alle schon wußte. (SZ)

Unser Sohn und Ladendiebstahl! Wie konnte er uns das nur antun? Haben wir ihm denn nicht alles gegeben?

(15)

Jetzt hör doch mit diesem Gejammere auf! Schau dir lieber diese Aussicht an! Ist die denn nicht herrlich?

Die

mit affirmativen rhetorischen Fragen entsprechen häufig negierten Behauptungen

(16)

Später hatte er zwei Ausdrucksformen dafür 'Ich bin doch kein Unmensch' und 'Bin ich denn ein Unmensch?' (Bö c, 195)

89)

Wirpiel (10) wäre akzeptabel bei kontrastiv akzentuiertem Sie; in diesem Fall sagen') genau ein anderer Sachverhalt ('jemand anderer konnte es mir nicht agen') impliziert, an den angeknüpft wird. 
In den W-FRAGESATZEN wird mit denn ebenfalls Bezug auf einen Vorgängerbeitrs genommen. Meist ist dies eine explizite Außerung des Gesprächspartners, zu def der momentane Sprecher mehr Information fordert (vgl. (17) oder (18)); es kgrit aber auch eine Beobachtung des Sprechers sein, die er dem Hörer - besonders wenn sie diesem nicht zugänglich ist - schildern kann (vgl. (19) oder (20)) odet die der Hörer erschließen muß (vgl. Franck 1980:223). Auch in $w$-Fragen kann ot denn also das Merkmal 〈KONNEX〉 angenommen werden.

(17) Nelli: Du kanns nich die Woche dazwischen?

Bea: Da bin ich wahrscheinlich gar nich in Köln.

Nelli: Wo bisde denn da? Wieder unterwegs? (BA, 70)

(18) Heinz: Ubrigens, Wanzen kann man riechen, nich, die riechen etwas Anna: Wie riechen die denn? (BA, 9)

(19) Was ist denn hier passiert? Hier riechts so komisch.

(20) Karl: Also Fredi hat sich nich geäußert darüber, un Kai auch nich. Iris:...Hör ma, was is denn das für 'n komisches Geräusch im Hintergrund? Karl: Ja, ich sag dir, die Ellen näht da in ihrem Zimmer. (BA, 152)

(21) "Schönen Dank", sagte Frau Jakobs, und das kam mir nun doch ein bißchen unheimlich vor. "Warum bedanken Sie sich denn?" (Bi, 81)

W-Fragen mit denn sind auch verkürzt häufig:

(22) Ruth: Ja, un (...) krieg ich . jetz . vorgestern en Bußgeldbescheid.

Andi: Ach je! Wieviel denn? (BA, 191)

In vielen Fällen kann - wie bei den Entscheidungsfragesätzen - der Anlaß der Frage für den Sprecher unerwartet sein; deshalb kann denn auch in w-Fragen in manchen Fällen mit dem Merkmal 〈UNERWARTET>v beschrieben werden. Mit der Frage fordert der Sprecher dann eine Ergänzung, Spezifizierung oder auch Begri ${ }^{n^{\prime}}$ dung für den vorangegangenen unerwarteten Sachverhalt (vgl. z.B. (21)).

Die Modalpartikel denn trägt also immer das Merkmal 〈KONNEX〉; das Mer $\mathrm{km}^{\mathrm{m}^{2}}$ 〈UNERWARTET>v ist in Entscheldungsfragen immer nachzuweisen, in w-Fragen ${ }^{j e}$ doch nur fakultativ. In belden Fragetypen wird also mit denn aup den unmitte ${ }^{\mid b^{8 t}}$, vorausgehenden Kontext Bezug genommeno und dabel an einen (meist unerwartén ten) Aspekt angeknüpft; deshalb sind diese Fragen auch sehr geeignet, 'side' sequences' einzuleiten (vgl. Franck 1980:225); der Sprecher fordert dann zunä ${ }^{\text {hlt }}$ eine weiterführende Information zu einem Aspekt des Vorgängerbeitrags (in Ent" scheidungsfragen fragt er nach der Gültigkeit eines Sachverhalts, der Voraus $\mathrm{s}^{\mathrm{t}^{\prime}}$ zung für den Vorgänger ist, in $w$-Fragen nach einer Spezifizierung oder Begrit ${ }^{\prime \prime}$ dung), bevor das Gespräch mit dem eigentlichen Thema weitergehen kann; vgl. oben (4): die Sprachenkenntnisse des Mädchens sind nicht das eigentliche The der Unterhaltung; vgl. auch:

90) Da denn-Fragen an einen äußeren Anlaß anknüpfen, nennen Hentschel/ $/$ fy $^{y^{\natural t}}$ (1983:268) diesen Typ "extern motiviert". 
Ella: Ich wollt mir nämlich grad was warmmachen, Essen is ja. zur Zeit nich mehr drin bei unsrer. vielen Arbeit, die wir haben.

Iris: Ja?

Ella: Naja, ich muß, bevor ich in Urlaub fahre, muß ich die steuererklärung Pertiggekriegt haben.

Iris: Wieso? Bis wann muß man die denn abgegeben haben? (BA, 122)

Eva: das heißt, wir haben, öh, irgendwie so'n Krimi Serie gcguckt, wie heißt nochmal? "Lieber Tennis als Kanonen"/

(...)

un . seit der Zeit handarbeite jch. Ach ich komm mit den Weihnachtsgeschenken, ich wer nich fertig!

Das pera: Was machsde denn? (BA, 167)

Verbir denn angenommene Merkmal 〈KONNEX〉 ist relativ unspezifisch, da eine Dizlogs Kohären $z u$ sehen ist - und insofern im Grunde nicht inarkiert werden muß; wenn ders in fehlt, z.B. bei Themenwechsel, wird dies eigens angezeigt. Denn - besonlicht $w$-Fragen, wo ja 〈UNERWARTET> nicht immer nachzuweisen ist - verdeutalso nur etwas (im Standardfall) ohnehin notwendigerweise Gegebenes. ${ }^{91}$

Aupgrund dieser unspezifischen Bedeutung liegt die Vermutung nahe, daß sich ${ }^{d} n_{n}$ zu einem reinen 'Frageanzeiger' entwickelt, ${ }^{92}$ daß denn also nur die FunkUrde anhand markieren, daß eine Außerung eine ('Standard'-)Frage ist. Diese These Sie

im Korpus zunächst durch die Frequenz von denn gestützt: Von 175 w-Fragesătzen $d_{e_{n, 93}}$ von Brons-Albert enthalten 83, also fast 50\%, die Modalpartikel Partikel Dieser Prozentsatz erhöht sich noch, wenn man die w-Fragesätze ohne arum? genauer betrachtet: An die 30 Außerungen sind verkürzte Fragen (was?, Partlkeln wieso?), die - vermutlich aus Okonomiegründen - häufiger ohne Modalas soll auftreten, und etwa 15 Fragen sind nahezu verfestigte Wendungen wie kelne man da machen?, wie soll ich sagen?, auf die der Sprecher auch meist Modalpartwort erwartet. Insgesamt stehen also ca 45 'richtige' $w$-Fragen ohne sind 10 w-Frage 83 mit denn gegenüber. Von diesen 45 Fragen ohne Modalpartikel seines $w$-Fragen, die einen Themenwechsel einleiten; hier wird denn eben wegen Merkmals 〈KONNEX〉 nicht verwendet; vgl.:

91)
Konjuner Funktion, eine 'reine' Verbindung zu signalisieren, gleicht denn der
es unktion und. Ich kann mich Franck (1980:65) nicht anschließen, die meint,
renz dad kaum einen neutralen Konnex; dieser komme ja bereits mittels Kohä-
Wăr dadurch zustande, da $\beta$ die $A u ß e r u n g e n$ nacheinander erfolgten, und rück-
Pür dennektierende Ausdrücke schlössen deshalb meist ein Urteil ein. Gerade
92) Insopern in $w$-Fragen läßt sich zeigen, da $\beta$ es nur den Konnex markiert und
Der Prozentsatz ist eher höher anzusetzen, da wegen der enklitischen Ver-
wendung von denn möglicherweise nicht alle Vorkommen transkriblert wurden. 
(25) Leo:...Dann hat se frei

Nina: Ja, hoffentlich geht's ihr schnell wieder besser.

Leo: Naja, och, an sich hat se ja alles ganz gut überstanden (..) aber so ${ }^{b}$ un zu kommt es schon mal.

Nina: Ja klar!

Leo: Samma, wann has du Geburtstag? Heute? (BA, 98)

(26) Heinz: Lieb von dir, daß du an uns denkst! - Aber was anderes: Was macht ihr heute abend? (BA, 2)

(27) Lisa: Ja, das geht schnell [sich erkälten]. Vor allen Dingen bei diesem Scheißwetter. Es is ma kalt un dann is ma warm un dann is ma wieder $50^{\circ}$ Mischmasch un so,

Anna: ja, em dann kommsde da mit nassen Haaren raus, ne

Lisa: ich habe mich auch wieder en bißchen erkältet... Und wie geht's Iris. in ihrer Ehe? (BA, 32)

Der Themenwechsel zeigt sich in diesen Beispielen allerdings nicht nur an def fehlenden Partikel denn, sondern auch an anderen Signalen: explizite Wendungen wie samma in (25), aber was anderes in (26) oder der Pause in (27).

Ein weiterer großer Teil von $w$-Fragen ohne Modalpartikel im Korpus von Brons" Albert läßt sich folgendermaßen erklären: Durch den von denn angezeigten $B e^{215}$ zur Vorgängeräußerung wird auch der Bezug zum Gesprächspartner aktualisiert, ${ }^{\text {ef }}$ wird mit einbezogen. (Deshalb kann denn - besonders in w-Fragen - auch da $z^{\downarrow}$ führen, daß die Frage 'freundlicher' wirkt. ${ }^{94}$ ) Wo nun der Aspekt des Bezugs ${ }^{2}{ }^{\text {m }}$ Gesprächspartner nicht relevant ist und reine Informationsfragen geäußert werdent tritt denn deshalb seltener auf, was das Fehlen von denn u.a. in folgenden $\mathrm{ET}^{\mathrm{g}^{\circ}}$ gen erklärt:

(28) (Es geht um den Kauf einer Eigentumswohnung)

Käuferin: Hm...WC, zwei Loggien. Ja. Und, öh, ich hab's inzwischen wieder vergessen, wieviel Quadratmeter sin es?9

Verkäuferin: Ncunzig sin das!

Käuferin: Neunzig, und was kostet es?
Verkäuferin: Ja, wir hatten 120.000 Mark angegeben wozu allerdings noc ${ }^{\text {h }}$ eine Tiefgarage kommt.

(...)

Käuferin: Und was wird der kosten?

Verkäuferin: (...)

Käuferin: (...) ach so, eins frag ich immer roch, em, wie un/ wie teuer sing ungefähr die Umlagen? (BA, 129)

Generell scheint auch eine unpersönlichere Beziehung zwischen den Gesprächspa $\mathrm{pl}^{\mathrm{t}}$ nern das Weglassen von denn zu erleichtern - in diesen Fällen muß der $B e^{q^{4 b}}$ zum Gesprächspartner nicht durch denn aktualisiert werden. Im Korpus von Bro ${ }^{\mathfrak{n}^{\prime}}$

94) Vgl. dazu die Ergebnisse des Tests von Hentschel/Weydt (1983). 94) Vgl. dazu die Ergebnisse des Tests von Hentschel/Weydt (1983).
95) Vgl. dagegen eine Frage gleichen Inhalts in einem Gespräch zwischen Muttet $^{t^{t}}$
und Tochter:

A: Oh, ich hab nich angerufen da . 2000 Mark is doch toll! (...)

B: Wieviel Quadratmeter warn das denn? (BA, 135) 
Albert weisen jedenfalls die Gespräche mit formellerer Beziehung zwischen den GeSprächspartnern verhältnismäßig mehr w-Fragen ohne Modalpartikel auf.96

Umgekehrt kann durch denn in phatischen Fragen in seltenen Fällen auch nur der Bezug zum Gesprächspartner aktualisiert werden, was folgende gesprächseinleitende denn-Frage erklärt:

(29)

Elke: Ja?

Mona: Tag, Elke, hier ist Mona!

Ein Elke: Jo, wie geht's denn so? (BA, 11)

letzter Typ von Fragen, in denen denn nicht verwendet wird, sind Fragen, die der Sprecher vor allem an sich selbst richtet, bei denen er also keine Antwort

(30)

Anna: Sind die (Wanzenl groß? kann man die sehen?

Heinz: Ja, wie wie e, wie Heftzwecken sind die.

Anna: Wie Heftzwecken, ja die müßte man doch finden!

Heinz: Wie heißen die nochma im Französischen? Wie heißt ne Heftzwecke im

(31) Französischen, punaise, woll, und punaise heißt gleichzeitig Wanze. (BA, 8)

Fllke: Ne, der Pastor, der macht alles (Beglaubigungen/ umsonst. Gut, ne?

Mona: Gut, ja. Muß ich mir merken. Wo gibts hier den nächsten Pastor?

Elke: Ja, bei uns is er direkt um die Ecke, bei euch weiß ich nich.

Mona: Scheiße, wo soll ich hicr nen Pastor herkriegen? Das kommt davon,

wenn man nich genug in die Kirche geht. (BA, 14/5)

Anke: insofern. hammer jetz hier High Life.

Peter: Ach so, bei euch heute abend?

Anke: Nee, überhaupt!

Peter: überhaupt ... ah

Anke: jo... Was kamma noch erzählen?

Die Auster: Jo, is schwierig (BA, 77)

-Frage im

marklert Standardfall die Modalpartikel denn enthält. Fragen ohne denn sind

'nformation', sei es, daß sie einen Themenwechsel einleiten, sei es, daß sie reine

oder keins ragen sind, sei es, daß sie an den Sprecher selbst gerichtet sind und/

die These Antwort erwartet wird. Zumindest für denn in $w$-Fragen läßt sich also

aufstellen, daß es als 'reine' Frageanzeiger fungiert.

dungspragen Entscheidungsfragen tritt denn wesentlich seltener auf: von 106 EntscheiSen Fällen bei Brons-Albert enthalten 22 (d.h. 20\%) die Partikel denn.97 In diespezifischere weist denn auch immer das Merkmal 〈UNERWARTET>v auf, hat also eine Bedeutung als in w-Fragen. Für Entscheidungsfragen kann man des-

\footnotetext{
96) So tritt

97) (S.126-1 Z.B. in dem ganzen Gespräch über den Kauf einer Eigentumswohnung

7) Hent-133; vgl. Beispiel (28)), kein einziges Mal denn in einer Frage auf. gaben els statistische Untersuchungen (1981:24) von "Alltagsgesprächen" erund geringere Werte: denn kommt demnach in 12\% aller Entscheidungsfragen $30 \%$ aller $w$-Fragen vor.
} 
halb bei denn nicht (noch nicht?) von einem reinen Frageanzeiger sprechen. Aller dings blockiert denn eine Aufforderungs-Interpretation; vgl.:

(33) Kannst du mir 50 Mark leihen? (Frage oder Aufforderung)

(33a) Kannst du mir denn 50 Mark leihen? (echte Frage)

(33b) Kannst du mir mal 50 Mark leihen? (Aufforderung)

Fragen mit denn zeigen Polgende Unterschiede zu Fragen mit anderen Partikeln: Bei denn geht der Sprecher immer davon aus, daß der Angesprochene die Frage beantworten kann; darin unterscheiden sich Fragen mit denn nicht nur von Fragen ohne Modalpartikel (vgl. (30)-(32)), sondern auch von solchen mit wohl, bloß oder nur. Der Sprecher drückt mit einer denn-Frage keine bestimmte Antworterwartunf aus; in dieser Hinsicht unterscheldet sich denn von etwa oder auch und nicht Fragen mit denn konnektieren primär, während beispielsweise Fragen mit etwa $\mathbb{t}^{\circ}$ sätzlich qualifizieren (vgl. Franck 1980:223). Denn ist also eine in ihrer Bedelv tung relativ unspezifische 'Fragepartikel'.

\subsubsection{Etwa}

Etwa läßt sich als Adverb mit der Bedeutung 'ungefähr' oder 'möglicherweise' un als Modalpartikel nachweisen. Als Modalpartikel tritt etwa (abgesehen von def Kombination mit nicht) nur in ENTSChEIDUNGSPRAGESATZEN auf, die als Fr8ge? oder als rhetorische Fragen zu interpretieren sind.

Fragen mit etwa nehmen - wie Fragen mit denn - Bezug auf etwas im Kontert Vorhergehendes. Deshalb kann auch etwa mit dem Merkmal (KONNEX) beschrieben werden. Dabei kann sich der Sprecher auf eine explizite Vorgängeräußerung (it in (1)) oder eine Beobachtung in der Situation (wie in (2)) beziehen; kann det Angesprochene die Beobachtung nicht selbst machen, wird der Sprecher sie sch hl $^{-}$ dern (wie in (3)) oder der Hörer muß sle erschließen:

(1) Uwe: Gestern war 'Dallas' vielleicht wieder spannend! Mona: Was?! Schaust du dir den Quatsch etwa an?

(2) Ein offensichtlich betrunkener Mann wankt mit dem Autoschlüssel in det Hand auf ein Auto zu. Ein Passant: Wollen Sie etwa in diesem Zustand noch Auto Pahren??

(3) Du, die Whisky-Flasche ist schon wieder leer. Trinkst du etwa heimlich?

(4) (Was ist denn das für ein Rauschen?) Regnet es etwa?

(5) Der Berufsberater: "Aber irgendwas müssen Sie doch machen, wenn Sie vorläuflg nicht studieren (...) Oder wollen Sie etwa...?" "Nach'm Westen? Nö." (B1, 51)

Wegen des Merkmals (KONNEX〉 kann auch etwa (wie denn) nicht in gespracheler" offnenden oder themenwechselnden Fragen verwendet werden; vgl.: 
(6)

Beim Nachhausekommen:

Sind meine Eltern da? vs. "Sind meine Eltern etwa da?

In diesem Fall wäre etwa nur möglich, wenn irgendeine Beobachtung (zum Beispiel Kopfer im Flur) den Sprecher vermuten läßt, daß der in der Frage dargestellte Sachverhalt zutrifft. Das Beispiel (6) zeigt auch, daß der Anlaß für die Frage mit etwa den Erwartungen des Sprechers widerspricht. Etwa drückt also - wie denn in Entscheidungsfragen - Staunen oder Oberraschung aus. Aufgrund dieser Funktion soll für etwa ebenfalls noch das Merkmal 〈UNERWARTET>v stehen, das sich auch hier immer aup eine sprachliche oder nichtsprachliche Vorgängerhandlung bezieht

Dieses Merkmal läßt sich an (1) beispielsweise folgendermaßen nachweisen: Mona War bisher davon ausgegangen, daß Uwe sich 'Dallas' nicht anschaut; seine Außerung aber widerspricht dieser Erwartung, was Anlaß für ihre Frage ist.

Der Sprecher fragt also mit etwa nach der Möglichkeit der Wahrheit eines für ihn unerwarteten Sachverhalts.

Die Gültigkeit des Sachverhal

drückten Proposition, Sachverhalts, also die Bestätigung der in der Frage ausge-

sition, widerspricht einer allgemeinen Erwartungsnorm (vgl. oben

(7) aber den individuellen Erwartungen des Sprechers; vgl. (7):

Ist der Tee etwa warm? Ich kann warmen Tee doch nicht ausstehen!

sentliält aber noch ein weiteres Merkmal - und darin besteht auch der wedruck, Unterschied zu Fragen mit denn: der Sprecher bringt mit etwa zum AusAntworterwartung er eine verrieinende Antwort erwartet oder genauer: erhofft. Diese $2 u(h)$. rwartung beruht aber nicht auf einem Wahrscheinlichkeitsurteil (wie bei 1977. sondern auf den wünschen und Bewertungen des Sprechers (vgl. König 2War präferiert. und Franck 1980:221). D.h. eine verneinende Antwort wird vom Sprecher auch die Wird nicht-präferierte Antwort erwarten bzw. befürchten. Für diese Funktion des in etwa zusätzlich das Merkmal 〈UNERWUNSCHT>s angenommen: die Gültigkcit $S_{\text {pre }}$ der Frage geäußerten Sachverhalts entspricht nicht den Präferenzen des (8)

Max zieht seinen Mantel an.

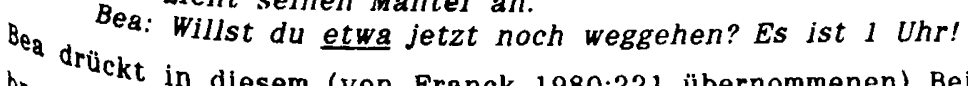

brauch in diesem (von Franck 1980:221 übernommenen) Beispiel durch den Ge-

Umstände "gzugehen (das Anziehen des Mantels) aber deuten darauf hin, daß Max vorhat, chere ist. Die Ist.

trifpt, - kann - je nach Kontext - unterschiedlich hoch sein. Spricht alles pür die 
Wahrheit des Sachverhalts (wie in (9)), so kann man im Grunde nicht mehr von einer echten Frage sprechen: der Sprecher muß es als (fast) sicher ansehen, daf der Sachverhalt zutrifft; seine Außerung hat dann vor allem die Funktion, seine subjektive Bewertung oder Einschätzung auszudrücken.

Er legt eine Packung Zigaretten und Streichhölzer auf den Tisch.

Sie: Rauchen Sie etwa?

Wenn sich nun die etwa-Frage - wie dies häufig der Fall ist (vgl. (8) oder (9)) auf Sachverhalte bezieht, für die der Gesprächspartner verantwortlich ist, die $e^{t}$ beeinflussen kann, so kann der Sprecher, indem er seine Präferenzen für einen bestimmten Sachverhalt äußert, den Gesprächspartner indirekt in seinem Verhaltel beeinflussen. Auf diese Weise kann, wenn es um zukünftige Handlungen geht (wil z.B. in (10)), der Angesprochene durch das negative Urteil eventuell von seinet Haltung oder Handlung abgebracht werden (vgl. König 1977a:127 oder Franck 1980: 221 ).

(10) Aber verrückt ist es schon, wenn du hier den Kommunisten spielst und dein Vater einem Arschloch wie mir für ein par Schillinge die Hand küßt, oder findest du nicht? Willst du etwa bestreiten, daß er's gewesen ist?

(M. Bieler, Der Kanal, Hamburg 1978:113)

Auf jeden Fall wird der Gesprächspartner nach einer derartigen etwa-Frage ( z.B. (9)) versuchen, sein Verhalten zu begründen oder zu rechtfertigen. Durch die negative Tendenz einer etwa-Frage kann also der Gesprächspartner indirekt in seinem Handeln beeinflußt werden; etwa ist aber (eben wegen (UNERWUNSCHT) nicht in Außerungen möglich, die direkt zu einer Handlung auffordern sollen, ds der Sprecher nicht zu etwas auffordern kann, was er gleichzeitig befürchtet; vgl:: (11) "Geben Sie mir etwa eine Zigarette?

Aufgrund der beschriebenen Bedeutung kann die Modalpartikel etwa als Gegenstick zu auch bezeichnet werden: auch (Merkmal (ERWUNSCHT>s) drückt die Präferent für die zustimmende, etwa (Merkmal 〈UNERWUUNSCCHT>s) für die verneinende $A^{n^{t}}$ wort aus. Der Unterschied zwischen auch und etwa besteht aber auch darin, d bei Fragen mit auch die bevorzugte Antwort auch als die erwartete, also als dif wahrscheinlichste angesehen wird, bei Fragen mit etwa dagegen der erwünschtet Antwort nicht mehr Wahrscheinlichkeit zugeordnet wird als der unerwünschten, sogar die erwünschte Antwort oft sehr unwahrscheinlich ist (vgl. (8) und (9)). De Sprecher zeigt also an, daß er von seinem Gesprächspartner eine wenig kooperat ve Reaktion befürchtet (vgl. Franck 1980:222). Deshalb bewirkt etwa im Dialo6 einen disharmonischen Ton. Aus diesem Grund ist auch bei einer etwa- $\mathrm{A}^{\mathrm{B}} \mathrm{e}^{\mathrm{r} \mathrm{U}^{\mathrm{n}}}$ der Sprecher dem Angesprochenen meist nicht untergeordnet, die Interaktion ${ }^{150}$ mindestens symmetrisch. In Fragen mit auch dagegen wird dem Hörer wesent mehr Kooperativität unterstellt (vgl. Franck 1979:8). 
Der Unterschied zu Fragen mit denn liegt darin, daß letztere neutral sind, nur Erstaunen ausdrücken, während bei Fragen mit etwa eine ausgeprägte negative Tendenz deutlich wird.

Fragen mit etwa können auch rhetorische Fragen sein; wie bei denn und im Unterschied zu schon ist auch in diesem Fall das Signal für Rhetorizität im Kontext 24 suchen.

(12) Mach mir bitte keine Vorwürfe! Hab ich dir damals etwa geraten, den Vertrag zu unterschreiben?

(13a)

Soll das etwa eine Entschuldigung sein?

Bei diesen Fragen gleichen sich etwa und die Modalpartikel vielleicht (sie tragen

auch beide das Merkmal (UNERWARTET〉):

(13b) Soll das vielleicht eine Entschuldigung sein?

)ie negative Tendenz der etwa-Fragen und damit das Merkmal 〈UNERWUNSCHT $s$

ist allerdings nicht in allen Fällen deutlich ausgeprägt. Es lassen sich auch Außerungen finden, in denen der Sprecher riur ein - allerdings sehr starkes, beitahe ungläubiges - Staunen zum Ausdruck bringt. Entscheidend ist hier der Kontext, die Einstellung des Sprechers und der Inhalt der Frage. Fragen, die sich auf Vergangene oder zukünftige Handlungen des Angesprochenen richten, zeigen, wenn sie einen nach allgemeiner Norm neutral oder negativ bewerteten Inhalt haben (wie (15)), immer negative Tendenz:

(15) Kommst du etwa mit?

Eragen die du das etwa gestchlen?

stellen (we einen - nach allgemeiner Norm - positiv bewerteten Sachverhalt darder Sple (16)), können auch nur ungläubiges Staunen ausdrücken (16a); außer ohnehin (16) negativ (16b).

(16a) Hast du etwa die steuererklärung gemacht?

(lob) (Das kann ich ja kaum glauben.)

Betripft dim Gottes willen, das kannst du doch gar nicht.)

negative die Handlung auch den Sprecher, so ist die dann durch etwa nahegelegte ( $v_{g}$ l. Tendenz als ein zum guten Ton gehörendes 'sich Zieren' zu verstehen (17) König 1977a:127):

Ahnlich Hast du etwa meine Sachen gebügelt? (Das wäre doch nicht nötig gewesen) Eine $F$ ist es bei Fragen, die sich auf Zustände im weitesten Sinne beziehen. heiratet? Hinweis? ist zunächst negativ zu verstehen, außer der Kontext gibt deutliche $k_{a n n}$, daß nur ungläubiges Staunen gemeint ist. Bei 'positivem' Inhalt wie (18) die Frage neutral sein und nur Staunen ausdrücken, sie kann aber auch 
durchaus die negative Tendenz anzeigen, wenn dies der Einstellung des Sprechers entspricht; in (18) z.B., wenn er an Sonnenallergie leidet (vgl. auch (19)).

(18) Scheint etwa die Sonne?

(19) Nun ist deutlich zu spüren, daß der bis hierhin mehr oder weniger geduldige Leser ungeduldig wird und sich die Frage stellt: verflucht, ist diese Leni etwa vollkommen? (Bö c, 50)

Grundsätzlich müssen also deutliche Kontexthinweise hinzutreten, damit eine etwa-Frage nicht die negative Tendenz aufweist - der Standardfall drückt jeden ${ }^{-}$ falls eine ablehnende Bewertung des Sachverhalts durch den Sprecher aus. Schließlich ist auch das von etwa in den anderen Fällen angezeigte ungläubige Stauren nicht unbedingt immer positiv zu werten; vgl.:

(20) kannst du etwa kochen? (Das hätte ich dir ja gar nicht zugetraut.)

Abschließend sei noch darauf hingewiesen, daß etwa in Verbindung mit nicht (z山r' Kombination doch nicht etwa s.u. S.223ff.) auch in Aussagesätzen mit dem Modal' verb sollen und in Imperativsätzen stehen kann - in beiden Fällen allerdings nutr wenn die Sätze ein verbum putandi oder sentiendi enthalten:

(21) Denk nicht etwa, daß ich das einfach so hinnehme!

(22) Also, ich ruf den Martin jetzt nicht an! Der soll nicht etwa glauben, ich lauf ihm nach!

Ungewöhnlich ist hier, daß die Partikel etwa nach der Negationspartikel nicht (e jn $^{\text {n }}$ anderer Negationsträger ist hier übrigens unmöglich) stehen muß; in den Fragen dagegen finden sich die regulären Stellungsbedingungen (Glaubst du mir etrir) nicht?). Allerdings wird hier die Modalpartikel trotz dieser Stellung nicht negiet d.h. sie liegt nicht im semantischen Bereich der Negation.99 Hier hat etwa eine andere Funktion als in den Fragen; es dient vermutlich $1 e^{\text {dif }}$ lich der Verstärkung; vgl.:

(21 a) Denk nicht, daß...! vs. Denk nicht etwa, daß...!

Eine Interpretation als Verstärkung erklärt allerdings nicht, warum die Negation ${ }^{\prime}$ partikel nicht vor etwa steht; vgl.:

(21b) Denk bloß/doch/JA nicht, daß... aber: Denk nicht etwa, daß...

Nicht ist hier ganz klar als Negationspartikel zu interpretieren, die auf der $\mathrm{pr}^{\mathrm{r}^{0^{0}}}$ positionalen Ebene negiert ( $\mathrm{vgl}$. die Beispiele $(2 \mathrm{la} / \mathrm{b})$ ), die angegebene Bedeut $\mathrm{ut}^{\mathrm{pl}^{\mathrm{b}}}$

98) Insofern scheint es mir problematisch, wenn die seltene und eher mar k $^{\mathrm{je}^{\text {fl }}}$ Verwendung von etwa ohne negative Tendenz als einzige hingestellt wird: gibt Kemme (1979) für etwa nur die kedeutung "Staunen" bzw. "ungläubjeg des Staunen" an (vgl. die Ubungen S.50f. und 65f.). Gerade im Unterricht vol Deutschen als Fremdsprache müßte jedoch auch die negative Tendent etwa, die ja auch einen ganz bestimmten 'Ton' bewirkt, deutlich werden.

99) Vgl. dagegen Weydt/Hentschel (1983:11) und Doherty (1985:72ff). 
von etwa, genauer: das Merkmal 〈UNERWUNSCHT>s, ist in der Kombination mit nicht allerdings nicht ausgeprägt.

Eventuell ist diese Variante von etwa auch als vorweggenommene Frage zu verstehen, im Sinne von $(21 \mathrm{c})$ :

(21c) Denkst du etwa, daß...? Denk nicht etwa, daß...!

Zu trennen ist die angeführte Variante von dem Vorkommen von nicht etwa vor allem in Aussagesätzen, die bezüglich der Verben keinen Restriktionen unterliegen. In diesem Fall hat etwa (dessen Einordnung in eine der Partikel-Funktionen noch Unklar ist) die Funktion, Kontrastnegation zu unterstreichen bzw. anzukündigen:

(23) Räuberkinder waschen sich nicht etwa, sondern schmieren sich das Gesicht mit Dreck ein.

(24)

Wortwahl, Rhythmus und Reim zielen nicht etwa auf Glücksverheißung. Sondern signalisieren Belehrung... (Sz) Ersetzung muß aber genannt werden oder erschließbar sein:

(23a) Räuberkinder waschen sich nicht. vs.

?"Räuberkinder waschen sich nicht etwa. (25) ...immerhin sieht er ein, daß derjenige, der Geld zu zahlen hat, es meistens
nicht so eilig hat wie der, der es bekommen will. Er will nicht etwa Krach machen, er will etwas Dampf hinter die Sache machen.

Auch (H.Fallada, Kleiner Mann - was nun? Reinbek b.Hamburg, 1980:174)

kein in dieser Verwendung ist etwa nur mit der Negationspartikel nicht und mit

(23b) anderen Negationszeichen möglich:

Räuberkinder waschen sich niemals, sondern.. vs.

$D_{i e}$ speziëuberkinder waschen sich niemals etwa, sondern..

zeigt sich funktion von etwa in Verbindung mit kontrastiv negierendem nicht

nur

(26) (..sondern auch) dazwischen stehen kann:

Er hat nicht etwa nur das Finanzamt betrogen, sondern auch das Gericht.

2.2 .13

Eigentlich

Eigentlich tritt zunächst (flektierbar) als Adjektiv auf; die Verwendung von

und der in Aussagesätzen ist aufgrund der Vorfeldfähigkeit, der Betonbarkeit

'echnen Paraphrasierbarkeit mit 'in Grunde', 'wirklich' zu den Satzadverbien zu

Als Modalo. S.26f.; vgl. dazu genauer Oppenrieder/Thurmair 1988).

SCHEIDUNartikel kann eigentlich demnach nur in Fragesätzen, und zwar in ENT-

hier zUNGFRAGESATZEN und in W-FRAGESATZEN auftreten. Beide Typen sollen usammen behandelt werden. 
(1) Franz: Gibts bloß Frauen in deiner Abteilung?

Ute: Nein, Männer gibts, wo leichtere Arbeit ham, und verdienen siebn und acht Mark Stundnlohn.

Peter: Des is ja eigentlich auch nicht richtig.

Franz: Möchtest du eigentlich lieber ein Mann sein?

Ute: Ja, sicher, erstens...(Kr, 29)

(2) Erwin: Stell dir vor, da steht: $100 \mathrm{~km}$ Stau!

Alois: Na, da wird's wieder gekracht haben!

Hans: Sag mal, wie hoch ist man eigentlich versichert, wenn's mal so richtig kracht?

Erst am späten Abend wagte er endlich die Frage zu stellen, die ihn seit dem Frühstück beschäftigte: "Wer ist eigentlich eure neue Haustochter? Gewiß ein gebildetes Mädchen aus guter Familie?" (En, 61)

Die wesentliche und entscheidende Leistung von eigentlich besteht darin, die Ein" bindung der Frage in den Gesprächszusammenhang zu markieren. Nach könis (1977a:123) steht eigentlich "in Opposition" zu denn und signalisiert, "daß die Frage vom Gesprächszusammenhang, oder allgemeiner, vom Interaktionszusammen" hang gelöst ist". ${ }^{100}$

Fragen mit eigentlich geben dem Gespräch immer eine neue Wendung, mit in n $^{\text {n }}$ wird ein neues Thema oder zumindest ein neuer Aspekt eines Themas ${ }^{101}$ eingé führt; vgl. die Beispiele oben und:

Mona: ...oh, ich hab dem Schulkollegium ein Photo von mir geschickt, das war das letzte, was ich auftreiben konnte, irgendwo / das hatt ich nie gewagt, irgendwo hinzugeben (..) $\mathrm{ja}$, da sah ich also / wie so ne Hexe als so unheimlich giftig guck ich da rein, naja.

Elke: Wie is es eigentlich, wenn man son Seminar mal doppelt belegt hat, ich seh närnlich da eben. Fénélon, (...) hab ich mal bei der Schabrowski und jetz auch bei der Bauer mal belegt.

Mona: Das is doch egal, das heißt doch nur, daß...(BA, 14)

(5) Bea: Ich mein, die erzählen immer viel von dieser Referendarzeit, ne. Am Anfang solls wohl gemütlich sein, hinterher sehr anstrengend, ich mach ${ }^{i l}$ da jetz keine Gedanken.

Nelli: Naja.

Bea: Am Anfang wirds sicherlich gemütlich; ne?

Nelli: Ach so, ja. Oder. jaja man hat nich allzuviel zu tun. Hör mal, weift du eigentlich, wie weit das mit dieser Neuregelung der Referendarbezüge (BA, 60)

In Beispiel (4) leitet Elke mit ihrer eigentlich-Frage ein völlig neues Thema ${ }^{\text {in }}$ (hier wird besonders deutlich, daß eigentlich-Fragen auch einen sehr unver" mittelten Themenwechsel anzeigen können); in (5) geht Nelli mit der Frage einem neuen Aspekt des Themas über (vgl. auch (1)). Typischerweise sind

100) Gegen die These Königs von einer Opposition zwischen denn und eigentijit spricht allerdings - und das merkt König (1977a:125) auch an - die Tatst che, daß denn und eigentlich kombinierbar sind.

101) Mit 'Einführung eines neuen Aspekts' (bzw. 'Aspektwechsel') ist gemeint, innerhalb eines übergreifenden Rahmenthemas ein neues 'Unterthema' $e^{\mathrm{in} b^{e^{\prime}}}$ führt wird. 
Fragen mit eigentlich deshalb eingeleitet mit Wendungen wie 'übrigens', 'hör mal', oder 'sag mal' (vgl. (5) und (3)). Diese Wendungen dienen auch dazu, an die Aupmerksamkeit und das Interesse des Partners zu appellieren.

$D_{a}$ eigentlich in Fragen also die Funktion hat, eine Wendung im thematischen

Verlauf anzuzeigen, soll es das Merkmal 〈UBBERGANG〉 erhalten. (Dieses Merkmal betrifft - wie 〈KONNEX〉 - den Bezug zur Vorgängeräußerung.) Mit diesem Merkmal ist auch erfaßt, daß eigentlich-Fragen nur gestellt werden können, wenn die Gesprächspartner bereits eine Weile miteinander gesprochen haben, oder doch zumindest ein "eine gewisse Weile andauerndes gesprächsermöglichendes situationelles Beieinander der Gesprächspartner" (Harweg 1974:18) bestanden hat. Deshalb können eigentlich-Fragen auch nicht gesprächseröffnend verwendet werden, was aber brundsätzlich für alle sprachlichen Mittel gilt, die einen Themenwechsel bzw. (bergang anzeigen (wie übrigens, ach, da fällt mir ein, sag mal etc.).

Der Anlaß für eine Frage mit eigentlich ist im Unterschied zu Fragen mit denn ein (interner) Denkproze $\beta$, ist also beim Sprecher selbst zu suchen. So ist z.B. in (4) der Anlaß für Elkes Frage vermutlich darin zu sehen, daß sie, während Mona spricht (es handelt sich um ein Telefongespräch), ihre Unterlagen studiert'102 (vgl. auch (3)). Für den Gesprächspartner ist der Denkprozeß, auf dem die eigentlichFrage beruht, meist nicht durchschaubar und nicht nachvollziehbar. (Bei dennFragen dagegen ist der (äußere) Anlaß für den Partner offenkundig oder kann zumindest leicht erschlossen werden. ${ }^{103}$ ) Bei einem durch eigentlich angezeigten Aspektwechsel kann ein nicht-zentraler und für den Angesprochenen gerade nicht

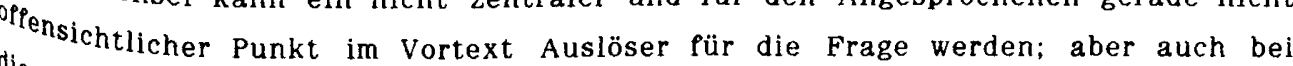
diesen Fragen liegt der Anlaß für die Frage beim Sprecher.

In der Literatur wird eigentlich oft (unzutreffend) zugeschrieben, eine Frage als bailäufig zu markieren (vgl. u.a. Weydt/Hentschel 1983:10, Harden 1983:63, Kohrt 1988:125). Eigentlich-Fragen leiten ein neues Thema ein, das dann aber auch Thema bleibt (vgl. die Beispiele oben). Insofern handelt es sich bei eigentlichAun nicht um eine (beiläufige) Abschweifung, bei der Rückkehr zu einem Relevasthema, zum 'wirklichen' Thema impliziert ist. ${ }^{104}$ Auch eine Minderung der eira, die der Begriff der Beiläufigkeit m.E. mitimpliziert, ist bei Fragen mit tich nicht festzustellen.

102) $\mathrm{Da}$ $\mathrm{Da}_{\mathrm{a}}$ in diesem Beispiel ein völlig abrupter Themenwechsel erfolgt, und Mona

auch keine Möglichkeit hat, den Anlaß, der zu der Frage führt, zu erschlie-

${ }_{103)}$ Ben, thematisiert Elke diesen Anlaß zusätzlich (ich seh da nämlich eben).

untschel/Weydt (1983:279) sehen den Unterschied zwischen Fragen mit denn

4) Die eigentlich in dem Merkmalpaar 'externe' vs.'interne' Motivation. e These von der Beiläufigkeit ist sicher auch darauf zurückzuführen, da $\beta$ sich die Forschung hauptsächlich mit Fragen wie Wie heißt du eigentlich? eschäftigt hat, die natürlich keine längere Dialogsequenz einleiten können. 
Fragesätze init der Modalpartikel eigentlich sind - und das läßt sich auch aul ihre stellung im Interaktionszusammenhang zurückführen - echte, aufrichtige $\mathrm{Fr}^{-}$ gen. Der Sprecher zeigt durch den Gebrauch von eigentlich wirkliches Interesse an der Beantwortung. Deshalb können mit derartigen Außerungen auch keine Aufforderungen ausgesprochen werden, und deshalb kann eigentlich auch nicht in rein phatischen Fragen vorkommen (vgl. König 1977a:124). Vgl. (6): Wer die eigentlichFrage äußert, will wirklich wissen, wie es dem Gesprächspartner geht: ${ }^{105}$

(6) Wie gehts dir? vs. Wie gehts dir eigentlich?

Eigentlich-Fragen sind auch keine rhetorischen Fragen (wie dies Albrecht (1977: 33P.) annimmt und ähnlich auch Meibauer (1986:123), der eigentlich als Rhetorizitätsverstärker sicht), wenn man davon ausgeht, daß eine rhetorische Frage eine implizite Behauptung ist. ${ }^{106}$

Da die Leistung von eigentlich also darin besteht, einen thematischen ubergang ${ }^{2}$ signalisieren, wird eigentlich nur mit dem Merkmal 〈UBERGANG〉 beschrieben.

\subsubsection{Bloß und Nur}

Da sich blo $\beta$ und nur weitgehend austauschen lassen, sollen diese beiden Modalpartikeln hier gemeinsam behandelt werden. Die beiden Lexeme treten außer in der Verwendung als Modalpartikeln auch als Gradpartikeln ${ }^{\mathbf{1 0 7}}$ und Konjunktionen auli bloß kommt auch als Adjektiv vor.

Als Modalpartikeln ${ }^{108}$ lassen sich blo $\beta$ und nur in $w$-Fragesätzen, $w$-Exklamativ sätzen, Wunschsätzen und in Imperativsätzen nachweisen.

Zunächst zu den W-FRAGESATZEN mit den Modalpartikeln blo $\beta$ und nur: 105) Die in der Literatur beschriebene Bewertung von Fragen durch eigentlich als
"freundlich" (Weydt/Hentschel 1983:10) oder als "aggressiv" (Albrecht 1977:33f. für jede "hörerbezogene" Verwendung) hat nichts mit der Leistunt
von eigentlich zu tun, sondern ist nur auf den semantischen Gehalt der $\mathrm{Je}^{-}$ weils untersuchten Beispielsätze zurückzuführen.

106) Die von Meibauer (S.223 und 250) angeführten Beispiele (z.B.: Ist In hell $^{\text {th }}$ eigentlich bewußt, wie preiswert wissenschaftliche Bücher sind?) sind echtite Behauptungen).

107) Als Gradpartikeln können bloß und nur in quantifizierender und in skalié render Weise verwendet werden ( $v g l$. dazu genauer Altmann 1976:101 pf.).

108) Die Unterscheidung zwischen Gradpartikel und Modalpartikel im Imperativ un in der w-Frage lassen sich meist durch Folgesätze verdeutlichen; vgl.: Geh nur, fahr nie mehr mit dem Auto! (quantifizierende Gradpartikel) Geh nur, lauf doch nicht immer so! (skalierende Gradpartikel)

Geh nur, ich habe nichts dagegen! (Modalpartikel) (nach Altmann 1976:270) $\mathrm{Ob}$ es sich um die Gradpartikel oder die Modalpartikel nur/blo $\beta$ handelt, ist also wenn nicht durch den Akzent, dann meist durch den Kontext ersicht ${ }^{1 i^{c h}}$ 
(1)

"Donnerwetter!", hörte Jaga ihn murmeln, "einfach fabelhaft!" Voller Bewunderung starrte er sie an. "Wo hast du das bloß gelernt?", wollte er wissen. (En, 39)

(2)

Das ging mir schon auf die Nerven, und da sag ich so zu ihm: "Hör ma, weißde, was wir jetz machen? wir gehn jetz in die Kneipe, ne." Da sagte der, "ja, das wollt ich auch schon grade sagen, aber wie kommwer hier bloß raus?" (BA, 39)

(3)

Wirklich ausgezeichnet, dieser Martini. Echter britischer Gordon Gin. Wo haben Sie den im vierten Kriegsjahr nur immer noch herbekommen, Monsieur Ferroud..." (Si, 334)

(4)

Falbala, nachdem Asterix und Obelix ihren Verlobten befreit haben: Danke! Danke! Wie soll ich euch nur danken? (A X, 47)

Bel den w-Fragen verstärken bloß und nur die lllokution der Außerung, die FraBehandlung. Sie zelgen an, daß das ganze Interesse des Sprechers auf den Frageakt gerichtet ist (ăhnlich schon Weydt 1969:38). Für diese Funktion von bloß und nur soll das Merkmal 〈VERSTARKUNG〉 angenommen werden. ${ }^{109}$ Vgl. zum Unterschled:

(5b) Wann kommt sie bloß?

In Fragen mit bloß und nur kommt wegen dieser Verstärkung ein besonderes subJektives Interesse des Sprechers zum Ausdruck. Das kann dazu führen, daß der Sprecher die Frage auch an sich selbst stellt, etwa umschreibbar mit 'ich frage Mich (wirklich)':

(6)

...die kleinen Kaffehaustische biegen sich. Wo sollen wir bloß anfangen?

Nehmen wir die Avocadocremesuppe (...) Als letzte Vorspeise ein Carpaccio. ersäuft in Limettensaft und OI: Was machen die Leute bloß mit dem schönen Fleisch? (SZ)

Die Feststellung Bublitz' (1978:70) allerdings, Fragen mit blo $\beta$ und nur selen vor allem Fragen an den Sprecher selbst, der weiß, daß weder er noch der Hörer die Antwort kennt, ist nicht immer zutreffend: Hier ist zunächst einmal der Inhalt der Prage entscheidend. So ist auf jeden Fall in den Fragen, die eine Handlung oder (3) oben oder (7), der Hörer sehr wohl zu einer Antwort verpflichtet, die er na-

(7)

"Was wollen Sie bloß mit all den Halmasteinen?" wurde gefragt und bald

In War ausverkauft. (Ke, 117)

In Fragen, die einen anderen semantischen Gehalt haben, kann der Hörer die Ant-

Wort wissen oder auch nicht - wie bei jeder Frage - aber keinesfalls geht der 109)

Die in den anderen Funktionen der Partikeln bloß und nur (Gradpartikel und Konjunktion) angezeigte Bedeutungskomponente 'Einschränkung' heißt für die Modalpartikel, daß der Sprecher sein ganzes Interesse 'einschränkt' und es nur aup seine Außerung richtet und alles andere ausschließt; genau daraus resultiert die durch die Modalpartikeln angezelgte Verstärkung. 
Sprecher von vornherein davon aus, der Hörer wisse die Antwort nicht (wie dies etwa bei Fragen mit wohl der Fall sein kann). Selbst wenn der Hörer die Antwort nicht kennt, wie es z.B. in (8) möglich sein könnte, ist der Angesprochene - eben wegen der verstärkenden Bedeutung von nur (bzw. bloß) - verpflichtet, zu reagieren (ebenso oben in (6)):

(8) Ich werd noch wahnsinnig!! Wo ist nur dieser blöde Autoschlüssel? (8a) Wo ist der Autoschlüssel? / Wo ist denn der Autoschlüssel?

Eine Antwort wie 'ich weiß es nicht' wäre hier nicht adäquat (in (8a) dagegen schon, wenn auch nicht sehr kooperativ), der Hörer muß noch auf eine andert Weise - zum Beispiel durch das Außern irgendeiner Vermutung - oder eine nicht sprachliche Handlung reagieren.

Durch den Gebrauch von bloß und nur wird also der Akt des Fragens verstärkt und unterstrichen. Das zeigt sich auch daran, da $\beta$ bloß/nur nicht in Fragen auf treten, die der phatischen Kommunikation dienen, also Fragen, bei denen der Sprecher wenig(er) Interesse an der Antwort hat; vgl.:

(9) ?Wie gehts dir bloß? / ?Wie gehts bloß Ihrer Familie?

Eine oft geäußerte These ist, daß bloß und nur in rhetorischen Fragen vorkommen könnten, bzw., daß Fragen mit bloß und nur auch rhetorische Fragen sein könn ${ }^{-}$ ten. ${ }^{110}$

Geht man nun davon aus, daß sich eine rhetorische Frage vor allem dadurch ${ }^{u^{S^{\prime}}}$ zeichnet, daß sie eine implizite Behauptung enthält, die in der Regel in der "dia" metralen Umdeutung" (nach Abdullaev 1977:267) und im Sonderfall in genau $e^{\text {in }^{e^{r}}}$ möglichen Füllung der Lücke (s.o. S.145) besteht, so ist das in den allgemein als rhetorischen Fragen angeführten Beispielen nicht der Fall; vgl.:

(10) Warum nur hast du mich bestohlen? (Berg 1978:78)

(11) Wie konnte er nur sein ganzes Geld in Asterix-Heftchen anlegen? (Bublitz 1978:70)

(12) Was ist das nur für eine Gesellschaft, die es sich leisten kann, intelligent und hochschulgebildete Menschen auf Halde zu legen? (Meibauer 1986:202)

Wenn die angeführten Beispiele rhetorische Fragen wären, so müßte ihnen $e^{\text {iñ }^{\natural}}$ Behauptung, wie sie etwa (10a) ausdrückt, zugrunde liegen:

(10a) Es gibt keinen Grund, warum du mich bestohlen haben könntest.

Meiner Ansicht nach will ein Sprecher, der (10) äußert, aber sehr wohl eine $\mathrm{A}^{\text {nt }}$ wort vom Hörer erhalten und impliziert nicht eine Behauptung wie (10a). Intere e $^{s^{\prime}}$ sant ist, daß die meisten der als rhetorische Fragen mit blo $\beta$ und nur geführt ${ }^{t^{n}}$ Außerungen in irgendeiner Form nach Gründen (dann eingeleitet mit warum) oder

110) Vgl. Z.B. Meibauer (1986:124): "Man kann also sagen, daß nur eine FTabe nicht rhetorisch macht, aber Rhetorizität verstärkt"; ähnlich auch bei $\mathrm{Be}^{\mathrm{c}^{\mathrm{k}}}$ (1976:10), Berg (1978:78ff.) und Bublitz (1978:69). 
Motiven (etwa: 'wie konntest du nur...') für eine Handlung fragen. Auch das ist m.E. ein starkes Indiz dafür, daß es sich eben nicht um rhetorische Fragen handelt, umso mehr, wenn sich die Fragen auf Handlungen oder Motive des Gesprächspartners beziehen. Mit w-Pronomina (wie wer) eingeleitete Fragen, die nur Oder bloß enthalten, können ohnehin nur als echte Fragen aufgefaßt werden; vgl.: (13) Wer will nur den Krieg? (kann nicht bedeuten: 'Niemand will den Krieg') Das von Meibauer als rhetorische Frage angeführte Beispiel (12) ist als w-ExklaMativsatz einzuordnen. Darauf deutet zum einen das Pronomen was für ein hin, zum anderen drückt der Sprecher mit einer solchen Außerung vor allem seine Verwunderung aus und weniger eine implizite Behauptung.

Dle oft angeführte zusätzliche Bedingung für rhetorische Fragen, der Sprecher erWarte keine Antwort, trifft auf die $w$-Exklamativsätze genauso zu, und ebenso trifft auf beide $z u$, daß der Hörer zu einer Reaktion verpflichtet ist.

Durch bloß und nur kann eine Fragehandlung also nicht dahingehend modifiziert Terden, daß die Außerung eine rhetorische Frage wird.

Neben dem Vorkommen in $w$-Fragen können bloß und nur also auch in W-EXKLAMATIVATZEN auftreten (vgl. dagegen Luukko-Vinchenzo 1988:29). Diese unterscheiden sich von den Fragen zum einen dadurch, daß der Sprecher keine Antwort Wohl aber eine Reaktion - erwartet, zum andern dadurch, daß die vom Sprecher ausgedrückte Einstellung mit 'ich wundere mich, w-' umschrieben werden kann. Deshalb können auch diese Xußerungen nicht zu den rhetorischen Fragen gerechnet werden; s.o. (12).) Das $w$-Wort ist in den allermeisten Fällen wie oder was für ein; vgl.:

(14)

Frau Kröhl (..) stand im Eßzimmer an der Heizung und lauschte. "Was hat

(15) er nur für einen leichten Anschlag!" (Ke, 135)

(16) Was hast du nur für schöne Zöpfe, mein Kind! (Ke, 10)

(17) Was hat er nur für einen schönen Kopf! (Ke, 135)

(18) Junge, wie siehst du bloß aus? Wie Buttermilch und Spucke. (Ke, 20)

Mein Vater war der gesündeste Mensch, den man sich denken konnte, der

(19) Vertrug ja Nägel. "Wie isser bloß gesund" (Ke, 79)

(20) Auf dem oktoberfest: Was ist das bloß für ein Gedränge hier!

$\mathrm{D}_{\mathrm{a \beta}}$ Welch tolle Leute kennst du $\underline{\mathrm{blo \beta}}$ !

ist ein das w-Wort welch in derartigen Außerungen auftreten kann (vgl. (20)), - Exklamateres Indiz dafür, daß es sich um Exklamativsätze handelt. Auch in den kution. Uim

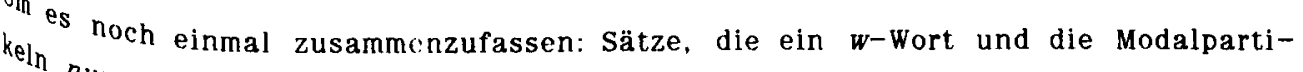
nur oder bloß enthalten, sind entweder Fragen oder Exklamative, aber keine 
rhetorischen Fragen; in beiden Fällen tragen die Partikeln das Merkmal 〈VERSTARKUNG>.

Auch in den WUNSCHSATZEN können $b l o \beta$ und nur mit diesem Merkmal beschrieben werden; vgl.:

(21) Ach, hätt ich meiner Tochter nur geglaubt!

(22) "Es ist ja zum Verzweifeln", sagte sie, "wären wir bloß zu Hause geblieben!" (Ke, 176)

(23) Du hast eine Anzeige wegen Beleidigung bekommen. Hättest du damals bloß/nur deinen Mund gehalten!

Hier bewirkt allerdings die Verstärkung des lllokutiven Akts durch die Modalpartikeln bloß und nur auch, daß die Interpretation als Wunschsatz eindeutig gesichert ist. Wie oben (s. S.24f. und S.117f.) schon erwähnt, sind in Wunschsätzen entweder die Partikeln bloß und nur oder doch (nahezu) obligatorisch. Die Annlichkeit von bloß und nur einerselts und doch andererseits im Wunschsatz (vgl. (22)) läßt sich so erklären: durch bloß und nur wird der Illokutionstyp verstärkt (Merkmal) 〈VERSTARKUNG〉), bei doch führt das Merkmal 〈KORREKTUR〉 (wenn es in dieser Verwendung im sinne einer gewünschten Korrektur der Wirklichkeit verstanden werden kann) letztlich auch zu einer Verstärkung des Wunsches.

(22a) Wären wir bloß zu Hause geblieben!

(22b) Wären wir $\underline{\text { doch }} z u$ Hause geblieben!

In den IMPERATIVSATZEN unterscheiden sich bloß und nur in ihrer Bedeutung. ${ }^{111}$ Für blo $\beta$ bedeutet das Merkmal 〈VERSTARKUNG> auch in den Imperativsätzen, $d a \beta$ der Aufforderungscharakter verstärkt wird - so sehr verstärkt wird, daß die $A^{u^{f}}$ forderung zu einer Drohung werden kann bzw. zu einer Warnung vor den Konsé quenzen, die aus dem Nichtbefolgen der Aufforderung entstehen würden ( $v g$. Franck 1980:227). In dieser Verwendung wird blo $\beta$ meist akzentuiert (zum $A k z^{\mathrm{e}^{\mathrm{l}}}$ s.o. S.22f.).

(24) "Kinder, liefert das bloß ab", sagte meine Mutter, "und am besten gar $n^{i c^{h t}}$ reinkucken." (Ke, 160)

(25) Abends probierte Ute meine Kluft an. "Laß das bloß keinen sehn!" (Ke, ${ }^{52)}$

(26) Hau bloß ab! Sonst kannst du was erleben.

(27) Führ dich bloß nicht wieder so auf heute abend! Sonst war es das letzte

Mal, daß ich dich auf ein Fest mitgenommen habe!
Sehr hăufig beschrelbt der Sprecher einer bloß-Aufforderung die für den Fall det Nichtbefolgung zu erwartenden Sanktionen im darauffolgenden Satz, eingeleitet it sonst, vgl. (26) und (27). Daraus läßt sich auch ablesen, warum bel Aufforder ${ }^{\mathfrak{D}^{\prime}}$

111) Hinzuweisen ist darauf, daß bloß und nur auch in Aussagesätzen mit Mold blof $^{\circ}$ nicht glauben...! 
gen mit bloß meist ein Autoritätsgefälle zwischen den Gesprächspartnern besteht. Nicht immer ist in diesen Aurforderungen allerdings der Sprecher auch der Sanktionsmächtige, vgl. (28):

(28) Mensch, mach bloß das Zelt zu! Sonst kommen wieder so viele Mücken rein! Hier handelt es sich eher um eine dringliche Bitte, die den Charakter einer Warnung oder eines Rates hat. Der Sprecher ist zwar in diesem Fall nicht sanktionsMächtig, unterstellt aber, daß der Angesprochene ein Interesse daran hat, die negativen Folgen der Nicht-Erfüllung zu vermeiden, wenn er diese kennt (vgl. Franck 1980:227). Diese negativen Folgen sind in (28) explizit erwähnt.

In negierten Imperativsätzen kann auch mit nur - wie mit bloß - eine Drohung ausgesprochen werden, allerdings wirkt nur hier wohl nicht so stark wie bloß:

(29a) Komm bloß nicht so spät nach Hause!

Komm nur nicht so spät nach Hause!

In diesem Fall spielt die Betonung eine wesentliche Rolle: wenn nur unbetont ist, handelt es sich wohl kaum um eine Drohung, bei betontem nur kann es als Drohung interpretiert werden - besonders dann, wenn ein Satz mit sonst folgt, der eventuelle Sanktionen enthält. $B l o \beta$ ist aber auf alle Fälle die stärkere Variante.112

In nicht-negierten Imperativsātzen unterscheiden sich bloß und nur deutlich voneinander: Nur wirkt hier abschwächend, es mildert die Aufforderung und gibt ihr einen beruhigenden Ton (vgl. Weydt 1969:35 oder Bublitz 1978:72); nur-Auffordeungen können oft Ermunterungen sein.113

$(30)$

Ilse macht einen Besuch bei Gerd. Sie steht schüchtern und verlegen

(31) herum. Gerd: Setz dich nur hin!

Asterix: Ich stehe die Nacht über Wache!

Obelix (druckst herum): Ah...man hat (...) ein Bankett organisiert und ich möchte es Idefix nicht vorenthalten.

(32a) Asterix: Geh nur, lieber Obelix! (A XIII, 8)

Eine Komm nur her! Ich tu dir doch nichts!

und derartige mildernde Bedeutungkomponente ist bei bloß nicht möglich; vgl. (32) and (33):

(32b)

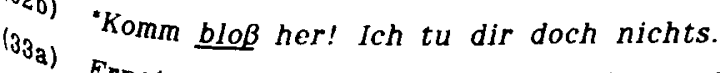

Ernst und Luise beim Essen. Es ist noch etwas Fleisch da.

(33b) Ernst: IB nur das Fleisch auf! Ich hab schon genug gehabt.

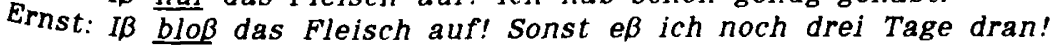

\footnotetext{
1.2) Bublitz (1978:72) hat auf ironische Verwendungen von nur/bloß hingewiesen, bei denen der Sprecher für die Befolgung der Aufforderung negative Sanktio-

$1_{13)}$ Ten androht: Komm bloß/nur her! (Dann kannst du was erleben.)

Wie es zu dieser Bedeutung kommen kann, vermag ich nicht zu erklären.
} 
Diese Bedeutung von nur soll hier mit dem zusätzlichen Merkmal 〈ZUSPRUCH〉 charakterisiert werden. Nur ähnelt in dieser Variante den Modalpartikeln mal und ruhig; vgl.:

(32c) Komm mal her! / Komm nur her! / Komm ruhig her!

In den meisten Fällen ist beim Außern einer nur-Aufforderung für den Sprechet bereits ersichtlich, daß der Gesprächspartner die Handlung ausführen will - das unterscheldet nur von mal. Zwischen ruhig und nur ist lediglich ein feiner Bedelltungsunterschied festzustellen: bei ruhig kommt hinzu, daß der Angesprochent meint, der Sprecher habe etwas gegen die Ausführung der Handlung: ruhig hat eine permissive Komponente (s.u. S.127f.), die nur nicht hat.

Unterschiede zwischen bloß und nur lassen sich also für die Verwendung im (nicht-negierten) Imperativsatz nachweisen. Außerdem unterscheiden sich die bei" den Modalpartikeln noch dadurch, daß bloß stärker ist als nur und stilistisch da $^{\circ}$ durch, daß blo $\beta$ eher in der gesprochenen sprache verwendet wird (vgl. Weydl Hentschel 1983:8).

Beide Modalpartikeln tragen das Merkmal 〈VERSTARKUNG〉, und nur erhält für die nicht-negierten Imperativsätze das Merkmal 〈ZUSPRUCH〉.

\subsubsection{Mal}

Mal kann neben seiner Verwendung als Modalpartikel auch als Adverb, und $2{ }^{4 t}$ als Temporaladverb, auftreten. Dabei handelt es sich um die verkürzte Form vol einmal. Die Modalpartikel mal ist wohl ursprünglich auch als verkürzte Form vol einmal zu sehen, wird aber heute in der langen Form kaum mehr verwendet. ( (in $^{\natural}$ Ausnahme stellt die süddeutsche Variante amal dar.)

Die Modalpartikel mal tritt auf in Imperativsätzen, bestimmten Entscheidungs s $^{8^{\prime}}$ ge- und Aussagesätzen. Alle diese Außerungen sind aber immer als Aufforderunf zu interpretieren.

Besonders in Aufforderungen, die die Form eines Imperativsatzes haben, ist äußerst frequent; $\mathrm{mal}$ ist hier ein "hochgradig konventionalisierter Bestandtell Satzes" (Weydt/Hentschel 1983:14). Einsilbige Imperative wie "Komm!" do "Schau!" werden fast immer mic einer Modalpartikel - meist mal - gebra ch $^{\text {h }}$ Auch die Tatsache, daß mal mit hör oder sag zu einem Gliederungssignal ${ }^{\text {er }}$ schmolzen ist (vgl. (1) und (2)), zeigt diese hohe Frequenz.

(1) Lisa: So, ich glaub, ich werd mal mein Zimmer aufräumen.

Anna: Ja. Hörmal. man kann dich doch (...) abends erreichen (BA, 50)

(2) Sachmal, Lore, du weiß auch keinen Rat, die Ulla hat einen Floh. (BA, ") 
In Aufforderungen, die die Form von Aussagesätzen haben, kann mal im allgemeinen auftreten in Verbindung mit den Modalverben ${ }^{114}$ können, seltener dürfen und sollen, wenn sich die Außerung an einen oder mehrere Gesprächspartner richtet, ${ }^{115}$ und wenn sich der Inhalt der Außerung auf die Zukunft bezieht.116 Bei Entscheidungsfragesätzen mit mal muß ebenfalls ein Gesprächspartner angesprochen Sein, und die Außerung muß sich auf die Zukunft beziehen. In beiden Fällen stehen die Verbformen auch häufig im Konjunktiv.

(3)

Und nun mach dich $\underline{\mathrm{mal}}$ an die Arbeit! Wir müssen heute fertig werden.

(4) "Du wirst lachen", sagte mein Bruder, "das Ding funktioniert noch immer.

Halt mal'n Daumen drunter!" (Ke, 23)

(6) Ich richte den Reissalat her. Du könntest mal nach den Getränken schauen.

Können Sie mir mal Feuer geben?

(7) Er sei kein richtiger Junge, meinte sie. Richtige Jungen kämen mit zerschundenen Knien und Löchern nach Hause. Die stiegen über jeden Zaun. "Würdest du mir mal bitte verraten, über welchen Zaun ich eigentlich stei-

(8) Gehst du $\underline{\mathrm{mal}}$ ans Telefon? gen soll?" (Ke, 14)

Die temporale Bedeutung des Adverbs scheint auch noch in der Modalpartikel vorhanden zu sein. (Die Grenzen sind fließend zwischen mal als Modalpartikel und mal als Temporaladverb; besonders in den Kombinationen sind diese beiden Varianten nicht immer zu trennen.) Durch den Gebrauch von mal wird der Ausführungszeitpunkt der gewünschten Handlung nicht präzisiert, sondern eher 'ver"ischt' - im Gegensatz zu 'sofort', mit dem mal dehalb auch nicht kombiniert werden kann. Es wird dem Angesprochenen (zumindest formal)117 Spielraum gegeben ¿Züglich des Zeitpunkts der Ausführung der gewünschten Handlung. Deshalb wirken Aupforderungen mit mal beiläufiger, abgeschwächter und meist auch höflicher als solche ohne mal.

Durch die Modalpartikel mal wird also der illokutive Akt 'Aufforderung' abge-

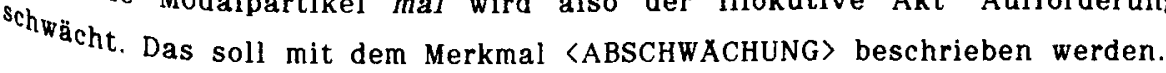

Die Modalpartikel mal kann also in Aussagesätzen nur auftreten, wenn deren dakutionstyp bereits durch Modalverben modifiziert ist; das zeigt wieder, da $\beta$ die Einstellungen modifizierenden Ausdrücke hierarchisch geordnet sind,

$1_{15}$ ) Und daß die Modalpartikeln 'über' den Modalverben liegen.

Als 'übermittelte' Aufforderung ist mal in Verbindung mit sollen allerdings

$l_{16)}$ auch möglich: Der soll mal kommen!

in Ausnahinefällen kann mal (wenn alle anderen Bedingungen zutreffen) auch

li Advussagesätzen ohne Modalverben auftreten, dann ist aber ein temporales Adverb wie jetzt nötig: Sie zeigen mir jetzt mal Ihre Papierc!

Stolt (1979:481) hat darauf hingewiesen, daß der Zeitpunkt der Ausführung nur scheinbar in das Ermessen des Angesprochenen gestellt wird; das ändert aber nichts an der Bedeutung von mal, sondern mu auf andere Faktoren zurückgeführt werden.
} 
Die Modalpartikel mal setzt voraus, daß eine Xußerung ein Aufforderungsakt ist oder aber diese Interpretation zumindest zuläßt. In Außerungen wie (9), die vom Illokutionstyp her Fragen oder Aufforderungen sein können, vereindeutigt mal dle Aufforderungslesart. Insofern wird durch mal der Funktionstyp geändert (von 'Pragen, ob' zu 'erreichen wollen, daß').

Liest du diesen Aufsatz (?/!)

\section{Exkurs: Die Partikel bitte}

Da die Kombinationsfähigkeit von bitte, mit denjenigen Modalpartikeln, die ir Aufforderungen auftreten, weitere Aufschlüsse geben kann, soll diese Partikel bel der Betrachtung der Kombinationen mit einbezogen werden.

Hier sei nur soviel gesagt: In der Regel wird aus jeder Aufforderung, in die bitte eingefügt wird, eine höfliche Aufforderung; vgl.:

(1) Machen Sie bitte drei Kopien von diesem Vertrag!

(2) Gehst du bitte ans Telefon?

(3) Sie könnten jetzt bitte das Fleisch servieren.

Bei diesen Aufforderungen besteht ein echtes Interesse des Sprechers an der $\mathrm{AuS}^{-}$ Pührung der Handlung; die Außerungen sind oft als Bitten zu verstehen:

(4) Leihst du mir bitte heute abend dein Auto?

Daß eine Aupforderung mit bitte nicht in allen Fällen höflich sein muß, zeigen:

(5) Du gehst bitte nach der Schule immer sofort nach Hause!

(6) Sie machen bitte den Vertrag fertig!

Hier wird die durch die Aussagesatzform ausgedrückte Aufforderung - die aulf grund der Form relativ stark ist - durch bitte abgeschwächt.

In den folgenden Beispielen kann bitte allerdings kaum mehr als abschwächend oder höplichkeitsanzeigend verstanden werden:

\section{Und wer soll das bitte bezahlen?}

(8) Wovon bitte sollen wir dann leben?

Die Funktion von bitte in $w$-Fragen ${ }^{118}$ wie (7) und (8) ist es, den Angesproche $e^{\prime}$ nen $z u$ einer Antwort aufzufordern; diese Außerungen haben meist einen 'spitz ${ }^{e^{\prime}}$ Unterton.

118) In 'echten' Entscheidungsfragen (d.h. solchen, die keine Aufforderungsint vol $^{\text {"n }}$ pretation zulassen) dagegen ist für mein Sprachgefühl diese Verwendung bitte ausgeschlossen; vgl.: "Hast du bitte die Rechnung bezahlt? Im öster ${ }^{\text {rt }}$ chischen Sprachgebiet aber scheint dies nicht der Fall zu sein, dort ${ }^{5}$ auch Außerungen wie: Ist bitte Anna da? zu hören. 


\subsubsection{Ruhig}

Das Lexem ruhig tritt auf als Adjektiv und als Modalpartikel. Daß sich die Funktion des Lexems ruhig von der propositionalen auf die illokutive Ebene verschoben hat, beweisen Außerungen wie (1):

(1) Machen Sie ruhig Krach! Die Kinder schlaPen noch nicht.

Die Modalpartikel ruhig läßt sich nachweisen in Imperativsätzen und in Aussagesătzen mit dem Modalverb können (daneben auch sollen und dürfen), die ein zukünftiges Geschehen zum Inhalt haben. Außerungen mit ruhig sind immer Aufforderungshandlungen:

(2)

Nina: Ja, also wenn ihr euch/ wenn sie sich wieder besser fühlt, dann .

Kommt ruhig/

Leo: ja

Nina: Das kommt auf einen oder zwei mehr überhaupt nich an. (BA, 100)

(4) Beim Friseur: Sagen Sie's ruhig, wenn es Ihnen nicht gefällt!

(5) Sie können ruhig rauchen, mich stört das nicht.

Er kann ruhig ein Taxi nehmen; geht alles auf Spesen!

Die Bedeutung des Adjektivs ruhig liegt auch der Verwendung des Ausdrucks als Modalpartikel zugrunde: mit der Modalpartikel ruhig wird ausgedrückt, daß der Angesprochene beruhigt sein kann, weil der Sprecher nichts dagegen hat, wenn der Angesprochene (oder ein Dritter bei 'übermittelten' Aufforderungen wie (5)) die entsprechende Handlung ausfuhrt, daß es also für ihn keine nachteiligen Folgen hat. (Bublitz (1978:83) umschreibt ruhig sehr treffend mit der Wendung nil obstat.) Für ruhig soll deshalb das Merkmal 〈ZUSPRUCH〉 stehen.

Die Handlung, zu der der Sprecher mit einer ruhig-Außerung aupfordert, muß eine Handlung sein, die der Partner offenkundig (oder für den Sprecher leicht er${ }^{8}$ chließbar) bereits vorhat, es muß also beim Gesprächspartner bereits ein Handlungsplan vorhanden sein. Das Interesse an der Ausführung der Handlung liegt hler vor allem beim Angesprochenen. Deshalb ist ruhig in Beispiel (6) inakzeptabel, wenn der Sprecher weiß, daß der Angesprochene Knoblauch nicht verträgt,

(6) auch unangemessen in (7):

Das nächste Mal kannst du ruhig Knoblauch in die Sauce tun, mir macht das nichts.

(7)

Hans und Bernd sitzen zusammen in einem Zimmer und arbeiten. Unvermit-

Die telt sagt Bernd: "Du kannst ruhig das Fenster aufmachen.

Aefforderung mit ruhig in (7) ist nur möglich, wenn Hans irgendwie zu erken-

In gibt, daß er das Fenster gerne öffnen würde.

In der Regel handelt es sich bei Aufforderungen mit ruhig um Handlungen, von 
cher etwas gegen die Ausführung hat. Das zeigt beispielsweise (2), wo Nina nach der ruhig-Aufforderung explizit mögliche beim Angesprochenen bestehende Hinderungsgründe entkräftet; und das erklärt, warum eine Aufforderung mit ruhig im Kontext von (8) unangebracht wirkt:

(8) Ehepaar Kolb ist bei Ehepaar Fischer zum Essen eingeladen. Nach der Begrüßung sagt Frau Fischer: ?Setzen Sie sich ruhig!

aber: Setzen Sie sich doch!

Ein explizites Verbot oder explizit vom Sprecher geäußerte Einwände gegen die Handlung (im Sinne von (9)) gehen einer ruhig-Außerungen selten voraus ( $v g^{\prime}$. aber (10)), meist wird nur dem Gesprächspartner unterstellt, er betrachte die Handlung möglicherweise als unerwünscht oder verboten.

(9) ?Ich mag Zigarrenrauch in meiner Wohnung ja eigentlich nicht, aber raucher Sie ruhig!

(10) Ulla: Tag, Kurt, ich wollt dich Pragen, kommt ihr nu?
Kurt: Ah, so (..) Wir rufen dich gleich an, wollt ihr (..) weg oder weswegen? Ulla: Ja, sons würden wer wegfahren.

Kurt: Sons fahrt ihr weg. Ja, fahrt schön weg!

(längeres Gespräch über ein anderes Thema)

Kurt: Weißde jetz Bescheid, nich! Also wir kommen dann nicht, woll!

Ulla: Ja, ihr könnt ruhig kommen, bloß/e (BA, 7/8)

Ulla hat in (10) am Anfang des Gesprächs zu erkennen gegeben, daß bei ihr vor behalte gegen den geplanten Besuch bestehen; diese Einwände hat ihr Gesprächs' partner aufgegriffen und seinen ursprünglichen Plan geändert (wir kommen dgrt nicht). Mit der ruhig-Aufforderung entkräftet Ulla nun diese Einwände, die kưrt von dem Besuch abhalten und fordert ihn zu der (ursprünglichen) Handlung gul. indem sie durch ruhig anzeigt, daß sie nichts gegen den Besuch hat.

Wenn also ein Handlungsplan des Gesprächspartners zu erkennen ist, kann de? Sprecher durch den Gebrauch von ruhig ausdrücken, daß er nichts dagegen ${ }^{n a t h}$ wenn der Hörer die Handlung ausführt. ${ }^{119}$

Die Modalpartikel ruhig modifizlert also den Illokutionstyp einer Außerung dah ${ }^{i n^{\prime}}$ gehend, daß eine Aufforderung als Erlaubnis zu verstehen ist, ruhig hat permilis siven Charakter (vgl. Franck 1980:264).

Der bei einer ruhig-Aufforderung bereits bestehende Handlungsplan des ${ }^{6} e^{\prime}$ sprächspartners könnte auch der Grund dafür sein, warum ruhig kaum in negier tê $^{n}$ Aufforderungen vorkommt (s.o. S.92). Geht man davon aus, daß die verwend ${ }^{\text {nt }}$. eines Negationszeichens in einer Aufforderung das Stoppen und Korrigieren $e^{\text {in }^{\mathrm{l}}}$ Handlungsplans bedeutet (vgl. Schmidt 1973:191), so würde das in der Kombingtiol

119) Das könnte erklären, warum ruhig nicht in Entscheidungsfragesätzen auftrén ten kann, auch wenn diese den kommunikativen Sinn einer Aufforder haben - im Unterschied zu mal (vgl. Bublitz 1978:84). 
mit ruhig heißen, daß der Sprecher den Hörer in einem Handlungsplan stoppt (durch die Verwendung des Negationsträgers) und gleichzeitig anzeigt, daß er nichts dagegen hat, daß der Hörer den Handlungsplan stoppt. Dies aber wäre Widersinnig. Wenn aber das Stoppen des Handlungsplans nicht in derselben Außerung erfolgt, wenn also die Negation nicht vom Sprecher eingeführt wird, sind ruhig-Außerungen mit einem Negationselement möglich. In diesem Fall ist der Inhalt der Aufforderung mit Negationszeichen bereits vorerwähnt. Dann besteht der Pür den Sprecher erkennbare Handlungsplan des Gesprächspartners in einem bestimmten Nicht-Tun. Dies stellt allerdings eine sehr markierte und deshalb sehr seltene Verwendung dar.

(1)

Ina: Ich habe noch soviel zu erledigen; aber ich weiß nicht, wie oft ich es mir leisten kann, nicht in dieses Seminar zu gehen.

Ute: Ach, geh ruhig nicht hin! Es ist eh eine Wiederholungsstunde.

a ruhig-Aufforderungen illokutiv als Erlaubnis zu interpretieren sind, ist eine Außerung wie (12) eher ironisch oder zynisch - auf keinen Fall aber wörtlich ¿u verstehen, denn bei Erlaubnissen wird "erstens ein Interesse des Angesprochenen an der erlaubten Handlung, zweitens ein vorangehendes Verbot vorausgesetzt" (Franck 1980:247; 'Verbot' ist hier wohl etwas zu stark).

(12) Du könntest dir ruhig ein bißchen mehr Mühe geben in

brauchst nicht zu glauben, dir fällt alles in den Schoß.
Jermutlich steuert die Verwendung des Konjunktivs diese Interpretation mit; konUnktivische ruhig-Aufforderungen können nicht wörtlich interpertiert werden.

Tin eine echte ironische Umkehr handelt es sich bei Außerungen wie (13), die als (13)

Von Fahr ruhig noch schneller, wenn du uns in den Himmel bringen willst!

dadufforderungen mit schon oder doch unterscheiden sich ruhig-Aufforderungen Harch, daß sie immer ein Interesse des Angesprochenen an der auszuführenden Der unt voraussetzen.

esse des Besprochene Angesprochenen stärker ist und deutlicher zu erkennen ist, daß der AnHandlung. Es

Tit Zwei zu überlegen, ob ruhig deshalb statt mit dem Merkmal 〈ZUSPRUCH〉 nicht (10)) Merkmalen wie 〈STOP〉〈KORREKTUR〉 beschrieben werden sollte (vgl. auch Auch das Verhalten bezüglich der Negation wäre so besser zu erklären. 


\subsubsection{Aber}

Die Partikel aber kommt als Konjunktion vor, die einen Gegensatz anzeigt, und als Modalpartikel.

Als Modalpartikel tritt aber nur ${ }^{120}$ in EXKLAMATIVSATZEN auf:121 vgl.:

(1) Als ich wieder im 'Clou' war, meinen Mantel ausgezogen und die Tasche (.) abgegeben hatte, sagte Effi: "Mensch, du bist aber blaß!" (Bi, 59)

(2) Beim Teutates! Du kannst aber viel essen! (A XIII, 8)

(3) Bist du heute aber schick!

(4) Während Lachsalven aus Männerkehlen (...) akzeptiert werden, wird vernehmliche weibliche Heiterkeit vielfach immer noch mit Verwunderung regi striert. "Die sind heut' aber lustig" ist eine der gängigsten Reaktionen. (5

Durch den Gebrauch der Modalpartikel aber zeigt der Sprecher seine Uberraschun an; d.h. genauer: er signalisiert, daß der betreffende Sachverhalt in seinem $A 4^{\circ}$ prägungsgrad für ihn unerwartet ist, also von seinen Erwartungen abweicht. Def halb soll für aber das Merkmal 〈UNERWARTET>s stehen.

Nun ist das Ausdrücken der Uberraschung bzw. des Erstaunens bereits eine ver" wendungsbedingung des Exklamativsatzes. Dennoch kann das Merkmal <UNERWAR TET> auch der Modalpartikel aber selbst zugeschrieben werden, denn ihr Gebrauch führt zu einer Vereindeutigung der durch den Satzmodus bereits ausgedrückten propositionalen Grundeinstellung und damit zu einer Verstärkung der Uber ${ }^{r^{8}}$ schung. Die Modalpartikel aber macht also eine Außerung eindeutig zum Exklam ${ }^{\prime}$ tiv und vereindeutigt somit den Illokutionstyp.

Das Erstaunen, das durch die Modalpartikel aber angezeigt wird, bezieht sith $^{\text {th }}$ nicht auf die Geltung des Sachverhalts, sondern auf den Ausprägungsgrad $e^{i^{\mathrm{n}^{t}}}$ Eigenschaft. Eine adäquate Umschreibung ist 'ich bin erstaunt, daß so sehr. oft enthalten diese Exklamativsätze deshalb intensivierbare Adjektive oder ${ }^{d^{\prime}}$ verbien ( $v g l$. oben in (1) 'blaß' oder in (3) 'schick'). Ist kein solcher Ausdruct"

120) Bel der von Helbig in Helbig/Kötz (1981:30) angepührten Verwendung in $\mathrm{Au}^{\mathrm{u}^{\prime \prime}}$ forderungssätzen handelt es sich eindeutig um die konjunktionale ver well

dung von aber.
121) Die von Asbach-Schnitker (1978:320) angeführte Verwendung von aber alle $e^{e^{10}}$ in mit wie eingeleiteten w-Exklamativsätzen (Wie bist du heute aber $1 j e^{b}$ ist in meinem Korpus nicht belegt und scheint mir auch nicht (mehr) bräuchlich zu sein. Lediglich in der Kombination aber auch ist aber in

122) Exk in der Literatur (u.a. bei Asbach-Schnitker 1978:308) öfter getroffe $\mathrm{pe}^{\mathrm{e}^{\mathrm{l}}}$ Feststellung, die Paraphrase sei nicht 'ich bin erstaunt, daß' ist zwar $202{ }^{2}$

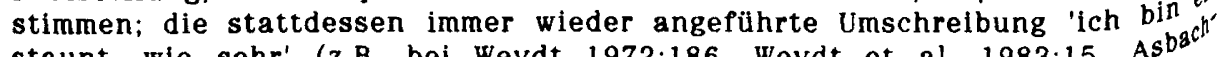
staunt, wie sehr' (z.B. bei Weydt 1972:186, Weydt et al. 1983:15, As $b^{b c}$ Schnitker 1978:308) gilt aber m.E. nur für den w-Exklamativsatz. 
Vorhanden, muß der Hörer ableiten, welche Eigenschaft nun von den Erwartungen des Sprechers abweicht; vgl. (5):

(5)

Mit (5) kann der Sprecher je nach Kontext anzeigen, daß es sich bei dem betrefMensch, ist das aber ein Schrank! handelt. Ahnlich ist es bei (6), wo ein besonders ausdauerndes oder besonders Propessionelles Tanzen gemeint sein kann:

(6) Können Sie aber tanzen!

Durch aber wird also ein Gegensatz zwischen Erwartung und tatsächlich Eingetretenem zum Ausdruck gebracht; hier liegt auch die gemeinsame Bedeutung der KonJunktion und der Modalpartikel (vgl. Helbig/Kötz 1981:30 oder Asbach-Schnitker 1978:323).

Der Sachverhalt, über den der Sprecher sein Erstaunen zum Ausdruck bringt, ist unmittelbar in der situation gegeben; insofern besteht ein direkter Bezug zum Kontext (und zwar zum sprachlichen oder zum situativen), der aber bei Ausrufen senerell vorhanden ist.

Bel

(dexamationen mit aber sind vor allem die Erwartungen des Sprechers relevant 'shalb erhält das Merkmal (UNERWARTET> den Index 'S' für sprecher), und nicht ${ }^{\text {so }}$ sehr die des Hörers; in dieser Hinsicht unterscheiden sich Exklamative mit aber von denen mit vielleicht. Allerdings ist der Sachverhalt, über den der Sprecher staunt, immer auch dem Hörer zugänglich; d.h. aus der Situation erschließbar. ${ }^{123}$ Wohl der Sprecher also mit aber vor allem auf seine eigenen Erwartungen Bezug nimmt, bzw. auf das Abweichen von seinen eigenen Erwartungen, ist ein anwesenGesprächspartner dennoch verpflichtet, in irgendeiner Form zu reagieren, sel 's, daß er die Uberraschung bestätigt (vgl. (7)), sei es, daß er die Uberraschung

(7)

Eine Frau öfnete, die hatte einen Topfkuchen in der Hand. "Haben Sie

(8) aber einen schönen Kuchen!" "Ja, nicht?" (Ke, 345)

Olga: Sie haben heute aber ein hübsches Kleid an!

Lena: - Ach. das hab ich schon lange./

- Naja, ist selber genäht./

- Das hab ich mal ganz günstig gekriegt.

\footnotetext{
(23) Weydt/Hentschel (1981:330) sprechen in diesem Zusammenhang von einem "Wir-Faktum", das ist ein Faktum, "das nach Meinung des Sprechers sowohl

hm als auch dem Hörer bekannt ist".
} 
Die Partikel vielleicht kommt auch als Satzadverb vor und kann in dieser Funktion mit mit 'es ist möglich' umschrieben werden. Als Modalpartikel läßt sich vilelleicht in Exklamativsätzen und in Entscheidungsfragesätzen nachweisen.

Zunächst zu den EXKLAMATIVSATZEN:

(1) ...und vorsichtshalber gebe ich ihrn einen Hunderter nach dem anderen hin. bis er sagt, 'Küß die Hand, Herr Direktor!', und weil ich ein bißchen angesoffen war, hab ich ihm die Hand hingehalten und gesagt: 'Bitte sehr! Bedienen Sie sich!' Der hat vielleicht Augen gemacht!

(M. Bieler, Der Kanal, Hamburg 1978:113)

(2) Mir war so übel, also die ersten drei Stunden hab ich da nur jammernd im Auto gesessen und mir meinen Magen gehalten, mir war so schlecht, aber ich konnte auch nich kotzen. Das war vielleicht ne schöne Fahrt! (BA, ${ }^{8}$

Und stell dir vor, der Jan hat gesagt, eine Frau sollte keine höhere Schulbildung haben als ihr Mann. Das ist vielleicht ein Chauvi!

(4) In einem Lied wurde furchtbar geflucht! "Kotz Mohren..." oder so. Das schrie er vielleicht heraus! (Ke, 125)

Auch mit der Modalpartikel vielleicht wird (wie mit aber) zunächst Staunen und Uberraschung ausgedrückt, also eine Diskrepanz zwischen der Erwartung und dem Eingetretenen angezeigt. Deshalb soll also auch vielleicht das Merkmal ${ }^{U}$ UNERWARTET> tragen.

Die Unterschiede zwischen aber und vielleicht lassen sich in zwei Bereichen fest machen: im Bezug zum Hörer und in der Tendenz.

Außerungen mit vielleicht weisen einen deutlicheren Hörerbezug und stärkere $e^{\text {n }}$ Mitteilungscharakter (ähnlich Weydt 1969:31, Bublitz 1978:55 oder Helbig/ $/ \mathrm{K}^{\text {th }}$ 1981:36) aup als Außerungen mit aber, die der Sprecher meistens direkt unter de Eindruck der subjektiven Wahrnehmung verwendet. Bei Exklamativen mit vielle $e^{\text {th }^{t}}$ ist der Sachverhalt deshalb für den Sprecher selbst nicht unbedingt neu; vgl. (5). wo das Adverb immer darauf hindeutet. Relevant ist in diesen Außerungen det Bezug zum Hörer; vgl. (6), wo für den Sprecher vor allem wichtig ist, daß der $G^{\prime}$ sprächspartner den Sachverhalt erkennt und entsprechend darauf reagiert:

Beim Braten von Fischstäbchen: Mensch, das spritzt vielleicht immer!

(6) Ein Kind kommt mittags von der Schule heim und sagt:

"Mann, ich hab vielleicht Hunger!"

Wegen dieses Hörerbezugs kann auch in Erzählungen, wenn also der Sachver ralt $^{\text {gt }}$ dem Sprecher bereits bekannt ist, im allgemeinen nur vielleicht und nicht ${ }^{95}$ sprecherbezogene aber verwendet werden;124 vgl. oben (1), (2) sowie (7):

124) Dies bestätigt auch der Test von Hentschel (1981:17f.). 
(7)

Eine Frau erzählt ihrem Mann von elnem Treffen mit einer Freundin: "...Und Clark jaulte die ganze Zeit, während Mira da war. Mein Gott, die verwöhnt den Jungen vielleicht!" (M. French, Frauen, Reinbek b.Hamburg 1983:103)

kmal 〈UNERWARTET> nimmt also in Erzählungen hauptsächlich auf die (ankenommenen) Erwartungen und die Vorstellungskraft des Hörers Bezug und muß Plglich zu 〈UNERWARTET> s spezifiziert werden.

Modalpartikel vielleicht kann aber nicht nur verwendet werden, wenn der herhalt lediglich dem Hörer neu ist, sondern auch, wenn er für beide GePrächspartner unerwartet ist. In diesen Fällen können sowohl aber als auch vielleicht eingesetzt werden. Der Unterschied zwischen beiden Modalpartikeln liegt ahn in der Bewertung des Sachverhalts: Exklamationen mit vielleicht sind tendenziöser als solche mit aber, ${ }^{123}$ vgl.:

Unem, . als ich fuhr, sagte meine Mutter, "Ja, Lisa, komm doch jetzt ma en bißchen ofter nach Hause!" Hab ich auch gedacht, "du hast vielleicht Ner-

(9) ven, du!" (BA, 46)

(10) Das ist vielleicht ein Depp!

Wie das so mit der ganzen Kultur gekommen ist. Und das meiste wär in Sachsen und Thüringen passiert. "Sonderbar. Und das sind vielleicht

Schnetzfinken..." Mein Vater mußte es wissen. (Ke, 185)

erste Bestätigung für die These, daß vielleicht tendenzlöser ist als aber

a hle ein kleiner Test, bei dem wahlweise aber oder vielleicht in Lückentexte

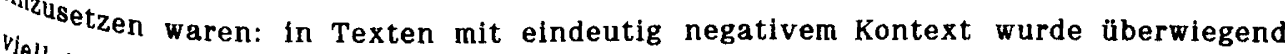
"lelleicht gewählt. ${ }^{126}$

ăchst on entiven Kontext haben, bei der Verwendung von vielleicht (unterstützt kön

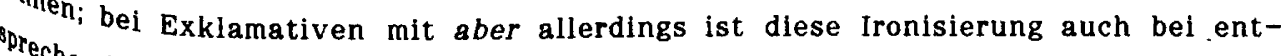
echender Intonation m.E. kaum möglich; vgl.:

125)

emgegenuber vertreten Weydt und Hentschel (vgl. Weydt/Hentschel 1981 und Hentschel 1981) die These, der Unterschied zwischen aber und vielleicht bebeide - wenn der Sachverhalt dem Sprecher und dem Hörer bekannt bzw. für mite zugänglich ist - darin, daß mit aber über eine besondere Quantität, mit vielleicht über elne besondere Qualität elnes Sachverhalts gestaunt wird. er von lhnen zur Überprüfung dieser These eingesetzte Test (vgl. Hentschel 1981:15ff. und Weydt/Hentschel 1981:327ff.) ist wenig elnleuchtend und m.E. ohne Aussagekraft. Auch in meinem eigenen Korpus konnte ich keinerlei Andoltspunkte für diese These finden. Weydt und Hentschel vertreten sie jevich konsequent: vgl. Weydt/Hentschel 1983:6, 17 (aber: Staunen über Maß,

Größeicht: Staunen über Form) und Weydt et al. 1983:19 (aber: Staunen über

Dlöße, Menge und Umfang; vielleicht: Staunen über Art, Form und Gestalt)

duren Test (mit einer Gruppe von ca 20 Personen) Puhrte Ch. Estran-Goecke urch, die mir ihre Ergebnisse freundlicherweise zur Verfügung gestellt hat. 
(11a) Du bist vielleicht ein Genie! (Bevor ich dir den Fernseher zur Repsrgtur gegeben habe, ist wenigstens noch ein Programm gelaufen; jetzt geht $b^{g}$ nichts mehr.)

(11b) Du bist aber ein Genie! (Seit du den Fernseher repariert hast, geht ef besser als zuvor.)

Umgekehrt kann die eindeutig negativ konnotierte Außerung in (8) (Du hast vil' leicht Nerven!), wenn vielleicht gegen aber ausgetauscht wird, nur in einem posit tiven Kontext wie z.B. in (12) verwendet werden:

(12) Nach dem Besuch eines Horrorfilms sagt ein Freund zum anderen: Du hast aber Nerven! Du bist ja selbst bei den schlimmsten Szenen völlig ruhib geblieben. Also mir ist öfters richtig schlecht geworden.

Aufgrund dieser tendenziosen Komponente soll vielleicht noch das fakultatist Merkmal 〈UNERWONSCHT>s erhalten; Pakultativ ist dieses Merkmal deshalb, well in Erzählungen die negative Konnotation nicht vorhanden seln braucht, da in diest Fall ohnehin nur vielleicht verwendet werden kann. Bei den meisten Belegen mei nes Korpus steht allerdings vielleicht in Erzählungen und hat negative Tendent (vgl. (2), (7), (8))

Die Tatsache, daß vielleicht eine negative Bewertung impliziert, zeigt sich ${ }^{3 c^{k}}$ noch besonders deutlich an der Verwendung in Fragen.

Bel den ENTSChEIDUNGSFRAGESATZEN gibt es keine klare Grenze zwischen wiel" leicht in Satzadverb-Funktion und vielleicht in Modalpartikel-Funktion. Ein $\mathrm{kf}^{\circ}$ terium ist, daß vielleicht im ersten Fall mit 'möglicherweise' paraphrasiert wefl kann und die Außerung eine echte Informationsfrage darstellt (vgl. (13)); im 2 ten Fall (Vgl. (14)) ist eine Paraphrase mit 'moglicherweise' nicht korrekt. wh ten Fall (vgl. (14)) ist eine Paraphrase mit 'moglicherweise' nicht korrekt.
vielleicht läßt sich in seiner Funktion mit der Modalpartikel etwa (s.0. S.170
vergleichen.

(13) Liegt der Grund für Ihr Verhalten vielleicht ('möglicherweise') darin, d\&

Kann ich viellelcht was dafür, daß das schiefgegangen ist?

In Außerungen wie (14) verdeutlicht der Sprecher durch den Einsatz der dod' $^{\prime}$ partikel vielleicht seine Antworterwartung: bei positiven Fragen erwartet def Sprecher elne negative Antwort, bel negativen dementsprechend eine positive An' wort (vgl. (15)-(17)); die Gültigkeit der Proposition des Fragesatzes ist also den Sprecher unerwünscht; den Sprecher unerwünscht;
(15) Rudi: Du hast mir doch immer geraten, in diese Firma zu investieren, und
jetzt sind die pleite. Lukas: Ja und? Ist das vielleicht meine Schuld?

(16) Der Vater zu seinem Sohn, der laute Rockmusik hört: Findest du dieses Geheule vielleicht schön? 
17)

Als wir in der Haustür standen (...), wollte er einen Kuß von mir haben.

"Wie kommst du denn darauf?" fragte ich. "Heute ist unsere Abiturfeier",

bel der Verte er (...). "Ist das vielleicht'n Grund?" (Bi, 49)

lejcht melst Ugeschist nachweisen. Das Merkmal 〈UNERWARTET〉, das vielleicht ja auch noch

belits a wurde, bezieht sich hier - wie auch bel Fragen mit etwa, wo dies

Wer nichtefuhrt wurde (s.o. S.171) - auf einen vorausgegangenen sprachlichen

ist $z$. S. Mep. In (15) der von Rudi mit seiner Außerung implizierte Vorwurf far Lukas Der artet.

or Obergang

dep Fragen ist fließend.127 Indizien sind hier der Kontext und der Inhalt

Ilcht sche: (16) z.B. kann kaum eine implizite Behauptung wie 'du findest das Die ${ }^{\prime}$ hnlit sein, und ist somit keine rhetorische Frage.

1/8 auch bemelinsam das (bei vielleicht fakultativ anzusetzende) Merkmal 〈UNERWONSCHT>s

(18a) hat, zeigen noch einmal die folgenden Gegenüberstellungen:

(18b) Hat es etwa ein elnziges Mal geregnet in Dallas? (von Meibauer 1986:203)

$\left(\mathrm{g}_{\mathrm{a}}\right)$ hat es viellelcht ein einziges Mal geregnet in Dallas?

('ob) Soll das vielleicht eine Entschuldigung sein?

Dle negativ das etwa eine Entschuldigung sein?

ist eln Indive Tendenz scheint mir bel Fragen mit etwa stărker zu sein; auch das

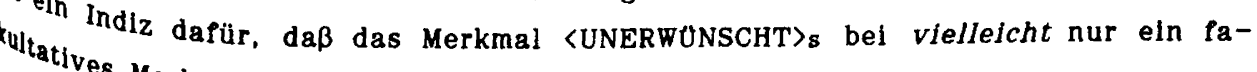
tives Merkmal ist.

2.2 .19

Mir

"I der Verwendung von mir, die traditionell "ethischer Dativ" genannt wird, und

$k_{\text {nn }}$ mir oben (S. 39ff.) vorgeschlagen - zu den Modalpartikeln gerechnet wird,

verden. aus jedem Satz ohne Anderung des propositionalen Gehalts weggelassen

"ch Außerungen mit und ohne mir (in Modalpartikel-Funktion) unterscheiden

ten lediglich in der konnotativen Bedeutung. Demnach llegt auch hier - wie bei

"uch andern Modalpartikeln - die Bedeutung im illokutiven Bereich. Das zelgt sich

(1) daran, daß Außerungen wie (1) möglich sind:

$V_{1 /} D_{a \beta}$ du mir dem nichts davon erzählst!

Ungen auf in Imperativsătzen (vgl. (2)/(3)), sehr hăufig auch in daß-Aufforde$((4) /(5))$, in bestimmten Aussagesătzen, die vom Illokutionstyp her Auffor-

127)

V I. dagegen Meibauer (1986:124), der meint, vielleicht erzeuge Rhetorizität. 
derungen sind $((6) /(7))$, und in Exklamativsätzen ${ }^{128}$ (vgl. (8)). Außerungen mit def Modalpartikel mir können also Aufforderungen oder Exklamationen sein.

(2) Hor mir auf mit diesen Geschichten!

(3) Und bleiben Sie mir gesund!

(4) Daß du mir nicht an die Pistole gehst (Ke, 221)

(5) Daß du mir nichts Unüberlegtes tust!

(6) Da gehst du mir nicht hin!

(7) Da hinauf zu deinem Liebhaber kommt mir das Kind nicht mehr!

(8) Du bist mir vielleicht ein Held!

Besonders in den Aufforderungen mit mir läßt sich der Zusammenhang mit de Personalpronomen deutlich sehen: mir könnte hier paraphrasiert werden mit 'es liegt mir daran, daß...'. Die Haltung, die der Sprecher durch den Gebrauch von tit ausdrücken und auch dem Hörer mittellen möchte, ist wohl am besten mit 'inter esse' zu umschreiben. Das persönliche Interesse des Sprechers an der Ausfưhrulb der Handlung ist der Grund dafür, daß ein Satz wie (9) in dem angegebenen k00 text kaum akzeptabel scheint.

(9) ?"Komm mir rechtzeitig heim heute abend. Mir persönlich ist es ja egal,

aber der Franz regt sich sonst wieder so auf.
Mir soll aufgrund dessen mit dem Merkmal 〈INTERESSE>s beschrieben werden. Damit hat der ethische Dativ eine sehr ähnliche Bedeutung wie viele sonstige ${ }^{8^{\prime}}$ tiv-Verwendungen. Der Unterschied liegt nur in der Verschiebung in den $110^{0}$ uti $^{-}$ ven Bereich (vgl. Jacobs 1986:106).

Aufgrund dieser Sprecherhaltung lassen sich auch die Restriktionen in der ver wendung von mir erklären: Mir kann nicht in Außerungen stehen, mit denen ${ }^{\text {in }}$ Rat gegeben wird (vgl. Jacobs 1986:106), denn in diesem Falle liegt das inter $\mathrm{e}^{\mathrm{s}^{\mathrm{f}}}$ an der Ausführung der Handlung beim Angesprochenen und nicht notwendiger ${ }^{\text {ist }}$ beim Sprecher.

(10) Ins: Wie komm ich denn morgen rechtzeitig zum Flughafen?

Ute: "Nimm mir ein Taxi!

Auch in Aufforderungssätzen, die eine Erlaubnis ausdrücken, kann mir nicht ver wendet werden (und ist deshalb übrigens auch nicht mit dem permissiven ruhig kombinieren); vgl.:

(11a) Bleib ruhig zum Essen da, das reicht schon für alle.

(11b) "Bleib mir zum Essen da, das reicht schon für alle.

128) In den meisten Fällen steht das Verb hier in Zweit-Stellung; Anfangsstell ${ }^{\text {n }}$ b

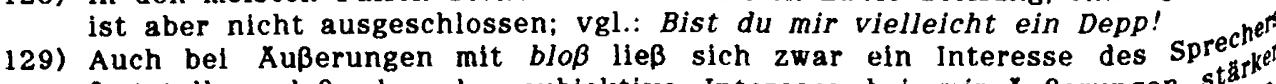

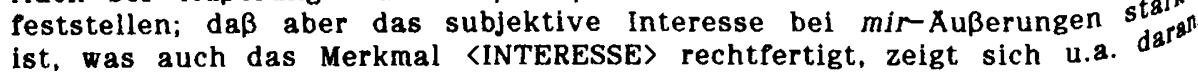
$\mathrm{da} \beta$ blo $\beta$ in einer $A u \beta e r u n g$ wie (9) nicht inadäquat wäre. 
Bel permissiven Außerungen geht der Sprecher davon aus, daß der Hörer gerne die Handlung ausführen würde, und kann insofern auch annehmen, daß sie ausgeführt -ird; bei mir-Aufforderungen dagegen kann der Sprecher dies nicht annehmen.

A $U_{8}$ ăhnlichen Gründen kann mir nicht in Aufforderungen verwendet werden, die vor allem aufgrund bestimmer Maximen der Höflichkeit geäußert werden; vgl.:

(12a) Nehmen $S^{\prime}$ doch noch ein Stück Apfelkuchen!

'Nehmen $S$ '

Die Außerung (12b) wäre nur in einem Kontext wie (12c) möglich, entspricht aber dann nicht den Konventionen:

(12c)

Mein Gott, nehmen $S^{\prime}$ mir noch ein Stück Apfelkuchen, ich muß ihn sonst bloß wegwerfen/mir schmeckt er nicht!

Vir kann schließlich auch nicht in Kommandos auftreten; hier hat der Sprecher keln subjektives, anteilnehmendes und besorgtes Interesse daran, daß der Befehl ausgefuhrt wird.

In Warnungen oder Drohungen dagegen ist mir - auch bei expliziter Nennung der Sanktion - wleder möglich:

(13)

Komm mir rechtzeitig heim heute abend, sonst gibts kein Taschengeld Auchste Woche!s

bracht werden:

(14)

Und bleib mir bitte nicht wieder in der Kneipe hängen!

Aufforderungen mit mir kommt also ein deutliches subjektives Interesse des prechers zum Ausdruck.

Aezlehung zwischen Sprecher und Hörer ist dabei meist asymmetrisch; d.h. die

Atorität llegt beim sprecher - 'klassische' Verwendungssituation von mir ist die von-Kind-Aufforderung; bei umgekehrtem Autoritatsgefälle wirkt die Verwendung

Von mir unangemessen:

(15)

Kind zur Mutter, die zum Einkaufen geht:

Bel ?Und vergiß mir die Gummibärchen nicht!

brach gerichteter Interaktion kann eine mir-Außerung ein manchmal unangetes besorgtes Interesse anzeigen.

Auch in den EXKLAMATIVSATZEN läßt sich in der Bedeutung der Partikel mir noch In Zusammenhang zum Personalpronomen nachweisen. Mit mir in Exklamativen Ird der Standpunkt des sprechers betont, seine Verwunderung über den für ihn unerwarteten Sachverhalt (im Gegensatz zur Verwendung von dir, das eindeutig horerbezogen ist). Auch hier kommt also ein besonderes Interesse des Sprechers an der Außerung zum Ausdruck. 
Hauptsächlich taucht mir in Exklamationen auf, in denen der Sprecher eine meist negativ zu wertende Feststellung (in Form einer Prädikation) über den oder die Gesprächspartner macht; vgl.:

(16) Du bist mir vielleicht ein Früchtchen!

(17) Ihr seid mir (ja) schöne Ingenieure! Jetzt ist der Fernseher total kaputt.

(18) Der japanische Ministerpräsident Nakasone...Das ist mir einer! Springt der doch Jeden Morgen die französische Nationalhymne singend in sein Schwimmbad!

Exklamative mit positiv zu wertendem Inhalt sind, wenn die Partikel mir auftitt. meist ironisch zu verstehen:

(19a) Du bist mir ein Genie! (Bevor ich dir den Fernseher zur Reparatur gegebel habe, ist wenigstens noch ein Programm gelaufen, jetzt geht gar nichts mehr.)

(19b) ?"Du bist mir ein Genie! (Seit du den Fernseher repariert hast, geht er besser als zuvor.)

In seiner negativen Tendenz gleicht mir der Modalpartikel vielleicht: Im Kontex (19a) ist nur vielleicht möglich, während in (19b) die Modalpartikel aber ste hen $^{\text {n }}$ mußte. Wegen dieser ähnlichen Tendenz treten mir und vielleicht häufig kombiniert aup (s.u. S.252), aber und mir dagegen sind kombiniert nur bedingt akzeptabel:

(20) ?Du bist mir gber ein Esei!

In der Bedeutung von dir, das (wenn es überhaupt noch gebräuchlich ist ${ }^{130}$ ) nut in Exklamativsätzen auftritt, ist ebenfalls die Bedeutung des Personalpronoment noch vorhanden: Exklamationen mit dir weisen einen starken Hörerbezug auf. Def Sprecher drückt nicht nur seine Verwunderung über den für ihn unerwarteten Sachverhalt aus, sondern möchte diese Einstellung dem Hörer mittellen, auf diesen übertragen und an ihn appellieren, seine Aufmerksamkeit auf den Auslöser des Ausrufs zu richten. Das Merkmal pür dir wăre demnach 〈IN'TERESSE>a.

(21) Das ist dir ein Korps Kerles, Bruder, deliziöse Burschen, sag ich dir! (F.Schiller, Die Räuber, II, 3).

(22) Du, der hat dir einen Blick ghabt!

(K.Kraus, Die letzten Tage der Menschheit, München 41974:108)

A so a hirndamischa Teifi, der Sepp!" höhnten die Mannsbilder: "Jetzt hot ma gmoant, er packt's ganz schlauch o, und bringt dós Weiberts los! Derweil nimmt er s' wieder auf! Mei Liaba, mei Liaba, is dir dös a Rindviehch!" (O.M.Graf, Der harte Handel, München 1981:153)

Aus diesem Grund kann dir auch in Kontexten stehen, in denen der entsprechen ${ }^{\text {de }}$ Sachverhalt für den Sprecher nicht unbedingt neu ist, also z.B. in Erzählungen:

130) Wie oben schon erwähnt, wird dir kaum verwendet und wird auch nic ht! $^{\text {ht }}$ (mehr) von allen Sprechern akzeptiert; im balrischen und im österreichis ${ }_{2}^{\text {b. }}$. Sprachraum aber scheint es noch etwas gebräuchlicher zu sein (vgl. (23)). 
(24)

Ich war gerad auf der Bank. Stell dir vor, die verlangen jetzt $18 \%$ Zinsen.

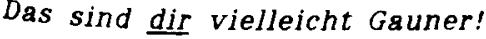

Die Hore

orientiertheit hat dir mit vielleicht gemeinsam, während das sprecherbe-

mir in dieser Hinsicht aber gleicht, sich von diesem aber durch die negati-

ve Tendenz unterscheidet.

2.3

Zusammenfassung

Die vorangegangenen Analysen haben deutlich gemacht, daß für jede Modalpartikel eine einzige Bedeutung angenommen werden kann. Die cbersicht auf der nächsten Selte zeigt noch einmal die Merkmale aller Modalpartikeln. Dabel wird - wo nötig danach spezifiziert, ob sich das Merkmal auf den Sprecher oder den Hörer bezieht. Das Merkmalpaar 〈ERWARTET>/〈UNERWARTET> erscheint zweimal, da es auch dazu dienen kann, eine (sprachliche oder nicht-sprachliche) Vorgängerhandlung zu markieren.

eingangs schon erwähnt, sind die Merkmale grundsätzlich binär. Nicht immer Jedoch beide Pole bei der Beschreibung der Modalpartikeln besetzt. In den "elsten Fällen kann dies damit erklärt werden, daß der 'Standardfall' nicht ge"ennzeichnet wird. So trägt beispielsweise die Modalpartikel ja das Merkmal 'BEKANNT), aber es gibt keine Modalpartikel, die das Merkmal 〈UNBEKANNT) hătte. Die Kennzeichnung einer Information als bekannt ist (nach den Konversa"Ionsmaximen von Grice (1975)) wichtig, da sonst eine Verletzung der Relevanzma-

'in Vorläge. Das 'Normale' aber, d.h. die Vermittlung neuer Information (mit

lich Aussagesatz) muß nicht durch eine Modalpartikel markiert werden. Aus ähnEenso Günden fehlt ein binäres Merkmal bei 〈EVIDENT).

Standardpall kein zweites Merkmal bei 〈EINSCHRANKUNG〉 angesetzt, weil der $P_{n \text { m }}$ ardill nicht gekennzeichnet wird: wird ein Außerungsakt in seiner typischen vollzogen, muß dies nicht eigens angezeigt werden.

Dle Obersicht zeigt auch, daß keine Modalpartikel in jedem der angeführten Bereiche mit einem Merkmal beschrieben ist. Das liegt zum einen daran, daß die einzel"en Partikeln sehr unterschiedliche Funktionen haben (das erklärt m.E. auch, watolm eine zutreffende Definition der Bedeutung oder Funktion aller und nur der Vodalpartikeln kaum möglich ist). Zum anderen liegt das aber auch daran, daß hier der (zentrale) Bedeutungskern beschrieben wurde. Zentral heißt in diesem Fall "ach, da $\beta$ das erfaßt wird, was eine Modalpartikel von einer anderen unterscheitet; diese Bedeutungsunterschiede sind ja nicht zuletzt bei der Beschreibung der ${ }^{*} d_{a l}$ partikel-Kombinationen relevant. 
Dies sei an einem Beispiel erläutert: Modalpartikeln wie $j a$, doch und eben wurden (u.a.) mit den Merkmalen 〈BEKANNT> bzw. 〈EVIDENT> beschrieben. Durch die Mar" kierung des Sachverhalts als bekannt bzw. evident wird natürlich auch die Geltung des Sachverhalts unterstrichen und letztlich auch die eigene Aussage bekräftigt. Da beides aber unmittelbar aus den angenommenen Merkmalen ab $\mathrm{U}^{-}$ leiten ist, und da dies keinen relevanten Unterschied zwischen diesen Modat partikeln darstellt, erübrigt sich die Annahme eines weiteren Merkmals, et 〈VERSTARKUNG〉.

Tabelle 10: Die Bedeutung der einzelnen Modalpartikeln

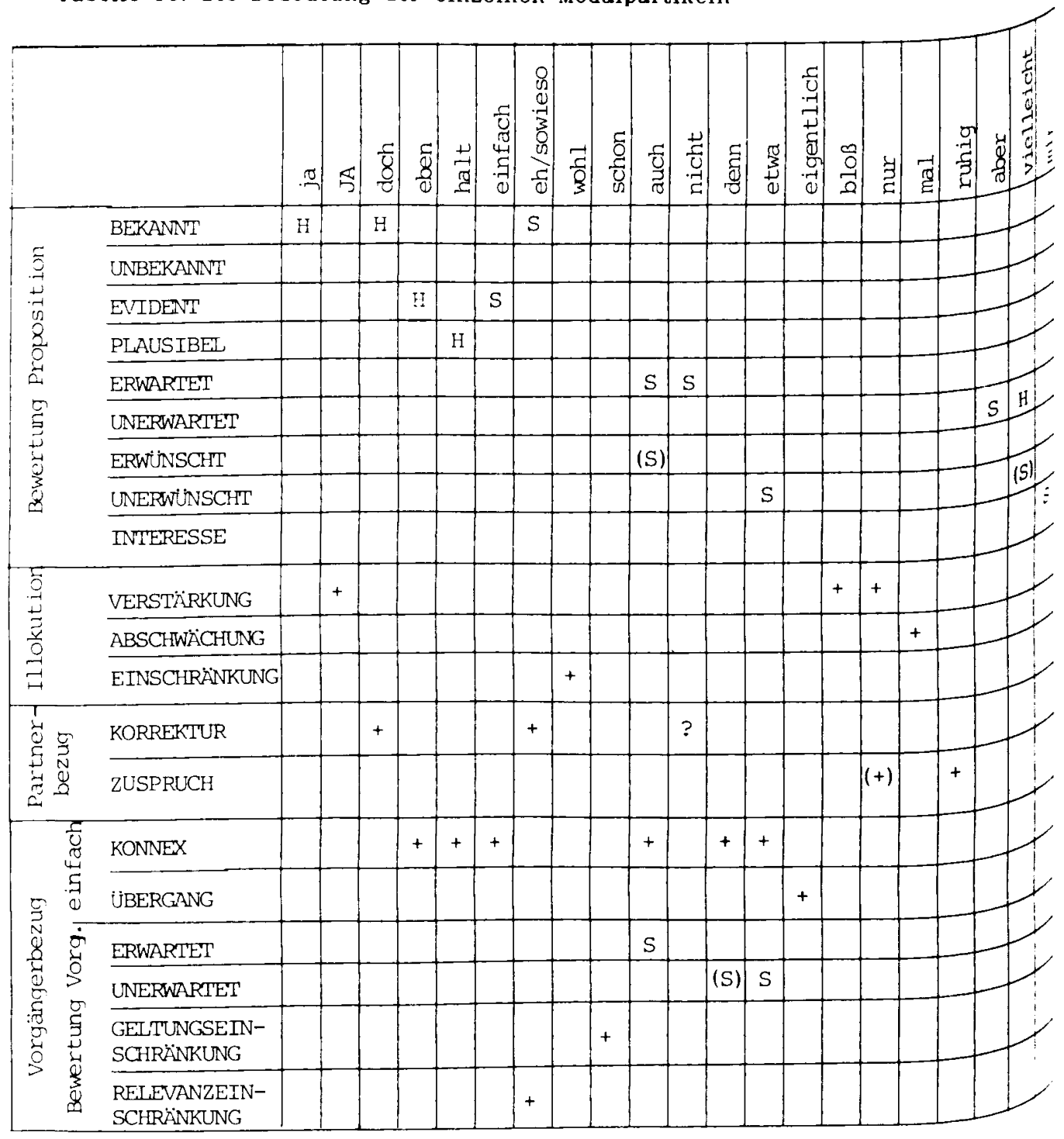


Das Zusammenspiel von Modalpartikel-Bedeutung und Funktions- oder Illokutionstyp der jeweiligen Außerung soll anhand von zwei Beispielen noch einmal gezeigt verden: Die Bewertung einer Proposition (z.B. als erwartet, erwünscht oder unerTünscht) führt bei Fragen zu einer ganz bestimmten Antwortpräferenz. Diese muß aber nicht in die Bedeutungsbeschreibung der Modalpartikel eingehen, sondern ist unmittelbar aus der Grundbedeutung der Modalpartikel im Zusammenspiel mit dem Illokutionstyp 'Frage' ableitbar.

Auch der Bezug eines Merkmals kann sich in Verbindung mit dem lllokutionstyp àndern: So ist ein Merkmal wie 〈BEKANNT) bei doch, das sich (als zu markierender 'Nicht-Standardfall' z.B. in der Aussage) auf den Hörer bezieht, in Außerungen, die Frage-Illokution haben, auf den Sprecher bezogen, da in Fragen die Wissensverteilung 'umgedreht' ist.

Inwieweit alle Modalpartikeln kraft ihrer speziellen Bedeutung Funktions- und Illokutionstypen modifizieren, wurde im vorangegangenen genau beschrieben. Zusammenfassend läßt sich dazu sagen, daß regelmäßige Umdeutungen durch drei ModalDartikeln erreicht werden: durch mal (ein Entscheidungsfragesatz wird zu einer Aupforderung) und durch schon und auch (ein wragesatz wird zu einer rhetorischen Frage).

Bei ruhig und mal im Aussagesatz ist die Umdeutung zur Aufforderung nicht nur Quf die Modalpartikel zurückzuführen, sondern auf das in diesen Sätzen obligatoPlsche Auftreten bestimmter Modalverben, insofern spezlfizieren die beiden ModalDartikeln lediglich den bereits bestehenden lllokutionstyp 'Aufforderung' (Das gilt auch für das - allerdings seltene - Auftreten von bloß, nur und $J A$ in derartigen Aussagesätzen.)

In allen anderen Fällen wird durch die jeweilige Modalpartikel der Illokutionstyp lediglich modifiziert.

Aufgrund der für Modalpartikeln festgestellten Satzmodusabhängigkeit bleibt die Prage, ob das Auftreten der Modalpartikeln von formalen oder von funktionalen Gesichtspunkten gesteuert wird, ob also der Formtyp einer Außerung oder der Punktions- bzw. Illokutionstyp für die Distribution der Modalpartikeln relevant ist. Eindeutigi3i läßt sich diese Frage nicht beantworten. ${ }^{132}$ Die wichtigsten Indizien für beides seien hier noch einmal zusammengefaßt:

131) Vgl. dagegen (unzutreffend) Heinrichs (1981:143), der davon ausgeht, daß sich die Distribution der Modalpartikeln nicht nach pragmatischen, sondern

132) nach "rein syntaktischen Gesichtspunkten" richte.

Daß diese Frage in der Modalpartikel-Literatur meines Wissens bisher noch nicht systematisch behandelt worden ist, liegt daran, daß die ModalpartikelForschung im Satzmodusbereich eine strikte Trennung von Formseite und Funktionsseite vernachlässigt hat. 
Für die Steuerung durch den Funktions-bzw. Illokutionstyp spricht:133

- Das Auftreten der 'Aupforderungspartikeln' ruhig, mal, JA und auch nur und blo $\beta$ in Aufforderungen, die durch andere Mittel - besonders Modalverben " modifizierte Aussagesätze sind.

- Das Auftreten von allen Modalpartikeln in der indirekten Rede - und damit auch in Gliedsätzen wie Akkusativ-Objektsätzen, in denen sonst Modalpartikeln überhaupt nicht zulässig sind.

- Das Auftreten von JA und nur in finalen Nebensätzen (und Attributsätzen), in denen sonst nur 'Aussagesatz'-Partikeln möglich sind.

- Das Auftreten von etwa in Aussagesätzen, die durch doch und andere Mittel ${ }^{50}$ modifiziert sind, daß sie dem Illokutionstyp 'Frage' zuzurechnen sind (meth dazu s.u. S.23fP.).

- Die Tatsache, daß ja und vielleicht in Ausrufen kombiniert werden könne? (mehr dazu s.u. S.53ff.).

Gegen die Steuerung durch den Funktions- oder Illokutionstyp und für e ine $^{\text {ne }}$ Steuerung durch den Formtyp spricht:

- Die Tatsache, daß die typischen 'Fragepartikeln' denn, etwa und eigentijch nicht in Verb-Letzt-Fragesätzen auftreten können.

- Die Tatsache, daß die 'Exklamativpartikeln' aber und vielleicht nicht in verbLetzt-Exklamativen auftreten können.

- Die Tatsache, daß Aussagesätze mit doch auch so modifiziert werden können. da $\beta$ sie Frage-Illokution haben und da $\beta$ doch damit zwar im Illokutionstyp 'Frage' auftreten kann, aber in der (funktionsgleichen) Entscheidungsfrage un zulässig ist.

- Die Tatsache, daß bloß und nur in w-Fragesätzen, aber nicht in Entscheidungsfragesătzen auptreten können (von ihrer Bedeutung her - Verstärkunk eines illokutionären Akts - dürften sie in Entscheidungsfragen nicht unzul: sig sein). ${ }^{134}$

133) Die Tatsache, daß Fragen mit denn, etwa und eigentlich nicht als Auffordé rungen fungieren können, wie dies für Fragen ohne Modalpartikeln (bei $\mathrm{ent}^{\text {nt }}$ sprechendem semantischen Gehalt) möglich ist, liegt an der Bedeutung Partikeln und ist kein Indiz für Illokutionstyp-Gesteuertheit.

134) Die unterschiedliche Distribution von Modalpartikeln in den beiden Fragety pen ist wohl ansonsten kein Argument für eine formtypgesteuerte selek $k^{\mathrm{ti}^{\mathrm{i}}}$ von Modalpartikeln; in den meisten Fällen läßt sich der Unterschied m.E. me der Bedeutung der Modalpartikeln erklären: was sollte z.B. etwa, das ja $e^{\mathrm{i} \mathrm{n}^{\ell}}$ Bewertung der Proposition ausdrückt, in den wesentlich 'offeneren' $w$-Fragel bewerten? 
3.

\section{MODALPARTIKEL-KOMBINATIONEN}

3.1

Zur Forschung

Modalpartikel-Kombinationen wurden bisher in der Forschung kaum behandelt.

Schon Collinson (1938:121) formuliert folgendes Desiderat:

It would be an alluring task to pick out in German a certain number of simple particles, combine them in pairs or triplets cr even larger groups, and try to discover which groups are the most commonly used, which have the most characteristic functions, and which cannot be combined with which, or at least not in a particular order.

Deydt

dalpart (1969), der bel seiner Bedeutungsanalyse zunächst nur alleinstehende Mo80p ) part), trennt dabei aber nicht zwischen Modalpartikel- und anderen (z.B. GradProblel-)Funktionen. Später bezeichnet Weydt die Kombinationen als "ungelöstes lóplem" (1972:181); an anderer Stelle heißt es (unter dem Stichwort "ForschungsPartik"): "Aber schon die Formulierung von Regeln über die Kombination zweier "ikeln macht Schwierigkeiten" (1981:53).

Andere macht Schwierigkeiten" (1981:53)

Gornil Autoren erwăhnen die Kombinationen nur belläufig: vgl. Bublitz (1978:43),

Hentk-Gerhardt (1981:126). Franck (1980:21), Heinrichs (1981:133ff.) und Auschel (1986:246ff.).

Ausfüh

Engel lo8el (vgl. 1968/1971:91ff.; 1970:53ff.; 1973:178ff.). und Helbig (vgl. Helbig/Buscha Bethe:445ff. sowie Helbig/Kötz 1981:41f.) auseinandergesetzt. Auf ihre Ergebnisse ich weiter unten ein.

Qline

lelse genauere Untersuchung von "Partikel-Kumbinationen in Alltags-Gesprächen"

Punt Rudolph (1983). Allerdings untersucht Rudolph Partikeln in verschiedenen dalpartionen (und zwar 50 Partikeln in 140 Kombinationen) und nicht speziell Moist partikelr. Dabei kommt sie zu folgendem Ergebnis: "Jede Partikel-Kombination Quch Unikat" (5), mit zwei Ausnahmen, nämlich den Kombinationen doch aber In und ja auch nur; diese Verbindungen tauchten in ihrem Korpus häufiger auf. $\ln G$

besegensatz zu Rudolph möchte ich mich hier auf Kombination von Modalpartikeln

banzränken; dabei lassen sich - besonders für Zweler-Gruppen - durchaus eine

zeihe fester, konventionalisierter Bildungen feststellen. 


\subsection{Beschreibung von Modalpartikel-Kombinationen}

Unter einer Modalpartikel-Kombination" soll hier das Vorkommen zweier Modalpar" tikeln in einem Satz verstanden werden; in der Regel folgen die Modalpartikeln unmittelbar aufeinander. Die Kombination von Modalpartikeln ist bestimmten $\mathrm{Ge}^{-}$ setzmäßigkeiten unterworfen, was die Möglichkeit der Kombination ganz allgemein betrifft (d.h. welche Modalpartikeln syntaktisch-distributionell und semantis th $^{\text {h }}$ 'verträglich' sind) und was die Reihenfolge in der Kombination betrifft.

Es soll hier davon ausgegangen werden, daß eine Kombination der Modalpartikel ${ }^{A}$ mit der Modalpartikel B eine Addition ihrer Bedeutung und damit ihrer Merkmale bedeutet; d.h. also, daß sich die Kombinationen in ihre Einzelteile zerlegen lassen. Setzt man nun voraus, daß die Bedeutung einer Modalpartikel-Kombination die Summe der Bedeutungen der Einzelpartikeln ist, so müssen diese Bedeutungen, d. h. ihre Merkmale verträglich sein. Insofern lassen sich an den Modalpartikel-Komblnationen die Thesen über die Bedeutung von Modalpartikeln verifizieren oder (al- $^{-}$ sifizieren; es müßte sich auch erklären lassen, warum zwei Modalpartikeln seman' tisch 'unverträglich' sind.

Im folgenden sollen die Modalpartikel-Kombinationen untersucht werden und 208 " sowohl akzeptable als auch in ihrer Akzeptabilität fragliche und inakzeptable Kombinationen. Die Bedeutungsbeschreibung basiert auf den Ergebnissen des vorangegangenen Kapitels.

Bei der Beschreibung der Kombinationen handelt es sich zunächst nur um Kombí nationen, bei denen die Modalpartikeln unmittelbar aufeinanderfolgen; auf $e^{i^{n} \ell}$ andere Art von Kombinationen gehe ich weiter unten (S.290ff.) ein.

Die Ubersicht unten auf S.278/9 zeigt alle prinzipiell möglichen Zweier-Kombin ${ }^{8^{-}}$ tionen $^{2}$ in alphabetischer Reihenfolge - außer der Kombination identischer parti keln, die grundsätzlich nicht möglich ist.

Bei der Betrachtung aller möglichen Kombinationen lassen sich zunächst zwei grope Gruppen feststellen: diejenigen, die syntaktisch verträglich sind und die dies nicht sind.

Wie oben (Kap. 1.3) ausfürlich dargestellt, sind Modalpartikeln stark satzmodus' abhängig; daraus folgt aber auch, daß zwei Modalpartikeln, die nur in unter

1) Es sollen hier nur Kombinationen von Partikeln betrachtet werden, die Modgl' partikel-Funktion haben; dabel gelten die oben in 1.2 und bei den jeweilib

2) Kombinationen mit mir sind in der ubersicht nicht aufgeführt; sie werden be den entsprechenden Partikeln erwähnt. 
schiedlichen Satzmodi auftreten, in der Regel nicht kombiniert werden können: sie sind aus syntaktisch-distributionellen Gründen unverträglich.

Un diese Unverträglichkeit zu zeigen, muß auf die Tabelle 5 von $\mathrm{S} .49$ verwiesen Perden, die die Distribution von Modalpartikeln auf die einzelnen Satzmodi darstellt.

Aus der Übersicht läßt sich ablesen, daß folgende Modalpartikel-Kombinationen aus

syntaktisch-distributionellen Gründen ${ }^{3}$ nicht möglich sind:4

Tabelle 11: Syntaktisch-distributionell nicht kompatible Modalpartikeln

ber $(E x)+b l o \beta / n u r(w-F R A / I M P / w U)$

der(Ex)+denn(ENT/W-FRA)

Qber (EX) + doch(AUS/W-FRA/IMP/WU/W-EX)

aber (Ex)+eben (AUs/IMP)

bet $(E x)+e h /$ sowleso(aus)

aber (Ex)+eigentlich(ENT/W-FRA)

dber (Ex)+einfach (AUS/ENT/IMP)

be(Ex)+etwa(ENT)

ofer(Ex)+halt (AUS/IMP)

aber(Ex)+ja (Aus)/JA(IMP)

ber(EX) +mal (AUS/ENT/IMP)

(EX)+nicht (ENT)

aber (Ex) + ruhig (AUS/IKP)

be (EX) + schon(AUS/W-FRA/IMP)

blop(EX) + wohl (AUS/ENT/W-FRA)

blog/nur(w-FRA/IMP/WU) +eh/sowieso(AUS)

bloB/nur(W-FRA/IMP/WU) +etwa(ENT)

blop/nur(w-FRA/MP/WU) +ja(AUS)

blop/nUr(W-FRA/IMP/WU) + nicht(ENT)

denh Ur $_{\text {(W-FRA/IMP/WU) + vielleicht:ENT/EX) }}$

denm(EMT/W-FRA) +eben(AUS/IMP)

denn(ENT/W-FRA) +halt (AUS/IMP)

$\operatorname{denn}_{(E M T / W-F R A)}+\mathbf{j a}$ (aus)/JA(ImP)

doch(AUS/W-FRA/IMP/WU/W-EX) +etwa(ENT)

doch (AUS/W-FRA/IMP/WU/W-EX) + nicht(ENT)

eben(AUS/IMP) +etwa(ENT)

eben(AUS/IMP) +eigentlich(ENT/W-FRA)

eben(AUS/IMP) + nicht (ENT)

eben(AUS/IMP) +vielleicht (ENT/EX)

eigentlich(ENT/W-FRA) thalt (AUS/IMP)

eigentlich(ENT/W-FRA) $+\mathbf{j a}$ (AUS)/JA(IMP)

eigentlich(ENT,W-FRA) + ruhig(AUS/IMP)

etwa(ENT) +halt(AUS/IMP)

etwa(ENT)+ja(AUS)/JA(IMP)

etwa(ENT) +ruhig(AUS/IMP)

etwa(ENT) + schon(AUS/W-FRA/IMP)

halt(AUUS/IMP) + nicht (ENT)

halt(AUS/IMP) + vielleicht(ENT/EX)

ja(AUS)/JA(IMP) + nicht(ENT)

ja(AUS) /JA(IMP) +vielleicht(ENT/EX)

JA(XMP) +eh/sowieso(AUS)

JA(IMP) + WOhl(AUS/ENT/W-FRA)

nicht(ENT) + ruhig(AUS/IMP)

nicht(ENT) +schon(AUS/W-FRA/IMP)

ruhig(AUS/IMP) +vielleicht(ENT/EX)

schon(AUS/W-FRA/IMP) +vielleicht(ENT/EX)

(aber(EX)+aUCh(AUS/ENT/W-FRA/IMP/W-EX) $)^{5}$

Von den oben aufgeführten Kombinationen sind ailerdings einige (wie z.B. aber +
duch und denn mit doch und ja im Aussagesatz) möglich. Das hieße, daß bestimmte
Hodalpartikeln in einer Kombination in Satztypen auftreten, in denen sie allein
nicht vorkommen. Darauf werde ich bei der Darstellung der akzeptablen Kombina-
tionen eingehen.

3)

Da die Modalpartikeln eh und sowieso in den Entscheidungsfragesätzen nicht betrachtet werden, werden auch die Kombinationen mit denn, etwa, eigentlich,

4) nicht und vielleicht nicht behandelt.

Die Indices stehen für die einzelnen Satzmodi: AUS für Aussagesatz, ENT für Entscheidungsfragesatz, W-FRA für w-Fragesatz, IMP für Imperativsatz, WU für

5) Wnschsatz, EX für (Satz-)Exklamativsatz, W-EX für W-Exklamativsatz.

Das Auftreten von aber in w-Exklamativsätzen ist heute kaum mehr gebräuchlich. 
Bei den verbleibenden Kombinationen lassen sich zwei Gruppen unterscheiden: die belegten und akzeptablen einerseits sowie eine Restgruppe andererseits.

Hier noch einmal ein Wort zum Belegmaterial: Auch bei den Modalpartikel-Kombi nationen stammen die Belege aus den zu Beginn (S.5P.) angegebenen Quellen. $20^{\circ}$ sätzlich mußte aber ein weiteres Verfahren angewendet werden: Nachdem die $\mathbf{s}^{\mathrm{y}^{\mathrm{n}}}$ taktisch unmöglichen Kombinationen ausgesondert waren, blieb eine umfangre che $^{\text {th }}$ Gruppe übrig. Innerhalb dieser war ein großer Teil von Kombinationen mehregch belegt. Die verbleibenden Kombinationen, die Restgruppe, waren Kombinationen, dif zwar syntaktisch möglich sind, aber nur einmal oder gar nicht belegt waren. Hijet mußte nun auf einen Akzeptabilitätstest zurückgegriffen werden.

Der Test sollte keine definitiven Aussagen über Akzeptabilität ermöglichen, son ${ }^{n^{-}}$ dern nur die Datenlage in meinem Korpus bestätigen. Nicht-Belegtheit kann ${ }^{\text {js }}$ entweder bedeuten, daß eine Kombination inakzeptabel ist, oder aber, daß sie sent selten auftritt. Hier sollte der Test helfen, mir Klarheit zu verschaffen, da ich mich nicht (nur) auf meine eigenen Intuitionen verlassen wollte. Bei dem Test mußten Sätze mit Modalpartikel-Kombinationen, die in kleine Texte eingebs th $^{\text {t }}$ waren, beurteilt werden. Zur Beurteilung der Sätze wurden drei Kriterien angegeben: 'akzeptabel', 'vielleicht akzeptabel' und 'nicht-akzeptabel'.

Bepragt wurden - in zwei Durchgängen - je 40 Testpersonen.

Bei der Auswertung des Tests ergaben sich in vielen Fällen relativ eindeutige ${ }^{\mathrm{Be}^{-}}$ wertungen sowohl hinsichtlich der Akzeptabilität als auch der Nicht-Akzeptabllität.

Die Gruppe von Modalpartikel-Kombinationen, bei denen sich keine eindeutige Vertellung zugunsten eines der Kriterien ergab, werden als in ihrer Akzeptabilit Pragliche Kombinationen bezeichnet. Auch in diesem Fall wird versucht, dafür e $^{\text {in }}$ Erklärung anzugeben.

Eine weitere Vorgehensweise muß be! der Beschreibung der Modalpartikel-Kombin ${ }^{8^{\prime}}$ tionen in stärkerem Maße angewendet werden als bei den Einzelbeschreibungen: Da in die Bedeutung einer Kombination ja immer zwel Einzelbedeutungen einge he $e^{\text {nt. }}$ ist es in vielen Fällen aufschlußreich, Außerungen mit einer Kombination Auße' rungen mit jeweils einer der beiden Modalpartikeln oder auch mit einer andere Kombination einander gegenüberzustellen und diese $\mathrm{zu}$ vergleichen. In diesem $F^{g}$ kann es nötig werden, Kontexte $z u$ konstruieren, die die jeweiligen Unters $\mathrm{ch}^{\mathrm{h}^{\mathrm{d}} \mathrm{d}^{\mathrm{e}}}$ deutlich machen. 


\section{Akzeptable Kombinationen}

It Polgenden werden die akzeptablen Kombinationen beschrieben. Die Reihenfolge der einzelnen Abschnitte richtet sich zum einen nach der Reihenfolge der Partikeln bei den Einzelanalysen (und damit sowohl nach dem Satzmodus - begonnen Mrd mit den 'aussagesatz-typischen' Modalpartikeln - als auch nach der Frequenz) und zum anderen nach der Zahl der zulässigen Kombinationen: Besonders 'kombinationspreudig' sind ja, doch, auch und denn (vgl. auch die Obersicht aup S.278/9); deshalb bilden diese Partikeln den Anfang. ${ }^{6}$

Die Analyse der einzelnen Kombinationen erfolgt nicht streng nach einem einheitichen Schema; das liegt daran, daß bei den einzelnen Kombinationen unterschiedliche Gesichtspunkte relevant sind.

So

in 'klaren' Fällen der Satzmodus, in dem die Kombination auftritt, nicht

genauer dargestellt: Bei den Kombinationen mit (unbetontem) ja z.B. erübrigt

slch das, da ja ohnehin nur in Aussagesätzen auftritt, und deshalb alle Kombina-

"lonen mit ja ebenfalls auf Aussagesätze beschränkt sind. Eine zusammenfassende

Obersicht über die Satzmodi, in denen die Kombinationen auftreten können, findet

${ }^{8}$ ich auf S.282. (Bei den Kombinationen habe ich mich im wesentlichen auf die

'Gundtypen' (vgl. 1.3.1) beschränkt.). Wenn allerdings eine Kombination in unter-

schledlichen Satzmodi auftritt, und besonders, wenn damit eine Anderung in der

Bedeutung oder auch Akzeptabillat der Kombination verbunden ist, werden die

inzelnen Satzmodi differenziert untersucht.

Zentrale Anliegen der Untersuchung der Kombinationen ist, zu beschreiben,

bete Bedeutung sie haben und wie diese sich aus den Einzelbedeutungen der

(eiligten Modalpartikeln zusammensetzen läßt. Wenn es sich anbietet (z.B. zur

bedingt lichung oder als sinnvolle Gegenüberstellung), gehe ich hier bereits auf

allo akzeptable oder inakzeptable Kombinationen ein. Gegebenenfalls werden

Verschiedene Kombinationen oder Kombinationen und Einzel-Vorkommen von

Bel den

on den meisten Kombinationen wird die Abgrenzung der Modalpartikel-Funktion

E Eebrissen anderen Partikel-Funktionen nicht mehr angesprochen; hier werden die Ben Kombinationen allerdings ist unklar, ob beide Partikeln wirklich als ModalparIn vorliegen. In diesen Fällen steht dann die Abgrenzungsproblematik im VorB)

\footnotetext{
Die Relhenfolge der Partikeln in der Kombination ist kein Kriterium für die Gliederung: d.h. eine Kombination wie denn auch ist bei den Kombinationen mit auch zu suchen, da diese vor denen mit denn besprochen werden.
} 
dergrund (und nicht die Bedeutungsbeschreibung). Es zeigt sich, da $\beta$ in der Kom bination Abgrenzungsprobleme biswellen deutlicher werden als bei Einzelvorkom" men: dies betrifft vor allem $m a l$ in Entscheidungsfragesätzen, doch in der Kom bination mit $j a$ und eben, eben in der Kombination mal eben und aber in aber auch. Grundsätzlich unklar in der Zuordnung ist das Auftreten von denn in $\mathrm{Aus}^{\mathrm{S}^{-}}$ sagesătzen; die entsprechenden Kombinationen werden hier mitbehandelt (s.s.222. 232. 236). Die Kategorisierung von wohl in Aussagesätzen war bereits be isolierten Auftreten unklar (Satzadverb oder Modalpartikel?; vgl. 2.2.7); deshalb wird bei der Kombinations-Analyse darauf nicht mehr eingegangen.

\subsubsection{Kombinationen mit $j a$}

Die Modalpartikel ja ist eine der häufigsten - wenn nicht die häufigste partikel. Aufgrund ihrer relativ unspezifischen Bedeutung (sie trägt nur das Merkmal 〈BEKANNT〉) läßt sie sich außerordentlich oft kombinieren.

\subsubsection{1 (Unbetontes) $j a$}

Das unbetonte $j a$ tritt in Aussagesătzen auf und ist dort mit fast allen Modalpar tikeln (außer halt) kombinierbar. Für alle Fälle läßt sich nachweisen, daß ja aucth in der Kombination der Außerung, in der es steht, das Merkmal 〈BEKANNT> hin $2^{4^{-}}$ fugt. $J a$ findet sich in Kombinationen immer an erster Stelle ( - es sei denn. ${ }^{s}$ wird mit mir kombiniert). Die Kombination ja vielleicht wird weiter unten ( $5.253^{\text {s }}$.) behandelt.

\section{1. ja such}

Die Kombination ja auch ist eine in Aussagesätzen sehr Prequente Kombination ' sie scheint wesentlich häufiger zu sein als auch allein.

(1) Und wie ich nach Hause kam: Ich stieg an der Haltestelle aus - meine froll stieg da ein. Sie wußte das ja nicht, daß ich kam, ich hatte ja auch nie geschrieben, konnte ja guch nicht. (BP, 23)

(2) Dauernd schielte sie zu Eckhoff hinüber, der wegen seines Geigenspiels auch hier gelandet war. Das aristokratische Profll, sein kurzes Kraushas", das war ja auch bewunderungswürdig. (Ke, 145)

(3) Martin: Mensch, Carola kann vielleicht gut singen! Lisa: Ja, die nimmt ja auch Gesangsstunden.

(4) Im Vergleich zu den beiden Münchner Universitäten ist die Medizinische Hochschule in Lubeck sicher (noch) sehr klein, aber sie ist ia auch erst der Aufbauphase. (SZ) 
Die oben beschriebene Bedeutung für die Modalpartikel auch läßt sich auch in der Kombination nachweisen: auch stellt eine Beziehung zu der Vorgängeräußerung her (Merkmal 〈KONNEX〉), indem der Sprecher durch auch signalisiert, daß der dort geàuerte Sachverhalt für inn durchaus erwartbar war (Merkmal (ERWARTET>v); die Außerung, in der auch steht, llefert dafür die Begründung oder Erklärung, und durch $j a$ wird diese Erklärung als auch für den Hörer bekannt markiert. Vgl. auch lolgendes Beispiel:

(5)

Iris: Aber der Fredi hat sich. öh an der Uni amüsiert oder nich?

Karl: Och, ich glaub schon.

Iris: Ja?

Karl: Ich mein, kenns ja Fredi, is ja auch ziemlich schüchtern un zurückIlis' haltend, ne. (BA, 152)

Frage läßt darauf schließen, daß irgendetwas an Fredis Verhalten darauf hin-

eutete, daß er sich möglicherweise nicht amüsiert hat. Durch den Gebrauch von auch zeigt Karl nun an, daß das Verhalten von Fredi normal und insofern erwartbar War, wobei er in seiner Außerung die Begründung dafür liefert. Diesen Sacherhalt kennzeichnet er als auch für Iris bekannt; darauf, daß es sich um Bemeinsames Wissen handelt, deutet auch die Außerung 'kenns ja Fredi' hin.

2. Ja doch

Dle Kombination dieser beiden Partikeln in Modalpartikel-Funktion(!) scheint nur Ausnahmefällen möglich; meistens handelt es sich bei doch nämlich um betontes ${ }^{\text {doch }}$ und damit um das Affirmationsadverb (s.o. S.110f.); besonders bei schriftlichen Belegen ist die Entscheidung, inwieweit doch in der Kombination akzentuiert (6)

und die einzige Möglichkeit, die sie sieht, aber die möcht ich Ihnen auf keinen Fall vorschlagen, $\ddot{o}, \dot{\delta}$, die wäre, daß Sie eine halbe Stelle abtreten. Aber erstensmal wäre das ja doch eine. ziemliche finanzielle Einbuße und

(7) o. zweitens, eine Viertelstelle bliebe jg dann doch übrig. (BA, 20)

Wenn es nach dir gegangen wär, hätte das Kind gesagt, Mama, $s$ ist ja gar keines da, s gibt ja gar keines - das hat Georg ja auch schon mal gesagt, weil ich gesagt hab, dann ruf mich, wenn du mich brauchst, ich bin ja doch (8) deine Mami. (FK III, 31)

Also ich würd mir in mein Auto schon Nebelscheinwerfer einbauen lassen, du bist ja doch recht häufig nachts auf Landstraßen unterwegs.

kel-Funk sehen, daßion (also mit unbetontem doch) nicht sehr häufig ist, läßt sich darin $S_{\text {achverhalt }}$ sich $j a$ und doch ohnehin relativ ăhnlich sind: beide markieren einen Rerhalt als für den Hörer bekannt (doch trägt zusätzlich das Merkmal <KORKTUR> ); Modalpartikeln mit sehr ähnlichen Bedeutungen aber werden kaum kom- 
biniert. Das Afpirmationsadverb doch dagegen trägt nicht das Merkmal (BEKANN ${ }^{\text {? }}$. sondern nur 〈KORREKTUR〉, und wird deshalb häufiger mit ja verbunden.

An dieser Kombination zeigt sich, daß doch als Modalpartikel und als Affirm tionsadverb nicht immer eindeutig abzugrenzen sind, was sicher auch daran liefh daß das Affirmationsadverb meist verwendet wird, um Implizites zurückzumeisen und dann in seiner Funktion der Modalpartikel gleicht.

\section{3. ja eben}

In Aussagesătzen kommt bei dieser Kombination zu dem Merkmal 〈EVIDENT) eben noch das Merkmal 〈BEKANNT> $\rangle_{\mathrm{B}}$ von $j a$ hinzu; die Kombination ist also $e^{\text {in }}$ stärkere Variante, da der Sachverhalt als für den Hörer bekannt und offensicht" lich markiert wird. Diese Kombination kommt vor allem in spontan gesprochen ne? $^{\text {f }}$ Sprache vor; vermutlich ist auch sle aufgrund der Bedeutungsähnlichkeit von ${ }^{j}$ und eben nicht so häufig.

(9) Vera: Aber ich würd sagen, wir machen das nächste Woche dann und m8chen dann/

Eva: mal alles aus

Vera: mal alles aus, weil wir ja eben wissen müssen, was wir noch kautent (BA, 165)

(10) Ins: Mit dem Examen kann man sowieso nix machen, da muß man erst $m^{8}$ noch die/die Referendarzeit machen.

Ute: Jaja, klar.

Ins: Das is ja eben das Doofe. (BA, 188)

(11) Nun gehört ja in die Kompetenz der Länder gehört ja eben die Kultur. deswegen wird das ja nicht vom Bund her gemacht (...) sondern eben von den verschiedenen Ländern her. (FK II, 341)

Auffallend ist, daß ja mit dem sogenannten Synonym von eben, nämlich halt, nilch kombinierbar ist (s.u. S.264).

\section{4. ja einfach}

Die Kombination ja einfach scheint etwas häufiger zu sein als ja eben. Hier wir durch einfach angezeigt, daß der Sachverhalt für den Sprecher evident ist, in $^{\text {í }}$ durch $j a$, daß er für den Hörer bekannt ist.

(12) Gerd: Jo. Hasde sonst irgendwie erfahrn, ich hatte das ja einfachheitshalbe einfach an die Tafel geschriebn, die Petra, die kommt wahrscheinlich und die Hedwig, die kann nich. (BA, 57)

Vielleicht kann ich heute abend ja einfach ein bißchen fernsehen!

Wesentlich häufiger ist allerdings die Kombination von einfach und doch. 
5. ja sowieso und ja eh

Diese beiden Verbindungen lassen sich in Aussagesätzen wieder recht häufig

hachweisen: Hier wird der Funktion von eh/sowieso, die Relevanz einer vorange-

Bangenen Außerung einzuschränken durch das Anführen eines für den Sprecher

schon vorher bekannten Sachverhalts, noch die Funktion von ja hinzugefügt, eben

diesen Sachverhalt als auch für den Hörer bekannt zu markieren. Zusätzlich wird

der Hörer durch den Gebrauch von eh/sowieso zu einer Korrektur seiner Annahmen angewiesen.

(14)

Franz: Der wird halt eine Hoffnung sehen, daß er sein Geld zurückbekommt. Rosi: Der hat ja sowieso noch viel zuwenig bezahlt und hat Schulden. (Kr.

88)

(15) Der Bernd, der hat ne eins minus gemacht, und da meinte der Reim, najs, es wär ja nich so schlimm bei ihm, er wollt ja sowieso an die Schule, aber an der Uni wär er damit wohl nichts geworden. (BA, 61)

Ruth: Kann mich ja niemand zwingen, meine Anlagen zum Konto zu holen. Andi: ((lacht)) Ja. Ja, ja.

Ruth: Die tu ich ja sowieso so/ also. das mach ich manchma Monate nich.

(1) (BA, 194)

De bu brauchst dich nicht mehr zu beeilen, jetzt ist es ja eh schon zu spät.

die bei der Beschreibung von eh/sowieso schon erwähnt, ist bei Außerungen mit

diesen Partikeln, bei denen eine Aussage über den Gesprächspartner gemacht wird, die Kombination mit entweder ja oder doch nahezu unerläßlich; vgl.:

Du kannst ja sowieso nicht kommen morgen; du mußt doch zu dieser Pres-

Hàufiger ist in

$j_{e_{s}, d a}$ ist in Verwendungsweisen wie (18) allerdings die Kombination doch so, da durch doch auch erinnert werden kann.

6. ja wohl

Auch hier handelt es sich um eine sehr frequente Kombination; sle vereinigt die

"ierkmale 〈BEKANNT>a und 〈EINSCHRANKUNG〉?

"Was machste denn da?" fragte er. Ich war völlig verdattert. "Ich will mir's Leben nehmen", sagte ich. "Hm", sagte er, "das hat ja wohl Zeit bis nach'm Abendbrot!" (Bi, 66)

"Aber die 'Jugendfreunde' denken -" "Was für 'Jugendfreunde'?" "In der FDJ reden wir uns doch mit 'Jugendfreund' an (...) Das wirste ja wohl wissen!"

Ich wußte's auch. Ich wollte sie bloß ärgern. (Bi, 42)

Das darf ja wohl nicht wahr sein.

7)

\footnotetext{
We bei der Analyse von wohl schon angesprochen, kann in Aussagesätzen die Modalpartikel-Funktion nicht immer klar von der Satzadverb-Funktion getrennt werden. Das gilt auch für wohl in Kombinationen.
} 
Mit dem Einsatz dieser Kombination kennzeichnet der Sprecher einen Sachver ( $^{\text {ll }}$ durch $j a$ als bekannt und schränkt die vollzogene Behauptung durch wohl wiedet ein (vgl. dazu auch die Ausführungen bei doch wohl, S.218ff.). Diesf Einschränkung erfolgt vor allem im Hinblick auf den Gesprächspartner: def Sprecher behauptet nicht unwiderruflich das Bestehen des Sachverhalts, sondert behauptet 'mit Einschränkung'. So stellt er sich durch den Gebrauch von wohl sul die Erwartungen des Gesprächspartners ein und läßt ihm mehr Raum, zuzustimmer oder abzulehnen. Auf diese Weise wird die Außerung verbindlicher als nur mit def Modalpartikel $j a$; vgl. (22) vs. (22a):

(22) Nelli: Is ja doof, ne. Und der Relm, läßt sich da auch nich so aus?

Bea: Ja, also er wird mich ja wohl nich grad dann nich verlängern, ne, d8s hängt von ihm $a b, o b, a ̈$, der verlängert wird oder nich. (BA, 62)

(22a) er wird mich ja nich grad dann nich verlängern.

\section{7. ja schon}

Diese Kombination ist in Aussagesätzen möglich und zwar nur in nicht-zukun ft $^{\circ}$ bezogenen Aussagesätzen.

(23) Ein bißchen netter könntest du ja schon zu mir sein, wo ich dir doch so oft aus der Klemme geholfen habe.

(24) Ja, aber die sin dann auf jeden Fall im Lande, das is ja schon viel wert. (BA, 57)

(25) Reporter: Und warum treten Sie die Kur nicht an, wo sie die doch wirklich dringend benötigen?

Silvia: Ich kann meine Kinder nicht noch öfter allein lassen, es ist ig schon schlimm genug, daß ich die Kleinen durch die vielen offiziellen alt tritte nicht so oft sehen kann.

Durch die Partikel schon schränkt der Sprecher die Vorgängeräußerung in $\mathrm{inh}^{\mathrm{re}^{\mathrm{f}}}$ Geltung ein (Merkmal (GELTUNGSEINSCHRANKUNG>v), indem er Gründe dafür liefer warum in diesem Fall die Feststellung des Vorgängers nicht zutrifft. Weiter ${ }^{b e^{n}}$ wurde schon die Funktion eines Einräumens in der Argumentation zugeschrie $e^{\text {be }^{n}}$ Durch die Kombination mit der Partikel $j a$, die diese Begründung auch noch ${ }^{\text {fls }}$ bekannt markiert, stärkt der Sprecher seine eigene Position; sein Gegenargument wird dadurch gewichtiger; vgl. z.B. (25): hier ließe sich ja schon umschreiben mil $^{\text {it }}$ 'Sie haben $z$ war grundsätzlich recht, aber in meinem Fall ist das etwas ande re $^{\mathrm{s}}$. denn - wie Sie wissen...'

In zukunftsbezogenen Aussagesätzen kann ja allein zwar durchaus auftreten. w es sich um einen für beide Gesprächspartner bekannten Sachverhalt handelt ( $v b^{l}$ (26)), nicht aber in der Kombination mit schon:

(26) Jetzt wein nicht! Sie wird ja wiederkommen. / Sie kommt ja wieder.

(27) Mach dir keine Sorgen wegen der Prüfung. 'Du wirst es ja schon schaffen. 
Der Grund für diese Inakzeptabilität ist darin zu sehen, daß die zukunftsbezogenen $A$ ußerungen mit schon, die dazu dienen, Befürchtungen des Gesprächspartners zurückzuweisen, immer als neue Information zu sehen sind; deshalb kann ja nicht verwendet werden.

8.

Ja mal und ja ruhig

Diese beiden Kombinationen lassen sich nur in Aussagesätzen, mit denen der Illo'utionstyp 'Aufforderung' realisiert wird, nachweisen; also in Aussagesätzen mit

bestimmten Modalverben. Dabei fügt ja der oben schon beschriebenen Bedeutung von mal und ruhig noch den Aspekt der Bekanntheit hinzu: in diesem Fall heißt das, daß die Handlung, zu der aufgefordert wird, dem Hörer bekannt ist, er wei $\beta$ also, daß er sie ausführen kann oder ausführen hätte können.

(28) Ich wasch das Gemüse. Du kannst ja mal die Zwiebeln schneiden.

(29) Vielleicht könnten wir später ja mal vierhändig spielen. (Ke, 142)

le Kombination von $j a$ und ruhig ist allerdings nur in einer ganz bestimmten VaPlante von ruhig-Aufforderungen möglich; und zwar in Aufforderungen, die oben

(S.189) als ironisch bzw. leicht zynisch bezelchnet wurden; vgl.: (30)

Die Mutter zum Sohn: Du könntest dir ja ruhig etwas mehr Mühe in der

(31) Schule geben.

Aupr könntet mir ja ruhig beim Abwaschen helfen.

Verderungen mit ruhig drücken in der Regel eine Erlaubnis aus, dabei werden Handlung auf, von der er annimmt, daß der Gesprächspartner sie vielleicht für Verboten oder unerwünscht hält. In Außerungen vom Typ (30) und (31) dagegen handelt es sich nicht um eine Erlaubnis (deshalb ist es auch eine nicht-wörtlicho erwendung von ruhig; darauf deutet auch der Konjunktiv hin), sondern es wird $2^{4}$ einer Handlung aufgefordert, von der der Hörer weiß, daß er sie längst schon hàtte ausführen müssen oder können; deshalb ist ja in dieser Art von ruhig-AufPorderungen möglich.

Elne Aufforderung, in der ruhig wörtlich zu verstehen ist, ist also eine Erlaubnis, und insofern handelt es sich immer um eine für den Gesprächspartner neue InforMation. Deshalb können solche Außerungen kein ja ruhig enthalten, sondern nur die Modalpartikel ruhig.

Th süddeutschen sprachgebiet wird in diesen Fällen ruhig sehr häufig mit fei ombiniert. Fei kennzeichnet einen Sachverhalt als neu und unerwartet; vgl. (32):

(3a) EVa ist bei Nora zu Besuch. Als Nora das Essen vorzubereiten anfängt, will Eva gehen. Darauf sagt Nora:

(32b) Du kannst ruhig zum Essen dableiben, das reicht schon. Du kannst fei ruhig zum Essen dableiben. 
(32c) 'Du kannst ja ruhig zum Essen dableiben.

(32c) könnte nur ironisch geäußert werden (und in diesem Fall wäre das verb wohl eher in der Konjunktivform), wenn der Sprecher weiß, daß der Hörer eigent' lich gehen möchte, im Sinne von (32d):

(32d) Ehefrau zu ihrem Mann: Ehefrau zu ihrem Mann:
Du könntest ja ruhig zum Essen dableiben. Die Kinder wissen ja schon glf $^{\prime}$
nicht mehr, wie du ausschaust.

Ja markiert also auch in den Kombinationen mit mal und ruhig einen Sachverhalt als bekannt; die Restriktionen in der Kombination mit ruhig sind auf die illok tive Funktion von ruhig zurückzuführen.

\subsubsection{2 (Betontes) JA}

Die betonte Variante $J A$, die vor allem in Imperativsätzen auftritt, ist lediglich ${ }^{2}$ kombinieren mit denjenigen 'Aupforderungspartikeln', die (wie JA auch) eine dring' liche Aufforderung, eine Warnung oder Drohung ausdrücken (wie blo $\beta$ und nut) oder zumindest diese Interpretation nicht verhindern (wie auch und $\mathrm{mir}^{\circ} \mathrm{JA}^{\mathrm{A}}$ steht in diesen Fällen immer an letzter Stelle. (Auch das unterschiedliche stel- $^{-}$ lungsverhalten ist ein Argument für die Trennung von ja und $J A$.)

In der Kombination mit nur (in negierten Imperativsätzen) und blo $\beta$ wird die dró hende Komponente durch $J A$ noch verstärkt:

(33) Komm mir bloß JA rechtzeitig nach Hause!

(34) Nach einer Schlägerei sagt der Wirt zum Gast:

....und lassen Sie sich hier nur JA nicht mehr blicken, sonst passiert $w^{g s .}$ dgs
In nicht-negierten Imperativsätzen ist JA mit der Variante von nur, die Merkmal 〈ZUSPRUCH〉 enthät, nicht zu kombinieren; vgl.:

(35) "Komm nur JA her, ich tu dir doch nichts.

Allerdings kann nur $J A$ auch in nicht-negierten Aufforderungen als Kombingtion verwendet werden - nur trägt dann nicht mehr das Merkmal (ZUSPRUCH〉:

(36) Sperr nur JA das Haus immer gut zu! Sonst wird nochmal eingebrochen.

In Beispielen wie (36) ist bloß allein akzeptabler als nur:

(36a) ?Sperr nur das Haus immer gut zu! Sonst...

(36b) Sperr bloß das Haus immer gut zu! Sonst...

In der Kombination mit mir, das in seiner Bedeutung weniger spezifisch ist ${ }^{8^{15}}$ $b l o \beta$, und auch, das lediglich anzeigt, daß der Sprecher die Ausführung der $\mathrm{Hand}^{\mathrm{n}^{\prime}}$ lung, zu der er auffordert, erwartet, wird die Aufforderung durch $J A z^{u} e^{\text {in }}$ Warnung oder Drohung: 8) Die Kombination von doch mit JA scheint merkwürdigerweise nur bedingt
zeptabel: ?Bring $\underline{\text { doch }} \underline{\text { JA das Geld mit! }}$ 
(37)

(38) Mach mir JA keinen Blödsinn. Du weißt, wie gefährlich diese Dinger sind.

(39) Daß du mir JA nicht durchfällst!

Und ich sollte mein Schulbrot guch JA aufessen, es wegzuwerfen, sei eine arge Unsitte. (Ke, 36)

Kombin

$v_{e n}$ Attronen mit $J A$ treten auch in finalen Nebensätzen und in nicht-restrikti-

(40) Atributsätzen auf (vgl. auch Kap.1.3.6):

Wenn ein Volk eine Regierung hat, die sogar Großversuche verfälscht, damit auch JA nicht sein muß, was nicht sein soll, kann es selber kaum einen

(4) anderen Bewußtseinsstand erreichen. (SZ)

Immer wieder sehen die drei nach hinten, um nur JA sicher zu sein, daß

Vereinzelt von niemandem bemerkt werden. (SZ)

auch dit scheint die Kombination auch $J A$ in Entscheidungsfragen möglich (vgl.

(42) Beisplele bel Hentschel 1986:154):

Hilep kann du auch JA aufpassen?

ren $S_{a t z m o d} J A$ alleine nicht auftreten, ist also in der Kombination in einem weitetzmodus möglich.

3.2 .1 .2

\section{Kombinationen mit doch}

Ole

kadalpartikel doch ist zum einen eine sehr frequente Partikel, zum andern $\left(\left.S_{a t z-}\right|_{i}\right.$ in relativ vielen Satzmodi auftreten (nicht in Entscheidungsfragen und Nerbar. Pill $]_{\text {en }}$. In der Kombination steht doch hinter ja (s.o.) und denn, in allen anderen Mòglich.

1. eben doch

hier oben schon zu der Kombination ja doch gesagt wurde, gilt hier genauso: Auch $k_{a n h, ~}$ legt eine (akzeptable) Kombination vor, bei der nicht entschieden werden $h_{\text {h }}$ delt beide Partikeln Modalpartikel-Funktion haben. In den allermeisten Fallen d d verb). sich in der Kombination um betontes doch (also das Affirmationsdeutung, vermutlich sind auch diese beiden Modalpartikeln zu ahnlich in ihrer Belot nur um hafufiger kombiniert zu werden. Beim Affirmationsadverb doch dagegen ${ }_{A N N T}$, elne starke Korrekturanweisung ausgedrückt und nicht das Merkmal <BE(1) deshalb ist diese Variante wohl hăufiger.

Ich bin froh, daß du nicht mehr alleine bist mit delner Tante. Hoffentlich aber er sich bald wieder zurechte. Du bist ja nicht auf'n Kopf gefallen, aer wen'n Mann im Haus is, gehts eben doch viel besser. (Bi, 222) 
Und da liegt natürlich manches im Argen. Aber manches hat sich eben doch auch sehr verbessert grade durch diese rückstrahlenden Farben (FK II. 115)

Die Entschejdung darüber, ob doch in dieser Kombination betont oder unbetont ist (und ob es dann Modalpartikel ist oder nicht), hängt hauptsächlich davon ab, auf die Kombination folgt. In der Reihenfolge doch eben allerdings, die auch aul tritt (vgl. (3)), ist doch immer unbetont und folgllch Modalpartikel:

(3) Ja natürlich wird die Kirche in Südamerika vom Vatikan angegriffen. Das ist doch eben genau das Problem.

Die Kombination doch eben oder eben doch ist gegenüber dem Gebrauch von ebell allein schwächer, da mit doch, das ja eine Korrekturanweisung ausdrückt, die $\mathrm{Po}^{-}$ sition des Gesprächspartners und dessen mögliche unterschiedliche Annahmen oder Erwartungen berücksichtigt werden; damit wird das Merkmal 〈EVIDENT〉 von eber abgeschwächt; vgl.:

(3) Das ist eben das Problem. vs. Das ist doch eben das Problem.

\section{2. halt doch}

Hier gilt bezüglich der Akzentuierung von doch das oben bei eben schon Gesagte. Auch bel dieser (eher seltenen) Kombination sind beide Stellungsvarianten möglich. halt doch ist allerdings häufiger:

(4) Es ist halt doch sehr die Frage, ob wir diesen mysteriösen Gangsterboß überhaupt zu Gesicht bekommen.

Hier wird der Sachverhalt durch den Gebrauch von halt als plausibel geken zeichnet.

\section{3. doch einfach}

Diese Kombination, die wesentlich häufiger auftritt als ja einfach, läßt sich in Aussagesätzen und in Imperativsätzen nachweisen:

(5) Anna: Was machst du denn, wenn die alle zum Essen bleiben? Bernd: Ach, da mach ich doch einfach Zwiebelkuchen, der paßt immer.

(6) Und wenn man sich anschaut, Kartoffeln und so, es gibt ja genug Sachen die gestiegen sind, daß man sie sich nimmer leisten kann. Und da muß einer doch einfach $z$ weitausend Mark verdienen beim heutigen Lebensstandard.

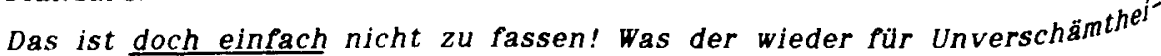
ten losläßt!

(8) Ja, da muß man sich doch einfach hinlegen!

(9) Ja, was machen wir da? (..) Ja, ich würd von mir aus, ich würd sagen, kommen Sie doch einfach, aber ich hoffe, daß es dann da is. (BA, 88) 
Dle Kombination doch einfach ist stärker als einfach allein, da in der Kombination der Sachverhalt (durch einfach) als für den sprecher evident, aber auch (durch doch) als für den Hörer bekannt gekennzeichnet wird, und der Hörer gleichzeitig angewiesen wird, sich in seinen Annahmen oder Erwartungen zu korrigieren. ParaPhrasieren ließe es sich mit : 'dieser Sachverhalt ist eine evidente, einfache Erklărung oder Lösung für ein Problem, und dieser Sachverhalt ist dir im Grunde bekannt, also korrigiere dich in diesem Punkt.'

Bei emphatischen Aussagen wie (7) und (8) wird mit der Korrekturanweisung von ${ }^{\circ}$ ch gleichzeitig an den Gesprächspartner appelliert, zuzustimmen.

4. doch sowieso und doch eh

Die Kombinationen doch sowieso und doch eh treten nur in Aussagesätzen aup; hier wird der Bedeutung von sowieso bzw. eh, ein Vorgängerargument abzuschwächen durch das Anführen eines für den Sprecher bereits länger bekannten Sachverhalts, noch das Merkmal 〈BEKANNT>a von doch hinzugefügt. Gleichzeltig wird die Korrekturanwelsung an den Hörer in dieser Kombination verstärkt, da ja soDhl doch als auch eh/sowieso das Merkmal 〈KORREKTUR〉 aufweisen. Die Kombinathon doch sowieso ist also stärker als sowieso, und enthält sehr häufig elne deutliche vorwurfskomponente.

(1)

Karl: Was sagst du?

Ellen: (Ich brauch nich an der Uni holen, wir könnja nachmittags!)

Karl: Ja, die is doch sowieso in der Uni!

(12) Iris: Ja, ich mein, ich kann auch von der Uni wieder zurückfahrn. (BA, 159)

Peter: ich seh im Moment noch fern, dann werd ich gleich mein Leergut an Flaschen wegbringen.

Anke: Oh, nee, dann will ich dich nich stören, dann / wieso, nee, die Geschärte ham doch sowieso schon zu!

(13) Peter: Nee, das mach ich hier unten in der Knelpe. (BA, 79)

Carla: Mensch, ich hab für heute abend vergessen, was einzukaufen.

Inge: Das macht nichts, wir sind doch sowieso bei Krauses eingeladen. Da

Dibts doch sicher was zu essen.

durcheutung der Kombination doch sowieso läßt sich an Beispiel (13) gut zeigen:

hicht den Gebrauch von sowieso gibt Inge zu verstehen, daß die Außerung Carlas Weiter problematisch ist und führt in ihrer Außerung eine Erklärung dafür an. Durch den gleichzeitigen Einsatz von doch allerdings zeigt sie Carla, daß diese 'Gentlich von der Einladung hätte wissen müssen und daß - wenn sie dieses Wis${ }^{8} e_{n}$ berücksichtigt hätte - auch ihre Außerung und die darin ausgedrückte Be${ }^{8}{ }^{8}$ gnis überflüssig gewesen wären. Insofern kann Inges Außerung einen leichten Orwure enthalten. Dieselbe Außerung ohne doch dagegen würde eine für Carla neue Information darstellen. 
Wie schon erwähnt, tritt diese Kombination häupig in Aussagen über eine (zukünttige) Handlung des Gesprächspartners auf; vgl.:

(13a) Wir gehen doch sowieso zu Krauses.

(13b) Wir gehen sowieso zu Krauses.

(13c) Du gehst doch sowieso zu Krauses.

(13d) Du gehst sowieso zu Krauses.

In (13a) und (13c) zeigt die Sprecherin durch doch sowieso an, daß sle schon lange von der Einladung wußte (sowieso) und daß auch die Gesprächspartnerin im Grunde davon weiß, dieses Wissen aber momentan nicht präsent hat (doch). In (13b) und (13d) ist der geäußerte Sachverhalt dagegen für die Gesprächspartnerin neu, was bei (13d) nicht gerade adäquat ist, wenn nicht die sprecherin eine Position innehat, die es ihr erlaubt, über die Pläne und Handlungen ihres Gegenubers zu verfügen.

\section{5. doch wohl}

Die Kombination doch wohl ist eine außerordentlich frequente Kombination. Ste tritt nur im Formtyp Aussagesatz auf, die Außerung kann aber - wle Außerungen mit doch bzw. wohl allein - auch als Frage zu verstehen sein. Oft weisen $A u \beta e^{-}$ rungen mit doch wohl eine expressive Färbung auf.

(14) Der General schickte die Meldung ins Hotel 'Lutetia' mit dem Vermerk, daß er sich jede Einmischung der Abwehr in militärische Fragen - und die Sprengung einer Brücke wäre doch wohl eine solche - geziemend verbäte! (Si, 378)

(15) Was helßt da, sie ist ja noch ein Kind? Ich kann doch wohl von einer 16jährigen erwarten, $d a \beta$ sie weiß, was sie tut, wenn sie klaut.

(16) Eva: Also, wenn ihr dann trotzdem in Ruhe essen könnt und könnt euch dann absetzen/

Nora: Ja, Mensch, anderthalb Stunden, das reicht doch wohl!

Eva: Ja, ich weiß nich, wie die Zähne vom Roland sind! (BA, 73)

In den Aussagen bzw. Behauptungen und den expressiven Aussagen mit doch wohl entspricht die Bedeutung von doch der oben bereits beschriebenen: Der sprecher verweist auf einen für den Hörer bekannten Sacherhalt, den dieser - was a $\mathbf{u}^{5}$ seinem spachlichen oder nicht-sprachlichen Verhalten ableitbar ist - offensichtlich nicht berücksichtigt. Damit wird durch doch der Sachverhalt also als bekannt gekennzeichnet; das macht die Kombination mit wohl etwas problematisch. d8 durch wohl ja die Außerung eingeschränkt wird.

Weydt et al. (1983:43) gehen davon aus, daß doch wohl-Außerungen 'unsiches Vermutung' ausdracken. Das widersprăche aber der Bedeutung von doch; auch eine Kombination wie ja doch wohl, bel der zwei Partikeln das Merkmal (BEKANNT' 
tragen, zeigt wohl kaum eine Vermutung an.9 Hier zeigt sich ganz deutlich, daß Wohl nicht die Gültigkeit des Sachverhalts einschränkt, sondern den Außerungsakt selbst, also etwa die Behauptung.

Die Kombination doch wohl kann (ähnlich wie ja wohl) so beschrieben werden: Der Sprecher macht eine Außerung, bei der der dargestellte Sachverhalt durch doch als bekannt und damit auch als gültig markiert wird, und schränkt diese Außerung dadurch wieder ein, daß er wohl hinzufügt. Diese nachträgliche Einschränkung erfolgt als Anpassung an den Gesprächspartner, sein (vermutetes) Wissen, seine Annahmen und Erwartungen; die Fortsetzungsmöglichkeiten des Gesprächspartners Werden ausgeweitet. Wohl ist dafür besonders geeignet. Eine Außerung mit doch "ohl ist also vom Sprecher intendiert wie dieselbe Außerung ohne wohl, wobei er tür den Gesprächspartner eln Zugeständnis - ausgedrückt durch wohl mit seinem Herkmal 〈EINSCHRANKUNG〉 - macht, dem Hörer Spielraum läßt, was die Behauptung abschwächt; dem Gesprächspartner wird eher die Möglichkeit gegeben, zuzustimmen oder zu widersprechen. Allerdings erwartet der Sprecher Zustimmung, was ${ }^{81} \mathrm{ch}$ aus dem Gebrauch von doch ableiten läßt. Vgl. folgendes Beispiel:

(17) Ein Betriebsrat soll zu einer Sitzung kommen, die in einem anderen ort stattfindet:

Ich sag: "Und wie ist das? Glauben Sie, ich fahr mitn Fahrrad nach Herne? Das kommt doch wohl nicht in Frage! Ihr habt soundsoviel Autos!" (BP, 26)

Aus dem vorhergehenden Kontext ist klar, da $\beta$ der Sprecher es für eine Zumutung hălt, von inm zu erwarten, er fahre mit dem Fahrrad nach Herne. Weiterhin hält er es auch für seine Gesprächspartner für bekannt und offensichtlich, daß 'das nicht in Frage kommt'. Insofern könnte die Außerung auch lauten: Das kommt doch nicht in Frage! Wohl schwächt nun hier die Außerung ab, soll aber gleichzeitig die Gesprächspartner davon überzeugen, zuzustimmen. Die gleiche Außerung ohne doch $\left\langle D_{2 s}\right.$ kommt wohl nicht in Frage) dagegen drückt eher eine Vermutung aus, und Dird deshalb auch eher als Frage interpretiert.

$V_{\text {gl. }}$ auch die Gegenüberstellung:

Der spinnt wohl! vs. Der spinnt doch wohl! vs. Der spinnt doch!

In den Außerungen mit doch wohl, die als Fragen zu interpretieren sind, gibt der Sprecher zunächst - was sich auf die Bedeutung von doch (Merkmal (BEKANNT>s) ¿urückführen läßt - eine starke Antworterwartung zu erkennen: er erwartet Zustimmung. Und auch hier wird durch wohl Einschränkung angezeigt.

(19) Polizei zum Hausmädchen: Sie haben doch wohl nichts dagegen, wenn wir uns hier ein bißchen umsehen?

9) Deshalb ist auch wohl in der Kombination mit doch in den allerwenigsten Fällen ersetzbar durch 'vermutlich'. 
(20) Es ist doch nicht etwa - Gisa, ihr müßt doch wohl nicht heiraten? (Hör zu) Es läßt sich hier eine Skala des Erwartungsgrades aufstellen (wohl - doch wohl' doch); vgl.:

(21) Und wir hörten doch wohl keine ausländischen Sender? "Robert, sieh mich an! Um Gottes willen! Ja nicht! Die kriegen alles 'raus." (Ke, 230)

(21a) Ihr hört wohl keine ausländischen Sender? (der Sprecher nimmt eher an, daß sie keine ausländischen Sender hören)

(21b) Ihr hört doch wohl keine ausländischen Sender? (der Sprecher vermutet (und in diesem Fall auch: hofft) stark, daß...)

(21c) Ihr hört doch keine ausländischen Sender? (der Sprecher ist eigentlich sicher, daß... und will sich nur rückversichern) Die Modalpartikel wohl bringt also in der Kombination durch das Merkmal $\left\langle\mathbb{E}^{-}\right.$ SCHRANKUNG> letztlich eine den Außerungsakt abschwächende Komponente, die sich darauf zurückführen läßt, daß der Standpunkt des Gesprächspartners mitbé rücksichtigt wird.

Diese Leistung von wohl wird m.k. dadurch noch verstärkt, daß es in Kombinatio" nen an zweiter Stelle steht. Geht man davon aus, daß dem letzten Element besondere Bedeutung zukommt, so wird dem Hörer bei einer Außerung mit doch wot eher die abschwächende Komponente von wonl und die damit verbundene Höflich keitsleistung im Gedächtnis bleiben.

\section{6. doch schon}

Die Verbindung von doch und schon läßt sich in Imperativsätzen und in Aussage sätzen finden. $\mathrm{Zu}$ den Imperativsätzen:

(22) Die Mutter will aus dem Haus gehen, aber die kleine Tochter trödelt ewig herum. Die Mutter: Jetzt komm doch schon her!

23) Mach doch schon endlich die Schneeketten runter! Die Straße ist doch viol' lig frei und so tief runter hats garantiert nicht geschneit.

Wie oben schon erwähnt wurde, ähneln sich schon und doch in Aufforderungen ${ }^{n-}$ sofern, als auch mit schon der Sprecher zu einer Handlung aufgefordert wird, die er längst hätte tun können. Der Unterschied zwischen doch und schon aber ${ }^{b e^{\prime}}$ steht darin, daß bei schon mögliche Gründe des Angesprochenen für sein zöge $e^{\text {th }}$ anerkannt werden und er aufgefordert wird, diese Gründe für den vorliegende ${ }^{n}$ Fall aufzugeben. Diese Bedeutungskomponente (Merkmal <GELTUNGSEINSCHR ${ }^{\mathrm{N}^{-}}$ $K U N G>v$ ) fügt schon einer doch-Aufforderung hinzu. In (23) z.B. räumt der $s p^{r^{e^{\prime}}}$ cher mögliche Bedenken oder Vorbehalte des Angesprochenen explizit aus. In den Aussagesătzen wird durch schon - wie oben dargestellt - die vorgänger äußerung oder auch eine nur angenommene (gegenläufige) Meinung des Gespra ${ }^{\text {h }}{ }^{5^{\prime}}$ 
Partners in ihrer Gültigkeit eingeschränkt; der Sprecher stimmt ihr nur teilweise 2u und bringt in der schon-Außerung Gründe dafür. Durch den Gebrauch von doch verden diese Gründe zusätzlich als bekannt markiert und der Gesprächspartner angewiesen, diese Gründe im weiteren zu berücksichtigen; insofern ist doch schon line stärkere Variante als schon und eine schwächere als doch, da bei doch eine mögliche abweichende Meinung des Gesprächspartners nicht akzeptiert wird.

Ole Skala doch - doch schon - schon zeigt Beispiel (24).

S handelt sich hier um ein Interview mit einem Kameramann der Olympischen

varum von 1936. Durch das ganze Interview zog sich unterschwellig die Frage,

sene, jemand zu dieser Zeit an den Spielen teilgenommen hat. Auf die erschlos-

Spielen seiner Meinung abweichende Behauptung 'man hätte damals an den (24) Ich wußte ja nicht, wann wir auf Sendung waren, also mußte ich den gan-

(24a) zen Tag am Sucher stehen und das ist doch schon ein gewaltiges Erlebnis.

Das ist schon ein gewaltiges Erlebnis.

Das ist doch schon ein gewaltiges Erlebnis.

In as ist doch ein gewaltiges Erlebnis.

Binwand Beispielen mit doch schon im Aussagesatz (vgl. auch (25) und (26)) ist der Beäuß dem mit schon teilweise widersprochen wird, in der Regel nicht explizit (25)

IEs geht um politische Betätigung.J Und bei Politik möcht ich nich direkt mitmischen, denn dazu versteht man doch zu wenig von der ganzen Sache,

(26) das möcht ich doch schon den befugteren Leuten überlassen. (BP, 70)

wschlug ihm Jochen Mariel, Talentsichter der lMaler-lInnung vor, doch einfach für die Bundesrepublik bei der Weltmeisterschaft an den Start zu gehen. "Da habe ich natürlich zugesagt. Nicht, weil ich ein Streber bin.

Die Aber mal nach Australien zu kommen, das ist doch schon super." (SZ)

ledoch solpartikein doch und schon treten zwar beide auch in $w$-Fragesätzen auf,

Sprecher

belpkt, weiß die Anitwort im Grunde), die sich mit schon, das ja Rhetorizität

7.

7. doch nicht vereinbaren läßt.

Diese auch

(27) erbindung läßt sich nur in Aussagesätzen nachweisen:

Ein Vater beklagt sich, daß seine Tochter so frech und unverschämt ist.

Die Großmutter: Was regst du dich denn auf? Du hast ihr doch auch immer $D_{i e}$ alles durchgehen lassen.

"ilcht ${ }^{8 D}$ richt, weiter überrascht, da der Sachverhalt durchaus ihren Erwartungen ent${ }^{8 i g h a l i s i e r t}$ ind eigene Außerung stellt eine Begründung dafür dar. Gleichzeitig kant sein sie durch doch, daß dieses Argument eigentlich auch dem vater besein sollte; dessen Klage aber läßt vermuten, daß er das Argument nicht. 
berücksichtigt hat, und die Sprecherin fordert ihn diesbezüglich zu einer Korrektut auf.

\section{8. denn doch}

Inwieweit es sich bei dieser Kombination um denn in Modalpartikel-Funktion han delt, ist nicht klar entscheidbar: Dagegen spricht, daß denn nur in der Kombination in Aussagesätzen auftritt, daß es nicht (wie in Fragen) $z u$ ' $n$ verkürzt wer'

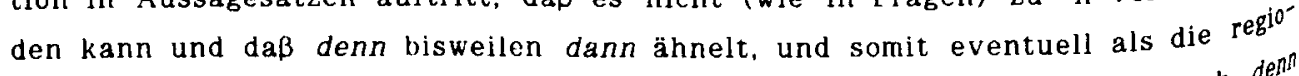
nale Variante von dann bezeichnet werden könnte. Allerdings können auch dens und dann gemeinsam auftreten; vgl. Beispiel (14) $\mathrm{S} .232$. Hinsichtlich des vorfeld verhaltens und der Nicht-Akzentuierbarkeit und auch von der Bedeutung her ähnelt dieses denn allerdings den Modalpartikeln. Es soll hier (mit Vorbehalt) 24 den Modalpartikeln gerechnet werden.

Denn kann also nur in der Kombination mit z.B. doch (auch in der Verbindung ${ }^{\text {j8 }}$ denn doch) in Aussagesätzen auftreten. ${ }^{10}$ Aussagesätze mit dern doch können un' markierte Aussagen sein (vgl. (28) und (29)), 11 weisen aber häufig expres ${ }^{s^{v^{v}}}$ Färbung auf; in der Verbindung ja denn doch sind es immer emphatische Aussage (28) Oder sollte diese vornehme Zurückhaltung am Ende doch mit der Tatsache zusammenhängen, daß Fischer (Stuttgart) im Schreiben einfach nicht so schnell war, wie Heidemann gerne bezahlt hätte? Das fänden wir denn doch eine zu banale Erklärung. (SZ)

(29) IEs geht um die Frühstückseier./ Natürlich ist der betreffende Mensch imstande, auf die Uhr zu sehenaber so einfach ist die Sache denn doch nicht. (SZ)

(30) Das geht denn doch ein bißchen weit! (Si, 18)

(31) Das ist denn doch ein starkes Stück! (31) Das ist denn doch ein starkes Stück!
(32) Das ist ja denn doch die Höhe! Mich zu beschuldigen! Wo ich doch Vorfaht
hatte!

Denn als Modalpartikel in Fragen wurde mit den Merkmalen 〈KONNEX〉 und 〈UNER' WARTET $>v$ (immer in Entscheidungsfragen, oft in w-Fragen) beschrieben. In det Kombination mit doch in Aussagesätzen läßt sich nun 〈UNERWARTET> nicht nach" weisen, zentral ist hier das Anknüpfen an die Vorgängeräußerung, also das Merk" mal 〈KONNEX〉. In dieser Hinsicht gleicht denn dem Adverb dann, das ja auch $e^{\text {in }^{n}}$ Verbindung anzeigt. Die Bedeutung von doch bzw. von ja entspricht der schon bet den Einzelanalysen angegebenen. Daß denn in den Aussagesätzen lediglich d $^{5}$

10) In w-Fragesätzen können denn und doch nicht kombiniert werden; s.u. $\begin{gathered}5.2^{69} \\ 9^{\prime}\end{gathered}$

11) In diesen Fällen (vor allem bei negierten Außerungen wie (29)) kann doch lerdings auch akzentuiert werden; möglicherweise handelt es sich dabe das Affirmationsadverb. 
Herkmal 〈KONNEX〉 aufweist, zeigt sich noch deutlicher an der weiter unten

(\$.232pf.) zu besprechenden Kombination denn auch.

8. doch nicht etwa

Die Modalpartikeln doch und etwa sind, wenn man ihre Distribution betrachtet, im

Grunde nicht kombinierbar. Nun läßt sich zwar etwa in Verbindung mit der Nega-

tonspartikel nicht auch in Aussagesätzen nachweisen (und in dieser Verbindung

$\mathrm{k}_{\mathrm{an}}$ es auch mit doch kombiniert werden); allerdings ist nicht etwa nur in ganz

estimmten Aussagesätzen, und zwar solchen mit dem Modalverb sollen, möglich

(Der soll nicht etwa glauben, ich würde mich bei ihm entschuldigen). Doch nicht

et dagegen unterliegt in dieser Hinsicht keinen Restriktionen: die Kombination

ritt in Außerungen auf, die die Form von Aussagesätzen haben, aber als Fragen

2u interpretieren sind. In dieser Variante ist nicht etwa allein nicht möglich.

ofensichtlich muß hier doch erscheinen, um die Frage-Lesart zu sichern.

,

loben (S.116f.) schon gezeigt, stellen Außerungen vom Typ (33) einen

steigenden) Mischtyp dar: es sind Aussagesätze (wegen der Verbstellung) mit oft

nicht-st Tonmuster; ${ }^{12}$ vom Illokutionstyp her sind die Außerungen (auch bei

(33) steigendem Tonmuster) eindeutig Fragen.

Aluch Sie haben den Katalog doch bis zur Eröffnung fertig?

hation Außerungen mit doch nicht etwa sind als Fragen zu interpretieren; die Into-

(34) kann steigend sein oder nicht.

Du hast doch nicht etwa das ganze Geld verspielt? Wir müssen doch unsere

(35) Schulden bezahlen!

Ein Mann und eine Frau haben eine Auseinandersetzung. Sie vermutet, daß er sie loswerden will.

"Nun werd man nicht übermütig (...) Du bildest dir doch nicht etwa ein,

(36) $d_{a \beta}$ du hier so einfach die Kurve kratzen kannst." (Bi, 153)

(37) Herr von Rumnitz? Wer ist denn das? Doch nicht etwa der frühere Besitzer?

$\mathrm{O}_{\mathrm{i}} \mathrm{D}_{\mathrm{u}}$ hast dich doch nicht etwa bereits in Vera verliebt, du Idiot? (Si, 382)

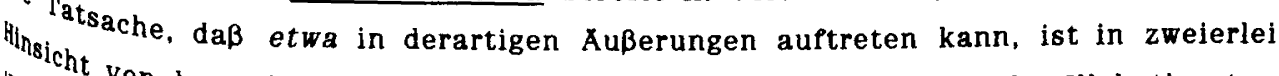

'Page' von besonderem Interesse: Zum einen zeigt es, daß hier der Illokutionstyp

It das Auftreten der Modalpartikel steuert und nicht der Formtyp (etwa kann

$d_{a \beta}$ do nur in Sätzen mit Verb-Erststellung auftreten). Zum anderen zeigt es,

Piler ${ }^{0}$ in diesen Außerungen die Frage-Lesart entscheidend mitbestimmt.

Men oben (S.116f.) wurde festgestellt, daß doch diese Funktion nur im ZusamAuBerun mit anderen Mitteln (steigendes Tonmuster und/oder Inhalt der g) übernehmen kann. Diese beiden 'Frage-Indizien' allein reichen aber of-

(2) Bei steigendern Tonmust

Steigendem Tonmuster liegt der Typ 'Assertive Frage' (s.o. S.69f.) vor. 
fensichtlich nicht aus, um die Frage-Lesart so eindeutig zu sichern, da $\beta$ etrs auftreten könnte; vgl.:

'Er kommt nicht etwa $\uparrow$ bzw. "Er kommt etwa $\uparrow$

"Du kommst nicht etwa $\uparrow \mathrm{bzw}$. "Du kommst etwa $\uparrow$

Wenn also ein Satz mit Verb-Zweitstellung durch doch und andere Mittel dahingehend modifiziert ist, daß er nur noch als Frage zu interpretieren ist, dann $\mathrm{ka}^{\mathrm{n}}$ auch etwa darin vorkommen. ${ }^{13}$ Außerungen vom Typ (34)-(37) sind also als for $^{-}$ male Mischtypen zu klassifizieren.

Die Antworterwartung bei Außerungen mit doch nicht und etwa bzw. doch und etwa nicht ist parallel (einmal abgesehen von der unterschiedlichen Form); vgl. (39) und (40):

(39) Du meinst das doch nicht im Ernst? vs. Meinst du das etwa im Ernst?

(40) Ruhe! Ich habe gesagt, wir gehen nach Lutetia, basta! Das wolltest du doch immer oder etwa nicht? (A XXI, 47)

Fragen mit doch sind Rückversicherungsfragen, also Fragen, die einen Sachverhalt erfragen, der auch dem Sprecher eigentlich bekannt ist. Deshalb wird bei doch ${ }^{-}$ Fragen Bestätigung erwartet, sie haben positive Tendenz; in Fragen mit Negation und doch wird als Antwort dementsprechend nein erwartet.

Etwa-Fragen dagegen weisen eine negative Tendenz auf, d.h. auf eine positive etwa-Frage wird nein als Antwort erwartet, genauer: nein wird präferiert.

Aufgrund dieser Bedeutungskomponente, die doch- und etwa-Fragen haben, nämlich bestimmte Antworterwartungen auszudrücken, die einander entgegengeset $t^{t}$ sind, läßt sich erklären, warum die Kombination von doch und etwa nur in ver bindung mit der Negationspartikel nicht möglich ist, einer Partikel, die die Te ${ }^{n^{-}}$ denz bzw. Antworterwartung für eine der beiden Modalpartikeln in das Gegenteil verkehrt. ${ }^{14}$

Bei Fragen mit doch nicht etwa erwartet der Sprecher die Antwort nein (b2 würde diese Antwort vorziehen), befürchtet aber - wie dies bei etwa-Fragen $\ddot{b}^{-}$ lich ist - die Antwort ja bzw. doch.

Das Merkmal 〈UNERWARTET>v (von etwa) läßt sich hier mit 〈BEKANNT> (von $d 0^{\text {h) }}$ ) deshalb kombinieren, weil sich ersteres auf die Vorgängeräußerung bezie ht. $^{\text {t. }}$ 〈BEKANNT〉 dagegen auf die momentane Außerung. Beispiel (39) soll das verde ${ }^{\mathrm{u}^{-}}$ lichen:

13) Xhnlich läßt sich auch die Kombination doch wohl nicht etwa erklären (s.u. S.261).

14) Vgl. dagegen Weydt/Hentschel (1983:11), die bei Vorkommen wie: Du hast doth nicht etwa das Fenster aufgelassen? (unzutreffend) davon ausgehen, die ver neinung könne "nicht auf der propositionalen Ebene interpretiert werden". 
(39) Er: Ich habe eine Hypothek auf das Haus aufgenommen.

Sie: Du meinst das doch nicht etwa im Ernst?

Der in der Vorgängeräußerung dargestellte Tatbestand ist für die sprecherin uner-

Martet und stellt den Anlaß für ihre Frage dar; gleichzeitig geht sie davon aus,

daß ihr Gesprächspartner diese Sachverhaltsbeschreibung 'nicht im Ernst meint',

muß aber befürchten, daß der Bericht der Wahrheit entspricht.

Die Kombination doch nicht etwa ist wegen der deutlichen Betonung des Gegensatzes zwischen dem, was der Sprecher wünscht, und dem, was zu erwarten ist, eine stärkere Variante als etwa. Eine noch deutlichere Variante stellt die Verbindung mit gar dar:

(41) Du hast doch nicht etwa gar den neuen Cadillac kaputtgefahren?!

10. doch blok und doch nur

Diese Kombinationen lassen sich in Wunschsätzen, Imperativsätzen und vereinzelt

in $w$-Exklamativsätzen nachweisen. ${ }^{15}$

In den Wunschsätzen stellt die Kombination doch bloß bzw. (etwas seltener) doch

nur gegenüber der Verwendung von doch bzw. bloß/nur allein diejenige Variante

dar, die die Illokution der Außerung am stärksten zum Ausdruck bringt:

(42) Ach, wäre er doch bloß am Schreibtisch seiner Dienststelle im Hotel 'Lutetia' geblieben! Theoretische Generalstabsarbeit - das war seine Stärke, nicht aber Taktik und Strategie. (Si, 359)

(43) Hätte er doch bloß nichts gesagt. (Bi, 113)

(44) Hätte ich doch nur den Herz-Zehner behalten!

$D_{a}$ die Funktion von bloß/nur und doch in wunschsätzen ohnehin sehr ähnlich ist

(s. S.117f.), wird durch die Kombination der geäußerte wunsch nur noch mehr verstärkt; vgl.:

(45)

Hätt ich nur meiner Tochter geglaubt!

Hätt ich doch meiner Tochter geglaubt!

Hätt ich doch nur meiner Tochter geglaubt!

Auch in den Imperativsätzen verstärken bloß und nur die lllokution; für doch

lassen sich die oben angegebenen Merkmale nachweisen; vgl.:

(46)

"Mädchen, Mädchen", murmelte Herr Löschke "sei doch bloß'n bißchen

freundlicher..." "Wieso?" fragte ich. "Weißte denn überhaupt, wer das is? mit

(47) dem de da eben jesprochen hast! Nee? Mensch, det is'n Bulle." (Bi, 59)

"Dein Bruder - " "Hör doch bloß endlich auf mit meinem Bruder" (Bi, 195)

15) Doch und bloß/nur treten zwar auch beide in w-Fragesätzen auf; jedoch stellen $w$-Fragesätze mit doch eine sehr markierte Variante dar, bei der der Sprecher die Antwort im Grunde wei $\beta$, was mit der illokutionsverstärkenden Funktion von bloß/nur nicht gut vereinbar scheint. Deshalb ist die Kombination in w-Fragesätzen nicht ganz akzeptabel: ?Wie heißt er doch bloß? 
(48) Machen Sie sich's doch bloß nicht so leicht! (Bi, 208)

Die Kombination doch bloß in (46) läßt sich so paraphrasieren: 'ich fordere dich ausdrücklich aup, dein bisheriges Verhalten zu korrigieren und etwas zu tun, was du eigentlich schon vorher hättest tun können'. Auf die Komponente, die doch in diese Kombination einbringt, nämlich zu einer Handlung aufzufordern, von der des Gesprächspartner weiß, daß er sie längst hätte tun können (Merkmal (BEKANNT) ), deutet in (47) auch das Adverb endlich hin. ${ }^{16}$

In der Kombination mit doch ist die Modalpartikel nur sowohl möglich in den negierten Aufforderungen - wo sie die gleiche Funktion hat wie bloß (vgl. (49)), als auch in den affirmativen Aufforderungen, wo sie das fakultative Merkmal 〈ZUSPRUCH〉 trägt (vgl. (50)); letztere Kombination gleicht doch ruhig.

Der Unternehmer Diederich will einen seiner Arbeiter entlassen, der aber etwas gegen ihn in der Hand hat.

Der Arbeiter: Herr Doktor, tun Sie doch nur nicht so. Wir beide: - Na ja, ich sage bloß, wir beide... (Ma, 298)

(50) Die Beine wurdon ihm weich, er setzte sich und brachte hervor: "So sag mil doch nur -. Ich will dir auch -"Er sah an Emmis Erscheinung hin, das Wort Verzeihung blieb ihm stecken. (Ma, 303)

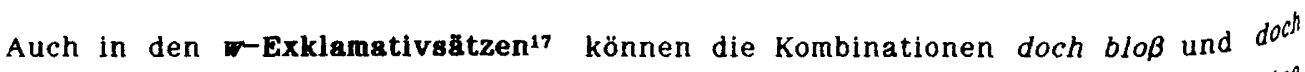
nur vereinzelt auftreten; auch hier bewirken nur und $b l o \beta$ in der Kombination e in $^{\text {ne }}$ Verstărkung des lllokutiven Akts:

(51) Der FC Bayern hat gestern verloren. Was war das doch nur für ein Spiel!!

\section{1. doch $\mathrm{mal}$}

Diese Kombination ist wohl die frequenteste und kann als stereotypisiert angesehen werden. Sie ist in Imperativsätzen und in Aussagesätzen mit dem Modalverb können möglich, d.h. immer nur im Illokutionstyp 'Aufforderung'. In Entscheidungs' fragesätzen, wo mal alleine ja durchaus auftreten kann, ist die Kombination wegen des syntaktischen Verhaltens von doch nicht möglich.

(52) Herr Löwenthal, dann haben Sie wenige Tage vorher dem Journalisten Kum' mer (...) gesagt, es gibt noch einen zweiten Zeugen für das tote Mädchen. Den hab ich noch in der Hinterhand. Nun machen Sie doch mal die Hinter hand auf, Herr Löwenthal. Die ist nämlich leer. (FK II, 245)

Und nur klagen sie doch mal dagegen, daß ich Sje einen Verleumder genannt habe! (FK II, 264)

16) Die Kombination von doch und $J A$ in Imperativsätzen ist dagegen nicht belef und merkwürdigerweise (im Unterschied $\mathrm{zu}$ doch bloß) auch nicht besonder

17) Die Tatsache, daß hier eine Kombination von nur und bloß mit doch mög ${ }^{1 i^{n}}$ ist, ist ein weiteres Indiz dafür, daß derartige Außerungen keine rhetorisc $\mathrm{h}^{\ell^{\mathrm{l}}}$ Fragen, sondern Exklamationen sind (s.o. S.180ff.). 
(54) Laß dir doch mal von der Wirklichkeit helfen, dachte ich, wenn die Fiktion schon so nachhaltig versagt. (Kr, 10)

(55) Mensch, mach doch mal das Maul auf! (Si, 478)

(56) Wir könnten den Martin und den Peter am Sonntag zum Essen einladen. Ruf doch die Jungs mal an!

(57) Ich würd gern mal wieder schwimmen gehen. Du könntest doch mal im Schwimmbad anrufen, wann die mit ihren Renovierungsarbeiten fertig sind.

$D_{0 c h}$ in Aufforderungen wurde beschrieben mit 'korrigiere dein jetziges Verhalten, Und führe die Handlung aus, von der du weißt, daß du sie ausführen kannst oder sollst'. Diese Bedeutung ist auch in der Kombination vorhanden, wobei durch mal dle Aufforderungsillokution abgeschwächt wird, die Aufforderung also beiläufiger Wird. Auch hier steht wieder die abschwächende Modalpartikel an zweiter Stelle.

Pür Aufforderungen mit mal, doch mal und doch und andere Aufforderungen läßt sich bezüglich der 'Stärke' des Aufforderungscharakters folgende Skala aufstellen:

(58) Mach mal das Fenster auf!

Mach doch mal das Fenster auf!

Mach doch das Fenster auf!

Mach das Fenster auf!

Mach $\underline{J A / b l o \beta}$ das Fenster auf!

Auppallend ist, daß doch mal eine in Werbeslogans häufige Kombination ist:

(59) Ruf doch mal an! / Schreib doch mal wieder! (Bundespost)

(60) Ein Paket braucht keinen besonderen Anlaß. Schicken Sie doch auch mal eins!

(61) Fühl doch mal, wie gut die sitzt! (Werbung für Jeans)

(62) Schauen Sie doch mal bei uns vorbei!

Hiler wäre vermutlich die Variante ohne doch zu belläufig, zu abgeschwächt, vgl.:

$\left(59_{a}\right)$ Ruf mal an!

Durch doch kommt hier eben noch zum Ausdruck, daß der Angesprochene, also der,

der durch den Werbespruch erreicht werden soll, bisher ein Verhalten gezeigt hat,

das der Aufforderung zuwiderläuft, und das er jetzt korrigieren soll.

12. doch ruhig

Diese Kombination ist - wie die eben besprochene - nur in Außerungen möglich,

de als Aufforderungen zu verstehen sind, d.h. in Imperativsätzen und in AussaBesătzen mit dem Modalverb können.

(63) Wir essen so um 7 Uhr. Komm doch ruhig etwas früher, dann können wir noch ein bißchen quatschen vorher!

(64) Also, du bist echt unmöglich! Stellt sich auf den Balkon, um zu rauchen. Du kannst doch ruhig rauchen, so militant sind wir auch wieder nicht. 
Bei der Kombination doch ruhig wird die von ruhig angezeigte permissive Komponente durch doch verdeutlicht. So z.B. in (64): Der Angesprochene hat die Handlung, deren Ausführung der Sprecher für selbstverständlich hält, bisher nicht vollzogen, da er sie für unangebracht oder unerwünscht hielt; nun fordert der Sprecher ihn zu einer diesbezüglichen Korrektur auf mit dem Hinweis darauf, dal er, der Sprecher, keine Einwände hat.

Diese Kombination läßt sich auch noch durch mal oder nur erweitern:

(65a) Komm doch nur ruhig vorbei!

(65b) Komm doch nur ruhig mal vorbei!

Hier wird durch mal Beiläufigkeit ausgedrückt und durch nur die zusprechende Komponente verstärkt.

\subsubsection{Kombinationen mit auch}

Die Modalpartikel auch, die in den meisten Satzmodi vorkommt (nicht im wunschsatz, (Satz-)Exklamativsatz und selten im Imperativsatz), läßt sich häufig mil anderen Modalpartikeln kombinieren. Die Verbindung mit ja und doch wurde bereits beschrieben, aber auch wird in 3.2.1.6 besprochen. Die Stellung von auch in der Kombination ist unterschiedlich.

\section{1. eben auch}

Die Kombination eben auch war in meinem Korpus kaum belegt; sie wurde deshalb mit Beispiel (1) getestet und von 95\% der Testpersonen als akzeptabel beurteilt:

(1) Max: Ich hab meinem Freund Geld geliehen für seine Firma und jetzt ist ef pleite. Das Geld seh ich sicher nie mehr wieder.

Ute: Du bist eben auch zu gutmütig.

Diese Kombination läßt sich wie die bisher beschriebenen auch als Addition det Einzelbedeutungen erklären: durch auch zeigt Ute in (1) an, daß der aus der vor gängeräußerung ableitbare Sachverhalt ('Max hat Pech gehabt') für sie erwartbat war und zwar aufgrund des in ihrer eigenen Außerung zum Ausdruck gebrachten Tatbestands ('du bist zu gutmütig'); mit eben signalisiert sie gleichzeitig, daß der Inhalt ihrer eigenen Aussage eine auch für Max evidente Tatsache ist (bzw. se $e^{\text {in }}$ sollte).

\section{2. halt auch}

Diese Kombination scheint etwas häufiger zu sein als eben auch. Sie kann genau ${ }^{50}$ beschrieben werden wie eben auch, mit dem Unterschied, daß der Sachverhalt in 
der halt auch-Außerung als plausibel markiert wird und die Außerung insofern Peniger apodiktisch ist als mit eben auch.

(2) Ilse: Du, der Herr Krause hat sein Auto verkauft. Der fährt jetzt nur noch mit dem Fahrrad.

Franz: Na ja, der muß halt auch ziemlich viel an seine geschiedene Frau zahlen; da kann er keine großen Sprünge mehr machen.

3. einfach such

Die Kombination der beiden Modalpartikeln auch und einfach ist in beiden Stellungsvarianten möglich; einfach auch scheint die häufigere Variante.

(3) Uli: Jetzt hab ich schon wieder ein Buch verlegt und kann es nicht finden. Ingo: Klar, dein Haus ist auch einfach zu groß mit seinen 12 Zimmern. Da würd ich auch nichts mehr finden.

(4) Kinderfrau: Also heute waren die Kinder fürchterlich! Nicht auszuhalten! Mutter: Ja, das war einfach auch zuviel für sie - der Umzug, die lange Reise und dann noch die Geschichte mit dem Pferd.

Diese beiden Partikeln ergänzen sich gut in ihrer Bedeutung. $\mathrm{Zu}$ der oben schon beschriebenen Bedeutung von auch kommt noch die von einfach dazu, den dargestellten Sachverhalt als pür den Sprecher evident ( $(E V I D E N T\rangle$ ) zu kennzeichnen; 'gl. (4): Die Kinderfrau äußert einen für sie unangenehmen und überraschenden Tatbestand; auf diese Außerung reagiert die Mutter, indem sie durch einfach auch in ihrem Beitrag anzeigt, daß für sie dieser Tatbestand erwartbar war, und dafür einen für sie selbst offensichtlichen Grund anführt.

4. Wohl auch

In der Kombination wohl auch schränkt der Sprecher durch wohl die von ihm vollzogene Behauptung ein, und läßt dem Gesprächspartner damit eher die Möglichkeit, ¿u widersprechen.

(5) Ich bin nicht kompetent zu beurteilen, bei wem die schuld liegt, ob sie umstritten ist oder nicht, es spielt wohl auch keine sehr wesentliche Rolle.

(6) Doris...ich bin jetz ehemüde gewordn.

Hans: Hm..Nee, so, also, hm, grade im ersten Jahr/solang du allein gelebt has, dann hasde doch so einige. Gewohnheiten angenommen, die's dann vielleicht, öh, . /wo's schwerfällt, die hinterher wieder aufzugeben ne. Und grade . das war wohl auch der Grund, warum wir uns im ersten Jahr so . mehr zusammenraufen mußten, als es. jetz is . (BA, 115)

Diese Kombination läßt sich auch in Verbindung mit ja nachweisen:

(7) Ich weiß nicht, irgendwie hab ich doch an ihm gehangen, er war immer nett und großzügig zu mir, und auf seine Art hat er mich ja wohl auch gern gehabt oder sogar geliebt. (Bö $\mathrm{c}, 228$ )

\footnotetext{
Die folgende Gegenüberstellung soll noch einmal alle Verbindungen von auch, das

Vor allem einen bestimmten Bezug zur Vorgängeräußerung markiert (〈ERWARTET>v),
} 
mit denjenigen Modalpartikeln zeigen, die die Proposition oder Illokution der mó $^{-}$ mentanen Außerung in irgendeiner Weise markieren. Dazu noch einmal folgendes Beispiel:

(4) Kinderfrau: Also heute waren die Kinder fürchterlich! Nicht auszuhalten! Mutter: Ja, das war (...) zuviel für sie - der Umzug, die lange Reise und dann noch die Geschichte mit dem Pferd.

(4a) Das war auch zuviel für sie.

(4b) Das war ja auch zuviel für sie.

(4c) Das war doch auch zuviel für sie.

(4d) Das war eben auch zuviel für sie.

(4e) Das war einfach auch zuviel für sie.

(4f) Das war wohl auch zuviel für sie.

In allen Fällen also zeigt die Mutter durch den Gebrauch von auch an, daß det von der Kinderfrau geäußerte Sachverhalt für sie erwartbar war und sie keineswegs überrascht, und liefert in ihrer eigenen Außerung dafür eine Begründung; das ist auf die Modalpartikel auch zurückzuführen (vgl. (4a)).

In der Kombination mit $j a$ wird der dargestellte Sachverhalt als bekannt markiert (〈BEKANNT>a) (vgl. (4b)); zusätzlich bewirkt ja aber auch eine Bestätigung der eigenen Aussage. Mit ja auch wird allerdings kein Vorwurf verbunden wie mit doct auch, durch dessen Gebrauch die Sprecherin gleichzeitig (aufgrund der Korrektur anweisung, die doch ausdrückt) der Partnerin zu verstehen gibt, daß sie den ${ }^{n-}$ geführten Tatbestand eigentlich hätte berücksichtigen müssen.

Am deutlichsten Kritik bringt die Außerung mit eben auch zum Ausdruck: hier wird die Vorgängeräußerung dadurch disqualipiziert, daß der von der Mutter darge stellte Sachverhalt als auch für die Gesprächspartnerin evident gekennzelchnet wird (Merkmal 〈EVIDENT>a Pür eben); die Kombination müßte umschrieben werden mit: 'es ist auch für dich offensichtlich (bzw. sollte sein), daß das für die kinder zu viel war und daraus hättest du folgern können, daß die Kinder sich unmöglict benehmen würden; damit sind deine Außerung und das darin implizierte staun ${ }^{\text {n }}$ überflüssig'. Vielleicht ist diese starke Kritik am Vorgängerbeitrag auch der Grund, warum eben auch nicht so häufig belegt ist. (Die Außerung mit eben a $^{\text {ch }^{\text {th }}}$ wäre m.E. auch passender gegenüber dem Vater der Kinder.)

Die Partikel einfach dagegen, die zwar wie eben auch Evidenz signalisiert, aber ${ }^{\circ}$ im Unterschied $\mathrm{zu}$ eben - nur bezogen aup den Sprecher (Merkmal (EVIDENT)s). kann genau deshalb diese Disqualifizierung nicht anzeigen; die sprecherin ${ }^{88^{8}}$ damit nur aus, daß der Sachverhalt für sie offensichtlich und die naheliegendste Erklärung für den im Vorgängerbeitrag geäußerten Sachverhalt darstellt. $\mathrm{Auc}^{\mathrm{h}}{ }^{\mathrm{n}}$ der Kombination wird also der Unterschied $z$ wischen eben und einfach deutlich. Bel der Kombination wohl auch schließlich schränkt die Sprecherin ihre eigene ${ }^{\mathbb{E r}^{\prime}}$ klärung für das Verhalten der Kinder ein, d.h. sie stellt es als nicht ganz $\mathrm{g}^{\mathrm{es}^{\mathrm{j}^{\prime}}}$ 
thert hin, ob ihre Außerung die zutreffende Erklärung ist. Damit läßt sle der Ge'prächspartnerin mehr Möglichkeit, elgene Erklärungen für das Verhalten der KinJer anzugeben.

Der vorangegangene Vergleich bestimmter Modalpartikel-Kombinationen hat gezeigt, $d_{a \beta}$ sich auch in den Kombinationen immer die Einzelbedeutung der Modalpartikeln nachweisen läßt, daß also eine Modalpartikel-Kombination durchaus als Addition iveler Bedeutungen zu sehen ist.

6. auch schon

Dle Verbindung von auch und schon ist in Aussagesatzen nicht möglich: beide Partikeln beziehen sich nämlich in einer sich widersprechenden Weise auf die VorBăngeräußerung: auch liefert eine Erklärung oder Begründung für den vorangeganBenen Beitrag und bestätigt inn demit, schon dagegen schrănkt den vorangegangenen Beitrag in seiner Gültigkeit ein, und der Sprecher liefert gleichzeitig eine BeBrindung für dlese Einschränkung.

In den

Pragen -Pragesătzen dagegen, die mit beiden Modalpartikeln als rhetorische kombi $\mathrm{zu}$ interpretieren sind, sind sie auch kombinierbar. Allerdings war diese ait (8) in meinem Korpus nur einmal belegt (vgl. (10)); zusätzlich wurde sie (8) und (9) getestet, und beide Beispiele wurden von fast $90 \%$ der Testper${ }^{8}$ hen akzeptiert. (Daß die Kombination selten ist, liegt auch daran, daß auch vor A in warum-Fragen auftritt, schon dagegen eher in Fragen mit anderen $w-$ (8) drucken.)

In dem Restaurant da drüben hat sich Susan ihre Muschelvergiftung geholt.

(9) Aber wer geht auch schon in so'ne üble Spelunke zum Muscheln-Essen?

Die Tante, die die neue Wohnung der Nichte besichtigt: "Also, die Farben von den Vorhängen und dem Teppich sind viel zu grell; außerdem passen sie ja gar nicht zusammen." Die Nichte denkt sich: "Ich hab mir ja gedacht.

(10) daß sie meckern würde. Was kann man der guch schon recht machen!"

Was heißt auch schon die sozigldemokratische Behauptung: "Wer Kohl wählt, In den rekommt automatisch Raketen"? (ZEIT; von Meibauer 1986:190)

Pell mit ablelt schon in rhetorischen Fragen meist nur eine aus der Vorgängeräußerung beltpare Folgerung zurückgewiesen wird und umgekehrt mit auch der VorgängerVermutlich als erwartet markiert, aber nicht unbedingt bestătigt wird.

"el] [lich werden die beiden Partikeln jedoch auch deshalb selten kombiniert, leistet beider Funktion vor allem darin besteht, Rhetorizität anzuzeigen; das aber bereits elne der beiden Partikeln. 


\section{6. denn auch}

Die ziemlich häufige Kombination denn auch läßt sich in beiden Arten von Fragesätzen und in Aussagesätzen nachweisen. In den Aussagesătzen ist denn - we schon erwähnt - nur innerhalb einer Kombination möglich (s. dazu auch denn doct S.222).

In Neapel gab es zu dieser Zeit keinen Gegenstand, für den man nicht ver" wendung gehabt hätte. So blieb denn auch von der 'Victory' nicht eine Niete übrig. (Si, 412)

Und wiederum meinte Rahel, es sei nicht gut, was Margret da treibe, gar nicht gut und werde ein böses Ende nehmen. Margrets Bleiben im Pensiona währte denn auch nicht lange; es kam alles heraus. (Bö c, 47) denn auch Wasser auf die Mühlen jener Politiker, für die das Wort}

Beispiele florierender Groß-und Kleinbetriebe türkischer Gastarbeiter sind "Rückkehrförderung" die Zauberformel ist. (SZ)

Die Modalpartikel denn in Fragen wurde mit dem Merkmal (KONNEX) und (fakulta" tiv) 〈UNERWARTET>v beschrieben. Letzteres widerspricht aber dem für auch angé nommenen Merkmal 〈ERWARTET〉v. Tatsächlich hat denn in Aussagesätzen schon bei denn doch angedeutet - nur die Funktion, den Bezug zum vorangegan" genen Beitrag zu verdeutlichen, trägt also nur das Merkmal 〈KONNEX〉. Beispiel (14), in dem dann neben denn auftritt, ist ein Hinweis darauf, daß $e^{5}$ sich bei denn in denn auch nicht unbedingt um die 'regionale' variante von dgn' handelt, sondern von diesem unterschieden werden muß - obwohl sich allerdin gewisse Gemeinsamkeiten in der Bedeutung feststellen lassen.

(14) In einer gewittrigen Nacht wechselten sie (die Waffen) in den Wäldern né ben der Landstraße, die von Belac nach Mortemart führt, dann denn auch die Besitzer. (Si, 301)

In den Fragesätzen läßt sich die Kombination denn auch sowohl in den Ents chei $^{i^{-}}$ dungsfragesätzen als auch in den w-Fragesätzen nachweisen:

W-Fragesătze mit der Kombination denn auch sind immer rhetorische Fragen auf auch zurückzuführen ist); vgl.:

(15) Und wozu stünden denn auch die Worte da, wenn nicht, um einen Sinn auszudrücken? (R.Musil; übernommen von Meibauer 1986:184) Hans: Hör mal, da steht, daß der Stadtteil $x y$ in München die höchste $k^{r^{i}}$
minalitätsrate hat. minalitätsrate hat.
Ruth: Das wundert mich nicht. Was sind das denn auch für Leute, die dort
wohnen?

Auch hier kann das Merkmal 〈UNERWARTET>v, das für denn in w-Fragesätzen $2 \nu^{\prime}$ mindest in manchen Verwendungen angenommen werden kann, nicht mehr $n a c^{h b^{e^{\prime}}}$ wiesen werden, da der Sprecher durch den Gebrauch von auch (Merkmal $\angle E^{R^{A}}$ $T E T>v$ ) eindeutig anzeigt, daß er den im vorangegangenen Beitrag dargeste 
Sachverhalt erwartet hat; demnach kann der Anlaß für die Frage nicht mehr unerWartet sein. Vgl. (16): Auch die Außerung Ruths 'das wundert mich nicht' ist ein Indiz dafür, daß der Sachverhalt ihren Erwartungen entspricht. Da in diesem Kontext denn alleine auch kaum möglich wäre (vgl. (16a)), deutet dies darauf hin, daß in der Kombination denn auch in $w$-Fragesätzen für denn immer nur eine Bedeutung angenommen werden kann, die darin besteht, eine Verbindung zur VorgänBeräußerung zu markieren ( $\langle K O N N E X\rangle)$, ohne daß dies in irgendeiner Form spezifiliert wäre.

(16a) (wie oben.)

Das wundert mich nicht. ?"Was sind das denn für leute, die dort wohnen?

Die Außerung (16a) wäre nur in einem Kontext wie (16b) möglich; dann allerdings

handelte es sich um eine echte Informationsfrage:

(16b) Hans: Hör mal, da steht, daß der Stadtteil xy in München die höchste Kriminalitätsrate hat.

Ruth: So? Was sind das denn für Leute, die da wohnen?

24 den Entscheidungsfragesătzen mit denn auch:

(17) Ein Kind kommt im Winter in einen Laden.

Kind: Geben Sie mir bitte ein Kilo Erdbeeren.

(18) Besitzer: Kannst du denn auch bezahlen?

Wir können jetzt losfahren. Haben wir denn auch genügend Geld dabei?

(19) Ich kann die Photos einfach nicht finden. Bist du denn auch ganz sicher, daß du sie aufgehoben hast?

(20) Vor dem Austeilen der Geschenke: Warst du denn auch brav?

in den Entscheidungsfragesätzen sind zwar die Merkmale von denn und auch inso-

Pern nicht unvereinbar, als sich ja 〈ERWARTET> von auch in diesen Fragen auf den in der Frage dargestellten Sachverhalt bezieht - und 〈UNERWARTET>v von $d^{e_{n}}$ aup die Vorgängeräußerung. Dennoch ist das Merkmal 〈UNERWARTET>v in deser Kombination nicht immer ausgeprägt. Der Anlaß für die Frage kann uner-artet sein (wie in (17)) - dann bringt auch eine denn auch-Frage Erstaunen Uum Ausdruck; meist aber ist dies nicht der Fall (vgl. (18)-(20)). Das liegt daran, ${ }^{d a \beta}$ - wie bereits beschrieben - das Zutreffen des in einer auch-Frage darge${ }^{8}{ }^{8}$ ll ten Sachverhalts Voraussetzung für eine weitere schon zur Diskussion stehende Handlung ist. Insofern aber ist der Anlaß für die Frage selten für den Sprecher "nerwartet.

A uf grund der Bedeutung von such welsen Fragen mit der Kombination denn auch

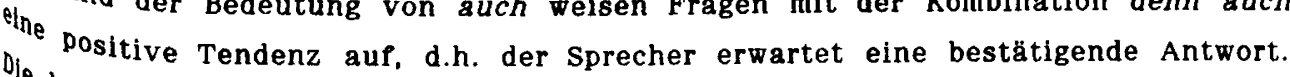
De belden Partikeln lassen sich auch deshalb kombinieren, weil denn hinsichtlich dep Antworterwartung neutral ist; die Kombination von auch und etwa dagegen ist "licht möglich, da sich ihre Anworterwartungen ausschließen. 
Dle Kombination von denn und auch hat also gezeigt, daß die für denn angenommene Funktion, zu markieren, daß eine vorangegangene Außerung oder Handlung für den Sprecher unerwartet ist, sich in dieser Kombination nicht nachweisen läpt. Man kann nun entweder annehmen, daß denn in dieser Kombination nur einen Tell seiner Bedeutung (Merkmal (KONNEX〉) einbringt und daß es sich in diesem Fall also nicht um reine Addition zweier Modalpartikel-Bedeutungen handelt. Oder $m^{2 n}$ müßte aufgrund dieser Ergebnisse die Beschreibung von denn überdenken. oben (Kap. 2.2.11) wurde ja schon gezeigt, daß denn in $w$-Fragen ein Frageanzeiger ist. Das Verhalten von denn in den Kombinationen (auch in den Entscheidungsfragen). in denen es nur das Merkmal 〈KONNEX〉 aufweist und damit eine relativ unspez ${ }^{-}$ fische Bedeutung hat, könnte darauf hinweisen, daß denn auch in Entscheidungs Pragen ein Frageanzeiger wird bzw. ist. ${ }^{18}$ Tatsächlich ist denn allein in den oben angeführten Außerungen vom Typ (18)-(20) zwar nicht gerade gebräuchlich, abet auch nicht ausgeschlossen. Das hieße aber, daß auch in Entscheidungsfragen das Merkmal 〈UNERWARTET>v for denn nicht immer angenommen werden kann. Aller dings zeigen Fragen wie (18)-(20) mit der Modalpartikel denn alleine eher staunen als mit denn auch.

\section{7. such blok und auch nur}

Die Kombination von auch und bloß/nur könnte in w-Fragesätzen und in $W-E x^{k a^{2}}$ mativsätzen auftreten. ${ }^{19}$

In - -Fragesătzen ist sie deshalb nicht möglich, weil hier die Funktion von $u^{u c^{\text {h }}}$. Rhetorizität anzuzeigen, mit der von bloß/nur, echte dringliche Fragen anzuzeigen. kollidiert; vgl.:

(21a) Warum hast du mich nur bestohlen?

(echte Frage, Sprecher möchte die Antwort wissen)

(21b) Warum hast du mich auch bestohlen?

(= 'es gab keinen Grund, mich zu bestehlen'; rhetorische Frage)

(21c) "Warum hast du mich auch nur bestohlen?

In w-Exklamativsătzen dagegen sind die Kombinationen auch blo $\beta$ und auch nut möglich; hier kommt zu der Bedeutung von auch die Verstärkung durch blo und $^{\text {d }}$ nur hinzu; vgl.:

(22) Eva: Du, heut ist bei Peters Auto die Handbremse eingefroren! Eva: Du, heut ist bei Peters Auto die Handbremse eingefroren!
Inge: Wie kann man auch bloß so blöd sein und im Winter die Handbremse
anziehen?!

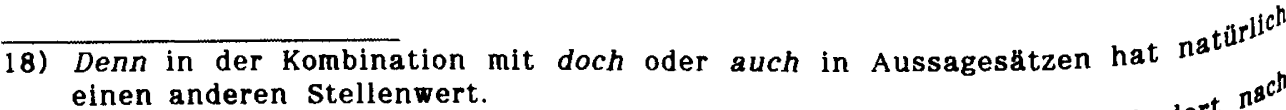
19) In Imperativsätzen tritt auch ohnehin recht selten auf und wird dort ${ }^{{ }^{8} c^{\text {h }}}$
meinen Beobachtungen nur mit JA kombiniert. 
(23) Tochter: Stell dir vor, der Charly hat mich bei diesen Börsenspekulationen schlichtweg betrogen.

Mutter: Wie konntest du auch nur diesem Halunken vertrauen?!

8. auch mal

(24) Eltern vor der Abreise: Und hilf der Großmutter auch mal!

Eine derartige Aufforderung kann z.B. dann geäußert werden, wenn die Eltern eine Reihe von Ermahnungen geben. In dieser Kombination ist mal allerdings eher als Temporaladverb zu interpretieren.

3.2.1.4 Kombinationen mit denn

$D_{a}$ denn eine relativ unspezifische Bedeutung hat, läßt es sich in Fragesätzen mit allen dort ebenfalls auftretenden Modalpartikeln kombinieren.20

In Aussagesätzen tritt denn ${ }^{21}$ nur in Kombination mit (ja) doch, auch und wohl auf; die ersten beiden Kombinationen wurden schon beschrieben - dabei wurde lestgestellt, daß sich das für denn in Fragen (fakultativ) angenommene Merkmal UUERWARTET>v nicht nachweisen läßt.

1. denn schon

Dle Kombination dieser zwei Modalpartikeln ist nur in w-Fragesätzen möglich, die inmer als rhetorische Fragen $\mathrm{zu}$ verstehen sind, da schon ein Indikator Pür thetorische Fragen ist; die Kombination denn schon ist eine Prequente Kombination.

(1) "Schlafen Sie auch 'ohne'?" "Wer schläft denn schon 'mit'?" (Ke, 219)

(2) Ich habe mich natürlich gefragt, was das für ne Frau ist, so schick immer und mit so nem schicken Auto; Frau oder Freundin von nem Parteibonzen hab ich gedacht - wer hat denn damals schon ein eigenes Auto fahren können -, Partei oder Industrie. (Bö c, 124)

(3)

Ein Versicherungsvertreter schlägt dem Kunden vor, für sein Auto eine Teilkasko-Versicherung abzuschließen. Der Vertreter: "Die kommt dann auch für Haarwildschäden auf."

Der Kunde: Aber Herr Bauer, wie oft hat man denn schon einen

(4) Zusammenstoß mit Haarwild?

Im Museum sprechen der Direktor und ein Angestellter über die Versiche-

rung eines modernen Kunstwerkes. Da sagt der Angestellte: "Wer klaut denn schon moderne Kunst?"

20) Die Kombination mit elnfach in den Entscheidungsfragesätzen wird weiter

21) unten in 3.2.1.7 beschrieben.

Aup die unklare Zuordnung von denn in Aussagesätzen wurde oben (S.222) bereits hingewiesen. 
(5) Ein Regierungschef antwortet auf die Frage, ob er wegen der Computer nicht Angst vor einer 'anonymen Maschinenbürokratie' hat: Ja, was wird denn schon in den Computern gespeichert? (Spiegel)

Die Funktion von schon entspricht in diesen Kombinationen der oben bereits beschriebenen: durch den Gebrauch von schon schränkt der Sprecher die Geltunb eines Aspekts der Vorgängeräußerung ein. Vgl. z.B. (3): der Versicherungsvertreter stellt es als ein besonders positives Kriterium seiner Versicherung heraus, daß sie auch bei Haarwildschäden aufkommt; dieses Argument bzw. die daraus ableitbare Folgerung ('man sollte die Versicherung abschließen') schränkt der Kunde mit dem Hinweis auf die Häufigkeit (bzw. Seltenheit) derartiger Zusammenstöße ein. Das Merkmal 〈UNERWARTET>v von denn läßt sich auch hier (wie in w-Fragen mit denn allein) nur teilweise nachweisen (z.B. in (1)).

\section{2. denn wohl}

Diese Kombination tritt auf in Aussagesätzen, Entscheidungsfragesätzen und Fragesätzen.

In den Aussagesătzen kann für denn - wie immer beim Auftreten in der Kombination in Aussagesätzen - nur die Funktion eines Anknüpfens an den vorangegangenen Beitrag (Merkmal (KONNEX〉) nachgewiesen werden; durch wohl wird die Behauptung eingeschränkt.22

(6) Gesiegt haben andere: Die bisher völlig unbekannte Italienerin (...)wurde überlegen Olympiasiegerin. Das ist denn wohl der vorläufige Höhepunkt der Misere des Deutschen Skiverbandes in dieser Disziplin. (SZ)

In den negativ konnotierten emphatischen Aussagen vom Typ (7) ist die Kom bination nicht möglich; vgl. (7a):

(7) Du spinnst wohl!

(7a) 'Du spinnst denn wohl!

In den w-Fragesătzen trägt denn in der Kombination denn wohl wieder lediglich das Merkmal 〈KONNEX〉; 〈UNERWARTET〉 kann nicht nachgewiesen werden. Da $\beth^{4}$ kommt die Funktion von wohl, anzuzeigen, daß eher nach Vermutungen un weniger nach dem wissen des Gesprächspartners gefragt wird und daß der Sprechef die Frage auch an sich selbst richtet.

(8) Wir kamen auch noch an einem andern, ovalen Porzellanschild vorbei, darauf stand: "Frau Emma Maierhöfer, Hebamme!" Was war denn wohl $e^{\text {ine }}$ Hebamme? (Brigitte)

Die Mutter, deren Kind zum ersten Mal im Urlaub ist, sagt zu ihrem Mann. Wie mags denn wohl der Elke gehen?

22) Im Aussagesatz ist allerdings für beide Partikeln nicht eindeutig entscheiden, ob sie in Modalpartikel-Funktion vorliegen. 
In den Entscheidungsfragesătzen tritt die Kombination denn wohl ebenfalls auf, und auch hier kann für denn lediglich das Merkmal 〈KONNEX〉 nachgewiesen Perden.

(10) Ich glaube, ich schaffs alleine nicht mit der Arbeit. Könnte deine Schwester mir denn wohl helfen, die Arbeit zu tippen?

(1) Könntest du mir denn wohl helfen, die Arbeit zu tippen?

Derartige Außerungen sind immer - und das ist auf denn zurückzuführen - als (echte) Fragen zu interpretieren (im Unterschied zu denselben Außerungen mit "ohl alleine, die teilweise als Aufforderungen zu beschreiben sind). Daß bei einer

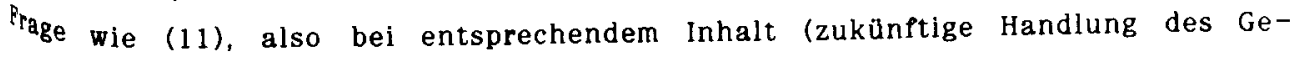
sprächspartners betreffend) und entsprechender Form (Modalverben, Konjunktiv), ler Sprecher durch die Beantwortung der Frage mit ja auch die Verpplichtung zu iner Handlung übernimmt, ändert nichts daran, daß es sich um Fragen handelt (vgl. auch (10)).

In den Verb-Erst-Aufforderungen mit starkem Akzent auf dem finiten Verb und 'allendem Tonmuster ist denn alleine nicht zulässig und folglich auch nicht die Kombination denn wohl:

(12) WIRST du wohl still sein!

(12a) "WIRST du denn wohl still sein!

3. denn etwa und denn vielleicht

Diese beiden Kombinationen treten nur in Entscheidungsfragesätzen auf, die echte Pagen oder auch rhetorische Fragen sein können:

(13) Diesen ganzen Wust von Daten! Willst du das denn etwa analysieren?

(4) ja, unter den Blicken, die ihn in seiner Verlassenheit musterten, ward er sichtlich verlegen. Man machte einander darauf aufmerksam - und sogar Diederich fragte sich, ob Frau Heßlings alte Skandalgeschichte denn etwa gar wahr sei? (Ma, 215)

...verteufelt sie vielleicht generell das Auto? "Nein, ich würde nie darauf verzichten." Ja, bildet sie sich denn etwa tatsächlich ein, sie könnte mit ihrem neuen Katalysator-Auto den Wald retten? (ADAC motorwelt)

Die Tochter kommt mit blauen Haaren nach Hause. Die Mutter: Findest du das denn vielleicht schön?

Und war denn Herr Gruyten, der Vater dieser merkwürdig sprachlosen Frau und spätere Geliebte dieser frechen rosa Halbnutte, war der denn etwa ein Gotteslamm in Kriegszeiten? (Bö c, 282)

$\mathrm{O}_{\mathrm{a}}$ denn und etwa in ihrer Bedeutung zum Teil ähnlich sind (beide tragen die "erkmale (KONNEX〉 und (UNERWARTET>v), läßt sich auch ihre Kombination leicht Prklăren: Mit beiden knüpft der Sprecher an eine vorangegangene sprachliche oder 
nicht-sprachliche Handlung an und zeigt, daß diese, der Anlaß für die Frage, für inn unerwartet ist.

Der Unterschied zwischen denn und etwa besteht lediglich hinsichtlich der Tendenz - deshalb trägt etwa zusätzlich das Merkmal 〈UNERWUNSCHT〉s. Bei positiven etwa-Fragen wird nein als Antwort erwartet bzw. erhofft, die Gültigkeit des dargestellten Sachverhalts wird als unerwünscht gekennzeichnet; denn-Fragen hingegen sind hinsichtlich der erwarteten bzw. präferierten Antwort neutral. Deshalb können die beiden Modalpartikeln durchaus kombiniert werden. Die Kombination denn etwa entspricht also ungefähr dem Gebrauch von etwa allein, allerdings scheinen mir die Fragen mit denn etwa mehr das Anknüpfen an den Vorgänger und die Uberraschung und weniger die negative Tendenz auszudrücken und deshalb etwas abgeschwächter; vgl.:

(17a) War der denn etwa ein Gotteslamm in Kriegszeiten? War der etwa ein Gotteslamm in Kriegszeiten?

Die Kombination denn vielleicht, die wesentlich seltener auftritt als denn etw hat eine mit denn etwa vergleichbare Bedeutung, da sich etwa und vielleicht in Fragesätzen ja sehr ähnlich sind (s.o. S.195); denn etwa ist aber die stärkere Variante (wie auch die Modalpartikel etwa allein stärker zu sein scheint als vielleicht).

\section{4. denn eigentlich}

Die Kombination denn eigentlich ist relativ häufig; sie kann in $w$-Fragesätzen und in Entscheidungsfragesätzen auftreten, findet sich aber meist in w-Fragesätzen.

(18) Sie verstehen eben nicht! Sie halten mich für eine kalte Ziege, die zwej liebende Herzen auseinanderreißen will! Sagen Sie mal - in welchem Jahrhundert leben wir denn eigentlich? (Bi, 208)

(19) Ja, und . das ging ja ziemlich plötzlich mit der Verlobung, ne. Dann is ef auch ein paarmal gefragt worden, em. "hör mal, wieso verlobst du dich denn eigentlich so schnell?" (BA, 40)

(20) Nun ist deutlich zu spüren, daß der bis hierhin mehr oder weniger geduldige Leser ungeduldig wird und sich die Frage stellt: verflucht, ist diese Leni etwa vollkommen? Antwort: fast. Andere Leser - je nach ideologische Ausgangsbasis - werden die Frage anders stellen: verflucht, was ist diese Leni denn eigentlich für ein Ferkel? Antwort: sie ist keins. (Bö c, 50)

Wie oben dargestellt, unterscheiden sich die beiden Modalpartikeln denn und eigentlich vor allem in ihrer Funktion, die Frage in den Gesprächszusammenhanb zu binden: Während denn anzeigt, daß die Außerung direkt an eine Vorgänger äußerung bzw. -handlung anknüpft (Merkmal 〈KONNEX〉), signalisiert eigentlich gerade einen thematischen Ubergang, genauer: einen Themenwechsel oder Aspekt' 
'echsel (d.i. der Ubergang zu einem neuen 'Unterthema' Innerhalb eines übergreitenden Rahmenthemas), was oben mit dem Merkmal 〈UBERGANG〉 beschrieben wurde. is läßt sich zeigen, daß bei der Kombination denn eigentlich nur eine Teilmenge der Verwendungen von denn mit elner Tellmenge der Verwendungen von eigentlich kombiniert werden kann.

Das folgende Beispiel zeigt einen Themenwechsel, der durch eine Frage mit eigent-

I'ch eingeleitet ist; hier ist die Kombination denn eigentlich nicht möglich:

Mona: ...ich hab dem Schulkollegium ein Photo von mir geschickt, das war das letzte, was ich auftreiben konnte (..) ja, da sah ich also wie so ne Hexe aus, so unheimlich giftig guck ich da rein, naja. Elke: Wie is es eigentlich, wenn man son Seminar mal doppelt belegt hat? (21a) (BA, 14)

(wie oben) "Wle is es denn eigentlich, wenn man...

$D_{i}$ Außerung (21a) wäre nur möglich, wenn das Thema bereits besprochen worden are.

"hn allerdings durch die eigentlich-Frage nur ein Aspektwechsel angezeigt wird,

knn auch die Kombination denn eigentlich verwendet werden:

$(2)$

Nelli und Bea sprechen über die Referendarzeit.

Bea: Am Anfang wirds sicherlich gemütlich, ne?

Nelli: Ach so, ja. Oder. jaja man hat nich allzuviel zu tun. Hör mal, weißt du eigentlich, wie weit das mit dieser Neuregelung der Referendarbezüge is?

$\left(2_{2}\right)(\mathrm{BA}, 60)$

Hör mal, weißt du denn elgentlich, wie weit..

Ugentlich kann also nur mit denn kombiniert werden, wenn es lediglich einen ${ }^{A}$ pektwechsel anzeigt. In diesem Fall signalisiert denn die Verbindung zum RahMenthema, eigentlich zeigt den Wechsel zu einem anderen Aspekt an. Auf diese Pise erklärt sich auch die Reihenfolge der beiden Partikeln in der Kombination: le Verbindung zu einem Rahmenthema muß vor dem Obergang signalisiert werden. Vl. auch (23): Hier bleibt die Sprecherin mit ihrer Frage im thematischen Rahmen 'Musikalische Betätigung'), führt aber einen neuen Aspekt des Themas ein.

(2) "...Musizieren Sie noch mit ihr?" "Manchmal," entgegnete Georg kühl.

"Vielleicht bitt ich sie, vom neuen Jahr an wieder mit mir zu korrepetieren. Ich weiß nicht, wieso es bis jetzt nicht dazu gekommen ist." Georg schwieg. "Und wie steht es denn eigentlich (...) mit eurer Oper?"

(A. Schnitzler, Der Weg ins Freie, Frankfurt 1978:115)

seinerseits kann genau dann in der Kombination denn eigentlich auftreten, es nur ganz allgemein eine Verbindung markiert, wenn also die Funktion von Nh, an einen für den Sprecher unerwarteten Anlaß anzuknüpfen und auf diese "ilse Uberraschung auszudrücken (Merkmal (UNERWARTET>v), nicht ausgeprägt ist. Adernfalls wäre ja ein thematischer Ubergang, wie ihn eigentlich markiert, nicht ${ }^{A}$ gllch; zudem kollidierte durch denn angezeigtes Erstaunen damit, daß bei "gentlich-Fragen zum Ausdruck kommt, daß sie auf einem Denkprozeß des 
Sprechers beruhen, daß die Frage den Sprecher also schon länger beschäftigt (in (23) z.B. ist das auch aus dem Vortext bereits ersichtlich).

Nun ist ja das Merkmal 〈UNERWARTET>v in w-Fragesätzen - wie schon mehrfach erwähnt - nur Pakultativ. Tatsächlich kann denn eigentlich nur in denn-Fragen auftreten, die kein deutliches Erstaunen des Sprechers anzeigen; in den anderen ist die Kombination nicht zulässig; vgl. (24):

(24) Lisa: Auch wenn ich bei meinem Onkel aufm Dorf bin, ne. Da in der Kneipe: "Ja Lisa, wie is das denn? Wann könn wer denn unsere Sonntagsschuhe anziehen?" - "Ja", sagich, "wieso das denn? Ich hoffe, die zieht ihr jeden Sonntag an!" "ja, wills du denn nich ma bald heiraten?" - Nee, wieso das denn?" "Ja, das macht man doch so!" (BA, 41)

(24a) Wie is das denn eigentlich?

Wann könn wer denn eigentlich unsere Schuhe anziehen?

Wieso das denn eigentlich?

Ja, wills du denn "elgentlich nich bald heiraten?

Nee, wieso das denn "eigentlich?

Auch in den Entscheidungsfragen kann denn eigentlich nicht auftreten, wenn die Frage deutlich Uberraschung zum Ausdruck bringen soll:

(25) Sohn: Kannst du mir einen Taschengeld-Vorschuß geben?

Mutter: Bist du denn schon wieder pleite?

(25a) "Bist du denn eigentlich schon wieder pleite?

Nun wurde aber das Merkmal 〈UNERWARTET>v für denn in Entscheidungsfragen fǘt alle Verwendungen angesetzt - das macht die Kombination mit eigentlich proble matisch. Interessanterweise sind die belegten Vorkommen von denn eigentlich aus ${ }^{5}$ schließlich Verwendungen in w-Fragesätzen; allerdings ist die Kombination den eigentlich in Entscheidungsfragen sicherlich nicht ausgeschlossen: vgl. (26) und (27), ein verändertes Beispiel aus dem Korpus von Brons-Albert:

(26) Ich muß Ihnen schon wieder einen Verweis geben. Ihr Mathematiklehrer hst $^{\mathrm{t}}$ sich beschwert. Haben Sie denn eigentlich noch nie darüber nachgedacht, $d a \beta$ Sie mit Ihrem Verhalten letztlich nur sich selbst schaden?

(27) Uli: Ist die Hiltrud da?

Caro: Nee, die is nich da, die is im Moment, ich glaub in Hilden oder so. bei ihrem Freund. Die wird also in den nächsten 2,3 Wochen kaum hier auftauchen.

Uli: Ah so! Hat denn elgentlich der Freund bestanden?

Wie schon bei denn auch (s.o. S.232ff.) dargelegt, muß man entweder davon ausger hen, daß denn in Kombinationen nur eine Teilbedeutung (Merkmal 〈KONNEX〉) $e^{\text {in }^{-}}$ bringt, oder man muß die Beschreibung für denn - genauer: das Merkmal $\langle\text { UNERWARTET }\rangle_{v}$ in den Entscheidungsfragen - revidieren.

Um es noch einmal zusammenzufassen: Die Kombination denn eigentlich hat die Funktion, eine Verbindung zu einem übergreifenden thematischen Rahmen $\mathrm{zu}^{\mathrm{ar}} \mathrm{r}^{-}$ kieren U. gleichzitig inuerhalb dieses Rahmens einen themat schen toergourg antutigh 
kieren und gleichzeitig innerhalb dieses Rahmens einen thematischen Ubergang anzureigen.

5. denn bloß und denn nur

Diese beiden ziemlich häufigen Kombinationen treten nur in w-Fragesätzen auf.

Zur Bedeutung von denn in $w$-Fragesätzen kommt hier noch hinzu, daß durch blo $\beta$

bw. nur der Akt des Fragens verstärkt wird; vgl.:

(28) Ich wollte seiner Hand ausweichen, aber er schlug gleich zweimal zu. "Was ist denn bloß mit dir?" ( $\mathrm{Bi}, 230)$

(29) Mit 40 noch ein Kind und keinen Vater! Was sollen denn bloß die Leute von dir denken! (Hör zu)

(30) Die Tochter von einem stellvertretenden Generalstaatsanwalt ist vor drei Wochen nach dem Westen abgehaun mit einem falschen $P a \beta$ - sollen wir den Mann vielleicht deswegen rausschmeißen? Wer hat dir denn bloß solche

(31) Flausen in den KopP gesetzt? (Bi, 95)

1) Was nun folgt, könnte die Uberschrift tragen: Leni begeht eine Dummheit, Leni verläßt den Pfad der Tugend - oder: Was ist denn nur mit Leni los?

(Bö c, 100)

(32) Also weißt du! Meine schöne weiße Bluse mit blauen Socken zusammen in die Waschmaschine zu tun! Was hast du dir denn nur dabei gedacht?

(33) Die Mutter: Zechine, ich glaube, das dicke Monstrum da mit seinen Hinkelsteinen hat eine Schwäche für dich...du solltest mal mit ihm reden." Zechine: Reden mit dem, der Obelix heißt? Weshalb denn nur? (A XXI, 24)

- Fragesätze mit der Kombination denn bloß bzw. denn nur sind als echte Fragen 24 bezeichnen. Sie können auch ein gewisses Erstaunen oder Verwunderung ausdricken, was auf die Bedeutung von denn zurückzuführen ist; vgl. (32): der Anlaß tîp die Frage, der vorher geschildert wird, war für den Sprecher unerwartet, in diesem Fall auch unangenehm - deshalb drückt die Frage auch einen leichten Vorwurp aus.

AuBerungen wie (32) oder auch (34) sind als Fragen zu bezeichnen und nicht als Rlamative oder rhetorische Fragen, der Hörer ist nämlich durchaus zu einer Antwort verplichtet. (34)

Wie kann man denn nur einen Salat für 5 Mark kaufen?

(34) drückt der Sprecher zwar Verwunderung aus (und zeigt möglicherweise ach an, daß er sich kaum eine plausible Antwort vorstellen kann), möchte aber Gliche Gründe wissen; die Außerung ist also eine Frage.

denn nicht

Oie Modalpartikel denn kann mit dem hier ebenfalls zu den Modalpartikeln gerech"eten nicht in Entscheidungsfragesätzen zusammen auftreten. 
(35) Tim: Naja, ich mein, solang sie [die Kinder] immer wieder von selbst nachhause kommen, gehts doch noch.

Doris: Naja, bloß Mensch, also nee, ich weiß nich, die fangen son richtiges Landstreicherleben an!

Tim: Ja, erzählen die denn nicht hinterher, wo sie gewesen sind? (BA,113)

(36) Heinz: Ich hab hier ganz gute Verbindungen. ich fahr zum Bahnhof und vol Bahnhof mit dem Flugzeug . mit dem Flughafenbus, der fährt/

Anna: Is das denn nich sehr lästig?

Heinz: Bitte?

Anna: Ist denn das nich lästig? (BA, 1)

Den beiden Partikeln wurden oben die Merkmale 〈UNERWARTET>v bzw. 〈ERWARTET) zugeschrieben. Kombinierbar sind sie aber deshalb, weil sich 〈UNERWARTET>v von denn auf den Anlaß für die Frage bezieht (also den vorangegangenen Beitrag). 〈ERWARTET> von nicht dagegen auf den Inhalt der Frage: die Gültigkeit des dar gestellten Sachverhalts wird erwartet.

In der Kombination denn nicht wird also durch nicht eine deutliche Antworterwartung zum Ausdruck gebracht, der Sprecher erwartet Bestätigung; deshalb ist nicht mit dem in dieser Hinsicht neutralen denn kombinierbar (dagegen z.B. nicht $\mathrm{m}^{\mathrm{il}}$ etwa).

Die Kombination denn nicht in (36) ist folgendermaßen zu beschreiben: der our Anna unerwartete Anlaß für thre Frage ist, daß Heinz bel dieser Reise entgegen seinen sonstigen Gewohnheiten mit dem Flughafenbus zum Flughafen fahren will. wobei Anna mit ihrer Frage impliziert, daß 'das lästig ist', d.h. sie erwartet gul inre Frage ein $j a$.

Aufgrund der deutlichen Antwortpräferenz in diesen Außerungen werden sie hauplib zu rhetorischen Fragen; vgl.:

(37) Unser Sohn beim Ladendiebstahl erwischt! Wie konnte er uns das antun! Haben wir ihm denn nicht alles gegeben?

Die rhetorischen Fragen mit denn nicht können funktional parallelisiert werden mit Behauptungen, die doch enthalten; vgl.:

(38) Wir haben ihm doch alles gegeben.

Die Bedeutung der Kombination denn nicht soll die folgende Gegenüberstellung noch einmal zeigen:

(37a) Haben wir ihm denn nicht alles gegeben?

(37b) Haben wir ihm denn alles gegeben?

(37c) Haben wir ihm nicht alles gegeben?

Die Kombination denn nicht (37a) tritt (wie oben ersichtlich) in einem Konte ${ }^{x^{t}}$ auf, in dem ein bestimmtes unerwartetes Ereignis - in diesem Fall die Tatsache. daß der Sohn gestohlen hat - der Auslöser für die Außerung ist; dies wird dur th $^{\text {h }}$ die Verwendung von denn angezeigt. Gleichzeitig macht der Sprecher durch $n^{i c^{\text {ht }}}$ 
deutlich, daß er Bestätigung erwartet, bzw. in diesem Fall - da es sich um eine thetorische Frage handelt - den Inhalt der Frage als Behauptung ('wir haben ihm ailes gegeben') unterstellt.

Bei der Verwendung von nicht allein wie in (37b) wird ebenfalls die Bestätigungserwartung zum Ausdruck gebracht, die Außerung kann aber in einem Kontext stehen, in dem für den Sprecher kein unerwartetes Ereignis vorangegangen ist; vgl.:

(37b) Ich bin froh, daß unser Sohn diese entzückende Millionärstocher heiratet. Aber wir haben auch unseren Tell dazu getan! Haben wir Ihm nicht alles gegeben? Eine gute Erziehung...23

Die Außerung (37c) dagegen ist als echte Frage zu verstehen (bzw. nur unter sehr Markierten Kontextbedingungen als rhetorische Frage zu sehen); vgl.:

(37c) Und der Psychonalaytiker sagt, wir hätten bei der Erziehung alles richtig gemacht. Aber: haben wir ihm denn alles gegeben?

$D_{8}$ in der Kombination denn nicht eln für den Sprecher unerwarteter Anlaß vorAlugeht, er aber durch nicht ausdrückt, daß er eine Bestätigung selner Frage erPartet, muß der vorangegangene Beitrag eine deutlich erkennbare Gegenposition zu den Erwartungen des Sprechers darstellen; in diesem Fall ist das eventuell für "I/cht anzusetzende Merkmal 〈KORREKTUR〉 deutlich ausgeprägt; vgl.:

${ }^{(39)}$. Nörgel doch nicht so rum! Ist die Gegend hier denn nicht phantastisch?!

Bei Außerungen mit nicht alleine dagegen muß keine explizite Gegenposition vor"'sgehen; hier kann auch nur möglichen anderen Ansichten vorgebeugt werden:

(40) Ui, schau mal dieses Panorama! Ist das nicht herrlich?

3.2 .1 .5

Kombinationen mit bloß, nur und mal

9.2.1.5.1 Kombinationen mit blok und nur

Ole Kombinationen der beiden Modalpartikeln mit ja, doch, auch und denn wurden ben bereits besprochen; in allen Fällen ließ sich eine durch bloß und nur er'lilchte Verstärkung des Illokutiven Akts nachweisen.

1.

elgentlich blop und eigentlich nur

Tegensatz zur Kombination denn bloß bzw. denn nur in w-Fragesätzen ist die Kombination von eigentlich und bloß/nur kaum gebräuchlich; deshalb wurde sie mit den Beispielen (1) und (2) getestet, die von $80 \%$ bzw. $75 \%$ der Testpersonen als "keptabel beurteilt wurden.

2) In diesem Beisplel ist zwar die Kombination denn nicht nicht inakzeptabel, Wurde aber nur verwendet, wenn der Sprecher auf eine von seinen Ansichten abweichende Haltung reagierte. 
(1) Inge: Monika ist jetzt schon ein Jahr arbeitslos.

Eva: Das ist schon schlimm. Aber weißt du, was ich nie verstanden habe: Warum ist sie eigentlich bloß von ihrer alten Firma weggegangen?

(2) Beate ist so komisch in letzter Zeit. Was ist eigentlich nur mit ihr los? Hier wird der Akt des Fragens sowohl durch eigentlich als auch durch bloß/nut verdeutlicht. Der Grund dafür, daß die Kombination kaum gebräuchlich ist, könnte darin liegen, daß bloß/nur-Fragen ein starkes subjektives Interesse ausdrucken, auch an den Sprecher selbst gerichtet sein können und der sprecher nicht unbedingt davon ausgeht, daß der Angesprochene die Frage beantworten kann; diesel Fragetyp scheint nicht besonders verträglich mit eigentlich-Fragen, die echte Fragen sind (im Sinne von 'der Sprecher will vom Hörer wirklich wissen, ob/w...').

\section{2. wohl blok und wohl nur}

Diese Kombinationen sind nur in w-Fragesätzen möglich; da sie in meinem Korpus nicht belegt waren, wurden sie getestet; (3) wurde dabei von $55 \%$ der Testpers ${ }^{0^{-}}$ nen akzeptiert und von 25\% 'vielleicht' akzeptiert.

Vor Weihnachten: Peter ist stundenlang im Keller und hämmert. Was hat def wohl nur vor?

Die Bedeutung der Kombination läßt sich so beschreiben: Mit wohl gibt der sprecher zu verstehen, daß er nicht nach dem Wissen des Hörers fragt, das diesel nicht unbedingt haben kann, sondern nach dessen Vermutungen oder Meinungen. Durch die Verwendung von bloß und nur wird der Akt des Fragens verstärkt. Mö $b^{-}$ licherweise liegt gerade hier der Grund, warum die Kombination nicht gebräuchlich und nicht voll akzeptabel erscheint: die durch bloß/nur angezelgte verstärkunb der lllokution scheint mit der durch wohl zum Ausdruck gebrachten Einschränkunk nicht unbedingt verbindbar zu sein.

\section{3. blok/nur mit mal und ruhig}

Wie oben bei der Beschreibung von nur und blo $\beta$ schon angesprochen, untersche ${ }^{i^{-}}$ det sich die Bedeutung der beiden Partikeln lediglich in nicht-negierten Imper ${ }^{8^{-}}$ tivsätzen: hier hat bloß die Funktion, die lllokution zu verstärken bis hin $z^{u} e^{j^{-}}$ ner Warnung oder Drohung, nur dagegen eine mildernde Komponente. Aufgrund dessen ist auch lediglich die Partikel nur mit mal, das ja auch eine Abschwäch I $^{\text {ng }}$ bewirkt, und ruhig, das - wie nur - das Merkmal 〈ZUSPRUCH〉 trägt, kombinierbar Mal und ruhig sind die einzigen Modalpartikeln, die nach nur stehen können.

(4) Komm nur mal her. Ich tu dir doch nichts. 
(5) Vera: Ja, also wir wären heut abend in München und wenn du nichts anderes vorhast, würden wir kommen...

Clara: Jaa, das ging schon.

Vera: Ja aber nur, wenn wir nicht stören, du mußt es sagen, wenn's dir nicht paßt.

Clara: Nein, nein, kommt nur ruhig vorbel! Das ist eine gute Idee.

Und ruf nur ruhig an, wenn du noch Probleme hast. Ich helf dir gerne.

"Wenn Sie wollen (...), so bleibe ich bei Ihnen." "Was fällt Ihnen ein, Georg. Gehen Sie nur ruhig nach Hause. Was soll ich noch alles von Ihnen verlangen?" (A.Schnitzler, Der Weg ins Freie, Frankfurt 1978:266)

In negierten Aufforderungen hat nur - wie bloß - ebenfalls eine die Aufforderung Verstärkende Funktion; in negierten Aufforderungen aber sind mal und ruhig ohnehin kaum möglich.

Hit bloß (oder auch $J A$ ) lassen sich weder mal noch ruhig kombinieren; vgl.: 18) 'Mach bloß mal das Zelt zu, sonst kommen wieder so viele Mücken rein!

(9) "Und vergessen sie bloß mal nicht, von jedem Kunden Adresse und Telefonnummer zu notieren!

(5a) "Kommt bloß ruhig vorbei!

(10) "Geh bloß ruhig rein!

Die Außerung (10) ist nur möglich, wenn ruhig ais Adverb interpretiert wird.

Dle beiden eine Aufforderung abschwächenden Modalpartikeln mal und ruhig sind 2lso lediglich mit nur kombinierbar; die Kombinationsfähigkeit mit anderen Parti$k_{e l n}$ ist hier ein weiteres Indiz für die Bedeutungsunterschiede, die zwischen nur und blo $\beta$ bestehen. 24

Wit der hauptsächlich im norddeutschen und westdeutschen sprachgebiet verwendeten Partikel man (vgl. (11) und (12)) ist blo $\beta$ und übrigens auch JA durchaus 20 kombinieren; dabei steht man an erster Stelle:

(1) $N u$ werd man nicht übermütig!(..) Du bildest dir doch nicht etwa ein, daß du hier so einfach die Kurve kratzen kannst. (Bi, 153)

(12) "Hej, du - was ist denn?" fragte er. "Ja, geh man", sagte ich. (Bi, 113)

(13) Mach man bloß die Fenster zu! Da kommt ein Gewitter!

(14) Geh man bloß nicht zu nah an die Maschine hin!

(15) Gehen Sie man JA dicht genug ran bei den Aufnahmen! Nicht so wie beim letzten $\mathrm{Mal}$.

24) Ein weiterer Unterschied zwischen nur und bloß ist die Kombinierbarkeit mit einfach; diese Kombinationen werden unten in 3.2.2.3 (S.272f.) beschrieben. 
4. nur und blok

Die beiden Modalpartikeln nur und $b l o \beta$ sind möglicherweise zu kombinieren - allerdings ist diese Variante nicht belegt; sie wurde im Test von $65 \%$ akzeptiert und von $25 \%$ der Testpersonen 'vielleicht' akzeptiert:

(16) Vater zur Tochter: Bring mir nur bloß kein uneheliches Kind heim!

In den Wunschsätzen scheint die Kombination kaum akzeptabel zu sein:

(17) ?*Könnte ich nur bloß Klavier spielen!

Vermutlich ist diese Kombination nicht gebräuchlich, da die beiden Partikeln hler nahezu bedeutungsgleich sind.

\subsection{Kombinationen mit mal}

Die Partikel mal ist mit den meisten Modalpartikeln kombinierbar, ${ }^{20}$ allerdings ${ }^{\text {ist }}$ oft nicht mehr genau festzustellen, ob es sich um die Modalpartikel(!) $m^{g}$ handelt, da der Obergang zwischen Temporaladverb und der Modalpartikel fließend ist.

In Kombinationen steht die Modalpartikel immer an letzter Stelle. ${ }^{26}$

\section{1. ruhig mal}

In dieser Kombination sind die Merkmale 〈ZUSPRUCH〉 und 〈ABSCHWACHUNG〉 vereint, Merkmale, die durchaus kompatibel sind. Mal fügt hier der Bedeutung von ruhig in Aufforderungen noch eine beiläufige, die Illokution abschwächende Nugnce hinzu.

Die Kombination tritt auf in Imperativsätzen und in Aussagesätzen mit den Mods ${ }^{-}$ verben können und sollen.

Ruhig mal ist der Kombination nur mal sehr ähnlich.

(18) Mach ruhig mal den Fernseher an! Ich bin sowieso fast fertig, und dieser Film würd mich auch interessieren.

(19) Komm ruhig mal bei mir vorbei, wenn du in der Nähe bist! Ich freu mich immer über Besuch.

(20) Ich hatte richtig Angst um die Kleine, denn immerhin war sie meine einzige Verwandte, denn Hete war doch nur angeheiratet, und Dieter saß in Brandenburg, und wenn sie sich jetzt mit ihrem Autoverleiher in SaInt Tropez oder Capri rumlümmelt, dann sollte sie ruhig mal an mich denken. (Bi, 19)

25) Die Kombination mit nicht wurde oben in Kapitel 1.4 bereits besprochen.

26) Bel mal eben (s.u.) liegt eben nicht als Modalpartikel vor. 
2. eben mal und halt mal

Die Kombinationen eben $\mathrm{mal}$ und halt $\mathrm{mal}$ treten nur in Aufforderungen auf. Hier Wird durch mal die Aufforderung abgeschwächt, die Funktion von eben bzw, halt entspricht der bel den Einzelanalysen schon besprochenen:

(21) Wenn du deine Arbeit rechtzeitig fertig bringen willst, dann bleib eben mal zu Hause und arbeite!

(22) Geh halt mal zum Finanzamt und frag nach wegen der Steuererklärung.

(23) Der Bruder, der aus dem Gefängnis zurückkommt, zu seiner Schwester: "Du mußt dann eben mal ne Weile bei Tante Hete schlafen (...) ich brauch 'n Zimmer für mich." (Bi, 200)

3. mal eben

Bei der Kombination mal eben llegt eben in einer anderen (eher temporalen) Valante vor: es läßt sich hier nicht mehr mit dem Merkmal (EVIDENT) beschreiben.

Hauptsächlich tritt dieses eben in der Verbindung mit mal auf.

Auch die Tatsache, daß in dieser Kombination halt nicht verwendet werden kann leben kann ja - wie oben schon angesprochen - in Imperativen immer durch halt ersetzt werden, umgekehrt allerdings nicht), ist ein Indiz dafür, daß die Funktion Von eben in dieser Variante anders beschrieben werden muß.

In der Kombination mal eben ist eben auch in Entscheidungsfragesätzen möglich 'ln zusätzliches Indiz dafür, daß es sich nicht um das 'Evidenz-eben' handelt:

(24) Geh mal eben zum Bäcker und hol ein paar frische Semmeln!

(25) Könnten Sie mal ebcn zur Tafel kommen?

(26) Würden sie mir mal eben helfen?

Auch in der Kombination mit doch und bitte tritt mal eben auf:

(27) Dann donnerte sie, mir zur Ablenkung ("Steh doch mal eben auf") ein neues Stück herunter. (Ke, 140)

(28) Hol sie doch mal eben runter, meln Junge. (Ke, 181)

(29) Else, bringen Sie doch bitte noch mal eben die Karaffe mit Rum...(Ke, 72)

${ }^{b_{e n}}$ in (eindeutiger) Modalpartikel-Funktion dagegen, das in Imperativsätzen anrelgt, daß die Handlung, zu der der Sprecher auffordert, eine evidente Lösung und

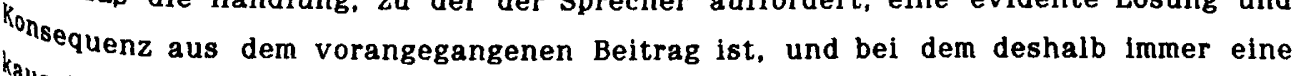
aluale Beziehung zum Vorgänger besteht (was auch daran deutlich wird, daß die e ${ }^{n}$-Aufforderungen oft mit dann eingeleitet werden), ist mit doch nicht komblNierbar, was sich auf das unterschiedliche Interesse des Sprechers an der Ausfüh(30) der Handlung zurückführen läßt; vgl.: Uli: Heute früh hab ich wieder die S-Bahn verpaßt.

$\left.{ }^{1} \mathrm{O}_{\mathrm{a}}\right)$ Nina: Dann steh eben morgen früher auf! 'Dann steh doch eben morgen früher auf! 
Bel dem eben der Kombination mal eben dagegen besteht keine kausale Beziehung zum Inhalt einer vorangegangenen Außerung (vgl. die Beispiele oben).

Schließlich spricht auch das Stellungsverhalten in der Kombination dafür, daß $\mathrm{ms}$ eben keine Kombination zweier Modalpartikeln ist (mal steht sonst nämlich immer an letzter stelle).

In dieser Variante kann eben mit 'schnell' oder 'gerade' beschrieben werden und ist deshalb aus dem Temporaladverb eben abzuleiten. ${ }^{27}$

In einer Aupforderung wird dadurch betont, daß die Handlung unmittelbar nach der Außerung ausgeführt werden soll. Dieser Aspekt ist auch noch in der Kombination mal eben nachzuweisen, obwohl er durch mal abgeschwächt wird. Deshalb ist die Kombination mal eben - im Unterschied zu mal allein - auch nicht möglich in Aufforderungen, die sich auf einen weiter entfernten bzw. nicht näher spezifizierten Zeitpunkt in der Zukunft beziehen; vgl.:

(31) Beim Abschied: Und schreib mir mal!

(31a) Beim Abschied: "Und schreib mir $\underline{m a l}$ eben!

Eben in der Kombination mal eben ist also als temporales Adverb und nicht als Modalpartikel zu bezeichnen.

\section{4. einfach mal}

Die Kombination dieser beiden Modalpartikeln in Aufforderungen ist unproblemstisch: durch den Gebrauch von einfach zeigt der sprecher an, daß die Handlung. zu der er auffordert, eine für ihn offensichtliche Lösung für ein vom Gesprächs' partner geäußertes Problem ist (Merkmal 〈EVIDENZ〉s); gleichzeitig schwächt der Sprecher durch den Gebrauch von mal die Aufforderung ab:

(32) Andi: Hasde die Quittung denn noch davon?

Ruth: Jaja.

Andi: Sonst rufsde einfach mal da an bei der Polizeistelle mal an und fragst. (BA, 194)

Thomas: Wenn ich nur wüßte, wie man bei Wildleder die Nähte versäubert!

Ina: $D u$, geh einfach mal in dieses Ledergeschäft hinter'm Dom und frag!

\section{5. eh/sowieso und $\mathrm{mal}$}

Die Kombination von eh/sowieso und mal kann nur in Aussagesätzen mit den $\mathbb{M}^{-}$

dalverben können und sollen auftreten.
Diese Kombination war nicht belegt, Beispiel (34) wurde aber von über $70 \%$ des Testpersonen akzeptiert: 27) Vgl. dagegen Hartog/Rüttenauer (1982:77), die eben hier (m.E. unzutreffend)
mit irgendwie ersetzen und als "geeignete Paraphrase" und auch wenn $e^{s}$ schwierig ist' angeben. 
(34) Frank: Ich geh mal ein bißchen an die frische Luft.

Inge: Ach, das ist gut; du könntest eh mal beim Schuster vorbeigehen und fragen, $o b$ die Schuhe schon fertig sind.

Auch hier wird durch eh und sowieso die Außerung in einen größeren argumentativen Zusammenhang gestellt; die Aufforderung ist nur möglich als Reaktion auf eine fremde Vorgängeräußerung.

6. Wohl mal

Die Partikel mal kann mit wohl zusammen in Entscheidungsfragesätzen auftreten:

(35) Könnten Sie mir wohl mal helfen, den Kinderwagen die Treppe raufzutragen?

In (35) handelt es sich vom kommunikativen Sinn her um eine Aufforderung, in (36) dagegen um eine echte Frage:

(36) Könnte Ihre Sekretärin wohl mal einen Termin für mich vereinbaren?

Mal liegt hier in einem obergangsbereich zum Temporaladverb.

In den Verb-Erst-Aufforderungen ist die Kombination wohl mal nicht möglich:

(37) "WIRST du wohl mal die Klappe halten!

7. mal und denn, etwg, eigentlich, vielleicht

Te bei der Besprechung von mal schon erwähnt, kommt mal auch in Entscheidungsfragesätzen vor. Deshalb kann mal mit den Partikeln denn, etwa, eigentlich und vielleicht zusammen auftreten. Allerdings handelt es sich - wie im folgenden gezelgt werden soll - in allen Fällen um das Temporaladverb mal mit der Bedeutung 'irgendwann einmal'; also nicht um eine Modalpartikel-Kombination.

Zunächst zu denn mal: Die Modalpartikel mal ist nur in Außerungen möglich, die de Funktion einer Allfforderung haben, genau diese Funktion aber kann eine denn-Frage nicht übernehmen. Insofern sind Außerungen mit der Kombination denn mal von der Funktion her als Fragen aufzufassen, und mal ist demnach in dieser Kombination als Temporaladverb mit der Bedeutung 'irgendwann einmal' einzuordnen:

(38)

\footnotetext{
Gehst du denn mal zum Chef?

Auch die Tatsache, daß die Kombination in Entscheldungsfragesätzen möglich ist, I denen die Modalpartikel (!) mal nicht auftreten kann (z.B. Fragen die sich auf de Vergangenheit beziehen; vgl. (39)), ist ein Indiz für das Vorliegen des Temporaladverbs. (39)

Je narst du denn mal in Afghanistan?

Dartner dem semantischen Gehalt der Frage kann allerdings für den Gesprächs-

belspine gewisse Verpflichtung zum Ausführen einer Handlung verbunden sein;

plelsweise dann, wenn die Frage sich direkt an den Gesprächspartner richtet
} 
und eine zukünftige Handlung zum Inhalt hat; vgl. (40) vs. (41). Die dadurch entstehende Verpflichtung des Gesprächspartners zur Ausführung der Handlung ist aber keineswegs auf mal zurückzuführen - und die Außerung bleibt eine Frage.

(40) Könnten Sie mir denn mal 5 Mark wechseln?

(41) Könnte dein Mann mir denn mal helfen? Der versteht doch was vom Angeln. Ein zusätzliches Argument dafür, daß es sich bel $m a l$ in der Verbindung denn $m^{2}$ um ein Temporaladverb handelt, ist die Tatsache, daß denn mal auch in w-Fragesätzen zulässig ist (die Modalpartikel mal dagegen nicht):

Was willst'n dann mal werden? ( $\mathrm{Bi}, 32)$

Wann gehen wird denn mal ins Kino?

Ein weiteres wesentliches Indiz dafür, daß es sich bei Außerungen, in denen den und mal zusammen auftreten, eben nicht um Aufforderungen handelt und mal polglich als Temporaladverb interpretiert werden muß, ist die Tatsache, daß sich in derartige Außerungen bitte kaum einfügen läßt - eine Partikel, die sonst in Aufforderungen mit mal immer auftreten kann;28 vgl.:

(43) ?'Könntest du denn bitte mal zum Babysitten kommen?

?"Könnten Sie mir denn bitte mal fünf Mark wechseln?

Daraus läßt sich schließen, daß denn eine Modalpartikel ist, die die Um-Interpretation eines Entscheidungsfragesatzes in eine Aufforderung verhindert und somit mit der Modalpartikel(!) mal, die genau dieses bewirkt, nicht kombiniert werden kann.

Noch deutlicher zeigt sich, daß mal Temporaladverb ist, wenn es zusammen mit eigentlich oder etwa vorkommt: Eigentlich markiert Fragen ais echte, ernsthafte Fragen, an deren Beantwortung der Sprecher aufrichtiges Interesse hat. Insofern kann mal, wenn es zusammen mit eigentlich auftritt, nur ein temporales Adverb mit der Bedeutung 'irgendwann' sein; vgl.:

(44) Könntest du eigentlich mal abends kommen?

(45) Eines Tages fragte mich Uli: Was willst du eigentlich mal studieren? (Bi ${ }^{32}$ ) In Fragen wie den oben bei denn beschriebenen, bei denen für den Sprecher durch die Beantwortung der Frage mit $j a$ eine gewisse Verpflichtung zum Ausführen $e^{\text {iner }}$ Handlung entsteht, ist eigentlich ohnehin kaum möglich; vgl.:

(46) Ein Passant zum anderen: ?"Könnten Sie mir eigentlich (mal) Feuer geben? Auch Fragen mit der Modalpartikel etwa (ähnlich auch vielleicht) lassen mal nur als Temporaladverb zu (vgl. (47)); in Fragen, die als Aufforderungen intendiert sind, ist die Kombination von etwa und mal nicht möglich, da die Funktion von 28) Die Kombinationen von bitte mit den Modalpartikeln, die in Aufforderungen
auftreten, werden weiter unten ( $(5.275 \mathrm{ff}$.) behandelt. 
(47) Waren Sie etwa mal Mitglied in der Partei?

(48) "Gehen Sie etwa mal ans Telefon?

Die im vorangegangenen untersuchten Kombinationen sind also zwar akzeptabeles handelt sich aber nicht um Modalpartikel-Kombinationen.

\subsubsection{Kombinationen mit aber und vielleicht}

1. aber auch

Dlese Kombination tritt in w-Exklamativsätzen mit Zweit-Stellung oder Endstellung des Verbs und in $d a \beta$-Exklamativsätzen auf; in den w-Exklamativsätzen scheint aber allein gar nicht und auch allein nur selten möglich (vgl. oben S.159 und S.190).29

(1)

Er könne schließlich nichts dafür, und müsse sich das dauernd anhören, die lynchten ihn, wenn er mit seinen Scheißrussen ankomme.

(2)

'Was sind das aber auch für welche!' Der letzte Dreck. (Ke, 178)

Ellen: Robert ist gestern in einer Kneipe zusammengeschlagen worden.

(3) Max: In was für Knelpen der sich aber auch immer rumtreibt!

(4) Was du aber auch für Leute kennst!

(4) Daß du aber auch nie deinen Mund halten kannst!

Dle Modalpartikeln aber und auch sind deshalb kombinierbar, weil sich das MerkMa] 〈UNERWARTET> von aber aup den Sachverhalt der Außerung, in der aber steht, bezieht, das Merkmal 〈ERWARTET>v von auch dagegen auf den im VorgänBerbeitrag geäußerten Sachverhalt. Darum sind Exklamativsätze mit dieser Kombihation immer nur als Reaktion auf einen Anlaß möglich, der für den Sprecher erMartbar sein kann.

Aufgrund des Merkmals 〈ERWARTET>v von auch ist die Kombination z.B. im folBenden Kontext inakzeptabel:

29) Vereinzelt ist aber auch in Außerungen vom Typ (i) zu finden:

(i) A: Findest du nicht, daß er mich nicht so anschreien hätte dürfen?

$B: N a, d u$ WAKST aber auch frech!

In diesem Fall könnte es sich um (Satz-)Exklamativsätze handeln. Allerdings

lst Verb-Erst-Stellung kaum gebräuchlich (jedoch nicht ausgeschlossen: Hat

$D E R$ aber auch geflucht!). Gegen eine Kategorisierung von (i) als Exklamativ-

satz spricht aber auch, daß der Akzent in diesen Fällen stellungsfest ist (was

sicher auch damit zusammenhängt, da $\beta$ auch-Außerungen notwendigerweise in

bestimmter Beziehung $\mathrm{zu}$ ihrer Vorgängeräußerung stehen). Außerdem liegt aber in diesen Fällen im ubergangsbereich zur Konjunktion oder ist Konjunktion. Wahrscheinlicher ist es also, daß es sich bei (i) um einen Aussagesatz mit Fokusakzent handelt. Auch bei den w-Exklamativen geht aber zum Teil über in die Konjunktions-Funktion. Es kann dann ohne Bedeutungsveränderung vor den $w$-Ausdruck oder die Konjunktion ins Vorvorfeld gestellt werden. Die Kombination aber auch zeigt m.E. wesentlich deutlicher die Probleme der Funktionsabgrenzung bei aber als die Verwendung der Partikel alleine. 
nation immer nur als Reaktion auf einen Anlaß möglich, der für den Sprecher erwartbar sein kann.

Aufgrund des Merkmals 〈ERWARTET>v von auch ist die Kombination z.B. im folgenden Kontext inakzeptabel:

(5) Max trifft Hans, als der aus einer Kneipe mit sehr üblem Ruf herauskommt. Max: 'In was für Kneipen du dich aber auch rumtreibst!

Dagegen wären im Kontext von Beispiel (5) die Außerungen (5a) und (5b) durchaus adäquat:

(5a) In was für Kneipen treibst du dich denn rum!

(5b) Du treibst dich aber/vielleicht in Kneipen rum!

In allen Fällen der Verwendung von aber auch in w-Exklamativen drückt der Sprecher also aus, daß die Vorgängeräußerung oder -handlung ihn nicht weiter überrascht und zwar aufgrund des in seinem eigenen Beitrag geäußerten Sachverhalts, wobei aber dieser Sachverhalt durchaus das Staunen des Sprecher erregt; so ließe sich aber auch in Beispiel (2) in etwa umschreiben mit: 'daß Robert zusammengeschlagen worden ist, wundert mich nicht, bel dem Umgang, den er immer pllegt, aber über diesen Umgang muß ich mich allerdings wundern'.

Die w-Exklamative mit aber auch führen also immer eine Begründung oder Erklärung für die Vorgängeräußerung an, und der in der aber auch-Außerung selbst dargestellte Sachverhalt entspricht nicht den Erwartungen des Sprechers.

Die Kombination der (mehr hörerbezogenen Modalpartikel) vielleicht mit auch ist dagegen in w-Exklamativsätzen kaum akzeptabel und in (Satz-)Exklamativsätzen kaum gebräuchlich; vgl.:

(6) ?Was sind das vielleicht auch für komische Leute hier!

(7) Das ist vielleicht auch 'n Ding! Der Typ von neulich hat mich angezeigt!

\section{2. aber und vielleicht mit mir}

Diese Kombinationen wurden bereits kurz erwähnt (s.o. S.198). Wegen der meist negativen Tendenz wird mir hauptsächlich mit vielleicht kombiniert; vgl.:

(8) "Was willst du mit dem Zettel?"(...)"Den schieb ich Reineboth unter die Weste." "Du bist mir vielleicht 'n Gauner", meinte Hortense verächtlich. (B.Apitz, Nackt unter Wölfen, Frankfurt/M. 1984:110)

(9) Du bist mir vielleicht ein Früchtchen!

Vereinzelt ist mis auch in Verbindung mit aber möglich (vgl. (10)), jedoch nicht. wenn der Sprecher eine wirklich positive Uberraschung ausdrückt (vgl. (11)):

(10) Die Wirtin lächelte geschmeichelt. "Na, Sie sind mir aber einer! Da muß ich mich ja mächtig anstrengen!" (Hör zu)

(11) ?'Du kannst mir aber gut singen! 


\section{3. aber vielleicht}

Die Kombination dieser beiden Modalpartikeln ist unproblematisch, wenn auch nicht sehr häufig. Hier ist das Merkmal 〈UNERWARTET〉, also die uberraschung besonders ausgeprägt; außerdem kommen noch die Sprecher- und die Hörerbezogenheit hinzu.

(12) Wie bitte? Wie dat geht? Sie sind aber vielleicht gut! Da darf ich ja gar nicht darüber reden. (J.v.Manger, Bleibense Mensch! München 1974:63)

(13) $A u, d a$ is der aber vielleicht böse...rollt er mitti Augen, daß man richtig merkt, dem paßt das nicht, daß der Tell ihn töten wollte. (J.v.Manger, Bleibense Mensch! München 1974:21)

(14) Du hast aber vielleicht einen Husten!

\section{4. ja vielleicht}

Bevor ich auf diese Kombination eingehe, sind einige allgemeine Probleme zu behandeln. Weiter oben (S.45) wurde bei der Beschreibung der einzelnen Satzmodi der (Satz-)Exklamativsatz etabliert, der sich neben anderen Kriterien wie z.B. einem (nicht stellungsfesten) Exklamativakzent oder dem Funktionstyp 'sich wundern, da $\beta^{\prime}$ auch dadurch definiert, da $\beta$ ein Wechsel der Verbstellung von Anfangsstellung zu Verb-Zweitstellung möglich ist, ohne daß sich die Funktion der Außerung ăndert; vgl. (15) vs. (15a):

(15) Mensch, hast du eine Nase! Mensch, hat die eine Nase! (Kr, 162)

(15a) Mensch, du hast eine Nase! Mensch, die hat eine Nase!

In den so definierten Exklamativsätzen sind neben mir nur die beiden Modalpartikeln aber und vielleicht zulässig.

Bei der Beschreibung der Modalpartikel ja hat sich herausgestellt, daß sie in Aus8agesätzen auftreten kann, die hier als emphatische Aussagen oder - etwas vage, ohne damit einen bestimmen Satzmodus zu meinen - als Ausrufe bezeichnet wurden (s.o. S.107f.). In diesem Fall trifft nun zwar das Kriterium des Vorliegens eines (nicht stellungsfesten) Exklamativakzentes zu, nicht mehr aber das Kriterium der fakultativen Verb-Stellung. Deshalb wurden diese Außerungen (wie etwa (16)) als Aussagesătze eingeordnet:

(16) Das ist ja einfach grauenhaft!

Die ist ja bescheuert!

Nun ist aber die Modalpartikel $j a$ in dieser Verwendung mit der 'echten' Exklamativpartikel vielleicht kombinierbar. ${ }^{30}$ In diesem Fall handelt es sich bei den

30) Die Ausrufe mit $j a$ wurden getrennt von allen Außerungen, die eine emphatische bzw. expressive Färbung aufweisen, aber nicht Staunen, daß ein Sachverhalt der Fall ist, zum Ausdruck bringen; wie z.B. Das ist doch das Letzte! Tatsächlich ist doch auch nicht mit aber oder vielleicht kombinierbar: In einer Außerung wie (i) ist aber als Konjunktion einzustufen - es kann auch 
Außerungen um Sätze mit (fester) Verb-Zweitstellung, die einen Exklamativakzent aufweisen, vgl. (17):

(17) SIE sind ja vielleicht ein Schlawiner!

Sie SIND ja vielleicht ein Schlawiner!

Dies wirft nun einige Probleme auf: Entweder das Kriterium der fakultativen Verb-Stellung für die Exklamativsätze wird fallengelassen; dann ergeben sich aber neue Abgrenzungsprobleme im Bereich der Sätze mit Verb-Zweitstellung: wo ist dann die Grenze zu ziehen zwischen Aussagesätzen und Exklamativsätzen?

Oder man ordnet Außerungen wie (17) als Aussagesätze ein; das ist aber m.E. unzutreffend und verdeckt die Funktion von vielleicht.

Die hier vorgeschlagene Lösung sieht folgendermaßen aus: Weil die beiden Modalpartikeln aber und vielleicht echte Exklamativpartikeln sind, sollen Außerungen, in denen andere Modalpartikeln (in diesem Fall ja) in Kombination mit diesen beiden auftreten und ein Exklamativakzent vorliegt, ebenfalls als Exklamativsätze bezeichnet werden, auch wenn in diesen Fällen nur Verb-Zweitstellung möglich ist. ${ }^{31}$

Die Kombination ja viellelcht tritt also nur in folgenden Exklamativsätzen auf:

(18) Du bist mir ja vielleicht ein Schlawiner!

(19) Iris: Fleischfondue hab ich noch nich gemacht.

Karl: . Aber du bis ja vielleicht ne Type, du

Iris: Wieso?

Karl: Jetz wollt ich am Samstag mit dir mal ne Runde drehn, da auf dem. öh, Ball oder was, un da warsde nich $z u$ erreichen (BA, 151) (...)

Iris: Ja aber hättsde das direkt gesagt, wärn wir direkt tanzen gegangen. Du bist ja auch vielleicht ne Type! (BA, 152)

(20) Du hast ja vielleicht 'nen Hau!

Die Verwendung dieser Kombination unterliegt - neben der syntaktischen Restriktion, daß sie nur in Sätzen mit Verb-Zweitstellung auftreten kann - weiter folgender Restriktion: Sie kann nicht verwendet werden in Erzählungen (in denen vielleicht allein durchaus gebräuchlich ist), wenn also der Ausruf sich auf etwas bezieht, was dem Hörer nicht bekannt ist. Der Grund dafür ist in der Bedeutung

ohne Bedeutungsveränderung im Vorvorfeld auftreten. (ii) zeigt die Inakzeptabllität von doch und vielleicht:

(1) Etwas später, in der Leipziger Straße bekam Diederich ohne Anlaß von Mahlmann eine Ohrfeige. Er sagte: "Au! Das ist aber doch eine - "Vor dem Wort 'Frechhelt' schrak er zurück. (Ma, 17)

(ii) Mein Vater hat gesagt, ich krieg kein Taschengeld, weil ich neulich so spät heimgekommen bin. "Der spinnt doch viellelcht!

31) Einen weiteren Sonderfall stellen Exklamativsätze vom Typ stellt der doch den Rotwein in den Kühlschrank! dar. Hier kann jedoch weder vielletcht noch aber auftreten, insofern ist auch eine Kombination mit doch nicht möglich. 
Von $j a$ zu suchen, das ja auch in den Ausrufen den Sachverhalt als für den Hörer bekannt oder zumindest zugänglich markiert; vgl.:

(21) Eine Frau erzählt ihrem Mann von einem Treffen mit einer Freundin:"...Und Clark jaulte die ganze Zeit, während Mira da war. Mein Gott, die verwöhnt den Jungen vielleicht!" (M.French, Frauen, Reinbek b.Hamburg 1983:103)

(21a) "Mein Gott, die verwöhnt den Jungen ja vielleicht!

Inwieweit Außerungen vom Typ (22) - bei denen der Hörer den Sachverhalt nicht unbedingt wahrnehmen kann - akzeptabel sind, ist praglich:

(22) Das Kind kommt von der Schule heim: ?Ich hab ja vielleicht einen Hunger!

Die Kombination von $j a$ und vielleicht, die sich eigentlich in den Merkmalen <BEKANNT> und 〈UNERWARTET〉 widersprechen, läßt sich nur so erklären: Es handelt sich bei den Außerungen um einen Sachverhalt, der Sprecher wie Hörer bekannt ist - zumindest für den Hörer wahrnehmbar ist (deshalb kann ja auftreten), zusătzlich drückt der Sprecher Uberraschung aus, daß der Sachverhalt in einem bestimmten Maße der Fall ist, und will diese Einstellung auf den Hörer übertragen.

Die Modalpartikel aber dagegen, die zum einen noch stärker die Uberraschung, also den Gegensatz zwischen Erwartung und Eingetretenem betont, und zum andern rein sprecherbezogen ist, läßt sich deshalb mit ja nicht kombinieren, vgl.:

(19a) 'Du bist ja aber eine Type, du!

Auch mit mir kann ja kombiniert werden. In diesem Fall steht die Partikel ja allerdings an zweiter Stelle.

(23) Du bist mir ja ne Type!

(24) Ihr seid mir ja tolle witzbolde!

\subsubsection{Kombinationen mit eben, halt, einfach, wohl und schon}

Das folgende Kapitel wird sich mit den restlichen noch akzeptablen Kombinationen beschäftigen. In der Hauptsache handelt es sich dabei um Kombinationen in Aussagesätzen.

\section{l. eben einfach und halt cinfach}

Dlese belden Kombinationen treten vor allem in Aussagesätzen auf, sind aber auch In Imperativsätzen möglich. Die beiden Partikeln halt und eben lassen sich problemlos mit einfach kombinieren: alle stellen einen bestimmten Bezug zur VorgänBeräußerung her; eben und einfach tragen beide das Merkmal 〈EVIDENT〉, sie unterscheiden sich nur im Bezug auf den Sprecher bzw. Hörer. 
(1) Reni: Und wies thr dann nachher schlecht gangen is, da hab ich es bereut, daß ich es ihr nicht gesagt hab, aber in dem Moment hätt sie es mir eh nicht glaubt.

Hanna: Ich bin eben einfach zu dick. Das ist die Schwierigkeit. (Kr, 164)

Ah so! Und wenn wir nächste Woch irgendwann mal sagen? Ihr könnt ja denn auch zu uns kommen, Eva. Ihr könnt. eben. einfach mal nur so vor bei/ braucht ja nich lange denn sein. (BA, 163)

(3) Und das find ich eben des - ich ich finde nicht - einfach zu sagen, schick ihn weg, das fänd ich eben einfach nur als(o) dumm. (FK III, 30)

Die Kombination eben einfach scheint schwächer zu sein als eben allein, weil hier mit der zweiten Modalpartikel etwas von der durch eben bewirkten Kategorizität und Unverbindlichkeit der Behauptung zurückgenommen wird, indem der sprecher mit der zweiten Partikel (einfach) den Sachverhalt nur für sich selbst als evident kennzeichnet.

Bezüglich des kategorischen und unverbindlichen Charakters einer Außerung läßt sich mit den Partikeln einfach und eben die Skala: einfach - eben einfach - eben aufstellen.

Die Kombination halt einfach ist im Unterschied zu eben einfach wesentlich abgemildert, was daran liegt, daß halt mit seinem Merkmal 〈PLAUSIBEL> weniger kategorisch ist als eben. Der Sprecher signalisiert durch den Gebrauch von halt, daß es auch noch andere Lösungen, Erklärungen oder Begründungen für die vorangegangene Außerung geben mag. Aus diesem Grund scheinen auch Außerungen mit halt einfach abgeschwächter zu sein als solche mit einfach allein.

(4) Reni: Klar könnte man sagen: wie weit mußt du einfach die Schule machen und wie weit kann man dazu Lust haben. ((Pause)) Aber mich störts halt einfach, wenns in der Wohnung so ausschaut. (Kr, 146)

Unter dem gewaltigen Druck der Kosten und der Großfirmen-Konkurrenz sel es halt einfach nicht mehr möglich, täglich fünfmal zu backen. (SZ)

(6) Hanna: Hab mich monatelang dagegen gewehrt. Vom Geld her hab ich das schon eingesehen, daß es besser ist, aber ich wollts halt einfach nicht. (Kr, 127)

Betrachtet man nun alle Kombinationen mit halt, eben und einfach, könnte die oben angesprochene Skala folgendermaßen aussehen:

(4a) Mich störts halt.

Mich störts halt einfach.

Mich störts einfach.

Mich störts eben einfach.

Mich störts eben.

Auch in den Imperativsätzen sind die Kombinationen eben einfach und halt ein' fach möglich; die Modalpartikeln haben jeweils die schon besprochene Bedeutung; die Aufforderung mit halt einfach ist auch hier wieder abgeschwächter: Mach halt einfach die Tür zu, wenn dich der Krach stört. 
(8) Sag ihm eben einfach, daß du dich wahnsinnig über ihn geärgert hast!

\section{2. halt eben}

Die Tatsache, daß diese beiden Modalpartikeln kombinierbar sind, ist ein weiteres Argument dafür, daß es sich hier eben nicht um regionale Varianten bzw. um Synonyme handelt. ${ }^{32}$ In dieser Kombination wird durch halt der durch eben angezeigte kategorische Charakter der Aussage zurückgenommen.

(9) Lisa: ..und da soll ihr Mann angeblich gesagt haben: "Nun laß mal, der is ganz in Ordnung, ich kenn ihn persönlich. Der ist halt eben Kommunist, und du bist schwarz." (Kr, 228)

(10) Ja, ja, da haben Sie schon recht. Aber das war halt eben genau die Schwierigkeit, denen klarzumachen, daß wir das Projekt nicht unter allen Umständen wollen.

(11) Franz: Aber es muß doch auch irgendwas gegeben haben, das Ihnen Freude gemacht hat?

Lisa: Ja. Er ist halt eben mit mir ausgegangen und hat mich ofters besucht. ( $\mathrm{Kr}, 238)$

Diese Kombination kann in Aussagesätzen und vereinzelt auch in Imperativsätzen auptreten.

\section{3. eben wohl und halt wohl}

Die Kombination eben wohl, die nur im Aussagesatz möglich ist, gehört zu denen, dle in meinem Korpus nur einmal belegt waren (vgl. (12)); deshalb wurde ihre Akreptabilität mit den Beispielen (13) und (14) getestet:

(12) Sie sehen also, daß nach wie vor die Hauptunfallursache eben beim Autofahrer wohl selbst zu suchen ist. (FK II, 88)

(13a) Ina: Peter benimmt sich in letzter Zeit so komisch.

(13b) Uli: Ach, weißt du, der kann eben wohl auch nicht so aus seiner Haut. (wie oben) Ach weißt du, der kann eben wohl nicht so aus seiner Haut.

(14) Männer sind eben wohl so.

Die Beispiele (13) und (14) ergaben im Test unterschiedliche Ergebnisse: (13a) Wurde von $42 \%$ der Testpersonen akzeptiert und von $34 \%$ 'vielleicht' akzeptiert, (13b) dagegen von $29 \%$ akzeptiert und von $39 \%$ 'vielleicht' akzeptiert. Beispiel (14) wurde von über $50 \%$ als akzeptabel beurteilt, allerdings ist dieses Beispiel nicht geeignet, da hier wahrscheinlich die Variante mit betontem wohl (also dem Apirmationsadverb) zugrundegelegt wurde. Vgl.:

(14a) A: Männer sind eben nicht so.

B: Männer sind eben WOHL so.

32) Hentschel (1986:256) führt (allerdings als Beleg von einem einzigen Sprecher) auch die Kombination in der Reihenfolge eben halt an. Sie ist mir jedoch in dieser Form nicht geläufig und ist auch in meinem Korpus nicht belegt. 
Interessant ist, daß die Variante (13a) wesentlich öfter als akzeptabel beurtellt wurde als (13b); die Partikel auch macht hier die Kombination offensichtlich akzeptabler.

Die Gründe, warum eben und wohl in der Kombination nicht unbedingt gebilligt wurden, sind in den Bedeutungen (Merkmal 〈EVIDENT $\rangle_{a}$ und Merkmal 〈EINSCHRAN ${ }^{-}$ KUNG $>$ ) dieser zwel Modalpartikeln zu suchen, die sich eigentlich widersprechen.

Eben stellt einen Sachverhalt als offensichtlich und damit als gegeben und abs $0^{-}$ lut gültig hin. An der Geltung des Sachverhalts, der mit eben behauptet wird, und an der Behauptung selbst läßt sich nicht zweifeln. Wohl dagegen schränkt die Behauptung ein.

Die Kombination eben wohl kann m.E. nur erklärt werden, wenn man davon ausgeht, daß sich der Sprecher während des Sprechens korrigiert. Eben wohl ist auch nicht als konventionalisierte Kombination - wie z.B. doch wohl - anzusehen; deshalb ist sie in meinem Korpus auch nur einmal belegt. Da dieser Beleg (vgl. (12)) aus einem Gesprächsmitschnitt stammt, kann auch hier von einer nachträglichen Korrektur durch den Sprecher ausgegangen werden.

Da die Modalpartikel halt weniger kategorisch ist als eben, ist sie wesentlich leichter kombinierbar mit dem einschränkenden wohl; Beispiel (15) wurde von $50^{4}$ der Testpersonen akzeptiert und von fast $25 \%$ 'vielleicht' akzeptiert.

(15) Inge: Warum bloß der Franz nicht kommt?

Lina: Ach, der hat halt wohl vergessen, daß heute Mittwoch ist.

\section{4. eben schon und halt schon}

Diese Kombinationen können in Aussagesätzen und in Imperativsätzen auftreten.

In Aussagesătzen allerdings sind die beiden Kombinationen selten, außerdem liegt schon hier wohl nur in der betonten Variante und damit als Affirmationsadverb vor.

(16) Hanna: Das is aber ein Schmarrn, das Denkn. Seit mir die Reni das gsagt hat, weiß ich es. (...) und wenns nur für eine Nacht is, is es gut, was danach kommt, is gar nicht so wichtig, so is!

Reni: Bloß daß bel dir das ebn schon wichtig war, was danach kommen is. $(\mathrm{Kr}, 158)$

(16a) (wie oben)

Blo $\beta$ da $\beta$ bei dir das halt schon wichtig war, was danach kommen is.

In diesem Fall zeigt schon widerspruch zur Vorgängerăußerung an, der als wider spruch angefuhrte Sachverhalt wird durch eben als offensichtlich markiert.

Daß die Modalpartikel(!) schon nicht mit eben oder halt kombiniert wird, liebt daran, daß diese Modalpartikeln einen unterschiedlichen Bezug zum Vorgänger her stellen: eben und halt bestätigen den Vorgänger meist insofern, als sie ihn erk ${ }^{\mathrm{la}^{-}}$ 
Pen oder begründen, die Modalpartikel schon dagegen schränkt inn in seiner Geltung ein.

In den Imperativsătzen ist nur die Modalpartikel-Kombination halt schon akzeptabel; Beispiel (17) wurde im Test von über $80 \%$ der Testpersonen akzeptiert:

(17) Mein Gott, jetzt mach halt schon! Ich kann doch nicht ewig warten.

Hler kommt zu der Bedeutung von schon in Aufforderungen noch eine abschwächende Nuance durch halt hinzu. Die Modalpartikel eben dagegen ist in Aufforderungen mit schon nicht kombinierbar (s.u. S.275); vgl.:

(17a) "Mein Gott, jetzt mach eben schon!

5. wohl einfach

In dieser Kombination schränkt der Sprecher seine Außerung durch den Gebrauch von wohl ein und zeigt gleichzeitig an, daß der Sachverhalt für ihn offensichtlich lst, bzw. eine offensichtliche Erklärung für den in der Vorgängeräußerung dargeBtellten Sachverhalt ist.

Auch hier wird wohl eher deshalb verwendet, um die Außerung auf die Erwartunsen des Gesprăchspartners abzustimmen.

It Unterschied zu eben und wohl scheint die Kombination einfach wohl deshalb Viel akzeptabler, weil sich bei einfach das Merkmal 〈EVIDENT〉 nur auf den Sprecher bezieht und der Sprecher den dargestellten Sachverhalt nicht als pür den Hôrer offensichtlich und damit auch nicht als allgemein gültig hinstellt:

(18) Inge: Wieso ist denn Bernd schon gegangen? War der sauer oder was? Uli: Ach nein, der hat wohl einfach keine Lust mehr gehabt.

In Beispiel (18) schränkt Uli seine Behauptung, die durch einfach als offensichtliche und naheliegende Erklärung für Bernds Verhalten gekennzeichnet ist, durch den Gebrauch von wohl ein; Ull stellt also seine Erklärung nicht als absolut zutrepfend und allein gültig hin; damit hat Inge gleichzeitig mehr Spielraum, weitere Erklärungen für Bernds Verhalten anzuführen.

6. Wohl sowieso und wohl eh

In dieser Kombination kommt zu der schon beschriebenen Bedeutung von sowieso 27. eh noch durch wohl die Einschränkung der momentanen Außerung hinzu.

(19) Bea: Dann mußt die ganzen Prüfungen in einem irrsinnig kurzen Abstand machen, ne?

Nelli: Hm. Ich mein, einerseits, das is egal, weils wohl sowieso Stress bedeutet, ne, da kommts da such nich mehr drauf an. (BA, 63)

(20) Und da ham Carla und Ina aber gesagt, sie ständen im Examen, un sie können das nich organisieren und Ina, die muß wohl sowieso unheimlich squer suf Hedwig sein. (BA, 184) 


\section{7. wohl schon}

Die Kombination wohl schon läßt sich nur in Aussagesätzen nachweisen; schor kann hier auch betont auftreten:

(21) Moni: Stell dir vor, vor dem Abflug, da haben die mein ganzes Gepräck kontrolliert; sogar die Zahnpastatube haben sie aufgeschraubt. Ist das nicht

verrückt?
Eva: Das müssen die wohl schon machen. Die haben halt wahnsinnige Angst vor Anschlägen.

(22) Lebensberatung: Sprechen Sie Ihren Kollegen einfach an und laden Sie ihn zum Kaffee ein! Dabei läßt sich dann wohl schon merken, ob Sie ihm ebenfalls sympathisch sind oder doch jedenfalls nicht ganz unsympathisch.

(23) Hanna: Morgen früh um acht is die Lore bei uns vorm Haus, weil die doch Winterreifen hat, und ich kann doch mit $n$ Sommerreifen nich in die Stadt

fahren, nich?
Iris: Och, in die Stadt wohl schon, aber nicht auf den Berg (...) (FK III. 73)

$\mathrm{zu}$ der Funktion von schon, ein Vorgängerargument teilweise zu bestätigen und ihm teilweise $\mathrm{zu}$ widersprechen und in der schon-Außerung die Gründe für den Tell-Widerspruch anzugeben, kommt durch wohl eine gewisse Einschränkung eben dieser Außerung hinzu; auf diese Weise wird der Teil-Widerspruch etwas zurückgenommen; vgl. (21) vs. (21a):

(21) Das müssen die wohl schon machen.

(21a) Das müssen die schon machen.

Ahnlich läßt sich auch (23) erklären; hier liegt schon allerdings im Ubergangsbereich zwischen Modalpartikel und Affirmationsadverb.

\section{8. wohl und etwa}

Dle beiden Modalpartikeln wohl und etwa treten zwar beide in Entscheidungsf ${ }^{-}$ gesätzen aup; dort sind sie allerdings kaum kombinierbar.

Das liegt zum einen daran, daß Verb-Erst-Fragen ${ }^{33}$ mit wohl eher selten sind $^{3}$ (Fragen mit wohl liegen ja meist in der Form 'ob-Verb-Letzt' vor), und vor allem auch daran, daß die Bedeutung von wohl, anzuzeigen, daß es sich um eine Frage handelt, die vor allem an den Sprecher selbst gerichtet ist und eher nach ver mutungen des Hörers Pragt, nicht mit der von etwa angezeigten Antworterwartunb kompatibel ist; vgl. (24):

(24a) Denkst du wohl an mich?

(24b) Denkst du etwa an mich?

(24c) 'Denkst du wohl etwa an mich?

33) In den Verb-Erst-Aupforderungen mit wohl (WIRST du wohl hergehen!) könne? etwa, vielleicht, auch oder nicht genausowenig auftreten wie denn und sind deshalb dort auch nicht mit wohl kombinierbar. 
Nun ist aber die Modalpartikel etwa in Verbindung mit nicht auch in Aussagesätzen möglich, wo wohl ebenfalls auftritt.

Dle Kombination von wohl und (nicht) etwa wurde in zwei Varianten ${ }^{34}$ getestet:

(25a) Max: Und gestern auf dem Ball der Einsamen Herzen, da...

UIf: Was? Du bist doch wohl nicht etwa dahin gegangen? Du spinnst ja!

(uber $80 \%$ akzeptabel, $15 \%$ vielleicht akzeptabel)

(25b) (wie oben)

Was? Du bist wohl nicht etwa dahingegangen? Du splnnst ja!

(30\% akzeptabel, $20 \%$ vielleicht akzeptabel)

Doch wohl nicht etwa ist von den getesteten Varianten auch die einzige, die in

melnem Korpus belegt ist: demnach ist die Kombination von wohl und etwa nur in

der Form doch wohl nicht etwa in Aussagesätzen möglich.

Die Bedeutung dieser Kombination entspricht der oben schon beschriebenen Bedeutung von doch nicht etwa (s.223ff.), wobel durch wohl noch eine einschränkende Komponente hinzukommt, die der von wohl in der Kombination doch wohl (s. S.218ff.) entspricht.

9. einfach mit denn, etwa und nicht

Die Modalpartikel elnfach tritt auch in Entscheidungsfragesătzen auf. Sie markiert dort die zur Frage gestellte Proposition als eine für den Sprecher evidente Erklärung für einen im Vorgängerbeitrag dargestellten Sachverhalt. Einfach ist hler kombinierbar mit denn, das Erstaunen anzeigt, mit etwa und mit nicht, die elne bestimmte Antworterwartung signalisieren.30 in den Kombinationen in Pragesătzen sind Modalpartikel-Funktion und Modaladverb-Funktion von elnfach nicht immer klar zu trennen.

(26) Irgendetwas mit dem Kontoauszug stimmt nicht. Hast du denn einfach diese Rechnung bezahlt? Wir wollten doch was einbehalten.

(27) Wieso stottert sie so? Hat sie etwa einfach ihren Text vergessen?

(28) Er ist ziemlich unfähig. Können wir ihn nicht einfach absetzen?

34) Elne weitere Variante betraf die Kombination von wohl und etwa; der Satz lautete: Was? "Bist du wohl etwa dahin gegangen? Du spinnst ja! Die Gründe

35) für die Inakzeptabilität wurden bereits beschrieben.

35) In der Kombination mit vielleicht (Hat sle vielleicht elnfach keine Lust mehr?) liegt vielleicht m.E. als Satzadverb vor. 


\subsubsection{Bedingt akzeptable und inakzeptable Kombinationen}

Neben den Kombinationen, die aufgrund syntaktisch-distributioneller Kriterien inakzeptabel sind, gibt es eine Reihe von Modalpartikeln, die aufgrund semantischer Eigenschaften nicht kombinierbar sind. Es muß hier wohl nicht betont werden, daß gerade auch die Unvertrăglichkeit zweier Modalpartikeln, die im gleichen Satzmodus auftreten, ein weiterer Bewels dafür ist, daß Modalpartikeln eine Bedeutung haben, die nicht nur darin bestehen kann, Außerungen abzutönen, und daß welter der Antell des Satzmodus an der Bedeutung der Modalpartikeln so groß nicht sein kann (vgl. dagegen Krivonosov 1977a:193).

Die semantisch unvertraglichen oder fraglichen Kombinationen (deren (In-) Akzeptabilităt - wie oben dargestellt - in vielen Fällen getestet wurde) werden hier deshalb auch im einzelnen analysiert, well sich die Unverträglichkeit ebenfalls aus den Einzelbedeutungen ableiten lassen muß. Bel der Darstellung dieser Kombinationen wird - der Deutlichkeit wegen - von den Satztypen ausgegangen. Die oben berelts angesprochenen inakzeptablen oder iraglichen Kombinationen werden nur noch kurz erwähnt.

Das Kriterium der Inakzeptabilităt wie auch der Akzeptabllităt bezieht sich auch hier Immer nur auf die Kombination zweier Modalpartikeln. Liegt eine der Partikeln oder auch beide in einer anderen Funktion vor, kann eine Kombination natürlich durchaus möglich sein.

Die Relhenfolge der Partikeln auch in den bedingt akzeptablen und inakzeptablen Kombinationen war erstaunlicherweise intuitiv hăufig klar - bedingt wohl auch durch das Verhalten der Partikeln in anderen (akzeptablen) Kombinationen. In den unklaren Fällen wurden beide Varianten getestet.

\subsubsection{Kombinationen in Aussagesåtzen}

1. eh/sowieso mit eben, halt und einfach

Die Kombinationen von eben, elnfach, halt mit eh bzw. sowieso wurden getestet: dabel zeigte sich, daß sie alle kaum akzeptabel sind - auch hier wurde wieder die Kombination mit halt am ehesten akzeptiert:

(1) Das macht nichts, $d a \beta$ du die Unterlagen vergessen hast. "Ich komm heut abend einfach eh bei dir vorbei! (80\% inakzeptabel) 
(2) Ina: Ich kann nicht verstehen, warum du dich so unmöglich benimmst deiner Schwiegermutter gegenüber.

Karl: Naja, "das ist jetzt eben sowleso schon egal. Wir können uns halt nicht ausstehen.

(65\% inakzeptabel und $25 \%$ vielleicht akzeptabel)

(3) Moni: Also, ich versteh das einfach nicht. Vorher machst du so eine Hektik und jetzt trödelst du selber rum.

Ina: ?Ach weißt du, jetzt sind wir halt eh schon zu spät dran.

(30\% inakzeptabel, fast $40 \%$ akzeptabel)

Der Grund für die Inakzeptabllität dieser Kombinationen liegt wohl darin, daß die Partikeln an ganz unterschiedlichen Stellen in der Argumentation stehen: eben, halt und einfach reagieren auf eine Vorgängeräußerung (melst ein problematischer Sachverhalt) und geben dafür eine Erklärung oder Begründung an; dabei wird aber der Vorgängerbeitrag in seiner Relevanz nicht direkt bewertet, letztlich aber doch bestätigt. Eh und sowieso dagegen schränken den Vorgăngerbeltrag durch Anführen elnes weiteren Argumentes in seiner Relevanz ein, bzw. erklären ihn für irrelevant.

Die Tatsache, daß halt auch hier wieder akzeptabler ist als eben, konnte allenfalls dadurch erklärt werden, daß halt verbindlicher ist als eben und damit auch elingesetzt werden kann, um eine Außerung etwas abzuschwächen.

\section{2. eh/sowieso mit schon}

Auch bel diesen belden Partikeln liegt die Inakzeptabilität ihrer Kombination vor allem darin, daß sie an sehr unterschiedlichen Stellen Im Dialog auftreten; wăhrend bei (dem nicht-futurischen) schon dem Vorgängerbeitrag tellweise widersprochen wird, aber auch tellweise zugestimmt wird, bzw. mögliche unterstellte Gegenargumente eingeschränkt werden (Merkmal (GELTUNGSEINSCHRANKUNG〉v), geht es bel sowieso und eh nicht um Bestätigung oder Widerspruch zu der Vorgängeräußerung, sondern darum, die Relevanz eines im Vorgängerbeitrag implizierten Problems durch das Anführen eines weiteren Sachverhalts zu entkräften (<RELEVANZEINSCHRANKUNG >v). Durch die eh/sowieso-Außerung wird der Vorgănger relativiert, ohne daß der Sprecher zur Geltung des Sachverhalts Stellung nimmt. Ein Kontext, In dem belde gleichermaßen möglich sind, ist kaum vorstellbar, insofern ist auch elne Kombination der beiden unmöglich; 36 vgl.:

(4) Ja, ja, manchmal ist es schon sowieso ganz schön schwierig.

(5) "Du wirst es schon sowieso schaffen. 36) Mit dem Temporaladverb(!) schon dagegen ist sowieso durchaus zu
kombinieren: Jetzt ist es sowieso schon zu spat. 


\section{3. eh/sowieso mit auch}

Diese beiden Partikeln gleichen sich insofern, als sie beide eine Außerung in einen größeren argumentativen Kontext einbetten. Die Art der Einbettung, also die Stellen in der Argumentation, an denen Außerungen mit eh/sowieso und mit auch stehen, sind allerdings unterschiedlicher Natur. Auch-Außerungen bestätigen und erklären oder begründen den Inhalt des Vorgängerbeitrags, eh/sowieso-Außerungen dagegen schränken den Vorgängerbeitrag in seiner Relevanz ein. Deshalb lassen sich auch kaum Kontexte finden, in denen beide Partikeln stehen können. ${ }^{37}$ Auch der Test bestätigt das: Beispiel (6) wurde von $75 \%$ der Testpersonen nicht akzeptiert und von fast $25 \%$ nur 'vielleicht' akzeptiert:

(6) Uli: Susanne war heute schon wieder beim Baden.

Ina: Ja, ja, die kann sich das leisten; 'die ist eh auch Beamtin und hat einen sicheren Posten.

\section{4. ja mit halt}

Die Verbindung von $j a$ und halt ist m.E. die überraschendste inakzeptable Komblnation. Daß sie wirklich inakzeptabel und nicht nur in meinem Korpus nicht belegt ist, hat der Test bestätigt: Beispiel (7) wurde von über $60 \%$ der Testpersonen nicht akzeptiert und von $35 \%$ 'vielleicht' akzeptiert.

(7) Uli: Was macht eigentlich Monika jetzt?

Eva: Naja, "die ist ja halt seit zwei Monaten mit ihrem studium fertig und jetzt ist sie arbeitslos und jobbt so rum.

Die Inakzeptabilität kann ich nur so erklären: durch den Gebrauch von halt mit seinem Merkmal 〈PLAUSIBEL〉 konzediert der Sprecher, daß es noch alternative Erklärungen oder Begründungen etc. geben kann - auf diese Weise kann halt elne Abschwächung der Außerung bewirken; und möglicherweise ist diese Abschwächung mit der durch $j a$ bewirkten Bestätigung einer Außerung nicht vereinbar.

\section{5. ruhig mit wohl und eh/sowieso}

In Aussagesätzen kann ruhig nur auftreten, wenn deren Illokutionstyp durch $\mathrm{MO}^{-}$ dalverben bereits so modifiziert ist, daß es sich um Aupforderungen handelt. Damit ist wohl nicht kompatibel:

(8) 'Du kannst ruhig wohl mehr Knoblauch nehmen.

Eh und sowieso können zwar in derartigen Aufforderungen auftreten (vgl. oben bei S.248f.), die Kombination mit ruhig ist aber Praglich; Beispiel (9) wurde nur von knapp 50\% der Testpersonen akzeptiert.

37) Zur unterschiedlichen Kontexteinbettung s. S.160 die Beispiele (25) und (26). 
(9) Du brauchst dir keine Jacke holen. ?Du kannst jetzt eh ruhig das Fenster zumachen. Wir haben genug frische Luft.

\subsubsection{Kombinationen in Fragesătzen}

\subsection{Entscheidungsfragesătze}

1. etwa und vielleicht mit auch und nicht

Die Modalpartikeln etwa und vielleicht wurden oben mit den Merkmalen <UNERWARTET>v und 〈UNERWUNSCHT>s beschrieben; 〈UNERWARTET> bezieht sich auf den Anlaß für die Frage, 〈UNERWúNSCHT> auf die Gültigkeit des in der Frage geäußerten Sachverhalts: Fragen mit etwa oder vielleicht zeigen eine eindeutige negative Tendenz.

Fragen mit der Modalpartikel auch dagegen, die die Merkmale 〈ERWARTET> und 〈ERWUNSCHT>s trägt, weisen eine positive Tendenz auf; deshalb sind etwa und vielleicht mit auch nicht kombinierbar. Tritt die Partikel auch mit der Partikel etwa (oder vielleicht) zusammen in einer Frage auf, so muß auch als Gradpartikel interpretiert werden; vgl.:

(la) Hast du auch deine Schuhe geputzt?

(möglicher Kontext: du kannst schon weggehen, aber:) ( auch = Modalpartikel)

(1b) Hast du etwa deine Schuhe geputzt? (möglicher Kontext: sowas macht man in unseren Kreisen doch nicht selbst) (etwa = Modalpartikel)

(1c) Hast du etwa auch deine Schuhe geputzt? (möglicher Kontext: jetzt hast du schon das Geschirr gespült, die Wäsche gewaschen etc.) (auch = Gradpartikel)

Aus den gleichen Gründen, aus denen auch mit etwa/vielleicht nicht kombinierbar ist, ist auch die Modalpartikel nicht mit etwa/vielleicht nicht verträglich: bei nicht-Fragen erwartet der Sprecher ebenfalls eine Bestätigung.

Wenn etwa oder vielleicht mit der Partikel nicht zusammen auftreten, kann es sich nur um die Negationspartikel nicht handeln, die in diesem Fall immer einen Akzent trägt; vgl.:

(2) Hast du etwa NICHT angerufen bei dieser Firma? Du hattest es mir doch fest versprochen.

\section{2. eigentlich mit etwa und vielleicht}

Sowohl die Verbindung von elgentlich mit etwa als auch die Verbindung von eigentlich mit vielleicht scheinen in ihrer Akzeptabilität sehr fraglich; vgl.: 
(3) Man unterhält sich über Sport, es zelgt sich daß ein Gesprächspartner sehr viele Sportarten betreibt; sein Gegenuber fragt:

?"Können Sie eigentlich etwa auch Golf spielen?

(4) "Hast du eigentlich etwa eine Hypothek aufgenommen?

(5) "Findest du vielleicht eigentlich dieses Geheule schön?

Belspiel (3) wurde im Test von nur 20\% der Testpersonen akzeptiert.

Der Grund für die Inakzeptabilităt dieser Kombinationen liegt zum einen darin, daß sich das von etwa und vielleicht immer angezeigte Staunen uber eine (unerwartete) Vorgängerhandlung, an die damit gleichzeitig auch angeknüpft wird, mit der Funktion von eigentlich-Fragen, die auf einem Denkproze $\beta$ des Sprechers beruhen und einen thematischen obergang bedingen, nicht vereinbaren laßt. Die Kombination ist zum anderen aber wahrscheinlich auch deshalb nicht akzeptabel, weil eigentlich-Fragen echte und hinsichtlich der Antworterwartung neutrale Fragen sind (was wohl auch daraup zurückzuführen ist, daß sle an Ubergangsstellen stehen und ein neues Thema einleiten), etwa- und vielleicht-Fragen dagegen eine deutliche Antwortpräferenz ausdrücken.

3. eigentlich mit auch und nicht

Aus ähnlichen Gründen, aus denen die vorherigen Kombinationen inakzeptabel waren, sind auch die folgenden in ihrer Akzeptabilität fraglich: Fragen mit nicht und auch bringen eine deutliche Antwortpräferenz zum Ausdruck; d.h. der Sprecher erwartet sehr stark die Gültigkeit des in der Frage dargestellten Sachverhalts; bel auch kommt noch hinzu, daß die Bestätigung der Gültigkeit die Voraussetzung for eine weitere Handlung oder Außerung ist.

Eigentlich-Fragen dagegen sind echte Fragen, d.h. die Gültigkeit des dargestellten Sachverhalts ist offen.

Die Kombination von eigentlich mit auch scheint etwas akzeptabler:

(6) Horst du mir such gut zu?

(6a) ?Hörst du mir eigentlich quch gut zu?

(7) Haben wir ihm nicht alles gegeben?

(7a) 9*Haben wir ihm eigentlich nicht alles gegeben?

\section{4. eigentlich mit wohl}

Auch die Verbindung dieser beiden Kombinationen ist in ihrer Akzeptabilitat sehr praglich, vermutlich deshalb, well Fragen mit wohl weniger nach dem wissen des Hörers Pragen, sondern nach seinen Erwartungen oder Annahmen; Fragen mit 
eigentlich dagegen sind echte Fragen, d.h. der Sprecher geht davon aus, daß der Gefragte die Antwort weiß.38

(8) "Ist Max elgentlich wohl schon da?

(9) ?*Ob Max eigentlich wohl schon da ist?

Beisplel (9) wurde nur von unter $30 \%$ der Testpersonen als akzeptabel beurteilt.

Eine syntaktisch-distributionelle Eigenschaft von wohl macht die Kombination zusătzlich schwierig: Fragen mit wohl werden meistens als ob-Fragesatze realisiert (und in diesen tritt eigentlich nicht bzw. kaum auf), Entscheidungsfragesätze mit der Modalpartikel wohl, die eine Fragehandlung ausdrücken, sind eher selten.

\section{5. eigentlich mit einfach}

Die Kombination von eigentlich und einfach in Entscheidungsfragesätzen ist deshalb nicht akzeptabel, weil sich die Funktion von eigentlich, einen thematischen Obergang zu markieren, nicht mit der von einfach, eine Erklärung für die Vorgängerăußerung anzubieten, vereinbaren läß:

(10) Wieso ist sie schon gegangen? "Hat sie eigentlich einfach keine Lust mehr?

\section{6. einfach mit auch}

Auch die Kombination von einfach mit auch in den Entscheidungsfragen ist nicht zulässig. Der Grund liegt in der unterschiedlichen Kontexteinbettung dieser Fragen: Fragen mit auch führen eine Voraussetzung für eine weitere Handlung an, solche mit einfach dagegen meist eine Erklärung oder Begründung.

\section{7. wohl mit vielleicht}

Dlese Kombination ist ebenfalls inakzeptabel; vgl. (11). Die Gründe dafür sind die gleichen, die oben (S.260) bei wohl und etwa in Entscheidungsfragesätzen angefürt wurden:

(11) Denkst du wohl an mich?

Denkst du vielleicht an mich?

Denkst du wohl vielleicht an mich?

In Verb-Erst-Sătzen vom Typ (12), die Aufforderungen darstellen mit einem speziellen Intonationsmuster (starker Akzent auf dem Verb und fallendes Tonmuster). ist vielleicht ohnedies nicht akzeptabel:

(12) WIRST du wohl still sein! "WIRST du vielleicht still sein!

38) Vgl. auch oben bei bloß/nur (S.244) die Kombination mit wohl. 


\section{8. vielleicht mit etwa}

Diese beiden Modalpartikeln haben in Entscheidungspragesätzen in etwa die gleiche Bedeutung (s.o. S.195), etwa scheint lediglich in seiner negativen Tendenz stärker zu sein.

Die Kombination der beiden Partikeln war in meinem Korpus nicht belegt und wurde deshalb getestet: (13) wurde von $45 \%$ der Testpersonen akzeptiert und von $29 \%$ 'vielleicht' akzeptiert; in der umgekehrten Reihenfolge (etwa vielleicht) wurde die Kombination von $50 \%$ der Testpersonen abgelehnt:

(13) Mutter zur Tochter, die mit grünen Haaren heimkommt: ?Findest du das vielleicht etwa schön?

Die Tatsache, daß die beiden Modalpartikeln so ähnlich sind in ihrer Bedeutung, ist wohl gerade der Grund, warum sie kaum kombiniert werden und ihre Kombination nicht besonders akzeptabel ist. Vermutlich käme in einer Kombination auch die negative Tendenz zu stark zum Ausdruck.

\section{9. such mit nicht}

Obwohl diese beiden Partikeln in Entscheidungsfragesätzen die gleiche Antworterwartung ausdrücken, sind sie kaum kombinierbar. Das liegt an der unterschiedlichen Einbettung in den Kontext.

Bei auch-Fragen wird die Bestätigung der Frage nicht nur erwartet, sondern auch erwünscht, da sie die Voraussetzung für eine weitere sprachliche oder nichtsprachliche Handlung ist.

Mit nicht-Fragen dagegen wendet sich der Sprecher meist gegen eine unterstellte abweichende Ansicht, er fordert Zustimmung, weswegen diese Fragen auch oft $2 \mathrm{u}$ rhetorischen Fragen werden.

(14) Sind Sie $\underline{a u c h}$ ein bekannter Schauspieler? (Sonst darf ich Sie nämlich nicht in die VIP-Lounge lassen.)

(15) Sind Sie nicht ein bekannter Schauspieler? (Ich bin mir nicht ganz sicher.)

(16) 'Sind Sie auch nicht ein bekannter Schauspieler?

Die Tatsache, daß auch und nicht nicht kombiniert werden können, ist ein Argument dafür, das für nicht zusätzlich vorgeschlagene Merkmal 〈KORREKTUR〉 doch anzusetzen.

39) Als Kombination von Modalpartikel-auch und Negationspartikel-nicht ist die Kombination eher akzeptabel; vgl.: (?)Hast du auch den Opa nicht geärgert? Ebenso ist die Kombination möglich, wenn auch Gradpartikel und nicht Modalpartikel ist (in diesem Fall allerdings in umgekehrter Reihenfolge); vgl.:

Sind Sie nicht auch Schauspieler? (Wie mein Vater?) 


\subsection{W-Fragesätze}

1. doch mit denn, eigentlich und wohl

Mit $w$-Fragesätzen, die doch enthalten, erfragt der Sprecher immer etwas, was inm im Grunde genommen schon bekannt ist (Merkmal (BEKANNT〉s), das er aber momentan nicht präsent hat. Aus diesem Grund kann doch mit all den Modalpartikeln nicht kombiniert werden, die echte Fragen anzeigen, also Außerungen, bei denen der Sprecher eine ihm unbekannte Information fordert; ${ }^{40} \mathrm{vgl}$ :

(17a) Wie hieß doch (gleich) seine erste Frau?

(17b) Wie hieß denn/eigentlich/wohl seine erste Frau?

(17c) 'Wie hieß denn doch/doch eigentlich/doch wohl seine erste Frau?

\section{2. schon mit bloß/nur}

Die Kombinationen nur schon bzw. bloß schon sind in w-Fragesätzen nicht akzeptabel; Beispiel (18) wurde von über $70 \%$ der Testpersonen nicht akzeptiert:

(18) Hans: Ich hab ganz schön Angst vor der Verhandlung morgen und vor allem vor dem Anwalt. Kurt: "Ach, was kann der nur schon unternehmen?

Die Kombination ist deshalb nicht akzeptabel, well w-Fragesätze mit schon immer rhetorische Fragen sind. Die zugrundeliegende Proposition muß also diametral umgedeutet werden, d.h. die durch das $w$-Wort eröffnete Lücke muß mit einem negierenden Pronomen, Adverb bzw. einem entsprechenden negierenden Ausdruck gefüllt werden. Bei Fragen mit nur und blo $\beta$ dagegen ist dies nicht der Fall, der Sprecher äupert eine echte Frage.

In Beispiel (18) beispielsweise müßte, wenn nur alleine steht, die Partikel ach Wegfallen, außerdem wäre die Außerung dem ersten Sprecher zuzuordnen; vgl..

(18a) Ich hab ganz schön Angst vor der Verhandlung morgen und vor allem vor dem Anwalt. Was kann der nur unternehmen?

Die Frage könnte hier paraphrasiert werden mit: 'ich möchte wirklich wissen, was der unternehmen kann'.

Die Außerung mit schon allein, die dann nur vom zweiten Sprecher, also nach einem Sprecherwechsel geäußert werden könnte, ließe sich so umschreiben:

(18) (wie oben) Ach, was kann der schon unternehmen? Der kann doch nichts unternehmen, also mach dir keine Sorgen.

40) Mit blo $\beta$ und nur, die ja vor allem die Frage verstärken und anzeigen können, daß der Sprecher die Frage auch an sich selbst richtet, ist doch eher kombinierbar: ?Wie hieß doch bloß seine erste Frau? 
Diese unterschiedlichen Funktionen von schon und bloß/nur erklären, warum sie nicht kombiniert werden können.

Das ist m.E. auch ein weiteres Argument gegen die öfters vertretene These, Fragesätze mit nur und bloß seien als rhetorische Fragen aufzufassen (vgl. oben S.180f.); wenn es wirklich rhetorische Fragen wären, müßten sie wohl auch mit schon kombinierbar sein; so wie ja auch schon und auch - beides Anzeiger für Rhetorizität - kombinierbar sind.

Die Außerungen mit nur und bloß dagegen, bei denen keine Antworterwartung besteht, sind als w-Exklamativsätze einzustufen, was oben bereits vorgeschlagen wurde - auch dort ist eine Kombination mit schon nicht möglich, da schon in $W^{-}$ Exklamativsätzen nicht zulässig ist; vgl.:

(19) Wie siehst du bloß aus!

(19a) "Wie siehst du Schon bloß aus?

In diesen Fällen sind bloß und nur dagegen mit auch kombinierbar (vgl. (20)), da auch in $w$-Exklamativen ebenfalls auftreten kann.41

(20) Wie kann man auch nur so blod sein und im Winter die Handbremse anziehen!?

Die Kombination von bloß/nur mit schon in Imperativsätzen wird weiter unten (s. S.273f.) besprochen.

\section{3. eigentllch mit schon}

Die Verbindung von eigentlich und schon ist nur in w-Fragesätzen möglich, ist dort allerdings nicht besonders akzeptabel; zum einen, well schon-Fragen einen bestimmten Bezug zur Vorgängeräußerung herstellen, eigentlich dagegen gerade einen Obergang markiert, und zum anderen, weil diese Außerungen durch schon zu rhetorischen Fragen werden, während eigentlich den Akt des Fragens verstärkt. Ein Ehepagr hat eine Auseinandersetzung; es geht darum, ob man die
Tochter mit ihrem Bruder und dessen Freunden in Urlaub fahren lassen
soll. Nachdem sich das Gespräch elnige Zeit lang um andere Dinge gedreht
hat, sagt die Frau: Ich glaube, wir sollten sie fahren lassen. ?“Was ist
eigentlich schon dabei, wenn sie mit ein par Jungen wegfahrt?

41) Die unterschiedliche Kombinierbarkeit von nur/bloß mit auch bzw. schon ist ein weiteres Indiz dafür, daß die oben für $A u \beta e r u n g e n$ mit nur und blo $\beta$ angenommene Klassifikation zutreffend ist. 


\subsubsection{Kombinationen In Imperativsatzen}

1. blok, JA, nur, ruhig mit eben

Diese Modalpartikeln treten alle in Imperativsătzen auf. Dennoch sind ihre Kombinationen nicht akzeptabel. Der Grund, warum sich eben weder mit nur, bloß und $J_{A}$ noch mit ruhig kombinieren läßt, liegt darin, daß Aufforderungen mit eben meist als Folgerung aus einer Vorgăngeräußerung geäußert werden und immer zu elner Handlung auffordern, die auch für den Hörer eine offensichtliche Lösung für den im Vorgängerbeitrag dargestellten Sachverhalt ist. In Aufforderungen mit nur und ruhig dagegen, die ja das Merkmal 〈ZUSPRUCH〉 tragen und eine Aufforderung abmildern bzw. elne Erlaubnis ausdrücken, wird zu einer Handlung aufgefordert, bel der der Angesprochene erst im Moment der Außerung erkennt, daß sie ohne Bedenken ausgeführt werden kann.

Eln weiterer Unterschied, der auch die Inakzeptabilităt von bloß/JA und eben erklärt, liegt darin, daß bei Aufforderungen mit eben der sprecher kein persönliches Interesse an der auszuführenden Handlung hat; die Aufforderung ist lediglich als Vorgeschlagene Lösung für den im Vorgängerbeitrag geăußerten Sachverhalt $z u$ sehen. Bei einer Aufforderung mit bloß oder $J A$ dagegen signalisiert der Sprecher sehr wohl eigenes Interesse daran, daß der Hörer der Aufforderung nachkommt. Aus diesem Grund sind eben und bloß (und auch eben und $J A$ ) nicht kombinierbar.

Dle Kombinationen von eben mit bloß, nur und ruhig wurden auf ihre Akzeptabilltat hin getestet; dabel bestätigte sich die Inakzeptabilitä. Vgl.:

(1) 'Hau eben bloß ab! Sonst wirst du dein blaues Wunder erleben! (90\% inakzeptabel)

(2) "Laß das Geschirr eben nur stehen, wenn du es so ellig hast, ich spül dann später $a b$. (60\% inakzeptabel)

(3a) Karin: Ich hab heute noch so furchtbar viel zu tun; und jetzt muß ich da $z u$ dieser bloden Fete.

Mutter: 'Dann komm eben ruhig rechtzeltig heim! (70\% inakzeptabel)

(3b) (wie oben) Mutter: "Geh eben nur schon früher von dem Fest weg! (85\% inakzeptabel)

(3c) (wie oben)

Mutter: "Geh eben bloß schon früher von dem Fest weg! (75\% inakzeptabel)

Dle Inakzeptabilitat der Kombination von bloß und ruhig wurde oben (S.245) schon erwăhnt. 


\section{2. blok, JA, nur, ruhig mit halt}

Die Kombination mit bloß, JA, nur und ruhig zeigt wieder einmal den Unterschied zwischen eben und halt: da halt (aufgrund des Merkmals (PLAUSIBEL)) auch in den Aufforderungen wesentlich weniger apodiktisch und abgeschwächter ist als eben, ist es auch nicht ganz so unverträglich mit nur und ruhig; dabei scheint mir die Variante mit ruhig noch akzeptabler; vgl.:

(4) Beim Babysitten.

Also, ich glaub, Sie haben jetzt alles. ?Und machen Sie halt nur den Fernseher an, wenn die Kleine nicht schlafen will!

(5) Komm halt ruhig heut abend zum Essen. Das reicht schon für vier.

Beispiel (5) wurde im Test von fast $45 \%$ akzeptiert und von $35 \%$ 'vielleicht' akzeptiert. Die Funktion, die halt in diese Aufforderung hineinbringt, ist m.E. mit einer leichten Resignation des Sprechers zu beschreiben: der Sprecher gibt resignierend seine Erlaubnis zu der Handlung - eine Komponente, die eben nicht enthalten kann.

Die Kombination mit bloß oder $J A$ ist auch bei der Modalpartikel halt nicht möglich, hier widersprechen sich die abschwächende Komponente von halt und die verstärkende, drohende von bloß bzw. JA:

(6a) "Mach halt bloß die Tür zu! Das Gehämmere geht mir echt auf die Nerven.

(6b) 'Mach halt JA die Tür zu!

\section{3. blok, JA, nur, ruhig mit einfach}

Die Modalpartikel einfach ähnelt insofern in ihrer Funktion eben, als sie auch einen Sachverhalt als evident anzeigt; in den Imperativsätzen wird die Handlung. zu der der Sprecher auffordert, als eine naheliegende und für den sprecher offensichtliche Lösung für einen im vorangegangenen Beitrag geäußerten problematischen Sachverhalt dargestellt. Insofern gleichen sich eben und einfach in inrer kontextuellen Einbettung.

Aufgrund dieser Funktion von einfach besteht auch bei diesen Aufforderungen kein echtes Sprecherinteresse an der Ausführung der Handlung, der sprecher ist eher bemüht, dem Gesprächspartner zu helfen; einfach-Aufforderungen sind als Vorschläge oder Ratschläge zu sehen. Das erklärt, warum einfach und bloß sowie einfach und $J A$ kaum kombinierbar sind; vgl.:

(7) Und wegen dem Meerschweinchen! ?'Mach bloß einfach die Tür zu!

(7a) 'Mach einfach JA die Tür zu!

Beispiel (7) wurde im Test zu je einem Drittel als akzeptabel, 'vielleicht' akzeptabel und inakzeptabel beurteilt. 
Die beiden Modalpartikeln nur und ruhig verhalten sich unterschiedlich in der Verbindung mit einfach:

Die Kombination von ruhig und einfach ist nahezu inakzeptabel; Beispiel (8) wurde Von 50\% der Testpersonen abgelehnt: 42

(8) Wir machen heut abend ein Fest. ?'Komm einfach ruhig vorbei!

Die Inakzeptabilität läßt sich folgendermaßen erklären: da ruhig permissiven Charakter hat und da bei Aufforderungen mit ruhig dem Sprecher im Regelfall bekannt oder zumindest für ihn ersichtlich ist, daß der Gesprächspartner die Handlung Berne ausführen würde, kann es nicht mit einfach verbunden werden, das ja eher dazu dient, einen Problemlösungsvorschlag bzw. allgemeiner: Vorschläge zu kennZeichnen.

Die Modalpartikel nur dagegen kann lediglich dazu dienen, eine Aufforderung abzumildern, den Gesprächspartner zu ermuntern. Bei nur muß nicht unbedingt für den Sprecher bereits ersichtlich sein, daß der Partner die Handlung gerne ausführen möchte. Und genau aus diesem Grund läßt sich nur mit einfach kombinieren (Beispiel (9) wurde von fast $90 \%$ der Testpersonen akzeptiert):

(9) Und wenn du dann gehst, zieh nur einfach die Tür hinter dir zu; das macht nichts, wenn du nicht absperrst.

Die Kombination nur elnfach ist also zu den akzeptablen Kombinationen zu zählen. Sie ist auch in umgekehrter Reihenfolge (einfach nur) möglich.

Die Tatsache, daß sich nur und ruhig, die hier in den nicht-negierten Imperativsätzen als einigermaßen bedeutungsgleich betrachtet wurden, bezüglich der Kombinlerbarkeit unterschiedlich verhalten, ist ein Indiz dafür, daß sie eben doch nicht bedeutungsgleich sind, und ein Argument dafür, bel der Beschreibung von ruhig die Bedeutungskomponente des Aufhebens eines Verbots, oder schwächer: das Aufheben von Bedenken des Hörers bei der Ausführung der Handlung mehr in den Vordergrund zu rücken. Das wäre ein weiteres Argument dapür, bei ruhig nicht das Merkmal 〈ZUSPRUCH〉 anzunehmen, sondern z.B. 〈STOP〉〈KORREKTUR〉.

4. bloß, JA, nur, ruhig mit schon

Auch diese Kombinationen sind in Aufforderungen nicht akzeptabel:

(10) Max macht einen Besuch bei Gerd, er ist schüchtern und steht verlegen da. Gerd: ?Setz dich nur schon hin!

(11) ?*Hau bloß schon ab! Sonst passiert was. / "Hau JA schon ab!

Bel Beispiel (10) ist man versucht, schon als Temporaladverb zu interpretieren, dann würde diese Aufforderung im entsprechenden Kontext akzeptabel.

42) Bei der m.E. akzeptableren Form: Komm ruhig einfach vorbei! liegt einfach wahrscheinlich als Modaladverb vor. 
Ebenso ist die Verbindung von schon und ruhig sehr fraglich; vgl.:

(12a) Der kleine Max besucht Peter. Dessen Mutter öffnet die Wohnungstür und zelgt Max Peters Zimmer. Max zögert, hineinzugehen. Die Mutter: ?*Geh ruhig schon rein!

(12b) (wie oben)

?"Geh schon ruhig rein!

(13) Mutter und Tochter machen einen Besuch. Als sie dort sind, versteckt sich die kleine Tochter hinter dem Rücken der Mutter. Die Mutter:

?"Jetzt geh schon ruhig und sag 'Guten Tag'.

Bei (12a) muß schon ebenfalls als Temporaladverb interpretiert werden, damit die Außerung akzeptabel ist; bei (12b) und (13) dagegen (also bei umgekehrter Reihenfolge) ist ruhig als Adverb zu interpretieren.

Die Tatsache, daß die Kombination von schon in Aufforderungen mit blo $\beta$, nur und ruhig kaum akzeptabel ist, läßt sich auf folgendes zurückführen: Aufforderungen mit schon fordern zu Handlungen auf, von denen der Angesprochene weiß, daß er sie lăngst hătte ausführen können und sollen; daher kommt der gereizte, drăngende Unterton, den schon-Aufforderungen oft haben. Der Sprecher schränkt durch den Gebrauch von schon mögliche Gegengründe ein, zusätzlich zeigt er ein subjektives Interesse an der Ausfahrung der Handlung.

Bei nur und ruhig dagegen liegt das Interesse zur Ausfuhrung der Handlung mehr aup der Selte des Angesprochenen (Merkmal 〈ZUSPRUCH〉).

Ein zusatzlicher Grund, der auch die Inakzeptabllitat der Kombination von blo $\beta$ mit schon erklärt, ist, daß für den Angesprochenen erst im Moment der Außerung ersichtlich ist, daß er die Handlung ausfüren kann und darf (nur und ruhig) bzw. ausfuhren sollte (bloß). Deshalb 'vertragen' sich bloß, nur und ruhig nicht oder nur schwer mit schon in Aufforderungen.

\section{6. ruhig mit auch}

Die Kombination dleser beiden Modalpartikeln in Imperativsatzen ist ebenfalls inakzeptabel. Das llegt daran, daß bel Aufforderungen mit auch, die ohnehin sehr selten sind, der Sprecher sehr stark die Ausfuhrung der Handlung erwartet und der Gesprächspartner dies auch weiß. Ruhig-Aufforderungen dagegen stellen eine Erlaubnis des Sprechers dar, d.h. aber auch, daß nach Ansicht des Hörers der Sprecher etwas gegen die Ausführung der Handlung haben könnte. Insofern ist die Kombination von ruhig mit auch nicht möglich.

\section{6. schon mit mal}

Aufforderungen mit der Kombination schon mal, bei denen belde Partikeln als Modalpartikeln vorliegen, scheinen ebenfalls kaum akzeptabel, vgl.: 
(14) Mutter: ?Jetzt geh schon mal und sag 'Guten Tag'.

Vermutlich ist die Fragwürdigkeit von schon mal (als Kombination zweler Modalpartikeln wohlgemerkt) ${ }^{43}$ in Aufforderungen darauf zurückzufuhren, daß schonAufforderungen meist eine Komponente des Drăngens enthalten, sie haben oft einen gereizten Unterton. Das aber ist mit mal, das ja Bellăufigkeit und Unauffălligkeit signalisiert, nicht vereinbar.

\section{7. schon mit eben und einfach}

Die Inakzeptabllităt der Kombinationen schon einfach und eben schon liegt auch hier wieder am unterschledlichen Interesse an der Ausfürung der Handlung; eben/einfach-Aufforderungen stellen Vorschläge oder Ratschlăge zur Lösung eines Problems dar, der Sprecher hat aber nicht unbedingt elgenes Interesse an der Ausführung der Handlung; bei Aufforderungen mit schon dagegen zeigt der sprecher durchaus Interesse, da er durch den Einsatz von schon ja auch deutlich macht, daß der Angesprochene der Aufforderung schon längst hătte nachkommen sollen.

(15) "Mach schon einfach/einfach schon eine Dose auf!

(16) 'Steh eben schon/schon eben früher auf!

Halt dagegen ist - wohl auch aufgund der resignierenden Komponente, die es anzeigen kann - mit schon durchaus kombinierbar (s.o. S.259); vgl.:

(17) Mein Gott, jetzt mach halt schon! Ich kann doch nicht ewig warten. (wurde von uber $80 \%$ akzeptiert)

Die Tatsache, daß halt hier kombinierbar ist, eben dagegen nicht, ist ein weiteres Argument dafur, daß halt kein Synonym von eben ist.

\section{Exkurs: bitte und die 'Aufforderungspartikeln'}

Wie schon erwähnt, wird durch die Partikel bitte eine Außerung ${ }^{44}$ höflicher. Gleichzeitig ist bitte aber auch als eln Hinwels darauf zu verstehen, daß der Sprecher an der Ausführung der Handlung interessiert ist; vgl. (18) und (19):

(18) Oberprü mal die Batterie!

(19) Oberprüf bitte die Batterie!

Belspiel (18) könnte in folgendem Kontext geăußert werden: eine Person bastelt an ihrem Auto herum, eine zweite Person, die mehr von Autos versteht, kommt hinzu, sleht sofort, woran der Fehler liegen könnte, und außert (18). In dlesem Fall hat

43) Bel der (akzeptablen) Außerung Geh schon mal vor, ich komm dann nach! muß schon als Temporaladverb interpretiert werden.

44) Die Ausnahmen wurden oben (S.186) bereits angesprochen. 
der Sprecher kein eigenes Interesse an der Ausführung der Handlung - außer dem, seinem Interaktionspartner zu helfen.

Außert ein Sprecher dagegen (19), so ist er sehr wohl an der Ausführung interessiert, in diesem Fall wäre es z.B. vorstellbar, daß es sich um ein Auto handelt, das der Sprecher noch benutzen will.45

Daß bitte zwar Aufforderungen höflich macht, aber nicht unbedingt die gleiche Abschwächungsfunktion erfüllt wie mal, läßt sich an den Fällen sehen, wo in AufPorderungen bitte, nicht aber mal angemessen ist; in der Regel handelt es sich dabel erstens um Aufforderungen, bel denen die Erfüllung der Aufforderung eher weiter in der Zukunft liegt und zweitens um Aufforderungen, die dem Angesprochenen einiges zumuten:

(20) Leih mir bitte übers Wochenende dein Segelboot!46

(21) ?Leih mir mal übers Wochenende dein Segelboot!

Hier spielt sicherlich der ursprünglich temporale Charakter von mal noch eine Rolle.

Bitte kann also nur dann eingesetzt werden, wenn der Sprecher ein Interesse an der Erfüllung der Aufforderung hat.

Aufgrund dessen ist bitte auch mit doch kombinierbar, eine außerordentlich hăufige Kombination; auch die Verbindung doch bitte mal wird oft verwendet:

(22) Geh doch bitte morgen zum Finanzamt!

(23) Rufen Sie doch bitte Herrn Dressler an!

(24) Hol doch bitte mal den Belichtungsmesser!

(25) Else, bringen Sie doch bitte noch mal eben die Karaffe mit Rum... (Ke, 72)

Die Inakzeptabilität der Kombination von bitte mit ebent ${ }^{47}$ einfach, nur und ruhig läßt sich ebenfalls mit dem Interesse des Sprechers an der Ausführung der Handlung erklären:

(26) "Steh bitte eben früher auf!

(27) ?*Bind dir bitte einfach ein Tuch um die Haare!

(28) "Setz dich bitte nur hin!

(29) "Mach bitte ruhig ein Photo!

Interessanterweise ist bitte mit der Modalpartikel halt verträglicher als mit eben (vgl. (30) und (31)); das liegt daran, daß bei halt-Aufforderungen das, wozu aufgefordert wird, auch im Interesse des Sprechers liegen kann, ja daß diese Auffor-

45) Ausgeschlossen ist hier natürlich nicht, daß auch in der zweiten situation Satz (18) geäußert werden kann, nur eben in der ersten Situation ist (19) nicht adäquat.

46) Allerdings würde eine derartige Bitte wohl eher in der Frageform geäußert.

47) Eben in (25) ist ein anderes eben. Vgl. o. S.247f. die Kombination mal eben. 
derungen - im Gegensatz zu solchen mit eben - auch Bitten sein können (s.auch oben S.124; z.B. (7)).

(30) ?Machen Sie halt bitte die Aufträge fertig! Ich kann ja auch nichts daran andern, daß der Chef es heute so eilig hat!

(31) Bleib halt bitte heute abend daheim!

Bel Aufforderungen mit der Partikel schon richtet sich der Sprecher an den Hörer und fordert ihn auf, die Handlung - an der dem Sprecher selbst gelegen ist auszuführen; diesen Außerungen geht in der Regel eine zögernde Haltung des Angesprochenen voraus, und durch den Gebrauch von schon weist der Sprecher den Hörer an, seine bisherige Haltung aufzugeben. Hier scheint die Kombination mit bitte nicht ganz so inakzeptabel wie bel den Partikeln eben und einfach; das liegt sicher auch daran, daß dem Sprecher bei Aufforderungen mit schon ein Interesse an der Ausführung der Handlung unterstellt werden darf; vgl.:

(32) ?Nun mach bitte schon die Steuererklärung fertig! Das Finanzamt wartet leider nicht.

Mit den beiden Modalpartikeln $b l o \beta$ und $J A$, die Aufforderungen als dringliche, manchmal auch als drohende Aufforderungen kennzeichen, ist bitte nur schwer zu kombinieren; vgl::

(33) ?'Paß bitte bloß auf die Geige auf! Das ist ein wertvolles Stück!

(34) ?Machen Sie bitte JA keine Aufnahmen im Gegenlicht! Die Leser wollen was sehen.

Die Tatsache, daß Beisplel (34) Im Gegensatz zu den Beispielen (26)-(29) oben nicht ganz inakzeptabel ist, zeigt, daß Aupforderungen mit bitte höflicher werden (wobel es sich trotzdem nicht immer um eine wirklich höfliche Aufforderung handelt), und zelgt zum anderen, daß bitte nur adäquat verwendet werden kann, wenn der Sprecher eigenes Interesse an der Ausführung der Handlung hat, was ja auch die reguläre Verwendungsbedingung für Aufforderungen darstellt.

\subsubsection{Zusammenfassung}

Die übersicht auf den nächsten Seiten zeigt zusammenfassend alle Kombinationen, die mit den hier besprochenen Modalpartikeln möglich sind und die alle im vorangegangenen beschrieben wurden.

Tabelle 12: Modalpartikel-Kombinationen 


\begin{tabular}{|c|c|c|c|c|c|c|c|c|c|c|c|}
\hline 278 & puch & blop & denn & doch & eben & eigentl. & einfach & etwa & halt & Ja & JA \\
\hline aber & $\begin{array}{l}\text { aber' } \\
\text { quéch }\end{array}$ & $\begin{array}{l}\text { aber } \\
\text { blop }\end{array}$ & $\begin{array}{l}\text { sbon } \\
\text { genn }\end{array}$ & $\begin{array}{l}\text { abor } \\
\text { goch }\end{array}$ & $\begin{array}{l}\text { abot } \\
\text { gben }\end{array}$ & $\begin{array}{l}\text { aber/ } \\
\text { ejgentl. }\end{array}$ & $\begin{array}{l}\text { abey } \\
\text { efhrach }\end{array}$ & $\begin{array}{l}\text { abed } \\
\text { etwa }\end{array}$ & $\begin{array}{l}\text { abep } \\
\text { hatt }\end{array}$ & 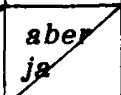 & \\
\hline auch & & $\begin{array}{l}\text { such } \\
\text { bloß }\end{array}$ & $\begin{array}{l}\text { denn } \\
\text { auch }\end{array}$ & $\begin{array}{l}\text { doch } \\
\text { auch }\end{array}$ & $\begin{array}{l}\text { eben } \\
\text { auch }\end{array}$ & $\begin{array}{l}\text { ?'auch } \\
\text { eigentl. }\end{array}$ & $\begin{array}{l}\text { such } \\
\text { einfach }\end{array}$ & $\begin{array}{l}\text { ?"such } \\
\text { etwa }\end{array}$ & $\begin{array}{l}\text { halt } \\
\text { auch }\end{array}$ & $\begin{array}{l}\text { Ja } \\
\text { auch }\end{array}$ & $\begin{array}{l}\text { auch } \\
J A\end{array}$ \\
\hline bloß & & & $\begin{array}{l}\text { denn } \\
\text { blop }\end{array}$ & $\begin{array}{l}\text { doch } \\
\text { blop }\end{array}$ & $\begin{array}{l}\text { "bloß } \\
\text { eben }\end{array}$ & $\begin{array}{l}\text { eigentl. } \\
\text { bloß }\end{array}$ & $\begin{array}{l}\text { blo } \beta \\
\text { einfach }\end{array}$ & $\begin{array}{l}\text { blop } \\
\text { etwa }\end{array}$ & $\begin{array}{l}\text { "blo } \\
\text { halt }\end{array}$ & ja & bIok \\
\hline denn & & & & $\begin{array}{l}\text { denn } \\
\text { doch }\end{array}$ & $\begin{array}{l}\text { denh } \\
\text { gren }\end{array}$ & $\begin{array}{l}\text { denn } \\
\text { eigentl. }\end{array}$ & $\begin{array}{l}\text { denn } \\
\text { einfach }\end{array}$ & $\begin{array}{l}\text { denn } \\
\text { etwa }\end{array}$ & $\begin{array}{l}\text { dend } \\
\text { halt }\end{array}$ & $\begin{array}{l}\text { ján } \\
\text { dén }\end{array}$ & \\
\hline doch & & & & & $\begin{array}{l}\text { doch } \\
\text { eben }\end{array}$ & "doch & $\begin{array}{l}\text { doch } \\
\text { elnfach }\end{array}$ & $\begin{array}{l}\text { doch } \\
\text { etwa }\end{array}$ & $\begin{array}{l}\text { doch } \\
\text { halt }\end{array}$ & $\begin{array}{l}\text { ja } \\
\text { doch }\end{array}$ & $\begin{array}{l}\text { ?doch } \\
\text { JA }\end{array}$ \\
\hline eben & & & & & & $\begin{array}{l}\text { eben } \\
\text { ejentl }\end{array}$ & $\begin{array}{l}\text { eben } \\
\text { einfach }\end{array}$ & $\begin{array}{l}\text { eber } \\
\text { gtwa }\end{array}$ & $\begin{array}{l}\text { halt } \\
\text { eben }\end{array}$ & \begin{tabular}{|l} 
ja \\
eben
\end{tabular} & $\begin{array}{l}\text { "eben } \\
\text { JA }\end{array}$ \\
\hline eigentl & lich & & & & & & $\begin{array}{l}\text { eigentl } \\
\text { einfach }\end{array}$ & $\begin{array}{l}\text { eigent } \\
\text { etwa }\end{array}$ & $\begin{array}{l}\text { eigent } \\
\text { hait }\end{array}$ & eigght & \\
\hline einfach & & & & & & & & $\begin{array}{l}\text { einfac. } \\
\text { etwa }\end{array}$ & $\begin{array}{l}\text { halt } \\
\text { elnfac. }\end{array}$ & $\begin{array}{l}\text { ja } \\
\text { einfac }\end{array}$ & einfac \\
\hline etwa & & & & & & & & & $\begin{array}{l}\text { etwo } \\
\text { hat }\end{array}$ & etwe & et: \\
\hline halt & & & & & & & & & & $\begin{array}{l}\text { "halt } \\
j a\end{array}$ & $\begin{array}{l}\text { halt } \\
\text { JA }\end{array}$ \\
\hline ja & & & & & & & & & & & \\
\hline JA & & & & & & & & & & & \\
\hline mal & & & & & & & & & & & \\
\hline nicht & & & & & & & & & & & \\
\hline nur & & & & & & & & & & & \\
\hline ruhig & & & & & & & & & & & \\
\hline schon & & & & & & & & & & & \\
\hline sowiesp & & & & & & & & & & & \\
\hline vielleic & cht & & & & & & & & & & \\
\hline
\end{tabular}




\begin{tabular}{|c|c|c|c|c|c|c|c|c|}
\hline mal & nicht & nur & ruhig & schon & sowieso & vielleicht & wohl & 279 \\
\hline $\begin{array}{l}\text { aber } \\
\text { mal }\end{array}$ & $\begin{array}{l}\text { aber } \\
\text { nicht }\end{array}$ & $\begin{array}{l}\text { aber } \\
\text { nur }\end{array}$ & $\begin{array}{l}\text { aber } \\
\text { ryhig }\end{array}$ & $\begin{array}{l}\text { aber } \\
\text { sehon }\end{array}$ & $\begin{array}{l}\text { aber } \\
\text { sowieso }\end{array}$ & $\begin{array}{l}\text { aber } \\
\text { viellei. }\end{array}$ & $\begin{array}{l}\text { aber } \\
\text { wohI }\end{array}$ & aber \\
\hline $\begin{array}{c}\text { ?auch } \\
\text { mal }\end{array}$ & $\begin{array}{l}\text { "auch } \\
\text { nicht }\end{array}$ & $\begin{array}{l}\text { guch } \\
\text { nur }\end{array}$ & $\begin{array}{l}\text { :auch } \\
\text { ruhig }\end{array}$ & $\begin{array}{l}\text { such } \\
\text { schon }\end{array}$ & $\begin{array}{l}\text { "auch } \\
\text { sowieso }\end{array}$ & $\begin{array}{l}\text { *auch } \\
\text { viellei. }\end{array}$ & $\begin{array}{l}\text { wohl } \\
\text { guch }\end{array}$ & auch \\
\hline $\begin{array}{l}\text { blo } \beta \\
m a l\end{array}$ & $\begin{array}{l}\text { blok } \\
\text { nicht }\end{array}$ & $\begin{array}{l}\text { nur } \\
\text { blo } \beta\end{array}$ & $\begin{array}{l}\text { "bloß } \\
\text { ruhig }\end{array}$ & $\begin{array}{l}\text { "bloß } \\
\text { schon }\end{array}$ & $\begin{array}{l}\text { blok } \\
\text { sowi }\end{array}$ & $\begin{array}{l}\text { bloß/1 } \\
\text { viellei. }\end{array}$ & $\begin{array}{c}\text { ?wohl } \\
\text { bloß }\end{array}$ & blo $\beta$ \\
\hline $\begin{array}{l}\text { ?denn } \\
\text { mal }\end{array}$ & $\begin{array}{l}\text { denn } \\
\text { nicht }\end{array}$ & $\begin{array}{l}\text { denn } \\
\text { nur }\end{array}$ & $\begin{array}{l}\text { denn } \\
\text { ryhig }\end{array}$ & $\begin{array}{l}\text { denn } \\
\text { schon }\end{array}$ & $\begin{array}{l}\text { denn } \\
\text { sonieso }\end{array}$ & $\begin{array}{l}\text { denn } \\
\text { viellei. }\end{array}$ & $\begin{array}{l}\text { denn } \\
\text { wohl }\end{array}$ & denn \\
\hline $\begin{array}{l}\text { doch } \\
\mathrm{mal}\end{array}$ & $\begin{array}{l}\text { doch } \\
\text { nicht }\end{array}$ & $\begin{array}{l}\text { doch } \\
\text { nur }\end{array}$ & $\begin{array}{l}\text { doch } \\
\text { ruhig }\end{array}$ & $\begin{array}{l}\text { doch } \\
\text { schon }\end{array}$ & $\begin{array}{l}\text { doch } \\
\text { sowieso }\end{array}$ & $\begin{array}{l}\text { ?"doch } \\
\text { viellei. }\end{array}$ & $\begin{array}{l}\text { doch } \\
\text { wohl }\end{array}$ & doch \\
\hline $\begin{array}{l}\text { eben } \\
\text { mal }\end{array}$ & $\begin{array}{l}\text { eben/ } \\
\text { njeht }\end{array}$ & $\begin{array}{l}\text { *eben } \\
\text { nur }\end{array}$ & $\begin{array}{l}\text { eben } \\
\text { ruhig }\end{array}$ & $\begin{array}{l}\text { eben } \\
\text { schon }\end{array}$ & $\begin{array}{l}\text { "eben } \\
\text { sowleso }\end{array}$ & $\begin{array}{l}\text { eben } \\
\text { viellei. }\end{array}$ & $\begin{array}{l}\text { ?eben } \\
\text { wohl }\end{array}$ & eben \\
\hline $\begin{array}{c}\text { ?elgent. } \\
\mathrm{e}^{\mathrm{mal}}\end{array}$ & $\begin{array}{l}\text { eigent. } \\
\text { nicht }\end{array}$ & $\begin{array}{l}\text { eigent. } \\
\text { nur } \\
\end{array}$ & $\begin{array}{l}\text { elgent. } \\
\text { ryhig }\end{array}$ & $\begin{array}{c}\text { ?eigent. } \\
\text { schon }\end{array}$ & $\begin{array}{l}\text { eigept. } \\
\text { sowieso }\end{array}$ & $\begin{array}{l}\text { eigent. } \\
\text { viellei. }\end{array}$ & $\begin{array}{l}\text { "eigent. } \\
\text { wohl }\end{array}$ & eigentl. \\
\hline $\begin{array}{l}\text { elnfach } \\
\text { mal }\end{array}$ & $\begin{array}{l}\text { einfach } \\
\text { nicht }\end{array}$ & $\begin{array}{l}\text { einfach } \\
\text { nur }\end{array}$ & $\begin{array}{l}\text { "einfach } \\
\text { ruhig }\end{array}$ & $\begin{array}{c}\text { einfach } \\
\text { schon }\end{array}$ & $\begin{array}{c}\text { "elnfach } \\
\text { sowieso }\end{array}$ & $\begin{array}{l}\text { einfach } \\
\text { viellei. }\end{array}$ & $\begin{array}{l}\text { einfach } \\
\text { wohl }\end{array}$ & einfach \\
\hline $\begin{array}{r}\text { ?etwa } \\
m a l\end{array}$ & $\begin{array}{l}\text { "etwa } \\
\text { nicht }\end{array}$ & $\begin{array}{l}\text { etwg } \\
\text { nur }\end{array}$ & $\begin{array}{l}\text { etwa } \\
\text { ryhig }\end{array}$ & $\begin{array}{l}\text { etwo } \\
\text { sehon }\end{array}$ & $\begin{array}{l}\text { etwg } \\
\text { sowieso }\end{array}$ & $\begin{array}{l}\text { Petwa } \\
\text { viellei. }\end{array}$ & $\begin{array}{l}\text { wohl } \\
\text { etwa }\end{array}$ & etwa \\
\hline $\begin{array}{l}\text { halt } \\
\text { mal }\end{array}$ & $\begin{array}{l}\text { halt } \\
\text { nicht }\end{array}$ & $\begin{array}{l}\text { ?halt } \\
\text { nur }\end{array}$ & $\begin{array}{l}\text { halt } \\
\text { ruhig }\end{array}$ & $\begin{array}{l}\text { halt } \\
\text { schon }\end{array}$ & $\begin{array}{l}\text { ?halt } \\
\text { sowieso }\end{array}$ & $\begin{array}{l}\text { hal } \\
\text { yie }\end{array}$ & $\begin{array}{l}\text { halt } \\
\text { wohl }\end{array}$ & halt \\
\hline $\begin{array}{l}\mathrm{ja} \\
\mathrm{mal}\end{array}$ & jacht & $\begin{array}{l}\text { ja } \\
\text { nur }\end{array}$ & $\begin{array}{l}\text { ja } \\
\text { ruhig }\end{array}$ & $\begin{array}{l}\text { ja } \\
\text { schon }\end{array}$ & $\begin{array}{l}\text { ja } \\
\text { sowieso }\end{array}$ & ja yiénéi. & $\begin{array}{l}\text { ja } \\
\text { wohl }\end{array}$ & $\mathrm{ja}$ \\
\hline \multirow[t]{8}{*}{$\begin{array}{l}\cdot J_{A} \\
m a l\end{array}$} & JA & $\begin{array}{l}\text { nur } \\
J A\end{array}$ & $\begin{array}{l}\text { JA } \\
\text { ruhig }\end{array}$ & $\begin{array}{l}\text { JA } \\
\text { schon }\end{array}$ & & & $J A$ & $\mathrm{JA}$ \\
\hline & $\begin{array}{l}\text { nicht } \\
\text { mal }\end{array}$ & $\begin{array}{l}\text { nur } \\
\text { mal }\end{array}$ & $\begin{array}{l}\text { ruhig } \\
\mathrm{mal}\end{array}$ & $\begin{array}{l}\text { ?schon } \\
\text { mal }\end{array}$ & $\begin{array}{l}\text { sowieso } \\
\text { mal }\end{array}$ & $\begin{array}{c}\text { ?viellei. } \\
\text { mal }\end{array}$ & $\begin{array}{l}\text { wohl } \\
\text { mal }\end{array}$ & $\mathrm{mal}$ \\
\hline & & $\begin{array}{l}\text { niche } \\
\text { nur }\end{array}$ & $\begin{array}{l}\text { nichy } \\
\text { rynig }\end{array}$ & $\begin{array}{l}\text { nicht } \\
\text { sehon }\end{array}$ & $\begin{array}{l}\text { nicht } \\
\text { sowieso }\end{array}$ & $\begin{array}{l}\text { "nicht } \\
\text { viellel. }\end{array}$ & $\begin{array}{c}{ }^{*} \text { nicht } \\
\text { wohl }\end{array}$ & nicht \\
\hline & & & $\begin{array}{l}\text { nur } \\
\text { ruhig }\end{array}$ & $\begin{array}{l}\text { ?"nur } \\
\text { schon }\end{array}$ & $\begin{array}{l}\text { nur } \\
\text { sowieso }\end{array}$ & . & $\begin{array}{l}\text { ?wohl } \\
\text { nur }\end{array}$ & nur \\
\hline & & & & $\begin{array}{r}\text { ?"ruhig } \\
\text { schon }\end{array}$ & $\begin{array}{c}\text { ?"ruhig } \\
\text { sowieso }\end{array}$ & $\begin{array}{l}\text { ruhig } \\
\text { yellei. }\end{array}$ & $\begin{array}{c}\text { ruhig } \\
\text { wohl }\end{array}$ & ruhig \\
\hline & & & & & $\begin{array}{l}\text { "schon } \\
\text { sowleso }\end{array}$ & $\begin{array}{l}\text { schop } \\
\text { yellei. }\end{array}$ & $\begin{array}{l}\text { wohl } \\
\text { schon }\end{array}$ & schon \\
\hline & & & & & & $\begin{array}{l}\text { sowioso } \\
\text { yellei. }\end{array}$ & $\begin{array}{l}\text { wohl } \\
\text { sowieso }\end{array}$ & sowieso \\
\hline & & & & & & & $\begin{array}{l}\text { viell } \\
\text { wohl }\end{array}$ & viell. \\
\hline
\end{tabular}


Die Kombinationen, die aus syntaktisch-distributionellen Gründen nicht zulässig sind, wurden in der vorangegangenen Tabelle durchgestrichen; ist eine Kombinstion dennoch möglich (d.h. tritt eine Modalpartikel in der Kombination in einem Satzmodus auf, in dem sie allein nicht möglich ist), wird dies durch eine durchbrochene Linie angezeigt. Das betrifft vor allem Kombinationen mit denn in Aussagesătzen (vgl. dazu die Ausführungen oben s.222).

Die semantisch inakzeptablen Kombinationen sind mit '*' oder (schwächer) '?"' versehen, die Praglichen mit '?'.48 (Bel den Kombinationen von mal mit auch, denn. eigentllch und etwa bezieht sich das Fragezeichen in der Tabelle allerdings nicht auf Pragliche (semantische) Akzeptabilitat, sondern auf die Tatsache, da $\beta m a l$ nicht in Modalpartikel-Funktion vorliegt.)

Bei den akzeptablen und gebräuchlichen Kombinationen wurden die Modalpartikeln in der richtigen Reihenfolge notiert; diese Kombinationen sind durch Fettdruck hervorgehoben.

Die Kombination von $j a$ und denn ist nur in der Form ja denn doch möglich, die von doch und etwa, bzw. von wohl und etwa nur in der form doch nicht etwa bzw. doch wohl nicht etwa.

Die Untersuchung der Modalpartikel-Kombinationen hat gezeigt, daß es eine große Anzahl häufig auftretender Kombinationen gibt: mit den in dieser Arbeit behandelten Modalpartikeln lassen sich (theoretisch) 171 (Zweier-)Kombinationen bilden; 49 verwendet werden davon etwa 50 Kombinationen.

Bel der Analyse der Modalpartikel-Bedeutungen hat sich die Ausgangshypothese, wonach eine Modalpartikel-Kombination als Summe der Einzelbedeutungen zu verstehen ist, bestätigt.

Auch die in Kapitel 2 angenommenen Bedeutungen für jede Modalpartikel, die die Grundlage der Kombinations-Analyse bildeten, konnten im wesentlichen bestätigt werden.

Lediglich bei denn ließ sich das Merkmal (UNERWARTET) (das allerdings auch bel alleinigem Auftreten in w-Fragesätzen nur fakultativ war) nicht uberall nachweisen; besonders in den Kombinationen in w-Fragesätzen und Aussagesätzen, aber zum Teil auch in den Entscheidungsfragesätzen, kann denn nur mit dem Merkmal 〈KONNEX〉 beschrieben werden.

48) Um es noch einmal zu betonen: Beim Vorliegen von anderen Partikel-Funktionen mag elne Kombination (bzw. das Auftreten von beiden Partikeln im selben Satz) natürlich durchaus möglich sein.

49) Bei dleser Zahl ist mir allerdings nicht berücksichtigt; die beiden Varianten von $j a$ wurden nur einmal gezähit. 
Für die Modalpartikel ruhig ist sowohl aufgrund des Verhaltens in bezug auf die Negation als auch aufgrund der Kombinatorik zu überlegen, ob nicht statt des Merkmals 〈ZUSPRUCH〉 zwei Merkmale wie 〈STOP〉〈KORREKTUR〉 angenommen werden sollten.

Bel den sogenannten 'Synonymen' eben und halt hat die Kombinatorik wesentliche Unterschiede zwischen den beiden Partikeln gezeigt und damit weitere Argumente für die oben bereits vertretene These geliefert, daß es sich hier keineswegs um Synonyme handelt.

Auch bei den beiden Partikeln nur und blok, die weitgehend synonym sind, hat die Kombinatorik noch einmal diejenigen Bereiche verdeutlicht, in denen sie unterschiedliche Funktionen erfüllen.

Schließlich wurden durch die möglichen Kombinationen auch bemerkenswerte Unterschiede zwischen (betontem) JA und bloß sichtbar; vgl.:

Komm doch bloß rechtzeitig heim! vs. Komm ?JA bloß rechtzeitig heim!

Komm ? auch bloß rechtzeitig heim! vs. Komm auch JA rechtzeitig heim!

Die Untersuchung der Modalpartikel-Kombinatorik konnte also weitere wesentliche Aufschlüsse uber die Bedeutung von Modalpartikeln liefern.

Die folgende Obersicht (Tabelle 13) zeigt die Distribution der gebräuchlichen Modalpartikel-Kombinationen in den einzelnen Satzmodi. ${ }^{30}$

In den meisten Făllen entsprechen die für eine Kombination zulässigen Satzmodi der Schnittmenge der Satzmodi, in denen die einzelnen Partikeln auftreten können: Zum Beispiel:

- die Kombination von doch (AUS/W-FRA/IMP/WU/W-EX) mit einfach (AUS/ENT/IMP) tritt auf in Aussagesätzen und Imperativsätzen;

- die Kombination von denn (ENT/W-FRA) mit eigentlich (ENT/W-FRA) ist in Entscheidungsfragen und $w$-Fragen zulässig.

Restriktionen ergeben sich:

- bei auch (AUS/ENT/W-FRA/IMP/W-EX) in Kombination mit schon (AUS/W-FRA/ IMP): die Kombination such schon ist in Aussagesätzen nicht zulässig;

- bei auch (AUS/ENT/W-FRA/IMP/W-EX) mit bloß/nur (W-FRA/IMP/WU/W-EX): die Kombinationen treten nicht in $w$-Fragesätzen auf;

- bei doch (AUS/W-FRA/IMP/WU/W-EX) mit bloB/nur (W-FRA/IMP/WU/W-EX): doch blo $\beta$ und doch nur sind in $W$-Fragesätzen kaum akzeptabel - wohl aber in Imperativsätzen, Wunschsätzen und w-Exklamativsätzen.

50) Der Satzmodus (Satz-)Exklamativsatz fehlt, da hier keine wirklich prequente Kombination auftritt. Auf den Sonderfall $j a$ vielleicht wurde oben (S.2539f.) schon hingewiesen. 
Die Gründe für die Inakzeptabilität wurden bei den jeweiligen Kombinationen beschrieben. Die Partikel denn (deren Klassifizierung allerdings unklar ist) in den Kombinationen in Aussagesätzen und etwa in doch (wohl) nicht etwa in Aussagesätzen stellen - wie schon erwähnt - insofern eine Ausnahme dar, als hier eine Partikel in der Kombination in einem Satzmodus auftritt, in dem sie alleine nicht zulässig ist.

Tabelle 13: Distribution der Modalpartikel-Kombinationen

\begin{tabular}{|c|c|c|c|c|c|}
\hline $\begin{array}{l}\text { AUSSAGE- } \\
\text { SATZ }\end{array}$ & $\begin{array}{l}\text { ENTSCHEI- } \\
\text { DUNGSFRAGE }\end{array}$ & $\begin{array}{l}\text { W-FRAGE- } \\
\text { SATZ }\end{array}$ & $\begin{array}{l}\text { IMPERATIV - } \\
\text { SATZ }\end{array}$ & WUNSCHSATZ & $\begin{array}{l}\text { W-EXKLAMA- } \\
\text { TIVSATZ }\end{array}$ \\
\hline $\begin{array}{l}\text { ja auch } \\
\text { ja eben } \\
\text { ja einfach } \\
\text { ja mal } \\
\text { ja schon } \\
\text { ja sowieso } \\
\text { ja wohl } \\
\text { doch sowieso } \\
\text { wohl auch } \\
\text { wohl sowieso } \\
\text { denn doch } \\
\text { doch wohl } \\
\text { doch nicht et }\end{array}$ & $\begin{array}{l}\text { such JA } \\
\text { denn eigentI } \\
\text { denn etwa } \\
\text { denn nicht }\end{array}$ & $\begin{array}{l}\text { denn eigentl } \\
\text { denn bloß } \\
\text { denn nur } \\
\text { denn schon } \\
\text { auch schon }\end{array}$ & $\begin{array}{l}\text { doch bloß } \\
\text { doch nur } \\
\text { doch einfach } \\
\text { eben einfach } \\
\text { halt eben } \\
\text { halt einfach } \\
\text { doch schon } \\
\text { doch Inal } \\
\text { doch ruhig } \\
\text { ruhig mal } \\
\text { auch JA } \\
\text { bloß JA } \\
\text { nur JA } \\
\text { nur mal } \\
\text { nur ruhig } \\
\text { halt schon } \\
\text { halt mal } \\
\text { eben mal }\end{array}$ & $\begin{array}{l}\text { doch bloß } \\
\text { doch nur } \\
\text { einfach mal }\end{array}$ & $\begin{array}{l}\text { auch blo } \\
\text { auch nur } \\
\text { aber auch }\end{array}$ \\
\hline
\end{tabular}

Da also - bis auf die eine (klare) Ausnahme doch nicht etwa - die Kombinationen nur in den Satzmodi auftreten, mit denen auch die Einzelpartikeln jeweils kompatibel sind, kann die Kombinationsfähigkelt von Modalpartikeln letztlich auch als Kriterium zur Identifikation von Satzmodi herangezogen werden.

51) Diese Kombinationen sind nur in Aussagesätzen möglich, die durch andere Mittel, vor allem Modalverben, so modifiziert sind, daß sie Aufforderungen darstellen. 
Ein Beispiel soll dies verdeutlichen: Außerungen mit w-Ausdrücken und nur/bloß wurden in dieser Arbeit - wie mehrfach dargestellt - als Fragen oder als w-Exklamative und nicht als rhetorische Fragen eingeordnet. Die Modalpartikel auch dagegen tritt in rhetorischen $w$-Fragen und in $w$-Exklamativen auf. Außerungen mit der Kombination auch bloß oder auch nur können nur $w$-Exklamativsätze sein, da in $w$-Fragen die Bedeutung von $b l o \beta / n u r$ mit dem rhetorizitätsanzeigenden auch nicht kompatibel ist. Aus diesem Grund ist bloß/nur mit schon, das ausschlleßlich in rhetorischen $w$-Fragen (und nicht in $w$-Exklamativen) auftritt, uberhaupt nicht kombinierbar. Wären $w$-Fragen mit bloß und nur (auch) rhetorische Fragen, so gäbe es keinen Grund, warum diese Partikeln mit schon überhaupt nicht und mit auch in bestimmten Vorkommen nicht vereinbar sein sollten: die beiden rhetorizitätsanzeigenden Modalpartikeln auch und schon sind nämlich kombinierbar.

In diesen Fällen kann also die Kombinierbarkeit und die Nicht-Kombinierbarkeit bei auch, bloß/nur und schon ein (zusätzliches) Argument zur Klassifizierung bestimmter Außerungen mit $w$-Ausdrücken llefern.

Die Kombinatorik kann letztlich auch zur Abgrenzung von Partikel-Funktionen dienlich sein: In einer Entscheidungsfrage beispielsweise, in der die Modalpartikeln denn, etwa, oder eigentlich auftreten, kann gleichzeitig vorkommendes mal nur Temporaladverbial sein

\subsection{Mehrfachkombinationen}

Wie schon einige Beispielsätze gezeigt haben, sind auch Mehrfachkombinationen von Modalpartikeln möglich. Belegt sind Gruppen von drei und - seltener - von vier Modalpartikeln.

Auf die Mehrfachkombinationen ausführlich einzugehen, würde hier zu weit führen; deshalb möchte ich nur ein paar allgemeine Voraussetzungen für die Kombination von mehr als zwei Modalpartikeln angeben.

Zunächst einmal müssen alle Modalpartikeln einer Mehrfachkombination distributionell kompatibel sein, d.h. sie müssen im selben Satzmodus auftreten.

Außerdem sind Dreier- und Vierergruppen nur möglich, wenn jede Partikel mit jeder aus der Gruppe semantisch kompatibel ist. Dies soll an einigen Beispielen verdeutlicht werden:

Aus der Ubersicht auf S.178/9 geht hervor, daß die Kombinationen denn schon, denn auch und auch schon akzeptabel und gebräuchlich sind. Auch eine Dreierkombination ist daher möglich; vgl.: 
(1) Inge: Der Peter war gestern unheimlich wütend, well Marion mit einem Arbeltskollegen ins Kino gegangen ist und erst um drei Uhr früh heimgekommen ist.

Reni: Da würd ich mich nicht aufregen, ich find das nicht schlimm.

Inge: Eben. Was ist denn auch schon dabel, wenn sle mit diesem Typen ins Kino geht?

(2) Nein gar nichts Schlimmes: Nur ein kleines Mädchen steht da mitten in der Fußgängerzone und plärrt hemmungslos seinen Schmerz und seinen Zorn in die Umwelt. Aber die Mammi ist ja dabei, und so braucht man sich nicht weiter darum zu kümmern. Was wird's denn auch schon groß sein? Vielleicht hat sich der blauäugige Blondengel an einem von den betonernen Blumenkübeln den Zeh angestoßen. (SZ)

Ebenso sind die Kombinationen doch ruhig, doch mal, nur ruhig und nur mal und ruhig mal möglich; deshalb lassen sich aus allen diesen Modalpartikeln folgende Gruppen bilden:

(3) Komm doch ruhig mal vorbei!

(4) Komm doch nur mal vorbeil

(5) Komm doch nur ruhig mal vorbei!

Dagegen ist eine Kombination wie in (5) mit bloß anstelle von nur nicht möglich (vgl. (5a)); bloß kann zwar mit doch zusammen auftreten, nicht aber mit mal oder ruhig, deswegen ist auch eine Vierergruppe mit diesen Modalpartikeln nicht akzeptabel:

(5a) "Komm doch bloß ruhig mal vorbel!

Andere Mehrfachkombinationen zeigen folgende Beispiele:

(6) Ich welß nicht, irgendwie hab ich doch an ihm gehangen, er war immer nett und großzügig zu mir, und auf seine Art hat er mich ja wohl auch gern gehabt oder sogar gellebt. (Bö c, 228)

(7) Es handelt sich offensichtlich um eine ernstzunehmende Panne. Sonst bräuchte sie ja wohl auch im vorliegenden Fall nicht beseitigt zu werden.

(8) Neffe: ...und dann haben sich die Eltern furchtbar aufgeregt, weil ich einfach ihr Auto genommen habe.

Tante: Na, das ist aber doch auch elne Frechheit!!

(9) Mein Gott, wie kann man nur an der steckdose was reparieren ohne die Sicherung rauszudrehen! Du bist doch aber auch $\mathrm{zu}$ dumm!

(10) Gestern war ich wieder bei Marion und Peter. Der Peter hat den ganzen Abend keinen Ton gesagt und nur wütend vor sich hin gestarrt. Den hab ich noch nie freundlich gesehen. Was ist das denn eigentlich nur für ein Mensch!

(11) Die Versicherung zahlt 10\% von dem Schaden. Das ist derin doch bloß Augenwischerei!

(12) Was ist das denn auch nur für eine Hochzeit, wo ein Vertrag vorgelesen Wird anstelle eines Eheversprechens?!

(13) Was wollen Sie damit erreichen? Daß ich eine Moralpredigt kriege? $\mathrm{Na}$ schön. Im übrigen aber, (..) was Ritterlichkeit ist, darüber denkt der Oberst denn doch wohl etwas anders als ein Herr, der sich nicht schlägt. (Ma, 305) 
(14) Mutter: Du bist mir ja ein Stoffel! Wenn du schon mal in Omas Nähe bist, hattest du ja doch wohl mal kurz bel ihr vorbeischauen können!

(15) Red doch nicht so lang rum! Sag halt schon einfach, was du willst!

Mehrfachkombinationen sind also nur zulăssig, wenn jede Modalpartikel mit jeder anderen aus der Gruppe 'verträglich' ist.

Eine Ausnahme stellen die Kombinationen ja denn doch und doch wohl nicht etwa dar: Die Verbindung von ja und denn ist nur mit doch möglich, ebenso sind wohl und etwa nur in der Verbindung doch wohl nicht etwa akzeptabel.

(16) Was? Du hast doch wohl nicht etwa das ganze Geld versplelt?

(17) Was soll denn das? Das ist ja denn doch die Höhe!

Für alle anderen Modalpartikeln aber gilt die oben aufgestellte Regel.

\subsection{Syntaktisches Verhalten}

\subsubsection{Die Relhenfolge innerhalb der Kombination}

\subsubsection{Zur Forschung}

Die Abfolge von (Modal-)Partikeln, der "adjungierten Adverbialia", wie er sie nennt, hat als erster Engel (1968/1971:91ff.) untersucht; er etabliert sieben Gruppen, die die Reihenfolge der Partikeln in Satz angeben: "treten Partikeln verschiedener Gruppen im selben Satz auf, so gilt die Reihenfolge $a-b-c-d-e-f^{\prime \prime} . A I-$ lerdings hat Engel nicht nur Modalpartikeln betrachtet und unterscheidet auch nicht immer klar zwischen den verschiedenen Funktionen.

Ahnlich verfahren Helbig/Kötz (1981:41f.). die folgende fünf Gruppen aufstellen:
a) denn, doch (unbetont), elgentlich, etwa, ja
b) aber, eben, halt, vielleicht, wohl
c) doch (betont), schon
d) auch, $\mathrm{mal}$
e) blok, nur

Hier zeigt sich ganz deutlich das Problem dieser Analyse, ein Problem, das auch bei Engel auftritt: In welcher Reihenfolge stehen Partikeln, die in derselben Gruppe sind? Muß die Reihenfolge denn-eigentlich oder elgentlich-denn, ja-denndoch oder denn-doch-ja lauten?

$\mathrm{Da}$ also sowohl bel den von Engel als auch bel den von Helbig aufgestellten Gruppen mehrere Elemente aus einer Gruppe zusammen auftreten können, deren Abfolge ebenso festgelegt ist und nicht der Reihenfolge der Notierung entspricht. ist es Praglich, ob das Aufstellen solcher Gruppen ubberhaupt sinnvoll ist.

\subsubsection{Stellungsregeln far die einzelnen Modalpartikein}

Die Obersicht auf $\mathrm{s} .178 / 9$ gibt bereits Aufschluß über die Stellungseigenschaften der einzelnen Modalpartikeln.

Zunächst soll für jede einzelne Modalpartikel (die jeweils durch Umrahmung hervorgehoben ist) die Stellung in der Kombination mit anderen angegeben werden, 
wobel selbstverständlich nur die akzeptablen Modalpartikel-Kombinationen berücksichtigt werden.

Dabei sind alle Modalpartikeln ihrer Reihenfolge entsprechend von links nach rechts angeordnet; aus den Stellungseigenschaften für jede einzelne Modalpartikel lassen sich also auch Regeln für die Serialisierung in Mehrfachkombinationen ablesen.

Zudem ist noch einmal ersichtlich, welche Modalpartikeln mit welchen kombiniert werden können; das ist besonders beim Vergleich der 'Synonyme' halt und eben sowie blo $\beta$ und nur interessant.

Die folgenden Stellungsregeln sind obligatorisch, wie die mit 'A' bezeichneten Beispiele zelgen.

Bei bestimmten Modalpartikeln sind in der Kombination beide Stellungsvarianten möglich; diese wurden mit Schrägstrich bzw. zweifach notiert.

ja -denn-doch-eben-wohl-einfach-sowieso-vielleicht-schon/auch-ruhig-mal

(1) Das ist ja vielleicht auch eine Frechheit!

(2) Der wird das ja doch wohl nicht von mir erwarten.

(3) Es ist ja einfach such so, daß wir die Finanzen berücksichtigen müssen.

(4) Du könntest ja ruhig mal etwas freundlicher sein.

(5) Der kann wohl ja auch nicht recht aus seiner Haut.

(6) 'Er kommt sowieso ja morgen.

mir-auch-nur-bloß-JA

(7) Mach mir auch JA immer delne Aufgaben ordentlich!

(8) "Sperren Sie JA bloß immer den Tresor zu!

(ja)-denn-nicht-doch-wohl-etwa-vielleicht-eigentlich-schon/auch-nur-bloß

(9) Darüber denkt der Oberst denn doch wohl anders als Sie.

(10) Was wird's denn auch schon groß sein?

(11) Das ist denn doch bloß Augenwischerei!

(12) 'Das ist denn ja doch die Höhe!

(13) "Was soll das nur denn?

ja-denn-aber-halt- doch -aber-eben-halt-wohl-(nicht)etwa-einfach/schon/auchsowieso-nur-blo $\beta$-ruhig-mal

(14) Das ist ja doch wohl das Vernünftigste.

(15) Das ist doch eben (auch) einfach (auch) die Schwierigkeit gewesen.

(16) Du bist doch aber auch zu dumm!

(17) Komm doch nur ruhig mal her!

(18) Bringen Sie doch bitte mal eben die Karaffe mit Wasser!

(19) 'Das ist doch ja sowleso nicht wahr.

ja-doch-eben-halt-einfach/auch-mal

(20) Das ist ja eben einfach das Problem. 
(21) Wir müssen unsere Schwierigkeiten eben halt auch zugeben.

doch-halt-doch-eben-wohl-schon-einfach/auch-ruhig-mal

(22) Sie müssen halt schon an die Benutzer denken.

(23) Mach halt ruhig mal zwei Kopien!

Ja-denn-halt/doch- wohl-(nicht)etwa-schon-einfach/auch-sowieso-mal

(24) Du willst doch wohl nicht etwa andeuten, daß ich dich bestohlen hätte?

(25) Man kann doch wohl schon auch von seiner Kreditwürdigkeit ausgehen.

(26) Es ist jetzt ja wohl sowieso zu spät für einen Rückzieher.

(27) Das ist doch wohl denn etwas anderes.

ja-doch-eben-halt-wohl-nur-auch-einfach-auch-nur-mal

(28) Wir haben ja wohl einfach kein Benzin mehr.

(29) Rufen Sie mich doch einfach mal an!

(30) "Sie hat elnfach ja wohl die Firma gekauft.

Ja-denn-doch-halt-wohl-auch- schon-auch

(31) Du kannst ja schon auch hingehen und dich entschuldigen.

(32) Das ist denn doch schon das Letzte!

(33) Jetzt mach halt schon!

ja-denn-doch-aber-eben-halt-wohl-schon-einfach-auch-schon-einfach-nurbloB-JA

(34) Wir können ja wohl schon auch von der Solidität dieser Firma ausgehen.

(35) Was ist denn auch schon dabei, wenn sie mit diesem Typen ins Kino geht?

(36) Sie hat halt auch einfach kein Geschick, mit diesen Leuten umzugehen.

(37) Und machen Sie auch JA viele Fotos - wir haben die Exklusivrechte.

(38) "Mach auch aber das Fenster zu!

Ja-doch-wohl-eh und sowieso

(39) Wir treffen uns morgen jg wohl sowleso bei diesem Vortrag.

mir-doch-aber -doch-auch-vielleicht

(40) Du bist doch aber auch zu dumm!

(41) Sie sind mir aber auch einer!

mir-ja-denn-aber- vielleicht

(42) Das sind ja viellelcht Gauner!

(43) "Kannst du mir vielleicht denn erklären, wer hier immer den Schnaps trinkt?

denn-doch(nicht)-wohl(nicht)- etwa

(44) Du hast doch wohl nicht etwa das Auto kaputtgefahren?

denn- eigentlich - (auch) -nur-bloß

(45) Was hast du dir denn eigentlich bloß dabei gedacht? 


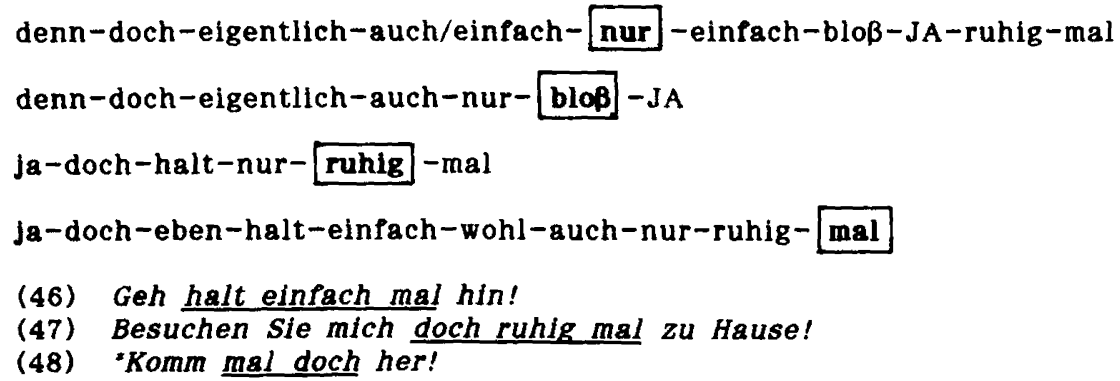

Wie die vorangegangene Aufstellung zeigt, ist die Reihenfolge der Modalpartikeln in der Kombination erstaunlich fest geregelt.

Fur die dem zugrundellegenden Gesetzmäßigkeiten kann ich nur - auf der synchronen Ebene bleibend - einige Hypothesen aufstellen; vermutlich spielen hier ganz verschiedene Kriterien eine Rolle, die sich auch stellenwelse überlagern.

1. Die Partikel mit der 'unspezifischsten' Bedeutung steht in der Kombination an erster Stelle.

Dafur spricht die Tatsache, daß $j a$ in allen Kombinationen vorne steht; es dient lediglich der Marklerung der Bekanntheit eines Sachverhalts, des Verweises auf eine gemeinsame Basis und damit auch der Bestätigung der Außerung.

Dafür spricht auch, daß denn immer an erster Stelle auftritt; auch denn hat unter den Partikeln, die in Fragesäzen auftreten, die unspezifischste Bedeutung. ${ }^{32}$

2. Die Modalpartikeln, deren Bedeutung sich auf die momentane Außerung bezieht. stehen vor denen, die eine qualifizierte Relation zum Vorgängerbeitrag herstellen und diesen in Irgendeiner Form 'beurtellen'.

Dafür spricht, daß sowieso und schon, die den Vorgängerbeitrag in seiner Relevanz oder Geltung einschränken, (in Aussagesätzen) immer hinter den Partikeln j8. doch, halt, eben und wohl stehen.

Problematisch in bezug auf diese Hypothese ist das Verhalten der Modalpartikel auch: zum einen ist sle in Aussagesătzen vor und nach einfach möglich; zum an deren steht sie in $\$$-Exklamativsătzen nach nur und bloß.s3 In allen anderen Fällen (z.B. in den Kombinationen mit doch, eben und halt) dagegen bestätigt int Stellungsverhalten die Hypothese. ${ }^{54}$

52) Dagegen konnte allerdings die Tatsache sprechen, daß auch mal immer an $^{n}$ letzter Stelle steht; das aber wird von Hypothese 3 und 4 erklärt.

53) Das wird von der vierten Hypothese erklärt.

54) Gegen die Hypothese 2 könnte auch sprechen, daß denn immer an erster stelle steht; allerdings ist das Merkmal 〈UNERWARTET>v für denn - wie sich gezeigt 
3. Diejenigen Modalpartikeln, durch die der Funktions- bzw. Mlokutionstyp elndeutig festgelegt wird (s.o. S.201), stehen an letzter Stelle in einer Kombination: das betrifft das Stellungsverhalten von mal, ruhig (das nur in der Kombination mit mal nicht an letzter Stelle steht), JA sowie schon und auch.ss

4. Diejenige Modalpartikel, deren Funktion in einem Abschwächen oder Verstărken der Illokution liegt, tritt in einer Kombination immer als zweite auf.

Dafür spricht, daß mal immer an letzter stelle steht ${ }^{36}$ und dafür spricht auch, daß nur, $J A$ und bloß an zweiter bzw. letzter Stelle auftreten. ${ }^{\circ 7}$

5. Diejenigen Modalpartikeln, durch die der Gesprächspartner in irgendeiner Weise in seinem sprachlichen oder nicht-sprachlichen Handeln besonders beeinflußt wird, stehen an zweiter Stelle.

Diese 'Beeinflussung' kann sich in Fragen darauf beziehen, daß der Sprecher vom Hörer eine bestimmte Antwort erwartet. Für diese Hypothese spricht, daß etwa und schonse und auch nicht in Fragen immer an zweiter Stelle in der Kombination stehen.

Ungeklärt bleibt die Reihenfolge der Modalpartikeln, die sich in Aussagesätzen auf den geäußerten Sachverhalt beziehen (also doch, halt, eben und einfach). Interessanterweise sind von diesen Kombinationen nur doch einfachos und eben einfach Wirklich festgelegt in ihrer Reihenfolge.

Grundsätzlich scheint in den Kombinationen die zweite bzw. die letzte Partikel die Wichtigere zu sein (das deckt sich auch mit der ersten Hypothese); insofern laßt sich erklären, warum diejenigen Modalpartikeln an letzter Stelle stehen, die den Gesprächspartner mehr betreffen: sei es, daß sie ihn in bestimmter Weise steuern, sel es, daß sie ihm deutliche Interpretationshilfen für die Außerung liefern.

hat - allenfalls fakultativ; etwa dagegen, das ebenfalls den Vorgăngerbeitrag als unerwartet bewertet, steht in Kombinationen an letzter Stelle.

55) Auch steht jedenfalls dann, wenn es den Funktionstyp umdeutet - nämlich in w-Fragesatzen - an zweiter Stelle (vgl. denn auch); allerdings nicht in der Kombination mit schon, das aber die gleiche Funktion hat. Mit anderen Partikeln ist such in w-Fragesätzen jedoch nicht möglich, so daß sein Stellungsverhalten kein starkes Argument für die dritte Hypothese liefert, da die Position hinter denn ja auch anders erklärt werden kann.

56) Die Kombination mal eben stellt keine Ausnahme dar, da mit eben in diesem Fall ein Temporaladverb vorliegt (s.S. 247f.).

57) Dles erklärt, warum auch vor nur und blok auftritt.

58) Bei schon ist die Antworterwartung natürlich so stark, daß eine Antwort sich erübrigt.

59) Die Tatsache, daß doch, das ja eine Korrekturanweisung an den Gesprächspartner zum Ausdruck bringt, hier am Anfang der Kombination steht, spricht gegen die fünfte Hypothese. 


\subsubsection{Die Stellung im Satz: offene und geschlossene Kombinationen}

Wie oben festgestellt, stehen Modalpartikeln immer im Mittelfeld eines Satzes. Innerhalb des Mittelfeldes aber ist ihre Position variabel (vgl. oben Kap. 1.2.5.2). Nur deshalb sind auch Modalpartikel-Kombinationen möglich, bei denen zwischen den beiden Partikeln ein oder mehrere Lexeme auftreten können; diese Art von Kombination soll hier 'offene' Kombination genannt werden im Gegensatz zu den 'geschlossenen' Kombinationen, bei denen die eine Modalpartikel unmittelbar auf die andere(n) folgt.

(1) Wie haben denn die Sportler $\underline{b l o \beta}$ diesen Streß überstanden?

(2) Könnte denn deine Schwester mir wohl helfen, die Arbeit zu tippen?

(3) Sie: Hast du vielleicht zufällig deinen Schlüssel dabei? Er: Hast du denn den deinen etwa vergessen?

(4) Wir könnten eigentlich Peter und Martin am Sonntag zum Essen einladen. Ruf doch die Jungs mal an!

(5) Nina: Die Müllers müssen ganz schön reich sein. Uwe: Stimmt; Cornelis hat ja von ihrem Vater auch zum Abitur ein neues Auto gekriegt.

(6) Der Kommissar: Was is'므 das eigentlich für eine Maschine?

(7) Anna: Is das denn nich sehr lästig?

Heinz: Bitte?

Anna: Ist denn das nich lästig? (BA, 1)

(8) Hör doch endlich $\underline{\mathrm{mal}}$ auf!

(9) Wer hat denn damals schon ein eigenes Auto fahren können? (Bö c, 124) Auch bei den offenen Kombinationen gelten die Restriktionen hinsichtlich der Kombinierbarkeit, wie sie im vorhergehenden dargestellt wurden. Ebenso gelten die Gesetzmäßigkeiten, wie sie für die Relhenfolge in der Kombination aufgestellt wurden, unverändert.

Die Stellung der beiden Modalpartikeln bei einer offenen Kombination ist im Satz nicht belleblg, und deshalb ist auch das, was zwischen zwei Modalpartikeln steht. gewissen Beschränkungen unterworfen. Vor allem die Position der zweiten bzw. letzten Modalpartikel im Satz hängt von der Thema-Rhema-Gliederung ab; vgl.:

(5a) Nina: Die Müllers müssen ganz schön reich sein. Uwe: Stimmt. Cornelia hat ja auch von ihrem Vater zum Abitur ein neues Auto gekriegt.

(5b) Cornelia hat von ihrem Vater ja auch zum Abitur ein neues Auto gekriegt. (5c) Cornelia hat von ihrem Vater zum Abltur ja quch ein neues Auto gekriegt.

(5d) Cornelia hat ja von ihrem Vater auch zum Abitur ein neues Auto gekriegt.

(5e) Cornelia hat von ihrem Vater ja zum Abjtur auch ein neues Auto gekriegt.

(5f) 'Cornelia hat von ihrem Vater zum Abitur ja ein neues Auto auch gekriegt.

(5g) Cornelia hat von ihrem Vater zum Abitur ein neues Auto ja auch gekriegt. 
Weiter oben (in 2.2.5) wurde schon darauf hingewiesen, daß Modalpartikeln oft die Funktion zugeschrieben wird, die Grenze zwischen Thema und Rhema bilden zu können (vgl. z.B. Krivonosov 1965b:502, 1966:139).

Als Ausnahmen wurden dort (S.29ff.) bereits die (allerdings seltenen) Fälle angePührt, wo thematische Elemente nach der Modalpartikel stehen können und die Fălle, in denen rhematische Elemente im Vorfeld stehen bzw. In denen das finite Verb das Rhema des Satzes ist.

Diese Gesetzmäßigkeiten und auch die angeführten Ausnahmen gelten für geschlossene Kombinationen gleichpalls.

Eine weitere Ausnahme zu der These, daß Modalpartikeln die Grenze zwischen Thema und Rhema darstellen, liegt nun vor, wenn eine offene Modalpartikel-Kombination auftritt.

In diesem Fall steht die zweite bzw. die letzte Modalpartikel immer noch vor dem Rhema, da eln rhematisches Element - wie z.B. in (5f) ein objekt mit indefinitem Artikelso - nicht $z$ wischen zwei Modalpartikeln auftreten kann. An dieser Position stehen also thematische Elemente, d.h. aber auch, da $\beta$ die erste Modalpartikel vor Teilen des Themas steht.

Interessant ist auch hier wieder das Stellungsverhalten der Pronomina. Wie oben (S.32ff.) schon dargestellt, können bestimmte Pronomina vor und nach einer Modalpartikel auftreten.

(10) Was ist denn das? vs. Was ist das denn?

Das kann ja ich machen vs. Das kann ich ja machen.

Genau die Pronomina nun, die vor und nach der Modalpartikel stehen können, sind auch innerhalb einer Kombination zulässig: bei den Pronomina der dritten Person sind es der/die/das (die oben als 'thematische' und 'auffällige' Elemente beschrieben wurden); vgl.:

(11) Der Kommissar entdeckt bei der Besichtigung des Tatortes einige Blütenblätter: Wie mögen denn die nur da hingekommen sein?

(12) Also der Joachim!! Was hat sich denn der bloß dabei gedacht, als er sich für die Rallye beworben hat?

Dle thematischen 'unauffälligen' Pronomina der dritten Person dagegen sind zwischen zwei Modalpartikeln nicht möglich; vgl.:

(12a) Also der Joachim!! 'Was hat sich denn er bloß dabei gedacht, als er sich für die Rallye beworben hat?

aber: Was hat $\underline{\text { er }}$ sich denn bloß dabei gedacht...?

60) Damit soll nicht gesagt werden, daß keine Nomina mit indefinitem Artikel innerhalb einer Modalpartikel-Kombination möglich seien; vgl.: Wie soll man denn elnen Menschen bloß nach so etwas fragen? Indefinite Artikel sind lediglich ein Hinweis auf Rhematizität, ein deutlicheres Anzeichen für thematische bzw. rhematische Elemente sind die Akzentuierung und der Kontext. 
Pronomina der 1. und 2. Person tragen, wenn sie von zwei Modalpartikeln eingeschlossen werden, meist einen Akzent - sind also als 'auffällige' Elemente einzustufen.

(13) Das wundert mich aber, daß ich Sie hier treffe! Wie sind denn SIE bloß hierhergekommen?

(14) Was hast denn DU schon geleistet?

(15) Mach doch DU mal deinen Mund zu!

Das Vorkommen der Pronomina zwischen zwei Modalpartikeln zeigt noch einmal das schon angesprochene besondere Stellungsverhalten von Elementen, die thematisch und auffällig sind und zelgt auch, daß nicht alle thematischen Elemente in einer offenen Kombination auftreten können.

Krivonosovs These, daß links von der Modalpartikel das Gegebene, rechts das Neue steht (1965b:501), muß auch aufgrund dieser Beobachtungen umformuliert werden: Nicht alles, was zum Thema gehört, kommt immer vor der Modalpartikel; im Falle einer offenen Kombination befindet sich ein Teil des Themas zwischen den beiden Partikeln und damit nach der ersten Modalpartikel. Das Rhema steht (im allgemeinen) nach der Partikel (so auch schon Krivonosov; vgl. auch Hentschel 1986: 212ff.); genauer läßt sich das so formulieren: Das Rhema steht nach der letzten Modalpartikel in einem Satz. Die Grenze zwischen Rhema und Thema wird also beim Auftreten nur einer Modalpartikel von dieser und bel offenen wie auch bel geschlossenen Kombinationen jeweils von der letzten Modalpartikel gebildet. Die mehrfach erwähnten Ausnahmen (Rhema im Vorfeld oder rhematisches Verb) bleiben allerdings weiterhin bestehen.

offene Kombinationen sind vermutlich bel den meisten Modalpartikeln möglich. Sie sind aber wesentlich seltener als geschlossene.

$\mathrm{Ob}$ es wirklich 'unzertrennliche' Kombinationen gibt, kann nicht mit Sicherheit festgestellt werden. Kandidaten dafür scheinen mir z.B. die Kombination doch nicht etw\& oder doch bloß/doch nur zu sein. 'Unzertrennlichkeit' wäre als ein weiteres Kriterium für die Konventionalisierung bzw. Verfestigung von Kombinationen zu sehen.

Dle geschlossenen Varianten der Modalpartikel-Kombinationen sind aber in jedem Fall weitaus häufiger und gebräuchlicher - auch das ein Indiz für die Verfestigung: es handelt sích eben nicht mehr nur um das ('zufallige') Auftreten zweier Partikeln im selben Satz, sondern in vielen Fällen um eine feste Einhelt, deren Bedeutung allerdings immer noch aus der Bedeutung der Einzelbestandteile zusammengesetzt werden kann. 


\section{ZUSAMMENFASSUNG}

In der vorangegangenen Untersuchung wurde versucht, die deutschen Modalpartikeln aus verschiedenen Perspektiven zu beleuchten.

Begonnen wurde dabei mit einer Klassifikation im Bereich der Partikeln: sie hat gezelgt, daß sich hier mit differenzierten, vor allem syntaktisch-distributionellen Kriterien die einzelnen Funktionen durchaus voneinander abgrenzen lassen, wenn sich auch bei manchen Partikeln - wie nicht zuletzt die Einzelanalysen der Modalpartikeln gezeigt haben - Ubergangsbereiche ergeben: die Gruppe der Modalpartikeln hat - wie andere auch - kelne scharfen Ränder. Mit sowieso und eh wurden in dieser Arbeit auch zwel Partikeln behandelt, die am Rande der Modalpartikelgruppe anzusiedeln sind. Das distributionelle Grundmuster im Zentrum der Modalpartikeln liegt mit halt vor.

Im Zuge der formalen Analyse wurde auch gezelgt, daß der ethische Dativ wesentliche Eigenschaften mit den Modalpartikeln teilt und folglich Modalpartikel-Funktion hat.

Ferner wurden die Stellungsbedingungen der Modalpartikeln genau untersucht. Besonderes Augenmerk wurde hier auf die Serialisierung von Modalpartikeln und Pronomina Im Mittelfeld gelegt; dabei konnten Regeln gefunden werden, die das unterschiedliche Stellungsverhalten bestimmter Pronomina in bezug auf Modalpartikeln beschreiben.

Bel der Analyse der Distribution der Modalpartikeln in den Satzmodi wurden alle Satztypen systematisch behandelt. Zugrunde lag dabei ein Satzmodussystem, das Form- und Funktionsseite von Außerungen genau trennt. Untersucht wurden neben den Typen mit Verb-Erst- und - Zweit-Stellung auch Sătze mit Endstellung des Verbs. Dabei wurde elne grundlegende Unterscheidung getroffen zwischen selbständigen und unselbständigen Sătzen (=Nebensätzen). Erstere wurden zunăchst genau nach formalen und auch funktionalen Kriterien untersucht und klassifiziert, bevor schließlich das Auftreten von Modalpartikeln in ihnen erforscht wurde: dabei zelgte sich, daß Modalpartikeln hier eine wichtige Rolle für dle Selbständigkeit der 
jeweiligen Sätze spielen - aber auch, daß sich das Vorkommen einzelner Modalpartikeln vom Vorkommen in den 'Grundtypen' doch wesentlich unterscheidet.

Auch bel den (unselbständigen) Nebensätzen brachte das Vorkommen und Nichtvorkommen von Modalpartikeln interessante Ergebnisse: Nicht zuletzt zur Klassifikation von Nebensätzen ist die Zulässigkeit oder Nicht-Zulässigkeit von Modalpartikeln relevant; bei Zulässigkeit ist außerdem die Tatsache, um welche Modalpartikeln es sich dabel handelt, aufschlußreich.

'Rand'- und 'Mischtypen' wie Alternativfragen, Rückfragen, Sätze mit infinitem Verb wurden ebenfalls untersucht und auf ihre Modalpartikel-Zulässigkeit hin überprüft.

Die Frage, ob das Auftreten von Modalpartikeln vom Formtyp oder vom Funktionsbzw. Illokutionstyp einer Außerung gesteuert wird, ist - nach den hier erarbeiteten Ergebnissen - nicht eindeutig zu beantworten.

Am Ende der formalen Analyse stand eine Untersuchung des Zusammenwirkens von Satzmodus, Negation und Modalpartikeln. Dabei wurde auch gezeigt, daß nicht in bestimmten Verwendungen in Modalpartikel-Funktion vorliegt.

Im zweiten Teil erfolgten die Einzelanalysen. Neben den 'anerkannten' Modalpartikein aber, auch, bloß, denn, doch, eben, eigentlich, elnfach, etwa, halt, ja, mal. nur, ruhig, schon, vielleicht, wohl wurden zusätzlich auch eh und sowieso, nicht und mir einbezogen. Im Zentrum stand dabei die Beschreibung der Bedeutung. Ausgehend vom Vorkommen einer Modalpartikel in den jewelligen Satzmodi gelang es, für jede Modalpartikel eine einzige Bedeutung zu ermitteln, die mit einem Merkmal bzw. mit einem Merkmalbündel aus einer kleinen elementaren Menge von Merkmalen beschrieben wurde. Da die einzelnen Modalpartikeln in verschiedenen für die Interaktion relevanten Bereichen Aufgaben wahrnehmen können, sind auch die zur Beschreibung eingesetzten Merkmale verschiedenen Bereichen zuzuordnen: etwa

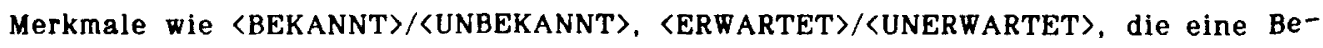
wertung der Proposition beschreiben, Merkmale die die Illokution betreffen ( $\langle$ VERSTARKUNG $\rangle /\langle A B S C H W A C H U N G\rangle)$ oder Merkmale, die die Sequenzierung angeben ( $\langle$ KONNEX $\rangle /\langle$ UBERGANG $\rangle$ ).

In die Untersuchung miteinbezogen wurde auch der Vergleich mit anderen Modalpartikeln, um Gemeinsamkeiten und Unterschiede festzustellen.

Aufgrund der Charakteristika der Modalpartikelverwendung wurde hier - stärker noch als im ersten Teil - authentisch gesprochenes Belegmaterial zur Grundlage der (teflweise auch konversationsanalytisch und argumentationstheoretisch orientierten) Analyse gemacht. 
Basierend auf den Ergebnissen der vorangegangenen Kapitel erfolgte schließlich im dritten Teil eine systematische Analyse aller Kombinationen von Modalpartikeln. Aus den in dieser Arbeit behandelten Modalpartikeln lassen sich 171 (Zweier-) Kombinationen bllden. Von diesen sind 45 aus syntaktisch-distributionellen Gründen nicht möglich: die beiden Modalpartikeln treten nicht im selben Satzmodus auf.

Die restlichen Kombinationen wurden einer genauen Analyse unterzogen; dabei konnte auf der Grundlage der Bedeutungsbeschreibungen aus Kapitel 2 sowohl die semantische Kompatibilităt als auch die semantische Inkompatibilität der einzelnen Kombinationen dargestellt und begründet werden. Dies diente letztlich auch zu einer Oberprüfung der Ergebnisse der Bedeutungsanalysen von Kapitel 2, die sich zum allergrößten Teil bestätigten.

Bei semantisch akzeptablen Kombinationen wurde deren Bedeutung genauer beschrieben und mit anderen Kombinationen oder mit dem Einzel-Vorkommen der jewelligen Modalpartikeln verglichen. (Die Lahl der gebräuchlichen ModalpartikelKombinationen liegt bei etwa 50.)

Die mögliche Kombinatorik machte auch die Verwendungsunterschiede bei 'synonymverdächtigen' Modalpartikelpaaren wle eben und halt, nur und blok, bloß und $J A$ deutlich.

Bei der Untersuchung hat sich zudem gezeigt, daß - gemäß der Ausgangshypothese - die Bedeutung von Modalpartikel-Kombinationen durchaus als Addition der Bedeutung der Einzelpartikeln verstanden werden kann und sich auch dementsprechend beschreiben läßt.

Für die akzeptablen Kombinationen wurde ferner die Distribution in den einzelnen Satzmodi angegeben. Dabei bestätigte sich, daß diese Satzmodi eine 'Schnittmenge' der zulässigen Satzmodi jeder einzelnen Partikel sein müssen. Damit kann aber umgekehrt die Kombinationsfähigkeit auch als Kriterium zur Identifikation von Satzmodi herangezogen werden. Schließlich kann die Kombinationsfähigkeit auch zur Abgrenzung der Modalpartikel-Funktion hilfreich sein.

Die Reihenfolge der einzelnen Modalpartikeln in der Kombination gehorcht Pesten Regeln, die (auch für Mehrfachkombinationen) detailliert dargestellt wurden. Für diese Reihenfolge wurden einige Erklärungen formuliert; dabei wurde gezeigt, daß die Reihenfolge von Modalpartikeln auch von pragmatischen Gegebenheiten bestimmt ist.

Die Tatsache, daß auch 'offene' Modalpartikel-Kombinationen möglich sind, lieferte ein weiteres Argument für die bereits in Kapitel 1 formulierte Modifizierung der Aussagen zur kommunikativen Gliederung des Satzes durch die Modalpartikeln. 
Abschließend möchte ich noch einmal auf stilistische Aspekte eingehen:

Schon zu Beginn dieser Arbeit wurde darauf hingewiesen, daß Modalpartikeln mitbestimmend für den Stil oder den Ton einer Außerung sein können.

Stil - verstanden als die Möglichkeit zur Wahl $z$ wischen verschiedenen sprachlichen Ausdrucksformen - setzt prinzipiell das Vorhandensein mehrerer Ausdrucksmöglichkeiten voraus. Wenn zwel Außerungen als stilistische Varianten gelten sollen, müssen sie in ihrem propositionalen Gehalt soweit übereinstimmen, daß mit innen derselbe Sachverhalt ausgedrückt wird. Nicht immer hat ein Sprecher allerdings (subjektiv gesehen) Prele Wahl, denn die Auswahl der Sprachmittel ist nicht willkürlich, sondern hängt von einer Reihe von Faktoren (wie: Beziehung der Gesprächspartner zueinander, Thema, Zweck der Kommunikation, Ort der Kommunikation etc.) ab, die zusammen die kommunikative Situation ergeben. Stilistische Angemessenheit ist damit vor allem die Angemessenheit des sprachlichen Ausdrucks in einer bestimmten Situation.

Im Rahmen dieser Arbeit interessierte vor allem der "Stil des Alltagsverkehrs" (nach Riesel/Schendels 1975), d.h. diejenigen Ausdrucksmittel, die im spontanen Alltagsgespräch verwendet werden, da hier der Hauptverwendungsbereich der Modalpartikeln liegt. Es ging also im wesentlichen um die Möglichkeiten, die ein Sprecher in der dialogischen Interaktion hat, mit den dargestellten Sachverhalten in bezug auf seinen Gesprächspartner 'umzugehen'.

Die verschiedenen Ausdrucksvarianten, die einem Sprecher in diesem Bereich zur Verfügung stehen, wurden in dieser Arbeit an der Gruppe der Modalpartikeln untersucht. Da die Modalpartikeln nicht auf der propositionalen Ebene wirken, sind sie ein wichtiges Mittel zur Erweiterung der Ausdrucksmöglichkeiten; sie bieten aufgrund ihrer unterschiedlichen Funktionen dem Sprecher auch eine Reihe von Möglichkeiten, den Ton eines Gesprächs zu gestalten - zumal sie im Unterschied zu anderen Mitteln auch noch 'Rückzugsmöglichkeiten' offenhalten.

Berücksichtigt man nun im Bereich der Modalpartikeln auch noch deren Kombinationen, so zeigt sich, daß damit dem Sprecher eine Vielzahl zusätzlicher sprachlicher Varianten gegeben sind, da (wie verschiedene Gegenüberstellungen gezeigt haben) Kombinationen immer - eben weil es sich um die Kombination zweier Bedeutungen handelt - eine dritte Variante gegenüber der Verwendung jeder Partikel allein darstellen.

Kornbinationen von Modalpartikeln sind also als ein weiteres wichtiges Mittel zur Gestaltung eines Dialogs und damit zur Ausgestaltung des Kontakts der $\mathrm{Ge}^{-}$ sprăchspartner untereinander zu sehen. 


\section{LITERATURVERZEICHNIS}

\section{Beispieltexte}

Asterix X. 1971. Asterix als Legionär. Stuttgart. (zitiert als 'A $X$ ')

Asterix XIII. 1972. Asterix und der Kupferkessel. Stuttgart. ('A XIII')

Asterix XXI. 1976. Das Geschenk Cäsars. Stuttgart. ('A XXI')

Bieler, Manfred. "1977. Maria Morzeck oder: Das Kaninchen bin ich. München. ('Bi')

Böll, Heinrich. 111972. Ansichten eines Clowns. München. ('Bö a')

Böll, Heinrich. ${ }^{31976}$. Die verlorene Ehre der Katharina Blum. München. ('Bö b')

Böll, Heinrich. 51975. Gruppenbild mit Dame. München. ('Bö c')

Bottroper Protokolle. '1970. Aufgezeichnet von Erika Runge. Frankfurt/Main. ('BP')

Brons-Albert, Ruth. 1984. Gesprochenes Standarddeutsch. Telefondialoge. Tübingen. ('BA')

Engelmann Bernt. ${ }^{3} 1979$. Eingang nur für Herrschaften. München. ('En')

Kempowsk1, Walter. '1982. Tadellöser \& Wolff. München. ('Ke')

Kroetz, Franz Xaver. 1977. Chiemgauer Gschichten. Köln. ('Kr')

Mann, Heinrich. ${ }^{10} 1977$. Der Untertan. München. ('Ma')

Simmel, Johannes M. 1976. Es muß nicht immer Kaviar sein. München-Zürich. ('Si')

Texte gesprochener deutscher Standardsprache II. 1974. Erarb. im Institut für deutsche Sprache. München (Heutiges Deutsch, Reihe II, Band 2). ('FK II')

Texte gesprochener deutscher Standardsprache III. 1975. Alltagsgespräche, erarb. im IdS. München (Heutiges Deutsch, Reihe II, Band 3). ('FK III')

\section{Wissenschaftliche Literatur}

Abdullaev, Sarchan. 1977. Zu den Möglichkelten der Transposition der Satzarten im Deutschen. Die Grundstruktur der rhetorischen Frage und des imperativischen Ausrufs. Deutsch als Fremdsprache 5. 263-270.

Abraham, Werner. 1971. Der "ethische" Dativ. Fragen der strukturellen Syntax und der kontrastiven Grammatik. Düsseldorf. 112-134.

Abraham, Werner. 1986. Die Bedeutungsgenese von Modalpartikeln. Die bedeutungskonstituierenden Variablen: 'Kontrastdomäne' und 'Kontext'. GAGL (Groninger Arbeiten zur germanistischen Linguistik) 27. 1-44.

Adler, H.G. 1964. Füllwörter. Muttersprache. 52-55.

Admoni, Wladimir. 1982. Der deutsche Sprachbau. 4. überarb. und erw. Aufl. München.

AKADEMIE-Grammatik. 1981. Grundzüge einer deutschen Grammatik, hg. v.e. Autorenkollektiv unter Leitung von K.E.Heidolph, w.Flämig und W.Motsch. Berlin.

Albrecht, Jörn. 1977. Wie ubbersetzt man eigentlich "eigentlich"? Weydt. H. (Hg.) 1977. 19-37. 
Altmann, Hans. 1976. Die Gradpartikeln im Deutschen. Untersuchungen zu ihrer Syntax, Semantik und Pragmatik. Tübingen.

Altmann, Hans. 1978. Gradpartikel-Probleme. Zur Beschreibung von gerade, genau, eben, ausgerechnet, vor allem. Tübingen.

Altmann, Hans. 1984. Linguistische Aspekte der Intonation am Beispiel Satzmodus. FIPKM (Forschungsberichte des Instituts für Phonetik und sprachliche Kommunikation der Universität München) 19. 132-152.

Altmann, Hans. 1987. Zur Problematik der Konstitution von Satzmodi als Formtypen. Meibauer, J. (Hg.) 1987. 22-56.

Asbach-Schnitker, Brigitte. 1975. Zur Wiedergabe deutscher Satzpartikeln im Englischen. Drachman, G. (Hg.) 1975. Akten der ersten Salzburger Frühlingstagung für Linguistik. Tübingen. 303-318.

Asbach-Schnitker, Brigitte. 1977. Die Satzpartikel "wohl". Weydt, H. (Hg.) 1977. $38-60$.

Asbach-Schnitker, Brigitte. 1978. Konnektoren und Partikeln. Eine Untersuchung zu syntaktischen, semantischen und pragmatischen Aspekten von deutsch aber und englisch but. Diss. Regensburg.

Austin, John L. 1979. Zur Theorie der Sprechakte. 2.Aufl. Stuttgart.

Batliner, Anton. 1988. Der Exklamativ: Mehr als Aussage oder doch nur mehr oder weniger Aussage? Experimente zur Rolle von Höhe und Position des Fo-Gipfels. Altmann, H. (Hg.) 1988. Intonationsforschungen. Tübingen. 243-271.

Bartsch, Renate. 1972. Adverbialsemantik. Frankfurt/Main.

Bastert, Ulrike. 1985. Modalpartikel und Lexikographie. Eine exemplarische Studie zur Darstellbarkeit von DOCH im einsprachigen Wörterbuch. Tübingen.

Becker, Norbert. 1976. Die Verknüpfungspartikeln "denn, mal, doch" und andere. Zielsprache Deutsch 3. 6-12.

Berg, Wolfgang. 1978. Uneigentliches Sprechen: Zur Pragmatik und Semantik von Metapher, Metonymie, Ironie, Litotes und rhetorischer Frage. Tübingen.

Bierwisch, Manfred. 1980. Semantic Structure and Illocutionary Force. Searle, J.R./ Kiefer, F./Bierwisch, M. (Hgg.) 1980. Speech Act Theory and Pragmatics. Dordrecht. $1-35$.

Blanken, Gerhard. 1983. Bestätigungsfragen mit nicht und doch. Deutsche Sprache 11. $250-260$.

Borst, Dieter. 1985. Die affirmativen Modalpartikeln doch, ja und schon. Ihre Bedeutung. Funktion, Stellung und ihr Vorkommen. Tübingen.

Brauße, Ursula. 1983. Bedeutung und Funktion einiger Konjunktionen und Konjunktionaladverbien: aber, nur, immerhin, allerdings, dafür, dagegen, jedoch. Linguistische Studien 104. 1-40.

Brauße, Ursula. 1986. Zum Problem der sogenannten Polyfunktionalität von Modalpartikeln. $J a$ und eben als Argumentationssignale. Zeitschrift für Phonetik, Sprachwissenschaft und Kommunikationsforschung 39. 206-223.

Brinkmann, Hennig. 1971. Die deutsche Sprache. Gestalt und Leistung. 2. neubearb. und erw. Auflage. Düsseldorf.

Bublitz, Wolfram. 1977. Deutsch aber als Konjunktion und als Modalpartikel. Sprengel, K. et al. (Hgg.) 1977. 199-209. 
Bublitz, Wolfram. 1978. Ausdrucksweisen der Sprechereinstellung im Deutschen und im Englischen. Tübingen.

Bublitz, Wolfram/Roncador, Manfred von. 1975. Uber die deutsche Partikel ja. Batori, I. et. al (Hgg.) 1975. Syntaktische und semantische Studien zur Koordination. Tübingen. 139-190.

Bühler, Karl 1965. Sprachtheorie. 2.Aufl. Stuttgart.

Burkhardt, Armin. 1982a. Gesprächswörter. Ihre lexikologische Bestimmung und lexikographische Beschreibung. Mentrup, W. (Hg.) 1982. Konzepte zur Lexikographie. Studien zur Bedeutungserklärung in einsprachigen Wörterbüchern. Tübingen. 138-171.

Burkhardt, Armin. 1982b. Abtönungspartikeln als Mittel des Vollzugs präsuppositionaler Akte. Zu Dittmanns und Rombouts Untersuchungen über die Abtönungsfunktion von auch, denn und doch. Zeitschrift für germanistische Linguistik 10. 85-112.

Burkhardt, Armin. 1982c. Die kommunikativen Funktionen von "ja" und ihre lexikographische Beschreibung in Wörterbüchern. Muttersprache 92. 337-361.

Buscha, Annerose. 1976. Isolierte Nebensätze im dialogischen Text. Deutsch als Fremdsprache 13. 274-279.

Bußmann, Hadumod. 1983. Lexikon der Sprachwissenschaft. Stuttgart.

Collinson, William E. 1938. Some German Particles and their English Equivalents. A Study in the Technique of Conversation. German Studies presented to H.G. Fiedler by pupils, colleagues and friends on his 75.birthday. Oxford. 106-124.

Conrad, Rudi. 1976. Ein Problem der Frage-Antwort-Beziehungen: strukturelle Antwortdetermination und Antworterwartung. Linguistische Arbeitsberichte 13. $9-93$.

Conrad, Rudi. 1978. Studien zur Syntax und Semantik von Frage und Antwort. (Studia grammatica XIX) Berlin.

Coseriu, Eugenio. 1980. Partikeln und Sprachtypus. Zur strukturell-funktionellen Fragestellung in der Sprachtypologie. Brettschneider, G./Lehmann, Ch. (Hgg.) 1980. Wege zur Universalienforschung. Sprachwissenschaftliche Beiträge zum 60.Geburtstag von Hansjakob Seiler. Tübingen. 199-206.

Daněs, František. 1974. Functional sentence perspective and the organization of the text. Ders. (Hg.) 1974. Papers on functional sentence perspective. Prag. 106-128.

Dittmann, Jürgen. 1980. Auch und denn als Abtönungspartikeln: Zugleich ein wissenschaftsgeschichtlicher Beitrag. Zeitschrift für germanistische Linguistik 8. $51-73$.

Doherty. Monika. 1982. Doch. Deutsch als Fremdsprache 19. 174-178.

Doherty, Monika. 1985. Epistemische Bedeutung. (Studia grammatica XXIII) Berlin.

DUDEN 1984. Grammatik der deutschen Gegenwartssprache, hg. von G.Drosdowski. 4. völlig neu bearb. und erw. Auflage. Mannheim etc.

Eder, Alois. 1975. Eh-Pragmatik. Wiener Linguistische Gazette 9. 39-57.

Ehrich, Veronika/Finke, Peter (Hgg.). 1975. Beiträge zur Grammatik und Pragmatik. IX. Ling. Koll. Bielefeld. Kronberg/Ts.

Eichler, Wolfgang/Bünting, Karl-Dieter. 1978. Deutsche Grammatik. Kronberg/Ts.

Eisenberg, Peter. 1986. Grundriß der deutschen Grammatik. Stuttgart. 
Engel, Ulrich. 1968/1971. Adjungierte Adverbialia. Zur Gliedfolge im Innenfeld. Engel, U./Vogel, I. (Hgg.) Forschungsberichte des IdS, Bd.1. Mannheim. 1968. Unveränderter Nachdruck 1971. 85-103.

Engel, Ulrich. 1970. Regeln zur Wortstellung. Ders. (Hg.) 1970. Forschungsberichte des IdS, Bd.5. Mannheim. 7-148.

Engel, Ulrich. 1973. Zur Abfolge der Adverbialia im deutschen Verbalsatz. Nickel, G. (Hg.) 1973. Angewandte Sprachwissenschaft und Deutschunterricht. München. $168-191$.

Engelen, Bernhard. 1975. Untersuchungen zu Satzbauplan und Wortfeld in der geschriebenen deutschen Sprache der Gegenwart. München.

Erben, Johannes. 1972. Deutsche Grammatik. Ein Abriß. 11.völlig neubearb. Auflage. München.

Flämig. Walter. 1977. Zur grammatischen Klassifizierung des Wortbestandes im Deutschen. Helbig, G. (Hg.) 1977. Beiträge zur Klassifizierung der Wortarten. Leipzig. 39-52.

Franck, Dorothea. 1975. Zur Analyse indirekter Sprechakte. Ehrich, V./Finke, P. (Hgg.) 1975. 219-231.

Franck, Dorothea. 1979. Abtönungspartikel und Interaktionsmanagement. Tendenzlöse Fragen. Weydt, H. (Hg.) 1979. 3-13.

Franck, Dorothea. 1980. Grammatik und Konversation. Stilistische Pragmatik des Dialogs und die Bedeutung deutscher Modalpartikeln. Königstein/Ts.

Fries, Norbert. 1983. Syntaktische und semantische Studien zum frei verwendeten Infinitiv und zu verwandten Erscheinungen im Deutschen. Tübingen.

Gewehr, Wolf. 1981. Man wird ja doch wohl noch fragen dürfen...: Sind die "flavoring particles" im Unterricht der Zielsprache Deutsch eigentlich tabu? Knapp, G./Schmitt, W. von (Hgg.) 1981. Sprache und Literatur. Festschrift für A.L. Streadbeck zum 65.Geburtstag. Bern etc.15-24.

Gornik-Gerhardt, Hildegard. 1981. Zu den Funktionen der Modalpartikel "schon" und einiger ihrer Substituentia. Tübingen.

Grésillon, Almuth. 1980. Zum linguistischen Status rhetorischer Fragen. Zeitschrift fur germanistische Linguistik 8. 273-289.

Grice, H.Paul. 1975. Logic and conversation. Cole, P./Morgan, J.L. (Hgg.) 1975. Speech acts. Syntax and Semantics Vol.3. New York. 41-58.

Gülich, Elisabeth/Ralble, Wolfgang. 1977. Linguistische Textmodelle. München.

Hang, Heinz-Günter. 1976. Die Fragesignale der gesprochenen deutschen Standardsprache. Göppingen.

Harden. Theo. 1983. An Analysis of the Semantic Field of the German Particles "überhaupt" and "eigentlich". Tübingen.

Harden, Theo/Rösler, Dietmar. 1981. Partikeln und Emotionen - zwei vernachlässigte Aspekte des gesteuerten Fremdsprachenerwerbs. Weydt, H. (Hg.) 1981. 67-80.

Hartmann, Dietrich. 1975. Zur Semantik von Satzpartikeln und zu ihren Funktionen in Texten. Ehrich, V./Finke, P. (Hgg.) 1975. 233-252.

Hartmann, Dietrich. 1976. Zum grammatischen Status von $j a$ und anderen Satzpartlkeln. Kern, R. (Hg.) 1976. Löwen und Sprachtiger. Akten des VIII. Ling. Koll. Louvain 1973. Tübingen. 111-125. 
Hartmann, Dietrich. 1977. Aussagesätze, Behauptungshandlungen und die kommunikativen Funktionen der Satzpartikeln ja, nämlich und einfach. Weydt, H. (Hg.) 1977. 101-114.

Hartmann, Dietrich. 1979. Syntaktische Eigenschaften und syntaktische Funktionen der Partikeln eben, eigentlich, einfach, nämlich, ruhig, vielleicht und wohl. Weydt, H. (Hg.) 1979. 121-138.

Hartmann, Dietrich. 1986. Semantik von Modalpartikeln im Deutschen. Zu Problemen ihrer Bedeutung und Bedeutungserfassung und deren Behandlung in der Modalpartikelforschung. Deutsche Sprache 14. 140-155.

Hartog, Jennifer/Rüttenauer, Martin. 1982. Ober die Partikel eben. Deutsche Sprache 10. 69-82.

Harweg, Roland. 1974. Retardierte Fragen: Ein Beitrag zur Pragmatik und Textologie der Fragesätze. Linguistics 134. 9-19.

Heinrichs, Werner. 1981. Die Modalpartikeln im Deutschen und im Schwedischen. Eine kontrastive Analyse. Tübingen.

Helbig, Gerhard. 1968. Zum Problem der Wortarten, Satzglieder und Formklassen in der deutschen Grammatik. Růžička, R. (Hg.) 1968. Probleme der strukturellen Grammatik und Semantik. Leipzig. 55-85.

Helbig, Gerhard. 1970. Sind Negationswörter, Modalwörter und Partikeln im Deutschen besondere Wortklassen? Deutsch als Fremdsprache 6. 393-401.

Helbig, Gerhard. 1977. Partikeln als lllokutlve Indikatoren im Dialog. Deutsch als Fremdsprache 14. 30-44.

Helbig, Gerhard. 1981. Die Preien Dative im Deutschen. Deutsch als Fremdsprache 18. $321-332$.

Helbig, Gerhard/Buscha, Joachim. 1980. Deutsche Grammatik. Ein Handbuch für den Ausländerunterricht. Leipzig. (6. unverănd. Aufl. der Ausgabe von 1972)

Helbig, Gerhard/Buscha, Joachim. 1986. Deutsche Grammatik. Ein Handbuch für den Ausländerunterricht. Leipzig. (9. unveränd. Aufl. der Ausgabe von 1984)

Helbig, Gerhard/Kötz, Werner. 1981. Die Partikeln. Lelpzig.

Henne, Helmut. 1978. Gesprächswörter. Für eine Erweiterung der Wortarten. Henne, H.et al. (Hgg.) 1978. Interdisziplinäres deutsches wörterbuch in der Diskussion. Düsseldorf. 42-47.

Henne, Helmut/Rehbock, Helmut. 1978. Einführung in die Gesprächsanalyse. Berlin, New York.

Hentschel, Elke. 1980. Abtönungspartikeln als stilistische Merkmale des Alltagsgespräches. Kählwein, W./Rasch, A. (Hgg.) 1980. Sprache und Verstehen. Kongreßberichte der 10. Jahrestagung der GAL e.V. Mainz 1979. Bd.2. Tubingen. $142-145$.

Hentschel, Elke. 1981. Partikeln und Hörereinstellung. Weydt, H. (Hg.) 1981. 13-30.

Hentschel, Elke. 1983. Partikeln und Wortstellung. Weydt, H. (Hg.) 1983. 46-53.

Hentschel, Elke. 1986. Funktion und Geschichte deutscher Partikeln. Tübingen.

Hentschel, Elke/Weydt, Harald. 1983. Der pragmatische Mechanismus: denn und eigentlich. Weydt, H. (Hg.) 1983. 263-273.

Hertel, Hans. 1962. Wert und Wirkung der 'Würzwörter'. Sprachpflege 10. $214 \mathrm{f}$.

Hinrichs, Uwe. 1979. Partikelgebrauch und Identităt am Beispiel des Deutschen Ja. Weydt, H. (Hg.) 1979. 256-268. 
Hinrichs, Uwe. 1983. Können Abtönungspartikeln metakommunlkativ funktionieren? Weydt, H. (Hg.) 1983. 274-290.

Husso, Alla. 1981. Zum Gebrauch von Abtönungspartikeln bei Ausländern. Weydt, H. (Hg.) 1981. 81-99.

Jacobs, Joachim. 1982. Syntax und Semantik der Negation im Deutschen. München.

Jacobs, Joachim. 1983. Fokus und Skalen. Zur Syntax und Semantik von Gradpartikeln Im Deutschen. Tübingen.

Jacobs, Joachim. 1986. Abtönungsmittel als Illokutionstypmodifikatoren. GAGL (Groninger Arbeiten zur germanistischen Linguistik) 27. 100-111.

Jacobson, Roman. 1960. Closing Statement: Linguistics and poetics. Sebeok. Th. (Hg.) 1960. Style in Language. Cambridge, Mass. 350-377.

Jespersen, Otto. 1924. The Philosophy of Grammar. London.

Kallmeyer, Werner/Schütze, Fritz. 1976. Konversationsanalyse. Studium Linguistik 1. $1-28$.

Kallmeyer, Werner et al. 1977. Lektürekolleg zur Textlinguistlk. Kronberg/Ts.

Kemme, Hans-Martin. 1979. "Ja", "denn", "doch" u.s.w. Die Modalpartikeln im Deutschen. Erklärungen und Obungen für den Unterricht an Ausländer. München.

Kirstein, B. 1983. Partikeln und Sprechsituation. Weydt, H. (Hg.) 1983. 213-225.

König, Ekkehard. 1977a. Modalpartikeln in Fragesätzen. Weydt, H. (Hg.) 1977. 115130.

König, Ekkehard. 1977b. Zur Syntax und Semantik von Gradpartikeln. Sprengel, K. et al. (Hgg.) 1977. 63-69.

Kohrt, Manfred. 1988. Eigentlich, das 'Eigentliche' und das 'Nicht-Eigentliche'. Deutsche Sprache 16. 103-130.

Krivonosov, Alexej. 1963. Die modalen Partikeln in der deutschen Gegenwartssprache. Berlin (masch. Diss.).

Krivonosov, Alexej. 1965a. Die Wechselbeziehung zwischen den modalen Partikeln und der Satzintonation im Deutschen. Zeitschrift für Phonetik, Sprachwissenschaft und Kommunikationsforschung 18. 573-589.

Krivonosov, Alexej. 1965b. Die Rolle der modalen Partikeln in der kommunikativen Gliederung der Sätze in bezug auf die Nebensatzglieder. Zeitschrift für Phonetik, Sprachwissenschaft und Kommunikationsforschung 18. 487-503.

Krivonosov, Alexej. 1966. Die Rolle der modalen Partikeln in der kommunikativen Gliederung der Aussagesätze, Fragesätze, Befehlssätze und der Nebensätze in bezug auf die Hauptsatzglieder. Zeitschrift für Phonetik, Sprachwissenschaft und Kommunikationsforschung 19. 131-140.

Krivonosov, Alexej. 1977a. Deutsche Modalpartikeln im System der unflektierten Wortklassen. Weydt, H. (Hg.) 1977. 176-216.

Krivonosov, Alexej. 1977b. Die Wechselbeziehungen der modalen Partikeln zu anderen Wortklassen. Sprachwissenschaft 2. 349-367.

Krivonosov, Alexej. 1978. Zum Problem der modalen Partikeln in der modernen Sprachwissenschaft. Sprachwissenschaft 3. 97-117.

Krohn, Dieter. 1980. Dativ und Pertinenzrelation. Göteborg.

Kürschner, Wilfried. 1983. Studien zur Negation im Deutschen. Tübingen. 
Lang, Ewald. 1979. Zum Status der Satzadverbiale. Slovo a Slovesnost XL. 200213.

Lang. Ewald. 1981. Was heißt eine Einstellung ausdrücken? Linguistische Studien 80. 89-121.

Lang. Ewald. 1983. Einstellungsausdrücke und ausgedrückte Einstellungen. Růžið̌ka, R./Motsch, W. (Hgg.) 1983. Untersuchungen zur Semantik. (Studia grammatica XXII) Berlin. 305-341.

Leisi, Ernst. 1973. Praxis der englischen Semantik. Heidelberg.

Lindner, Katrin. 1983. Sprachliches Handeln bei Vorschulkindern. Tübingen.

Lühr, Rosemarie. 1985. Sonderfälle der Vorfeldbesetzung im heutigen Deutsch. Jeutsche Sprache 13. 1-23.

Lütten, Jutta. 1977. Untersuchungen zur Leistung der Partikeln in der gesprochenen deutschen Sprache. Göppingen.

Lütten, Jutta. 1979. Die Rolle der Partikeln doch, eben und ja als Konsensus-Konstitutiva in gesprochener Sprache. Weydt, H. (Hg.) 1979. 30-38.

Luukko-Vinchenzo, Leila. 1988. Formen von Fragen und Funktionen von Fragesätzen. Tübingen.

Meibauer, Jörg. 1986. Rhetorische Fragen. Tübingen.

Meibauer, Jörg. 1987. Zur Form und Funktion von Echofragen. Rosengren, I. (Hg.) 1987. Sprache und Pragmatik. Lunder Symposium 1986. Lund. 335-356.

Meibauer, Jörg (Hg.) 1987. Satzmodus zwischen Grammatik und Pragmatik. Tübingen.

Ohlschläger, Günther. 1985. Untersuchungen zu den Modalpartikeln des Deutschen. Zeitschrift für germanistische Linguistik 13. 350-366.

Opalka, Hubertus. 1977. Zum Verhältnis von Intonation und Abtönungspartikeln. Sprengel, K. et al. (Hgg.) 1977. 255-266.

Oppenrieder, Wilhelm. 1987. Aussagesătze im Deutschen. Meibauer. J. (Hg.) 1987. $161-189$.

Oppenrieder, Wilhelm/Thurmair, Maria. 1988. Was ist elgentlich 'eigentlich' EIGENTLICH? Ms. München (ersch. vorauss. in Deutsche Sprache).

Pavlidou, Theodossia. 1980. Zur Rolle einiger Modalpartikeln bel der Problematisierung von Handlungen. Tschauder, G./Weigand, E.(Hgg.) 1980. Perspektive: textextern. Akten des XIV. Ling.Koll. Bochum 1979, Bd.2. Tübingen. 107-116.

Rath, Rainer. 1975. 'Doch'. Eine Studie zur Syntax und kommunikativen Funktion einer Partikel. Deutsche Sprache 3. 222-242.

Reis, Marga. 1977. Präsuppositionen und Syntax. Tübingen.

Reiter, Norbert. 1979. Partikeln als gruppendynamische Regulative. Weydt, H. (Hg.) 1979. $75-83$.

Reiter, Norbert. 1980. Die Perfidie des deutschen fa. Deutsche Sprache 8. 342-355.

Riesel, Elise/Schendels, E. 1975. Deutsche Stilistik. Moskau.

Rombouts, Jos. 1982. Kann man Abtönungspartikeln paraphrasieren? Zeitschrift für germanistische Linguistik 10. 63-84.

Roncador, Manfred von. 1977. Zur Linguistik der intensivierenden Ausrufe. Sprengel, K. et al. (Hgg.) 1977. 103-114. 
Rösler, Dletmar. 1983. Der Erwerb von Abtönungspartikeln im institutionalisierten Lernprozeß Deutsch als Fremdsprache. Weydt, H. (Hg.) 1983. 291-300.

Rudolph, Elisabeth. 1983. Partikel-Kombinationen in Alltags-Gesprächen. Weydt, H. (Hg.) 1983. 54-68.

Sandig. Barbara. 1978. Kolloquium deutsche Sprachpartikeln vom Interesse an Pragmatik her dargestelit. Zeitschrift für germanistische Linguistik 6. 84-88.

Sandig. Barbara. 1979. Beschreibung des Gebrauchs von Abtönungspartikeln im Dialog. Weydt, H. (Hg.) 1979. 84-94

Schank, Gerd/Schoenthal Gisela. 1976. Gesprochene Sprache. Eine Einführung in Forschungsansătze und Analysemethoden. Tübingen.

Schlieben-Lange, Brigitte. 1979. Bairisch eh - halt - fei. Weydt, H. (Hg.) 1979. $307-317$.

Schmidt, Siegfried J. 1973. Texttheoretische Aspekte der Negation. Zeitschrift für germanistische Linguistik 1. 178-208.

Scholz, Ulrike. 1987. Wunschsătze im Deutschen - Pormale und Punktionale Beschreibung. Meibauer, J. (Hg.) 1987. 234-258.

Schröder, Gisela. 1965. Zu einigen bedeutungsgeminderten Adverbien (Würzwörter). Deutsch als Fremdsprache 1. 31-33; 44-46.

Schulz, Dora/Griesbach, Heinz. 1980. Grammatik der deutschen Sprache. 11.Aufl. München.

Searle, John R. 1971. Sprechakte. Frankfurt/Main.

Sekiguchi, Tsugio. 1977. Was heißt 'doch'? Weydt, H. (Hg.) 1977. 3-9.

Sennekamp, Marita. 1979. Die Verwendungsmöglichkeiten von Negationszeichen in Dialogen. München.

Settekorn, Wolfgang. 1977. Minimale Argumentationsformen. Untersuchungen zur Abtönung im Deutschen und Französischen. Schecker, M. (Hg.) 1977. Theorie der Argumentation. Tübingen. 391-415.

Sökeland, Werner. 1980. Indirektheit von Sprechhandlungen. Eine linguistische Untersuchung. Tübingen.

Sprengel, Konrad et al. (Hgg.) 1977. Semantik und Pragmatik. Akten des XI. Ling. Koll. Aachen, Bd.2. Tübingen.

Sprengel, Konrad. 1980. Uber semantische Merkmale. Kastovsky, D. (Hg.) 1980. Perspektiven der lexikalischen Semantik. Beiträge zum Wuppertaler Semantikkoll. 1977. Bonn. 145-177.

Stolt, Birgit. 1979. Ein Diskussionsbeitrag zu mal, eben, auch, doch aus kontrastiver Sicht (Deutsch-Schwedisch). Weydt, H. (Hg.) 1979. 479-487.

Thlel, Rudolf. 1962. Würzwörter. Sprachpflege 4. 71-73.

Thim-Mabrey, Christiane. 1985. Satzkonnektoren wie allerdings, dennoch und übrigens. Frankfurt/Main etc.

Thim-Mabrey, Christiane. 1988. Satzadverbiale und andere Ausdrücke im Vorvorfeld. Deutsche Sprache 16. 52-67.

Thurmalr, Maria. 1988. Rezension von: Elke Hentschel (1986). Funktion und Geschichte deutscher Partikeln. Linguistische Berichte 114. 175-179. 
Trömel-Plötz, Senta. 1978. Die Rolle von Adverbien und Partikeln bei der Indirektheit von Außerungen. Habilitationsvortrag. Universität Konstanz (unveröPf. Manuskript).

Trömel-Plötz, Senta. 1979. Männer sind eben so: Eine linguistische Beschreibung von Modalpartikeln, aufgezeigt an der Analyse von dt. eben und engl. just. Weydt, H. (Hg.) 1979. 318-334.

Trogsch, Friedrich. 1962. Welche Rolle spielen die 'Würzwörter' in der Sprache? Sprachpflege 10. 214.

Vater, Heinz. 1975. Werden als Modalverb. Calbert, J./Vater, H. (Hgg.) 1975. Aspekte der Modalität. Tübingen.

Velde, Marc van de. 1977. Zur mehrfachen Vorfeldbesetzung im Deutschen. Conte, M. et al. (Hgg.) 1977. Wortstellung und Bedeutung. Akten des XII. Ling. Koll. Pavia 1977, Bd.1.Tübingen. 131-143.

Vorderwülbecke, Klaus. 1981. Progression, Semantisierung und Ubungsformen der Abtönungspartikeln im Unterricht Deutsch als Fremdsprache. Weydt, H. (Hg.) 1981. 149-160.

Wahrig, Gerhard. 1973. Anleitung zur grammatischen Beschreibung lexikalischer Einheiten. Tübingen.

Watzlawick, Paul et al. 1982. Menschliche Kommunikation. Formen, Störungen, Paradoxien. 4. unveränd.Aufl. Bern etc.

Wegener, Heide. 1985. Der Dativ im heutigen Deutsch. Tübingen.

Weinrich, Harald. 1975. Uber Negationen in der Syntax und Semantik. Ders. (Hg.) 1975. Positionen der Negativität. München. 39-63.

Weinrich, Harald. 1982. Textgrammatik der Pranzösischen Sprache. Stuttgart.

Weuster, Edith. 1983. Nicht-eingebettete Satztypen mit Verb-Endstellung im Deutschen. Olszok, K./Weuster, E. (Hgg.) 1983. Zur Wortstellungsproblematik im Deutschen. Tübingen.

Weydt, Harald. 1969. Abtönungspartikel. Bad Homburg.

Weydt, Harald. 1972. Die Behandlung der Abtönungspartikel beim Unterricht des Deutschen als Fremdsprache. Nickel, G./Raasch, A.(Hg.) 1972. Kongreßbericht der 3.Jahrestagung der GAL e.V. Heidelberg. 180-187.

Weydt, Harald. 1977. Nachwort. Ungelöst und strittig. Ders. (Hg.) 1977. 217-225.

Weydt, Harald (Hg.). 1977. Aspekte der Modalpartikeln. Studien zur deutschen Abtönung. Tübingen.

Weydt, Harald (Hg.). 1979. Die Partikeln der deutschen Sprache. Berlin, New York.

Weydt, Harald. 1981. Methoden und Fragestellungen der Partikelforschung. Ders. (Hg.) 1981. 45-64.

Weydt, Harald (Hg.). 1981. Partikeln und Deutschunterricht. Abtönungspartikeln für Lerner des Deutschen. Heidelberg

Weydt, Harald (Hg.). 1983. Partikeln und Interaktion. Tübingen.

Weydt, Harald. 1986. Betonungsdubletten bei deutschen Partikeln. Weiss, W. et al. (Hgg.) 1986. Textlingulstik contra Stilistik? Wortschatz und Wörterbuch. Grammatische oder pragmatische Organisation von Rede? Tübingen. 393-403.

Weydt, Harald/Hentschel, Elke. 1981. Ein Experiment zur Entwicklung der verbalen Interaktionsfahlgkeit bei Kindern. Zeitschrift für germanistische Linguistik 9. 326-336. 
Weydt, Harald/Hentschel, Elke. 1983. Kleines Abtönungswörterbuch. Weydt, H. (Hg.) 1983. 3-24.

Weydt, Harald et al. 1983. Kleine deutsche Partikellehre. Ein Lehr-und Ubungsbuch für Deutsch als Fremdsprache. Stuttgart.

Willkop, Eva-Maria. 1988. Gliederungspartikeln im Dialog. München.

Wolski, Werner. 1986. Partikellexikographie. Tübingen.

Wunderlich, Dieter. 1976. Studien zur Sprechakttheorie. Frankfurt/Main.

Wunderlich, Dieter. 1986. Echofragen. Studium Linguistik 20. 44-62.

Zellweger, Rudolf. 1982. Die Modalpartikeln im Deutschunterricht für Frankophone. Bulletín CILA 36. 38-55.

Zlfonun, Gisela. 1983. Man nehme: 3 doch, 4 denn...'Würzwörter für Dialoge'. Zum Internationalen Kolloquium 'Funktionen der Partikeln in dialogischer Interaktion'. Deutsche Sprache 11. 78-86.

Zimmermann, Klaus. 1981. Warum sind Modalpartikeln ein Lernproblem? Weydt, H. (Hg.) 1981. 111-122. 